\author{
UNIVERSIDADE DE SÃO PAULO \\ FFCLRP - DEPARTAMENTO DE PSICOLOGIA \\ PROGRAMA DE PÓS-GRADUAÇÃO EM PSICOLOGIA
}

\title{
Impacto do treinamento no trabalho: \\ determinantes individuais e contextuais em cursos corporativos a distância
}

Lara Barros Martins

Tese apresentada à Faculdade de Filosofia, Ciências

e Letras de Ribeirão Preto da USP, como parte das exigências para a obtenção do título de Doutor em Ciências, Área: Psicologia.

RIBEIRÃO PRETO - SP 

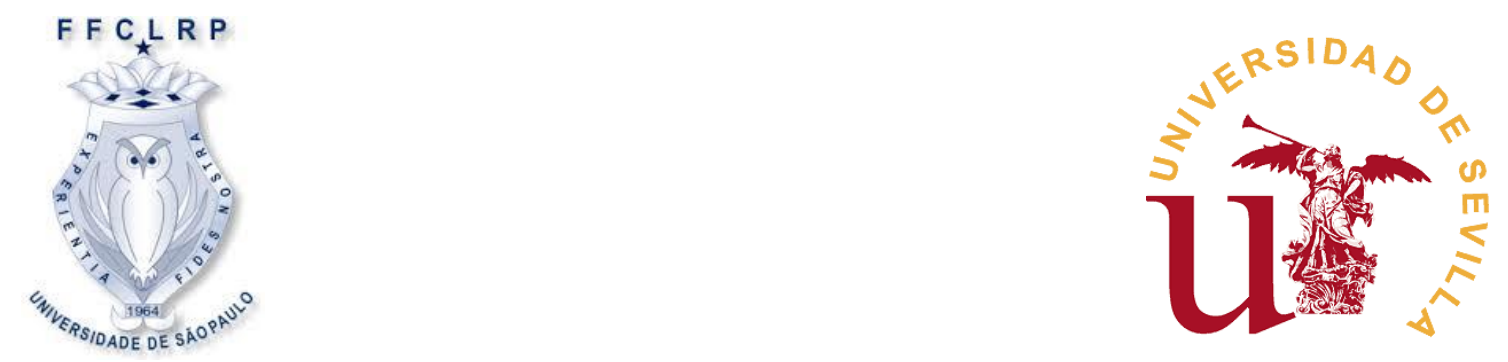

Impacto do treinamento no trabalho:

determinantes individuais e contextuais em cursos corporativos a distância

Lara Barros Martins

Tese desenvolvida em regime de cotutela entre a

Universidade de São Paulo (USP, Brasil) e a

Universidad de Sevilla (US, Espanha).

Orientadores: Profa. Dra. Thaís Zerbini (USP) e Prof.

Dr. Francisco José Medina Díaz (US)

RIBEIRÃO PRETO - SP

2016 
Autorizo a reprodução e divulgação total ou parcial deste trabalho, por qualquer meio convencional ou eletrônico, para fins de estudo e pesquisa, desde que citada a fonte.

\section{Martins, Lara Barros}

Impacto do treinamento no trabalho: determinantes individuais e contextuais em cursos corporativos a distância. Ribeirão Preto, 2016.

284 p. : il. ; $30 \mathrm{~cm}$

Tese de Doutorado, apresentada à Faculdade de Filosofia, Ciências e Letras de Ribeirão Preto/USP. Área de concentração: Psicologia.

Orientadores: Zerbini, Thaís.

Medina, Francisco José.

1. Treinamento a distância. 2. Avaliação. 3. Impacto do treinamento no trabalho. 


\title{
Impacto do treinamento no trabalho: determinantes individuais e contextuais em cursos corporativos a distância
}

\author{
Tese parcialmente financiada pela \\ CAPES/CNPq, Brasil. \\ Apoio do Grupo Tordesillas/Santander \\ Universidades, da Fundación Carolina e do \\ II Plan Propio de Docencia da Universidad \\ de Sevilla, Espanha.
}


Nome: Martins, L. B.

Título: Impacto do treinamento no trabalho: determinantes individuais e contextuais em cursos corporativos a distância

Tese apresentada à Faculdade de Filosofia, Ciências e Letras de Ribeirão Preto da Universidade de São Paulo para obtenção do título de Doutor em Ciências, Área: Psicologia

Aprovada em: 21 de outubro de 2016.

Banca Examinadora:

Profa. Dra. Thaís Zerbini - Presidente da Comissão Julgadora

Instituição: Departamento de Psicologia, Universidade de São Paulo, SP, Brasil.

Prof. Dr. Francisco José Medina Díaz - Membro Titular

Instituição: Departamento de Psicología Social, Universidad de Sevilla, Sevilha, Espanha.

Prof. Dr. Jairo Eduardo Borges-Andrade - Membro Titular

Instituição: Departamento de Psicologia Social e do Trabalho, Universidade de Brasília, DF, Brasil.

Profa. Dra. Marina Greghi Sticca - Membro Titular

Instituição: Departamento de Psicologia, Universidade de São Paulo, SP, Brasil.

Prof. Dr. Sigmar Malvezzi - Membro Titular

Instituição: Departamento de Psicologia Social e do Trabalho, Universidade de São Paulo, SP, Brasil.

Prof. Dr. José Dutra de Oliveira Neto - Membro Titular

Instituição: Departamento de Contabilidade, Universidade de São Paulo, SP, Brasil. 


\section{Agradecimentos}

Aos meus orientadores, Thaís Zerbini e Francisco Medina, por compartilhar ensinamentos e contribuições acadêmico-científicas, pela confiança e pelo acompanhamento próximo do meu desenvolvimento profissional como pesquisadora e docente em formação.

À banca examinadora, pela leitura criteriosa e pelas sugestões dadas ao aprimoramento deste trabalho.

Aos demais docentes, pelas orientações e pelos esclarecimentos sobre questões teóricometodológicas que surgiram durante a pesquisa.

À organização participante, representada pela Diretoria de Gestão de Pessoas e pelos funcionários que responderam à pesquisa, viabilizando a sua execução e a produção de conhecimentos na área.

Às instituições e agências de fomento (CAPES, Grupo Tordesillas/Santander Universidades, Fundación Carolina e II Plan Propio de Docencia da Universidad de Sevilla), pelo reconhecimento da relevância da pesquisa e apoio.

Aos colegas dos grupos de pesquisa, da USP e Universidad de Sevilla, e integrantes do LabPOT e Indrho, pela disponibilidade em ajudar e pelas trocas de experiências.

À minha família e aos meus amigos, pelo incentivo e acolhimento, e pela presença e torcida por meu sucesso. 


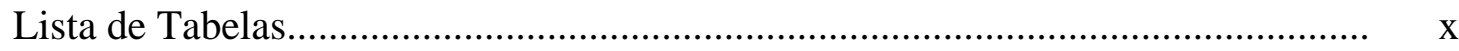

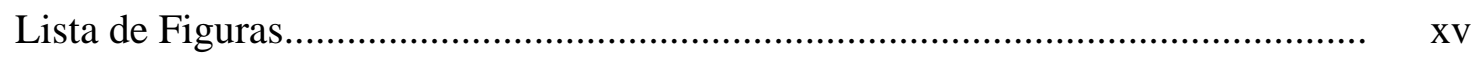

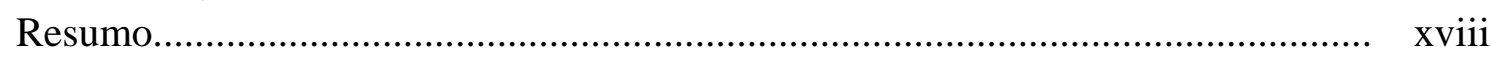

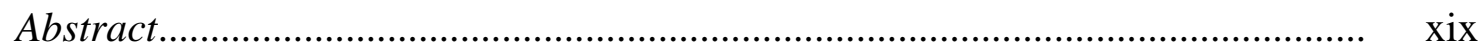

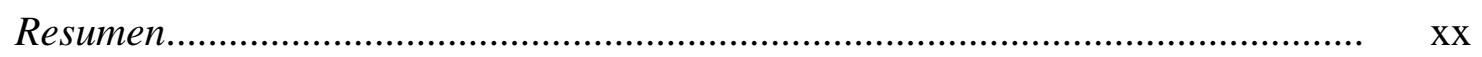

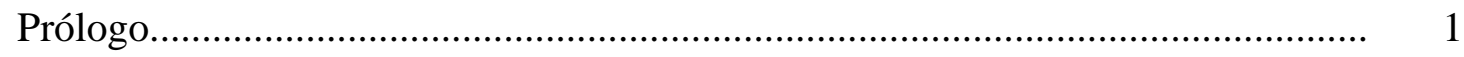

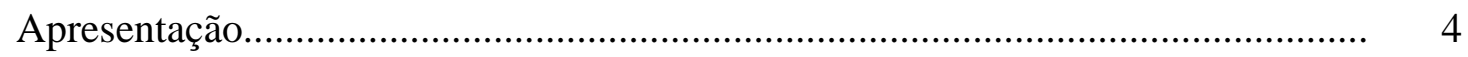

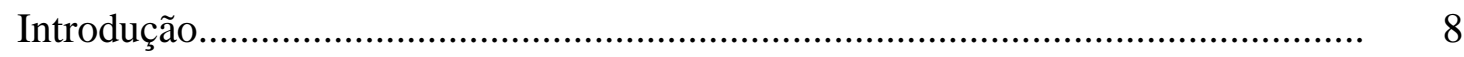

1. Modelo de Investigação, Variáveis de Interesse e Hipóteses.............................. 16

1.1. Determinantes Individuais.................................................................... 18

1.1.1. Variáveis do aprendiz.............................................................................. 18

1.1.1.1. Estratégias de aprendizagem................................................................ 18

1.2. Determinantes Contextuais......................................................................... 29

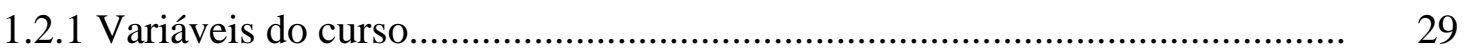

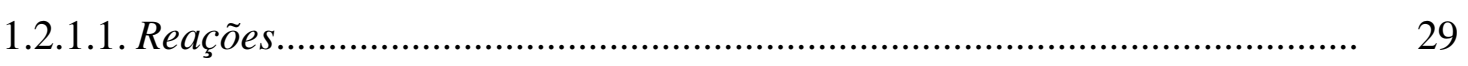

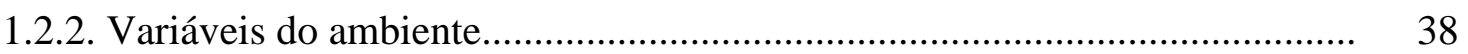

1.2.2.1. Suporte à transferência ........................................................................... 38

1.2.2.2. Barreiras e facilitadores em EAD ......................................................... 47

1.2.3. Variáveis de efetividade de treinamento..................................................... 52

1.2.3.1. Impacto do treinamento no trabalho......................................................... 53

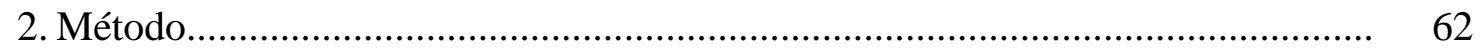

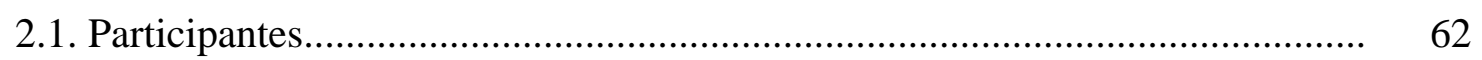

2.1.1. Organização brasileira....................................................................... 62

2.1.2. Curso "Eficiência Operacional"................................................................ 63

2.2. Instrumentos de Medida................................................................................ 64

2.3. Procedimentos de Coleta de Dados................................................................. 65

2.4. Procedimentos de Análise de Dados............................................................. 67

3. Resultados e Discussão............................................................................... $\quad 70$

3.1. Adaptação dos Instrumentos de Medida...................................................... 70

3.1.1. Estratégias de aprendizagem................................................................... $\quad 72$

3.1.2. Reações.............................................................................................. 74

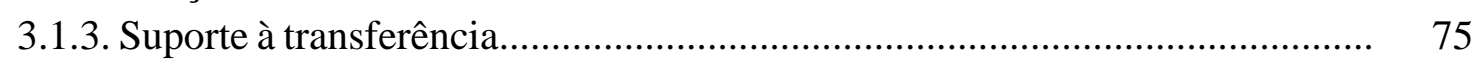

3.1.4. Barreiras e facilitadores em EAD ........................................................... 76

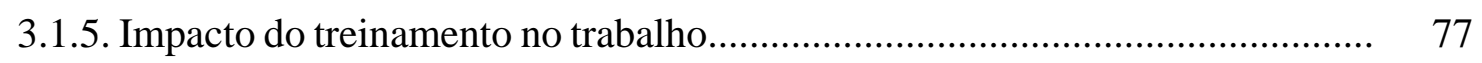

3.2. Análises Teóricas dos Instrumentos de Medida............................................... 79

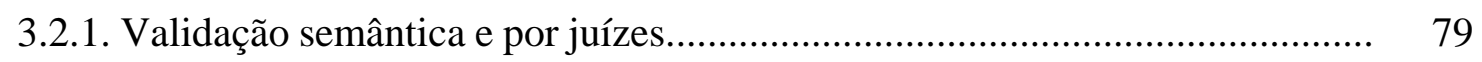

3.3. Estudo Piloto........................................................................................ 80

3.3.1. Análises estatísticas dos instrumentos de medida (espanhol)....................... 82

3.3.1.1. Análises descritivas.............................................................................. 82

3.3.1.1.1. Estratégias de aprendizagem............................................................. 82

3.3.1.1.2. Reações........................................................................................ 84

3.3.1.1.3. Suporte à transferência .................................................................. 86 
3.3.1.1.4. Barreiras e facilitadores em EAD

3.3.1.1.5. Impacto do treinamento no trabalho..................................................... 90

3.3.1.2. Análises de consistência interna ............................................................... 91

3.3.1.3. Análises fatoriais exploratórias............................................................... 94

3.3.1.3.1. Estratégias de aprendizagem.............................................................. 94

3.3.1.3.2. Reaçôes............................................................................................. 97

3.3.1.3.3. Suporte à transferência ....................................................................... 99

3.3.1.3.4. Barreiras e facilitadores em EAD...................................................... 101

3.3.1.3.5. Impacto do treinamento no trabalho..................................................... 104

3.4. Estudo de Campo.................................................................................. 104

3.4.1. Análises estatísticas dos instrumentos de medida (português)....................... 107

3.4.1.1. Análises descritivas............................................................................... 107

3.4.1.1.1. Estratégias de aprendizagem........................................................... 107

3.4.1.1.2. Reação aos procedimentos instrucionais............................................... 109

3.4.1.1.3. Suporte à transferência ..................................................................... 110

3.4.1.1.4. Barreiras e facilitadores em EAD ..................................................... 112

3.4.1.1.5. Impacto do treinamento no trabalho em profundidade ............................. 114

3.4.1.1.6. Impacto do treinamento no trabalho em amplitude .................................. 116

3.4.1.2. Análises de consistência interna .......................................................... 118

3.4.1.3. Análises fatoriais exploratórias........................................................... 120

3.4.1.3.1. Estratégias de aprendizagem................................................................ 120

3.4.1.3.2. Reação aos procedimentos instrucionais............................................... 122

3.4.1.3.3. Suporte à transferência ...................................................................... 123

3.4.1.3.4. Barreiras e facilitadores em EAD ........................................................ 125

3.4.1.3.5. Impacto do treinamento no trabalho em profundidade ............................. 128

3.4.1.3.6. Impacto do treinamento no trabalho em amplitude .................................. 130

3.4.1.4. Análises fatoriais confirmatórias.......................................................... 131

3.4.1.4.1. Estratégias de aprendizagem.............................................................. 134

3.4.1.4.2. Reação aos procedimentos instrucionais................................................ 136

3.4.1.4.3. Suporte à transferência ...................................................................... 137

3.4.1.4.4. Barreiras e facilitadores em EAD ......................................................... 141

3.4.1.4.5. Impacto do treinamento no trabalho em profundidade ............................ 143

3.4.1.4.6. Impacto do treinamento no trabalho em amplitude .................................. 146

3.4.2. Análises de regressão múltipla................................................................ 149

3.4.2.1. Autoavaliação............................................................................... 149

3.4.2.2. Heteroavaliação............................................................................ 153

3.4.3. Equações estruturais - teste do modelo de investigação............................... 155

3.4.3.1. Autoavaliação.................................................................................... 157

3.4.3.1.1. Impacto do treinamento no trabalho em profundidade ............................ 157

3.4.3.2. Heteroavaliação.................................................................................. 164

3.4.3.2.1. Impacto do treinamento no trabalho em profundidade ............................. 164

3.4.4. Relações de mediação e moderação entre variáveis...................................... 168

3.4.4.1. Hipótese mediadora .......................................................................... 168

3.4.4.1.1. Outras relações de mediação.......................................................... 171 


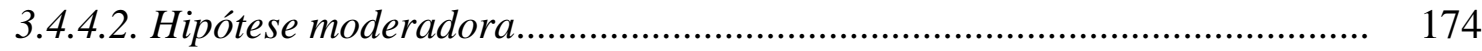

3.4.4.2.1. Outras relações de moderação........................................................... 177

3.4.5. Teste de hipóteses................................................................................ 188

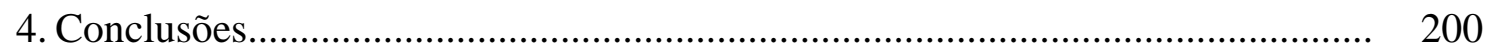

4.1. Evidências de Validade dos Instrumentos de Medida..................................... 200

4.2. Implicações Empíricas - Teste de Hipóteses dos Modelos............................... 203

4.3. Implicações Teórico-Metodológicas........................................................... 207

4.4. Implicações Práticas................................................................................ 209

4.5. Limitações ......................................................................................... 211

4.6. Pesquisas Futuras e Agenda de Pesquisa...................................................... 220

4. Conclusiones................................................................................................ 223

4.1. Evidencias de Validez de las Escalas................................... 223

4.2. Implicaciones Empíricas - Teste de Hipótesis de los Modelos............... 226

4.3. Implicaciones Teóricas y Metodológicas...................................................... 230

4.4. Implicaciones Prácticas.......................................................................... 232

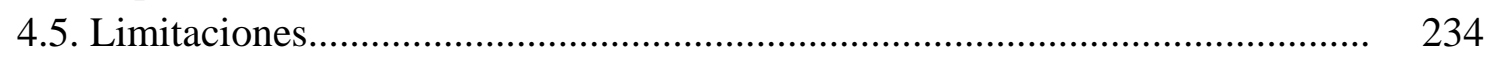

4.6. Investigaciones Futuras y Agenda de Investigación........................ 243

Referências....................................................................................... 246

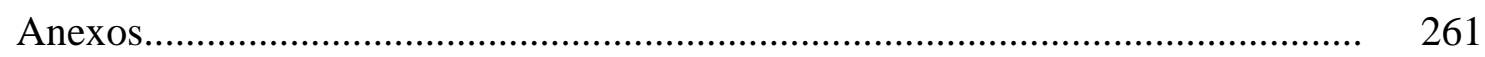


Tabela 1. Classificação e definições das estratégias de aprendizagem (Warr \& Allan, 1998; Zerbini, 2007)

Tabela 2. Pesquisas sobre Estratégias de Aprendizagem..

Tabela 3. Pesquisas sobre Reações......

Tabela 4. Pesquisas sobre Suporte à Transferência.

Tabela 5. Pesquisas sobre Barreiras e Facilitadores em EAD.

Tabela 6. Resultados de pesquisas sobre impacto do treinamento no trabalho em revisões de literatura (Burke \& Hutchins, 2007; Grossman \& Salas, 2011).

Tabela 7. Características formais do curso Eficiência Operacional.

Tabela 8. Perfil da amostra de alunos da Universidad de Sevilla (Espanha) participantes do estudo piloto

Tabela 9. Resultados descritivos do instrumento de "Estrategias de Aprendizaje"...

Tabela 10. Resultados descritivos do instrumento de "Reacción a los Procedimientos de Formación".

Tabela 11. Resultados descritivos do instrumento de "Reacción a la Calidad del Tutor"....

Tabela 12. Resultados descritivos dos itens referentes ao apoio dos supervisores do instrumento de "Apoyo a la Transferencia"...

Tabela 13. Resultados descritivos dos itens referentes ao apoio dos colegas do instrumento de "Apoyo a la Transferencia".

Tabela 14. Resultados descritivos dos itens referentes ao apoio material do instrumento de "Apoyo a la Transferencia".

Tabela 15. Resultados descritivos do instrumento de "Barreras y Facilitadores en la Enseñanza Virtual".

Tabela 16. Resultados descritivos do instrumento de "Impacto de la Formación en el Trabajo en Amplitud".

Tabela 17. Comparação dos alfas e número de itens entre as escalas em português e espanhol.

Tabela 18. Resumo das informações psicométricas dos instrumentos utilizados em estudos anteriores.

Tabela 19. Estrutura empírica do instrumento de "Estrategias de Aprendizaje"....... Tabela 20. Valores próprios empíricos e aleatórios dos primeiros dez componentes da escala de "Estrategias de Aprendizaje".

Tabela 21. Estrutura empírica do instrumento de "Reacción a los Procedimientos de Formación".

Tabela 22. Estrutura empírica do instrumento de "Reacción a la Calidad del Tutor".

Tabela 23. Estrutura empírica do instrumento de "Apoyo a la Transferencia".

Tabela 24. Valores próprios empíricos e aleatórios dos primeiros dez componentes da escala de "Apoyo a la Transferencia". 
Tabela 25. Estrutura empírica do instrumento de "Barreras y Facilitadores en la Enseñanza Virtual"

Tabela 26. Valores próprios empíricos e aleatórios dos primeiros dez componentes da escala de "Barreras y Facilitadores en la Enseñanza Virtual"

Tabela 27. Estrutura empírica do instrumento de "Impacto de la Formación en el Trabajo en Amplitud".

Tabela 28. Perfil da amostra de funcionários participantes do curso Eficiência Operacional.....

105

Tabela 29. Perfil da amostra de gestores.

Tabela 30. Resultados descritivos do instrumento de "Estratégias de Aprendizagem" no curso Eficiência Operacional.

Tabela 31. Resultados descritivos do instrumento de "Reação aos Procedimentos Instrucionais" no curso Eficiência Operacional.

Tabela 32. Resultados descritivos dos itens referentes ao apoio dos supervisores do instrumento de "Suporte à Transferência" no curso Eficiência Operacional........ Tabela 33. Resultados descritivos dos itens referentes ao apoio dos colegas do instrumento de "Suporte à Transferência" no curso Eficiência Operacional...

Tabela 34. Resultados descritivos dos itens referentes ao apoio material do instrumento de "Suporte à Transferência" no curso Eficiência Operacional.....

Tabela 35. Resultados descritivos do instrumento de "Barreiras e Facilitadores em EAD" no curso Eficiência Operacional.

Tabela 36. Resultados descritivos do instrumento de autoavaliação de "Impacto do Treinamento em Profundidade" no curso Eficiência Operacional.

Tabela 37. Resultados descritivos do instrumento de heteroavaliação de "Impacto do Treinamento em Profundidade" no curso Eficiência Operacional.

Tabela 38. Resultados descritivos do instrumento de autoavaliação de "Impacto do Treinamento em Amplitude" no curso Eficiência Operacional.

Tabela 39. Resultados descritivos do instrumento de heteroavaliação de "Impacto do Treinamento em Amplitude" no curso Eficiência Operacional.

Tabela 40. Informações psicométricas dos instrumentos utilizados na pesquisa.

Tabela 41. Comparação dos alfas e número de itens entre as escalas originais e as do estudo de campo.

Tabela 42. Estrutura empírica do instrumento de "Estratégias de Aprendizagem"... Tabela 43. Estrutura empírica do instrumento de "Reação aos Procedimentos Instrucionais"....

Tabela 44. Estrutura empírica do instrumento de "Suporte à Transferência"....

Tabela 45. Pares de itens altamente correlacionados entre si no instrumento de "Barreiras e Facilitadores em EAD".

Tabela 46. Estrutura empírica do instrumento de "Barreiras e Facilitadores em EAD".

Tabela 47. Estrutura empírica do instrumento de autoavaliação de "Impacto do Treinamento em Profundidade". 
Tabela 48. Estrutura empírica do instrumento de heteroavaliação de "Impacto do Treinamento em Profundidade".

Tabela 49. Estrutura empírica do instrumento de autoavaliação de "Impacto do Treinamento em Amplitude"...

Tabela 50. Estrutura empírica do instrumento de heteroavaliação de "Impacto do Treinamento em Amplitude".

Tabela 51. Valores de referência dos indicadores de bondade de ajuste do modelo..

Tabela 52. Indicadores de ajuste para os modelos original e re-especificados do instrumento de "Estratégias de Aprendizagem".

Tabela 53. Indicadores de ajuste para os modelos original e re-especificados do instrumento de "Reação aos Procedimentos Instrucionais".

Tabela 54. Indicadores de ajuste para os modelos original e re-especificados do instrumento de "Suporte à Transferência".

Tabela 55. Indicadores de ajuste para as escalas do instrumento de "Suporte à Transferência".

Tabela 56. Indicadores de ajuste para os modelos original e re-especificados do instrumento de "Barreiras e Facilitadores em EAD".

Tabela 57. Indicadores de ajuste para os modelos original e re-especificados do instrumento de autoavaliação de "Impacto do Treinamento no Trabalho em Profundidade".

Tabela 58. Indicadores de ajuste para os modelos original e re-especificados do instrumento de heteroavaliação de "Impacto do Treinamento no Trabalho em Profundidade".

Tabela 59. Indicadores de ajuste para os modelos original e re-especificados do instrumento de autoavaliação de "Impacto do Treinamento no Trabalho em Amplitude".

Tabela 60. Indicadores de ajuste para os modelos original e re-especificados do instrumento de heteroavaliação de "Impacto do Treinamento no Trabalho em Amplitude".

Tabela 61. Regressão múltipla padrão para o Impacto do Treinamento no Trabalho em Profundidade.

Tabela 62. Regressão múltipla padrão para o Impacto do Treinamento no Trabalho em Amplitude.

Tabela 63. Correlações entre as variáveis independentes e dependentes na auto e heteroavaliação de impacto em profundidade e em amplitude.

Tabela 64. Indicadores de ajuste para o modelo estrutural com o Impacto do Treinamento no Trabalho em Profundidade como variável dependente.

Tabela 65. Efeitos estandardizados totais, diretos e indiretos das variáveis independentes com a variável dependente "Impacto do Treinamento no Trabalho em Profundidade".

Tabela 66. Indicadores de ajuste para o modelo estrutural com o Impacto do Treinamento no Trabalho em Amplitude como variável dependente. 
Tabela 67. Efeitos estandardizados totais, diretos e indiretos das variáveis independentes com a variável dependente "Impacto do Treinamento no Trabalho em Amplitude".

Tabela 68. Indicadores de ajuste para o modelo estrutural com as variáveis dependentes IP e IA.

Tabela 69. Efeitos estandardizados totais, diretos e indiretos das variáveis independentes com a variável dependente "Impacto do Treinamento no Trabalho em Profundidade".

Tabela 70. Efeitos estandardizados totais, diretos e indiretos das variáveis independentes com a variável dependente "Impacto do Treinamento no Trabalho em Amplitude".

Tabela 71. Indicadores de ajuste para o modelo estrutural com o Impacto do Treinamento no Trabalho em Profundidade como variável dependente.

Tabela 72. Efeitos estandardizados totais, diretos e indiretos das variáveis independentes com a variável dependente "Impacto do Treinamento no Trabalho em Profundidade".

Tabela 73. Indicadores de ajuste para o modelo estrutural com o Impacto do Treinamento no Trabalho em Amplitude como variável dependente

Tabela 74. Efeitos estandardizados totais, diretos e indiretos das variáveis independentes com a variável dependente "Impacto do Treinamento no Trabalho em Amplitude".

Tabela 75. Indicadores de ajuste para o modelo estrutural com as variáveis dependentes IP e IA.

Tabela 76. Efeitos estandardizados totais, diretos e indiretos das variáveis independentes com a variável dependente "Impacto do Treinamento no Trabalho em Profundidade".

Tabela 77. Efeitos estandardizados totais, diretos e indiretos das variáveis independentes com a variável dependente "Impacto do Treinamento no Trabalho em Amplitude".

Tabela 78. Regressão simples de Reação aos Procedimentos Instrucionais sobre o Impacto do Treinamento no Trabalho em Profundidade e em Amplitude.

Tabela 79. Regressão simples de Suporte à Transferência sobre o Impacto do Treinamento no Trabalho em Profundidade e em Amplitude

Tabela 80. Regressão múltipla de Reação aos Procedimentos Instrucionais e Suporte à Transferência sobre o Impacto do Treinamento no Trabalho em Profundidade e em Amplitude.

Tabela 81. Resultados para mediação simples de reação aos procedimentos instrucionais sobre suporte à transferência e impacto do treinamento no trabalho.... Tabela 82. Regressão simples de Estratégias de Aprendizagem sobre o Impacto do Treinamento no Trabalho em Profundidade e em Amplitude.

Tabela 83. Regressão múltipla de Reação aos Procedimentos Instrucionais e Estratégias de Aprendizagem sobre o Impacto do Treinamento no Trabalho em Profundidade e em Amplitude. 
Tabela 84. Resultados para mediação simples de reação aos procedimentos instrucionais sobre estratégias de aprendizagem e impacto do treinamento no trabalho.

Tabela 85. Regressão múltipla de Reação aos Procedimentos Instrucionais e Barreiras e Facilitadores em EAD sobre o Impacto do Treinamento no Trabalho em Profundidade e em Amplitude.

Tabela 86. Resultados para mediação simples de reação aos procedimentos instrucionais sobre barreiras e facilitadores em EAD e impacto do treinamento no trabalho.

Tabela 87. Papel moderador do suporte à transferência sobre as estratégias de aprendizagem na explicação de impacto do treinamento no trabalho

Tabela 88. Resumo das relações preditivas significativas na autoavaliação e heteroavaliação de impacto do treinamento no trabalho.

Tabela 89. Resumo das relações de mediação na autoavaliação de impacto do treinamento no trabalho...

Tabela 90. Resumo das relações de moderação na autoavaliação de impacto do treinamento no trabalho.

Tabela 91. Coeficientes de regressão para as relações entre as variáveis e índices de ajuste dos modelos 
Figura 1. Estrutura geral de desenvolvimento do texto.......................................... 6

Figura 2. Modelo de investigação proposto.......................................................... 17

Figura 3. Distribuição dos valores próprios (scree plot) da escala de "Estrategias de Aprendizaje".....

Figura 4. Distribuição dos valores próprios (scree plot) da escala de "Apoyo a la Transferencia".

Figura 5. Distribuição dos valores próprios (scree plot) da escala de "Barreras y Facilitadores en la Enseñanza Virtual”.

Figura 6. Cargas fatoriais estandardizadas, coeficientes de correlação e erros padrão da AFC para o instrumento de Estratégias de Aprendizagem (modelo reespecificado 2).

Figura 7. Cargas fatoriais estandardizadas, coeficientes de correlação e erros padrão da AFC para o instrumento de Reação aos Procedimentos Instrucionais (modelo re-especificado 2).

Figura 8. Cargas fatoriais estandardizadas, coeficientes de correlação e erros padrão da AFC para o instrumento de Suporte à Transferência (modelo hipotético inicial).

Figura 9. Cargas fatoriais estandardizadas, coeficientes de correlação e erros padrão da AFC para a escala de Suporte de Supervisores e Material do instrumento de Suporte à Transferência.

Figura 10. Cargas fatoriais estandardizadas, coeficientes de correlação e erros padrão da AFC para a escala de Suporte de Pares e Material do instrumento de Suporte à Transferência......

Figura 11. Cargas fatoriais estandardizadas, coeficientes de correlação e erros padrão da AFC para o instrumento de Barreiras e Facilitadores em EAD (modelo re-especificado 3).

Figura 12. Cargas fatoriais estandardizadas, coeficientes de correlação e erros padrão da AFC para o instrumento de autoavaliação de Impacto do Treinamento no Trabalho em Profundidade (modelo re-especificado 1).

Figura 13. Cargas fatoriais estandardizadas, coeficientes de correlação e erros padrão da AFC para o instrumento de heteroavaliação de Impacto do Treinamento no Trabalho em Profundidade (modelo re-especificado 2).

Figura 14. Cargas fatoriais estandardizadas, coeficientes de correlação e erros padrão da AFC para o instrumento de autoavaliação de Impacto do Treinamento no Trabalho em Amplitude (modelo re-especificado 2).

Figura 15. Cargas fatoriais estandardizadas, coeficientes de correlação e erros padrão da AFC para o instrumento de heteroavaliação de Impacto do Treinamento no Trabalho em Amplitude (modelo hipotético inicial)

Figura 16. Modelo simplificado com os coeficientes de regressão estandardizados significativos na autoavaliação de Impacto do Treinamento no Trabalho em Profundidade. 
Figura 17. Modelo simplificado com os coeficientes de regressão estandardizados significativos na autoavaliação de Impacto do Treinamento no Trabalho em Amplitude.

Figura 18. Modelo simplificado com os coeficientes de regressão estandardizados significativos $(* p<0,000)$.

Figura 19. Modelo simplificado com os coeficientes de regressão estandardizados significativos $\left(* p<0,000 \mathrm{e}^{* *} p<0,05\right)$.

Figura 20. Efeitos indiretos positivos de variáveis independentes sobre o Impacto em Amplitude na autoavaliação.

Figura 21. Modelo simplificado com os coeficientes de regressão estandardizados significativos $(* * p<0,05)$.....

Figura 22. Modelo simplificado com os coeficientes de regressão estandardizados significativos $(* p<0,000 ; * * p<0,05)$

Figura 23. Efeitos indiretos positivos de variáveis independentes sobre o Impacto em Amplitude na heteroavaliação.

Figura 24. Modelo da variável mediadora reação aos procedimentos instrucionais entre suporte à transferência e impacto do treinamento no trabalho.

Figura 25. Efeito mediador das reações aos procedimentos instrucionais entre as estratégias de aprendizagem e o impacto do treinamento no trabalho na autoavaliação.

Figura 26. Modelo da variável moderadora suporte à transferência entre barreiras e facilitadores em EAD e impacto do treinamento no trabalho.

Figura 27. Efeito moderador do suporte material sobre barreiras e facilitadores em EAD e o impacto em profundidade na autoavaliação..

Figura 28. Relação entre as barreiras e facilitadores em EAD e o impacto em profundidade em função do suporte material.

Figura 29. Efeito moderador de reações aos procedimentos instrucionais sobre barreiras e facilitadores em EAD e o impacto em profundidade na autoavaliação.... Figura 30. Efeito moderador de reações aos procedimentos instrucionais sobre barreiras e facilitadores em EAD e o impacto em amplitude na autoavaliação.

Figura 31. Moderadores das barreiras e facilitadores em EAD sobre os indicadores de efetividade de treinamento na autoavaliação.

Figura 32. Relação entre as barreiras e facilitadores em EAD e o impacto em profundidade em função das reações ao curso.

Figura 33. Relação entre as barreiras e facilitadores em EAD e o impacto em amplitude em função das reações ao curso.

Figura 34. Efeito moderador do suporte material sobre as estratégias cognitivas e busca de ajuda e o impacto em profundidade na autoavaliação.

Figura 35. Efeito moderador do suporte material sobre as estratégias de controle da emoção e o impacto em profundidade na autoavaliação.

Figura 36. Efeito moderador do suporte de pares sobre as estratégias de elaboração e aplicação prática e o impacto em amplitude na autoavaliação.

Figura 37. Relação entre as estratégias de aprendizagem de controle da emoção e o impacto em profundidade em função do suporte material. 
Figura 38. Relação entre as estratégias de aprendizagem de elaboração e aplicação prática e o impacto em amplitude em função do suporte de pares.............................. Figura 39. Efeito moderador de reações aos procedimentos instrucionais sobre as estratégias cognitivas e busca de ajuda e o impacto em profundidade na autoavaliação.

Figura 40. Moderadores das estratégias de aprendizagem cognitivas e busca de ajuda sobre o impacto em profundidade na autoavaliação.

Figura 41. Relação entre as estratégias de aprendizagem cognitivas e busca de ajuda e o impacto em profundidade em função das reações ao curso.

Figura 42. Relação entre as estratégias de aprendizagem cognitivas e busca de ajuda e o impacto em profundidade em função do suporte material. 


\section{Resumo}

Mudanças recentes na área de Treinamento, Desenvolvimento e Educação (TD\&E) introduzem novas formas de oferecer programas instrucionais, que passam a ser realizados via internet, suscitando discussões acerca de sua viabilidade, efetividade e potencial para retornar melhorias aos seus participantes e benefícios tangíveis às organizações. A avaliação da efetividade de ações de TD\&E exige medir seus efeitos sobre o desempenho individual dos egressos, incluindo uma complexa gama de variáveis da organização, do treinamento e do indivíduo explicativas do processo de transferência de competências adquiridas ao ambiente de trabalho. Nesse sentido, o presente estudo teve como objetivo propor e testar um modelo de avaliação de ações educacionais corporativas ofertadas a distância, visando identificar fatores que influenciam na efetividade de treinamentos dessa natureza, entre variáveis do indivíduo (estratégias de aprendizagem), de reação ao curso (procedimentos instrucionais e desempenho do tutor) e do ambiente (barreiras e facilitadores em contexto a distância e suporte à transferência de treinamento), tendo como variável critério o impacto do treinamento no trabalho, medida em termos de desempenhos específicos (impacto em profundidade) e gerais (impacto em amplitude) no trabalho. A coleta de dados foi realizada por meio da aplicação virtual de questionários aos membros de uma organização pública brasileira do setor bancário, que participaram de um treinamento a distância (autoavaliação), e a seus superiores hierárquicos (heteroavaliação). Foram realizadas a adaptação e a validação teórica de instrumentos nacionais utilizados na coleta de dados; tradução ao espanhol dos instrumentos de medida e aplicação em estudo piloto na Espanha que antecedeu o estudo de campo principal; análises estatísticas (descritivas, consistência interna, fatoriais exploratórias e confirmatórias) para a verificação de evidências de validade dos instrumentos de medida; regressões múltiplas e modelagem por equações estruturais para testar o conjunto de relações entre as variáveis presentes no modelo de investigação proposto (predição, mediação e moderação). Foram confirmadas a validade e a confiabilidade dos instrumentos, configurando-se como ferramentas de avaliação úteis ao diagnóstico da efetividade de treinamentos em ambientes corporativos. Os achados, baseados nos altos níveis de ajuste dos modelos encontrados, comprovaram o poder explicativo da satisfação com os procedimentos instrucionais, das estratégias de aprendizagem, sobretudo as de elaboração e aplicação prática, e do suporte à transferência (material e de pares), para o processo subsequente de aplicação das novas habilidades no trabalho, na autoavaliação de ambos tipos de impacto; na heteroavaliação, o suporte de supervisores e as estratégias cognitivas e busca de ajuda explicaram, respectivamente, a ocorrência do impacto em profundidade e em amplitude; além da identificação do papel mediador/moderador das reações e do suporte à transferência. Os resultados empíricos obtidos por meio da utilização de modelos mais sofisticados de análise de dados e combinado à inclusão de hipóteses preditoras, mediadoras e moderadoras para a investigação do fenômeno do resultado do treinamento no desempenho dos egressos suprem lacunas de pesquisa e oferecem importantes subsídios à área de avaliação de programas de TD\&E, beneficiando o desenvolvimento do campo científico, em termos de avanços teórico-metodológicos, e trazendo implicações práticas, ao apresentar orientações aos profissionais que influenciam sobre o desempenho de suas atividades e facilitam as intervenções em contextos organizacionais e de trabalho.

Palavras-chave: treinamento a distância; avaliação; impacto do treinamento no trabalho. 


\begin{abstract}
Recent changes in the field of training introduce new ways to offer these programs in organizations, which are currently delivered by the Internet, raising questions about their feasibility, effectiveness and potential to return improvements to the participants' performance and tangible benefits to organizations. The evaluation of e-training effectiveness requires measuring its effects on the individual employees' performance, including a large and complex range of organizational, training design and individual variables that explain the transfer of training process at the workplace. Though, the present study aimed to propose and test an assessment model in a distance corporate context, to identify factors relating to individual characteristics (learning strategies), reaction (instructional procedures and tutor's performance) and the work environment (barriers and facilitators in e-learning and support to training transfer) that can influence e-training outputs. To measure the effectiveness of training at work, the dependent variable was the transfer of training, measured in terms of specific (in depth impact) and overall (in width impact) performance at work. Data collection was conducted through online questionnaires delivered to members of a Brazilian public organization of the banking sector that had participated in an e-training (self-evaluation), and to their supervisors (hetero-evaluation). Adaptation and content validation of national instruments used in data collection were conducted; translation into Spanish of the measuring instruments and application in a pilot study in Spain prior to the main study; statistical analysis (descriptive, internal consistency, exploratory and confirmatory factor analysis) to verify the reliability of the scales; multiple regressions and structural equation modeling to test the relationships between the variables in the proposed research model (prediction, mediation and moderation). The validity and reliability of the instruments indicate them as useful assessment tools in diagnosing the effectiveness of training in corporate environments. The findings, based on the high level of fit for the models, confirm that the trainee satisfaction with the instructional procedures, the learning strategies, mainly the elaboration and practical application strategies, and the perception of material and peer support, contributed to the subsequent process of applying the new skills at work in the self-evaluation of both types of impact; in the hetero-evaluation, the supervisor support and the cognitive and help-seeking strategies explained, respectively, the in depth and in width impact; besides, the mediating/moderating role of reaction and support to transfer was identified. The empirical results obtained through the use of more sophisticated models of data analysis and combined with the inclusion of predictive, mediating and moderating effects to investigate the transfer of training in the employees' performance clarify research gaps and provide important subsidies to the training evaluation field, benefiting the development of the scientific literature, in terms of theoretical and methodological advances, and bringing practical implications, offering guidance to professionals that influences on the performance of their activities and facilitates interventions at work and organizational settings.
\end{abstract}

Keywords: distance training; assessment; transfer of training. 


\section{Resumen}

Los cambios recientes en el área de formación en las empresas introducen nuevas formas de ofrecer programas de formación a los trabajadores al utilizar la Internet. Sobre las teleformaciones, surgen cuestiones con respecto a su viabilidad, eficacia y potencial de ofrecer mejoras a sus participantes y beneficios tangibles a las organizaciones. La evaluación de la eficacia de las formaciones requiere medir sus efectos sobre el rendimiento individual de los egresados, incluyendo un amplio y complejo abanico de variables de la organización, de la formación y del individuo que expliquen el proceso de transferencia de las habilidades en el trabajo. En ese sentido, la presente investigación tuvo como objetivo proponer y poner a prueba un modelo de evaluación de programas de formación en las empresas ofrecidos telemáticamente, para identificar los factores que influyen en la efectividad de ese tipo de formación, entre variables individuales (estrategias de aprendizaje), de reacción al curso (procedimientos de formación y calidad del tutor) y del entorno laboral (barreras y facilitadores en la enseñanza virtual y apoyo a la transferencia). La variable dependiente fue el impacto de la formación en el trabajo, medida en términos de rendimientos específicos (impacto en profundidad) y generales (impacto en amplitud) en el trabajo. La recogida de datos se llevó a cabo a través de la aplicación online de los cuestionarios a los miembros de una organización pública brasileña del sector bancario, que participaron en una teleformación (autoevaluación), y a sus superiores jerárquicos (heteroevaluación). Fueron realizadas la adaptación y validación teórica de los instrumentos nacionales utilizados en la recogida de datos; traducción al español de los instrumentos y aplicación en un estudio piloto en España antes del estudio de campo; análisis estadísticos (descriptivos, consistencia interna, factorial exploratorio y confirmatorio) para la verificación de la validez de los instrumentos de medida; regresiones múltiples y modelos de ecuaciones estructurales para comprobar el conjunto de relaciones entre las variables del modelo de investigación propuesto (predicción, mediación y moderación). La validez y fiabilidad de los instrumentos fueron confirmados, indicándolos como herramientas de evaluación de la efectividad de la formación en las empresas. Los resultados, basados en los altos niveles de ajuste de los modelos, corroboraron que la satisfacción con los procedimientos de formación, las estrategias de aprendizaje, sobre todo las de elaboración y aplicación práctica, y el apoyo a la transferencia (material y de pares) explicaron el subsecuente proceso de transferencia de las nuevas habilidades en el trabajo, en la autoevaluación de los dos tipos de impacto; en la heteroevaluación, el apoyo de los supervisores y las estrategias cognitivas y de búsqueda de ayuda explicaron, respectivamente, la ocurrencia del impacto en profundidad y en amplitud; además de la identificación del rol mediador/moderador de las reacciones y del apoyo a la transferencia. Los resultados empíricos obtenidos a través del uso de modelos más sofisticados de análisis de datos suplen lagunas de investigación y proporcionan subsidios importantes al área de evaluación de los programas de formación, beneficiando el desarrollo del campo científico, en función de los avances teóricos y metodológicos, y traen implicaciones prácticas, al proporcionar orientación a los profesionales que influye en el ejercicio de sus actividades y facilita las intervenciones en contextos organizacionales y de trabajo.

Palabras-clave: teleformación; evaluación; transferencia de la formación. 


\section{Prólogo}

O desenvolvimento do projeto de pesquisa concernente à presente tese doutoral, tendo como objetivo principal a avaliação de treinamentos corporativos a distância em termos dos determinantes individuais e contextuais influentes no processo de transferência das novas competências adquiridas para o trabalho, contou com períodos de investigação no exterior, financiados por agências de fomento estrangeiras.

O projeto de pesquisa foi inscrito primeiramente em um processo seletivo do Grupo Tordesillas, apoiado pelo Santander Universidades, o qual disponibilizava, através da Universidad de Sevilla (Espanha), cinco bolsas de estudos em sua convocatória de 2013-2014 a alunos matriculados em um dos programas de doutorado na área de Psicologia Organizacional e do Trabalho das seis universidades integrantes do Colegio Doctoral Tordesillas (CDT-POT), dentre elas a Universidade de São Paulo (USP). Durante um período de cinco meses, a aluna participou das atividades desenvolvidas pelo CDT-POT no Departamento de Psicologia Social da Universidad de Sevilla, além de dar seguimento ao seu projeto de pesquisa (melhora do desenho metodológico da investigação, elaboração de hipóteses de pesquisa, revisão de literatura científica e adaptação ao espanhol dos instrumentos de medida a ser utilizados na coleta de dados), sob a supervisão do tutor designado, Prof. Dr. Francisco José Medina Díaz. Nessa ocasião, a aluna foi convidada a desenvolver o projeto de tese em regime de cotutela entre a USP e a Universidad de Sevilla (US) e começou a preparar a documentação necessária para firmar um convênio de colaboração institucional bilateral entre ambas universidades, que visava estabelecer as condições formais de coordenação do projeto de tese por parte da USP, orientada pela Profa. Dra. Thaís Zerbini, e pela US, pelo Prof. Dr. Francisco José Medina Díaz, e a consequente obtenção da dupla titulação com a superação da defesa da tese doutoral ao final do processo.

Em seguida, a convocatória de 2014-2015 do Programa "Movilidad de Profesores e Investigadores Brasil-España” da Fundación Carolina - instituição governamental espanhola sumamente prestigiosa que promove relações culturais e de cooperação educacional e científica entre Espanha e países iberoamericanos, sendo referência em mobilidade acadêmica e bolsas internacionais -, surgiu como uma oportunidade de dar prosseguimento ao trabalho iniciado no ano anterior na US, enquanto tramitava o convênio de cotutela. Durante o período de três meses financiado pela referida instituição, além de várias atividades formativas e a efetivação da matrícula da aluna no Programa de Doutorado de Psicologia dos Recursos Humanos da US, realizou-se a adaptação ao 
espanhol e a aplicação dos instrumentos a uma amostra de estudantes universitários ou pós-graduandos em estudo piloto conduzido na US (validação semântica, análises descritivas, fatoriais exploratórias e de consistência interna das medidas em espanhol); bem como foram contatadas organizações espanholas para apresentar-lhes o projeto de tese e propor-lhes a avaliação de alguns de seus programas de treinamentos online.

Finalmente, no ano seguinte (2015), com a aprovação e a assinatura do convênio de cotutela ${ }^{1}$, a aluna teve acesso a um auxílio do II Plan Propio de Docencia da Universidad de Sevilla, "Acciones de Movilidad e Internacionalización: Apoyo al Desarrollo de Tesis Cotuteladas", que apoiava justamente o desenvolvimento de projetos de pesquisa de estudantes na condição de cotutela entre universidades. Esse período contou com a participação da aluna em atividades promovidas pelo Programa de Doutorado em Psicologia de Recursos Humanos e o pleno aproveitamento na execução da pesquisa: análise de dados coletados em organização brasileira (estudo de campo), validação dos instrumentos de medida, sistematização dos resultados e discussão em capítulos da tese, redação de relatórios à instituição parceira e de artigos científicos para sua publicação em revistas indexadas, nacionais e internacionais.

Todos os períodos de investigação anteriormente aludidos, alternados com períodos de permanência no Brasil, conforme prevê o convênio de cotutela, permitiram o desenvolvimento da pesquisa, tendo impactado em alterações no projeto inicialmente proposto. Além disso, possibilitaram que as medidas nacionais fossem adaptadas ao espanhol, podendo ser utilizadas em pesquisas futuras em países que tenham o castelhano como idioma, uma vez que não foram identificados instrumentos internacionais similares, apontando a importância da adaptação dessas medidas; e a realização de um estudo piloto, sendo um teste em pequena escala do estudo completo. A princípio, a intenção era firmar parceria de pesquisa nos contextos brasileiro e espanhol para realizar um estudo comparativo entre amostras provindas de empresas do mesmo setor (bancário) de ambos países, comparar os resultados obtidos e as possíveis diferenças culturais, o que não foi possível.

Além disso, participar em programas de mobilidade internacional configuram-se em ocasiões ímpares para promover o intercâmbio científico em ambientes de pesquisa caracterizados por alunos e professores, de diferentes origens, altamente produtivos e comprometidos com a produção de conhecimento; angariar informações e aprender novas

\footnotetext{
${ }^{1} \mathrm{O}$ convênio de cotutela de tese doutoral prevê, dentre outros aspectos, a redação da tese no idioma português, complementada por um resumo e conclusões no idioma espanhol.
} 
técnicas e métodos; compartilhar uma bagagem de formação intelectual e de investigação no grupo de pesquisa do país de origem; e trazer contribuições para os grupos brasileiros de pesquisa, especialmente da Universidade de São Paulo, e pesquisadores da comunidade científica com forte atuação no Brasil na área de POT.

Essas considerações são feitas para contextualizar as circunstâncias sobre as quais o projeto de tese doutoral foi desenvolvido e referendar o reconhecimento e apoio que o mesmo recebeu, junto à candidata ao título de doutorado, durante seu processo de pesquisadora em formação. 


\section{Apresentação}

Programas de Treinamento, Desenvolvimento e Educação (TD\&E) ocupam uma posição estratégica nas organizações, pois oferecem a oportunidade de promover a aprendizagem contínua e de desenvolver e consolidar competências técnicas e comportamentais essenciais ao desempenho profissional de seus membros, melhorando a sua performance no trabalho (Salas, Tannenbaum, Kraiger \& Smith-Jentsch, 2012). Tais eventos instrucionais vêm acompanhando as mudanças ocorridas em contextos organizacionais nas últimas décadas, as quais colocam condições dinâmicas tanto para o trabalho como para a forma de oferecimento de ações educacionais. No cenário nacional e internacional, programas de TD\&E adotam atualmente, em larga escala, processos educacionais assentados na internet e nas novas tecnologias da informação e comunicação (NTICs).

$\mathrm{O}$ advento da tecnologia e sua presença cotidiana em quase todos os aspectos da vida humana atinge hoje em dia também os treinamentos, afetando o modo como se aprende (Salas et al., 2012). A eliminação das barreiras temporais e espaciais permitida por tais inovações, combinada à relevância da aprendizagem ao longo da vida, impulsiona a emergência de novos cenários educacionais ou a transformação daqueles vigentes (Coll, Mauri \& Onrubia, 2010). A diversificação das modalidades de entrega dos eventos educacionais introduz questões que merecem atenção e precisam ser discutidas como forma de atestar a qualidade e eficácia das ações a distância. Além disso, deve-se garantir que os resultados pretendidos por ações dessa natureza sejam alcançados e estejam de acordo com os objetivos previamente estabelecidos pela organização e pela própria ação educacional.

Ações educacionais são consideradas bem-sucedidas quando as competências adquiridas ou aprofundadas em TD\&E são aplicadas e transferidas apropriadamente para o contexto de trabalho (Aguinis \& Kraiger, 2009; Borges-Andrade, 1997; Meneses, Zerbini \& Abbad, 2010), sendo essencial a produção de conhecimento sobre o que ajuda e o que prejudica a efetividade de treinamentos (Salas et al., 2012). Nesse sentido, o interesse de pesquisa na área de avaliação de sistemas instrucionais a distância acompanha as transformações e inovações dos cursos ofertados em ambientes abertos de trabalho, tais como os oferecidos pelo Sistema $\mathrm{S}^{2}$ e corporativos.

\footnotetext{
${ }^{2}$ Compõem o Sistema S: SEBRAE (Serviço Brasileiro de Apoio às Micro e Pequenas Empresas); SENAI (Serviço Nacional de Aprendizagem Industrial); SESI (Serviço Social da Indústria); SENAC (Serviço Nacional de Aprendizagem Comercial); SESC (Serviço Social do Comércio); SENAR (Serviço Nacional
} 
Embora haja um interesse crescente de pesquisadores em contribuir com a área de avaliação de sistemas instrucionais ofertados a distância, apontando que a ciência tenta acompanhar a velocidade da prática, há ainda um grande descompasso entre a quantidade de estudos produzidos e o número de programas vigentes (Abbad, Zerbini \& Souza, 2010; Martins \& Zerbini, 2014a; Zerbini \& Abbad, 2010a). Há ainda muito a ser investigado sobre a melhor forma de projetar o ambiente de e-learning, como otimizar a sua entrega, e identificar o que funciona, quando e por quê (DeRouin, Fritzsche \& Salas, 2005). Diante desse cenário, a discussão sobre a avaliação de ações educacionais a distância, mediadas pela internet, e a sistematização de conhecimentos sobre o tema, é de extrema relevância (Abbad, Carvalho \& Zerbini, 2006; Martins, 2012; Salas \& Cannon-Bowers, 2001; Zerbini, 2007).

A análise da literatura mostra um expressivo número de pesquisas que nas últimas décadas buscam investigar variáveis que podem influenciar os resultados de ações educacionais, principalmente presenciais (Coelho, 2004; Lacerda \& Abbad, 2003; Meneses \& Abbad, 2003; Mourão, 2004; Pilati, 2004; Sallorenzo, 2000; Tamayo, 2002), e mais recentemente, produções científicas comparam os resultados de aprendizagem obtidos em programas de e-learning aos tradicionais, realizados em sala de aula (Carrol \& Burke, 2010; DeRouin et al., 2005; Ruth \& Conners, 2010; Shen, Chung, Challis \& Cheung, 2007).

Apesar das contribuições de tais estudos, em sua maioria, estudos de caso, artigos conceituais ou descritivos e com a proposição de modelos empíricos testados por meio de correlações e regressões (Burke \& Hutchins, 2007; Martins \& Zerbini, 2014a), para a produção de conhecimentos na área são necessárias investigações mais robustas que mostrem se os modelos empíricos corroboram a teoria, ou seja, se as relações estatísticas encontradas se confirmam na teoria. DeRouin et al. (2005) sinalizam a necessidade de mais teoria para orientar o desenho, a entrega, a implementação e a avaliação do $e$ learning, que informe como promover resultados positivos de aprendizagem baseados em resultados de pesquisa. Estudos sistemáticos para testagem de modelos, com a aplicação de metodologias mais avançadas e rigorosas, são particularmente escassos na produção científica brasileira, sendo fundamental ampliar o campo de conhecimento na área de avaliação de treinamentos corporativos a distância para ratificar ou refutar achados dos trabalhos empíricos já realizados na literatura internacional. 
A presente pesquisa visa contribuir com as áreas de avaliação e de efetividade de sistemas instrucionais, já que pretende construir e verificar evidências de validade de medidas de treinamento, bem como testar modelos de relacionamento de variáveis. $\mathrm{O}$ objetivo principal consiste em propor e testar um modelo de avaliação de ações educacionais corporativas ofertadas a distância, no qual seja possível identificar e mensurar os fatores que influenciam na efetividade de treinamentos dessa natureza, analisando o desempenho posterior do egresso no ambiente de trabalho, entre variáveis do indivíduo, de reação ao curso e do ambiente, e a variável critério do modelo será o Impacto do Treinamento no Trabalho, em profundidade e em amplitude. Para tanto, serão adaptadas e construídas medidas de avaliação em TD\&E, além da realização de análises estatísticas que alcancem os objetivos desta investigação.

Para facilitar o acompanhamento do texto, a Figura 1 mostra o modo como as (sub)seções estão estruturadas e sua sequência de apresentação no presente estudo.

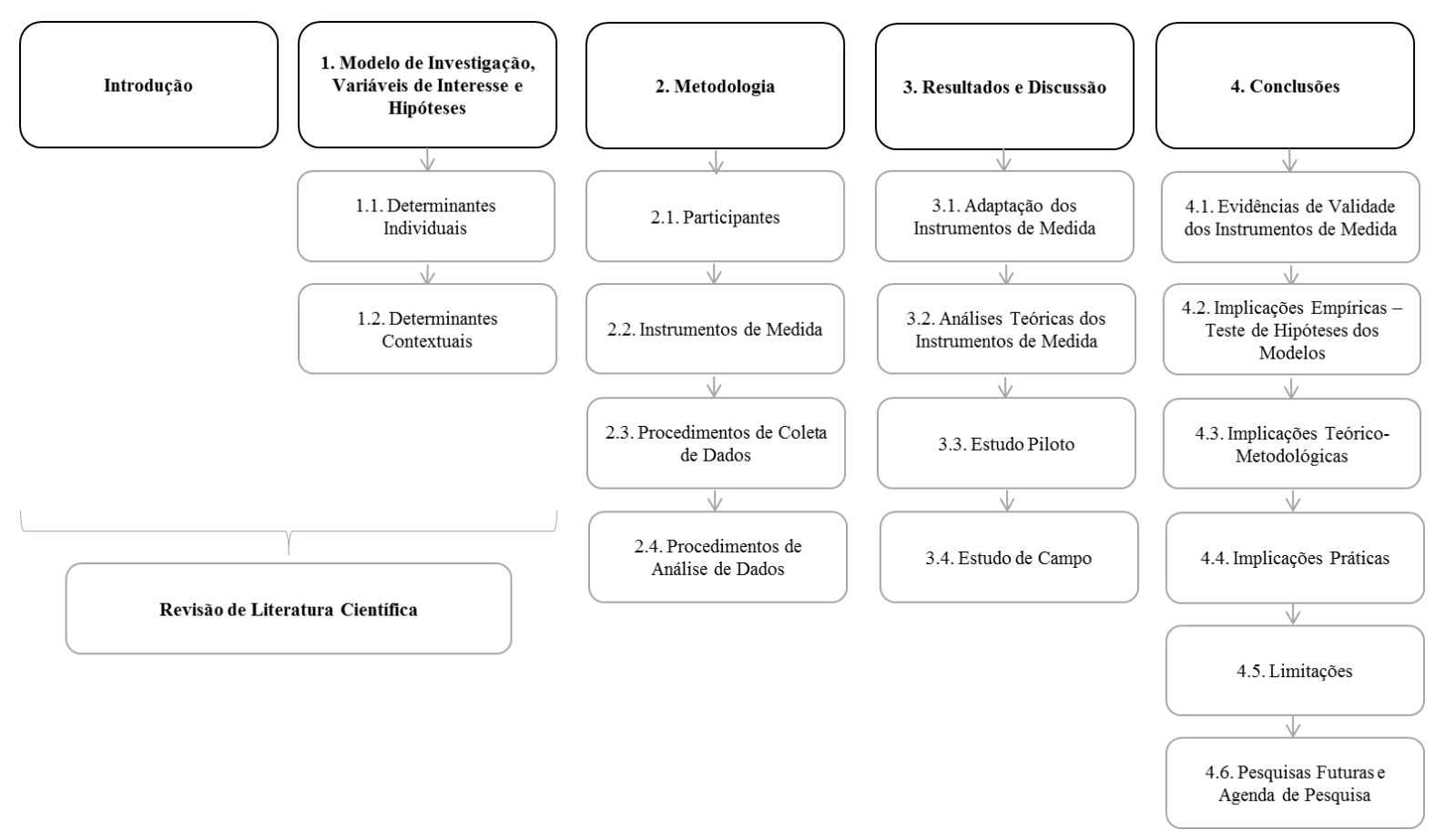

Figura 1. Estrutura geral de desenvolvimento do texto.

A Introdução e a seção 1, "Modelo de Investigação, Variáveis de Interesse e Hipóteses", apresentam o contexto e a temática da pesquisa, apontando os avanços e os desafios para a área de avaliação e efetividade de treinamentos a distância em contextos corporativos, bem como expõem os objetivos e a relevância da presente investigação, os 
resultados de pesquisa sobre as variáveis de interesse que compõem o modelo de investigação proposto e as hipóteses, teoricamente elaboradas, a serem testadas.

Na seção 2, "Metodologia", definem-se as características dos participantes e do curso avaliado, os instrumentos de medida, os procedimentos de coleta e de análise de dados utilizados.

A seção 3, "Resultados e Discussão", apresenta os processos de adaptação e validação teórica dos instrumentos de medida, descreve o estudo piloto realizado na Espanha, além de exibir o estudo de campo e as análises estatísticas derivadas do mesmo.

A seção 4, "Conclusões", indica as principais implicações teóricas, metodológicas, empíricas e práticas do presente trabalho para a área de avaliação e efetividade de treinamentos a distância em contextos corporativos, as limitações e algumas recomendações para as pesquisas futuras, além de propor uma agenda de pesquisa. 


\section{Introdução}

Processos de TD\&E são ações educacionais sistematizadas que promovem a aquisição de novas competências, visando a produção de mudanças cognitivas e comportamentais permanentes, com o propósito de aumentar o desempenho eficaz no trabalho (Bedwell \& Salas, 2010; Grossman \& Salas, 2011; Salas et al., 2012), sendo esperados efeitos na satisfação com o evento, na aprendizagem de habilidades e na consequente transferência das mesmas para o contexto das equipes e organizações (Aguinis \& Kraiger, 2009; Carvalho \& Abbad, 2006).

De acordo com Salas et al. (2012), as atividades de treinamento e desenvolvimento são fundamentais para a construção e a manutenção de uma força de trabalho efetiva, bem como permitem que as organizações se adaptem, compitam, inovem, produzam, mantenham-se seguras, melhorem o atendimento e atinjam metas. Além dos objetivos de aprender e transferir novos conhecimentos, habilidades e atitudes (CHAs) para o ambiente de trabalho, proporcionados pelos eventos instrucionais, as organizações esperam que essas novas competências adquiridas possam provocar impactos nos processos de trabalho das equipes e resultados organizacionais (Aguinis \& Kraiger, 2009; Zerbini et al., 2012a); transpondo assim o nível individual, mas agregando valor também nos níveis meso e macro (Burke \& Hutchins, 2007).

Para alcançar os efeitos de longa duração no desempenho dos indivíduos, não basta ser avaliada a satisfação dos participantes com os cursos ou a aquisição de aprendizagem decorrente da participação em ações educacionais específicas, mas devese buscar aferir de que forma e em que medida treinamentos afetam a performance dos participantes no trabalho (Burke \& Saks, 2009; Velada, Caetano, Michel, Lyons \& Kavanagh, 2007; Roszkowski \& Sovon, 2010; Vo \& Hannif, 2012; Zerbini et al., 2012a). Dessa forma, a avaliação da efetividade de ações de TD\&E exige medir seus efeitos sobre o desempenho individual dos egressos, por meio do uso de construtos úteis para tal finalidade, tais quais: transferência de treinamento e impacto do treinamento no trabalho (em profundidade e em amplitude).

$\mathrm{Na}$ literatura internacional, o fenômeno de resultado do treinamento no desempenho dos egressos é quase que invariavelmente denominado de "transfer of training” ou "training transfer". No Brasil, no entanto, a tradução literal deste conceito, ou seja, transferência de treinamento, é usada somente nas investigações que tratam dos ambientes abertos de trabalho, cabendo aos casos de pesquisas em contextos corporativos 
o termo impacto do treinamento no trabalho (profundidade e amplitude). Este termo é adotado no presente trabalho já que a operacionalização da pesquisa acontece em contexto corporativo. Portanto, ao longo do texto, os estudos internacionais consultados e os resultados de pesquisa cotejados que usavam como variável o termo "transfer of training/training transfer" serão entendidos como impacto do treinamento no trabalho. A análise e a discussão conceitual sobre os termos existentes na literatura nacional e estrangeira serão aprofundadas na seção 1.2.3.1, que trata da variável Impacto do Treinamento no Trabalho.

A importância da mensuração do impacto do treinamento no trabalho em programas de TD\&E é frequentemente propagada, já que visa verificar em que medida os investimentos constantes em ações formais e sistemáticas de TD\&E feitos pelas organizações resultam, de fato, na produção de resultados expressos sob a forma de novas competências no trabalho no nível do desempenho dos egressos (Borges-Andrade, Abbad \& Mourão, 2012; Cheng \& Hampson, 2008; Griffin, 2012; Grossman \& Salas, 2011).

Investimentos maciços em processos contínuos de aprendizagem e de desenvolvimento de competências continuam sendo diferenciais competitivos e estratégicos para as organizações (Abbad, Côrrea \& Meneses, 2010; Aguinis \& Kraiger, 2009), principalmente porque as exigências de desenvolvimento de competências críticas, pela atual economia global para a manutenção de vantagem competitiva, crescem e modificam-se rapidamente (Aguinis \& Kraiger, 2009) e dependem, em grande parte, da qualificação da força de trabalho (Salas et al., 2012). Para atender às constantes demandas de qualificação pessoal e profissional, os programas de TD\&E passam por alterações, que possibilitam a sua adaptação às aceleradas e recentes mudanças ocorridas em contextos organizacionais, ao adotar a mediação das NTICs e a internet como meio de entrega de suas ações educacionais.

\section{$\underline{\text { Treinamentos a distância em organizações e trabalho }}$}

O uso da Educação a Distância (EAD) em contextos corporativos permite acompanhar os processos de fusões e internacionalização de empresas, que requerem treinamentos capazes de atender simultaneamente públicos numerosos e dispersos por condições geográficas, físicas ou ocupacionais (Castro \& Ferreira, 2006), lidando, em muitos casos, com uma força de trabalho transcultural, formada por grupos heterogêneos, que devem colaborar a distância (Salas et al., 2012). Por exemplo, nota-se que 
funcionários que trabalham nas mesmas organizações, mas em regiões ou países diferentes, requerem tipos diferenciados de programas de e-learning. Essas variações nas preferências de e-learning exigem que as organizações o personalizem, alinhando as suas estratégias às dos participantes, visando atender necessidades e expectativas específicas. A adoção desta abordagem provavelmente tenha impacto sobre a satisfação dos treinandos, bem como melhore a aprendizagem no e-learning (Derouin et al., 2005).

Atualmente, situações mais complexas surgem em função das mudanças no mundo do trabalho, afetando também os modos de oferecer treinamentos. Salas et al. (2012) comentam que, dentre algumas das oportunidades e desafios de hoje que podem ter implicações para a área de TD\&E, destacam-se a presença de uma nova geração atuante no mercado de trabalho com diferentes motivações, expectativas e abordagens à aprendizagem. Para estes jovens, amplamente acostumados com a presença diária da internet e de múltiplas tecnologias, é que as ações educacionais devem ser desenhadas e ajustadas às suas características (Martins, 2012). Uma população que vive constantemente "conectada" provavelmente anseia obter uma experiência de aprendizagem que seja ao mesmo tempo relevante e interessante, podendo não se adaptar a uma abordagem de transmissão de informações por meio de longas aulas presenciais (Garrison \& Vaughan, 2008). Nesse contexto, a EAD passa a ser considerada uma importante alternativa educacional disponível para ampliar e democratizar o acesso às oportunidades de treinamento, viabilizando a construção de mecanismos que proporcionem situações de aprendizagem e de qualificação contínuas, além de ser um meio de ensino adequado a adultos e que pode ser utilizado no próprio ambiente de trabalho (Abbad et al., 2010).

Estudiosos consideram os treinamentos baseados em computadores ou o $e$ learning como potenciais mecanismos de entrega e ferramentas de ensino úteis para retornar benefícios tangíveis para as organizações, quando devidamente projetados, executados e avaliados (Bedwell \& Salas, 2010; Derouin et al., 2005). Ao passo que as novas tecnologias tornam-se amplamente difundidas e disponíveis a baixos custos, as organizações deparam-se com alternativas cada vez mais viáveis para a implementação de treinamentos que exploram o uso de videoconferências, sistemas eletrônicos de apoio ao desempenho, vídeos e cursos online usando a internet ou a intranet. Ainda que o $e$ learning venha sendo considerado mais conveniente do que os métodos de treinamento tradicionais (Derouin et al., 2005), Bedwell e Salas (2010) advertem que nem sempre as opções mais sofisticadas são a melhor solução, sendo importante considerar outros 
métodos que possam conduzir igualmente a treinamentos eficazes e que atendam a necessidades formativas específicas.

Uma instrução bem projetada funciona independentemente do modo de entrega ou dos meios utilizados e, para ser efetiva, deve ter um propósito claro, planejar todos os aspectos instrucionais cuidadosamente e incorporar os princípios de aprendizagem adequados (Bedwell \& Salas, 2010; Salas et al., 2012). Dessa forma, embora o e-learning venha se tornando um método dominante de entrega de treinamentos em ambientes de trabalho (Derouin et al., 2005), nem sempre a sua qualidade acompanha o aumento quantitativo expressivo observado na oferta dessas ações (Joo, Lim \& Park, 2011) e muito ainda permanece desconhecido nesse campo, cada vez mais importante, do $e$-learning nas organizações (Garavan, Carbery, O’Malley \& O’Donnell, 2010).

Ainda que as tecnologias emergentes sejam bastante promissoras enquanto recursos instrucionais, não garantem por si só a aprendizagem; por isso, deve-se investigar mais sobre o que funciona e o porquê, e quais as características específicas dessas novas tecnologias que contribuem realmente para a aquisição de habilidades (Salas et al., 2012). A ciência do treinamento, por meio de pesquisa básica e aplicada atualmente em curso, tenta acompanhar o desenvolvimento avançado e a influência da tecnologia no desenho e entrega de sistemas de treinamento, bem como dedica-se a descobrir como pode melhorar o desempenho humano, por meio da definição de princípios, diretrizes e critérios no acompanhamento de cursos a distância.

Os treinamentos a distância podem ser definidos como um conjunto de ações educacionais sistematicamente planejadas que são desenvolvidas de forma flexível nos âmbitos físico e temporal - ao passo que os conteúdos podem ser acessados em qualquer lugar e a qualquer hora -, promovem interações síncronas ou assíncronas entre os participantes, envolvem interatividade (grau de interação entre o aluno e o material do curso) e são constituídos por meios tecnológicos (recursos multimídia com figuras, animações e recursos de áudio, internet, intranet, videoconferências, etc.) que criam oportunidades diferenciadas para receber as informações (Derouin et al., 2005; Zerbini \& Abbad, 2005).

A adoção de uma ampla variedade de procedimentos, recursos e meios instrucionais, calcados em ferramentas virtuais e interativas, introduz condições diferenciadas de aprendizagem aos participantes, demandando deles, por exemplo, o uso efetivo de ferramentas computacionais ou da web para um bom aproveitamento do curso. Além de favorecer a interação entre os atores, promover a interatividade tecnológica e 
pedagógica, complementar a entrega dos conteúdos, flexibilizar e diversificar as atividades e estimular a aprendizagem colaborativa (Badia \& Monereo, 2010; Carvalho \& Abbad, 2006; Coll, 2004; Derouin et al., 2005; Martins, 2012; Mauri, Onrubia, Coll \& Columbia, 2005; Onrubia, 2005; Vaughan, 2007),

Inúmeras vantagens sobre os cursos a distância podem ser ressaltadas, como: aprendizagem mais independente e flexível, individualização do estudo com respeito ao ritmo, espaço e tempo do treinando, permanência do colaborador no ambiente organizacional - reduzindo gastos com viagens para participação em treinamentos -, formação concomitante de vários colaboradores distantes fisicamente, acesso simultâneo de um ambiente de simulação pelos alunos e aprendizagem coletiva (Alonso, 2010; Carswell \& Venkatesh, 2002; Castro \& Ferreira, 2006; Cheung, 2000; Döös \& Wilhelmson, 2011; Zerbini \& Abbad, 2010a). Considerando tais benefícios, aliados à redução de custos (Bedwell \& Salas, 2010), as organizações passam a considerar a modalidade a distância como uma medida viável para ofertar seus treinamentos.

Contudo, os fatores que podem facilitar ou limitar os efeitos exercidos pela EAD sobre o desempenho posterior do egresso no ambiente de trabalho têm sido pouco investigados (Brown, 2005; Welsh et al. 2003 citado por Aguinis \& Kraiger, 2009), principalmente em contextos corporativos (Abbad et al., 2010; Derouin et al., 2005; Joo et al., 2011) - a maior parte dos estudos sobre a efetividade do e-learning é realizada em ambientes educacionais, desde o ensino fundamental até o superior (Derouin et al., 2005) -, havendo poucas pesquisas sobre transferência de treinamento em ambientes abertos de trabalho, e impacto do treinamento no trabalho, medido em profundidade e em amplitude, em contextos corporativos de aprendizagem online (e.g. Garavan et al., 2010; Gunawardena, Linder-VanBerschot, LaPointe \& Rao, 2010; Joo et al., 2011; Mourão, Abbad \& Zerbini, 2014). A esse respeito, Salas et al. (2002) argumentam que, embora os resultados de pesquisa da área da educação tragam contribuições importantes, não podem ser transpostos para o contexto organizacional, pois o ambiente, as demandas e os objetivos do treinamento são substancialmente diferentes.

Os contextos virtuais de ensino apresentam particularidades que precisam ser identificadas para oferecer propostas de intervenção mais efetivas, sendo necessário empreender esforços no sentido de produzir, sistematizar e acumular conhecimentos na área que permitam atingir respostas úteis ao aperfeiçoamento de cursos $\mathrm{EAD}$, atestar a aplicabilidade da modalidade, obter informações pertinentes para efetuar alterações importantes visando resultados melhores e mais efetivos, oferecer subsídios para a 
aplicação de instrumentos em contextos específicos e orientações que possam auxiliar tanto desenhistas instrucionais a construir programas de treinamento na modalidade, quanto as equipes de Gestão de Pessoas responsáveis pela avaliação desses programas.

\section{Antecedentes da efetividade de treinamento no trabalho}

$\mathrm{Na}$ área de avaliação de TD\&E, os principais determinantes de impacto do treinamento no trabalho identificados são: desenho do treinamento ou aspectos facilitadores, fatores individuais ou características dos treinandos, ambiente de trabalho ou clima para transferir (Baldwin \& Ford, 1988; Velada et al., 2007). Nos estudos, há a utilização predominante da perspectiva do indivíduo em detrimento dos aspectos contextuais que podem afetar o desempenho, ainda que as variáveis situacionais venham apresentando maior poder de predição de impacto do treinamento (Abbad et al., 2012a; Aguinis \& Kraiger, 2009; D’netto, Bakas \& Bordia, 2008; Salas \& Cannon-Bowers, 2001; Zerbini \& Abbad, 2010b).

As condições individuais e ambientais pré e pós-treinamento impactam nos efeitos dos treinamentos (Derouin et al., 2005; Salas \& Cannon-Bowers, 2001; Salas et al., 2012; Tannenbaum \& Yukl, 1992). No pré-treinamento, importam em conjunto a maneira que o programa foi planejado e as habilidades dos treinandos ou sua experiência anterior para a produção de resultados bem-sucedidos (Salas et al., 2012); no pós, os egressos deixam o treinamento com novas habilidades e a intenção de aplicá-las no trabalho, mas limitações no ambiente interferem na transferência de tais habilidades, podendo inibir a aplicação dos conhecimentos adquiridos, sendo necessário portanto, diagnosticar o ambiente de trabalho para identificar e remover os potenciais obstáculos à eficácia da formação (Salas et al., 2012).

É amplamente aceito que as características dos treinandos possuem um poderoso papel no impacto do treinamento no trabalho (Burke \& Hutchins, 2007), relacionando-se positivamente com os efeitos de programas instrucionais. As características individuais dos aprendizes, os hábitos de vida, as expectativas, as estratégias utilizadas para alcançar aprendizagens, as motivações, os interesses e as metas podem influenciar na aquisição de competências durante um evento instrucional e na sua posterior aplicação em situações de trabalho (Meneses, Abbad, Zerbini \& Lacerda, 2006), portanto, conhecer o perfil dos participantes permite ajustar os programas instrucionais às suas características individuais e necessidades (Zerbini, 2007). 
Na revisão de literatura realizada por Burke e Hutchins (2007), as características dos aprendizes que apresentaram relacionamentos forte ou moderado com impacto do treinamento no trabalho são: autoeficácia, motivação pré-treinamento, capacidade cognitiva, utilidade percebida do treinamento - os novos conhecimentos e habilidades devem ser percebidos como aspectos relevantes que poderão melhorar o desempenho no trabalho (Baldwin \& Ford, 1988) -, planejamento de carreira e comprometimento organizacional. Os autores alertam que o desafio das pesquisas é estabelecer não apenas relações diretas, mas os efeitos da interação entre as variáveis individuais e os resultados de treinamento e, em seguida, incorporar estes resultados na avaliação de necessidades e intervenções.

As características pessoais gerais como gênero, idade, nível de escolaridade, cargo/função, anos de experiência de trabalho encontram-se majoritariamente presentes nas pesquisas da área de avaliação de eventos instrucionais, nas quais são medidos os efeitos dessas variáveis demográficas e funcionais em resultados de aprendizagem e impacto do treinamento no trabalho, pois indicam necessidades e disponibilidade dos participantes para o treinamento (Meneses et al., 2006) - embora muitos estudos mostrem que diferentes perfis da clientela não atuam como preditores e não têm impactos significativos sobre os resultados de efetividade do treinamento (e.g. Depieri, 2006; Hanke, 2006 citados por Pereira, 2009). Garavan et al. (2010) afirmam que em situações de e-learning, que requerem dos alunos cotas mais altas de responsabilidade e envolvimento, além de comportamentos autodirigidos e independentes, essas características podem ter maior relevância, ao lado de outras variáveis disposionais (e.g. autoeficácia, locus de controle, motivação para aprender, repertório de entrada, estratégias de aprendizagem, etc.), já apontadas em estudos anteriores como boas preditoras da participação em treinamentos.

A inserção e a análise das características individuais em pesquisas podem auxiliar na compreensão do processo de aprendizagem em adultos, identificar aquelas que podem melhorar o desempenho em atividades e contribuir para o desenvolvimento de modelos teóricos de treinamento e de avaliação (Warr \& Allan, 1998; Warr \& Downing, 2000). Várias questões levantadas na área de TD\&E podem ser respondidas por meio do estudo das características da clientela, como: a (in)satisfação com o curso, a aquisição ou não de aprendizagem, a possibilidade de transferir novos conhecimentos e habilidades, o fato de indivíduos apresentarem diferentes resultados ao final de um mesmo programa de TD\&E, e quais características influenciam de fato os resultados de um processo de aprendizagem. 
Essas informações permitiriam a implementação bem-sucedida de programas educacionais e a adoção de estratégias de ensino capazes de beneficiar todos os participantes dessas ações.

Salas et al. (2012) apontam que treinamentos devidamente projetados funcionam e a maneira pela qual se dá sua entrega e implementação pode influenciar sobremaneira em sua efetividade. O sucesso de um programa de treinamento depende da sua congruência com as metas organizacionais, das condições de trabalho e tecnologia existentes, do clima organizacional, dos recursos disponíveis, das restrições e dos suportes à transferência (Salas \& Cannon-Browers, 2001; Wexley, 1984). Os estudos sobre impacto do treinamento no trabalho validam a importância do ambiente organizacional, devendo-se examinar o ambiente de transferência de forma cuidadosa para identificar aspectos situacionais facilitadores e restritores, e propor maneiras para preparar os egressos a lidar com os restritores ou modificar o ambiente pós-treinamento para estimular a aplicação do que foi aprendido em ambientes de trabalho (Tannenbaum \& Yukl, 1992). Os aspectos do ambiente de trabalho que comprovadamente apresentam forte ou moderado relacionamento com o impacto do treinamento no trabalho são: clima para transferência, apoio gerencial e de pares, motivação e oportunidade para transferir criar ou prover oportunidades para o uso de novos aprendizados no ambiente de trabalho (Burke \& Hutchins, 2007; Salas et al., 2012).

Os estudos atuais, que aprofundam a explicação da influência de variáveis ambientais no treinamento, buscam desenvolver ferramentas práticas e de diagnóstico para determinar o contexto organizacional concernente ao treinamento, já que ao analisar os eventos que asseguram a aplicação dos recentes CHAs adquiridos e ao determinar quais fatores afetam o impacto do treinamento no trabalho, pode-se agir de modo a maximizá-los (Aguinis \& Kraiger, 2009; Salas \& Cannon-Bowers, 2001), além de ter como foco as interações entre variáveis individuais e contextuais como importantes determinantes para beneficiar a efetividade de ações instrucionais e investigar como influem no processo de aplicação eficaz no contexto de trabalho dos CHAs adquiridos durante ações instrucionais (Bhatti, Battour, Sundram \& Othman, 2013; Chiaburu \& Tekleab, 2005; Pilati \& Borges-Andrade, 2012).

Nesse sentido, pesquisas apontam para a necessidade de investigar os preditores da aplicação no trabalho das aprendizagens adquiridas nos treinamentos mediados pelas NTICs, as características pessoais dos participantes de treinamentos online (autoeficácia, motivação para aprender, satisfação, estratégias de aprendizagem) que interferem em sua 
aprendizagem, os aspectos referentes ao evento instrucional (natureza, desenho, volume, conteúdo e qualidade do treinamento) ou ao ambiente social e/ou organizacional circundante (suporte, cultura, clima) que influenciam os resultados de treinamento e podem interferir no desempenho (Abbad et al., 2010; Alvarez, Salas \& Garofano, 2004; Meneses \& Zerbini, 2005; Meneses, Zerbini \& Martins, 2012; Salas \& Cannon-Bowers, 2001; Tannenbaum \& Yukl, 1992); bem como despender esforços para entender o alcance e a influência de moderadores individuais e situacionais e explicar como operam para afetar a aprendizagem e o impacto do treinamento no trabalho, suprindo lacunas de pesquisas (Aguinis \& Kraiger, 2009).

Sobre o papel dos moderadores, Aguinis e Kraiger (2009) afirmam que a pesquisa científica em treinamento tem encontrado suporte para suas relações com intervenções, aprendizagem e performance no trabalho. E que o foco dos estudos dos moderadores da relação treinamento-impacto do treinamento no trabalho sobretudo se dá sobre fatores interpessoais e grupais, como os apoios de pares e chefias, e aspectos organizacionais, tais quais clima para transferir e ambiente de trabalho, sendo que os primeiros apresentam resultados mais consistentes.

Considerando que a explicação para cada nível de avaliação depende de uma complexa gama de variáveis pertencentes à organização, ao treinamento e ao indivíduo (Abbad, Gama \& Borges-Andrade, 2000), o presente estudo pretende contribuir para a produção de conhecimentos acerca do tema, ao propor e testar um modelo de avaliação de ações educacionais corporativas ofertadas a distância, no qual seja possível identificar fatores que influenciam na efetividade de treinamentos dessa natureza, entre variáveis do indivíduo (estratégias de aprendizagem), de reação ao curso (procedimentos instrucionais e desempenho do tutor) e do ambiente (barreiras e facilitadores em contexto a distância e suporte à transferência).

\section{Modelo de Investigação, Variáveis de Interesse e Hipóteses}

O modelo de investigação proposto foi baseado em modelos teóricos e empíricos previamente apresentados na literatura da área de avaliação de TD\&E; mais especificadamente, naqueles que propuseram investigar a efetividade de treinamentos, incluindo antecedentes, resultados e condições que incidem sobre ela (Abbad, 1999; Baldwin \& Ford, 1988; Borges-Andrade, 1982, 2006; Grossman \& Salas, 2011; Zerbini, 2007). Os fatores presentes nos modelos, que apresentam os mais fortes e consistentes 
relacionamentos com impacto do treinamento no trabalho (Grossman \& Salas, 2011), estão relacionados às características dos treinandos (e.g. capacidade cognitiva, autoeficácia, motivação, utilidade percebida do treinamento), aos aspectos do treinamento (e.g. modelagem comportamental, gestão de erros, ambientes de treinamento realistas) e do ambiente de trabalho (e.g. clima para transferência, suporte, oportunidade para transferir, follow-up).

O presente modelo almeja incluir além de variáveis comprovadamente relacionadas a impacto do treinamento no trabalho, como suporte e reações, algumas que têm sido negligenciadas na literatura da área ou que apresentam, até o momento, relações menos consistentes (por exemplo, estratégias de aprendizagem e barreiras e facilitadores em contexto a distância), mas que os estudos existentes apontam achados promissores quanto aos seus efeitos sobre o fenômeno de resultado do treinamento no desempenho do egresso. Dessa forma, com a testagem do modelo (Figura 2), contribuições podem ser dadas para que a área de avaliação de TD\&E avance em termos teóricos e empíricos.

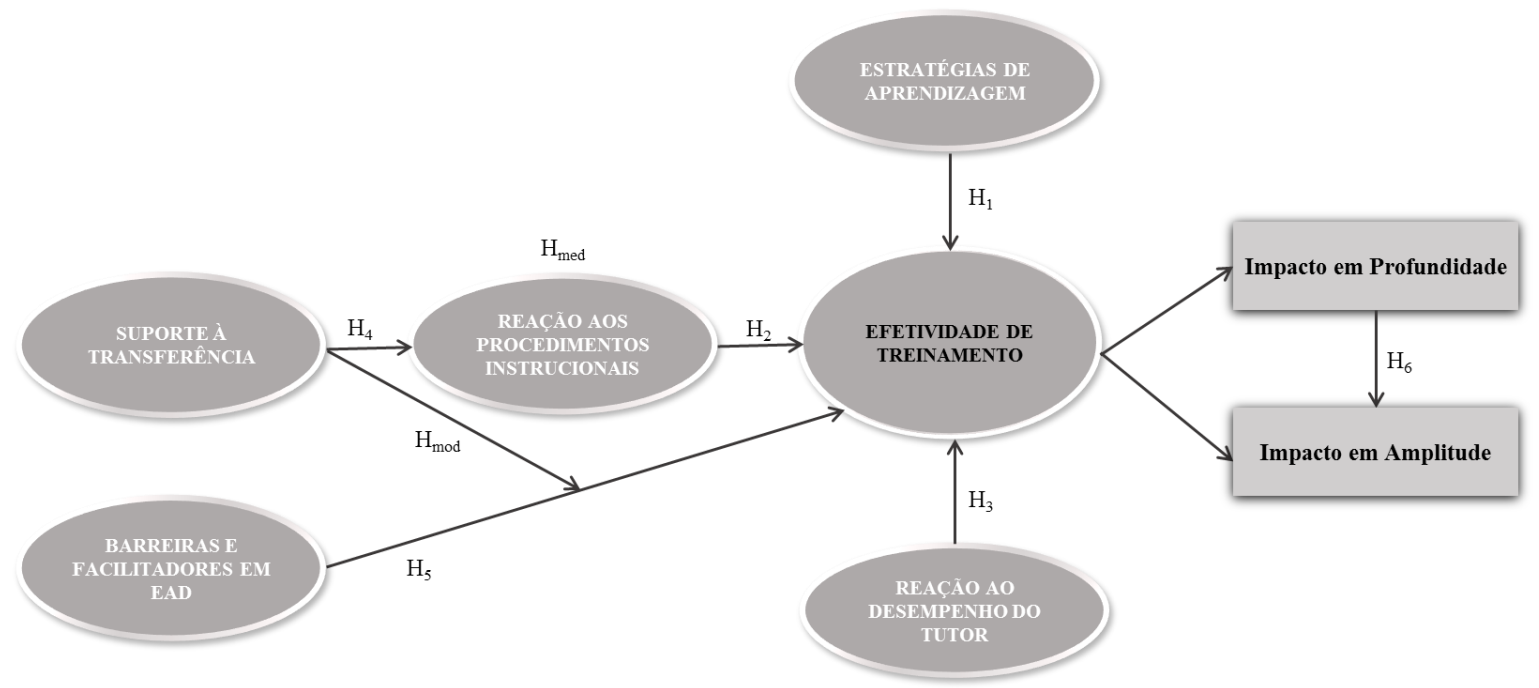

Figura 2. Modelo de investigação proposto.

$\mathrm{H}_{1 \mathrm{a}}$ : As estratégias de aprendizagem serão preditores positivos dos indicadores de efetividade de treinamento.

$\mathrm{H}_{1 b}$ : As estratégias de aprendizagem autorregulatórias interferirão mais sobre os indicadores de efetividade de treinamento do que as estratégias cognitivas e comportamentais.

$\mathrm{H}_{2}$ : A satisfação com os aspectos formais do curso será preditor positivo dos indicadores de efetividade de treinamento.

$\mathrm{H}_{3}$ : A satisfação com o desempenho do tutor será preditor positivo dos indicadores de efetividade de treinamento.

$\mathrm{H}_{\text {med: }}$ As reações aos procedimentos instrucionais do curso mediarão o suporte à transferência e os indicadores de efetividade de treinamento.

$\mathrm{H}_{4 a}$ : $\mathrm{O}$ suporte à transferência de novas competências adquiridas em treinamento estará positivamente relacionado aos indicadores de efetividade de treinamento.

$\mathrm{H}_{4 b}$ : $\mathrm{O}$ suporte psicossocial interferirá mais sobre os indicadores de efetividade de treinamento do que o suporte material.

$\mathrm{H}_{5}$ : À medida em que os participantes perceberem os recursos como facilitadores e não como barreiras será positivamente relacionada com os indicadores de efetividade de treinamento. 
$\mathrm{H}_{\text {mod: }} \mathrm{O}$ suporte à transferência atuará como moderador da relação entre as barreiras e facilitadores em EAD e os indicadores de efetividade de treinamento.

$\mathrm{H}_{6}$ : Os participantes que aplicarem as novas competências diretamente em seus cargos (impacto em profundidade) também modificarão seu desempenho global, motivação e atitudes (impacto em amplitude).

A seguir, são delimitados e definidos os construtos presentes no modelo de investigação proposto, apontando os efeitos já conhecidos de cada conceito sobre o impacto do treinamento no trabalho, previamente demonstrados em estudos existentes na literatura, tendo como foco o contexto de investigação específico considerado: treinamentos virtuais; seguidos das hipóteses que se pretendem testar, elaboradas com base na análise dos resultados de pesquisa cotejados.

As seções foram organizadas segundo os eixos: 1) Determinantes Individuais: Variáveis do Aprendiz (Estratégias de Aprendizagem) e 2) Determinantes Contextuais: Variáveis do Curso (Reações), Variáveis do Ambiente (Suporte à Transferência e Barreiras e Facilitadores em EAD) e Variáveis de Efetividade de Treinamento (Impacto do Treinamento no Trabalho).

\subsection{Determinantes Individuais}

\subsubsection{Variáveis do aprendiz.}

\subsubsection{Estratégias de aprendizagem.}

Para facilitar a aquisição, o armazenamento e a posterior aplicação dos conhecimentos aprendidos em ações educacionais, são utilizados pelos aprendizes procedimentos denominados de Estratégias de Aprendizagem. Estas compreendem um conjunto de capacidades cognitivas complexas, habilidades comportamentais e de autocontrole emocional, que é lançado mão de maneira consciente, intencional e adaptado às condições do contexto para alcançar objetivos de aprendizagem específicos (Badia \& Monereo, 2010; Beluce \& Oliveira, 2012).

As estratégias de aprendizagem cognitivas e comportamentais são usadas diretamente no momento de contato do aprendiz com o material a ser aprendido, sendo úteis para selecionar, decodificar, organizar, armazenar, elaborar e recuperar as informações. As autorregulatórias, ou metacognitivas, têm um impacto indireto, influenciando como os aprendizes mantêm a motivação para aprender, a autogestão de esforços e de automonitoramento do progresso durante a aprendizagem e o controle de 
ansiedade diante de determinadas situações (Oliveira, Boruchovitch \& Santos, 2009; Warr \& Allan, 1998).

Warr e Allan (1998) propuseram um sistema de classificação dos diferentes tipos de estratégias de aprendizagem, divididas em três componentes: 1) cognitivas: repetição mental, organização e elaboração; 2) comportamentais: busca de ajuda interpessoal, busca de ajuda ao material didático e aplicação prática; 3) autorregulatórias: controle da emoção, controle da motivação e monitoramento da compreensão.

Na Tabela 1 a seguir são apresentadas mais detalhadamente cada uma das estratégias de aprendizagem citadas.

Tabela 1. Classificação e definições das estratégias de aprendizagem (Warr \& Allan, 1998; Zerbini, 2007).

- Repetição: abrange procedimentos de repetição mental da informação na forma em que foi apresentada

- Organização: consiste na identificação de ideias centrais do material e criação de esquemas mentais que agrupam e relacionam elementos a serem aprendidos

- Elaboração: avalia ou reflete sobre implicações e conexões possíveis entre o material aprendido e o conhecimento já existente

- Busca de ajuda interpessoal: obtenção de auxílio de outras pessoas, como pares e professores, para tirar dúvidas sobre o material (representa um comportamento proativo

do indivíduo de solicitar ajuda ao invés de utilizar apenas as informações do próprio
procedimento instrucional)
procedimento instrucional)

- Busca de ajuda no material didático: obtenção de informações em documentos escritos, manuais de instruções, programas de computador e outras fontes que não envolvam contato social

- Aplicação prática: aprimoramento do conhecimento por meio de aplicação prática do que foi aprendido

- Controle da emoção: controle da ansiedade e prevenção de dispersões de concentração, causadas por sentimentos de ansiedade

- Controle da motivação: controlar a motivação e a atenção, apesar de existência de um interesse limitado na tarefa a ser aprendida

- Monitoramento da compreensão: a avaliação do processo de aquisição de aprendizagem e modificação do comportamento do indivíduo quando necessário

Tannenbaum e Yukl (1992) já alertavam que as rápidas mudanças tecnológicas exigiriam o desenvolvimento de novas tarefas e procedimentos de trabalho, os quais requereriam maiores esforços cognitivos. Em contextos organizacionais, as estratégias de aprendizagem corresponderiam às ações e medidas cognitivas efetuadas pelo indivíduo visando a compreensão de determinado objeto (Sonnentag, Niesse \& Ohly, 2004), envolvendo fatores de natureza diversa, inclusive motivacionais, que podem alavancar o seu uso (Souza, 2010). 
À faculdade de planificar, de dirigir a compreensão e de avaliar o que foi aprendido, ou seja, o uso da capacidade de conhecer o funcionamento de alguns processos cognitivos como a memória, a atenção ou a compreensão, denomina-se metacognição (Flavell, 1970). Enquanto as estratégias cognitivas estão voltadas ao cumprimento de tarefas, as estratégias metacognitivas relacionam-se à ordenação, regulação e monitoramento das primeiras, possibilitando verificar se a estratégia utilizada está gerando os resultados pretendidos (Souza, 2010) e refletir acerca das ações tomadas para o alcance do conhecimento, alterando e elaborando novos meios que permitam sanar dificuldades ou obstáculos (Oliveira et al., 2009).

A cobrança por competências diferenciadas, que incluam o autogerenciamento dos processos subjacentes à aprendizagem, reflexões e interpretações sobre possíveis erros cometidos, e que levem à aquisição do conhecimento, estende-se por toda a vida, não se restringindo apenas aos contextos escolares, sendo fundamental possuí-las como um dos fatores de sobrevivência nos atuais cenários de ensino virtuais e como elementos essenciais para a aprendizagem bem-sucedida (Bjork, Dunlosky \& Kornell, 2013). Os programas de e-learning nas organizações tendem a oferecer aos treinandos, cada vez mais, maiores quantidades de controle sobre a sua própria aprendizagem (Derouin et al., 2005), e as competências requeridas para ensinar e aprender em um contexto distante, virtual, provavelmente, diferem daquelas necessárias em um contexto local (Badia \& Monereo, 2010; Tichon, 2007; Wang \& Haggerty, 2009) - como já apontam alguns resultados de pesquisa que compararam as estratégias de aprendizagem usadas por universitários em diferentes modalidades (Donolo, Chiecher \& Rinaudo, 2004; Riveiro \& Nieto, 2004), com destaque para o maior uso de estratégias comportamentais (busca por ajuda interpessoal) na presencial e de estratégias cognitivas (e.g. repetição, organização) e autorregulatórias na virtual ou híbrida -, modelo de ensino que combina práticas pedagógicas das modalidades presencial e a distância, também conhecido como blended-learning.

Aqueles que são treinados em uma estratégia efetiva alcançam melhor desempenho (Tannenbaum \& Yukl, 1992; Wexley, 1984). Logo, deve-se identificar as diferentes estratégias de aprendizagem usadas pelos treinandos e investir em estudos a respeito do emprego das mais adequadas e que produzem melhores resultados, considerando as necessidades e particularidades da modalidade EAD e os alertas sobre o papel importante das habilidades de autorregulação da aprendizagem nas ações educacionais a distância (Vovides, Sanchez-Alonso, Mitropoulou \& Nickmans, 2007). 
As características individuais podem ter maior influência nos efeitos de treinamentos a distância do que nos presenciais, por se tratar de uma aprendizagem que parece depender mais do esforço do próprio indivíduo (autogerenciamento da aprendizagem) do que dos recursos instrucionais (Zerbini, 2007). Além das características mais estudadas tais como gênero, idade, motivação, ansiedade e autoeficácia, devem-se investigar variáveis cognitivo-comportamentais, tais como as estratégias de aprendizagem utilizadas pelos alunos durante ações educacionais de natureza diferentes (Meneses et al., 2006; Warr \& Allan, 1998; Warr \& Downing, 2000). O estudo das estratégias de aprendizagem usadas pelos aprendizes pode auxiliar no planejamento instrucional de cursos a distância, podendo os resultados de pesquisa ser utilizados no delineamento e aperfeiçoamento dos mesmos (Santos et al., 2004; Zerbini, 2007). Ou ainda, por serem passíveis de serem aprendidas e modificadas, o ensino de tais estratégias implicariam, não necessariamente, na mudança dos procedimentos instrucionais, mas afetariam a maneira como os aprendizes procedem ao aprender.

Entender a competência das pessoas enquanto aprendizes e como elas podem aprender melhor como se aprende (Warr \& Allan, 1998) é fundamental ao considerar que o "aprender a aprender" é estratégico (Oliveira et al., 2009; Zabalza, 2005) no contexto atual que exige continuamente o gerenciamento da informação e a sua transformação em conhecimento (Badia \& Monereo, 2010). Os novos cenários, bem como as ferramentas e finalidades colocadas pelas modalidades de ensino online, por serem mais personalizadas e autônomas, permitem a assunção de cotas maiores de autoaprendizagem, exigindo que as pessoas se tornem aprendizes permanentes e aptos a planejar, autorregular e autoavaliar seus próprios processos de aprendizagem (Badia \& Monereo, 2010).

Estudiosos recomendam que mais investigações são necessárias para entender se e como as estratégias de aprendizagem estão relacionadas a resultados como desempenho, aquisição de conhecimentos e diferenças qualitativas em entendimento e inovação (Holman, Epitropaki \& Fernie, 2001). Uma quantidade crescente de evidências empíricas sugere que os processos de autorregulação dos aprendizes mediam a relação treinamentoaprendizagem (Aguinis \& Kraiger, 2009) e que estratégias de autogerenciamento são também relevantes para o impacto do treinamento no trabalho, pois fornecem ao aprendiz habilidades que o auxiliam a transferir com sucesso quando volta ao local de trabalho (Burke \& Hutchins, 2007). A autorregulação, segundo Salas et al. (2012), refere-se às cognições que podem ajudar o aprendiz a manter sua atenção focada na aprendizagem por meio do automonitoramento de desempenho, comparação do progresso para atingir 
um objetivo final e ajuste do esforço e da estratégia de aprendizagem conforme seja apropriado. Burke e Hutchins (2007) advertem que embora progressos nesse campo venham sido feitos na última década, o foco recai sobre o processo de aprendizagem e somente, indiretamente e em menos casos, sobre o impacto do treinamento no trabalho. Os estudos sobre as habilidades metacognitivas dos treinandos, isto é, a capacidade de automonitorar e autorregular as suas estratégias de aprendizagem para maximizar a aprendizagem e o desempenho precisam evoluir e as perspectivas de isso acontecer são promissoras.

Durante o processo de aquisição de conhecimentos, aprendizes devem ser orientados, auxiliados e incentivados a usar as estratégias mais adequadas e saber identificar as estratégias de (in)sucesso, reconsiderando e aprimorando os passos a serem tomados. Há a necessidade de envolver os aprendizes em processos autorregulatórios durante o treinamento, para incentivá-los a refletir se estão aprendendo o que deveriam aprender e a ajustar a aquisição dos novos aprendizados, quando necessário (Salas et al., 2012), uma vez que as estratégias de aprendizagem vêm sendo comprovadamente e positivamente relacionadas a bons resultados e sucesso acadêmico em ambientes de aprendizagem online (Costa \& Boruchovitch, 2009; Johnson, Gueutal \& Falbe, 2009; Martins, 2012; Oliveira et al., 2009; Warr \& Bunce, 1995; Warr \& Downing, 2000), especialmente aquelas que promovem o monitoramento da compreensão e o controle da motivação, ansiedade e atenção no momento de estudo, ou seja, as autorregulatórias.

Da mesma forma, destacam-se as evidências relacionadas à combinação de distintas estratégias, inclusive as cognitivas e comportamentais, como influentes na predição de impacto do treinamento a distância no trabalho, melhor desempenho acadêmico e resultados de aprendizagem (Warr \& Downing, 2000; Zerbini \& Abbad, 2010b). Em cursos técnicos, as estratégias cognitivas (repetição mental e reflexão ativa), comportamentais (busca de ajuda no material escrito e aplicação prática) e autorregulatórias (controle da emoção e controle da motivação) estiveram positivamente relacionadas a mudanças no conhecimento (Warr \& Downing, 2000). As estratégias de repetição mental e comportamentais usadas durante o treinamento avaliado por Warr e Allan (1998) estiveram positivamente correlacionadas à transferência. Em Zerbini e Abbad (2008a, 2010a), os participantes de um curso aberto de qualificação profissional ofertado a distância, que utilizaram com mais frequência as estratégias de aprendizagem de elaboração e monitoramento da compreensão, foram os que relataram impacto do 
treinamento no trabalho; e os que elaboraram o plano de negócios usaram mais frequentemente a estratégia de busca de ajuda interpessoal.

As interações com pares e professores, para tirar dúvidas ou buscar auxílio (Testa \& Luciano, 2010), estão marcadamente presentes nos estudos, relacionando-se à aquisição, retenção e transferência de novas competências (Brandão \& Borges-Andrade, 2011; Pantoja \& Borges-Andrade, 2009), junto às estratégias de aplicação prática (Zerbini \& Abbad, 2005; Pantoja, 2004), indicando a importância das estratégias de natureza comportamental para aprender e transferir em contextos organizacionais.

As estratégias de aprendizagem também são estudadas como maneiras pelas quais os indivíduos adquirem novos conhecimentos, habilidades e atitudes no ambiente de trabalho, como por exemplo: por meio de cursos e programas de treinamento, ao trabalhar com ou observar outras pessoas, tentativa e erro, lendo ou pesquisando, refletindo sobre ações, feedback e replicação (Crouse, Doyle \& Young, 2011). Além de haver estudos que confirmem que as estratégias de aprendizagem utilizadas por adultos no ambiente de trabalho são semelhantes àquelas usadas em contextos educacionais (Holman et al., 2001). No estudo de Crouse et al. (2011), por exemplo, os participantes (gerentes de RH) tendiam a usar estratégias de aprendizagem que envolviam a realização de seu trabalho, o que se assemelha às estratégias de aplicação prática. De acordo com Salas et al. (2012), as oportunidades de prática durante a ação educacional devem possibilitar aos treinandos o envolvimento em semelhantes processos cognitivos que serão demandados quando retornarem ao trabalho.

Uma importante linha de pesquisa sobre estratégias de aprendizagem existe no Brasil, com enfoque tanto nas estratégias aplicadas pelos indivíduos para aprender durante ações formais de treinamento, como nas práticas, manifestas e encobertas, utilizadas por profissionais para auxiliar a aquisição informal de conhecimentos e habilidades em seu ambiente de trabalho (Brandão \& Borges-Andrade, 2011; Brant, Pilati \& Borges-Andrade, 2015; Pantoja \& Borges-Andrade, 2009). As estratégias de aprendizagem no trabalho configuram-se como um dos elementos decisivos à otimização dos processos de aprendizagem dos indivíduos em ambientes organizacionais (Pantoja \& Borges-Andrade, 2009), contextos em que há demandas constantes por resultados de aprendizagem (Moraes \& Borges-Andrade, 2010a), e ao mesmo tempo, oportunidades para promovê-la por meio de observações do comportamento dos outros, reflexão sobre a própria conduta, orientações recebidas de supervisores, etc. (Brandão \& BorgesAndrade, 2011). 
Os estudos que vêm sendo realizados têm como objetivo validar escalas que medem estratégias de aprendizagem no trabalho (e.g. Brandão \& Borges-Andrade, 2011; Brant, Pilati \& Borges-Andrade, 2015; Moraes \& Borges-Andrade, 2010b; Pilati \& Borges-Andrade, 2005), as quais se assemelham às dimensões de estratégias de aprendizagem propostas em outros contextos (Borges-Ferreira, 2005; Martins \& Zerbini, 2014b; Zerbini \& Abbad, 2008), e buscam identificar as estratégias mais utilizadas para aprender no trabalho, sua influência na aquisição, retenção e aplicação das novas competências adquiridas, bem como detectar preditores do uso dessas estratégias empreendidas pelo trabalhador entre características do indivíduo, do posto de trabalho e dos contextos das organizações. Alguns resultados mostram que as estratégias de aprendizagem mais utilizadas por gestores de um banco público foram busca de ajuda interpessoal e reflexão ativa (Brandão \& Borges-Andrade, 2011); em processos de aprendizagem informal, diferentes categorias profissionais usaram mais frequentemente as estratégias de aplicação prática e de busca de ajuda interpessoal (Pantoja \& BorgesAndrade, 2009); e as de busca de ajuda interpessoal, aplicação prática, reflexão intrínseca e extrínseca, busca de ajuda em material escrito foram preditoras da expressão de competências de liderança dentre gestores de equipes (Lins \& Borges-Andrade, 2014).

A Tabela 2 mostra resultados de pesquisa sobre as estratégias de aprendizagem. 
Tabela 2. Pesquisas sobre Estratégias de Aprendizagem.

\begin{tabular}{|c|c|c|c|c|c|}
\hline Autores & Objetivo & Amostra/Contexto & $\begin{array}{c}\text { Procedimentos de } \\
\text { coleta de dados }\end{array}$ & $\begin{array}{l}\text { Procedimentos de } \\
\text { análise de dados }\end{array}$ & Resultados \\
\hline $\begin{array}{l}\text { Warr \& } \\
\text { Downing } \\
(2000)\end{array}$ & $\begin{array}{l}\text { Validar uma escala de } \\
\text { estratégias de aprendizagem e } \\
\text { investigar a relação entre } \\
\text { estratégias de aprendizagem, } \\
\text { ansiedade para aprender e } \\
\text { aquisição de conhecimento }\end{array}$ & $\begin{array}{l}152 \text { participantes de } \\
\text { um curso de mecânica } \\
\text { básica }\end{array}$ & $\begin{array}{l}\text { Aplicação de } \\
\text { questionários }\end{array}$ & $\begin{array}{l}\text { Análise fatorial } \\
\text { exploratória }\end{array}$ & $\begin{array}{l}\text { Apenas busca por ajuda } \\
\text { interpessoal e monitoramento da } \\
\text { compreensão não foram } \\
\text { positivamente relacionadas a } \\
\text { mudanças no conhecimento; } \\
\text { Estratégias de ensaio, busca de } \\
\text { ajuda interpessoal e de material } \\
\text { escrito, controle emocional e } \\
\text { motivacional são mais utilizadas } \\
\text { pelos participantes com alta } \\
\text { ansiedade em relação a tarefa de } \\
\text { aprendizagem; } \\
\text { Participantes com altos níveis de } \\
\text { motivação anterior a aprendizagem } \\
\text { usam mais reflexão ativa, controle } \\
\text { emocional e monitoramento da } \\
\text { compreensão; } \\
\text { Participantes com trabalhos } \\
\text { anteriores relevantes usam menos } \\
\text { busca de ajuda interpessoal e de } \\
\text { material escrito e controle } \\
\text { emocional; } \\
\text { Participantes mais velhos usam } \\
\text { mais a estratégia de ensaio. }\end{array}$ \\
\hline
\end{tabular}


Tabela 2. Pesquisas sobre Estratégias de Aprendizagem. (Continuação)

\begin{tabular}{|c|c|c|c|c|c|}
\hline Autores & Objetivo & Amostra/Contexto & $\begin{array}{l}\text { Procedimentos de } \\
\text { coleta de dados }\end{array}$ & $\begin{array}{l}\text { Procedimentos de } \\
\text { análise de dados }\end{array}$ & Resultados \\
\hline $\begin{array}{l}\text { Holman, } \\
\text { Epitropaki \& } \\
\text { Fernie (2001) }\end{array}$ & $\begin{array}{l}\text { Validar uma escala de } \\
\text { estratégias de aprendizagem, } \\
\text { provinda de ambiente } \\
\text { educacional, em um contexto } \\
\text { organizacional }\end{array}$ & $\begin{array}{l}628 \text { agentes de call } \\
\text { center de um Banco } \\
\text { (Reino Unido) }\end{array}$ & $\begin{array}{l}\text { Aplicação de } \\
\text { questionários }\end{array}$ & $\begin{array}{l}\text { Análises fatoriais } \\
\text { exploratórias e } \\
\text { confirmatórias }\end{array}$ & $\begin{array}{l}\text { - } \text { As estratégias de aprendizagem } \\
\text { utilizadas por adultos em contextos } \\
\text { de trabalho são similares às usadas } \\
\text { em ambientes educacionais; } \\
\text { - } 22 \text { itens; } 6 \text { fatores divididos em } 2 \\
\text { tipos de estratégias: cognitivas } \\
\text { (reprodução, organização e } \\
\text { elaboração) e comportamentais } \\
\text { (busca de ajuda interpessoal, busca } \\
\text { de ajuda ao material didático e } \\
\text { aplicação prática). }\end{array}$ \\
\hline $\begin{array}{l}\text { Zerbini \& } \\
\text { Abbad (2005) }\end{array}$ & $\begin{array}{l}\text { Relacionar o uso de } \\
\text { estratégias de aprendizagem } \\
\text { às reações aos procedimentos } \\
\text { instrucionais de um curso via } \\
\text { internet e reações ao tutor e } \\
\text { impacto do treinamento no } \\
\text { trabalho }\end{array}$ & $\begin{array}{l}188 \text { e } 354 \text { participantes } \\
\text { do curso a distância } \\
\text { IPGN (SEBRAE) }\end{array}$ & $\begin{array}{l}\text { Aplicação de } \\
\text { questionários online }\end{array}$ & $\begin{array}{l}\text { Análise fatorial } \\
\text { exploratória } \\
\text { Análise de regressão } \\
\text { múltipla }\end{array}$ & $\begin{array}{l}\text { Apenas as estratégias de } \\
\text { elaboração e aplicação prática } \\
\text { explicaram o impacto do } \\
\text { treinamento no trabalho. }\end{array}$ \\
\hline Pantoja (2004) & $\begin{array}{l}\text { Investigar o relacionamento } \\
\text { entre estratégias de } \\
\text { aprendizagem, características } \\
\text { da organização e percepções } \\
\text { de suporte à aprendizagem } \\
\text { contínua }\end{array}$ & $\begin{array}{l}900 \text { trabalhadores de } \\
16 \text { categorias distintas } \\
\text { atuantes em diferentes } \\
\text { segmentos } \\
\text { organizacionais }\end{array}$ & $\begin{array}{l}\text { Aplicação de } \\
\text { questionários }\end{array}$ & $\begin{array}{l}\text { Teste de } 5 \text { modelos } \\
\text { multiníveis para } \\
\text { verificação do efeito } \\
\text { específico de } \\
\text { variáveis preditoras } \\
\text { nas estratégias de } \\
\text { aprendizagem no } \\
\text { local de trabalho } \\
\text { Análise fatorial } \\
\text { exploratória }\end{array}$ & $\begin{array}{l}\text { Diferentes correlações encontradas } \\
\text { entre as variáveis individuais } \\
\text { (idade, gênero, anos de estudo, } \\
\text { categoria profissional) e a } \\
\text { utilização de estratégias de } \\
\text { aprendizagem no local de trabalho; } \\
\text { Destaque para a estratégia } \\
\text { aplicação prática para a } \\
\text { aprendizagem dos indivíduos; } \\
\text { Há diferenças significativas entre } \\
\text { as estratégias de aprendizagem } \\
\text { utilizadas no local de trabalho } \\
\text { conforme a categoria profissional. }\end{array}$ \\
\hline
\end{tabular}


Tabela 2. Pesquisas sobre Estratégias de Aprendizagem. (Continuação)

\begin{tabular}{|c|c|c|c|c|c|}
\hline Autores & Objetivo & Amostra/Contexto & $\begin{array}{l}\text { Procedimentos de } \\
\text { coleta de dados }\end{array}$ & $\begin{array}{l}\text { Procedimentos de } \\
\text { análise de dados }\end{array}$ & Resultados \\
\hline $\begin{array}{l}\text { Pantoja \& } \\
\text { Borges- } \\
\text { Andrade (2009) }\end{array}$ & $\begin{array}{l}\text { Mapear estratégias de } \\
\text { aprendizagem no trabalho } \\
\text { com o objetivo de classificar } \\
\text { dezesseis ocupações } \\
\text { profissionais, em quatro } \\
\text { categorias de postos de } \\
\text { trabalho, bem como descrever } \\
\text { e comparar as estratégias } \\
\text { utilizadas pelos indivíduos } \\
\text { para aprenderem, em seu dia- } \\
\text { a-dia no trabalho, nessas } \\
\text { diferentes categorias } \\
\text { profissionais }\end{array}$ & $\begin{array}{l}12 \text { coordenadores de } \\
\text { RH e } 55 \text { representantes } \\
\text { das dezesseis } \\
\text { ocupações } \\
\text { profissionais estudadas }\end{array}$ & $\begin{array}{l}\text { Entrevistas } \\
\text { semiestruturadas } \\
\text { baseadas na técnica } \\
\text { de incidentes críticos }\end{array}$ & Análise de conteúdo & $\begin{array}{l}\text { As estratégias aplicação prática e } \\
\text { busca de ajuda interpessoal } \\
\text { exerceram papel primordial nos } \\
\text { processos de aquisição, retenção e } \\
\text { transferência de novas } \\
\text { competências em âmbito laboral; } \\
\text { Diferentes configurações de uso de } \\
\text { estratégias de aprendizagem } \\
\text { estiveram associadas às categorias } \\
\text { profissionais estudadas. }\end{array}$ \\
\hline $\begin{array}{l}\text { Zerbini e } \\
\text { Abbad (2008a, } \\
\text { 2010a) }\end{array}$ & $\begin{array}{l}\text { Identificar variáveis } \\
\text { explicativas da aplicação de } \\
\text { habilidades ensinadas aos } \\
\text { participantes de um curso de } \\
\text { qualificação profissional a } \\
\text { distância, via internet }\end{array}$ & $\begin{array}{l}4.719 / 470 \\
\text { participantes do curso } \\
\text { a distância IPGN } \\
\text { (SEBRAE) }\end{array}$ & $\begin{array}{l}\text { Aplicação de } \\
\text { questionários online }\end{array}$ & $\begin{array}{l}\text { Análise fatorial } \\
\text { exploratória } \\
\text { Análise de regressão } \\
\text { múltipla }\end{array}$ & $\begin{array}{l}\text { Participantes que utilizaram com } \\
\text { mais frequência as estratégias de } \\
\text { aprendizagem elaboração e } \\
\text { monitoramento da compreensão } \\
\text { foram os que relataram maior } \\
\text { ocorrência de impacto do } \\
\text { treinamento no trabalho; } \\
\text { Os participantes que elaboraram o } \\
\text { plano de negócios utilizaram com } \\
\text { mais frequência a estratégia de } \\
\text { aprendizagem busca de ajuda } \\
\text { interpessoal. }\end{array}$ \\
\hline $\begin{array}{l}\text { Abbad, Côrrea } \\
\& \text { Meneses } \\
(2010)\end{array}$ & $\begin{array}{l}\text { Analisar as relações entre } \\
\text { estratégias de aprendizagem e } \\
\text { satisfação com treinamentos a } \\
\text { distância }\end{array}$ & $\begin{array}{l}216 \text { participantes de } \\
\text { cinco cursos realizados } \\
\text { a distância }\end{array}$ & $\begin{array}{l}\text { Aplicação de } \\
\text { questionários }\end{array}$ & $\begin{array}{l}\text { Análise fatorial } \\
\text { exploratória } \\
\text { Análises de } \\
\text { correlações bivariadas }\end{array}$ & $\begin{array}{l}\text { Padrões de associação entre } \\
\text { determinadas estratégias cognitivas } \\
\text { de aprendizagem e satisfação com } \\
\text { o desempenho da tutoria, com os } \\
\text { procedimentos e os resultados e } \\
\text { com a interface gráfica do curso. }\end{array}$ \\
\hline
\end{tabular}


Tabela 2. Pesquisas sobre Estratégias de Aprendizagem. (Continuação)

\begin{tabular}{|c|c|c|c|c|c|}
\hline Autores & Objetivo & Amostra/Contexto & $\begin{array}{l}\text { Procedimentos de } \\
\text { coleta de dados }\end{array}$ & $\begin{array}{l}\text { Procedimentos de } \\
\text { análise de dados }\end{array}$ & Resultados \\
\hline $\begin{array}{l}\text { Testa \& } \\
\text { Luciano (2010) }\end{array}$ & $\begin{array}{l}\text { Investigar o papel } \\
\text { desempenhado pelas } \\
\text { estratégias de aprendizagem } \\
\text { utilizadas na regulação de } \\
\text { recursos de aprendizagem em } \\
\text { ambientes virtuais de ensino }\end{array}$ & $\begin{array}{l}\text { Participantes: } 28 \\
\text { (entrevistados) e } 104 \\
\text { (questionários) }\end{array}$ & $\begin{array}{l}\text { Entrevistas } \\
\text { semiestruturadas e } \\
\text { abertas; análise de } \\
\text { documentos e de } \\
\text { registros; observação } \\
\text { direta; e pesquisa } \\
\text { survey }\end{array}$ & $\begin{array}{l}\text { Análise de conteúdo } \\
\text { Análise fatorial } \\
\text { exploratória }\end{array}$ & $\begin{array}{l}\text { - Participantes que mais } \\
\text { frequentemente estabeleceram } \\
\text { interações com pares e professores, } \\
\text { para tirar dúvidas ou buscar } \\
\text { auxílio, atingiram as mais elevadas } \\
\text { médias nos itens interesse, } \\
\text { persistência, percepção de } \\
\text { autoconfiança e gestão do } \\
\text { ambiente social da escala MSLQ } \\
\text { (Motivated Strategies for Learning } \\
\text { Questionnaire); } \\
\text { Correlações significativas entre as } \\
\text { elevadas taxas de satisfação com o } \\
\text { estudo e desempenho acadêmico e } \\
\text { a utilização de estratégias para } \\
\text { gestão do tempo e esforço. } \\
\text { Implicações práticas: estabelecer } \\
\text { prazos curtos e frequentes para a } \\
\text { conclusão das tarefas; fixar nos } \\
\text { critérios avaliativos elementos que } \\
\text { tratem do gerenciamento de tempo; } \\
\text { investir em interações viabilizadas } \\
\text { pelo recurso do chat ou por meio } \\
\text { de videoconferências; sugerir } \\
\text { atividades não formais nas quais os } \\
\text { estudantes partilhem preferências, } \\
\text { opiniões, etc. }\end{array}$ \\
\hline $\begin{array}{l}\text { Brandão \& } \\
\text { Borges- } \\
\text { Andrade (2011) }\end{array}$ & $\begin{array}{l}\text { Desenvolver uma escala de } \\
\text { estratégias de aprendizagem } \\
\text { no trabalho e verificar a } \\
\text { frequência com que estas são } \\
\text { utilizadas. }\end{array}$ & $\begin{array}{l}881 \text { gestores de } \\
\text { agências bancárias } \\
\text { públicas brasileiras }\end{array}$ & $\begin{array}{l}\text { Levantamento } \\
\text { documental, } \\
\text { entrevistas e } \\
\text { questionários }\end{array}$ & $\begin{array}{l}\text { Análises descritivas e } \\
\text { fatoriais exploratórias }\end{array}$ & $\begin{array}{l}\text { As estratégias de aprendizagem } \\
\text { busca de ajuda interpessoal e } \\
\text { reflexão ativa foram as mais } \\
\text { utilizadas pela amostra. }\end{array}$ \\
\hline
\end{tabular}


Evidências empíricas relativas ao uso de estratégias de aprendizagem como importante conjunto de variáveis para a compreensão da ocorrência de impacto do treinamento no trabalho (Pantoja \& Borges-Andrade, 2009; Pilati \& Borges-Andrade, 2012; Zerbini \& Abbad, 2010b) - sobretudo achados que correlacionam positivamente as estratégias cognitivas e comportamentais usadas durante o treinamento com o processo de transferência (Ford \& Kraiger, 1995; Holladay \& Quinones, 2003; Warr \& Allan, 1998) - e a necessidade de aprofundar as discussões sobre as estratégias de aprendizagem em contextos de EAD, especialmente as estratégias autorregulatórias, que vêm sendo apontadas como diferenciais para se estudar e aprender a distância (Martins \& Zerbini, 2014b), auxiliando mais no aprendizado de novos conteúdos entregues virtualmente do que as cognitivas e comportamentais - embora haja ainda uma grande lacuna entre a investigação desses processos metacognitivos e as habilidades de autogerecenciamento dos treinandos (Burke \& Hutchins, 2007; Grossman \& Salas, 2011) - levaram a testar as seguintes hipóteses:

Hipótese 1a: As estratégias de aprendizagem serão preditores positivos dos indicadores de efetividade de treinamento (impacto do treinamento em profundidade e em amplitude).

Hipótese $1 b$ : As estratégias de aprendizagem autorregulatórias interferirão mais sobre os indicadores de efetividade de treinamento (impacto do treinamento em profundidade e em amplitude) do que as estratégias cognitivas e comportamentais.

\subsection{Determinantes Contextuais}

\subsubsection{Variáveis do curso.}

\subsubsection{Reações.}

As Reações podem ser definidas como a opinião dos treinandos sobre diversos aspectos do treinamento e sua satisfação com o mesmo (Hamblin, 1978). Os participantes julgam a qualidade do plano instrucional ou de sua programação (e.g. objetivos, sequência, estratégias, meios, duração), a qualidade de sua execução (e.g. desempenho do tutor) e o apoio oferecido à execução do treinamento (e.g. instalações e materiais didáticos) (Abbad, 1999; Borges-Andrade, 1982; Lima \& Borges-Andrade, 1985).

As reações são indicadores da qualidade de entrega da instrução, refletindo a satisfação do aprendiz com o ritmo, o formato, a organização e o quanto foi aprendido 
durante o treinamento, podendo ser consideradas como os resultados afetivos de um curso (Klein, Noe \& Wang, 2006) ou também podem ser uma medida da utilidade do mesmo (Morgan \& Casper, 2000). Discute-se a importância de se discriminar as reações afetivas (satisfação geral com o treinamento) das de utilidade (e.g. em que medida os egressos sentem que o treinamento foi útil para ajudá-los a realizar seus trabalhos), já que a segunda está mais fortemente relacionada à aprendizagem (Aguinis \& Kraiger, 2009; Morgan \& Casper, 2000). A mensuração e a coleta de informações sobre a satisfação dos participantes com o curso visam aprimorar métodos e estratégias instrucionais, para facilitar o alcance de resultados de aprendizagem e de desempenho almejados por uma organização (Zerbini \& Abbad, 2010c).

As reações estão marcadamente presentes nos estudos da área de avaliação de TD\&E, como mostram revisões de literatura antigas e recentes (Aguinis \& Kraiger, 2009; Campbell, 1971; Martins \& Zerbini, 2014a; Tannenbaum \& Yukl, 1992; Zerbini \& Abbad, 2010c). A preocupação atual dos estudos concentra-se particularmente em torno da questão de como usar as reações para melhorar o desenho e a entrega de treinamentos (Aguinis \& Kraiger, 2009), não utilizando esta medida como o único critério de eficácia do treinamento (Allinger \& Janak, 1989; Tannenbaum \& Yukl, 1992), mas associada a outras variáveis que possam conduzir ao aprimoramento do planejamento instrucional conforme dados sobre a avaliação de efeitos produzidos (Zerbini \& Abbad, 2010c).

A esse respeito, notam-se progressos nas pesquisas que passam cada vez mais a utilizar (a) triangulações teóricas e metodológicas - inclusão e diversificação das áreas do conhecimento para a fundamentação teórica, a análise e a discussão dos dados, e o uso simultâneo de metodologias quanti e qualitativas (questionários e entrevistas, por exemplo), o que contribui para a busca por resultados complementares e soluções para questões diversas que cerceiam a realidade -, (b) uso de mais de uma fonte de informação, incluindo-se outros atores envolvidos enquanto respondentes - mesmo que a tarefa de reunir várias medidas a partir de múltiplas fontes seja uma tarefa difícil no local de trabalho (Burke \& Hutchins, 2007), e (c) teste dos efeitos de reações como variáveis moderadoras (Gunawardena et al., 2010).

É importante entender a utilidade de se medir as reações de ações educacionais online e aperfeiçoar o uso de tais informações (Long, DuBois \& Faley, 2008), já que os contextos de EAD apresentam especificidades (procedimentos instrucionais apoiados em tecnologias, tutoria online, ambiente virtual de aprendizagem) que podem influenciar a 
aquisição de aprendizagem e efetividade, que precisam ser identificadas para permitir propostas interventivas apropriadas (Martins, 2012).

A satisfação pode levar a níveis mais altos de engajamento, aprendizagem e sucesso na EAD (Sahin \& Shelley, 2008), de modo que conhecer os fatores capazes de interferir na (in)satisfação de participantes de treinamentos online permite otimizar o impacto dos programas de e-learning, oferecer subsídios para intervenções e aumentar a retenção de aprendizagem (Chyung \& Vachon, 2005).

Zerbini e Abbad (2005) e Carvalho e Abbad (2006), acompanhando as novas tendências de oferecimento de programas educacionais a distância, propuseram medidas específicas de reação para cursos dessa natureza, considerando as novas competências e habilidades por parte do tutor e o ambiente virtual envolvido. Tais medidas buscam aferir a satisfação dos participantes com a qualidade dos procedimentos do curso (objetivos, estratégias e meios de ensino, conteúdos, sequência, avaliações de aprendizagem) e também quanto às ferramentas da web (links, fóruns, chats, etc.). O desempenho do tutor é avaliado segundo a percepção do participante sobre a qualidade da interação do tutor com os alunos, domínio do conteúdo e uso de estratégias de ensino.

As reações favoráveis dos participantes aos procedimentos instrucionais e ao desempenho do tutor podem estar relacionadas à obtenção de bons resultados ao final do curso e, consequentemente, com o sucesso da ação empreendida, pois são aspectos caracterizadores de um curso ou treinamento específico, configurando-se como uma das variáveis influentes no processo de aprendizagem (Martins, 2012). De fato, fatores relativos ao sistema (funcionalidade, interação e resposta) e ao instrutor (atitude, habilidades técnicas e método de ensino) têm apresentado influências positivas relevantes sobre a efetividade do e-learning (Tien-Chen, 2012).

As medidas de reação devem fornecer informações sobre a adequação dos conteúdos e do desenho do treinamento, sendo a relevância e a utilidade, duas das dimensões atuais empregadas para medir reações ao treinamento (Alvarez et al., 2004). A relevância dos conteúdos - existe uma estreita relação entre o conteúdo do treinamento e as tarefas de trabalho para transferir as competências aprendidas para o ambiente de trabalho? -, as estratégias e os métodos de ensino, e a escolha e a adoção da mídia instrucional são apontados como fatores importantes para que ocorra o impacto do treinamento no trabalho (Burke \& Hutchins, 2007).

Os procedimentos instrucionais são constituídos por diferentes estratégias e princípios de ensino, como ferramentas, métodos e o próprio contexto que são 
combinados e integrados para criar uma abordagem de entrega do treinamento, pois a forma que este foi planejado, organizado e estruturado importa para que tenha êxito (Salas et al., 2012). Os procedimentos instrucionais adequados devem ser elegidos de acordo com resultados prévios que mostraram vínculos com o processo de transferência (Burke \& Hutchins, 2007).

Além de modificar os procedimentos instrucionais, a integração das tecnologias no processo de ensino-aprendizagem e os novos contextos educacionais a distância promovem influências na atividade docente. São introduzidas novas condições e requeridas competências diferenciadas para sua atuação, modificando o perfil deste profissional. O papel desempenhado pelo tutor, em ambientes virtuais de aprendizagem, é fundamental durante o processo de entrega de conteúdos por meio de tecnologias, já que estas ainda não são capazes de integrar a efetividade instrucional e as necessidades dos treinandos sem o auxílio de um esforço colaborativo feito por uma equipe de conteudistas, desenhistas instrucionais e especialistas em tecnologia (Bedwell \& Salas, 2010). Trata-se de um dos principais atores em contextos EAD, pois tem o propósito de facilitar a transferência do conhecimento, funcionando como um mediador que presta auxílio conveniente e adequado às necessidades educacionais do aprendiz e é capaz de evocar todos os fatores da aprendizagem eficaz, como a motivação e a autorregulação, além dos estritamente cognitivos (Mauri \& Onrubia, 2010).

A efetividade do e-learning é ainda prioritariamente avaliada por meio da medida de reações. De modo geral, os estudos apontam que os participantes apresentam reações favoráveis (Lim, Morris \& Kupritz, 2007; Nogueira, 2006; Vargas, 2002; Vaughan, 2007; Vaughan \& MacVicar, 2004), além de positivas atitudes frente ao $e$-learning, mostrando inclusive preferência pelo método a distância em comparação com outros modos de instrução, como os em sala de aula (DeRouin et al., 2005).

O estudo de Womble (2008) visava investigar de que forma a satisfação estava correlacionada à utilidade em um contexto de e-learning e à autoeficácia. Os participantes do treinamento online que o consideraram útil e acreditavam que o mesmo iria melhorar seu desempenho no trabalho, ficaram também satisfeitos com o treinamento.

Mathieu, Tannenbaum e Salas (1992) encontraram relações de moderação (relacionamento entre motivação e aprendizagem) e mediação (motivação e pontuações no pós-teste) das reações ao treinamento, sendo que os melhores resultados obtidos foram dos treinandos motivados e que reagiram positivamente ao programa, concluindo o papel importante e complexo das reações na explicação de efetividade de treinamento. 
Estudos mostram a contribuição da variável reação aos procedimentos instrucionais como preditora do processo de transferência de treinamento ou impacto do treinamento em profundidade (Carvalho \& Abbad, 2006; Zerbini \& Abbad, 2005; Zerbini \& Abbad, 2010b; Zerbini, 2007) ou ainda como preditora de aprendizagem (Martins, 2012). E resultados de pesquisas em ambientes universitários mostram que a interação instrutor-aluno tem influências para a efetividade da aprendizagem a distância (Marks, Sibley \& Arbaugh, 2005), além do grau de satisfação dos alunos com o e-learning estar positivamente relacionado à atuação profissional do tutor (Özkan, Köseler \& Baykal, 2009).

Embora alguns estudos não tenham obtido achados semelhantes, uma vez que as reações positivas não se associam a melhores níveis de aprendizagem (Martins, 2012), nem ao impacto de treinamento no trabalho (Borges-Ferreira \& Abbad, 2009; Zerbini \& Abbad, 2010b), a avaliação da satisfação dos participantes com o desempenho do tutor deve permanecer nos modelos para testar relacionamento entre variáveis em contextos de EAD, pois o instrutor parece ter grande importância sobre a satisfação geral com o treinamento (Morgan \& Casper, 2000). As pesquisas futuras devem buscar compreender quais são os fatores que contribuem para a satisfação com o instrutor, devendo-se distinguir os antecedentes de instrução bem-sucedida em contextos organizacionais e acadêmicos, pois estes guardam diferenças e especificidades - por exemplo, o instrutor em treinamentos corporativos normalmente não é responsável pelo desenvolvimento dos materiais e testes do curso como o são nos casos dos educadores nas universidades (Morgan \& Casper, 2000).

A Tabela 3 expõe resultados de pesquisa sobre reações. 
Tabela 3. Pesquisas sobre Reações.

\begin{tabular}{|c|c|c|c|c|c|}
\hline Autores & Objetivo & Amostra/Contexto & $\begin{array}{l}\text { Procedimentos de } \\
\text { coleta de dados }\end{array}$ & $\begin{array}{l}\text { Procedimentos } \\
\text { de análise de } \\
\text { dados }\end{array}$ & Resultados \\
\hline $\begin{array}{l}\text { Morgan \& Casper } \\
(2000)\end{array}$ & $\begin{array}{l}\text { Examinar a estrutura } \\
\text { fatorial de reações de } \\
\text { participantes ao } \\
\text { treinamento }\end{array}$ & $\begin{array}{l}9.128 \text { funcionários de } \\
\text { uma agência } \\
\text { governamental com } \\
750.000 \text { membros }\end{array}$ & $\begin{array}{l}\text { Aplicação de } \\
\text { questionários }\end{array}$ & $\begin{array}{l}\text { Análises } \\
\text { fatoriais } \\
\text { exploratórias e } \\
\text { confirmatórias }\end{array}$ & 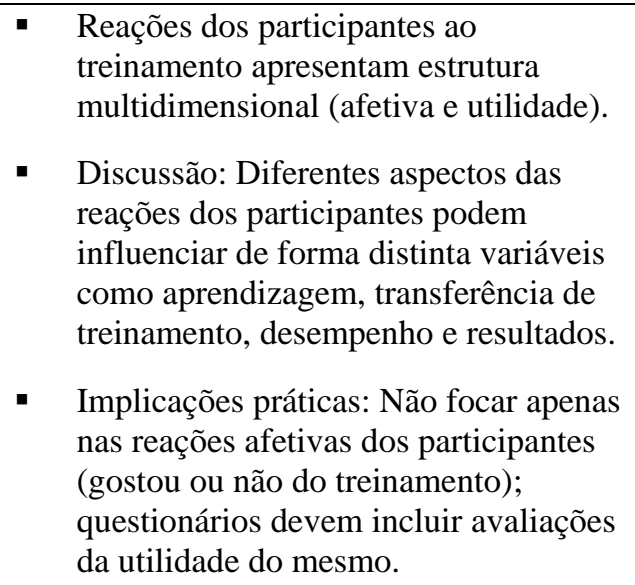 \\
\hline $\begin{array}{l}\text { Vaughan \& } \\
\text { MacVicar (2004) }\end{array}$ & $\begin{array}{l}\text { Identificar as atitudes dos } \\
\text { participantes com relação } \\
\text { ao treinamento a distância }\end{array}$ & 58 funcionários & $\begin{array}{l}\text { Respostas a questões: } \\
\text { sensibilização para o } e \text { - } \\
\text { learning; } \\
\text { oportunidades para } \\
\text { treinamento; suporte } \\
\text { de chefes; barreiras } \\
\text { para o } e \text {-learning; } \\
\text { contato pessoal; } \\
\text { mecanismos de apoio; } \\
\text { métodos de avaliação; } \\
\text { motivação e } \\
\text { autodisciplina; estilos } \\
\text { e atitudes de } \\
\text { aprendizagem para o } e \text { - } \\
\text { learning. }\end{array}$ & $\begin{array}{l}\text { Estatísticas } \\
\text { descritivas }\end{array}$ & 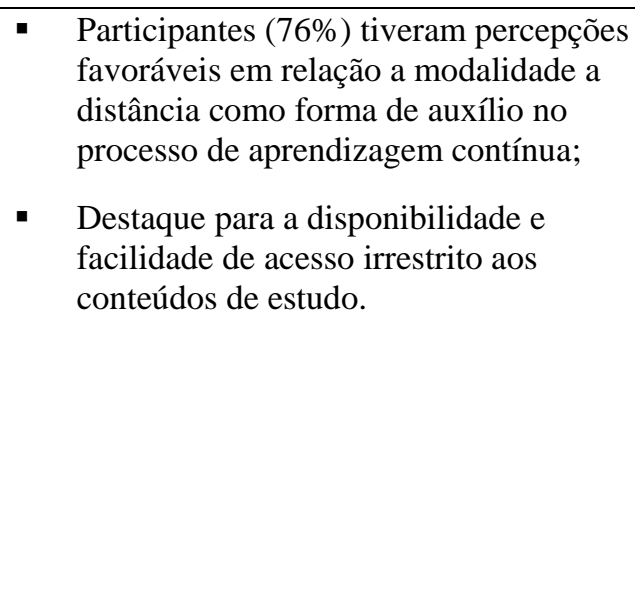 \\
\hline
\end{tabular}


Tabela 3. Pesquisas sobre Reações. (Continuação)

\begin{tabular}{|c|c|c|c|c|c|}
\hline Autores & Objetivo & Amostra/Contexto & $\begin{array}{l}\text { Procedimentos de } \\
\text { coleta de dados }\end{array}$ & $\begin{array}{l}\text { Procedimentos } \\
\text { de análise de } \\
\text { dados }\end{array}$ & Resultados \\
\hline Brown (2005) & $\begin{array}{l}\text { Testar um modelo } \\
\text { hierárquico de reação e } \\
\text { examinar hipóteses que } \\
\text { consideravam aspectos } \\
\text { motivacionais e } \\
\text { situacionais como } \\
\text { determinantes de } \\
\text { satisfação }\end{array}$ & $\begin{array}{l}435 \text { funcionários de } \\
\text { um dos maiores } \\
\text { Bancos da Índia }\end{array}$ & $\begin{array}{l}\text { Aplicação de } \\
\text { questionários enviados } \\
\text { por e-mail }\end{array}$ & $\begin{array}{l}\text { Análise fatorial } \\
\text { confirmatória }\end{array}$ & $\begin{array}{l}\text { Apoiaram o modelo hierárquico e } \\
\text { apontaram que a motivação é um } \\
\text { correlato de satisfação, ou seja, } \\
\text { motivação esteve positivamente } \\
\text { relacionada à satisfação. }\end{array}$ \\
\hline Womble (2008) & $\begin{array}{l}\text { Avaliar as relações entre a } \\
\text { satisfação do aprendiz com } \\
\text { a autoeficácia e a utilidade } \\
\text { de um treinamento online }\end{array}$ & $\begin{array}{l}440 \text { funcionários de } \\
\text { uma agência } \\
\text { governamental } \\
\text { (Estados Unidos) }\end{array}$ & $\begin{array}{l}\text { Aplicação de } \\
\text { questionários }\end{array}$ & $\begin{array}{l}\text { Análises de } \\
\text { regressão } \\
\text { múltipla }\end{array}$ & $\begin{array}{l}\text { Correlações positivas significativas } \\
\text { entre as três variáveis, sendo a mais } \\
\text { forte entre a satisfação do aluno e a } \\
\text { utilidade do curso - este resultado } \\
\text { sugere que os trabalhadores que } \\
\text { acreditavam que participar do } \\
\text { treinamento online iria melhorar seu } \\
\text { desempenho, estavam também } \\
\text { satisfeitos com o treinamento. }\end{array}$ \\
\hline $\begin{array}{l}\text { Gunawardena, } \\
\text { Linder- } \\
\text { VanBerschot, } \\
\text { LaPointe \& Rao } \\
\text { (2010) }\end{array}$ & $\begin{array}{l}\text { Investigar fatores } \\
\text { preditores de satisfação do } \\
\text { aprendiz e da transferência } \\
\text { de aprendizagem para o } \\
\text { trabalho }\end{array}$ & $\begin{array}{l}79 \text { funcionários de } \\
\text { uma empresa } \\
\text { multinacional; } \\
\text { instrutores e } \\
\text { desenhistas } \\
\text { instrucionais }\end{array}$ & $\begin{array}{l}\text { Aplicação de } \\
\text { questionários via e- } \\
\text { mail (treinandos) e } \\
\text { entrevistas (instrutores } \\
\text { e desenhistas } \\
\text { instrucionais) }\end{array}$ & $\begin{array}{l}\text { Análise de } \\
\text { regressão } \\
\text { múltipla }\end{array}$ & $\begin{array}{l}\text { Autoeficácia online foi o mais forte } \\
\text { preditor de satisfação do aprendiz; } \\
\text { Apoio de pares foi o mais forte preditor } \\
\text { de transferência de aprendizagem } \\
\text { (impacto do treinamento em } \\
\text { profundidade). }\end{array}$ \\
\hline
\end{tabular}


Tabela 3. Pesquisas sobre Reações. (Continuação)

\begin{tabular}{|c|c|c|c|c|c|}
\hline Autores & Objetivo & Amostra/Contexto & $\begin{array}{l}\text { Procedimentos de } \\
\text { coleta de dados }\end{array}$ & $\begin{array}{l}\text { Procedimentos } \\
\text { de análise de } \\
\text { dados }\end{array}$ & Resultados \\
\hline $\begin{array}{l}\text { Giangreco, } \\
\text { Carugati, } \\
\text { Sebastiano \& } \\
\text { Della Bella } \\
(2010)\end{array}$ & $\begin{array}{l}\text { Testar modelo que avalia a } \\
\text { satisfação total de } \\
\text { treinandos (VD) com o } \\
\text { treinamento - utilidade do } \\
\text { treinamento, desempenho } \\
\text { do instrutor e eficiência do } \\
\text { treinamento (VIs) }\end{array}$ & $\begin{array}{l}13.753 \text { treinandos, } \\
\text { agrupados em } 1.230 \\
\text { cursos, envolvendo } \\
3.047 \text { empresas }\end{array}$ & $\begin{array}{l}\text { Aplicação de } \\
\text { questionários online }\end{array}$ & $\begin{array}{l}\text { Análise fatorial } \\
\text { exploratória } \\
\text { Análise de } \\
\text { regressão } \\
\text { múltipla }\end{array}$ & $\begin{array}{l}\text { As três variáveis antecedentes tiveram } \\
\text { papel na satisfação total dos treinandos } \\
\text { com o treinamento; } \\
\text { Participação feminina tem um efeito } \\
\text { positivo sobre a moderação da relação } \\
\text { entre a satisfação total e o desempenho } \\
\text { do instrutor. }\end{array}$ \\
\hline $\begin{array}{l}\text { Zerbini \& Abbad } \\
(2010 a)\end{array}$ & $\begin{array}{l}\text { Identificar variáveis } \\
\text { explicativas da aplicação } \\
\text { de habilidades ensinadas } \\
\text { aos participantes de um } \\
\text { curso de qualificação } \\
\text { profissional a distância, via } \\
\text { internet }\end{array}$ & $\begin{array}{l}470 \text { participantes do } \\
\text { curso a distância } \\
\text { IPGN (SEBRAE) }\end{array}$ & $\begin{array}{l}\text { Aplicação de } \\
\text { questionários online }\end{array}$ & $\begin{array}{l}\text { Análise fatorial } \\
\text { exploratória }\end{array}$ & $\begin{array}{l}\text { - Participantes com reações favoráveis } \\
\text { aos procedimentos instrucionais do } \\
\text { curso relataram maior ocorrência de } \\
\text { impacto do treinamento em } \\
\text { profundidade; } \\
\text { - A variável "reação ao desempenho do } \\
\text { tutor" não consistiu em variável } \\
\text { explicativa de efetividade em cursos a } \\
\text { distância e o tutor foi pouco acessado ao } \\
\text { longo do curso. }\end{array}$ \\
\hline $\begin{array}{l}\text { Ramayah, Ahmad } \\
\text { \& Hong (2012) }\end{array}$ & $\begin{array}{l}\text { Determinar os fatores } \\
\text { críticos que influenciam a } \\
\text { efetividade de treinamento } \\
\text { a distância }\end{array}$ & $\begin{array}{l}163 \text { funcionários de } \\
\text { organizações } \\
\text { multinacionais } \\
\text { (Malásia) }\end{array}$ & $\begin{array}{l}\text { Aplicação de } \\
\text { questionários }\end{array}$ & $\begin{array}{l}\text { Análise fatorial } \\
\text { confirmatória }\end{array}$ & $\begin{array}{l}\text { Motivação para aprender, suporte } \\
\text { gerencial e suporte da organização } \\
\text { foram preditores significativos de } \\
\text { satisfação; } \\
\text { - Autoeficácia, facilidade de uso e } \\
\text { conteúdo do treinamento, não; } \\
\text { - Satisfação do usuário não influenciou o } \\
\text { benefício líquido, mas foi um forte } \\
\text { preditor da intenção de continuar o } \\
\text { treinamento a distância. }\end{array}$ \\
\hline
\end{tabular}


Tabela 3. Pesquisas sobre Reações. (Continuação)

\begin{tabular}{|c|c|c|c|c|c|}
\hline Autores & Objetivo & Amostra/Contexto & $\begin{array}{l}\text { Procedimentos de } \\
\text { coleta de dados }\end{array}$ & $\begin{array}{c}\text { Procedimentos } \\
\text { de análise de } \\
\text { dados }\end{array}$ & Resultados \\
\hline $\begin{array}{l}\text { Teo \& Wong } \\
(2013)\end{array}$ & $\begin{array}{l}\text { Explorar preditores de } \\
\text { satisfação com o } e \text { - } \\
\text { learning: qualidade do } \\
\text { tutor, utilidade percebida, } \\
\text { facilidade de uso } \\
\text { percebida, entrega do } \\
\text { curso, de condições } \\
\text { facilitadoras e satisfação } \\
\text { com o curso }\end{array}$ & $\begin{array}{l}387 \text { participantes } \\
\text { (professores) }\end{array}$ & $\begin{array}{l}\text { Aplicação de } \\
\text { questionários }\end{array}$ & $\begin{array}{l}\text { Modelagem por } \\
\text { Equações } \\
\text { Estruturais }\end{array}$ & $\begin{array}{l}\text { Todos os construtos foram preditores } \\
\text { significativos da satisfação com o } e \text { - } \\
\text { learning, menos as condições } \\
\text { facilitadoras; } \\
\text { - Contudo, as condições facilitadoras } \\
\text { mediaram a percepção de facilidade de } \\
\text { uso e a satisfação com o curso. }\end{array}$ \\
\hline $\begin{array}{l}\text { Khasawneh \& Al- } \\
\text { Zawahreh (2015) }\end{array}$ & $\begin{array}{l}\text { Validar uma medida de } \\
\text { reação ao treinamento, } \\
\text { investigar o nível de } \\
\text { satisfação geral dos } \\
\text { treinandos e testar um } \\
\text { modelo de reações } \\
\text { (instrutor, utilidade e } \\
\text { processo de gestão do } \\
\text { treinamento, materiais e } \\
\text { estrutura do curso) }\end{array}$ & $\begin{array}{l}304 \text { participantes } \\
\text { (Universidade } \\
\text { pública na Jordânia) } \\
\text { de programas de } \\
\text { treinamento } \\
\text { relacionados à } \\
\text { carreira (Recursos } \\
\text { Humanos) }\end{array}$ & $\begin{array}{l}\text { Aplicação de } \\
\text { questionários }\end{array}$ & $\begin{array}{l}\text { Análise fatorial } \\
\text { exploratória } \\
\text { Análise de } \\
\text { regressão }\end{array}$ & $\begin{array}{l}\text { - Altos níveis de satisfação dos } \\
\text { participantes com todos os aspectos dos } \\
\text { programas de treinamento avaliados; } \\
\text { A utilidade do treinamento teve maior } \\
\text { variância explicada, seguida pelos } \\
\text { materiais e estrutura do curso. }\end{array}$ \\
\hline
\end{tabular}


Considerando que as medidas de reações vêm sendo relacionadas ao impacto do treinamento no trabalho (Zerbini \& Abbad, 2010c), sendo explicativas da aplicação de novas habilidades aprendidas, uma vez que indivíduos satisfeitos com o curso têm maior propensão a transferir essas competências quando retornam a seus postos de trabalho; ainda que não sejam suficientes para atestar a efetividade de treinamentos, devendo ser combinadas a outros fatores influentes no processo de transferência, é necessário que sejam incluídas em modelos que visam a explicação do fenômeno do resultado do treinamento no desempenho dos egressos, tanto como preditoras diretas, quanto como mediadoras/moderadoras de outras variáveis, as seguintes hipóteses foram testadas:

Hipótese 2: A satisfação com os aspectos formais do curso será preditor positivo dos indicadores de efetividade de treinamento (impacto do treinamento em profundidade e em amplitude).

Hipótese 3: A satisfação com o desempenho do tutor será preditor positivo dos indicadores de efetividade de treinamento (impacto do treinamento em profundidade e em amplitude).

Hipótese mediadora: As reações aos procedimentos instrucionais do curso mediarão o suporte à transferência e os indicadores de efetividade de treinamento (impacto do treinamento em profundidade e em amplitude).

\subsubsection{Variáveis do ambiente.}

\subsubsection{Suporte à transferência.}

O Suporte à Transferência trata-se de uma variável contextual que avalia o apoio recebido por egressos de treinamentos para aplicar as novas habilidades adquiridas no trabalho (Abbad et al., 2012a). O construto compreende características situacionais importantes, sendo o apoio material e psicossocial, os principais fatores estudados em pesquisas. O suporte psicossocial refere-se ao apoio gerencial, social (colegas ou pares) e organizacional à aplicação de novas aprendizagens no trabalho, que se dá por meio do estabelecimento de metas, oferecimento de assistência (discutir e encorajar o uso de novos CHAs no trabalho) e feedback (Abbad et al., 2012a; Burke \& Hutchins, 2007); enquanto 
que o suporte material avalia os recursos materiais e financeiros disponíveis e a adequação do ambiente físico do local de trabalho à aplicação no trabalho das novas competências adquiridas em treinamento (Abbad et al., 2012a).

Pesquisas realizadas em contextos, treinamentos e amostras de participantes diferentes indicam o papel importante exercido pelo suporte à transferência na explicação de impacto de treinamento no trabalho, mostrando por meio de correlações fortes e moderadas entre estas variáveis que a aplicação de novas aprendizagens no trabalho depende do apoio oferecido pela organização e pelos seus membros (chefes e colegas) aos egressos de treinamentos (Abbad et al., 2012a; Abbad, Pilati \& Pantoja, 2003; Aguinis \& Kraiger, 2009; Burke \& Hutchins, 2007; Joo et al., 2011; Pantoja, Porto, Mourão \& Borges-Andrade, 2005), sendo o apoio do supervisor e de pares os preditores mais consistentes de resultados de impacto do treinamento no trabalho encontrados (Burke \& Hutchins, 2007; Chiaburu, van Dam \& Hutchins, 2010).

A Tabela 4 expõe resultados de pesquisa sobre suporte à transferência. 
Tabela 4. Pesquisas sobre Suporte à Transferência.

\begin{tabular}{|c|c|c|c|c|}
\hline Autores & Objetivo & Amostra/Contexto & $\begin{array}{l}\text { Procedimentos de } \\
\text { análise de dados }\end{array}$ & Resultados \\
\hline $\begin{array}{l}\text { Chiaburu \& } \\
\text { Tekleab (2005) }\end{array}$ & $\begin{array}{l}\text { Investigar antecedentes individuais e } \\
\text { contextuais de transferência de } \\
\text { aprendizagem, generalização e } \\
\text { manutenção de treinamento no } \\
\text { trabalho. }\end{array}$ & 119 funcionários & $\begin{array}{l}\text { Análise de } \\
\text { regressão } \\
\text { hierárquica }\end{array}$ & $\begin{array}{l}\text { - Resultados apoiam a relação entre a cultura de } \\
\text { aprendizagem contínua, o apoio gerencial e a } \\
\text { motivação para o treinamento. }\end{array}$ \\
\hline $\begin{array}{l}\text { Carvalho e } \\
\text { Abbad (2006) }\end{array}$ & $\begin{array}{l}\text { Identificar variáveis explicativas da } \\
\text { aplicação de habilidades ensinadas } \\
\text { aos participantes de um curso de } \\
\text { qualificação profissional a distância, } \\
\text { via internet }\end{array}$ & $\begin{array}{l}335 \text { e } 340 \text { participantes do } \\
\text { curso IPGN/ SEBRAE }\end{array}$ & $\begin{array}{l}\text { Análise fatorial } \\
\text { exploratória } \\
\text { Análise de } \\
\text { regressão múltipla }\end{array}$ & $\begin{array}{l}\text { Reação aos resultados e aplicabilidade, falta de } \\
\text { suporte à transferência e elaboração de plano de } \\
\text { negócio explicam a ocorrência positiva de } \\
\text { impacto em amplitude e profundidade. }\end{array}$ \\
\hline $\begin{array}{l}\text { Nijman, Nijhof, } \\
\text { Wognum \& } \\
\text { Veldkamp } \\
\text { (2006) }\end{array}$ & $\begin{array}{l}\text { Investigar, por meio de uma } \\
\text { abordagem sistêmica, diferentes } \\
\text { efeitos de suporte gerencial sobre o } \\
\text { impacto do treinamento no trabalho. }\end{array}$ & $\begin{array}{l}179 \text { treinandos e } 32 \\
\text { supervisores; } 4 \text { programas de } \\
\text { treinamentos e } 3 \\
\text { organizações }\end{array}$ & $\begin{array}{l}\text { Análise de } \\
\text { regressão stepwise }\end{array}$ & $\begin{array}{l}\text { Relações indiretas entre apoio gerencial e } \\
\text { impacto do treinamento no trabalho foram } \\
\text { encontradas - efeitos são melhorados se houver } \\
\text { clima para transferência no trabalho e motivação } \\
\text { para transferir dos treinandos. } \\
\text { - Resultados de aprendizagem foram os mais } \\
\text { fortes preditores de impacto do treinamento no } \\
\text { trabalho. }\end{array}$ \\
\hline $\begin{array}{l}\text { Velada, Caetano, } \\
\text { Michel, Lyons \& } \\
\text { Kavanagh } \\
(2007)\end{array}$ & $\begin{array}{l}\text { Examinar a relação entre três } \\
\text { preditores de impacto do } \\
\text { treinamento no trabalho: desenho do } \\
\text { treinamento, características } \\
\text { individuais e ambiente de trabalho. }\end{array}$ & $\begin{array}{l}182 \text { funcionários de uma } \\
\text { rede de supermercados } \\
\text { (Portugal) }\end{array}$ & $\begin{array}{l}\text { Análise fatorial } \\
\text { Análise de } \\
\text { regressão } \\
\text { hierárquica }\end{array}$ & $\begin{array}{l}\text { Autoeficácia, desenho e retenção de treinamento, } \\
\text { e feedback de desempenho estiveram } \\
\text { significativamente relacionados com impacto do } \\
\text { treinamento no trabalho; apoio gerencial, não. } \\
\text { Discussão: Considerando o contexto específico, } \\
\text { talvez, intervenções do supervisor antes e/ou } \\
\text { durante o treinamento poderiam ter impacto mais } \\
\text { forte sobre o impacto do treinamento no } \\
\text { trabalho. }\end{array}$ \\
\hline
\end{tabular}


Tabela 4. Pesquisas sobre Suporte à Transferência. (Continuação)

\begin{tabular}{|c|c|c|c|c|}
\hline Autores & Objetivo & Amostra/Contexto & $\begin{array}{l}\text { Procedimentos de } \\
\text { análise de dados }\end{array}$ & Resultados \\
\hline $\begin{array}{l}\text {-Eisa, } \\
\text { Irayyan \& } \\
\text { lhemoud } \\
\text { 009) }\end{array}$ & $\begin{array}{l}\text { Examinar as influências da autoeficácia e } \\
\text { do apoio gerencial na intenção de } \\
\text { transferir; e o papel mediador de } \\
\text { motivação para aprender. }\end{array}$ & $\begin{array}{l}287 \text { funcionários } \\
\text { públicos (Arábia } \\
\text { Saudita) }\end{array}$ & Análise de regressão & $\begin{array}{l}\text { Apoio gerencial foi o fator mais saliente que } \\
\text { afeta a intenção para transferir; } \\
\text { Motivação para aprender influencia } \\
\text { diretamente a intenção para transferir e tem } \\
\text { efeito parcial mediador sobre as relações da } \\
\text { intenção para transferir com apoio gerencial e } \\
\text { autoeficácia. }\end{array}$ \\
\hline $\begin{array}{l}\text { iaburu } \\
\text { 010) }\end{array}$ & $\begin{array}{l}\text { Investigar o poder preditivo de três tipos } \\
\text { de suporte (pares, gerencial e } \\
\text { organizacional) sobre a transferência de } \\
\text { treinamento e manutenção de } \\
\text { treinamento. }\end{array}$ & 440 funcionários (EUA) & $\begin{array}{l}\text { Análise de } \\
\text { correlação e } \\
\text { regressão stepwise }\end{array}$ & $\begin{array}{l}\text { O apoio de pares foi mais importante para a } \\
\text { transferência de treinamento e manutenção das } \\
\text { habilidades no trabalho que os suportes } \\
\text { gerencial e organizacional. }\end{array}$ \\
\hline $\begin{array}{l}\text { hiaburu, van } \\
\text { am \& } \\
\text { utchins } \\
\text { 010) }\end{array}$ & $\begin{array}{l}\text { Examinar o poder preditivo de dois } \\
\text { suportes sociais (gerencial e } \\
\text { organizacional) sobre o impacto do } \\
\text { treinamento no trabalho. }\end{array}$ & $\begin{array}{l}111 \text { funcionários; estudo } \\
\text { longitudinal }\end{array}$ & $\begin{array}{l}\text { Modelagem por } \\
\text { Equações } \\
\text { Estruturais }\end{array}$ & $\begin{array}{l}\text { O apoio social aumenta a autoeficácia para o } \\
\text { treinamento, a orientação de metas para a } \\
\text { aprendizagem e a motivação para transferir dos } \\
\text { treinandos; } \\
\text { O apoio gerencial influencia positivamente a } \\
\text { motivação para transferir mais que o apoio } \\
\text { organizacional. }\end{array}$ \\
\hline $\begin{array}{l}\text { o, Lim \& } \\
\text { rk (2011) }\end{array}$ & $\begin{array}{l}\text { Investigar as relações entre suporte } \\
\text { organizacional, fluxo de aprendizagem, } \\
\text { satisfação dos alunos e impacto do } \\
\text { treinamento no trabalho em profundidade. }\end{array}$ & $\begin{array}{l}379 \text { funcionários de uma } \\
\text { grande empresa coreana }\end{array}$ & $\begin{array}{l}\text { Modelagem por } \\
\text { Equações } \\
\text { Estruturais }\end{array}$ & $\begin{array}{l}\text { O suporte organizacional e o fluxo de } \\
\text { aprendizagem tiveram efeitos diretos sobre o } \\
\text { impacto do treinamento no trabalho em } \\
\text { profundidade e satisfação dos alunos. } \\
\text { Fluxo de aprendizagem mediou o apoio } \\
\text { organizacional e a satisfação dos alunos. }\end{array}$ \\
\hline
\end{tabular}


Tabela 4. Pesquisas sobre Suporte à Transferência. (Continuação)

\begin{tabular}{|c|c|c|c|c|}
\hline Autores & Objetivo & Amostra/Contexto & $\begin{array}{l}\text { Procedimentos de } \\
\text { análise de dados }\end{array}$ & Resultados \\
\hline $\begin{array}{l}\text { lati \& Borges- } \\
\text { adrade (2012) }\end{array}$ & $\begin{array}{l}\text { Investigar características individuais e } \\
\text { fatores ambientais na explicação de } \\
\text { efetividade de treinamento. }\end{array}$ & 652 bancários (Brasil) & $\begin{array}{l}\text { Análise fatorial } \\
\text { confirmatória }\end{array}$ & $\begin{array}{l}\text { Estratégias para a transferência de } \\
\text { conhecimentos, percepção de suporte da } \\
\text { organização para a transferência e } \\
\text { compromisso com o trabalho foram preditores } \\
\text { significativos de efetividade de treinamento } \\
\text { (impacto em profundidade e em amplitude). }\end{array}$ \\
\hline $\begin{array}{l}\text { am, Segers \& } \\
\text { jselaers } \\
\text { 012) }\end{array}$ & $\begin{array}{l}\text { Examinar a influência de fatores do } \\
\text { ambiente de trabalho sobre o impacto do } \\
\text { treinamento no trabalho, tendo em conta o } \\
\text { papel das estratégias de transferência dos } \\
\text { treinandos. }\end{array}$ & $\begin{array}{l}167 \text { treinandos de } 8 \\
\text { MBAs (Vietnã) }\end{array}$ & $\begin{array}{l}\text { Modelagem por } \\
\text { Equações } \\
\text { Estruturais }\end{array}$ & $\begin{array}{l}\text { Apoio gerencial, autonomia, suporte preferido } \\
\text { pelo treinando foram associados } \\
\text { significativamente com o impacto do } \\
\text { treinamento no trabalho; mediados por } \\
\text { estratégias de transferência (técnicas } \\
\text { cognitivas e comportamentais que incluem } \\
\text { estabelecer metas, analisar situações de } \\
\text { trabalho, superar dificuldades, absorver apoio } \\
\text { e aproveitar as oportunidades de usar os } \\
\text { conhecimentos e as habilidades adquiridas no } \\
\text { trabalho). }\end{array}$ \\
\hline
\end{tabular}

Simosi (2012) Explorar os diferentes papéis que o suporte organizacional, de supervisores e de pares desempenham sobre o impacto do

251 recém-contratados de uma empresa de serviços (Grécia)

Análise de regressão

treinamento no trabalho e o comprometimento no trabalho (afetivo e normativo)
- Os três tipos de apoio apresentaram efeitos independentes e diretos sobre as variáveis dependentes;

- O suporte organizacional atuou como moderador na relação entre suporte de supervisores-impacto do treinamento no trabalho e suporte de pares-comprometimento afetivo, reforçando esses relacionamentos entre as variáveis. 
Tabela 4. Pesquisas sobre Suporte à Transferência. (Continuação)

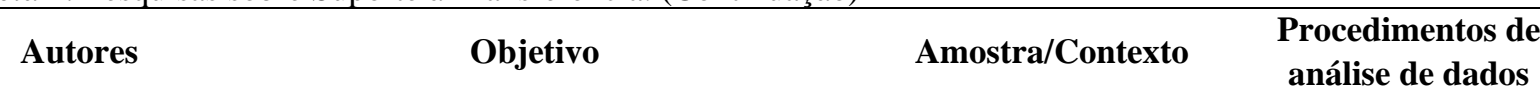

\begin{tabular}{llll}
\hline Bhatti, Battour, & Destacar a importância de fatores & 503 funcionários de um & Modelagem por \\
Sundram \& & ambientais, situacionais e individuais no & Banco da Malásia & Equações \\
Othman (2013) & impacto do treinamento no trabalho. & & Estruturais
\end{tabular}

\section{Resultados}

- O apoio de supervisores e de pares aumenta o nível de motivação do treinando para transferir as habilidades aprendidas para o trabalho;

- Recompensas intrínsecas influem sobre a retenção e transferência de competências para o trabalho.

\begin{tabular}{|c|c|c|c|c|}
\hline $\begin{array}{l}\text { Dermol \& Čater } \\
\text { (2013) }\end{array}$ & $\begin{array}{l}\text { Investigar as relações entre construtos } \\
\text { relacionados ao treinamento, resultados do } \\
\text { treinamento em nível da organização e } \\
\text { desempenho da organização. }\end{array}$ & $\begin{array}{l}247 \text { organizações de } \\
\text { serviços }\end{array}$ & $\begin{array}{l}\text { Modelagem por } \\
\text { Equações } \\
\text { Estruturais }\end{array}$ & $\begin{array}{l}\text { Forte relação entre: } \\
\begin{array}{l}\text { - O apoio gerencial e o volume e a qualidade } \\
\text { do treinamento; } \\
\text { O apoio gerencial e os incentivos } \\
\text { organizacionais para o impacto do } \\
\text { treinamento no trabalho. }\end{array}\end{array}$ \\
\hline $\begin{array}{l}\text { Mourão, Abbad } \\
\& \text { Zerbini } \\
(2014)\end{array}$ & $\begin{array}{l}\text { Verificar a efetividade de um treinamento } \\
\text { (curso na área comercial) a distância entre } \\
\text { atitudes dos participantes em relação à } \\
\text { educação a distância, avaliação de } \\
\text { necessidade do treinamento, suporte à } \\
\text { aplicação do treinamento e o impacto do } \\
\text { treinamento no trabalho (profundidade e } \\
\text { amplitude) }\end{array}$ & $\begin{array}{l}742 \text { funcionários de uma } \\
\text { instituição bancária de } \\
\text { grande porte (Brasil) }\end{array}$ & $\begin{array}{l}\text { Análise fatorial } \\
\text { exploratória, } \\
\text { consistência interna } \\
\text { Análise de } \\
\text { regressão múltipla, } \\
\text { teste } t \text { e correlações }\end{array}$ & $\begin{array}{l}\text { Os participantes que perceberam maior } \\
\text { suporte na aplicação do treinamento, que } \\
\text { tinham atitudes mais favoráveis à educação a } \\
\text { distância e, sobretudo, que percebiam maior } \\
\text { necessidade do treinamento, relataram maior } \\
\text { ocorrência de impacto do treinamento no } \\
\text { trabalho. }\end{array}$ \\
\hline $\begin{array}{l}\text { Homklin, } \\
\text { Takahashi \& } \\
\text { Techakanont } \\
\text { (2014) }\end{array}$ & $\begin{array}{l}\text { Investigar o efeito moderador do suporte } \\
\text { social e organizacional na relação entre a } \\
\text { retenção de aprendizagem e o impacto do } \\
\text { treinamento no trabalho. }\end{array}$ & $\begin{array}{l}217 \text { participantes de um } \\
\text { sistema de certificação } \\
\text { de uma indústria } \\
\text { automotiva (Tailândia) }\end{array}$ & $\begin{array}{l}\text { Análise de } \\
\text { regressão } \\
\text { hierárquica }\end{array}$ & 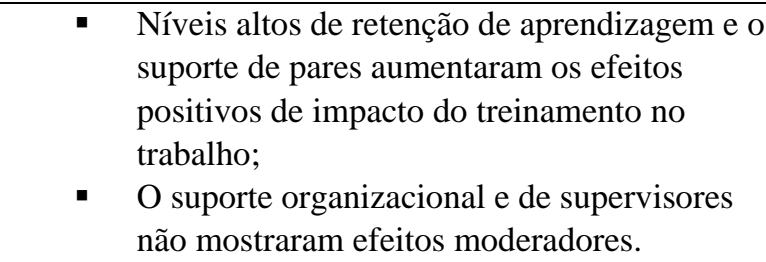 \\
\hline
\end{tabular}


Tabela 4. Pesquisas sobre Suporte à Transferência. (Continuação)

\begin{tabular}{|c|c|c|c|c|}
\hline Autores & Objetivo & Amostra/Contexto & $\begin{array}{l}\text { Procedimentos de } \\
\text { análise de dados }\end{array}$ & Resultados \\
\hline $\begin{array}{l}\text { mrah \& Boyle } \\
\text { D15) }\end{array}$ & $\begin{array}{l}\text { Investigar o papel do apoio } \\
\text { organizacional sobre a satisfação } \\
\text { no trabalho e a efetividade do } \\
\text { treinamento no trabalho. }\end{array}$ & $\begin{array}{l}222 \text { participantes do } \\
\text { treinamento "Gestão } \\
\text { Financeira Básica" e } 222 \\
\text { supervisores } \\
\text { Organizações públicas na } \\
\text { Malásia }\end{array}$ & $\begin{array}{l}\text { Modelagem por } \\
\text { Equações Estruturais }\end{array}$ & $\begin{array}{l}\text { O suporte organizacional mediou a satisfação } \\
\text { no trabalho e o impacto do treinamento no } \\
\text { trabalho; } \\
\text { A percepção de apoio organizacional influi } \\
\text { sobre a satisfação dos trabalhadores e } \\
\text { consequentemente aumenta a transferência de } \\
\text { competências para o trabalho. }\end{array}$ \\
\hline
\end{tabular}


Ambos tipos de suporte, gerencial e de pares, influenciam significativamente a propensão dos treinandos para utilizar as novas competências no local de trabalho (Grossman \& Salas, 2011). As pesquisas mostram o papel importante desses fatores interpessoais enquanto moderadores da relação entre treinamento-impacto do treinamento no trabalho (Aguinis \& Kraiger, 2009; Burke \& Hutchins, 2007). Estes suportes mais próximos e concretos, em comparação ao mais distante e difuso provindo da organização, possuem influências positivas sobre o impacto do treinamento no trabalho, ao lado de outros fatores individuais (motivação, autoeficácia, orientação de metas para a aprendizagem) (Chiaburu et al., 2010). Ainda, o apoio de pares mostrou-se mais forte para o impacto do treinamento no trabalho que os demais (gerencial e organizacional), talvez pelo contato direto estabelecido, mesmo status funcional e contínuo fluxo de informações entre colegas de trabalho (Chiaburu, 2010; Homklin, Takahashi \& Techakanont, 2014) - embora ainda haja poucas evidências sugerindo que um tipo de apoio exerça uma influência mais forte sobre o impacto do treinamento no trabalho do que o outro (ou seja, supervisor versus pares) (Grossman \& Salas, 2011; Van den Bossche, Segers \& Jansen, 2010).

Em Velada et al. (2007), o suporte gerencial não apresentou relação significativa com impacto do treinamento no trabalho, contrariando a literatura dominante e as expectativas dos autores, que discutiram que tal resultado pode ter sido devido ao contexto específico avaliado (supermercados) e por ter sido consideradas somente as dimensões de supervisão pós-treinamento, como reuniões e feedback. Os autores argumentam que talvez intervenções de supervisão antes ou durante o treinamento poderiam ter influência mais forte sobre o impacto do treinamento no trabalho. Outros estudos também mostram influências divergentes quanto ao apoio dos supervisores sobre a transferência, podendo ocorrer de maneira direta ou indireta, positiva ou negativa, e até mesmo apresentam alguns resultados mistos (Ghosh, Chauhan \& Rai, 2015).

Esses achados indicam a grande importância das relações humanas ante as condições materiais para o sucesso do processo de transposição do aprendido em treinamentos para o ambiente de trabalho. Como os estudos enfatizam a importância do envolvimento e da participação dos supervisores no treinamento para propiciar resultados de transferência de treinamento (Blume, Ford, Baldwin \& Huang, 2010; Ghosh et al., 2015; Grossman \& Salas, 2011) e que sua postura e opinião afetam os treinandos (Salas et al., 2012), sugere-se que antes do início do treinamento, os supervisores devem guiar e preparar os treinandos para o treinamento certo, familiarizar-lhes com o programa, 
esclarecer as suas expectativas - para tanto, devem ser envolvidos no processo prévio de avaliação de necessidades para que entendam a necessidade do treinamento e possam fornecer informações precisas e motivadoras sobre o mesmo (Salas et al., 2012) -, definir metas, comunicar os objetivos com relação ao desempenho desejado, as condições sob as quais o desempenho deverá ocorrer no local de trabalho e os critérios de desempenho considerado aceitável (Burke \& Hutchins, 2007). Após o término do treinamento, os supervisores devem adotar uma postura positiva frente ao mesmo, remover obstáculos, garantir ampla oportunidade para que os egressos possam aplicar as habilidades recémadquiridas e oferecer feedback oportunamente (Ghosh et al., 2015; Salas et al., 2012).

Ao passo que os suportes à transferência são comprovadamente fatores que mantêm forte e consistente relacionamento com impacto do treinamento no trabalho, medido em profundidade e em amplitude, torna-se necessário investigá-los em um nível mais profundo, ou seja, se são mais importantes antes, durante ou depois do treinamento (Grossman \& Salas, 2011), já que na literatura predominam as medidas pós-treinamento (Velada et al., 2007). Além disso, deve-se seguir investigando de que forma atuam como moderadores do impacto do treinamento no trabalho (Aguinis \& Kraiger, 2009) para explicar as condições em que um efeito ou relação é suscetível de estar presente e, provavelmente, ser mais forte.

Diante do exposto, foram testadas as seguintes hipóteses, que visavam corroborar a relevância do suporte à transferência de treinamento, já amplamente atestada por estudos empíricos e parte do arcabouço teórico dominante da área, bem como investigar o papel do apoio psicossocial como sendo mais importante que o material para o processo de transferência de competências, conforme indicações de pesquisas recentes (Aguinis \& Kraiger, 2009; Al-Eisa, Furayyan \& Alhemoud, 2009; Burke \& Hutchins, 2007; Chiaburu, 2010; Homklin et al., 2014; Pantoja, Porto, Mourão \& Borges-Andrade, 2005; Pham, Segers \& Gijselaers, 2012):

Hipótese 4a: $\mathrm{O}$ suporte à transferência de novas competências adquiridas em treinamento estará positivamente relacionado aos indicadores de efetividade de treinamento (impacto do treinamento no trabalho em profundidade e em amplitude).

Hipótese 4b: O suporte psicossocial interferirá mais sobre os indicadores de efetividade de treinamento (impacto do treinamento no trabalho em profundidade e em amplitude) do que o suporte material. 


\subsubsection{Barreiras e facilitadores em $E A D$.}

Diferentes características disposicionais e contextuais, que podem igualmente auxiliar ou prejudicar o desempenho durante um treinamento, impactando em seus resultados, são denominados de Barreiras e Facilitadores. Este conjunto de fatores pode estar relacionado a características pessoais do próprio aprendiz, aos aspectos referentes ao evento instrucional ou ao ambiente social e/ou organizacional circundante (Abbad, 2007; Sales, 2009; Shin \& Kim, 1999; Xenos, Pierrakeas \& Pintelas, 2002). Mesmo que as barreiras ou facilitadores não estejam baseadas em eventos ou condições reais, pois estão pautadas na percepção, elas têm influência sobre a participação em treinamentos e no comportamento do aprendiz, também em contextos atuais de e-learning (Garavan et al., 2010).

As barreiras podem ser definidas como fatores que evitam, impedem ou interrompem a aprendizagem ou encerram este processo prematuramente, como por exemplo, restrições de recursos (finanças, tempo, conhecimento, etc.). Já os facilitadores são fatores que auxiliam os aprendizes a adquirir novos conhecimentos e habilidades, sendo capazes de motivar, sustentar e/ou melhorar a aprendizagem (Crouse et al., 2011; Hicks, Bagg, Doyle \& Young, 2007). Crouse et al. (2011), em análise de pesquisas sobre o tema, constataram que compartilhadas ou específicas barreiras/facilitadores de aprendizagem existem entre diversas categorias profissionais.

Esses construtos abrangem diversas variáveis que interferem na ocorrência da desistência/persistência e expressam possibilidades ou obstáculos que os aprendizes podem experimentar durante programas de treinamento. Em cursos a distância, novos e específicos fatores estão presentes como: o desempenho do tutor - questões relativas à qualidade do exercício profissional docente em contextos de ensino online; as características peculiares do desenho instrucional, tais quais, a interface gráfica e o ambiente virtual de aprendizagem; a disponibilidade de apoio técnico e psicossocial fornecido pelos pares e organização aos treinandos, bem como quando e a forma que lhes é prestado; a disponibilidade, a utilidade e a facilidade de uso da tecnologia (Martins \& Kellermanns, 2004; Umekawa, 2013).

Segundo Meneses et al. (2006), qualquer indivíduo possui a capacidade de aprender e de transferir novas habilidades, contanto que o desenho instrucional e as condições de apoio à aprendizagem e à transferência favoreçam esse processo de mudança comportamental. Fatores externos ao indivíduo, em cursos a distância pela 
internet, podem funcionar como barreiras ao seu desempenho, incluindo limitações de tempo, a relação aluno-tutor e aspectos relacionados à tecnologia (Hillesheim, 1998).

Para Klein et al. (2006), as condições ou eventos ambientais podem ser percebidos como uma ajuda ou um obstáculo por indivíduos diferentes, ou como uma combinação de ambos, por uma mesma pessoa, dependendo de características pessoais e da própria instrução. Os autores afirmam ainda que os facilitadores ou barreiras impactam sobre o desempenho de forma indireta por afetar a motivação do aprendiz, que mostra-se menos propenso a lutar por um resultado quando percebe que seus esforços serão impedidos e, ao contrário, está mais propenso a fazê-lo, quando percebe que seus esforços serão ajudados. A percepção de barreiras frustra o indivíduo, diminuindo a sua motivação para aprender e reduzindo o seu esforço, uma vez que não acredita que o esforço adicional vai se traduzir em um melhor desempenho (Mathieu et al., 1992); os facilitadores têm efeito oposto e podem levar a avaliações mais positivas da efetividade do e-learning pelos participantes (Garavan et al., 2010).

Especificadamente no tocante ao perfil da clientela de cursos EAD, Abbad (2007) sinaliza que é constituída por adultos profissionalmente ativos, que necessitam de contínua atualização e requalificação de conhecimentos; possuem várias experiências de vida e acúmulo de diferentes papéis. Portanto, almejam que seus conhecimentos e suas experiências anteriores sejam levados em conta durante o treinamento, com a proposição de situações complexas de aplicação prática e resolução de problemas que tenham impacto relevante e favorável na vida profissional; esperam que o planejamento da ação instrucional considere o fato de que deverão conciliar as atividades de estudo com responsabilidades pessoais e profissionais, sendo compatível e adequado às rotinas de trabalho.

Ao realizar um treinamento virtual, esse participante provavelmente considerará os fatores presentes em si ou no contexto externo como facilitadores ou como barreiras, a depender do quanto domina as tecnologias aplicadas e requeridas, consegue organizar e gerenciar os estudos concomitantemente a outras atividades desempenhadas, se o curso corresponde às expectativas pessoais e profissionais, o tempo disponível e os gastos para lograr estudar.

Um número bastante reduzido de estudos investigou a percepção de restrições situacionais (barreiras) e de apoios sociais (facilitadores) em contextos de e-learning (Garavan et al., 2010). A Tabela 5 expõe alguns resultados de pesquisas sobre barreiras e facilitadores em contextos EAD. 
Tabela 5. Pesquisas sobre Barreiras e Facilitadores em EAD.

\begin{tabular}{|c|c|c|c|c|}
\hline Autores & Objetivo & Amostra/Contexto & $\begin{array}{l}\text { Procedimentos } \\
\text { de análise de } \\
\text { dados }\end{array}$ & Resultados \\
\hline $\begin{array}{l}\text { Klein, Noe \& } \\
\text { Wang (2006) }\end{array}$ & $\begin{array}{l}\text { Examinar a motivação para aprender como } \\
\text { mediador das relações entre modo de } \\
\text { entrega, orientação de metas para a } \\
\text { aprendizagem, percepção de barreiras e } \\
\text { facilitadores e os resultados de curso } \\
\text { híbrido e em sala de aula }\end{array}$ & 600 universitários & $\begin{array}{l}\text { Regressão } \\
\text { múltipla } \\
\text { hierárquica }\end{array}$ & $\begin{array}{l}\text { - Alunos do curso híbrido, com alta orientação de } \\
\text { metas para a aprendizagem e que perceberam } \\
\text { características ambientais como facilitadores em } \\
\text { vez de barreiras tiveram significativamente maior } \\
\text { motivação para aprender; } \\
\text { - Motivação para aprender esteve } \\
\text { significativamente relacionada com os resultados } \\
\text { do curso (satisfação, metacognição e notas). }\end{array}$ \\
\hline Sales (2009) & $\begin{array}{l}\text { Estudar a relação entre as características } \\
\text { do curso, da clientela e do contexto de } \\
\text { estudo e a evasão em treinamentos a } \\
\text { distância }\end{array}$ & $\begin{array}{l}626 \text { egressos de } \\
\text { treinamentos a distância } \\
\text { oferecidos pela Embrapa } \\
\text { (Brasil) }\end{array}$ & $\begin{array}{l}\text { Regressão } \\
\text { logística }\end{array}$ & $\begin{array}{l}\text { Quanto mais favoráveis forem as autoavaliações } \\
\text { em relação à disciplina e ao interesse pelo curso, } \\
\text { reações positivas ao desempenho do tutor, } \\
\text { domínio de ferramentas tecnológicas, mais } \\
\text { chances o participante tem de concluir o } \\
\text { treinamento a distância. }\end{array}$ \\
\hline $\begin{array}{l}\text { Brauer, Abbad } \\
\text { \& Zerbini } \\
(2009)\end{array}$ & $\begin{array}{l}\text { Analisar o relacionamento entre sexo, } \\
\text { idade, escolaridade e região geográfica e } \\
\text { as barreiras à conclusão do curso } \\
\text { (regularidade de acesso ao curso, falta de } \\
\text { tempo e dificuldades pessoais e com a } \\
\text { interface) }\end{array}$ & $\begin{array}{l}451 \text { egressos de curso } \\
\text { gratuito a distância do } \\
\text { SEBRAE (Brasil) }\end{array}$ & $\begin{array}{l}\text { Regressão } \\
\text { múltipla padrão }\end{array}$ & $\begin{array}{l}\text { - A idade e a região geográfica explicaram uma } \\
\text { pequena parte da variabilidade de barreiras à } \\
\text { regularidade no acesso à internet; } \\
\text { Mulheres apresentaram maiores barreiras } \\
\text { relacionadas a dificuldades pessoais e com a } \\
\text { interface, mas o sexo explicou muito pouco essa } \\
\text { variável. }\end{array}$ \\
\hline $\begin{array}{l}\text { Garavan, } \\
\text { Carbery, } \\
\text { O’Malley \& } \\
\text { O'Donnell } \\
\text { (2010) }\end{array}$ & $\begin{array}{l}\text { Examinar a influência dos fatores } \\
\text { características pessoais (idade, experiência } \\
\text { laboral), motivação para aprender, } \\
\text { autoeficácia, barreiras e facilitadores } \\
\text { situacionais e características do desenho } \\
\text { instrucional na participação em atividades } \\
\text { voluntárias de e-learning }\end{array}$ & $\begin{array}{l}557 \text { funcionários de } 275 \\
\text { organizações (Irlanda) }\end{array}$ & $\begin{array}{l}\text { Modelagem por } \\
\text { Equações } \\
\text { estruturais }\end{array}$ & 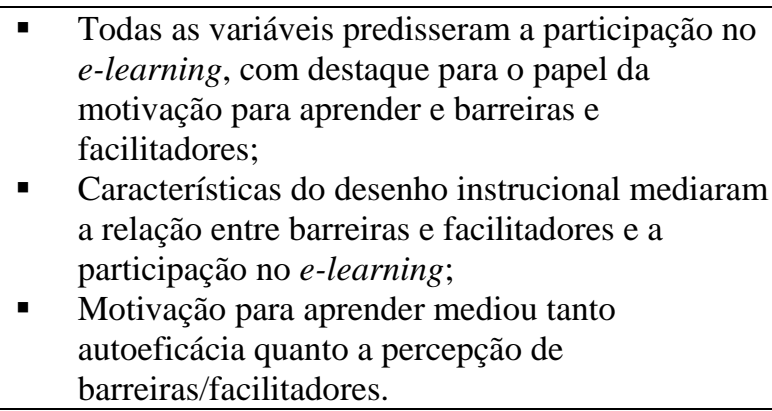 \\
\hline
\end{tabular}


No estudo de Crouse et al. (2011), no qual entrevistas com gerentes da área de Recursos Humanos foram realizadas, identificaram-se algumas das principais barreiras e facilitadores encontrados por eles no ambiente de trabalho. As barreiras levantadas estavam relacionadas a variadas limitações de recursos como: falta de tempo, sobrecarga de trabalho - apesar de não aparecer na literatura, é provável que esteja expressa em muitos estudos como a falta de tempo, segundo os autores -, falta de dinheiro, não contar com suficientes processos de tecnologia implementados, falta de acesso a recursos de aprendizagem e computadores (Hicks et al., 2007), acessibilidade e barreiras pessoais (falta de interesse por parte do aluno). Tais barreiras são condizentes com pesquisas anteriores, mas outras que os autores esperavam serem listadas não foram mencionadas no estudo, e incluem: restrições interpessoais, limitações estruturais e culturais, conteúdo e modo de entrega do curso, relações de poder e mudança.

Os facilitadores dizem respeito a aprender com e dos outros, apoio organizacional e gerencial, tecnologia (acesso a computadores e à web), atributos pessoais (iniciativa do próprio participante, capacidade de priorizar o aprendizado e refletir sobre eventos, vontade de aprender, identificar por si suas necessidades e ter interesse nisso), questões relacionadas ao trabalho/tarefa e à família. Os respondentes referiram usar webinars e salas virtuais de aprendizagem para comunicarem-se com outras pessoas e trocar experiências; nesse contexto, uma fala mostrou-se bastante expressiva "a partilha das melhores práticas acontece online", confirmando o mais citado (e talvez mais importante) facilitador: aprender com e dos outros. Os autores concluem que justamente a tecnologia e o uso de websites podem atuar como uma forma de superar as barreiras e facilitar a aprendizagem individual e grupal por meio da interação ao vivo. Klein et al. (2006) relataram que os participantes de eventos educacionais online tiveram uma maior motivação para aprender quando perceberam as condições ambientais, tais como tempo e acesso à internet como facilitadores de aprendizagem, e não como barreiras.

Outras pesquisas, igualmente pouco numerosas e conclusivas, que se relacionam a esta temática são as que buscam investigar de que forma os facilitadores ou as barreiras podem influenciar na permanência ou evasão dos participantes em cursos a distância (Abbad, 2007; Abbad et al., 2010; Almeida, Abbad, Meneses \& Zerbini, 2013; Leung \& Li, 2006; Meneses et al., 2012; Vaughan, 2007).

Os fatores de sucesso ou os restritores que podem influenciar a decisão de permanência ou de abandono em cursos dessa natureza estão também relacionados ao aluno, ao curso e ao contexto. Abbad et al. (2010) traçaram um panorama das pesquisas 
em evasão, destacando como fatores influentes: a falta de habilidade para administrar o tempo de estudo e para conciliar as atividades concorrentes, a falta de suporte de outros participantes da ação educacional para atingir bons resultados de aprendizagem, as percepções equivocadas sobre a natureza e a complexidade do curso, a frustração de expectativas pessoais quanto ao curso e à tutoria - disponibilização de informações e feedback. O conflito com os horários de trabalho e a falta de tempo para realizar as atividades de treinamento foram os motivos principais apontados por Henke e Russum (2002) para a não conclusão dos treinamentos pelos participantes. E na revisão de Lee e Choi (2011), os fatores relacionados à persistência/evasão em cursos online referem-se: i) às características do aluno: aprendizes com níveis mais baixos de desempenho acadêmico (notas), menor experiência profissional e nenhuma participação anterior em outros treinamentos a distância foram aqueles que mais evadiram; ii) níveis mais elevados de autoeficácia, de satisfação com o curso e a utilização de mecanismos autorregulatórios de aprendizagem com frequência e de modo eficaz estiveram positivamente relacionados à persistência; iii) o desenho do curso (programa, valor instrumental, possibilidade de interação proporcionada e exercida pelos participantes) e o apoio institucional (suporte familiar, de colegas e da organização onde trabalha) se mostraram positivamente correlacionados com a decisão de persistir em cursos a distância.

De modo geral, esses estudos apontam, dentre os fatores que podem influenciar a decisão de persistência/evasão, as características demográficas (sexo e idade), as de natureza cognitiva, como os processos autorregulatórios de aprendizagem, as competências de gestão do tempo e da ansiedade, a satisfação com o curso, aspectos contextuais e do próprio treinamento (Abbad et al., 2006; Abbad et al., 2010).

Os facilitadores e as barreiras propostos no modelo conceitual de avaliação foram testados como antecedentes que poderiam afetar o impacto do treinamento no trabalho, partindo da premissa de que a percepção dos recursos como facilitadores e não como barreiras levaria a maiores níveis de impacto do treinamento no trabalho; além da proposição de que o suporte recebido pelos indivíduos influenciaria nessa percepção, atuando como moderador da relação entre as variáveis, conforme as seguintes hipóteses:

Hipótese 5: À medida em que os participantes perceberem os recursos como facilitadores e não como barreiras será positivamente relacionada com os indicadores de efetividade de treinamento (impacto do treinamento no trabalho em profundidade e em amplitude). 
Hipótese moderadora: $\mathrm{O}$ suporte à transferência atuará como moderador da relação entre as barreiras e facilitadores em EAD e os indicadores de efetividade de treinamento (impacto do treinamento no trabalho em profundidade e em amplitude).

\subsubsection{Variáveis de efetividade de treinamento.}

Cabe neste momento diferenciar a avaliação de treinamento da efetividade de treinamento, como descrito por Alvarez et al. (2004). A avaliação de treinamento propõe a medição do grau que o treinamento atendeu os objetivos pretendidos (i.e., os resultados de treinamento), ou seja, examinar os benefícios do treinamento para os indivíduos, em termos de ganhos de aprendizagem e melhor desempenho no trabalho. As medidas de avaliação dependem dos objetivos previamente estabelecidos, podendo incluir a avaliação de conteúdos e desenho do treinamento, as mudanças nos aprendizes e as recompensas geradas para a organização.

O momento de avaliação permite que as organizações continuem a realizar treinamentos que funcionam e possam modificar ou descontinuar aqueles que não funcionam (Salas et al., 2012). Segundo Goldstein (1991), a avaliação de treinamento constitui-se em um processo sistemático de coleta de informações que irá proporcionar a revisão e o aprimoramento dos eventos por meio de decisões referentes à seleção, adoção, valorização e modificação dos aspectos instrucionais existentes. Desse modo, os principais objetivos da avaliação de treinamento são: obter controle sobre o processo, retroalimentar o sistema, tomar decisões sobre o treinamento e torná-lo capaz de provocar modificações em seu ambiente.

Aguinis e Kraiger (2009) recomendam que a avaliação de treinamento inclua a finalidade da avaliação, as necessidades e a sofisticação do público-alvo, e as variáveis relacionadas às reações, tanto de utilidade quanto afetivas. Completam que os benefícios do treinamento além de serem maximizados, devem ser documentados; e que a medida do quanto um treinamento acresce, precisa levar em conta as perspectivas dos diferentes atores envolvidos no processo, ou seja, os participantes, aqueles que o entregam e os que o financiam.

Por outro lado, a efetividade de treinamento examina aspectos do ambiente, do treinamento e dos treinandos que fazem com que os programas sejam bem ou malsucedidos, buscando entender os resultados, ou seja, se houve ou não, aprendizado. Tratase do estudo de variáveis que podem influenciar os resultados de treinamento em 
diferentes fases (antes, durante ou depois) do processo, já que têm o potencial de aumentar ou diminuí-los, e são tradicionalmente estudadas e classificadas em: características individuais, do treinamento e organizacionais.

Vale salientar, como estudos anteriores já alertaram, que a eficácia não garante necessariamente a efetividade de uma ação educacional, que se constitui em uma das principais preocupações e objetivos da área de TD\&E, e é fundamentalmente avaliada por meio do indicador impacto do treinamento no trabalho (Joo et al., 2011). Estes autores sinalizam a necessidade de investigações que discutam o processo de transferência em contextos virtuais de aprendizagem, visando compreender os mecanismos e os fatores que influenciam a efetividade do e-learning corporativo, uma vez que ainda se trata de uma temática desafiadora, mas valiosa e útil.

A seguir, apresenta-se a variável critério do presente estudo, atendendo a agendas de pesquisas que afirmaram que a pesquisa empírica futura deveria avaliar diretamente o Impacto do Treinamento no Trabalho como variável critério (Burke \& Hutchins, 2007).

\subsubsection{Impacto do treinamento no trabalho.}

Um dos interesses da área de avaliação de TD\&E reside na mensuração do efeito do treinamento no trabalho do egresso (Abbad, 1999; Salas \& Cannon-Bowers, 2001), ou seja, pretende compreender como e em que medida o treinamento produz mudanças no comportamento subsequente do treinado, afetando a execução de suas atividades, concernentes às atribuições específicas na organização, quando ele retorna à sua vida laboral diária (Pilati \& Abbad, 2005). Salas et al. (2012) afirmam que o sistema de treinamento deve promover a aplicação de habilidades recém-adquiridas para o trabalho, pois melhorias na aprendizagem não significam necessariamente mudanças no comportamento dos egressos - grau em que as habilidades aprendidas são transferidas para o trabalho -, e estas modificações comportamentais são raramente objeto de estudos empíricos, importantes para oferecer subsídios para a tomada de decisão se o e-learning é uma estratégia de formação viável (Derouin et al., 2005), pesando seus benefícios e suas desvantagens, caso a caso.

Os estudos sobre esse tema centram-se em variáveis que afetam o impacto do treinamento sobre o desempenho do egresso, no que tange à aplicação das novas competências adquiridas em treinamento no trabalho, bem como em intervenções destinadas a melhorá-lo (Aguinis \& Kraiger, 2009). Embora o alcance desse objetivo de 
investigação seja uma preocupação compartilhada por pesquisadores e profissionais, são atribuídas terminologias nada consensuais aos conceitos referentes ao nível de efeito póstreinamento.

Existe um leque de conceitos para descrever o fenômeno de resultado do treinamento no desempenho, que dependendo da origem dos autores, principal campo do saber em que se insere o estudo ou das características próprias do contexto de investigação, adotam-se termos diferentes. Na literatura internacional, o conceito que remete a tal fenômeno é o de Transferência de Treinamento, que diz respeito à aplicação eficaz no contexto de trabalho dos CHAs adquiridos durante ações instrucionais (Baldwin \& Ford, 1988; Burke \& Hutchins, 2007; Ford \& Kraiger, 1995; Tannenbaum \& Yukl, 1992) e é aplicável a quaisquer tipos e modalidades de ações de TD\&E.

Estudiosos brasileiros reservaram o termo "transferência de treinamento" aos ambientes abertos de trabalho, nos quais não seja possível observar os efeitos da ação instrucional no comportamento subsequente do indivíduo em seu cargo dentro de uma organização, pois o ambiente de transferência é diversificado, podendo o indivíduo aplicar os conhecimentos adquiridos em diferentes contextos de trabalho (Zerbini, 2007). Para diferenciá-lo, nos eventos educacionais corporativos, o termo impacto do treinamento no trabalho (Zerbini et al., 2012a) foi adotado, tal como apresenta-se no modelo clássico de avaliação de treinamento de Hamblin (1978), no nível de comportamento do cargo, no qual o conceito de transferência de treinamento pode ser medido de duas formas: impacto do treinamento em profundidade e impacto do treinamento em amplitude.

Para Abbad (1999), o impacto do treinamento no trabalho nem sempre se reduz à transferência de aprendizagem ou de treinamento, uma vez que para além do fenômeno de resultado do treinamento no desempenho também podem ser observados efeitos sobre as atitudes e motivações dos egressos em relação ao seu trabalho. Segundo Pilati e Abbad (2005), além dos treinamentos que visam produzir resultados favoráveis e permanentes no uso de habilidades, há programas de TD\&E que são planejados para aumentar a motivação e/ou o comprometimento organizacional, reduzir tensões e/ou conflitos internos e/ou facilitar a aceitação de mudanças organizacionais. Nesses casos, é inadequado falar em transferência de treinamento ou de aprendizagem, devendo-se adotar o termo impacto do treinamento no trabalho.

Por isso, o Impacto do Treinamento no Trabalho é predominantemente utilizado na literatura nacional, sendo o principal indicador da efetividade de ações de treinamento 
no nível individual (Pilati \& Abbad, 2005), dividido e medido tanto em profundidade como em amplitude. O Impacto do Treinamento em Profundidade é o efeito direto da transferência de treinamento sobre o desempenho subsequente do egresso. São enfocados os efeitos diretos e específicos de uma ação de TD\&E, relacionados aos objetivos instrucionais, sobre o comportamento no cargo dentro da organização (Zerbini et al., 2012a). Já o Impacto do Treinamento em Amplitude refere-se à influência indireta da ação educacional sobre o desempenho global, as atitudes e a motivação do indivíduo (Abbad, Pilati, Borges-Andrade \& Sallorenzo, 2012b; Pilati \& Abbad, 2005).

São as medidas baseadas nesses construtos que permitem verificar se, após a participação de uma ação educacional, o indivíduo passou a aplicar as novas competências desenvolvidas em seu cargo (impacto do treinamento em profundidade) ou se elas tiveram influências no seu desempenho global, incluindo atitudes e estados motivacionais (impacto do treinamento em amplitude). Zerbini et al. (2012a) afirmam, a partir da análise de importantes pesquisas sobre essas variáveis, que há a maior adoção de instrumentos de avaliação de impacto em amplitude em contrapartida aos de impacto em profundidade - estes são mais complexos e difíceis de serem construídos e validados, pois requerem a análise dos objetivos instrucionais, que nem sempre estão disponíveis e que variam de um curso para outro, criando a necessidade de instrumentos específicos para cada curso oferecido nos programas de treinamento.

Portanto, essa escolha conceitual permite diferenciar as possíveis (e desejadas) influências que o treinamento pode ter sobre os comportamentos do indivíduo, avaliando os efeitos diretos (profundidade) e indiretos (amplitude) no desempenho do egresso. Algumas das vantagens em utilizar dois tipos diferentes de medidas, em oposição à medida única, consistem em avaliar de forma mais específica os ganhos atingidos por determinada ação instrucional e se esta provocou de fato e de maneira efetiva mudanças no desempenho das atividades demandadas pela função ou se, adicionalmente, gerou benefícios para a performance do indivíduo no trabalho de forma mais ampla.

A medida de impacto em profundidade permite avaliar os efeitos de um dado treinamento, e se os resultados são consonantes com os objetivos educacionais previamente estabelecidos; em outras palavras, possibilita verificar se a finalidade do treinamento em desenvolver ou aperfeiçoar determinadas competências expressas pelos objetivos instrucionais foi atendida e se esse conjunto de CHAs está sendo aplicado no trabalho após a participação no evento instrucional. Por outro lado, a medida de impacto em amplitude - que se assemelha mais às medidas de transferência de treinamento usadas 
em estudos estrangeiros - possibilita a autoavaliação do participante acerca dos efeitos produzidos pelo treinamento em seus níveis subsequentes de desempenho, motivação, autoconfiança e abertura a mudanças nos processos de trabalho (Abbad, 1999). Segundo Pilati e Abbad (2005), medidas de avaliação de impacto em amplitude padronizam os indicadores de avaliação, tornando-os genéricos e objetivos, sendo bastante úteis na comparação de efeitos de treinamentos diversos sobre o comportamento de seus participantes.

O uso simultâneo de ambas medidas representa um avanço para as investigações da área, já que o teste de relações empíricas entre variáveis individuais e contextuais e a influência de cada uma delas sobre cada tipo de impacto permite identificar, além dos fatores com maior valor preditivo, sobre qual impacto se dá sua incidência.

Vários estudos empíricos, revisões de literatura e meta-análises têm produzido valiosas informações sobre o impacto do treinamento no trabalho (Burke \& Hutchins, 2007; Grossman \& Salas, 2011). As revisões de literatura realizadas por Grossman e Salas (2011) e Salas et al. (2012), que cotejam resultados de outras revisões e trabalhos empíricos (por exemplo, Burke \& Hutchins, 2007; Velada et al., 2007), apontam as principais variáveis que exibem, continuamente nas pesquisas, os mais fortes e consistentes relacionamentos com impacto do treinamento no trabalho, classificadas segundo três categorias: i) características do treinando: capacidade cognitiva, autoeficácia, motivação, percepção de utilidade do treinamento; ii) desenho do treinamento: modelagem comportamental, gestão de erros, ambientes de treinamento realistas; iii) ambiente de trabalho: clima para transferência, suporte, oportunidade para desempenhar, follow-up.

A Tabela 6 mostra uma combinação dos principais e coincidentes relacionamentos de variáveis com impacto do treinamento no trabalho encontrados em grandes revisões de literatura atuais (Burke \& Hutchins, 2007; Grossman \& Salas, 2011), bem como uma série de construtos que têm apresentado influência direta ou indireta sobre a transferência perpassando pelo processo de aprendizagem (Burke \& Hutchins, 2007). Pode-se observar as variáveis que vêm apresentando relacionamento forte a moderado com impacto; aquelas que não alcançaram resultados conclusivos (suporte misto) nos estudos já realizados, ora relacionando-se com impacto, ora não; ou sobre as quais ainda há pouca pesquisa empírica, indicando a necessidade de mais investigações para analisar seus efeitos sobre o impacto do treinamento no trabalho. 
Em negrito, destacam-se as variáveis relativas às estratégias de autogerenciamento - que incluem comportamentos autorregulatórios capazes de equipar os treinandos com competências necessárias para ajudá-los a transferir com sucesso para o local de trabalho (Burke \& Hutchins, 2007) - e os diferentes tipos de suporte (gerencial e pares) que devem ser alvo de pesquisas futuras para consolidar resultados ou esclarecer os existentes, conforme recomendações dos autores das revisões, já que tanto em pesquisas nacionais quanto em estrangeiras, as variáveis de suporte vêm sendo apontadas como as mais importantes preditoras de impacto do treinamento no trabalho a longo prazo (Abbad, Pilati \& Pantoja, 2003; Salas \& Cannon-Bowers, 2001). Vale salientar que estas são variáveis foco do presente estudo (estratégias de aprendizagem e suporte), ao lado de outras menos exploradas na literatura dominante da área de TD\&E, contudo, típicas de contextos educacionais online, como as barreiras e os facilitadores encontrados por participantes durante a realização de cursos a distância e as medidas de reações específicas a aspectos referentes aos treinamentos virtuais - procedimentos instrucionais e tutor. A análise de novas relações entre diferentes fatores que podem influenciar no impacto do treinamento no trabalho ratifica a originalidade e relevância da presente pesquisa. 
Tabela 6. Resultados de pesquisas sobre impacto do treinamento no trabalho em revisões de literatura (Burke \& Hutchins, 2007; Grossman \& Salas, 2011).

\begin{tabular}{|c|c|c|c|c|c|c|}
\hline Níveis & Variáveis & Comentários & $\begin{array}{l}\text { Relacionamento } \\
\text { forte a } \\
\text { moderado com } \\
\text { impacto }\end{array}$ & $\begin{array}{c}\text { Suporte } \\
\text { misto }\end{array}$ & $\begin{array}{l}\text { Pouca } \\
\text { pesquisa } \\
\text { empírica }\end{array}$ & $\begin{array}{c}\text { Mais } \\
\text { pesquisas } \\
\text { são } \\
\text { necessárias }\end{array}$ \\
\hline \multirow{14}{*}{ 承 } & Capacidade cognitiva & $\begin{array}{l}\text { Aprendizes com capacidade cognitiva mais alta têm maior } \\
\text { sucesso em processar, reter e generalizar habilidades } \\
\text { aprendidas. }\end{array}$ & 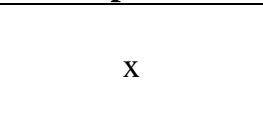 & & & \\
\hline & Autoeficácia & $\begin{array}{l}\text { Aprendizes com alta autoeficácia têm maior confiança na } \\
\text { habilidade pessoal para aprender e aplicar competências } \\
\text { aprendidas e são mais propensos a persistir ao executar tarefas } \\
\text { difíceis. }\end{array}$ & $\mathrm{x}$ & & & \\
\hline & Motivação pré-treinamento & \multirow{4}{*}{$\begin{array}{l}\text { A transferência é facilitada quando os aprendizes estão } \\
\text { motivados a aprender e transferir durante o processo do } \\
\text { treinamento }\end{array}$} & $\mathrm{x}$ & & & \\
\hline & Motivação para aprender & & & & $\mathrm{x}$ & $\mathrm{x}$ \\
\hline & Motivação para transferir & & & & $\mathrm{x}$ & $\mathrm{x}$ \\
\hline & Motivação intrínseca vs. extrínseca & & & $\mathrm{x}$ & & $\mathrm{x}$ \\
\hline & Ansiedade & & $\mathrm{x}$ & & & \\
\hline & Consciência & & & $\mathrm{x}$ & & $\mathrm{x}$ \\
\hline & Abertura à experiência & & $\mathrm{x}$ & & & $\mathrm{x}$ \\
\hline & Extroversão & & & & $\mathrm{x}$ & $\mathrm{x}$ \\
\hline & Utilidade percebida do treinamento & $\begin{array}{l}\text { Aprendizes que percebem o treinamento como útil e válido } \\
\text { são muito mais propensos a aplicar as novas competências no } \\
\text { trabalho }\end{array}$ & $\mathrm{x}$ & & & \\
\hline & Planejamento de carreira & & $\mathrm{x}$ & & & \\
\hline & Comprometimento organizacional & & $\mathrm{x}$ & & & \\
\hline & $\begin{array}{l}\text { Locus de controle interno vs. } \\
\text { externo }\end{array}$ & & & $\mathrm{x}$ & & $\mathrm{x}$ \\
\hline \multirow[b]{4}{*}{$\underset{\mathscr{E}}{\Xi}$} & Análise de necessidades & & & & $\mathrm{x}$ & $\mathrm{x}$ \\
\hline & Objetivos de aprendizagem & & $\mathrm{x}$ & & & \\
\hline & Relevância do conteúdo & & $\mathrm{x}$ & & & \\
\hline & Prática e feedback/Follow-up & $\begin{array}{l}\text { Treinamentos e práticas conduzidos em ambientes } \\
\text { semelhantes ao local de trabalho aumentam a probabilidade } \\
\text { das competências adquiridas sejam transferidas; } \\
\text { O treinamento formal deve ser seguido por oportunidades de } \\
\text { aprendizagem adicionais (revisões, feedback, ajudas de } \\
\text { trabalho, etc.). }\end{array}$ & $\mathrm{x}$ & & & \\
\hline
\end{tabular}


Tabela 6. Resultados de pesquisas sobre impacto do treinamento no trabalho em revisões de literatura (Burke \& Hutchins, 2007; Grossman \& Salas, 2011). (Continuação)

\begin{tabular}{|c|c|c|c|c|c|c|}
\hline Níveis & Variáveis & Comentários & $\begin{array}{l}\text { Relacionamento } \\
\text { forte a } \\
\text { moderado com } \\
\text { impacto } \\
\end{array}$ & $\begin{array}{c}\text { Suporte } \\
\text { misto }\end{array}$ & $\begin{array}{l}\text { Pouca } \\
\text { pesquisa } \\
\text { empírica }\end{array}$ & $\begin{array}{l}\text { Mais } \\
\text { pesquisas } \\
\text { são } \\
\text { necessárias }\end{array}$ \\
\hline \multirow{7}{*}{ 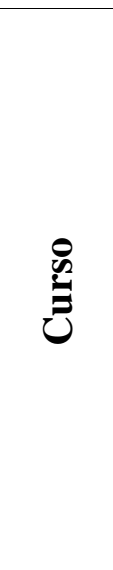 } & Over-learning & & & & & $\mathrm{x}$ \\
\hline & Sobrecarga cognitiva & & & & & $\mathrm{x}$ \\
\hline & Aprendizagem ativa & & & & $\mathrm{x}$ & $\mathrm{x}$ \\
\hline & Modelagem comportamental & $\begin{array}{l}\text { Facilita a transferência quando ambos modelos, positivo e } \\
\text { negativo, são usados e quando são fornecidas oportunidades } \\
\text { para a prática }\end{array}$ & $\mathrm{x}$ & & & \\
\hline & Gestão de erros & $\begin{array}{l}\text { Promove o impacto do treinamento no trabalho ao permitir } \\
\text { aos aprendizes antecipar problemas potenciais, fornecendo- } \\
\text { lhes conhecimento para lidar com tais problemas, e ao } \\
\text { ressaltar os resultados negativos que podem ocorrer caso não } \\
\text { haja a transferência }\end{array}$ & $\mathrm{x}$ & & & $\mathrm{x}$ \\
\hline & $\begin{array}{l}\text { Estratégias de } \\
\text { autogerenciamento }\end{array}$ & & & $\mathrm{x}$ & & $\mathrm{x}$ \\
\hline & Suporte tecnológico & & & & $\mathrm{x}$ & $\mathrm{x}$ \\
\hline \multirow{6}{*}{$\frac{0}{2}$} & $\begin{array}{l}\text { Ligação com a estratégia } \\
\text { organizacional }\end{array}$ & & & & $\mathrm{x}$ & $\mathrm{x}$ \\
\hline & Clima para transferir & $\begin{array}{l}\text { Pistas situacionais e consequências em grande parte } \\
\text { determinam se as competências aprendidas são aplicadas no } \\
\text { local de trabalho }\end{array}$ & $\mathrm{x}$ & & & $\mathrm{x}$ \\
\hline & Suporte gerencial & \multirow[t]{2}{*}{ Ambos são críticos para o impacto do treinamento no trabalho } & $\mathrm{x}$ & $\mathrm{x}$ & & $\mathrm{x}$ \\
\hline & Suporte de pares & & $\mathrm{x}$ & & & \\
\hline & Oportunidade para o desempenho & $\begin{array}{l}\text { Para que ocorra a transferência, os aprendizes necessitam de } \\
\text { recursos e oportunidades para aplicar as novas competências } \\
\text { aprendidas no trabalho }\end{array}$ & $\mathrm{x}$ & & & \\
\hline & Responsabilidade & & & & $\mathrm{x}$ & $\mathrm{x}$ \\
\hline
\end{tabular}


Nas pesquisas brasileiras que investigaram o impacto do treinamento no trabalho, em amplitude e em profundidade, tendo empregado medidas de auto e heteroavaliação a amostras predominantemente compostas por funcionários de organizações de natureza pública e privada (Abbad, Pilati \& Pantoja, 2003) que participaram de cursos presenciais, a variável explicativa mais importante verificada e que apresenta correlações positivas moderadas a fortes com o impacto é o suporte psicossocial (Lacerda \& Abbad, 2003; Meneses \& Abbad, 2003; Mourão, 2004; Pilati, 2004; Sallorenzo, 2000; Tamayo, 2002). Esses achados indicam o papel do apoio oferecido pela organização, por meio dos chefes e colegas, aos egressos de treinamentos para a aplicação de novas aprendizagens no ambiente de trabalho (Abbad et al., 2012b; Borges-Andrade, Abbad \& Mourão, 2006; Pereira, 2009).

As variáveis relativas a características da clientela e do treinamento, reações e aprendizagem têm apresentado menor poder de explicação da ocorrência de impacto do treinamento no trabalho do que as variáveis contextuais em pesquisas sobre avaliação dos efeitos de eventos instrucionais no desempenho do indivíduo nos últimos anos em TD\&E (Abbad, Pilati \& Pantoja, 2003; Zerbini, 2007). Interessante constatar que, de modo geral, as variáveis contextuais, como as de apoio, apresentam maior poder preditivo dos níveis de impacto do treinamento também na modalidade a distância (Chiaburu, 2010; Coelho, 2004; Gunawardena et al., 2010; Zerbini \& Abbad, 2005, 2010a) e constituem-se como um resultado de implicação prática expressivo na área de avaliação de TD\&E (Aguinis \& Kraiger, 2009; Grossman \& Salas, 2011).

Nota-se, a partir da presente revisão da literatura, que as investigações sobre os diferentes tipos de suporte, por se tratarem de variáveis que vêm sendo estudadas na área de avaliação e de efetividade de treinamentos há anos e por apresentarem continuamente consistentes resultados preditivos sobre o impacto do treinamento no trabalho, são caracterizadas por avanços teórico-metodológicos, utilizando procedimentos de análise de dados mais complexos e avançados, além de extrapolar as relações de predição, usando também as de mediação e moderação (Dermol \& Čater, 2013; Joo et al., 2011; Pham et al., 2012).

Ao lado da variável de suporte, certas estratégias de aprendizagem cognitivas e comportamentais (Brandão \& Borges-Andrade, 2011; Pantoja, 2004; Pantoja \& BorgesAndrade, 2009; Testa \& Luciano, 2010, Zerbini \& Abbad, 2005, 2008a, 2010a) e a reação favorável dos participantes a aspectos do curso (procedimentos instrucionais e instrutor), também foram variáveis explicativas de impacto do treinamento no trabalho, medido em 
profundidade (Pilati, 2004; Zerbini \& Abbad, 2005, 2010a) e em amplitude (Lacerda \& Abbad, 2003; Sallorenzo, 2000). Isso demonstra que embora sejam condições necessárias, as variáveis situacionais não são suficientes para garantir o impacto do treinamento no trabalho, devendo-se incluir outras variáveis para a ampla compreensão desse fenômeno e explicação de sua ocorrência (Zerbini \& Abbad, 2010b).

Um número bastante limitado de estudos examinou empiricamente os efeitos do e-learning sobre o comportamento dos egressos (Derouin et al., 2005). Encontram-se lacunas na literatura empírica sobre impacto do treinamento no trabalho no que diz respeito ao desenho da instrução, às variáveis individuais e aos fatores ambientais organizacionais (Velada et al., 2007). As pesquisas que se dedicam às estratégias de aprendizagem e às barreiras e facilitadores em contextos de EAD e sua influência sobre o impacto do treinamento no trabalho ainda são limitadas. Deve-se investir em pesquisas que privilegiem o estudo de características individuais de caráter cognitivocomportamental, como as estratégias de aprendizagem - com foco nas explicações que as estratégias autorregulatórias podem propiciar ao entendimento do processo de aprendizagem e transferência de competências para o trabalho - principalmente nas ações de educação corporativa, formação e qualificação profissional ofertadas a distância (Zerbini, 2007), e que se atenham às possíveis dificuldades encontradas pelos participantes para concluírem cursos online. Urgem pesquisas para auxiliar no desenvolvimento teórico do campo, que adotem procedimentos de análise de dados mais robustos e rigorosos para o teste de relações entre variáveis de TD\&E (Pilati \& BorgesAndrade, 2006) e que se dediquem ao vasto campo dos treinamentos a distância.

A hipótese testada, que se relaciona ao impacto do treinamento no trabalho em profundidade e em amplitude, supunha que os efeitos diretos do treinamento avaliado sobre as competências específicas desenvolvidas influenciariam o desempenho geral dos participantes, uma vez que a performance ocorre de maneira conjugada, como se expõe a seguir:

Hipótese 6: Os participantes que aplicarem as novas competências diretamente em seus cargos (impacto em profundidade) também modificarão seu desempenho global, motivação e atitudes (impacto em amplitude). 


\section{Método}

\subsection{Participantes}

\subsubsection{Organização brasileira.}

O contato com a organização participante, instituição financeira brasileira de grande porte pertencente ao setor bancário público, foi feito por meio de um dos seus assessores empresariais, integrante da Diretoria de Gestão de Pessoas, a quem encaminhou-se o projeto com a solicitação de parceria de pesquisa. A busca por essa organização específica deveu-se ao fato de colaborar, há muito tempo, com grupos de pesquisa na área de Psicologia Organizacional e do Trabalho no país, estando aberta a cooperar com o desenvolvimento de projetos científicos, diferentemente da maioria das organizações às quais não se consegue acesso, tampouco estabelecer parcerias de pesquisa, sendo muito difícil realizar investigações em contextos corporativos. Além disso, a empresa oferece programas de treinamentos a distância a seus membros, temática de interesse e objeto de estudo da presente investigação. Devido ao interesse e à demanda por avaliação de cursos em termos do impacto do treinamento no trabalho por parte da equipe responsável pelas avaliações de treinamentos, foi agendada uma reunião com os seus membros diretores, na qual foram esclarecidos os objetivos da pesquisa e os procedimentos que seriam utilizados. Logo, mantiveram-se contatos com a referida equipe para acertar os aspectos relativos ao instrumental, à escolha dos cursos a serem avaliados e à coleta de dados.

Para dar início ao desenvolvimento do projeto e das atividades de pesquisa, foram firmados uma autorização para a realização da pesquisa e um Termo de Compromisso para Trabalhos Acadêmicos entre a pesquisadora responsável pela investigação e a organização participante. Tais documentos tinham por objetivo estabelecer a parceria de pesquisa, visando a conjugação de esforços entre os partícipes por meio da utilização de seus recursos humanos científicos, tecnológicos e materiais disponíveis para a implementação da pesquisa e a autorização para o levantamento e a utilização de dados referentes aos treinamentos avaliados, sob as seguintes condições: a) preservação do anonimato e sigilo dos pesquisados e assegurar-lhes a participação voluntária no estudo; b) apresentação de devolutiva ao Banco por meio de relatório com os dados apurados; c) utilização das informações coletadas exclusivamente para fins desta pesquisa; d) seguir os objetivos e procedimentos metodológicos estabelecidos no projeto de pesquisa previamente apresentado ao Banco. 


\subsubsection{Curso "Eficiência Operacional".}

A organização oferece virtualmente, por meio de sua Universidade Corporativa, que mantém portal web, programas de capacitação que se caracterizam como treinamentos internos a distância, mediados por intranet, e têm como principal públicoalvo os funcionários do Banco.

O curso "Eficiência Operacional", de caráter autoinstrucional, deveria ser realizado pelos funcionários durante a jornada de trabalho, tendo uma carga horária total de 2 horas. Apresentam-se mais detalhes sobre seus aspectos formais na Tabela 7.

Tabela 7. Características formais do curso Eficiência Operacional.

\begin{tabular}{|c|c|}
\hline Curso & Eficiência Operacional \\
\hline Características & $\begin{array}{l}\text { - A distância } \\
\text { - Autoinstrucional } \\
\text { - Ofertado virtualmente a todos os funcionários do Banco por meio do portal da } \\
\text { Universidade Corporativa } \\
\text { - Público-alvo (potencial a ser atingido): } 109.026 \text { funcionários/5.060 agências }\end{array}$ \\
\hline $\begin{array}{l}\text { Objetivo geral de } \\
\text { aprendizagem }\end{array}$ & $\begin{array}{l}\text { - Identificar formas de promoção da eficiência operacional nas atividades de } \\
\text { trabalho }\end{array}$ \\
\hline Duração & $\begin{array}{l}\text { - } 2 \mathrm{~h} \text { (carga horária total) } \\
\text { - Realizado durante a jornada de trabalho } \\
\text { - } 2^{\circ} \text { semestre/2014: 01/07/14 a 31/12/14 } \\
\end{array}$ \\
\hline Estrutura & $\begin{array}{l}\text { - } 6 \text { Unidades } \\
\text { - Avaliação: exercícios de fixação ao final de cada unidade (domínio } \\
\text { cognitivo/nível conhecimento e compreensão) }\end{array}$ \\
\hline Conteúdos & $\begin{array}{l}\text { - Sequenciados por ordem de complexidade e articulam-se de modo adequado às } \\
\text { Unidades: 1) Introdução; 2) Eficiência e eficácia; 3) Tendências e cenário } \\
\text { bancário; 4) Mensuração da eficiência operacional; 5) Contribuições para } \\
\text { melhoria da eficiência operacional; 6) Promoção da eficiência operacional. }\end{array}$ \\
\hline $\begin{array}{l}\text { Análise dos } \\
\text { objetivos }\end{array}$ & $\begin{array}{l}\text { - Não havia a descrição de objetivos educacionais no material instrucional do } \\
\text { curso }\end{array}$ \\
\hline
\end{tabular}

Trata-se de um curso de curta duração e baixa complexidade, não contando com tutoria online - inviabilizando a avaliação do desempenho do tutor, como previsto. Embora não constassem os objetivos educacionais na introdução do material instrucional, para a construção do instrumento de impacto do treinamento no trabalho em profundidade, foram criadas, junto aos membros diretores em Gestão de Pessoas do Banco parceiro, as competências a serem observadas em desempenhos específicos no trabalho a partir da realização do curso, a saber:

- Identificar, nas atividades de trabalho, oportunidades que minimizem o consumo de recursos (materiais, mão de obra, financeiros, tempo) e maximizem resultados.

- Aplicar recursos materiais, financeiros, mão de obra e tempo, visando à sobrevivência da empresa e manutenção de seus resultados. 
- Compartilhar com os colegas ações que podem ser implementadas para promoção da eficiência operacional.

- Empregar ações para reduzir as despesas administrativas no dia a dia (controle de gastos com energia, reuniões por videoconferência, redução do volume de impressões, uso racional do telefone, etc.).

- Realizar ações de contenção de gastos sem promover a perda de capacidade operacional ou elevação dos riscos.

- Incentivar os clientes a reduzir o consumo de recursos do Banco (uso de canais automatizados para realizar transações, cadastramento de débito automático, uso de cartões para pagamentos, etc).

- Conceder créditos, prestar serviços (produtos de seguridade e cartão de crédito, por exemplo) e captar recursos (LCI e LCA) como formas para aumentar as receitas operacionais do Banco.

- Acompanhar os indicadores de eficiência operacional do Banco ao longo do tempo para contribuir para a sua melhoria.

Nota-se que tratam de comportamentos no nível de aplicação no trabalho das competências aprendidas; da mesma forma, os objetivos instrucionais deveriam enquadrar-se no mesmo nível de complexidade. Contudo, as avaliações ao longo da instrução, através dos exercícios de fixação propostos, apenas exigiam os níveis de conhecimento e compreensão do domínio cognitivo, tornando-a pouco complexa e com um alcance, em termos de aprendizagem, inferior à sua potencialidade e, principalmente, ao que se espera dos funcionários treinados no ambiente de trabalho, ou seja, a transferência das competências adquiridas. Em outras palavras, o curso poderia exigir mais de seus participantes, propondo exercícios práticos ou simular situações reais que tivessem relação com a rotina de trabalho.

\subsection{Instrumentos de Medida}

Os instrumentos de medida existentes na literatura que foram utilizados na pesquisa foram desenvolvidos em estudos nacionais anteriores, nos quais foram analisadas estatisticamente suas evidências de validade e confiabilidade, tendo todos índices considerados bons ou excelentes $(0,72<\alpha<0,98)$ - as demais informações psicométricas podem ser visualizadas na Tabela 18. 
Todos passaram por importantes processos de adaptação visando aperfeiçoá-los e adequá-los a contextos organizacionais, com especial enfoque na redução de itens e número de pontos da escala, na busca por instrumentos mais parcimoniosos e que facilitassem a aplicação e, por conseguinte, a avaliação de treinamentos corporativos. Foram adaptados também ao espanhol, e posteriormente realizaram-se novamente análises teóricas (validação semântica e/ou por juízes) e análises estatísticas para verificar as evidências de validade e consistência interna e sua adequação a novas amostras e a contextos diferentes (brasileiro e espanhol). A listagem dos instrumentos usados, os processos de adaptação e validação (semântica e/ou por juízes e estatística) aos quais foram submetidos, bem como os resultados dessas adequações são apresentados na seção de Resultados e Discussão.

Após firmar parceria de pesquisa com a organização participante, algumas modificações nos instrumentos foram necessárias para adequarem-se à realidade organizacional e às características específicas do treinamento avaliado, como por exemplo, a retirada dos itens que tratavam da figura do tutor ou interações dos treinandos com o mesmo, uma vez que o curso avaliado não contava com tutoria, o que impossibilitou a aplicação do instrumento de Reação ao Desempenho do Tutor na amostra do estudo principal e as consequentes verificação das evidências de validade e confirmação da estrutura empírica da medida, bem como a inclusão da variável como antecedente no modelo proposto. Contudo, a versão em português deste instrumento passou pela validação semântica e por juízes e, posteriormente, foi adaptada ao espanhol e aplicada em estudo piloto (Anexo D), conforme relata-se nas seções subsequentes. Esse processo de ajustes foi feito em conjunto, com sucessivas validações, por parte da equipe responsável pelas avaliações de treinamentos do Banco e a pesquisadora. As versões finais dos instrumentos que foram aplicados à amostra participante do estudo podem ser vistos nos anexos: I) Estratégias de Aprendizagem; J) Reação aos Procedimentos Instrucionais; L) Suporte à Transferência; M) Barreiras e Facilitadores em EAD; N) Impacto do Treinamento no Trabalho em Profundidade (auto e heteroavaliação); O) Impacto do Treinamento no Trabalho em Amplitude (auto e heteroavaliação).

\subsection{Procedimentos de Coleta de Dados}


A coleta de dados foi realizada a distância, via intranet, por meio da qual os instrumentos digitalizados foram enviados em formato de questionário para serem aplicados virtualmente aos funcionários da organização parceira contatada.

O questionário de autoavaliação - que continha todos os instrumentos anteriormente mencionados e outras questões adicionadas pelo Banco sobre a necessidade e utilização do treinamento - foi enviado em junho de 2015, e esteve disponível aproximadamente durante uma semana, a uma amostra composta por 3600 funcionários que realizaram o curso "Eficiência Operacional" no período de 01/07/14 a 31/12/14; bem como o questionário de heterovaliação, apenas com os instrumentos de impacto (profundidade e amplitude) e as questões específicas referidas, foi emitido a seus gestores na mesma ocasião. Os índices de retorno totais obtidos foram de $61,1 \%(N=2201)$ e $66,9 \%$ $(N=2241)$, respectivamente, para a auto e heteroavaliação. Houve um intervalo entre a realização do treinamento e a sua avaliação (de seis meses a um ano) para possibilitar que seus efeitos pudessem ser observados no nível individual, em termos de desempenhos específicos (impacto em profundidade) e gerais (impacto em amplitude) no trabalho.

Idealmente, a coleta dos dados deveria ser realizada em etapas, de acordo com o momento mais oportuno de recolhida das informações de cada variável (durante, imediatamente ao final, após o treinamento): as medidas de reação deveriam ser coletadas logo ao final do curso, no último dia, por exemplo (Meneses et al., 2010); por outro lado, as estratégias de aprendizagem utilizadas pelos participantes poderiam ter sido coletadas durante ou ao final do curso; e as barreiras e facilitadores em EAD e o apoio dado à aplicação do treinamento, quando de seu término. Dessa maneira, teriam sido acatadas recomendações quanto aos procedimentos metodológicos de pesquisa e conferido mais fidedignidade aos dados, porque ao transcorrer muito tempo desde a conclusão da ação educacional e sua avaliação pode-se perder detalhes importantes. Vale salientar que as medidas de impacto foram coletadas na ocasião adequada.

No que diz respeito aos aspectos éticos, o projeto foi aprovado pelo Comitê de Ética em Pesquisa da Faculdade de Filosofia, Ciências e Letras de Ribeirão Preto - USP (CAAE no 46449615.0.0000.5407), e previamente à aplicação dos questionários, os participantes foram esclarecidos sobre os objetivos da pesquisa e seus procedimentos. $\mathrm{O}$ Termo de Consentimento Livre e Esclarecido (Anexo A), no caso de aplicação a distância, estava localizado na página anterior ao link que conduzia ao questionário. Foi assegurada ao participante a manutenção de sigilo e anonimato acerca de sua identidade, o caráter de 
sua participação voluntária e solicitada a autorização do uso de suas informações no estudo.

\subsection{Procedimentos de Análise de Dados}

Para aplicação dos procedimentos de análise de dados, foram consultadas as orientações de Hair, Anderson, Tatham e Black (2005), Pasquali (2004), Tabachnick e Fidell (2007), Baron e Kenny (1986), Hayes (2013) e Byrne (2010). As análises estatísticas dos dados foram realizadas mediante o uso dos programas SPSS (Statistical Package for the Social Science) e SPSS AMOS, versão 22.0:

a) Análises descritivas (média, desvio-padrão, moda, mínimo e máximo) e exploratórias dos dados (entrada dos dados, presença de casos extremos, distribuição dos casos omissos, distribuição de frequência das variáveis e tamanho das amostras);

b) Análises fatoriais exploratórias, utilizando os métodos dos componentes principais (Principal Components - PC) e de fatoração dos eixos principais (Principal Axis Factoring - PAF), e de consistência interna (Alfa de Cronbach), para a verificação de evidências de validade e da confiabilidade dos instrumentos de medida;

c) Análises fatoriais confirmatórias (AFC) das estruturas empíricas das escalas;

d) Análises de regressão e Modelagem por Equação Estrutural (MEE) para testar o conjunto de relações entre os construtos do modelo de investigação proposto e identificar diferentes relacionamentos entre as variáveis (predição, mediação e moderação);

e) Análises de regressão e uso do procedimento PROCESS (método bootstrap) para estimar os mediadores e moderadores das relações entre as variáveis antecedentes do modelo e o impacto do treinamento no trabalho.

Procedimentos de análises de dados mais robustos e rigorosos para o teste de relações entre variáveis de TD\&E, como a AFC e MEE, auxiliam no desenvolvimento teórico do campo, sendo recomendados em agendas de pesquisa da área de avaliação instrucional (Pilati \& Borges-Andrade, 2006; Zerbini, 2007); além de predominarem em investigações estrangeiras na área de avaliação de ações educacionais a distância (Freeze, Alshare, Lane \& Wen, 2010; Lee, Tseng, Liu \& Liu, 2007; Lu \& Chiou, 2010; Sahin \& Shelley, 2008; Siritongthaworn \& Krairit, 2006). Isso indica que as pesquisas nacionais devem progredir na utilização de análises estatísticas mais avançadas, para que sejam testadas teorias e modelos no campo de variáveis de interesse em TD\&E. 
No Brasil, ainda há o predomínio de estudos com a proposição e testagem de modelos sistemáticos de avaliação que usam análises inferenciais menos complexas, como as correlações e as regressões múltiplas (Martins \& Zerbini, 2014a), fato também verificado em revisões de literatura internacionais (Burke \& Hutchins, 2007). O número de trabalhos nacionais que faz uso da MEE encontrado por Pilati e Laros (2007) foi bastante inferior quando comparado à produção científica internacional que usa a técnica há mais tempo. Observa-se que, apesar da crescente inserção da EAD em ambientes corporativos, a área de avaliação e de efetividade de treinamentos a distância ainda carece de pesquisas que possam discutir como ocorre o processo de transferência de competências, explicar os mecanismos mediadores e moderadores existentes e quais variáveis têm maior influência sobre ele.

Considerando-se a necessidade de avanços metodológicos no campo, a MEE apresenta-se como uma técnica que se destaca entre os métodos quantitativos por sua alta capacidade de articulação de variáveis, examinando uma série de relações de dependência simultaneamente, sendo adequada à análise de fenômenos complexos, como os de interesse dos cientistas psicólogos (Codes, 2005; Pilati \& Laros, 2007). Permite a testagem de modelos constituídos de múltiplas variáveis simultâneas, latentes ou observadas (Pilati \& Laros, 2007). As primeiras são medidas não diretamente observadas, mas derivadas de indicadores observáveis (e.g. itens de uma escala), definidas por Hair et al. (2005) como a operacionalização de construtos em MEE. Os construtos, por sua vez, são variáveis não diretamente observadas, mensuradas de forma indireta por meio de variáveis observadas. Finalmente, as variáveis observadas ou manifestas são os indicadores de uma variável latente ou construto (Hair et al., 2005).

A MEE é uma transição da análise exploratória (AFE) para a AFC. Na AFE, o método e os dados estatísticos definem a natureza das relações e a matriz de correlações procura os fatores; já na AFC, uma relação pré-especificada é testada: uma estrutura teórica preliminar é imposta aos dados e, em seguida, é verificada se ela se adapta aos dados empíricos expressos pela matriz de correlações. Ao propor testar um modelo teórico, a MEE extrapola os alcances dos métodos inferenciais e exploratórios, pois permite verificar se as relações preditivas entre variáveis encontradas em pesquisas empíricas anteriores confirmam-se na teoria. Além disso, oferece a possibilidade de 
representar conceitos não observados e explicar erro de mensuração ${ }^{3}$ no processo de estimação, fornecendo estimativas mais precisas das relações causais.

A MEE caracteriza-se como uma estratégia de teste estrutural de modelos teóricos e possui caráter confirmatório, exigindo a definição prévia, antes da análise dos dados, do tipo de relações existentes entre as variáveis do modelo que está sob investigação (Pilati \& Laros, 2007). Por isso, os autores afirmam que para a formulação de hipóteses de relações entre variáveis do modelo estrutural em teste e aplicação da MEE, necessitamse medidas de boa qualidade psicométrica, tendo sua validade já demonstrada, e basearse em pressupostos teóricos sólidos e fundamentados nas evidências empíricas de pesquisas anteriores. Portanto, apresenta-se como uma técnica adequada a campos de investigação que possuam evidências consistentes.

A adoção desse método contribui para a área de avaliação e produção de conhecimentos no campo da EAD em contextos corporativos, suprindo lacunas de pesquisas (Aguinis \& Kraiger, 2009) a respeito do alcance e da influência de mediadores e moderadores no processo de aprendizagem e de impacto do treinamento no trabalho.

Por outro lado, o uso da AFC é recomendável para que os avanços na adaptação dos instrumentos sejam acompanhados de análises confirmatórias de suas estruturas empíricas, atendendo recomendações das pesquisas que já utilizaram métodos exploratórios de análise para a verificação de evidências de validade dos mesmos, obtendo bons índices de consistência interna (Abbad et al., 2012c; Abbad \& Sallorenzo, 2001; Martins \& Zerbini, 2014b; Zerbini \& Abbad, 2008a, 2009a, 2009b). Como tratam de medidas que obtiveram uma grande profusão nos estudos nacionais na área de avaliação de ações educacionais, nos quais corroborações sucessivas foram encontradas quanto aos resultados e qualidades psicométricas dos instrumentos, independente do contexto de aplicação, isto é, instrucional ou organizacional, essa técnica é adequada aos objetivos pretendidos.

\footnotetext{
${ }^{3}$ Erro de mensuração é o grau em que as variáveis possíveis de se medir não descrevem perfeitamente o construto latente de interesse. Todos os construtos apresentam algum erro de mensuração, mesmo com os melhores indicadores. Para explicar os erros de mensuração, a MEE fornece o modelo de mensuração que especifica as regras de correspondência entre as variáveis manifestas (observáveis) e latentes, ou seja, com este modelo é possível avaliar a contribuição de cada item da escala e o quanto a escala mede bem o conceito.
} 


\section{Resultados e Discussão}

\subsection{Adaptação dos Instrumentos de Medida}

\section{$\underline{\text { Adaptação do conteúdo }}$}

Um dos esforços desta pesquisa tratou-se das adaptações de instrumentos de medida já existentes na literatura nacional. Foram consultados e modificados instrumentos já amplamente utilizados e que possuem evidências de validade de construto e índices de consistência interna considerados bons ou excelentes, apontados em investigações como aplicáveis a diferentes contextos e amostras.

Contudo, tais instrumentos continham muitos itens - desrespeitando alguns dos critérios psicométricos para a construção de itens em questionários, como o da precisão (os itens devem ser distintos entre si, não se devendo elaborar itens semelhantes com variações apenas linguísticas) e o da amplitude do conjunto de itens (o conjunto de itens referentes ao mesmo critério de avaliação deve cobrir toda a extensão dele, mas os questionários não devem ser inflados com itens desnecessários) - e a análise de investigações e instrumentos internacionais mostrou uma tendência de usar menos itens, principalmente nos casos em que a medida é unifatorial. Além disso, a presença de itens altamente correlacionados entre si apontavam, em muitos casos, similaridade de conteúdo na redação dos mesmos - a presença de multicolinearidade denota que os itens são tão correlacionados entre si que parecem sinônimos, devendo-se eliminar um deles. Os próprios trabalhos que publicaram as evidências de validade das medidas discutem esse fato, sugerindo que tal redundância deveria ser eliminada para que a adequação dos instrumentos fosse melhorada (Pilati \& Abbad, 2005) ou justificam que a opção pela não exclusão de itens decorria do fato de ser a primeira aplicação e testagem das escalas em um contexto inédito (Martins, 2012; Martins \& Zerbini, 2014b).

Cada instrumento foi analisado separadamente, com base em estudos da literatura da área e outras escalas, nacionais e estrangeiras, e os itens foram reagrupados em temas/conteúdos ou em fatores pré-existentes, ponderando-se as características semânticas e analisando as semelhanças e diferenças existentes; consideraram-se também os aspectos psicométricos, como as cargas fatoriais, multicolinearidade, Alfa de Cronbach se o item fosse excluído, etc., para que itens similares fossem reescritos e vários deles, eliminados. Essa etapa de reedição resultou em instrumentos mais parcimoniosos, evitando repetições desnecessárias de assuntos tratados nos itens, tornando-os mais enxutos, fáceis e rápidos de aplicar. Teve-se como foco o contexto específico de aplicação 
para o qual servirão neste estudo: participantes de treinamentos corporativos ofertados a distância; mas todos os questionários podem e devem ser utilizados em outras amostras e contextos, inclusive em ambientes acadêmicos.

\section{$\underline{\text { Adaptação das escalas }}$}

Outra modificação diz respeito às escalas dos instrumentos. Os itens estavam associados a escalas Likert de 11 pontos, que são pouco utilizadas, de modo geral. A maioria das medidas brasileiras utiliza escalas tipo Likert de 5 pontos (Abbad et al., 2012c; Siqueira, 2008, 2014) - de 71 escalas analisadas, 50\% usam a ancoração de 1 a 5, e todos os outros 8 tipos, em conjunto, somam os $50 \%$ restantes. Escalas de 5 e 7 pontos são também majoritariamente comuns em estudos internacionais (Colman, Norris \& Preston, 1997; Preston \& Colman, 2000).

Naturalmente, a decisão pela quantidade de pontos da escala depende dos objetivos do estudo e dos interesses do investigador, mas Lissitz e Green (1975) indicam que a determinação do número ideal de pontos da escala deva levar em conta os efeitos do mesmo na confiabilidade do instrumento. A partir de 5 pontos, verificaram que não há aumento na confiabilidade, que pode inclusive baixar se o número de pontos supera 5 . No mesmo sentido, Weijters, Cabooter e Schillewaert (2010) indicam que o uso de escalas de 5 pontos é mais adequado para populações que não apresentam alta capacidade cognitiva, habilidades verbais e/ou experiência prévia com questionários - nos casos em que estas qualidades estão presentes, como por exemplo, em amostras de estudantes com alto nível de escolaridade, as de 7 pontos são apropriadas. Os autores ainda sugerem que as escalas devam ter um ponto central, podendo estar totalmente ancoradas ou, nos casos em que se pretende realizar análises de correlação, regressão ou MEE, categorizar somente as extremidades.

Quando observados a confiabilidade, a validade e o poder de discriminação, os índices foram significativamente maiores para as escalas com mais categorias de resposta, até cerca de 7 pontos (Preston \& Colman, 2000). Ademais, as escalas de 5 pontos foram classificadas como relativamente fáceis e rápidas de usar e mais apropriadas a circunstâncias em que haja maior pressão de tempo, para prevenir que os respondentes se sintam frustrados ou desmotivados a responder aos questionários. Em contrapartida, nos casos em que na pesquisa importa que os participantes expressem seus sentimentos de 
forma mais acurada, são recomendadas as escalas de 10 pontos (Preston \& Colman, 2000).

Considerando os argumentos anteriormente apresentados quanto às influências do número de pontos da escala sobre aspectos psicométricos dos instrumentos de medida e que os participantes da presente pesquisa provavelmente irão responder aos questionários em seus ambientes de trabalho e são pessoas que possuem muitas atividades concomitantes, as escalas com 5 pontos parecem ser recomendadas.

A seguir são apresentadas as características gerais dos instrumentos que serão utilizados na coleta de dados e com base em quais escalas foram feitas as adaptações.

\subsubsection{Estratégias de aprendizagem.}

O instrumento de Estratégias de Aprendizagem já foi aplicado em ambientes de trabalho e contextos universitários, como cursos técnicos profissionalizantes (Warr \& Downing, 2000), treinamentos a distância (Zerbini, Carvalho \& Abbad, 2005; Zerbini, Abbad, Mourão \& Martins, 2015), cursos de qualificação profissional a distância (Borges-Ferreira, 2005; Zerbini \& Abbad, 2008a) e contexto de ensino superior híbrido (Martins \& Zerbini, 2014b) e a distância (Umekawa, 2013).

Originalmente, Warr e Allan (1998) propuseram a classificação das estratégias de aprendizagem em nove dimensões teóricas, já apresentadas anteriormente, e Warr e Downing (2000) criaram um instrumento baseado nestas categorias e o testaram, obtendo uma versão da escala com 45 itens associados a uma escala Likert de frequência de 4 pontos, com os seguintes fatores: 1) reflexão ativa (organização e elaboração) (10 itens, $\alpha=0,90) ; 2$ ) controle da emoção ( 5 itens, $\alpha=0,85$ ); 3) monitoramento da compreensão ( 5 itens, $\alpha=0,85)$; 4) controle da motivação ( 5 itens, $\alpha=0,89)$; 5) busca de ajuda ao material didático ( 5 itens, $\alpha=0,89)$; 6) busca de ajuda interpessoal (5 itens, $\alpha=0,84)$; $)$ aplicação prática ( 2 itens, $\alpha=0,78$ ); e 8) repetição mental ( 7 itens, $\alpha=0,81$ ).

Algumas pesquisas brasileiras basearam-se no instrumento de Warr e Downing (2000) para avaliar as estratégias de aprendizagem. Em Zerbini et al. (2005), o instrumento contava com 20 itens (escala Likert de frequência de 11 pontos), e uma estrutura com 3 fatores: busca de ajuda interpessoal ( 8 itens, $\alpha=0,85$ ); elaboração e aplicação prática ( 5 itens, $\alpha=0,75$ ); repetição, organização e ajuda do material ( 7 itens, $\alpha=0,78)$. Na revalidação da escala por Borges-Ferreira (2005) também foi encontrada uma estrutura tridimensional composta pelos fatores busca de ajuda interpessoal (6 itens, 
$\alpha=0,87$ ), estratégias de elaboração e aplicação prática (5 itens, $\alpha=0,76$ ) e estratégias de repetição, organização e ajuda ao material ( 8 itens, $\alpha=0,80)$ - não inclusão das estratégias autorregulatórias em ambos estudos aludidos.

Depois, a escala utilizada por Zerbini e Abbad (2008a) apresentou 28 itens e 8 fatores, a saber: controle da emoção ( 5 itens, $\alpha=0,89$ ), busca de ajuda interpessoal ( 6 itens, $\alpha=0,89$ ), repetição e organização (5 itens, $\alpha=0,77$ ), controle da motivação (4 itens, $\alpha=0,84$ ), elaboração ( 3 itens, $\alpha=0,8$ ), busca de ajuda ao material didático ( 2 itens, $\alpha=0,75$ ) e monitoramento da compreensão ( 3 itens, $\alpha=0,82$ ).

Em seguida, Martins e Zerbini (2014b) obtiveram uma escala com 29 itens e formada por 4 fatores denominados: estratégias cognitivas ( 15 itens, $\alpha=0,90$ ), controle da emoção ( 4 itens, $\alpha=0,77$ ), estratégias autorregulatórias ( 7 itens, $\alpha=0,86$ ) e busca de ajuda interpessoal (3 itens, $\alpha=0,68$ ). Finalmente, Zerbini et al. (2015) encontraram resultados que indicaram uma escala de 5 fatores: controle da emoção ( 4 itens, $\alpha=0,91$ ), repetição e organização (6 itens, $\alpha=0,83$ ), controle da motivação ( 4 itens, $\alpha=0,97$ ), elaboração (3 itens, $\alpha=0,89$ ) e monitoramento da compreensão ( 6 itens, $\alpha=0,91$ ). As estratégias de busca de ajuda interpessoal e busca de ajuda ao material didático não figuraram como potenciais fatores, uma vez que o desenho do curso avaliado não apresentava material didático, tampouco oferecia tutoria ativa aos participantes.

Os achados mostram que a estrutura fatorial do instrumento de Estratégias de Aprendizagem mantém os bons índices de consistência interna e difere empiricamente entre os estudos existentes com a medida, indicando que em diferentes contextos e amostras, e conforme as especificidades do curso em questão avaliado, é demandado o uso de determinadas estratégias de aprendizagem. O mesmo ocorre também nos estudos que enfocam as estratégias de aprendizagem no trabalho, incluindo situações de aprendizagem informal, havendo sido encontradas diferentes estruturas empíricas, de cinco fatores: reprodução, aplicação prática, busca de ajuda interpessoal, busca de ajuda em material escrito e reflexão ativa (intrínseca e extrínseca) (Brandão \& Borges-Andrade, 2011; Moraes \& Borges-Andrade, 2010b); de seis fatores, entre estratégias cognitivas (reprodução, organização e elaboração) e comportamentais (busca de ajuda interpessoal, busca de ajuda ao material didático e aplicação prática) (Holman et al., 2001); e apenas dois fatores (estratégias comportamentais e cognitivo-afetivas) (Brant, Pilati \& BorgesAndrade, 2015; Pilati \& Borges-Andrade, 2005; Pilati \& Gonzaléz, 2009). O que corrobora a assertiva de Levin (1986) de que não há uma melhor estratégia, mas alternativas mais eficazes que variam de acordo com diferentes contextos de 
aprendizagem e consonantes com os procedimentos empregados pelos participantes para conhecer, controlar e regular a aprendizagem.

Nesta pesquisa, uma versão com 21 itens (Anexo B), que medem a frequência de uso das diferentes estratégias de aprendizagem de 1 (nunca) a 5 (sempre) pelos participantes, foi testada (exemplos de itens: "Mantive a calma quando tive dificuldades durante o curso", "Busquei compreender melhor os conteúdos ao estudá-los nos materiais didáticos do curso", "Busquei auxílio do tutor para esclarecer minhas dúvidas sobre os conteúdos do curso", "Li o conteúdo do curso várias vezes como método para aprender", "Refleti sobre as implicações que os conteúdos aprendidos poderiam ter", "Associei os conteúdos do curso aos meus conhecimentos anteriores").

\subsubsection{Reações.}

Os instrumentos de Reações foram construídos com base na adaptação e revalidação previamente realizadas por Martins e Zerbini (2015) em contexto de ensino superior híbrido. Ambas as escalas apresentam evidências de validade de construto e possuem estruturas empíricas unifatoriais: 1) "Procedimentos Instrucionais em EAD" (17 itens, $\alpha=0,96$ e cargas fatoriais entre 0,60 e 0,86); e 2) "Desempenho do Tutor" (27 itens, $\alpha=0,98$ e cargas fatoriais entre 0,67 e 0,88$)$.

Tratam-se de instrumentos que já foram muitas vezes utilizados em pesquisas nacionais, inclusive em diferentes contextos EAD, como cursos técnicos e profissionalizantes, abertos e gratuitos de alcance nacional (Borges-Ferreira, 2005; Carvalho \& Abbad, 2006; Silva, 2004; Zerbini \& Abbad, 2005; Zerbini \& Abbad, 2009a; Zerbini \& Abbad, 2009b; Zerbini \& Abbad, 2010a), mantendo as boas qualidades psicométricas e índices de consistência interna considerados excelentes. Porém, o número excessivo de itens (17 e 27 itens) em soluções de fator único, para avaliar a satisfação dos participantes, e os altos índices de confiabilidade $(0,96<\alpha<0,98)$ podem sugerir que há repetição de conteúdo ou sobreposição de aspectos avaliados pelos itens - no instrumento de Reação aos Procedimentos Instrucionais havia 4 pares de itens altamente correlacionados entre si e no de Reação ao Desempenho do Tutor, 10 pares. Os estudos anteriores optaram pela não exclusão de itens por se tratarem das primeiras aplicações e testagens dos instrumentos em contextos específicos a distância. Contudo, a literatura mostra que instrumentos dedicados a medir reações costumam ter um número bastante reduzido de itens, cerca de 5, em soluções unifatoriais (Klein et al., 2006). A exclusão de 
vários itens e uma adaptação mais expressiva das escalas eram necessárias para gerar instrumentos mais parcimoniosos, rápidos e fáceis de aplicar, e, principalmente, consonantes com os existentes na literatura internacional.

Após a adaptação, os questionários de Reação aos Procedimentos Instrucionais (Anexo C) e Reação ao Desempenho do Tutor (Anexo D), ficaram com 5 e 6 itens, respectivamente, que avaliam a satisfação dos participantes com relação à qualidade dos procedimentos do curso (exemplos de itens: "Programação das atividades", "Recursos didáticos virtuais disponíveis (fóruns, chats, etc.)", "Interação interpessoal entre participantes") e desempenho do tutor (exemplos de itens: "Incentivo à discussão dos participantes nos fóruns", "Respeito ao ritmo de aprendizagem dos participantes", “Esclarecimento das dúvidas dos participantes"). Em ambos instrumentos, os itens devem ser respondidos segundo uma escala Likert de 5 pontos que varia de 1 (muito ruim) a 5 (muito boa) - outra modificação feita nos instrumentos, que utilizavam uma escala de 11 pontos, no primeiro, de qualidade e no segundo, de frequência.

\subsubsection{Suporte à transferência.}

Dentre os instrumentos de avaliação específicos para determinados programas de treinamentos e amostras, o instrumento nacional de Suporte à Transferência de Treinamento (Abbad, 1999; Abbad \& Sallorenzo, 2001) é composto por duas dimensões, a saber: a) Suporte Psicossocial à Transferência (11 itens, $\alpha=0,91)$ : avalia os fatores situacionais de apoio percebidos (organizacional, gerencial e social) pelos egressos e as consequências associadas ao uso das novas habilidades no trabalho - itens que medem as reações de colegas, pares ou superiores hierárquicos ao impacto do treinamento no trabalho; b) Suporte Material à Transferência (5 itens, $\alpha=0,86$ ): refere-se aos elementos de apoio ambiental oferecidos pela organização para que o treinando tenha a possibilidade de aplicar eficazmente no trabalho as novas habilidades aprendidas em eventos instrucionais, ou seja, mensuram a qualidade, suficiência e disponibilidade de recursos materiais e financeiros, além da adequação do ambiente físico ao impacto do treinamento no trabalho (Abbad et al., 2012a).

Com base nas versões do instrumento de Suporte à Transferência de Treinamento de Abbad (1999) e Abbad e Sallorenzo (2001), na escala unifatorial de Suporte Gerencial de Yarnall (1998) (5 itens, $\alpha=0,91$ ), posteriormente revalidada por Chiaburu e Tekleab (2005) (7 itens, $\alpha=0,95)$, e no instrumento de Tracey e Tews (2005), “General Training 
Climate Scale (GTCS)" (15 itens, 3 fatores de suporte: gerencial, trabalho e organizacional, $0,85<\alpha<0,87)$ - apesar do construto avaliado ser clima para transferência, esta variável é correlata a suporte (Abbad et al., 2012b), e o instrumento faz alusão e pretende medir aspectos relativos ao que se denomina suporte, como é observado pela própria nomeação dos fatores obtidos, contendo itens bastante similares aos das outras escalas citadas -, foi elaborado um novo instrumento para mensurar o suporte à transferência recebido pelos egressos de treinamentos quando retornam ao ambiente de trabalho.

$\mathrm{O}$ instrumento de Suporte à Transferência (Anexo E) é composto por 8 itens, associados a uma escala Likert de frequência de 5 pontos (1-nunca a 5-sempre), que mensuram o suporte psicossocial oferecido por supervisores e colegas (exemplos de itens: "Encorajam a aplicação no trabalho de novas habilidades aprendidas em treinamento", "Fornecem feedback quanto à aplicação no trabalho das novas habilidades adquiridas em treinamento", "Removem as dificuldades ao uso eficaz das novas habilidades aprendidas em treinamento") e o suporte material fornecido pela organização (exemplos de itens: "São fornecidos os recursos materiais necessários para a aplicação eficaz das novas habilidades aprendidas em treinamento" e "É disponibilizado local de trabalho adequado à aplicação eficaz das novas habilidades aprendidas em treinamento") à aplicação no trabalho das novas competências aprendidas em treinamento.

A grande modificação realizada no instrumento foi adequar os itens com foco na ação, já que as medidas, apesar de abordarem conjuntamente o apoio de supervisores e colegas como pressupõe o conceito de suporte psicossocial à transferência, o separavam em seus itens: alguns deles avaliavam somente o apoio oferecido pelos supervisores e outros, em menor número, o apoio dos pares. A sugestão proposta permite avaliar os dois tipos de suporte e em que medida seu oferecimento é percebido pelos egressos de treinamentos, bem como tal separação possibilita a realização de análises para verificar se há um apoio mais importante que o outro e seus efeitos sobre o impacto do treinamento no trabalho.

\subsubsection{Barreiras e facilitadores em EAD.}

O questionário de Barreiras e Facilitadores em EAD foi construído com base nos instrumentos de Fatores relacionados à Evasão e à Persistência em EAD de Sales (2009) - 63 itens, 8 fatores, $0,72<\alpha<0,96$, posteriormente revalidado por Umekawa (2013) - 
41 itens, 4 fatores (Suporte tecnológico e de tutoria, Características exógenas ao curso, Características do aluno, Desenho do curso), 0,75< $\alpha<0,93$ - que buscava investigar a influência de restrições individuais e ambientais que poderiam levar à evasão. E no de Ambiente de Estudo e Procedimentos de Interação de Zerbini e Abbad (2008b) - 18 itens, 3 fatores (Contexto de estudo, Custos pessoais e profissionais associados à participação em cursos a distância, Ferramentas de interação), $0,83<\alpha<0,85$ - que tinha como finalidade levantar os aspectos do contexto pessoal de estudo do aluno e do próprio curso que poderiam dificultar a sua permanência neste (e.g. regularidade de estudo, disponibilidade do computador, conciliação de atividades). As autoras indicavam como agenda de pesquisa a necessidade de aprimorar e revalidar esse instrumento e, principalmente, alertavam para a imprecisão na definição do construto "Ambiente de Estudo".

O instrumento de Barreiras e Facilitadores em EAD (Anexo F) possui 22 itens, associados a uma escala Likert de 5 pontos, que varia de 1 (não dificultou o desempenho) a 5 (dificultou totalmente o desempenho). Pretende avaliar o quanto cada fator descrito nos itens dificultou o desempenho do participante, ou seja, atuou como uma barreira durante o curso, dentre os quais: papel do tutor; relacionamento entre os participantes (tutor e pares); suporte técnico (institucional) fornecido; características do curso (duração, conteúdo, recursos educacionais e quantidade de atividades) e do alunado (habilidades de autogerenciamento dos estudos e para o uso das ferramentas web); disponibilidade, acesso e custos dos recursos; e conciliação de diferentes atividades (tempo, trabalho e família) pelos aprendizes.

\subsubsection{Impacto do treinamento no trabalho.}

Neste estudo, foi elaborado um instrumento para medir impacto em profundidade do treinamento avaliado. Com base nos desempenhos específicos esperados no trabalho, a partir da realização do curso "Eficiência Operacional", as competências foram mapeadas, junto aos membros diretores em Gestão de Pessoas do Banco parceiro, e constituíram os itens do instrumento. Todos os itens expressam comportamentos observáveis e que podem ser avaliados de maneira objetiva tanto pelos próprios participantes do treinamento (autoavaliação) como por seus supervisores (heteroavaliação). A escala "Impacto do Treinamento em Profundidade" (Anexo N) para o referido curso apresentou evidências empíricas de validade (estrutura unifatorial com 8 
itens, $\alpha=0,85$; cargas fatoriais entre 0,44 e 0,77 ), podendo ser considerado um instrumento adequado para mensurar os resultados do curso em questão.

Para aferir impacto em amplitude, foi utilizado como base o instrumento de Impacto do Treinamento em Amplitude de Pilati e Abbad (2005), com 12 itens ( $\alpha=0,93)$ associados a uma escala de concordância do tipo Likert de 5 pontos. A estrutura empírica unidimensional do instrumento em questão foi confirmada pelas técnicas de análise de dados ao qual foi submetido (Análise Fatorial Confirmatória e Modelagem por Equações Estruturais) em Pilati e Abbad (2005), assim como foi corroborada a estrutura teórica proposta por Abbad (1999) nas três amostras testadas.

Foram encontradas covariâncias entre os erros dos pares de itens 8 ("Aumentou minha motivação para o trabalho") e 9 (“Aumentou minha autoconfiança”) e 10 (“Sugiro com mais frequência mudanças nas rotinas") e 11 ("Estou mais receptivo a mudanças"), o que levou à re-especificação do modelo, gerando melhoria em todos os índices (Pilati \& Abbad, 2005). Os autores afirmam que a correlação entre os itens pode ter sido causada por uma sobreposição conceitual, uma vez que seus conteúdos tratam de conceitos atitudinais, mais especificamente, os efeitos atitudinais provocados pelo treinamento motivação e autoconfiança e mudanças no trabalho.

Embora os indicadores de adequação do modelo re-especificado fossem bastante satisfatórios, Pilati e Abbad (2005) afirmam que há ainda algumas possibilidades de aprimorar a escala e, por conseguinte, seus índices de adequação, por meio: a) da substituição dos dois itens superpostos ( 8 e 9) por apenas um item genérico, que buscasse aferir os indicadores motivacionais do trabalho do indivíduo; b) da supressão de um dos itens (10 e 11), pois a evidência de que os treinandos interpretam a proposição de mudanças e a receptividade a mudanças como o mesmo fenômeno é bastante forte, ou c) os itens que apresentaram covariância podem ser suprimidos e que novos indicadores dos eventos mensurados por esses itens sejam formulados, acabando com a redundância observada nos mesmos. Acatando tais sugestões, os itens 9 e 11 foram eliminados, outros ajustes e cortes foram realizados, e uma versão adaptada do instrumento com 7 itens (Anexo G) foi testada (exemplos de itens: "Aproveito as oportunidades que tenho para praticar as novas habilidades", "Cometo menos erros no trabalho", "Meus colegas aprendem comigo").

Como em estudos anteriores (Chiaburu \& Tekleab, 2005; Velada et al., 2007), as medidas de impacto do treinamento no trabalho foram autorrelatadas, confirmando a competência dos treinandos em expor seus próprios níveis de impacto do treinamento no 
trabalho, além de serem a fonte mais importante e válida da medição da efetividade de treinamento (Garavan et al., 2010); embora seja aconselhável utilizar várias fontes (por exemplo, supervisores, colegas e subordinados), visando reforçar as estimativas provindas dos treinandos, ou ainda, quando possível, usar medidas diretas e objetivas de desempenho no trabalho do egresso (Velada et al., 2007).

\subsection{Análises Teóricas dos Instrumentos de Medida}

\subsubsection{Validação semântica e por juízes.}

A análise teórica visa identificar e, eventualmente, corrigir possíveis falhas presentes nos instrumentos de medida. As versões em português dos instrumentos foram submetidas à validação por juízes, que consistiu na avaliação por especialistas da adequação dos instrumentos produzidos (revisão dos itens, avaliando a clareza, precisão e objetividade da redação dos mesmos; análise da adequação das escalas de mensuração, das instruções de preenchimento e da necessidade de incluir ou excluir itens, etc.) - com exceção do instrumento de Estratégias de Aprendizagem que recentemente passou por esse processo de validação (Martins \& Zerbini, 2014b) e não sofreu mudanças substanciais neste estudo que o justificassem novamente.

Como os instrumentos de Suporte à Transferência, Barreiras e Facilitadores em EAD e Impacto do Treinamento no Trabalho trataram de adaptações de instrumentos existentes e não da construção de novos itens, considerou-se a prévia validação semântica dispensável; por sua vez, os instrumentos de Reação aos Procedimentos Instrucionais e Reação ao Desempenho do Tutor sofreram maiores ajustes e construção de novos itens, portanto, a validação semântica seria necessária. De qualquer forma, a validação por juízes cumpriu também a função de análise do conteúdo das novas versões produzidas.

Cada instrumento anteriormente mencionado foi analisado por dois juízes. As sugestões consistiram em pequenas alterações na redação de alguns itens, para que se mantivesse o paralelismo entre eles - por exemplo, no caso do instrumento de Suporte à Transferência, todos os itens da escala começam com verbos na terceira pessoa do plural para referir-se aos supervisores e pares (e.g. "Encorajam a aplicação no trabalho de novas habilidades aprendidas em treinamento" e "Removem as dificuldades ao uso eficaz das novas habilidades aprendidas em treinamento"), com exceção de um que tratava do apoio fornecido pela organização "O local de trabalho é adequado à aplicação eficaz das novas habilidades aprendidas em treinamento"; portanto, foi sugerida e acatada a modificação 
na sua redação para "É disponibilizado local adequado à aplicação eficaz das novas habilidades aprendidas em treinamento". Um ponto importante discutido foi a percepção de que em algumas escalas não havia ponto neutro, equidistante dos extremos tanto qualitativa como quantitativamente; e que três dos cinco pontos ancorados possuíam conotação positiva (exemplo: 1 "péssimo", 2 "razoável”, 3 "bom”, 4 "muito bom” e 5 "excelente"). Logo, para que os pontos fossem equidistantes entre si e respeitassem a uma ordem, tais escalas foram modificadas, ao incluir as etiquetas em todos os pontos, mas distribuindo-se melhor os qualificadores (exemplo: 1 "péssima", 2 "ruim", 3 "regular", 4 "boa" e 5 "excelente").

\subsection{Estudo Piloto}

Em seguida às validações teóricas, o conjunto final de itens em português, as instruções de preenchimento e as escalas foram traduzidas ao espanhol e revisadas por nativos no idioma. No caso das versões em espanhol, todas foram submetidas à validação semântica em estudo piloto, que consistiu na avaliação de cada item quanto à representatividade, precisão, clareza e objetividade (item gera dúvida ou ambiguidade?), bem como quanto à adequação das escalas de mensuração e das instruções de preenchimento, por alunos de (pós-)graduação - estudantes da Universidad de Sevilla (US, Espanha) do curso de Psicologia e dos Mestrados "Psicología de los Recursos Humanos" (Facultad de Ciencias del Trabajo/US) e "Psicología de las Organizaciones y del Trabajo" (Facultad de Psicología/US). Esse processo de aplicação dos questionários a uma amostra de 192 estudantes nativos em castelhano (Tabela 8), com taxa de respostas de $100 \%$, permitiu verificar eventuais falhas nos procedimentos de coleta de dados propostos (materiais, métodos, etc.), além de validar semanticamente os instrumentos. As modificações sugeridas foram avaliadas e os itens, as escalas e as instruções, então, reelaborados.

A relevância de se conduzir um estudo piloto deve-se principalmente ao fato de ser a primeira vez que se adapta instrumentos de medida bastante aplicados em pesquisas brasileiras a outro idioma e a um contexto com características próprias. Ademais, a oportunidade de realizar em pequena escala uma versão do estudo completo, possibilitou testar, avaliar, revisar e aprimorar os instrumentos (os bons índices de confiabilidade e de validade interna dos instrumentos de medida seriam mantidos?) e os procedimentos 
metodológicos na fase que antecede a investigação em si, bem como antever resultados e julgar se estes seriam pertinentes para responder às questões colocadas pela pesquisa.

Idealmente, o estudo piloto deveria ser feito com indivíduos com características bastante próximas às da amostra real da investigação; mas, como conseguir parcerias de pesquisa consiste em uma tarefa bastante árdua, principalmente ter acesso às organizações (Burke \& Hutchins, 2007), sendo este um dos principais entraves para a pesquisa em contextos corporativos, considerou-se aceitável a realização da adaptação transcultural dos instrumentos com estudantes oriundos do país onde o presente estudo também se daria. A princípio, a intenção era realizar um estudo comparativo entre amostras brasileiras e espanholas, provindas de empresas do mesmo setor (bancário), para avaliar treinamentos a distância oferecidos pelas organizações parceiras a seus membros, comparar os resultados obtidos e as possíveis diferenças entre os países - inclusão de variáveis para controle dos efeitos, etc. Como não foi possível firmar parceria de pesquisa em ambos contextos, o estudo piloto realizado com uma amostra de estudantes permitiu realizar análises estatísticas (descritivas, consistência interna, fatoriais exploratórias) para verificar as evidências de validade das escalas e sua adequação ao contexto espanhol, sendo uma contribuição a ser melhor aproveitada em pesquisas vindouras, uma vez que não foram identificados instrumentos espanhóis similares, apontando a importância da adaptação dessas medidas. Os resultados de tais análises são apresentados a seguir.

Tabela 8. Perfil da amostra de alunos da Universidad de Sevilla (Espanha) participantes do estudo piloto.

\begin{tabular}{|c|c|c|c|c|c|}
\hline Variável & $F$ & $\%$ & Variável & $\boldsymbol{F}$ & $\%$ \\
\hline Graduação (Psicologia) & 142 & 74 & $\begin{array}{l}\text { Pós-graduação } \\
\text { (Psicologia RH/POT) }\end{array}$ & 49 & 25,5 \\
\hline Sexo & & & Idade & & \\
\hline Feminino & 145 & 75,5 & 18 a 20 & 88 & 45,9 \\
\hline Masculino & 46 & 24,0 & 21 a 24 & 48 & 25,1 \\
\hline Experiência profissional & & & 25 a 28 & 36 & 18,7 \\
\hline Não & 110 & 57,3 & Acima de 29 & 19 & 9,8 \\
\hline Sim & 81 & 42,2 & Média & 23 & \\
\hline Anos de experiência & 72 & 37,5 & Desvio-padrão & 6,0 & \\
\hline Até 1 & 21 & 10,9 & Moda & 19 & \\
\hline $2-8$ & 37 & 17,7 & Mínimo & 18 & \\
\hline Acima de 10 anos & 14 & 7,1 & Máximo & 57 & \\
\hline
\end{tabular}

Notas: $N=192 /$ Casos omissos=1. $F=$ Frequência absoluta e \%=Porcentagem. 
Os alunos de graduação em Psicologia predominam na caracterização da amostra (74\%); a maioria é do sexo feminino (75,5\%), sem experiência profissional $(57,3 \%)$ e possui, em média, 23 anos de idade $(D P=6,0)$, sendo 19 anos a idade mais frequente, 18 anos a mínima e 57 anos, a máxima.

As estatísticas descritivas relativas à aplicação das medidas no estudo piloto são apresentadas a seguir no intuito de disponibilizar informações adicionais sobre a amostra participante e os seus padrões de uso de estratégias de aprendizagem, a satisfação com os procedimentos do curso em andamento (graduação e pós-graduação), possíveis barreiras encontradas ao seu aproveitamento, percepção de apoios fornecidos e influências na atuação profissional atual ou futura, ainda que o objetivo principal do estudo piloto fosse a validação semântica dos instrumentos, antecipando a aplicação em uma amostra inserida em contexto organizacional na Espanha, o que permaneceu como agenda de pesquisa. Do mesmo modo, as análises fatoriais exploratórias das medidas fornecem dados sobre as evidências de validade das mesmas, servem para realizar investigações futuras e comparar os achados com amostras similares, objetivando identificar semelhanças e diferenças quanto aos aspectos avaliados mencionados, incluindo estudos interculturais.

\subsubsection{Análises estatísticas dos instrumentos de medida (espanhol).}

\subsubsection{Análises descritivas.}

\subsection{Estratégias de aprendizagem.}

Os resultados descritivos dos 21 itens do instrumento de "Estrategias de Aprendizaje" associados a uma escala de frequência de comportamento que varia de 1 ("Nunca") a 5 ("Siempre") podem ser visualizados na Tabela 9.

Tabela 9. Resultados descritivos do instrumento de "Estrategias de Aprendizaje".

\begin{tabular}{|c|c|c|c|c|c|c|c|}
\hline \multirow{2}{*}{ Itens } & \multirow{2}{*}{$\begin{array}{c}\text { Casos } \\
\text { Omissos }\end{array}$} & \multirow{2}{*}{ Média } & \multirow{2}{*}{$\begin{array}{l}\text { Desvio } \\
\text { Padrão }\end{array}$} & \multirow{2}{*}{ Moda } & \multicolumn{3}{|c|}{$\begin{array}{l}\text { Concentração de } \\
\text { Respostas (\%)* }\end{array}$} \\
\hline & & & & & $1-2$ & 3 & $4-5$ \\
\hline $\begin{array}{l}\text { 16. Hice anotaciones, resúmenes y/o esquemas } \\
\text { de los contenidos de la formación como un } \\
\text { método para aprender. }\end{array}$ & 0 & 4,13 & 1,04 & 5 & 8,9 & 14,6 & 76,5 \\
\hline $\begin{array}{l}\text { 13. Realicé los ejercicios prácticos propuestos } \\
\text { a lo largo del curso para ayudarme a aprender. }\end{array}$ & 0 & 4,06 & 0,91 & 4 & 5,2 & 19,8 & 75,0 \\
\hline $\begin{array}{l}\text { 8. Pedí la ayuda de mis compañeros para } \\
\text { aclarar mis dudas sobre los contenidos de la } \\
\text { formación. }\end{array}$ & 0 & 4,03 & 0,92 & 4 & 7,8 & 12,5 & 79,7 \\
\hline
\end{tabular}


Tabela 9. Resultados descritivos do instrumento de "Estrategias de Aprendizaje". (Continuação)

\begin{tabular}{|c|c|c|c|c|c|c|c|}
\hline \multirow[t]{2}{*}{ Itens } & \multirow{2}{*}{$\begin{array}{l}\text { Casos } \\
\text { Omissos }\end{array}$} & \multirow{2}{*}{ Média } & \multirow{2}{*}{$\begin{array}{l}\text { Desvio } \\
\text { Padrão }\end{array}$} & \multirow[t]{2}{*}{ Moda } & \multicolumn{3}{|c|}{$\begin{array}{l}\text { Concentração de } \\
\text { Respostas (\%)* }\end{array}$} \\
\hline & & & & & $1-2$ & 3 & $4-5$ \\
\hline $\begin{array}{l}\text { 4. Me esforcé más cuando me di cuenta de que } \\
\text { estaba perdiendo la concentración. }\end{array}$ & 0 & 3,97 & 0,87 & 4 & 6,8 & 16,1 & 77,1 \\
\hline $\begin{array}{l}\text { 6. Me esforcé para verificar si entendía lo que } \\
\text { se enseñaba. }\end{array}$ & 0 & 3,95 & 0,82 & 4 & 5,7 & 17,7 & 76,6 \\
\hline $\begin{array}{l}\text { 20. Asocié el contenido de la formación a mis } \\
\text { conocimientos previos. }\end{array}$ & 0 & 3,93 & 0,94 & 4 & 9,4 & 18,8 & 71,8 \\
\hline $\begin{array}{l}\text { 10. Busqué comprender los contenidos al } \\
\text { estudiarlos en el material didáctico de la } \\
\text { formación. }\end{array}$ & 1 & 3,91 & 0,84 & 4 & 4,7 & 22,9 & 71,9 \\
\hline $\begin{array}{l}\text { 9. Busqué la solución a mis dudas al consultar } \\
\text { el material didáctico de la formación. }\end{array}$ & 0 & 3,85 & 0,94 & 4 & 7,8 & 24,5 & 67,7 \\
\hline $\begin{array}{l}\text { 19. Intenté hacerme una idea general del } \\
\text { contenido de la formación asociando elementos } \\
\text { entre sí. }\end{array}$ & 0 & 3,81 & 0,89 & 4 & 6,8 & 26,0 & 67,2 \\
\hline $\begin{array}{l}\text { 15. Repetí mentalmente el contenido de la } \\
\text { formación que tenía que aprender hasta que me } \\
\text { diera cuenta de que lo entendía. }\end{array}$ & 0 & 3,68 & 1,06 & 4 & 14,6 & 24,0 & 61,5 \\
\hline $\begin{array}{l}\text { 21. Revisé los contenidos relativos a los } \\
\text { ejercicios en que cometí errores. }\end{array}$ & 0 & 3,66 & 1,06 & 4 & 15,1 & 22,9 & 62,0 \\
\hline $\begin{array}{l}\text { 14. Leí el contenido de la formación varias } \\
\text { veces como un método para aprender. }\end{array}$ & 0 & 3,63 & 1,01 & 4 & 14,6 & 27,1 & 58,3 \\
\hline $\begin{array}{l}\text { 1. Mantuve la calma cuando tuve dificultades } \\
\text { durante la formación. }\end{array}$ & 0 & 3,57 & 0,84 & 4 & 9,4 & 35,9 & 54,7 \\
\hline $\begin{array}{l}\text { 18. Identifiqué situaciones cotidianas en las } \\
\text { que yo podría aplicar el contenido de la } \\
\text { formación. }\end{array}$ & 0 & 3,53 & 0,90 & 4 & 11,5 & 35,4 & 53,1 \\
\hline $\begin{array}{l}\text { 5. Me esforcé más cuando me di cuenta de que } \\
\text { estaba perdiendo el interés en el tema. }\end{array}$ & 0 & 3,40 & 1,06 & 3 & 21,4 & 32,3 & 46,3 \\
\hline $\begin{array}{l}\text { 3. Mantuve la calma con los errores que cometí } \\
\text { en las actividades de la formación. }\end{array}$ & 0 & 3,39 & 0,87 & 3 & 14,6 & 39,1 & 46,4 \\
\hline $\begin{array}{l}\text { 11. Busqué otras fuentes de información } \\
\text { relacionadas con la formación para ayudarme a } \\
\text { aprender. }\end{array}$ & 0 & 3,24 & 1,02 & 3 & 22,9 & 39,6 & 37,5 \\
\hline $\begin{array}{l}\text { 2. Mantuve la calma ante la amenaza de tener } \\
\text { un rendimiento inferior al esperado. }\end{array}$ & 0 & 3,14 & 0,88 & 3 & 21,9 & 44,3 & 33,9 \\
\hline $\begin{array}{l}\text { 17. Ponderé las implicaciones que los } \\
\text { contenidos aprendidos podrían tener. }\end{array}$ & 5 & 3,13 & $\mathbf{1 , 0 7}$ & 3 & 27,1 & 31,8 & 38,6 \\
\hline $\begin{array}{l}\text { 12. Busqué comprender el contenido } \\
\text { aplicándolo en la práctica, en lugar de pasar el } \\
\text { tiempo leyendo o pidiendo ayuda a alguien. }\end{array}$ & 0 & 3,04 & 0,88 & 3 & 28,6 & 40,1 & 31,2 \\
\hline $\begin{array}{l}\text { 7. Solicité la ayuda del tutor para aclarar mis } \\
\text { dudas sobre los contenidos de la formación. }\end{array}$ & 0 & 2,95 & 1,22 & 2 & 40,0 & 24,0 & 36,0 \\
\hline
\end{tabular}

Notas: $N=192 ; * 1-2$ (nunca/raramente), 3 (a veces), 4-5 (a menudo/siempre)

A média de uso das estratégias de aprendizagem descrita nos itens teve uma variação de 2,95 a 4,13. Dos 21 itens presentes no questionário, 17 apresentaram maior concentração de respostas nos pontos mais altos da escala (entre 38,6\% e 76,5\%), 3 concentram-se nos pontos médios $(39,6 \%$ e 44,3\%), e em apenas 1 item a concentração de respostas esteve nos pontos mais baixos (40,0\%). Os valores da moda também são diversificados, obtendo pontuações que passam por 2, 3, 4 e 5. As discrepâncias 
observadas nas concentrações de respostas, valores das modas, médias e desvios-padrão, podem sugerir o padrão e a frequência diferenciados de uso das estratégias de aprendizagem pelos alunos.

Os 9 itens que apresentaram as médias mais altas foram: $16(M=4,06$ e $D P=1,04)$, $13(M=4,06$ e $D P=0,91), 8(M=4,03$ e $D P=0,92), 4(M=3,97$ e $D P=0,87), 6(M=3,95$ e $D P=0,82), 20(M=3,93$ e $D P=0,94), 10(M=3,91$ e $D P=0,84), 9(M=3,85$ e $D P=0,94)$ e $19(\mathrm{M}=3,81$ e $D P=0,89)$. Esse conjunto de itens contém estratégias cognitivas, comportamentais e autorregulatórias, pertencentes a todos os fatores propostos por Warr e Allan (1998), com exceção o de "controle da emoção".

A maior ocorrência de médias altas concentra-se, respectivamente, nos fatores "repetição" (estratégia cognitiva), "aplicação prática" e "busca de ajuda interpessoal" (estratégias comportamentais); seguida das estratégias autorregulatórias de "controle da motivação" e "monitoramento da compreensão"; e logo pelas cognitivas "elaboração" e "organização" e a comportamental "busca de ajuda ao material didático".

Já os 4 itens que apresentaram as médias mais baixas foram: $2(M=3,14 \mathrm{e}$ $D P=0,88), 17(M=3,13$ e $D P=1,07), 12(M=3,04$ e $D P=0,88)$ e $7(M=2,95$ e $D P=1,22)$. Tais itens representam estratégias de "controle da emoção" (item 2), "elaboração" (item 17), “aplicação prática” (item 12) e "busca de ajuda interpessoal” (item 7) provavelmente este item recebeu a menor pontuação por tratar da figura do tutor, não presente na plataforma virtual das disciplinas cursadas na universidade.

\subsection{Reações.}

Os resultados descritivos dos 5 e 6 itens, respectivamente, dos instrumentos "Reacción a los Procedimientos de Formación" e "Reacción a la Calidad del Tutor", associados a escalas de qualidade que variam de 1 ("Muy mala") a 5 ("Muy buena") podem ser visualizados nas Tabelas 10 e 11 .

Tabela 10. Resultados descritivos do instrumento de "Reacción a los Procedimientos de Formación".

\begin{tabular}{|c|c|c|c|c|c|c|c|}
\hline \multirow[t]{2}{*}{ Itens } & \multirow{2}{*}{$\begin{array}{c}\text { Casos } \\
\text { omissos }\end{array}$} & \multirow{2}{*}{ Média } & \multirow{2}{*}{$\begin{array}{l}\text { Desvio } \\
\text { Padrão }\end{array}$} & \multirow[t]{2}{*}{ Moda } & \multicolumn{3}{|c|}{$\begin{array}{l}\text { Concentração de } \\
\text { Respostas (\%)* }\end{array}$} \\
\hline & & & & & $1-2$ & 3 & 4-5 \\
\hline 3. Interacción interpersonal entre los participantes. & 0 & 3,89 & 0,90 & 4 & 6,3 & 22,9 & $\mathbf{7 0 , 8}$ \\
\hline 2. Actividades, contenidos, lecturas. & 0 & 3,68 & 0,84 & 4 & 8,3 & 29,7 & 62,0 \\
\hline $\begin{array}{l}\text { 4. Los recursos de aprendizaje virtuales disponibles } \\
\text { (foros, chats, etc.). }\end{array}$ & 0 & 3,65 & 1,01 & 4 & 11,0 & 28,1 & 60,9 \\
\hline
\end{tabular}


Tabela 10. Resultados descritivos do instrumento de "Reacción a los Procedimientos de Formación". (Continuação)

\begin{tabular}{|c|c|c|c|c|c|c|c|}
\hline \multirow{2}{*}{ Itens } & \multirow{2}{*}{$\begin{array}{c}\text { Casos } \\
\text { omissos }\end{array}$} & \multirow{2}{*}{ Média } & \multirow{2}{*}{$\begin{array}{l}\text { Desvio } \\
\text { Padrão }\end{array}$} & \multirow{2}{*}{ Moda } & \multicolumn{3}{|c|}{$\begin{array}{l}\text { Concentração de } \\
\text { Respostas (\%)* }\end{array}$} \\
\hline & & & & & 1-2 & 3 & 4-5 \\
\hline $\begin{array}{l}\text { 5. La información disponible en el entorno virtual } \\
\text { de la formación (noticias, recordatorios, enlaces, } \\
\text { etc.). }\end{array}$ & 0 & 3,62 & 0,97 & 4 & 13,5 & 25,0 & 61,5 \\
\hline 1. Programación de las actividades. & 0 & 3,46 & 0,84 & 4 & 13,6 & 32,3 & 54,2 \\
\hline
\end{tabular}

Notas: $N=192 ; * 1-2$ (muy mala/mala), 3 (ni mala, ni buena), 4-5 (buena/muy buena)

De forma geral, observa-se que os alunos julgaram que a qualidade dos procedimentos instrucionais utilizados ao longo do curso é boa, uma vez que as médias variam entre 3,46 e 3,89, estando razoavelmente satisfeitos com os procedimentos adotados. Como os valores dos desvios-padrão não foram altos na maioria dos itens, podese considerar que houve concordância de opiniões entre os respondentes quanto aos aspectos avaliados. Todos os itens apresentaram concentração de respostas superior a $50 \%$ nos pontos mais altos da escala e valor de moda igual a 4 .

O item 3 recebeu as melhores avaliações $(M=3,89$ e $D P=0,90)$ pelos alunos, com concentração de respostas superior a $70 \%$ entre os pontos de 4 a 5 na escala, indicando estarem satisfeitos com a interação interpessoal entre colegas - como a plataforma virtual não oferece a opção de interação síncrona ou assíncrona entre os alunos, estes avaliaram provavelmente o bom relacionamento entre si em sala de aula. $\mathrm{O}$ item 1 recebeu avaliações um pouco mais baixas $(M=3,46$ e $D P=0,84)$, tendo obtido concentração de respostas igual a 54,2\% nos pontos mais altos da escala, mostrando que os alunos não julgaram tão bem a adequação da programação das atividades.

Tabela 11. Resultados descritivos do instrumento de "Reacción a la Calidad del Tutor".

\begin{tabular}{|c|c|c|c|c|c|c|c|}
\hline \multirow[t]{2}{*}{ Itens } & \multirow{2}{*}{$\begin{array}{l}\text { Casos } \\
\text { omissos }\end{array}$} & \multirow{2}{*}{ Média } & \multirow{2}{*}{$\begin{array}{l}\text { Desvio } \\
\text { Padrão }\end{array}$} & \multirow{2}{*}{ Moda } & \multicolumn{3}{|c|}{$\begin{array}{l}\text { Concentração de } \\
\text { Respostas (\%)* }\end{array}$} \\
\hline & & & & & $1-2$ & 3 & $4-5$ \\
\hline 6. Esclarecimiento de las dudas de los participantes. & 1 & 3,99 & 0,88 & 4 & 6,3 & 15,1 & $\mathbf{7 8 , 1}$ \\
\hline $\begin{array}{l}\text { 3. Comprometerse con las actividades de tutoría } \\
\text { (disponibilidad, puntualidad, lenguaje, participación } \\
\text { en las actividades, etc.). }\end{array}$ & 2 & 3,73 & 0,87 & 4 & 8,3 & 26,6 & 64,1 \\
\hline $\begin{array}{l}\text { 5. Articulación entre teoría y práctica en sus } \\
\text { explicaciones. }\end{array}$ & 1 & 3,65 & 0,89 & 4 & 10,9 & 27,6 & 60,9 \\
\hline $\begin{array}{l}\text { 2. Facilitar las relaciones interpersonales con los } \\
\text { participantes. }\end{array}$ & 1 & 3,52 & $\mathbf{1 , 0 3}$ & 4 & 15,1 & 27,1 & 57,3 \\
\hline $\begin{array}{l}\text { 4. Respeto al ritmo de aprendizaje de los } \\
\text { participantes. }\end{array}$ & 1 & 3,39 & 0,96 & 4 & 16,1 & 35,4 & 47,9 \\
\hline $\begin{array}{l}\text { 1. Promover la discusión de los participantes en los } \\
\text { foros. }\end{array}$ & 2 & 3,33 & 1,14 & 4 & 20,9 & 30,2 & 47,9 \\
\hline
\end{tabular}

Notas: $N=192 ; * 1-2$ (muy mala/mala), 3 (ni mala, ni buena), 4-5 (buena/muy buena) 
Os alunos, de modo geral, avaliaram positivamente os tutores (na verdade, professores), estando satisfeitos com a qualidade de seus desempenhos, pois as médias variaram de 3,33 a 3,99; a concentração de respostas foi superior a $60 \%$ nos pontos mais altos da escala, na metade dos itens; e os valores da moda foram iguais a 4 em todos eles. Os valores dos desvios-padrão não foram altos na maioria dos itens, indicando concordância de opiniões quanto aos aspectos avaliados.

O item $6(M=3,99$ e $D P=0,88)$ recebeu as melhores avaliações e apresentou concentração de respostas igual a 78,1\% entre os pontos 4 e 5 da escala, o que mostra satisfação dos alunos com os comportamentos dos professores para esclarecer suas dúvidas. Já o item $1(M=3,33$ e $D P=1,14)$ recebeu avaliações mais baixas e obteve um desvio-padrão mais alto, possivelmente por tratar da promoção por parte do "tutor" de discussões entre alunos nos fóruns, inexistentes na plataforma virtual - os alunos podem terem se sentido confusos ao respondê-lo.

\subsection{Suporte à transferência.}

Os resultados descritivos dos 6 itens, respectivamente, referentes ao suporte oferecido por "Supervisores" e "Compañeros", seguidos dos 2 itens que tratam do apoio material dado pela organização/instituição que compõem o instrumento "Apoyo a la Transferencia" estão associados a uma escala de frequência que varia de 1 ("Nunca") a 5 ("Siempre") podem ser visualizados nas Tabelas 12, 13 e 14.

Tabela 12. Resultados descritivos dos itens referentes ao apoio dos supervisores do instrumento de "Apoyo a la Transferencia".

\begin{tabular}{|c|c|c|c|c|c|c|c|}
\hline \multirow[t]{2}{*}{ Itens } & \multirow{2}{*}{$\begin{array}{c}\text { Casos } \\
\text { omissos }\end{array}$} & \multirow{2}{*}{ Média } & \multirow{2}{*}{$\begin{array}{l}\text { Desvio } \\
\text { Padrão }\end{array}$} & \multirow[t]{2}{*}{ Moda } & \multicolumn{3}{|c|}{$\begin{array}{l}\text { Concentração de } \\
\text { Respostas }(\%)^{*}\end{array}$} \\
\hline & & & & & $1-2$ & 3 & $4-5$ \\
\hline $\begin{array}{l}\text { 2. Se ofrecen las informaciones necesarias para el } \\
\text { uso eficaz de las nuevas habilidades aprendidas en } \\
\text { la formación. }\end{array}$ & 4 & 3,57 & 0,93 & 4 & 12,5 & 27,1 & 58,3 \\
\hline $\begin{array}{l}\text { 1. Se alienta la aplicación de las nuevas habilidades } \\
\text { aprendidas en la formación. }\end{array}$ & 6 & 3,52 & 0,97 & 3 & 13,6 & 34,4 & 49,0 \\
\hline $\begin{array}{l}\text { 5. Se ofrece feedback sobre la aplicación de las } \\
\text { nuevas habilidades aprendidas en la formación. }\end{array}$ & 5 & 3,42 & 1,01 & 4 & 19,8 & 26,0 & 51,6 \\
\hline $\begin{array}{l}\text { 4. Se crean oportunidades para utilizar en el trabajo } \\
\text { las nuevas habilidades aprendidas en la formación. }\end{array}$ & 3 & 3,42 & 0,95 & 4 & 14,5 & 34,9 & 48,9 \\
\hline $\begin{array}{l}\text { 3. Se eliminan las dificultades para el uso eficaz de } \\
\text { las nuevas habilidades aprendidas en la formación. }\end{array}$ & 6 & 3,32 & 0,94 & 3 & 17,7 & 37,5 & 41,7 \\
\hline $\begin{array}{l}\text { 6. Se tienen en cuenta mis sugerencias, en cuanto a } \\
\text { lo que se aprendió en la formación, en el entorno } \\
\text { laboral. }\end{array}$ & 3 & 3,07 & 1,04 & 3 & 27,6 & 38,5 & 32,3 \\
\hline
\end{tabular}


Tabela 13. Resultados descritivos dos itens referentes ao apoio dos colegas do instrumento de "Apoyo a la Transferencia".

\begin{tabular}{|c|c|c|c|c|c|c|c|}
\hline \multirow[t]{2}{*}{ Itens } & \multirow{2}{*}{$\begin{array}{l}\text { Casos } \\
\text { omissos }\end{array}$} & \multirow{2}{*}{ Média } & \multirow{2}{*}{$\begin{array}{l}\text { Desvio } \\
\text { Padrão }\end{array}$} & \multirow[t]{2}{*}{ Moda } & \multicolumn{3}{|c|}{$\begin{array}{l}\text { Concentração de } \\
\text { Respostas (\%)* }\end{array}$} \\
\hline & & & & & $1-2$ & 3 & $4-5$ \\
\hline $\begin{array}{l}\text { 3. Se eliminan las dificultades para el uso eficaz de } \\
\text { las nuevas habilidades aprendidas en la formación. } \\
6 \text { Se tienen en cuenta mis sugerencias en cuanto a }\end{array}$ & 4 & 3,57 & 0,96 & 4 & 13,6 & 28,6 & 55,7 \\
\hline $\begin{array}{l}\text { lo que se aprendió en la formación, en el entorno } \\
\text { laboral. }\end{array}$ & 4 & 3,56 & 1,02 & 4 & 15,1 & 27,6 & 55,2 \\
\hline $\begin{array}{l}\text { 1. Se alienta la aplicación de las nuevas habilidades } \\
\text { aprendidas en la formación. }\end{array}$ & 4 & 3,45 & 0,86 & 4 & 10,9 & 37,5 & 49,5 \\
\hline $\begin{array}{l}\text { 2. Se ofrecen las informaciones necesarias para el } \\
\text { uso eficaz de las nuevas habilidades aprendidas en } \\
\text { la formación. }\end{array}$ & 6 & 3,42 & 0,93 & 4 & 16,6 & 32,8 & 47,4 \\
\hline $\begin{array}{l}\text { 5. Se ofrece feedback sobre la aplicación de las } \\
\text { nuevas habilidades aprendidas en la formación. }\end{array}$ & 3 & 3,39 & 1,07 & 4 & 19,3 & 27,1 & 52,1 \\
\hline $\begin{array}{l}\text { 4. Se crean oportunidades para utilizar en el trabajo } \\
\text { las nuevas habilidades aprendidas en la formación. }\end{array}$ & 5 & 3,34 & 0,98 & 4 & 21,9 & 29,2 & 46,3 \\
\hline
\end{tabular}

Notas: $N=192 ; * 1-2$ (nunca/raramente), 3 (a veces), 4-5 (a menudo/siempre)

Tabela 14. Resultados descritivos dos itens referentes ao apoio material do instrumento de "Apoyo a la Transferencia".

\begin{tabular}{|c|c|c|c|c|c|c|c|}
\hline \multirow[t]{2}{*}{ Itens } & \multirow{2}{*}{$\begin{array}{c}\text { Casos } \\
\text { omissos }\end{array}$} & \multirow{2}{*}{ Média } & \multirow{2}{*}{$\begin{array}{l}\text { Desvio } \\
\text { Padrão }\end{array}$} & \multirow{2}{*}{ Moda } & \multicolumn{3}{|c|}{$\begin{array}{c}\text { Concentração de } \\
\text { Respostas (\%)* }\end{array}$} \\
\hline & & & & & $1-2$ & 3 & $4-5$ \\
\hline $\begin{array}{l}\text { 7. Se proveen los recursos materiales necesarios } \\
\text { para la aplicación eficaz de las nuevas habilidades } \\
\text { aprendidas en la formación. }\end{array}$ & 3 & 3,67 & 0,89 & 4 & 8,9 & 29,7 & 59,9 \\
\hline $\begin{array}{l}\text { 8. Se provee un entorno laboral adecuado para la } \\
\text { aplicación eficaz de las nuevas habilidades } \\
\text { aprendidas en la formación. }\end{array}$ & 3 & 3,52 & 0,93 & 4 & 11,5 & 35,4 & 51,6 \\
\hline
\end{tabular}

Notas: $N=192 ; * 1-2$ (nunca/raramente), 3 (a veces), 4-5 (a menudo/siempre)

A frequência com que supervisores (professores), colegas e organização (instituição de ensino superior - US) ofereceram os apoios descritos nos itens aos alunos não variaram muito entre si, estando concentrados nos pontos mais altos da escala e as médias foram de 3,07 a 3,67. Não há discrepância tampouco entre os diferentes tipos de suporte psicossocial (supervisores $\mathrm{x}$ colegas), com médias bastante semelhantes e próximas - em um contexto corporativo e com base nos achados da literatura científica (estudos empíricos), é provável que esses dados sejam diferentes.

O item com maior média, $7(M=3,67$ e $D P=0,89)$, trata do apoio material fornecido pela instituição, percebido pelos alunos como frequentemente presente. $\mathrm{O}$ item com menor média, $6(M=3,07$ e $D P=1,04)$ refere-se à consideração das sugestões dadas em ambiente de trabalho. Como muitos alunos somente estudam (57,3\%), esse item - e outros - não fazia muito sentido.

Comparando os suportes dos supervisores e colegas, nos itens que tratam do fornecimento de informações e da criação de oportunidades para a aplicação das 
habilidades adquiridas, o apoio dos supervisores parece ser mais frequente; já para o encorajamento, remoção de dificuldades, feedback e consideração das sugestões, a maioria dos alunos afirma que o suporte dos colegas é mais frequente.

Respectivamente, os itens 3 "Removem as dificuldades ao uso eficaz das novas habilidades aprendidas em treinamento" e 6 "Consideram minhas sugestões, em relação ao que foi aprendido no treinamento, no ambiente de trabalho" apresentam as maiores médias $(M=3,57$ e $D P=0,96 ; M=3,56$ e $D P=1,02)$, ou seja, são apoios mais frequentemente percebidos pelos alunos advindos de seus companheiros, e justamente são os que têm as menores médias quando se avalia o suporte provindo dos supervisores/professores $(M=3,32$ e $D P=0,94 ; M=3,07$ e $D P=1,04)$. Parece que os pares, com maior frequência que os supervisores/professores, removem dificuldades à aplicação do aprendido no trabalho e acatam sugestões relativas aos novos aprendizados.

\subsection{Barreiras e facilitadores em EAD.}

Os resultados descritivos dos 22 itens do instrumento de "Barreras y Facilitadores en la Enseñanza Virtual" associados a uma escala de comportamento que varia de 1 ("No dificultó el desempeño") a 5 ("Dificultó totalmente el desempeño") podem ser visualizados na Tabela 15 .

Tabela 15. Resultados descritivos do instrumento de "Barreras y Facilitadores en la Enseñanza Virtual".

\begin{tabular}{|c|c|c|c|c|c|c|c|}
\hline \multirow{2}{*}{ Itens } & \multirow{2}{*}{$\begin{array}{l}\text { Casos } \\
\text { omissos }\end{array}$} & \multirow{2}{*}{ Média } & \multirow{2}{*}{$\begin{array}{l}\text { Desvio } \\
\text { Padrão }\end{array}$} & \multirow{2}{*}{ Moda } & \multicolumn{3}{|c|}{$\begin{array}{l}\text { Concentração de } \\
\text { Respostas (\%)* }\end{array}$} \\
\hline & & & & & $1-2$ & 3 & $4-5$ \\
\hline 16. El tiempo disponible para estudiar. & 2 & 3,22 & 1,17 & 4 & 27,6 & 22,9 & 48,4 \\
\hline $\begin{array}{l}\text { 17. La conciliación de la formación con otras } \\
\text { actividades de estudio. }\end{array}$ & 0 & 2,93 & 1,15 & 3 & 34,9 & 30,2 & 34,9 \\
\hline $\begin{array}{l}\text { 15. La conciliación de la formación con los } \\
\text { compromisos de la familia. }\end{array}$ & 2 & 2,64 & 1,21 & 3 & 44,2 & 29,2 & 25,6 \\
\hline $\begin{array}{l}\text { 9. Los gastos económicos asociados a las } \\
\text { tecnologías y los materiales necesarios para la } \\
\text { formación (acceso a Internet, mantenimiento } \\
\text { del ordenador, etc.). }\end{array}$ & 3 & 2,63 & 1,14 & 3 & 43,3 & 30,2 & 25,0 \\
\hline $\begin{array}{l}\text { 13. La cantidad de las actividades propuestas } \\
\text { durante la formación. }\end{array}$ & 1 & 2,61 & 1,19 & 3 & 44,8 & 31,3 & 23,4 \\
\hline 6. La conexión a Internet. & 2 & 2,51 & 1,24 & 1 & 48,9 & 26,6 & 23,4 \\
\hline $\begin{array}{l}\text { 14. La conciliación de la formación con las } \\
\text { actividades profesionales. }\end{array}$ & 2 & 2,50 & 1,20 & 1 & 49,0 & 27,1 & 23,0 \\
\hline 5. El apoyo técnico ofrecido por la institución. & 1 & 2,40 & 1,05 & 3 & 52,6 & 32,3 & 14,6 \\
\hline 10. La duración de la formación. & 0 & 2,32 & 1,03 & 3 & $\mathbf{5 5 , 7}$ & 29,7 & 14,6 \\
\hline $\begin{array}{l}\text { 20. La correspondencia entre la formación y las } \\
\text { expectativas personales. }\end{array}$ & 0 & 2,32 & 1,06 & 2 & 61,5 & 22,9 & 15,6 \\
\hline $\begin{array}{l}\text { 18. Las condiciones del ambiente de estudio en } \\
\text { casa. }\end{array}$ & 0 & 2,30 & 1,29 & 1 & 57,3 & 21,4 & 21,3 \\
\hline
\end{tabular}


Tabela 15. Resultados descritivos do instrumento de "Barreras y Facilitadores en la Enseñanza Virtual". (Continuação)

\begin{tabular}{|c|c|c|c|c|c|c|c|}
\hline \multirow[t]{2}{*}{ Itens } & \multirow{2}{*}{$\begin{array}{c}\text { Casos } \\
\text { omissos }\end{array}$} & \multirow{2}{*}{ Média } & \multirow{2}{*}{$\begin{array}{l}\text { Desvio } \\
\text { Padrão }\end{array}$} & \multirow[t]{2}{*}{ Moda } & \multicolumn{3}{|c|}{$\begin{array}{l}\text { Concentração de } \\
\text { Respostas (\%)* }\end{array}$} \\
\hline & & & & & 1-2 & 3 & 4-5 \\
\hline $\begin{array}{l}\text { 7. El acceso al entorno virtual de la formación } \\
\text { con la regularidad propuesta. }\end{array}$ & 2 & 2,28 & 1,14 & 1 & 54,7 & 29,2 & 15,1 \\
\hline 11. El contenido de la formación. & 0 & 2,24 & 0,95 & 2 & 59,9 & 29,7 & 10,4 \\
\hline $\begin{array}{l}\text { 21. Las habilidades personales para organizar y } \\
\text { planificar las actividades de estudio. }\end{array}$ & 1 & 2,22 & 1,24 & 1 & 62,5 & 18,2 & 18,7 \\
\hline $\begin{array}{l}\text { 1. La promoción por parte del tutor de la } \\
\text { interacción social entre los participantes de la } \\
\text { formación. }\end{array}$ & 13 & 2,05 & 1,00 & 1 & 60,4 & 27,1 & 5,8 \\
\hline 8. Los materiales didácticos de la formación. & 2 & 2,01 & 0,99 & 1 & 71,9 & 19,3 & 7,8 \\
\hline 19. Mi estado de salud durante la formación. & 0 & 1,98 & 1,16 & 1 & 71,3 & 13,5 & 15,1 \\
\hline $\begin{array}{l}\text { 3. La relación entre compañeros y tutores en } \\
\text { cuanto al proceso de aprendizaje durante la } \\
\text { formación. }\end{array}$ & 2 & 1,92 & 0,98 & 1 & 71,9 & 21,9 & 5,2 \\
\hline $\begin{array}{l}\text { 12. Los recursos educativos utilizados (figuras, } \\
\text { vídeos, diapositivas, etc.). }\end{array}$ & 0 & 1,82 & 0,93 & 1 & 76,0 & 19,3 & 4,6 \\
\hline $\begin{array}{l}\text { 22. Las habilidades personales para utilizar los } \\
\text { recursos Web (chats, correos electrónicos, } \\
\text { foros, etc.). }\end{array}$ & 1 & 1,82 & 1,13 & 1 & 75,6 & 13,0 & 10,9 \\
\hline $\begin{array}{l}\text { 2. El uso de los recursos Web (chats, correos } \\
\text { electrónicos, foros, etc.) para la comunicación } \\
\text { con los tutores y compañeros. }\end{array}$ & 1 & 1,75 & 1,00 & 1 & $\mathbf{8 0 , 2}$ & 10,9 & 8,4 \\
\hline $\begin{array}{l}\text { 4. Las orientaciones proporcionadas por el } \\
\text { tutor. }\end{array}$ & 1 & 1,75 & 0,91 & 1 & $\mathbf{7 9 , 7}$ & 15,1 & 4,6 \\
\hline
\end{tabular}

Notas: $N=192$; *1-2 (no dificultó el desempeño/dificultó poco), 3 (ni poco, ni mucho), 4-5 (dificultó mucho/dificultó totalmente el desempeño)

De forma geral, observa-se que a maioria dos alunos não considera os aspectos descritos como fatores que dificultaram o seu desempenho, ou seja, atuaram como barreiras durante o curso, uma vez que a maioria dos itens apresenta uma concentração de respostas nos pontos mais baixos da escala; os valores de médias variaram de 1,75 a 3,22 , indicando pouca dificuldade encontrada; e os de moda, passaram pelos valores 1,2 , 3 e 4. Apesar disso, vale ressaltar que o desvio-padrão foi alto na maioria dos itens e os valores de moda diversos (1, 2, 3 ou 4), o que indica heterogeneidade de respostas entre os alunos.

O item 16 , com a média mais alta $(M=3,22$ e $D P=1,17)$, trata do tempo disponível para estudar e recebeu $48,4 \%$ das pontuações concentradas entre os valores 4 e 5 da escala. Como em outros estudos, o tempo aparece como fator preponderante que pode influenciar de maneira negativa/prejudicar o desempenho durante o curso.

O item $17(M=2,93$ e $D P=1,15)$ aponta para controvérsias quanto à conciliação do curso com outras atividades de estudo: para alguns alunos (34,9\%), não aparece como fator que dificultasse o desempenho, para outros $(34,9 \%)$, sim - provavelmente se perguntássemos à amostra sobre a concomitância da realização de outras atividades 
acadêmicas/escolares (cursos de idiomas, etc.) com o curso assumido na universidade, essa diferença poderia ser explicada.

Os itens com as médias mais baixas, $12(M=1,82$ e $D P=0,93), 22(M=1,82$ e $D P=1,13), 2(M=1,75$ e $D P=1,00)$ e $4(M=1,75$ e $D P=0,91)$ abordam os recursos virtuais e interativos/aprendizagem e as habilidades de usá-los como não dificultadores de desempenho. Isso aponta para o fato de que, mesmo sendo alunos de cursos essencialmente presenciais, não encontram problemas para utilizar ferramentas web e que estas possuem papel facilitador, não obstaculizando o desempenho dos alunos durante o curso. E o item 4 deixa clara a importância dada às orientações prestadas pelo tutor/professor, sendo um fator que não dificulta o desempenho, mas o contrário.

\subsection{Impacto do treinamento no trabalho.}

Os resultados descritivos dos 7 itens do instrumento de "Impacto de la Formación en el Trabajo en Amplitud" associados a uma escala de concordância que varia de 1 ("Totalmente en desacuerdo") a 5 ("Totalmente de acuerdo") podem ser visualizados na Tabela 16.

Tabela 16. Resultados descritivos do instrumento de "Impacto de la Formación en el Trabajo en Amplitud".

\begin{tabular}{|c|c|c|c|c|c|c|c|}
\hline \multirow[t]{2}{*}{ Itens } & \multirow{2}{*}{$\begin{array}{l}\text { Casos } \\
\text { Omissos }\end{array}$} & \multirow{2}{*}{ Média } & \multirow{2}{*}{$\begin{array}{l}\text { Desvio } \\
\text { Padrão }\end{array}$} & \multirow{2}{*}{ Moda } & \multicolumn{3}{|c|}{$\begin{array}{l}\text { Concentração de } \\
\text { Respostas }(\%)^{*}\end{array}$} \\
\hline & & & & & $1-2$ & 3 & $4-5$ \\
\hline \multirow{2}{*}{$\begin{array}{l}\text { 1. Aprovecho las oportunidades que tengo para } \\
\text { practicar las nuevas habilidades aprendidas. } \\
\text { 4. Ha mejorado la calidad de mi trabajo. }\end{array}$} & 0 & 4,04 & 0,85 & 4 & 4,6 & 17,2 & 78,2 \\
\hline & 0 & 3,86 & 0,84 & 4 & 4,7 & 22,9 & 72,4 \\
\hline 3. Realizo mi trabajo con más agilidad. & 0 & 3,73 & 0,77 & 4 & 5,2 & 27,1 & 67,7 \\
\hline 5. Ha aumentado mi motivación para trabajar. & 0 & 3,67 & 0,99 & 4 & 11,9 & 24,5 & 63,6 \\
\hline $\begin{array}{l}\text { 6. He sido capaz en mayor medida que antes de } \\
\text { sugerir innovaciones y cambios en mi trabajo. }\end{array}$ & 0 & 3,67 & 0,91 & 4 & 7,8 & 31,3 & 61,0 \\
\hline $\begin{array}{l}\text { 2. Tengo un menor número de errores en el } \\
\text { trabajo. }\end{array}$ & 0 & 3,62 & 0,81 & 4 & 6,3 & 34,4 & 59,3 \\
\hline $\begin{array}{l}\text { 7. Mis compañeros han aprendido de mis } \\
\text { habilidades adquiridas. }\end{array}$ & 0 & 3,29 & 0,93 & 3 & 15,6 & 43,8 & 40,6 \\
\hline
\end{tabular}

Notas: $N=192 ; * 1-2$ (totalmente en desacuerdo/un poco en desacuerdo), 3 (ni en desacuerdo, ni de acuerdo), 4-5 (de acuerdo/totalmente de acuerdo)

Observa-se que a maioria dos alunos afirma que o curso impacta de maneira positiva no seu trabalho - ou o fará no futuro - e que aproveita as oportunidades que tem para colocar em prática o aprendido (Item 1: $M=4,04$ e $D P=0,85$ ), uma vez que as médias variaram entre 3,29 a 4,04 e os valores de desvio-padrão são baixos, indicando 
concordância de opiniões quanto aos aspectos avaliados. Interessante notar que o item que recebeu as pontuações mais baixas (Item 7: $M=3,29$ e $D P=0,93$ ) trata da transferência horizontal (entre pares/colegas), possivelmente por considerarem que se encontram em um mesmo nível de desenvolvimento acadêmico/profissional e aprendem menos uns com os outros, mas em maior medida, com o professor.

\subsubsection{Análises de consistência interna.}

A análise de consistência interna foi realizada, como é majoritariamente feita em outros estudos empíricos que pretendem a avaliação da qualidade de instrumentos com métrica de perfil latente, por meio do cálculo do Alfa de Cronbach ( $\alpha$ ), que consiste em um modelo para análise de confiabilidade baseado na correlação média entre os itens. Tal medida de consistência interna prevê que os itens da escala devem medir o mesmo construto e, assim, estar altamente intercorrelacionados. $\mathrm{O}$ valor assumido para $\alpha$ está entre 0 e 1 , sendo que quanto mais próximo de 1 estiver seu valor, maior a fidedignidade das dimensões do construto. Valores iguais a 0,7 são considerados como mínimo ideal (Hair et al., 2005) e desejáveis para pesquisas preliminares; 0,8 para pesquisa básica e 0,9 para pesquisa aplicada.

A Tabela 17 mostra as comparações entre os índices de consistência interna e o número de itens dos instrumentos brasileiros (português) e as versões em espanhol aplicadas aos alunos no estudo piloto - na Tabela 18 adiante, pode-se observar mais detalhadamente os valores de $\alpha$, número de itens e cargas fatoriais das escalas originais.

Tabela 17. Comparação dos alfas e número de itens entre as escalas em português e espanhol.

\begin{tabular}{lccccc}
\hline \multirow{2}{*}{\multicolumn{1}{c}{ Instrumento }} & \multicolumn{2}{c}{ Estudo Piloto } & \multicolumn{2}{c}{ Originais } & $\mathbf{N}^{\mathbf{0}}$ itens \\
\cline { 2 - 5 } & $\mathbf{N}^{\mathbf{0}}$ itens & $\boldsymbol{\alpha}$ & $\mathbf{N}^{\mathbf{0}}$ itens & $\boldsymbol{\alpha}$ & reduzidos \\
\hline Estratégias de Aprendizagem & 21 & 0,81 & 29 & 0,92 & 08 \\
Reação aos Procedimentos Instrucionais & 05 & 0,64 & 17 & 0,96 & 12 \\
Reação ao Desempenho do Tutor & 06 & 0,78 & 27 & 0,98 & 21 \\
Barreiras e Facilitadores em EAD & 22 & 0,82 & 63 & $0,72 / 0,96$ & 41 \\
Suporte à Transferência & 08 & 0,78 & 16 & $0,86 / 0,91$ & 08 \\
Impacto em Amplitude & 07 & 0,81 & 12 & 0,93 & 05 \\
\hline
\end{tabular}

De modo geral, mesmo com o corte brusco do número de itens, a maioria dos instrumentos manteve ótimos índices de consistência interna $(0,78<\alpha<0,82)$ - com exceção do instrumento de Reação aos Procedimentos Instrucionais $(\alpha=0,64)$ - indicando adequação ao idioma e ao contexto espanhol. Os valores de alfas obtidos, apesar de mais 
baixos, no geral, que os das escalas originais em português $(0,72<\alpha<0,98)$, são bons e aceitáveis, devendo-se levar em conta os ganhos com a diminuição do número de itens (facilidade e agilidade na aplicação dos instrumentos quando da coleta de dados, por exemplo) após as importantes modificações no processo de adaptação.

As diferenças encontradas podem ser explicadas a partir das especificidades e limitações do contexto e da amostra, que respondeu a instrumentos destinados a contextos corporativos e julgou aspectos não condizentes à sua realidade: alunos de cursos presenciais, que utilizam uma plataforma virtual, em oposição à amostra real do estudo de campo formada por trabalhadores participantes de treinamentos online. A possibilidade de que houvesse um incremento nos valores dos alfas quando as escalas fossem aplicadas a amostras com características mais apropriadas às medidas e aos construtos que se pretendem avaliar foi confirmada. De qualquer forma, o estudo piloto impediu que os baixos alfas fossem detectados somente após a coleta de dados do estudo principal e serviu para repensar as adaptações com tempo hábil para tomar decisões antes da coleta de dados, permitindo o ajuste e a melhoria dos instrumentos e a consequente influência sobre os resultados. Foi repensada principalmente a adaptação dos instrumentos de reações, optando-se por usar as escalas originais com menores modificações.

No caso do instrumento de Reação aos Procedimentos Instrucionais, a proposta adaptada aplicada aos estudantes espanhóis no estudo piloto possuía apenas 5 itens (Anexo C). Em decorrência da diminuição do seu índice de consistência interna obtido no estudo piloto comparado ao da escala original (de $\alpha=0,96$ para $\alpha=0,64$ ), para o estudo de campo, foi aplicada à amostra principal uma versão que continha 12 itens (ver Anexo H). Esta versão, quando apresentada à equipe de avaliações do Banco parceiro, teve de ser novamente adaptada para que fosse condizente à realidade organizacional específica avaliada. Foram retirados dois itens que tratavam de recursos de interação, não disponíveis no curso online ("Fóruns e chats" e "Troca de mensagens entre os alunos"), além do item "Leituras recomendadas"; portanto, a escala aplicada à amostra do estudo de campo principal continha 9 itens (Anexo J).

A Tabela 18 apresenta as informações psicométricas dos instrumentos brasileiros originais, a partir dos quais foram feitas as adaptações, resultando em versões com menos itens utilizadas no presente estudo. 
Tabela 18. Resumo das informações psicométricas dos instrumentos utilizados em estudos anteriores.

\begin{tabular}{|c|c|c|c|c|c|c|c|}
\hline \multirow[t]{2}{*}{ Adaptação } & \multirow[t]{2}{*}{ Instrumento } & \multirow[t]{2}{*}{ Fatores obtidos } & \multirow{2}{*}{$\begin{array}{c}\mathbf{N}^{\mathbf{o}} \\
\text { itens }\end{array}$} & \multirow{2}{*}{$\underset{\text { itens }}{\Sigma}$} & \multirow[t]{2}{*}{ Alfa } & \multicolumn{2}{|c|}{$\begin{array}{c}\text { Cargas } \\
\text { fatoriais }\end{array}$} \\
\hline & & & & & & Mín. & Máx. \\
\hline \multirow{14}{*}{ 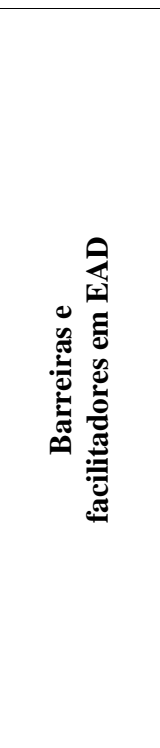 } & \multirow{3}{*}{$\begin{array}{l}\text { Ambiente de Estudo e } \\
\text { Procedimentos de Interação } \\
\text { (Zerbini \& Abbad, 2008a) }\end{array}$} & Contexto de estudo & 8 & \multirow{3}{*}{18} & 0,85 & 0,44 & 0,84 \\
\hline & & $\begin{array}{l}\text { Custos pessoais e } \\
\text { profissionais }\end{array}$ & 5 & & 0,84 & $-0,35$ & $-0,95$ \\
\hline & & Ferramentas de interação & 5 & & 0,83 & $-0,31$ & $-0,92$ \\
\hline & \multirow{7}{*}{$\begin{array}{l}\text { Escala de Fatores } \\
\text { Relacionados à Evasão e à } \\
\text { Persistência em EAD } \\
\text { (Sales, 2009) }\end{array}$} & Desempenho do tutor & 14 & \multirow{7}{*}{63} & 0,96 & 0,61 & 0,91 \\
\hline & & Desenho do curso & 19 & & 0,90 & 0,34 & 0,76 \\
\hline & & $\begin{array}{l}\text { Disciplina e interesse do } \\
\text { aluno }\end{array}$ & 9 & & 0,89 & 0,41 & 0,86 \\
\hline & & $\begin{array}{l}\text { Experiências e habilidades } \\
\text { importantes para os cursos } \\
\text { a distância }\end{array}$ & 5 & & 0,75 & 0,42 & 0,86 \\
\hline & & Tempo disponível & 6 & & 0,85 & 0,38 & 0,88 \\
\hline & & Apoio no trabalho & 5 & & 0,84 & 0,43 & 0,90 \\
\hline & & Questões familiares & 5 & & 0,72 & 0,38 & 0,77 \\
\hline & \multirow{4}{*}{$\begin{array}{l}\text { Fatores Relacionados à } \\
\text { Evasão e à Persistência em } \\
\text { EAD (Umekawa, 2013) }\end{array}$} & $\begin{array}{l}\text { Suporte tecnológico e de } \\
\text { tutoria }\end{array}$ & 18 & \multirow{4}{*}{41} & 0,93 & 0,40 & 0,93 \\
\hline & & $\begin{array}{l}\text { Características exógenas } \\
\text { ao curso }\end{array}$ & 11 & & 0,84 & 0,30 & 0,78 \\
\hline & & Características do aluno & 8 & & 0,86 & 0,35 & 0,71 \\
\hline & & Desenho do curso & 4 & & 0,75 &,- 64 & 0,33 \\
\hline \multirow{11}{*}{ 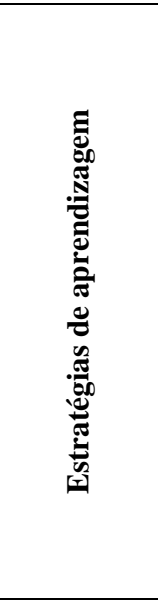 } & \multirow{7}{*}{$\begin{array}{l}\text { Estratégias de } \\
\text { Aprendizagem (Zerbini \& } \\
\text { Abbad, 2008b) }\end{array}$} & Controle da emoção & 5 & \multirow{7}{*}{28} & 0,89 & 0,48 & 0,91 \\
\hline & & $\begin{array}{l}\text { Busca de ajuda } \\
\text { interpessoal }\end{array}$ & 6 & & 0,89 & 0,66 & 0,83 \\
\hline & & Repetição e organização & 5 & & 0,77 & $-0,35$ & $-0,77$ \\
\hline & & Controle da motivação & 4 & & 0,84 & 0,69 & 0,86 \\
\hline & & Elaboração & 3 & & 0,83 & 0,54 & 0,91 \\
\hline & & $\begin{array}{l}\text { Busca de ajuda ao material } \\
\text { didático }\end{array}$ & 2 & & 0,75 & 0,68 & 0,82 \\
\hline & & $\begin{array}{l}\text { Monitoramento da } \\
\text { compreensão }\end{array}$ & 3 & & 0,82 & $-0,49$ & $-0,75$ \\
\hline & \multirow{4}{*}{$\begin{array}{l}\text { Estratégias de } \\
\text { Aprendizagem (Martins \& } \\
\text { Zerbini, 2014b) }\end{array}$} & Estratégias cognitivas & 15 & \multirow{4}{*}{29} & 0,90 & 0,33 & 0,72 \\
\hline & & Controle da emoção & 4 & & 0,77 & 0,46 & 0,76 \\
\hline & & $\begin{array}{l}\text { Estratégias } \\
\text { autorregulatórias }\end{array}$ & 7 & & 0,86 & $-0,50$ & $-0,69$ \\
\hline & & $\begin{array}{l}\text { Busca de ajuda } \\
\text { interpessoal }\end{array}$ & 3 & & 0,68 & 0,45 & 0,69 \\
\hline \multirow{3}{*}{ 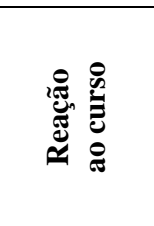 } & \multirow{2}{*}{$\begin{array}{l}\text { Reação aos Procedimentos } \\
\text { Instrucionais (Zerbini \& } \\
\text { Abbad, 2009a) }\end{array}$} & $\begin{array}{l}\text { Procedimentos } \\
\text { tradicionais }\end{array}$ & 12 & \multirow[t]{2}{*}{15} & 0,91 & 0,53 & 0,79 \\
\hline & & Recursos da $w e b$ & 3 & & 0,76 & 0,40 & 0,88 \\
\hline & $\begin{array}{l}\text { Reação aos Procedimentos } \\
\text { Instrucionais em EAD } \\
\text { (Martins \& Zerbini, 2015) }\end{array}$ & $\begin{array}{l}\text { Procedimentos } \\
\text { Instrucionais em EAD }\end{array}$ & 17 & 17 & 0,96 & 0,60 & 0,86 \\
\hline \multirow{2}{*}{ 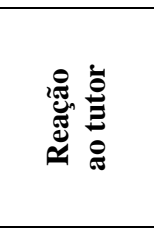 } & $\begin{array}{l}\text { Reação ao Desempenho do } \\
\text { Tutor (Zerbini \& Abbad, } \\
\text { 2009b) }\end{array}$ & Desempenho do tutor & 27 & 27 & 0,98 & 0,69 & 0,88 \\
\hline & $\begin{array}{l}\text { Reação ao Desempenho do } \\
\text { Tutor (Martins \& Zerbini, } \\
\text { 2015) }\end{array}$ & Desempenho do Tutor & 27 & 27 & 0,98 & 0,67 & 0,88 \\
\hline 冚 & $\begin{array}{l}\text { Impacto do Treinamento no } \\
\text { Trabalho (Pilati \& Abbad, } \\
\text { 2005) }\end{array}$ & Impacto em amplitude & 12 & 12 & 0,93 & 0,57 & 0,98 \\
\hline \multirow{2}{*}{ 焉离 } & \multirow{2}{*}{$\begin{array}{l}\text { Suporte à Transferência de } \\
\text { Treinamento (Abbad \& } \\
\text { Sallorenzo, 2001) }\end{array}$} & Suporte Psicossocial & 11 & \multirow{2}{*}{16} & 0,91 & 0,46 & 0,86 \\
\hline & & Suporte Material & 5 & & 0,86 & 0,56 & 0,82 \\
\hline
\end{tabular}




\subsubsection{Análises fatoriais exploratórias.}

Anteriormente à realização das análises fatoriais, análises exploratórias dos dados permitiram verificar a entrada dos dados, a presença de casos extremos, o tamanho das amostras e a distribuição dos casos omissos e de frequência das variáveis. Os seguintes critérios foram considerados: os casos omissos, quando presentes, foram substituídos pela média, devido ao tamanho limitado da amostra; exclusão dos casos extremos univariados; correlações de Pearson para análise da linearidade, multicolinearidade e singularidade (acima de 0,80 e 0,90); tamanho das correlações (50\% acima de 0,30); teste KMO (índice de adequação da amostra próximo a 1); número de componentes indicado pela análise dos valores próprios (eigenvalues $\geq 1$ ), variância explicada (porcentagem mínima de $3 \%$ da variância total) e scree plot; cargas fatoriais superiores a 0,30; análise dos índices de consistência interna dos itens e análise da interpretabilidade das soluções propostas. Para as análises fatoriais exploratórias, foram utilizados os métodos dos componentes principais (Principal Components - PC) e de fatoração dos eixos principais (Principal Axis Factoring - PAF) - rotação oblíqua e tratamento pairwise para os casos omissos.

Nos casos em que os critérios convencionais e de relevância do fator anteriormente citados ainda deixavam dúvidas quanto ao número de componentes da estrutura, foram utilizados os critérios estatísticos (testes de significância), por meio da realização da análise paralela de Horn, que compara valores próprios empíricos, obtidos pela análise da $P C$, com valores próprios aleatórios, em função da quantidade de variáveis e do tamanho da amostra - os fatores são retirados da estrutura quando apresentam valor próprio empírico igual ou menor que os valores aleatórios (Laros, 2004).

Não foram identificados outliers univariados; a partir da elaboração e análise da matriz de covariância verificou-se que não houve relacionamentos não lineares entre as variáveis (linearidade), nem a presença de singularidade e multicolinearidade.

Os principais índices analisados, os resultados obtidos por meio da $P C$ e $P A F$ sobre a estrutura empírica das escalas, as cargas fatoriais, as comunalidades $\left(h^{2}\right)$, as médias $(M)$ e os desvios-padrão $(D P)$ dos itens, os índices de consistência interna, os valores próprios e os percentuais de variância explicada de cada fator podem ser visualizados a seguir.

\subsection{Estratégias de aprendizagem.}


Tabela 19. Estrutura empírica do instrumento de "Estrategias de Aprendizaje".

\begin{tabular}{|c|c|c|c|c|c|c|}
\hline \multirow{2}{*}{ Itens } & \multicolumn{3}{|c|}{ Cargas fatoriais } & \multirow{2}{*}{$h^{2}$} & \multirow{2}{*}{$\boldsymbol{M}$} & \multirow{2}{*}{$D P$} \\
\hline & 1 & 2 & 3 & & & \\
\hline $\begin{array}{l}\text { 1. Mantuve la calma cuando tuve dificultades durante la } \\
\text { formación. }\end{array}$ & & 0,66 & & 0,53 & 3,57 & 0,84 \\
\hline $\begin{array}{l}\text { 2. Mantuve la calma ante la amenaza de tener un } \\
\text { rendimiento inferior al esperado. }\end{array}$ & & 0,73 & & 0,63 & 3,14 & 0,88 \\
\hline $\begin{array}{l}\text { 3. Mantuve la calma con los errores que cometí en las } \\
\text { actividades de la formación. }\end{array}$ & & 0,60 & & 0,41 & 3,39 & 0,87 \\
\hline $\begin{array}{l}\text { 4. Me esforcé más cuando me di cuenta de que estaba } \\
\text { perdiendo la concentración. }\end{array}$ & 0,51 & & & 0,28 & 3,97 & 0,87 \\
\hline $\begin{array}{l}\text { 5. Me esforcé más cuando me di cuenta de que estaba } \\
\text { perdiendo el interés en el tema. }\end{array}$ & 0,50 & & & 0,34 & 3,40 & 1,06 \\
\hline $\begin{array}{l}\text { 6. Me esforcé para verificar si entendía lo que se } \\
\text { enseñaba. }\end{array}$ & 0,47 & & & 0,25 & 3,95 & 0,82 \\
\hline $\begin{array}{l}\text { 7. Solicité la ayuda del tutor para aclarar mis dudas } \\
\text { sobre los contenidos de la formación. }\end{array}$ & & & $-0,42$ & 0,29 & 2,95 & 1,22 \\
\hline $\begin{array}{l}\text { 8. Pedí la ayuda de mis compañeros para aclarar mis } \\
\text { dudas sobre los contenidos de la formación. }\end{array}$ & & & & 0,09 & 4,03 & 0,92 \\
\hline $\begin{array}{l}\text { 9. Busqué la solución a mis dudas al consultar el } \\
\text { material didáctico de la formación. }\end{array}$ & & & 0,45 & 0,44 & 3,85 & 0,94 \\
\hline $\begin{array}{l}\text { 10. Busqué comprender los contenidos al estudiarlos en } \\
\text { el material didáctico de la formación. }\end{array}$ & & & 0,34 & 0,47 & 3,91 & 0,84 \\
\hline $\begin{array}{l}\text { 11. Busqué otras fuentes de información relacionadas } \\
\text { con la formación para ayudarme a aprender. }\end{array}$ & 0,41 & & & 0,17 & 3,24 & 1,02 \\
\hline $\begin{array}{l}\text { 12. Busqué comprender el contenido aplicándolo en la } \\
\text { práctica, en lugar de pasar el tiempo leyendo o pidiendo } \\
\text { ayuda a alguien. }\end{array}$ & 0,37 & & & 0,16 & 3,04 & 0,88 \\
\hline $\begin{array}{l}\text { 13. Realicé los ejercicios prácticos propuestos a lo largo } \\
\text { del curso para ayudarme a aprender. }\end{array}$ & 0,47 & & & 0,25 & 4,06 & 0,91 \\
\hline $\begin{array}{l}\text { 14. Leí el contenido de la formación varias veces como } \\
\text { un método para aprender. }\end{array}$ & 0,49 & & & 0,32 & 3,63 & 1,01 \\
\hline $\begin{array}{l}\text { 15. Repetí mentalmente el contenido de la formación } \\
\text { que tenía que aprender hasta que me diera cuenta de } \\
\text { que lo entendía. }\end{array}$ & 0,31 & & & 0,15 & 3,68 & 1,06 \\
\hline $\begin{array}{l}\text { 16. Hice anotaciones, resúmenes y/o esquemas de los } \\
\text { contenidos de la formación como un método para } \\
\text { aprender. }\end{array}$ & 0,43 & & & 0,24 & 4,13 & 1,04 \\
\hline $\begin{array}{l}\text { 17. Ponderé las implicaciones que los contenidos } \\
\text { aprendidos podrían tener. }\end{array}$ & 0,34 & & & 0,12 & 3,13 & 1,06 \\
\hline $\begin{array}{l}\text { 18. Identifiqué situaciones cotidianas en las que yo } \\
\text { podría aplicar el contenido de la formación. }\end{array}$ & 0,45 & & & 0,28 & 3,53 & 0,90 \\
\hline $\begin{array}{l}\text { 19. Intenté hacerme una idea general del contenido de } \\
\text { la formación asociando elementos entre sí. }\end{array}$ & 0,58 & & & 0,39 & 3,81 & 0,89 \\
\hline $\begin{array}{l}\text { 20. Asocié el contenido de la formación a mis } \\
\text { conocimientos previos. }\end{array}$ & 0,54 & & & 0,37 & 3,93 & 0,94 \\
\hline $\begin{array}{l}\text { 21. Revisé los contenidos relativos a los ejercicios en } \\
\text { que cometí errores. }\end{array}$ & 0,56 & & & 0,33 & 3,66 & 1,06 \\
\hline$N$ & 192 & 192 & 192 & & & \\
\hline Eigenvalue (Valor próprio) & 4,62 & 2,06 & 1,74 & & & \\
\hline \% da Variância Explicada $(P A F)$ & 18,77 & 7,44 & 5,16 & & & \\
\hline No. de itens & 14 & 3 & 3 & & & \\
\hline $\operatorname{Alfa}(\alpha)$ & 0,79 & 0,76 & 0,43 & & & \\
\hline KMO & 0,74 & & & & & \\
\hline \% da variância total explicada $(P C)$ & 61,79 & & & & & \\
\hline
\end{tabular}

Inicialmente, a $P C$ sugere uma estrutura empírica com 7 componentes que explicam, em conjunto, $61,79 \%$ da variância total das respostas dos participantes aos itens 
do questionário. No entanto, a análise dos valores próprios, variância explicada e scree plot (Figura 3) apontam para a possibilidade de uma solução com 3 ou 4 fatores para o instrumento, ratificada pela análise paralela de Horn (Tabela 20).

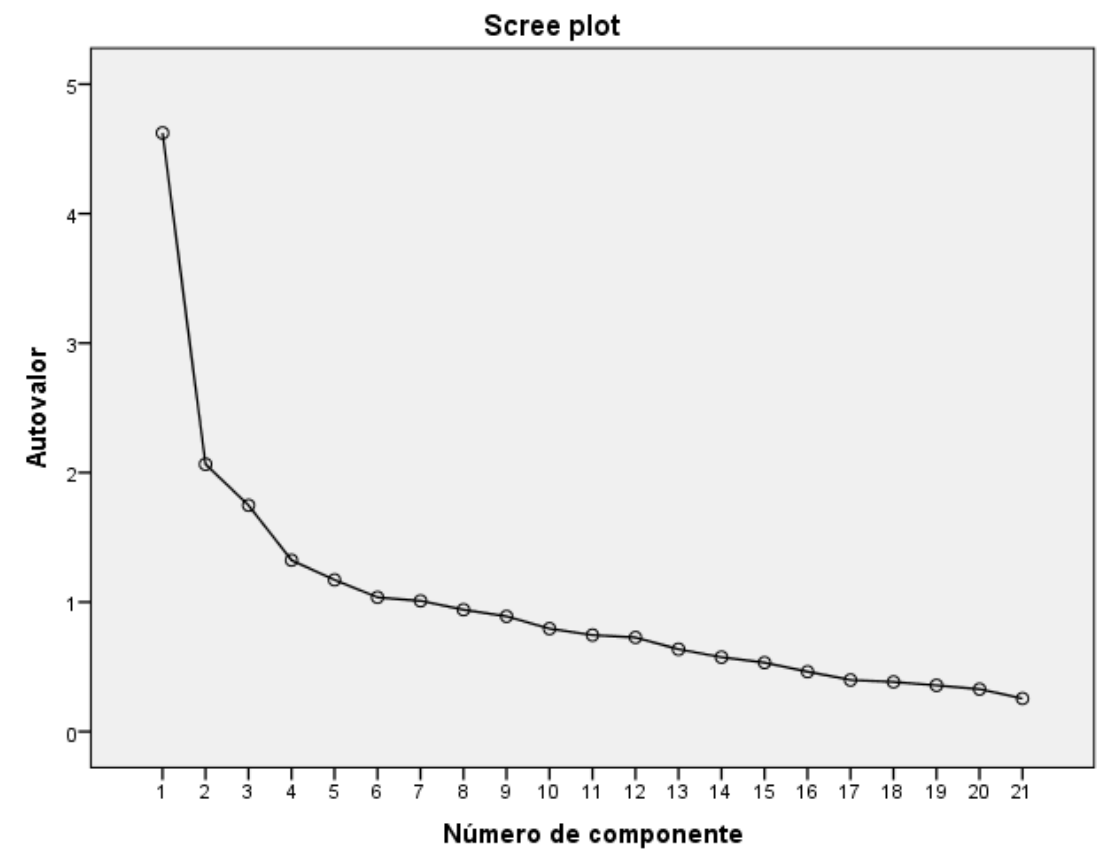

Figura 3. Distribuição dos valores próprios (scree plot) da escala de "Estrategias de Aprendizaje".

Tabela 20. Valores próprios empíricos e aleatórios dos primeiros dez componentes da escala de "Estrategias de Aprendizaje".

\begin{tabular}{lcccccccccc}
\hline Valores & \multicolumn{10}{c}{ Componentes } \\
\cline { 2 - 13 } Próprios & 1 & 2 & 3 & 4 & 5 & 6 & 7 & 8 & 9 & 10 \\
\hline Empírico & $\mathbf{4 , 6 2}$ & $\mathbf{2 , 0 6}$ & $\mathbf{1 , 7 4}$ & 1,32 & 1,17 & 1,03 & 1,01 & 0,94 & 0,89 & 0,79 \\
\hline Aleatório & $\mathbf{1 , 6 5}$ & $\mathbf{1 , 5 2}$ & $\mathbf{1 , 4 3}$ & 1,36 & 1,29 & 1,23 & 1,17 & 1,11 & 1,07 & 1,01 \\
\hline
\end{tabular}

Notas: No. de itens (21); $N=192$

Em seguida, a $P A F$ com a fixação de 3 fatores mostrou que as estratégias de aprendizagem estariam agrupadas assim: 1) Estratégias Cognitivas (14 itens: 4, 5 e 6 e do 11 ao 21; $\alpha=0,79$; cargas fatoriais: 0,31 a 0,58); 2) Estratégias Autorregulatórias/Controle da Emoção (3 itens: 1, 2 e 3; $\alpha=0,76$; cargas fatoriais: 0,60 a 0,73) e 3) Estratégias Comportamentais/Busca de Ajuda ao Material Didático e ao Tutor (3 itens: 7, 9 e 10; $\alpha=0,43$; cargas fatoriais: 0,34 a 0,45 ). O item 8 "Pedí la ayuda de mis compañeros para aclarar mis dudas sobre los contenidos de la formación" (estratégia comportamental de busca de ajuda interpessoal) não se manteve na estrutura empírica - resultado não esperado, pois esta estratégia foi apontada pelos resultados descritivos da escala como uma das mais usadas pelos alunos ( $3^{\mathrm{a}}$ estratégia que obteve média mais alta). 
O fator 1, "Estratégias Cognitivas" reúne todas as estratégias cognitivas (repetição, organização e elaboração), além de itens provenientes das estratégias autorregulatórias (monitoramento da compreensão e controle da motivação) e comportamentais (aplicação prática). O fator 2, "Controle da Emoção", tem sido sucessivamente encontrado e mantido na estrutura empírica do instrumento, separado das demais estratégias, em estudos anteriores. O fator 3, "Busca de Ajuda ao Material Didático e ao Tutor", engloba estratégias de obtenção de auxílio de outras pessoas e de informações no material da instrução para estudar; possui compartilhamento de cargas fatoriais com o fator 1 e semelhante a resultados prévios, tem o menor alfa comparado aos outros fatores (Martins \& Zerbini, 2014b; Zerbini \& Abbad, 2008b).

A solução com 4 fatores também foi testada, mas os 3 itens (4, 5 e 19) pertencentes ao quarto fator possuíam suas cargas fatoriais compartilhadas com os do fator 1 e a solução com 3 fatores mostrou-se mais apropriada teoricamente - embora a solução com 4 fatores também apresentasse sentido teórico e foi encontrada em estudo prévio (Martins \& Zerbini, 2014b). O fator 4 seria formado por 2 estratégias autorregulatórias de controle da motivação e o item 19, "Intenté hacerme una idea general del contenido de la formación asociando elementos entre sí”, iria manter-se de qualquer forma no fator das estratégias cognitivas, por fazer mais sentido teórico e empírico - estratégia cognitiva de organização.

\subsection{Reações.}

Tabela 21. Estrutura empírica do instrumento de "Reacción a los Procedimientos de Formación".

\begin{tabular}{|c|c|c|c|c|}
\hline Itens & $\begin{array}{l}\text { Cargas } \\
\text { fatoriais }\end{array}$ & $h^{2}$ & $M$ & $D P$ \\
\hline 1. Programación de las actividades. & 0.56 & 0.31 & 3.46 & 0,84 \\
\hline 2. Actividades, contenidos, lecturas. & 0,60 & 0,37 & 3,68 & 0,84 \\
\hline 3. Interacción interpersonal entre los participantes. & 0,30 & 0,09 & 3,89 & 0,90 \\
\hline $\begin{array}{l}\text { 4. Los recursos de aprendizaje virtuales disponibles (foros, chats, } \\
\text { etc.). }\end{array}$ & 0,54 & 0,29 & 3,62 & 0,97 \\
\hline $\begin{array}{l}\text { 5. La información disponible en el entorno virtual de la formación } \\
\text { (noticias, recordatorios, enlaces, etc.). }\end{array}$ & 0,57 & 0,33 & 3,65 & 1,01 \\
\hline $\bar{N}$ & 192 & & & \\
\hline Eigenvalue (Valor próprio) & 2,09 & & & \\
\hline \% da Variância Explicada $(P A F)$ & 28,01 & & & \\
\hline No. de itens & 5 & & & \\
\hline Alfa $(\alpha)$ & 0,64 & & & \\
\hline KMO & 0,61 & & & \\
\hline \% da variância total explicada $(P C)$ & 46,59 & & & \\
\hline
\end{tabular}


A princípio, a $P C$ sugere uma estrutura empírica com 2 componentes que explicam, em conjunto, $46,59 \%$ da variância total das respostas dos participantes aos itens do questionário. Nessa solução, houve compartilhamento de cargas fatoriais entre os 2 fatores nos casos dos itens 2 e 4, e o item 3 não permaneceu na estrutura. Uma estrutura unifatorial faria mais sentido empírico e teórico, portanto, fixou-se apenas um fator na $P A F$, resultando em uma escala com 5 itens, cujas cargas fatoriais variam entre $0,30 \mathrm{e}$ 0,60, e índice de consistência interna equivalente a 0,64 - o fator único explica 28,01\% da variância total das respostas aos itens do instrumento. Além do alfa, o índice de adequação da amostra também apresenta um valor considerado muito baixo $(\mathrm{KMO}=0,61)$, indicando que as variáveis não têm muita variância em comum.

Claramente, este instrumento apresenta falhas no processo de adaptação que acabam por incidir nos resultados obtidos no processo de verificação de suas evidências de validade. Para o estudo principal, foi utilizada outra versão adaptada (Anexo H), mas com alterações menos drásticas - seguindo mais uma vez as indicações da análise de multicolinearidade, que apontava itens altamente correlacionados entre si e a necessidade de aperfeiçoamento de sua redação, para que pudessem ser diferenciados uns dos outros (Martins \& Zerbini, 2015), além das sugestões obtidas no processo de validação por juízes.

Tabela 22. Estrutura empírica do instrumento de "Reacción a la Calidad del Tutor".

\begin{tabular}{|c|c|c|c|c|}
\hline \multirow[t]{2}{*}{ Itens } & $\begin{array}{c}\text { Cargas } \\
\text { fatoriais }\end{array}$ & $h^{2}$ & \multirow[t]{2}{*}{$M$} & \multirow[t]{2}{*}{$D P$} \\
\hline & 1 & & & \\
\hline 1. Promover la discusión de los participantes en los foros. & 0,57 & 0,33 & 3,33 & 1,13 \\
\hline 2. Facilitar las relaciones interpersonales con los participantes. & 0,61 & 0,38 & 3,52 & 1,03 \\
\hline $\begin{array}{l}\text { 3. Comprometerse con las actividades de tutoría (disponibilidad, } \\
\text { puntualidad, lenguaje, participación en las actividades, etc.). }\end{array}$ & 0,54 & 0,29 & 3,72 & 0,87 \\
\hline 4. Respeto al ritmo de aprendizaje de los participantes. & 0,63 & 0,40 & 3,39 & 0,96 \\
\hline 5. Articulación entre teoría y práctica en sus explicaciones. & 0,78 & 0,61 & 3,65 & 0,89 \\
\hline 6. Esclarecimiento de las dudas de los participantes. & 0,56 & 0,32 & 3,99 & 0,88 \\
\hline $\bar{N}$ & 191 & & & \\
\hline Eigenvalue (Valor próprio) & 2,93 & & & \\
\hline \% da Variância Explicada $(P A F)$ & 39,20 & & & \\
\hline No. de itens & 6 & & & \\
\hline Alfa $(\alpha)$ & 0,78 & & & \\
\hline KMO & 0,77 & & & \\
\hline \% da variância total explicada $(P C)$ & 48,94 & & & \\
\hline
\end{tabular}


A escala "Reacción a la Calidad del Tutor" apresenta 6 itens, cujas cargas fatoriais variam entre 0,54 e 0,78 , em uma estrutura unifatorial $(\alpha=0,78)$ - o fator único explica $39,20 \%$ da variância total das respostas aos itens do instrumento.

Os ganhos com a adaptação desta escala são bastante importantes, uma vez que possuía 27 itens em uma estrutura de fator único com alfa muito elevado $(\alpha=0,98)$, o que de fato indicava a presença de conteúdos similares na redação dos itens - os estudos de Martins \& Zerbini (2015) e Zerbini e Abbad (2009b) apontaram, respectivamente, 10 e 25 pares de itens altamente correlacionados entre si presentes na escala - a primeira composta por 27 itens e a segunda, originalmente, por 33 itens, dos quais 6 foram excluídos posteriormente ao processo de identificação da presença de multicolinearidade, tendo sido mantidos os demais, pois, segundo as autoras, representavam diferentes comportamentos observáveis e específicos referentes às estratégias de ensino do tutor. Os valores de alfas e as cargas fatoriais obtidos, apesar de mais baixos que os das escalas originais, são aceitáveis e compensam pela diminuição do número de itens, impactando sobre a facilidade e a agilidade na aplicação do instrumento, que segue avaliando a satisfação dos participantes com a atuação profissional do tutor conforme indicação dos aspectos psicométricos analisados.

\subsection{Suporte à transferência.}

Tabela 23. Estrutura empírica do instrumento de "Apoyo a la Transferencia".

\begin{tabular}{|c|c|c|c|c|c|c|}
\hline \multirow{2}{*}{$\begin{array}{l}\text { Tipo de } \\
\text { Suporte }\end{array}$} & \multirow[t]{2}{*}{ Itens } & \multicolumn{3}{|c|}{$\begin{array}{c}\text { Cargas } \\
\text { fatoriais }\end{array}$} & \multirow{2}{*}{\multicolumn{2}{|c|}{$h^{2}$}} \\
\hline & & 1 & 2 & 3 & & \\
\hline \multirow{6}{*}{ 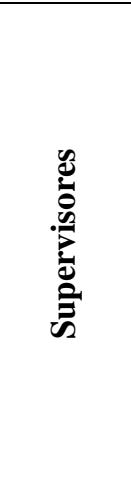 } & $\begin{array}{l}\text { 1. Se alienta la aplicación de las nuevas habilidades } \\
\text { aprendidas en la formación. }\end{array}$ & 0,47 & & & $0,373,52$ & 0,95 \\
\hline & $\begin{array}{l}\text { 2. Se ofrecen las informaciones necesarias para el uso eficaz } \\
\text { de las nuevas habilidades aprendidas en la formación. }\end{array}$ & 0,58 & & & $0,523,57$ & 0,92 \\
\hline & $\begin{array}{l}\text { 3. Se eliminan las dificultades para el uso eficaz de las nuevas } \\
\text { habilidades aprendidas en la formación. }\end{array}$ & 0,48 & & & $0,293,32$ & 0,93 \\
\hline & $\begin{array}{l}\text { 4. Se crean oportunidades para utilizar en el trabajo las nuevas } \\
\text { habilidades aprendidas en la formación. }\end{array}$ & 0,52 & & & $0,413,4$ & 0,94 \\
\hline & $\begin{array}{l}\text { 5. Se ofrece feedback sobre la aplicación de las nuevas } \\
\text { habilidades aprendidas en la formación. }\end{array}$ & 0,63 & & & $0,533,42$ & 1,00 \\
\hline & $\begin{array}{l}\text { 6. Se tienen en cuenta mis sugerencias, en cuanto a lo que se } \\
\text { aprendió en la formación, en el entorno laboral. }\end{array}$ & 0,53 & & & $0,313,07$ & 1,04 \\
\hline \multirow{4}{*}{ 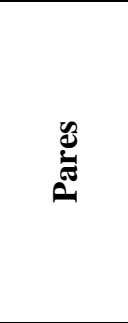 } & $\begin{array}{l}\text { 7. Se alienta la aplicación de las nuevas habilidades } \\
\text { aprendidas en la formación. }\end{array}$ & & 0,38 & & $0,303,45$ & 0,85 \\
\hline & $\begin{array}{l}\text { 8. Se ofrecen las informaciones necesarias para el uso eficaz } \\
\text { de las nuevas habilidades aprendidas en la formación. }\end{array}$ & & 0,34 & & $0,383,42$ & 0,91 \\
\hline & $\begin{array}{l}\text { 9. Se eliminan las dificultades para el uso eficaz de las nuevas } \\
\text { habilidades aprendidas en la formación. }\end{array}$ & & 0,37 & & $0,303,57$ & 0,95 \\
\hline & $\begin{array}{l}\text { 10. Se crean oportunidades para utilizar en el trabajo las } \\
\text { nuevas habilidades aprendidas en la formación. }\end{array}$ & & 0,39 & & $0,383,3$ & 0,97 \\
\hline
\end{tabular}


Tabela 23. Estrutura empírica do instrumento de "Apoyo a la Transferencia". (Continuação)

\begin{tabular}{|c|c|c|c|c|c|}
\hline \multirow{2}{*}{$\begin{array}{l}\text { Tipo de } \\
\text { Suporte }\end{array}$} & \multirow{2}{*}{ Itens } & \multicolumn{3}{|c|}{ Cargas fatoriais } & \multirow{2}{*}{$h^{2} \quad M \quad D P$} \\
\hline & & 1 & 2 & 3 & \\
\hline \multirow{2}{*}{$\stackrel{\mathscr{E}}{E}$} & $\begin{array}{l}\text { 11. Se ofrece feedback sobre la aplicación de las nuevas } \\
\text { habilidades aprendidas en la formación. }\end{array}$ & & 0,45 & & $0,363,391,07$ \\
\hline & $\begin{array}{l}\text { 12. Se tienen en cuenta mis sugerencias, en cuanto a lo que se } \\
\text { aprendió en la formación, en el entorno laboral. }\end{array}$ & & 0,37 & & $0,323,561,01$ \\
\hline \multirow{2}{*}{ 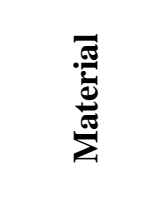 } & $\begin{array}{l}\text { 13. Se proveen los recursos materiales necesarios para la } \\
\text { aplicación eficaz de las nuevas habilidades aprendidas en la } \\
\text { formación. }\end{array}$ & & & \multicolumn{2}{|c|}{$0,700,653,670,89$} \\
\hline & $\begin{array}{l}\text { 14. Se provee un entorno laboral adecuado para la aplicación } \\
\text { eficaz de las nuevas habilidades aprendidas en la formación. }\end{array}$ & & & \multicolumn{2}{|c|}{$0,470,403,520,93$} \\
\hline \multicolumn{2}{|c|}{$N$} & 192 & 192 & 192 & \\
\hline \multicolumn{2}{|c|}{ Eigenvalue (Valor próprio) } & 3,71 & 2,15 & 1,39 & \\
\hline \multicolumn{2}{|c|}{ \% da Variância Explicada $(P A F)$} & 22,29 & 10,98 & 6,53 & \\
\hline \multicolumn{2}{|c|}{ No. de itens } & 6 & 6 & 2 & \\
\hline \multicolumn{2}{|c|}{$\operatorname{Alfa}(\alpha)$} & 0,78 & 0,74 & 0,66 & \\
\hline \multirow{2}{*}{\multicolumn{2}{|c|}{ KMO }} & 0,77 & & & \\
\hline & \% da variância total explicada $(P C)$ & 59,47 & & & \\
\hline
\end{tabular}

Inicialmente, a $P C$ sugere uma estrutura empírica com 4 componentes que explicam, em conjunto, $59,47 \%$ da variância total das respostas dos participantes aos itens do questionário. Contudo, a análise dos valores próprios, variância explicada, scree plot (Figura 4) e análise paralela de Horn (Tabela 24) apontam para a possibilidade de uma solução com 3 fatores.

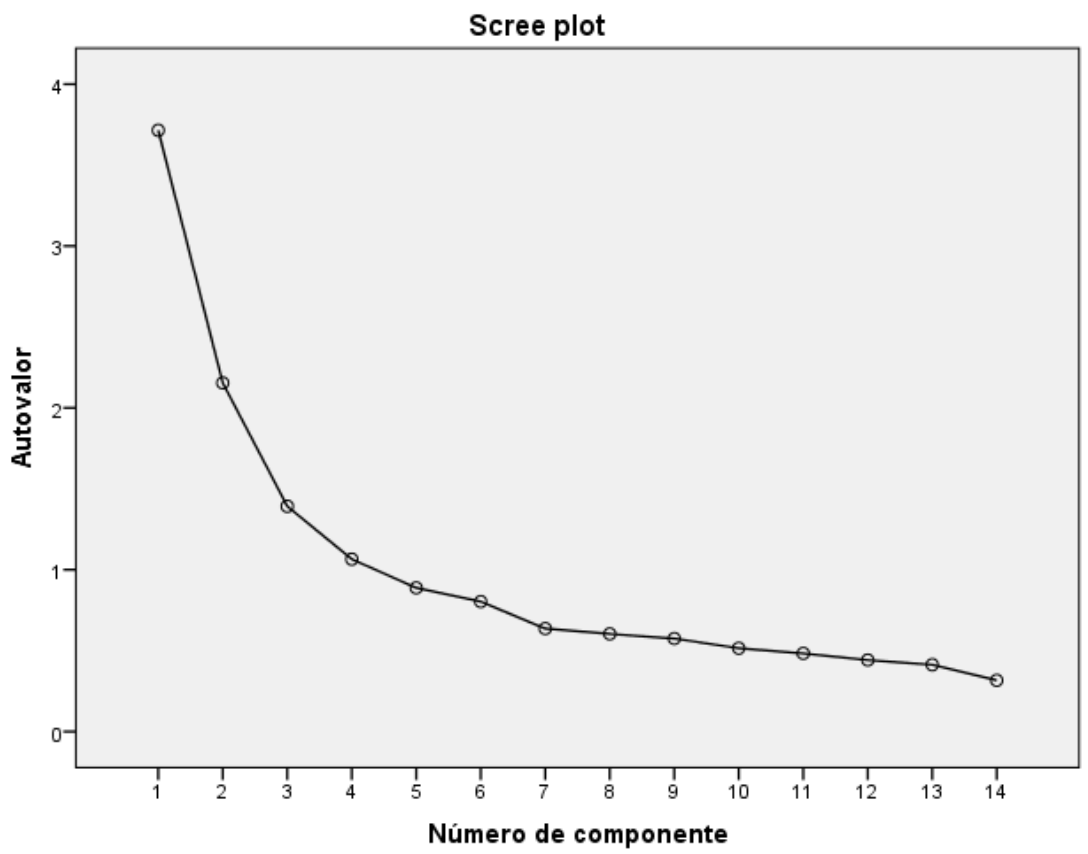

Figura 4. Distribuição dos valores próprios (scree plot) da escala de "Apoyo a la Transferencia". 
Tabela 24. Valores próprios empíricos e aleatórios dos primeiros dez componentes da escala de "Apoyo a la Transferencia".

\begin{tabular}{lcccccccccc}
\hline Valores & \multicolumn{10}{c}{ Componentes } \\
\cline { 2 - 11 } Próprios & 1 & 2 & 3 & 4 & 5 & 6 & 7 & 8 & 9 & 10 \\
\hline Empírico & $\mathbf{3 , 7 1}$ & $\mathbf{2 , 1 5}$ & $\mathbf{1 , 3 9}$ & 1,06 & 0,88 & 0,80 & 0,63 & 0,60 & 0,57 & 0,51 \\
\hline Aleatório & $\mathbf{1 , 4 8}$ & $\mathbf{1 , 3 6}$ & $\mathbf{1 , 2 7}$ & 1,19 & 1,13 & 1,06 & 1,01 & 0,95 & 0,89 & 0,84 \\
\hline
\end{tabular}

Notas: No. de itens (14); $N=192$

Com a fixação de 3 fatores por meio da $P A F$, obteve-se a seguinte configuração dos tipos de suporte presentes no instrumento: 1) Suporte de Supervisores (6 itens; $\alpha=0,78$; cargas fatoriais: 0,47 a 0,63 ); 2) Suporte de Pares (6 itens; $\alpha=0,74$; cargas fatoriais: 0,34 a 0,45) e 3) Suporte Material/da Organização (2 itens; $\alpha=0,66$; cargas fatoriais: 0,47 a 0,70). Esta estrutura empírica encontrada mostra-se bastante adequada tanto teórica como empiricamente e valida a adaptação feita no instrumento, na qual os tipos de suporte psicossocial (supervisores e pares) foram medidos separadamente, além do suporte material oferecido pela organização. Vale salientar que houve compartilhamento de cargas fatoriais entre os itens pertencentes ao fator 1 e 2 , ou seja, fatores referentes aos suportes psicossociais; porém, o tamanho das cargas fatoriais indicava que os primeiros 6 itens deveriam compor o primeiro fator (Suporte de Supervisores), e os 6 itens subsequentes - idênticos em conteúdo, mas relativos ao apoio dado pelos companheiros de trabalho -, ao segundo fator (Suporte de Pares). Igualmente, os itens do fator 3 tiveram cargas fatoriais compartilhadas com o primeiro fator, mas a decisão por mantê-los no terceiro justifica-se pela definição conceitual encontrada na literatura para esse tipo de suporte (material), bem como pelo tamanho das cargas fatoriais.

\subsection{Barreiras e facilitadores em EAD.}

Tabela 25. Estrutura empírica do instrumento de "Barreras y Facilitadores en la Enseñanza Virtual".

\begin{tabular}{|c|c|c|c|c|c|c|}
\hline \multirow{2}{*}{ Itens } & \multicolumn{3}{|c|}{ Cargas fatoriais } & \multirow{2}{*}{$h^{2}$} & \multirow{2}{*}{$M$} & \multirow{2}{*}{$D P$} \\
\hline & 1 & 2 & 3 & & & \\
\hline $\begin{array}{l}\text { 1. La promoción por parte del tutor de la interacción } \\
\text { social entre los participantes de la formación. }\end{array}$ & 0,41 & & & 0,24 & 2,11 & 0,99 \\
\hline $\begin{array}{l}\text { 2. El uso de los recursos Web (chats, correos } \\
\text { electrónicos, foros, etc.) para la comunicación con los } \\
\text { tutores y compañeros. }\end{array}$ & 0,42 & & & 0,28 & 1,76 & 1,00 \\
\hline $\begin{array}{l}\text { 3. La relación entre compañeros y tutores en cuanto al } \\
\text { proceso de aprendizaje durante la formación. }\end{array}$ & 0,53 & & & 0,45 & 1,93 & 0,98 \\
\hline 4. Las orientaciones proporcionadas por el tutor. & 0,52 & & & 0,34 & 1,76 & 0,92 \\
\hline 5. El apoyo técnico ofrecido por la institución. & & 0,43 & & 0,27 & 2,40 & 1,04 \\
\hline 6. La conexión a Internet. & & 0,34 & & 0,61 & 2,52 & 1,23 \\
\hline $\begin{array}{l}\text { 7. El acceso al entorno virtual de la formación con la } \\
\text { regularidad propuesta. }\end{array}$ & & 0,42 & & 0,47 & 2,29 & 1,13 \\
\hline 8. Los materiales didácticos de la formación. & & 0,33 & & 0,33 & 2,02 & 0,99 \\
\hline
\end{tabular}


Tabela 25. Estrutura empírica do instrumento de "Barreras y Facilitadores en la Enseñanza Virtual". (Continuação)

\begin{tabular}{|c|c|c|c|c|c|c|}
\hline \multirow{2}{*}{ Itens } & \multicolumn{3}{|c|}{ Cargas fatoriais } & \multirow{2}{*}{$h^{2}$} & \multirow{2}{*}{$M$} & \multirow{2}{*}{$D P$} \\
\hline & 1 & 2 & $\mathbf{3}$ & & & \\
\hline 9. Los gastos económicos asociados a las tecnologías y & & & & & & \\
\hline los materiales necesarios para la formación (acceso a & & & & 0,16 & 2,64 & 1,13 \\
\hline Internet, mantenimiento del ordenador, etc.). & & & & & & \\
\hline 10. La duración de la formación. & 0,43 & & & 0,18 & 2,32 & 1,03 \\
\hline 11. El contenido de la formación. & 0,52 & & & 0,29 & 2,24 & 0,95 \\
\hline $\begin{array}{l}\text { 12. Los recursos educativos utilizados (figuras, vídeos, } \\
\text { diapositivas, etc.). }\end{array}$ & 0,56 & & & 0,39 & 1,82 & 0,93 \\
\hline $\begin{array}{l}\text { 13. La cantidad de las actividades propuestas durante la } \\
\text { formación. }\end{array}$ & 0,52 & & & 0,39 & 2,61 & 1,18 \\
\hline $\begin{array}{l}\text { 14. La conciliación de la formación con las actividades } \\
\text { profesionales. }\end{array}$ & & $-0,33$ & & 0,47 & 2,51 & 1,19 \\
\hline $\begin{array}{l}\text { 15. La conciliación de la formación con los } \\
\text { compromisos de la familia. }\end{array}$ & & $-0,39$ & & 0,47 & 2,64 & 1,21 \\
\hline 16. El tiempo disponible para estudiar. & & $-0,50$ & & 0,47 & 3,21 & 1,16 \\
\hline $\begin{array}{l}\text { 17. La conciliación de la formación con otras } \\
\text { actividades de estudio. }\end{array}$ & & $-0,49$ & & 0,41 & 2,93 & 1,15 \\
\hline 18. Las condiciones del ambiente de estudio en casa. & & & $-0,39$ & 0,40 & 2,30 & 1,29 \\
\hline 19. Mi estado de salud durante la formación. & & & $-0,49$ & 0,46 & 1,98 & 1,16 \\
\hline $\begin{array}{l}\text { 20. La correspondencia entre la formación y las } \\
\text { expectativas personales. }\end{array}$ & & & $-0,41$ & 0,40 & 2,32 & 1,06 \\
\hline $\begin{array}{l}\text { 21. Las habilidades personales para organizar y } \\
\text { planificar las actividades de estudio. }\end{array}$ & & & $-0,41$ & 0,43 & 2,22 & 1,24 \\
\hline $\begin{array}{l}\text { 22. Las habilidades personales para utilizar los recursos } \\
\text { Web (chats, correos electrónicos, foros, etc.). }\end{array}$ & 0,50 & & & 0,26 & 1,82 & 1,13 \\
\hline N & 192 & 192 & 192 & & & \\
\hline Eigenvalue (Valor próprio) & 5,01 & 2,32 & 1,75 & & & \\
\hline \% da Variância Explicada $(P A F)$ & 19,75 & 7,64 & 5,25 & & & \\
\hline No. de itens & 9 & 8 & 4 & & & \\
\hline $\operatorname{Alfa}(\alpha)$ & 0,77 & 0,64 & 0,72 & & & \\
\hline KMO & 0,75 & & & & & \\
\hline \% da variância total explicada $(P C)$ & 59,08 & & & & & \\
\hline
\end{tabular}

A princípio, a $P C$ sugere uma estrutura empírica com 6 componentes que explicam, em conjunto, 59,08\% da variância total das respostas dos participantes aos itens do questionário. A partir da análise dos valores próprios, variância explicada e scree plot (Figura 5) verificou-se a possibilidade de uma solução com 3 ou 4 fatores para o instrumento. A análise paralela de Horn aponta para 4 fatores a serem mantidos na estrutura (Tabela 26). 


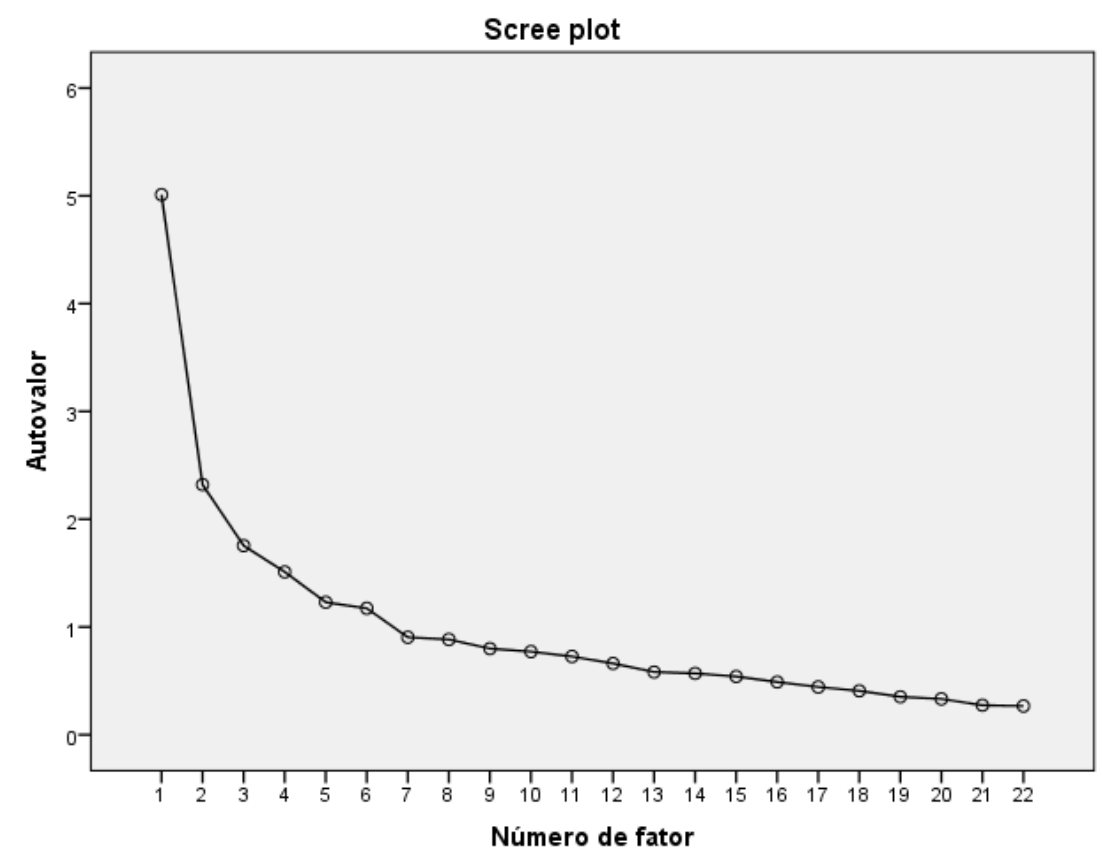

Figura 5. Distribuição dos valores próprios (scree plot) da escala de "Barreras y Facilitadores en la Enseñanza Virtual".

Tabela 26. Valores próprios empíricos e aleatórios dos primeiros dez componentes da escala de "Barreras y Facilitadores en la Enseñanza Virtual".

\begin{tabular}{|c|c|c|c|c|c|c|c|c|c|c|}
\hline \multirow{2}{*}{$\begin{array}{l}\text { Valores } \\
\text { Próprios }\end{array}$} & \multicolumn{10}{|c|}{ Componentes } \\
\hline & 1 & 2 & 3 & 4 & 5 & 6 & 7 & 8 & 9 & 10 \\
\hline Empírico & 5,01 & 2,32 & 1,75 & 1,51 & 1,22 & 1,17 & 0,90 & 0,88 & 0,79 & 0,77 \\
\hline Aleatório & 1,66 & 1,54 & 1,45 & 1,37 & 1,31 & 1,25 & 1,19 & 1,14 & 1,08 & 1,04 \\
\hline
\end{tabular}

Na solução com 3 fatores, os itens estariam agrupados da seguinte forma: 1) Desenho do curso e Interação social/Tutoria (9 itens: 1, 2, 3, 4, 10, 11, 12, 13 e 22; $\alpha=0,77$; cargas fatoriais: 0,41 a 0,56 ); 2) Condições pessoais e tempo disponíveis (8 itens: 5, 6, 7, 8, 14, 15, 16 e 17; $\alpha=0,64$; cargas fatoriais: $-0,33$ a -0,50); 3) Características do aluno (4 itens: 18, 19, 20 e 21; $\alpha=0,72$; cargas fatoriais: $-0,39$ a -0,49). O item 9 "Los gastos económicos asociados a las tecnologías y los materiales necesarios para la formación (acceso a Internet, mantenimiento del ordenador, etc.)" não permaneceu na solução encontrada. Houve compartilhamento de carga fatorial entre os itens 6, 7 e 8 e do 14 ao 21 (fator 1) com os dos demais fatores. A decisão por deixá-los pertencendo aos fatores 2 e 3 justifica-se pela similaridade de conteúdo, indicando o mesmo conjunto de aspectos avaliados, e/ou pelo tamanho das cargas fatoriais. 
A solução com 4 fatores também foi testada, mas os 3 itens $(3,6$ e 7) pertencentes ao quarto fator possuíam suas cargas fatoriais compartilhadas com os dos fatores 1 e 2 e a solução com 3 fatores mostrou-se mais apropriada teoricamente.

\subsection{Impacto do treinamento no trabalho.}

Tabela 27. Estrutura empírica do instrumento de "Impacto de la Formación en el Trabajo en Amplitud".

\begin{tabular}{|c|c|c|c|c|}
\hline Itens & $\begin{array}{c}\text { Cargas } \\
\text { fatoriais } \\
1 \\
\end{array}$ & $h^{2}$ & $M$ & $D P$ \\
\hline $\begin{array}{l}\text { 1. Aprovecho las oportunidades que tengo para practicar las nuevas } \\
\text { habilidades aprendidas. }\end{array}$ & 0,37 & 0,45 & 4,04 & 0,85 \\
\hline 2. Tengo un menor número de errores en el trabajo. & 0,64 & 0,71 & 3,62 & 0,81 \\
\hline 3. Realizo mi trabajo con más agilidad. & 0,76 & 0,79 & 3,73 & 0,77 \\
\hline 4. Ha mejorado la calidad de mi trabajo. & 0,75 & 0,78 & 3,86 & 0,84 \\
\hline 5. Ha aumentado mi motivación para trabajar. & 0,65 & 0,72 & 3,67 & 0,99 \\
\hline $\begin{array}{l}\text { 6. He sido capaz en mayor medida que antes de sugerir innovaciones } \\
\text { y cambios en mi trabajo. }\end{array}$ & 0,66 & 0,73 & 3,67 & 0,91 \\
\hline 7. Mis compañeros han aprendido de mis habilidades adquiridas. & 0,53 & 0,62 & 3,29 & 0,93 \\
\hline$N$ & 192 & & & \\
\hline Eigenvalue (Valor próprio) & 3,41 & & & \\
\hline \% da Variância Explicada $(P A F)$ & 41,0 & & & \\
\hline No. de itens & 7 & & & \\
\hline $\operatorname{Alfa}(\alpha)$ & 0,81 & & & \\
\hline KMO & 0,82 & & & \\
\hline \% da variância total explicada $(P C)$ & 48,78 & & & \\
\hline
\end{tabular}

A escala "Impacto de la Formación en el Trabajo en Amplitud" apresenta 7 itens, cujas cargas fatoriais variam entre 0,37 e 0,76 , em uma estrutura unifatorial $(\alpha=0,81)-\mathrm{o}$ fator único explica $41,0 \%$ da variância total das respostas aos itens do instrumento. Comparada à escala original, mantém as evidências de validade de construto, mas os índices são mais baixos: cargas fatoriais dos 12 itens variam entre 0,57 e 0,98, e o índice de consistência interna igual a 0,93 (Pilati \& Abbad, 2005).

\subsection{Estudo de Campo}

O estudo de campo foi realizado em uma organização brasileira do setor bancário, com uma amostra de funcionários que haviam participado do treinamento a distância "Eficiência Operacional" e seus gestores. Os dados obtidos dos 2201 e 2411 
respondentes $^{4}$, respectivamente, da auto (funcionários treinados) e heteroavaliação (superiores), foram analisados quantitativamente por meio das análises estatísticas previstas - os resultados são apresentados nas seções subsequentes.

Os dados demográficos e funcionais dos funcionários treinados e dos gestores podem ser visualizados, respectivamente, nas Tabelas 28 e 29.

Tabela 28. Perfil da amostra de funcionários participantes do curso Eficiência Operacional.

\begin{tabular}{|c|c|c|c|c|c|c|c|}
\hline \multicolumn{2}{|c|}{ Variável } & \multirow{3}{*}{$\begin{array}{c}\boldsymbol{F} \\
708\end{array}$} & \multirow{3}{*}{$\begin{array}{c}\% \\
43,2\end{array}$} & \multicolumn{2}{|c|}{ Variável } & \multirow{2}{*}{$\begin{array}{c}F \\
5\end{array}$} & \multirow{2}{*}{$\frac{\%}{0,2}$} \\
\hline \multirow{5}{*}{ Gênero } & Femining & & & \multirow{5}{*}{$\begin{array}{c}\text { Nível de } \\
\text { escolaridade }\end{array}$} & Ens. Fund. & & \\
\hline & \multirow{4}{*}{ Masculino } & & & & $\begin{array}{l}\text { Ensino } \\
\text { Médio }\end{array}$ & 235 & 10,7 \\
\hline & & \multirow{3}{*}{931} & \multirow{3}{*}{56,8} & & Graduação & 739 & 33,6 \\
\hline & & & & & & & \\
\hline & & & & & $\begin{array}{l}\text { Pós- } \\
\text { Graduação }\end{array}$ & 660 & 30,0 \\
\hline \multirow{5}{*}{$\begin{array}{l}\text { Idade } \\
\text { (anos) }\end{array}$} & 18 a 25 & 21 & 1,0 & \multirow{5}{*}{$\begin{array}{l}\text { Local de } \\
\text { trabalho } \\
\text { (Unidade) }\end{array}$} & Negócios & 678 & 30,8 \\
\hline & 26 a 35 & 400 & 18,2 & & Apoio & 831 & 37,8 \\
\hline & 36 a 45 & 469 & 21,3 & & Tática & 41 & 1,9 \\
\hline & 46 a 55 & 574 & 26,1 & & Estratégica & 82 & 3,7 \\
\hline & Mais de 56 & 174 & 7,9 & & Outro & 7 & 0,3 \\
\hline \multirow{5}{*}{ Formação } & Administração & 451 & 20,5 & \multirow{5}{*}{$\begin{array}{l}\text { Experiência na } \\
\text { função } \\
\text { (anos) }\end{array}$} & Menos de 1 & 108 & 4,9 \\
\hline & Direito & 170 & 7,7 & & 1 a 3 & 447 & 20,3 \\
\hline & Contabilidade & 129 & 5,9 & & 4 a 6 & 406 & 18,4 \\
\hline & Economia & 92 & 4,2 & & 7 a 9 & 269 & 12,2 \\
\hline & Outras* & 332 & 15,1 & & 10 ou mais & 408 & 18,5 \\
\hline
\end{tabular}

Notas: $N=1639 ; F=$ Frequência/\%=Porcentagem

Os funcionários participantes do curso Eficiência Operacional que responderam ao questionário demográfico-funcional $(N=1639)$ são, a maioria, do sexo masculino (56,8\%), encontra-se na faixa etária de 46 a 55 anos $(26,1 \%)$, trabalha na Unidade de Apoio aos Negócios e à Gestão (37,8\%), possui experiência na função de 1 a 3 anos (20,3\%), e com Graduação (33,6\%), predominantemente no curso de Administração $(20,5 \%)$. Dentre as outras formações acadêmicas $(15,1 \%)$ citadas pelos funcionários, encontram-se principalmente cursos de gestão (RH, empresarial, financeira), MBAs, bem

\footnotetext{
${ }^{4}$ Como o número de respostas obtidas varia de acordo com cada instrumento, indica-se nas tabelas ou como notas abaixo delas, o $N$ respectivo alcançado na avaliação. Não foram identificados outliers univariados em toda a amostra.
} 
como graduações em diferentes áreas de Humanas, Biológicas e Exatas (Letras, Marketing, Psicologia, Educação Física, Controladoria, Finanças, etc.).

Tabela 29. Perfil da amostra de gestores.

\begin{tabular}{|c|c|c|c|c|c|c|c|}
\hline \multicolumn{2}{|c|}{ Variável } & \multirow{2}{*}{$\begin{array}{c}\boldsymbol{F} \\
731\end{array}$} & \multirow{2}{*}{$\frac{\%}{32,3}$} & \multicolumn{2}{|c|}{ Variável } & \multirow{2}{*}{$\begin{array}{c}\boldsymbol{F} \\
2\end{array}$} & \multirow{2}{*}{$\begin{array}{c}\% \\
0,1\end{array}$} \\
\hline \multirow{4}{*}{ Gênero } & Feminino & & & \multirow{4}{*}{$\begin{array}{c}\text { Nível de } \\
\text { escolaridade }\end{array}$} & Ens. Fund. & & \\
\hline & \multirow{3}{*}{ Masculino } & \multirow{3}{*}{1530} & \multirow{3}{*}{67,7} & & $\begin{array}{l}\text { Ensino } \\
\text { Médio }\end{array}$ & 181 & 7,5 \\
\hline & & & & & Graduação & 817 & 33,9 \\
\hline & & & & & $\begin{array}{l}\text { Pós- } \\
\text { Graduação }\end{array}$ & 1264 & 52,4 \\
\hline \multirow{5}{*}{$\begin{array}{l}\text { Idade } \\
\text { (anos) }\end{array}$} & 18 a 25 & 7 & 0,3 & \multirow{5}{*}{$\begin{array}{l}\text { Local de } \\
\text { trabalho } \\
\text { (Unidade) }\end{array}$} & Negócios & 650 & 27,0 \\
\hline & 26 a 35 & 326 & 13,5 & & Apoio & 1425 & 59,1 \\
\hline & 36 a 45 & 672 & 27,9 & & Tática & 88 & 3,6 \\
\hline & 46 a 55 & 1005 & 41,7 & & Estratégica & 97 & 4,0 \\
\hline & Mais de 56 & 255 & 10,6 & & Outro & 3 & 0,1 \\
\hline \multirow{5}{*}{ Formação } & Administração & 834 & 34,6 & \multirow{5}{*}{$\begin{array}{l}\text { Experiência } \\
\text { na função } \\
\text { (anos) }\end{array}$} & Menos de 1 & 63 & 2,6 \\
\hline & Direito & 261 & 10,8 & & 1 a 3 & 662 & 27,5 \\
\hline & Contabilidade & 191 & 7,9 & & 4 a 6 & 567 & 23,5 \\
\hline & Economia & 139 & 5,8 & & 7 a 9 & 404 & 16,8 \\
\hline & Outras* & 374 & 15,5 & & 10 ou mais & 567 & 23,5 \\
\hline
\end{tabular}

Notas: $N=2261 ; F=$ Frequência/\%=Porcentagem

Os gestores que responderam ao questionário demográfico-funcional ( $N=2261)$ são, a maioria, do sexo masculino (67,7\%), encontra-se na faixa etária de 46 a 55 anos (41,7\%), trabalha na Unidade de Apoio aos Negócios e à Gestão (59,1\%), possui experiência na função de 1 a 3 anos $(27,5 \%)$, com Pós-Graduação $(52,4 \%)$ e formação acadêmica no curso de Administração (34,6\%). Dentre as outras formações acadêmicas $(15,5 \%)$ citadas pelos gestores, estão majoritariamente os cursos de gestão, como por exemplo: de pessoas, empresarial, pública, financeira, bancária, processos/projetos, negócios, estratégica; MBAs; além de graduações em diferentes áreas de Humanas, Biológicas e Exatas (História, Logística, Marketing, Psicologia, Controladoria, Finanças, etc.).

Similarmente ao exposto anteriormente, as estatísticas descritivas referentes à amostra de participantes do estudo de campo principal auxiliam na exploração inicial dos resultados obtidos, possibilitando um melhor entendimento de como se comportam e subsidiam a interpretação dos demais achados, tratados mediante análises mais complexas, conforme expõe-se e discute-se nas seções subsequentes. 


\subsubsection{Análises estatísticas dos instrumentos de medida (português).}

\subsubsection{Análises descritivas.}

\subsection{Estratégias de aprendizagem.}

Os resultados descritivos dos 20 itens do instrumento de "Estratégias de Aprendizagem" associados a uma escala de frequência de comportamento que varia de 1 ("Nunca") a 5 ("Sempre”) podem ser visualizados na Tabela 30.

Tabela 30. Resultados descritivos do instrumento de "Estratégias de Aprendizagem" no curso Eficiência Operacional.

\begin{tabular}{|c|c|c|c|c|c|c|c|c|}
\hline \multirow{2}{*}{ Itens } & \multirow{2}{*}{\multicolumn{2}{|c|}{$\frac{\mathrm{N}}{\text { VálidoAusente }}$}} & \multirow{2}{*}{ Média } & \multicolumn{2}{|c|}{ Desvio Moda } & \multicolumn{3}{|c|}{$\begin{array}{l}\text { Concentração de } \\
\text { Respostas }(\%) *\end{array}$} \\
\hline & & & & Padrão & & $1-2$ & 3 & $4-5$ \\
\hline $\begin{array}{l}\text { 1. Mantive a calma quando tive dificuldades } \\
\text { durante o curso. }\end{array}$ & 2010 & 191 & 4,55 & 0,63 & 5 & 0,8 & 4,0 & 86,5 \\
\hline $\begin{array}{l}\text { 6. Esforcei-me para verificar minha } \\
\text { compreensão sobre o que estava sendo } \\
\text { ensinado. }\end{array}$ & 1987 & 214 & 4,42 & 0,71 & 5 & 1,7 & 5,9 & 82,7 \\
\hline $\begin{array}{l}\text { 4. Esforcei-me mais quando percebi que estava } \\
\text { perdendo a concentração. }\end{array}$ & 1943 & 258 & 4,39 & 0,76 & 5 & 2,0 & 7,2 & 79,1 \\
\hline $\begin{array}{l}\text { 12. Realizei os exercícios práticos propostos ao } \\
\text { longo do curso para me ajudar a aprender. }\end{array}$ & 1979 & 222 & 4,36 & 0,83 & 5 & 3,2 & 8,5 & 78,2 \\
\hline $\begin{array}{l}\text { 19. Associei os conteúdos do curso aos meus } \\
\text { conhecimentos anteriores. }\end{array}$ & 1974 & 227 & 4,29 & 0,75 & 5 & 1,9 & 9,8 & 78,0 \\
\hline $\begin{array}{l}\text { 3. Mantive a calma diante dos erros que cometi } \\
\text { ao realizar atividades do curso. }\end{array}$ & 1983 & 218 & 4,29 & 0,76 & 5 & 1,8 & 11,0 & 77,4 \\
\hline $\begin{array}{l}\text { 5. Esforcei-me mais quando percebi que estava } \\
\text { perdendo o interesse no assunto. }\end{array}$ & 1889 & 312 & 4,21 & 0,86 & 5 & 4,0 & 10,0 & 71,8 \\
\hline $\begin{array}{l}\text { 2. Mantive a calma com a possibilidade de ter } \\
\text { um rendimento abaixo do esperado. }\end{array}$ & 1957 & 244 & 4,17 & 0,91 & 5 & 4,4 & 12,6 & 72,0 \\
\hline $\begin{array}{l}\text { 17. Identifiquei situações diárias em que eu } \\
\text { pudesse aplicar os conteúdos do curso. }\end{array}$ & 1970 & 231 & 4,15 & 0,81 & 4 & 2,7 & 14,0 & 72,8 \\
\hline $\begin{array}{l}\text { 16. Refleti sobre as implicações que os } \\
\text { conteúdos aprendidos poderiam ter. }\end{array}$ & 1977 & 224 & 4,13 & 0,84 & 4 & 3,3 & 14,1 & 72,4 \\
\hline $\begin{array}{l}\text { 9. Busquei compreender melhor os conteúdos } \\
\text { ao estudá-los nos materiais didáticos do curso. }\end{array}$ & 1955 & 246 & 4,13 & 0,94 & 4 & 5,1 & 12,0 & 71,7 \\
\hline $\begin{array}{l}\text { 18. Busquei desenvolver uma ideia global sobre } \\
\text { como os conteúdos do curso se relacionavam } \\
\text { entre si. }\end{array}$ & 1959 & 242 & 4,08 & 0,85 & 4 & 4,0 & 14,6 & 70,5 \\
\hline $\begin{array}{l}\text { 8. Busquei solucionar minhas dúvidas ao } \\
\text { consultar os materiais didáticos do curso. }\end{array}$ & 1948 & 253 & 4,02 & 1,04 & 5 & 7,9 & 13,3 & 67,2 \\
\hline $\begin{array}{l}\text { 20. Revisei os conteúdos relativos aos } \\
\text { exercícios em que cometi erros. }\end{array}$ & 1948 & 253 & 3,88 & 1,04 & 4 & 9,3 & 17,3 & 61,8 \\
\hline $\begin{array}{l}\text { 11. Tentei entender o conteúdo ao aplicá-lo na } \\
\text { prática, ao invés de dedicar tempo lendo ou } \\
\text { pedindo ajuda a alguém. }\end{array}$ & 1929 & 272 & 3,83 & 1,02 & 4 & 8,7 & 18,9 & 60,0 \\
\hline $\begin{array}{l}\text { 14. Repeti mentalmente os conteúdos do curso } \\
\text { que gostaria de aprender até perceber que havia } \\
\text { entendido. }\end{array}$ & 1936 & 265 & 3,44 & 1,13 & 4 & 16,5 & 26,7 & 44,9 \\
\hline $\begin{array}{l}\text { 13. Li o conteúdo do curso várias vezes como } \\
\text { método para aprender. }\end{array}$ & 1941 & 260 & 3,35 & 1,12 & 4 & 18,9 & 27,0 & 42,2 \\
\hline
\end{tabular}


Tabela 30. Resultados descritivos do instrumento de "Estratégias de Aprendizagem" no curso Eficiência Operacional. (Continuação)

\begin{tabular}{|c|c|c|c|c|c|c|c|c|}
\hline \multirow[t]{2}{*}{ Itens } & \multirow{2}{*}{\multicolumn{2}{|c|}{$\frac{\mathrm{N}}{\text { VálidoAusente }}$}} & \multirow{2}{*}{-Média } & \multicolumn{2}{|c|}{ Desvio Moda } & \multicolumn{3}{|c|}{$\begin{array}{c}\text { Concentração de } \\
\text { Respostas (\%)* }\end{array}$} \\
\hline & & & & Padrão & & $1-2$ & 3 & $4-5$ \\
\hline $\begin{array}{l}\text { 15. Fiz anotações, resumos e/ou esquemas dos } \\
\text { conteúdos do curso como método para } \\
\text { aprender. }\end{array}$ & 1951 & 250 & 3,22 & 1,32 & 4 & 27,0 & 20,0 & 41,6 \\
\hline $\begin{array}{l}\text { 7. Busquei auxílio de colegas para esclarecer } \\
\text { minhas dúvidas sobre os conteúdos do curso. }\end{array}$ & 1896 & 305 & 2,93 & 1,35 & 3 & 33,0 & 21,2 & 31,9 \\
\hline $\begin{array}{l}\text { relacionadas ao curso para me ajudar a } \\
\text { aprender. }\end{array}$ & 1927 & 274 & 2,82 & 1,31 & 3 & 36,2 & 22,6 & 28,8 \\
\hline
\end{tabular}

A média de uso das estratégias de aprendizagem descrita nos itens teve uma variação de 2,82 a 4,55. Dos 20 itens presentes no questionário, 18 apresentaram maior concentração de respostas nos pontos mais altos da escala (entre $41,6 \%$ e $86,5 \%$ ) e apenas 2 concentraram-se nos pontos mais baixos $(33,0 \%$ e 36,2\%). Os valores da moda também são diversificados, obtendo pontuações que passam por 3, 4 e 5. As discrepâncias observadas nas concentrações de respostas, valores das modas, médias e desvios-padrão, podem sugerir o padrão e a frequência diferenciados de uso das estratégias de aprendizagem pelos participantes.

Os 8 itens que apresentaram as médias mais altas, com valores de moda iguais a 5, foram: $1(M=4,55$ e $D P=0,63), 6(M=4,42$ e $D P=0,71), 4(M=4,39$ e $D P=0,76), 12$ $(M=4,36$ e $D P=0,83), 19(M=4,29$ e $D P=0,75), 3(M=4,29$ e $D P=0,76), 5(M=4,21$ e $D P=0,86), 2(M=4,17$ e $D P=0,91)$. Esse conjunto de itens contém estratégias autorregulatórias (controle da emoção e controle da motivação), cognitiva (elaboração) e comportamental (aplicação prática), segundo classificação proposta por Warr e Allan (1998).

Já os 2 itens que apresentaram as médias mais baixas foram: $7(M=2,93 \mathrm{e}$ $D P=1,35)$ e $10(M=2,82$ e $D P=1,31)$. Tais itens representam estratégias comportamentais, respectivamente, de busca de ajuda interpessoal e busca de ajuda ao material didático.

De acordo com os resultados sobre a frequência de uso das estratégias de aprendizagem, o curso estimulou a adoção principalmente de procedimentos autorregulatórios de controle da emoção e da motivação, que preveem o controle da ansiedade, motivação e atenção, bem como a prevenção de dispersões de concentração durante os estudos. O uso de processos autorregulatórios parece ser bastante adequado no estudo autoinstrucional a distância: estudar no ambiente de trabalho pode demandar maior 
esforço, exigir atenção concentrada e automonitoramento da aprendizagem; ademais, requer habilidades para conciliar o trabalho com o estudo e, além disso, as metas de desempenho com as necessidades de aprendizagem.

Em seguida, foram mais frequentemente usadas as estratégias de elaboração e de aplicação prática que requerem, respectivamente, a avaliação e reflexão sobre possíveis implicações e conexões entre o material aprendido e o conhecimento já existente, e a busca por aprimorar o conhecimento por meio da aplicação, em situações de trabalho, do que foi aprendido. Tais estratégias são compatíveis à amostra de participantes que são trabalhadores, pois estes tentam, ao adquirir novos conhecimentos, relacioná-los aos já obtidos e também perceber a utilidade e a aplicabilidade que terão nas atividades práticas laborais diárias.

As estratégias de aprendizagem menos utilizadas foram as estratégias comportamentais de busca de ajuda interpessoal e busca de ajuda ao material didático. $\mathrm{O}$ curso autoinstrucional a distância parece não oferecer ferramentas de interação para que os participantes interatuem durante o curso, explicando a baixa frequência de uso dessa estratégia que representa um comportamento proativo do indivíduo de solicitar auxílio a outras pessoas para tirar dúvidas sobre os conteúdos presentes no material, ao invés de utilizar apenas as informações do próprio procedimento instrucional.

E os participantes tampouco pesquisam em outras fontes de informação - sites na internet, documentos escritos, manuais de instruções, programas de computador e outras fontes, diferentes das disponibilizadas no curso, que não envolvam contato social conteúdos similares aos do curso como auxiliares no aprendizado. Isso pode apontar que o material didático disponível é suficiente para solucionar possíveis dúvidas que surjam no decorrer da instrução e que o nível de complexidade do curso não demanda maiores explicações advindas de outros participantes, nem de outros materiais.

\subsection{Reação aos procedimentos instrucionais.}

Os resultados descritivos dos 9 itens do instrumento de "Reação aos Procedimentos Instrucionais" associados a uma escala de qualidade que varia de 1 ("Péssima") a 5 ("Excelente") podem ser visualizados na Tabela 31. 
Tabela 31. Resultados descritivos do instrumento de "Reação aos Procedimentos Instrucionais" no curso Eficiência Operacional.

\begin{tabular}{|c|c|c|c|c|c|c|c|c|}
\hline \multirow[t]{2}{*}{ Itens } & \multicolumn{2}{|c|}{$\mathbf{N}$} & \multirow{2}{*}{ Média } & \multicolumn{2}{|c|}{ Desvio Moda } & \multicolumn{3}{|c|}{$\begin{array}{l}\text { Concentração de } \\
\text { Respostas (\%)* }\end{array}$} \\
\hline & Válido & usente & & Padrão & & $1-2$ & 3 & $4-5$ \\
\hline 4. Linguagem utilizada no material do curso. & 1898 & 303 & 4,30 & 0,63 & 4 & 0,8 & 5,2 & 80,3 \\
\hline $\begin{array}{l}\text { 3. Sequência de apresentação do conteúdo } \\
\text { do curso. }\end{array}$ & 1896 & 305 & 4,20 & 0,64 & 4 & 0,9 & 7,6 & 77,7 \\
\hline $\begin{array}{l}\text { 1. Correspondência entre o conteúdo } \\
\text { proposto e os objetivos do curso. }\end{array}$ & 1903 & 298 & 4,20 & 0,61 & 4 & 0,4 & 7,3 & $\mathbf{7 8 , 8}$ \\
\hline $\begin{array}{l}\text { 8. Conteúdos disponibilizados em cada } \\
\text { unidade. }\end{array}$ & 1871 & 330 & 4,15 & 0,64 & 4 & 0,8 & 8,7 & 75,5 \\
\hline $\begin{array}{l}\text { 2. Correspondência entre o conteúdo do } \\
\text { curso e os seus objetivos pessoais. }\end{array}$ & 1900 & 301 & 4,11 & 0,68 & 4 & 1,3 & 11,2 & 73,8 \\
\hline $\begin{array}{l}\text { 6. Atividades/tarefas propostas ao final de } \\
\text { cada unidade. }\end{array}$ & 1875 & 326 & 4,09 & 0,68 & 4 & 1,3 & 10,9 & 73,0 \\
\hline $\begin{array}{l}\text { 5. Novidades, lembretes e links divulgados } \\
\text { no ambiente virtual do curso. }\end{array}$ & 1848 & 353 & 4,07 & 0,71 & 4 & 1,5 & 12,9 & 69,5 \\
\hline 9. Horas de estudo sugeridas para o curso. & 1882 & 319 & 4,01 & 0,79 & 4 & 3,3 & 14,0 & 68,2 \\
\hline $\begin{array}{l}\text { 7. Orientação para solução de erros nas } \\
\text { atividades/tarefas. }\end{array}$ & 1835 & 366 & 3,99 & 0,73 & 4 & 2,5 & 14,2 & 66,7 \\
\hline
\end{tabular}

Nota: *1-2 (péssima/ruim), 3 (regular), 4-5 (boa/excelente)

De forma geral, observa-se que os participantes julgaram que a qualidade dos procedimentos instrucionais utilizados ao longo do curso é boa, uma vez que as médias variam entre 3,99 e 4,30, estando satisfeitos com os procedimentos adotados. Como os valores dos desvios-padrão foram baixos, pode-se considerar que houve concordância de opiniões entre os respondentes quanto aos aspectos avaliados. Todos os itens apresentaram concentração de respostas superior a $65 \%$ nos pontos mais altos da escala e valor de moda igual a 4 .

Os itens $4(M=4,30$ e $D P=0,63), 3(M=4,20$ e $D P=0,64)$ e $1(M=4,20$ e $D P=0,61)$ receberam as melhores avaliações pelos treinados, com concentração de respostas superior a 77\% nos pontos 4-5 na escala, indicando estarem satisfeitos com a linguagem utilizada no material do curso, a sequência de apresentação do conteúdo e a correspondência entre o conteúdo proposto e os objetivos do curso. Os itens $9(M=4,01 \mathrm{e}$ $D P=0,79)$ e $7(M=3,99$ e $D P=0,73)$ receberam avaliações um pouco mais baixas, tendo obtido concentração de respostas, respectivamente, de $68,2 \%$ e $66,7 \%$ nos pontos mais altos da escala, mostrando que os participantes, apesar de um pouco menos, também julgaram bem a quantidade de horas sugeridas para a realização do curso e a orientação para solução de erros nas atividades/tarefas.

\subsection{Suporte à transferência.}


Os resultados descritivos dos 6 itens, respectivamente, referentes ao suporte oferecido por "Supervisores" e "Colegas", seguidos dos 2 itens que tratam do apoio material dado pela organização que compõem o instrumento "Suporte à Transferência" estão associados a uma escala de frequência que varia de 1 ("Nunca") a 5 ("Sempre") podem ser visualizados nas Tabelas 32, 33 e 34 .

Tabela 32. Resultados descritivos dos itens referentes ao apoio dos supervisores do instrumento de "Suporte à Transferência" no curso Eficiência Operacional.

\begin{tabular}{|c|c|c|c|c|c|c|c|c|}
\hline \multirow{2}{*}{ Itens } & \multicolumn{2}{|c|}{$\mathbf{N}$} & \multirow{2}{*}{ Média } & \multicolumn{2}{|c|}{${ }^{\text {Desvio }}$ Moda } & \multicolumn{3}{|c|}{$\begin{array}{l}\text { Concentração de } \\
\text { Respostas (\%)* }\end{array}$} \\
\hline & \multicolumn{2}{|c|}{ VálidoAusente } & & \multicolumn{2}{|c|}{ Padrão } & $1-2$ & 3 & $4-5$ \\
\hline $\begin{array}{l}\text { 1. Encorajam a aplicação no trabalho de novas } \\
\text { habilidades aprendidas em treinamento. }\end{array}$ & 1526 & 675 & 3,94 & 1,01 & 4 & 5,6 & 14,2 & 49,6 \\
\hline $\begin{array}{l}\text { 2. Fornecem as informações necessárias ao uso } \\
\text { eficaz das novas habilidades aprendidas em } \\
\text { treinamento. }\end{array}$ & 1520 & 681 & 3,86 & 1,0 & 4 & 6,2 & 15,4 & 47,5 \\
\hline $\begin{array}{l}\text { 3. Removem as dificuldades ao uso eficaz das } \\
\text { novas habilidades aprendidas em treinamento. } \\
\text { 6. Consideram minhas sugestões, em relação }\end{array}$ & 1502 & 699 & 3,79 & 0,99 & 4 & 6,3 & 16,4 & 45,5 \\
\hline $\begin{array}{l}\text { ao que foi aprendido no treinamento, no } \\
\text { ambiente de trabalho. }\end{array}$ & 1512 & 689 & 3,74 & 1,03 & 4 & 7,7 & 16,5 & 44,6 \\
\hline $\begin{array}{l}\text { 4. Criam oportunidades de utilizar no trabalho } \\
\text { as novas habilidades aprendidas em } \\
\text { treinamento. }\end{array}$ & 1497 & 704 & 3,74 & 1,02 & 4 & 7,0 & 18,3 & 42,8 \\
\hline $\begin{array}{l}\text { 5. Fornecem feedback quanto à aplicação no } \\
\text { trabalho das novas habilidades adquiridas em } \\
\text { treinamento. }\end{array}$ & 1506 & 695 & 3,62 & 1,12 & 4 & 11,0 & 16,6 & 40,7 \\
\hline
\end{tabular}

Nota: * 1-2 (nunca/raramente), 3 (às vezes), 4-5 (frequentemente/sempre)

Tabela 33. Resultados descritivos dos itens referentes ao apoio dos colegas do instrumento de "Suporte à Transferência" no curso Eficiência Operacional.

\begin{tabular}{|c|c|c|c|c|c|c|c|c|}
\hline \multirow[t]{2}{*}{ Itens } & \multirow{2}{*}{\multicolumn{2}{|c|}{$\frac{\mathrm{N}}{\text { VálidoAusente }}$}} & \multirow{2}{*}{ Média } & \multicolumn{2}{|c|}{ Desvio Moda } & \multicolumn{3}{|c|}{$\begin{array}{l}\text { Concentração de } \\
\text { Respostas (\%)* }\end{array}$} \\
\hline & & & & Padrão & & $1-2$ & 3 & $4-5$ \\
\hline $\begin{array}{l}\text { 1. Encorajam a aplicação no trabalho de novas } \\
\text { habilidades aprendidas em treinamento. } \\
\text { 6. Consideram minhas sugestões, em relação }\end{array}$ & 1503 & 698 & 3,70 & 1,02 & 4 & 7,4 & 19,5 & 41,5 \\
\hline $\begin{array}{l}\text { ao que foi aprendido no treinamento, no } \\
\text { ambiente de trabalho. }\end{array}$ & 1493 & 708 & 3,68 & 0,98 & 4 & 6,9 & 19,5 & 41,4 \\
\hline $\begin{array}{l}\text { 2. Fornecem as informações necessárias ao uso } \\
\text { eficaz das novas habilidades aprendidas em } \\
\text { treinamento. }\end{array}$ & 1495 & 706 & 3,66 & 0,99 & 4 & 7,4 & 19,4 & 41,1 \\
\hline $\begin{array}{l}\text { 3. Removem as dificuldades ao uso eficaz das } \\
\text { novas habilidades aprendidas em treinamento. } \\
\text { 4. Criam oportunidades de utilizar no trabalho }\end{array}$ & 1474 & 727 & 3,63 & 0,96 & 4 & 7,2 & 20,1 & 39,6 \\
\hline $\begin{array}{l}\text { as novas habilidades aprendidas em } \\
\text { treinamento. }\end{array}$ & 1470 & 731 & 3,58 & 1,0 & 4 & 8,0 & 21,2 & 37,5 \\
\hline $\begin{array}{l}\text { 5. Fornecem feedback quanto à aplicação no } \\
\text { trabalho das novas habilidades adquiridas em } \\
\text { treinamento. }\end{array}$ & 1486 & 715 & 3,42 & 1,08 & 4 & 12,0 & 21,8 & 33,6 \\
\hline
\end{tabular}

Nota: * 1-2 (nunca/raramente), 3 (às vezes), 4-5 (frequentemente/sempre) 
Tabela 34. Resultados descritivos dos itens referentes ao apoio material do instrumento de "Suporte à Transferência" no curso Eficiência Operacional.

\begin{tabular}{|c|c|c|c|c|c|c|c|c|}
\hline \multirow[t]{2}{*}{ Itens } & \multirow{2}{*}{\multicolumn{2}{|c|}{$\frac{\mathrm{N}}{\text { VálidoAusente }}$}} & \multirow{2}{*}{ eMédia } & \multicolumn{2}{|c|}{ Desvio Moda } & \multicolumn{3}{|c|}{$\begin{array}{l}\text { Concentração de } \\
\text { Respostas }(\%)^{*}\end{array}$} \\
\hline & & & & Padrão & & 1-2 & 3 & $4-5$ \\
\hline $\begin{array}{l}\text { 7. São fornecidos os recursos materiais } \\
\text { necessários para a aplicação eficaz das novas } \\
\text { habilidades aprendidas em treinamento. } \\
\text { 8. É disponibilizado local de trabalho adequado à } \\
\text { aplicação eficaz das novas habilidades aprendidas } \\
\text { em treinamento (por exemplo, espaço físico, } \\
\text { iluminação, mobiliário, nível de ruído). }\end{array}$ & 1448 & 753 & 3,70 & 0,89 & 4 & 4,8 & 17,7 & 40,7 \\
\hline
\end{tabular}

A frequência com que supervisores, colegas e organização oferecem os apoios descritos nos itens aos funcionários treinados não variaram muito entre si, estando todos concentrados nos pontos mais altos da escala e as médias foram de 3,62 a 3,94 (supervisores), 3,42 a 3,70 (colegas) e 3,70 a 3,77 (material). Os valores de moda iguais a 4 indicam que os participantes julgam que os apoios estão frequentemente presentes. Não há discrepância tampouco entre os diferentes tipos de suporte psicossocial (supervisores x colegas), com médias bastante semelhantes e próximas.

Comparando os suportes dos supervisores e colegas, o item 1 "Encorajam a aplicação no trabalho de novas habilidades aprendidas em treinamento" apresentou a maior média em ambos os casos $(M=3,94$ e $D P=1,01 ; M=3,70$ e $D P=1,02)$, indicando que o apoio de supervisores e pares no incentivo ao uso no trabalho das novas competências desenvolvidas em treinamento é feito de maneira igualmente frequente. Da mesma forma, os itens 4 "Criam oportunidades de utilizar no trabalho as novas habilidades aprendidas em treinamento" e 5 "Fornecem feedback quanto à aplicação no trabalho das novas habilidades adquiridas em treinamento" apresentaram as menores médias, ou seja, são os apoios menos frequentemente percebidos pelos funcionários tanto advindos de seus supervisores, como de seus companheiros.

\subsection{Barreiras e facilitadores em EAD.}

Os resultados descritivos dos 18 itens do instrumento de "Barreiras e Facilitadores em EAD" associados a uma escala de comportamento que varia de 1 ("Não dificultou o desempenho") a 5 ("Dificultou totalmente o desempenho") podem ser visualizados na Tabela 35 . 
Tabela 35. Resultados descritivos do instrumento de "Barreiras e Facilitadores em EAD" no curso Eficiência Operacional.

\begin{tabular}{|c|c|c|c|c|c|c|c|c|}
\hline \multirow[t]{2}{*}{ Itens } & \multirow{2}{*}{\multicolumn{2}{|c|}{$\frac{\mathrm{N}}{\text { VálidoAusente }}$}} & \multirow{2}{*}{ Média } & \multicolumn{2}{|c|}{ Desvio Moda } & \multicolumn{3}{|c|}{$\begin{array}{l}\text { Concentração de } \\
\text { Respostas (\%)* }\end{array}$} \\
\hline & & & & Padrão & & 1-2 & 3 & 4-5 \\
\hline $\begin{array}{l}\text { 10. Conciliação do curso com as atividades } \\
\text { profissionais. }\end{array}$ & 1755 & 446 & 2,43 & 1,34 & 1 & 44,9 & 14,2 & 20,6 \\
\hline 12. Tempo disponível para estudar. & 1749 & 452 & 2,40 & 1,28 & 1 & 46,1 & 14,9 & 18,4 \\
\hline 2. Conexão à internet. & 1768 & 433 & 2,28 & 1,35 & 1 & 49,7 & 12,6 & 18,0 \\
\hline 14. Condições do ambiente de estudo em casa. & 1422 & 779 & 2,17 & 1,37 & 1 & 42,6 & 7,6 & 14,4 \\
\hline $\begin{array}{l}\text { 3. Acesso ao ambiente virtual do curso com a } \\
\text { regularidade proposta. }\end{array}$ & 1769 & 432 & 2,16 & 1,32 & 1 & 52,5 & 11,3 & 16,6 \\
\hline $\begin{array}{l}\text { 13. Conciliação do curso com outras atividades } \\
\text { de estudo. }\end{array}$ & 1668 & 533 & 2,13 & 1,29 & 1 & $\mathbf{5 0 , 5}$ & 10,0 & 15,3 \\
\hline 1. Suporte técnico oferecido pela instituição. & 1630 & 571 & 2,05 & 1,30 & 1 & 50,4 & 9,8 & 13,8 \\
\hline 6. Duração do curso. & 1768 & 433 & 2,00 & 1,32 & 1 & 57,6 & 7,9 & 14,8 \\
\hline $\begin{array}{l}\text { 16. Correspondência do curso às expectativas } \\
\text { pessoais. }\end{array}$ & 1681 & 520 & 1,99 & 1,32 & 1 & 54,7 & 6,9 & 14,7 \\
\hline $\begin{array}{l}\text { 11. Conciliação do curso com os compromissos } \\
\text { familiares. }\end{array}$ & 1667 & 534 & 1,97 & 1,31 & 1 & 54,3 & 7,1 & 14,2 \\
\hline $\begin{array}{l}\text { 17. Habilidades pessoais de organização e } \\
\text { planejamento de atividades de estudo. }\end{array}$ & 1715 & 486 & 1,97 & 1,35 & 1 & 56,7 & 5,9 & 15,2 \\
\hline $\begin{array}{l}\text { 18. Habilidades pessoais para uso das } \\
\text { ferramentas web (e-mails, fóruns, etc). }\end{array}$ & 1703 & 498 & 1,97 & 1,37 & 1 & 56,0 & 5,7 & 15,6 \\
\hline 4. Material didático do curso. & 1754 & 447 & 1,96 & 1,34 & 1 & 58,3 & 6,1 & 15,3 \\
\hline $\begin{array}{l}\text { 9. Quantidade das atividades propostas durante o } \\
\text { curso. }\end{array}$ & 1767 & 434 & 1,96 & 1,32 & 1 & 59,1 & 6,0 & 15,2 \\
\hline $\begin{array}{l}\text { 8. Recursos de ensino utilizados (figuras, vídeos, } \\
\text { slides, etc). }\end{array}$ & 1755 & 446 & 1,94 & 1,35 & 1 & $\mathbf{5 8 , 9}$ & 5,1 & 15,7 \\
\hline $\begin{array}{l}\text { 5. Custos financeiros associados às tecnologias e } \\
\text { materiais necessários durante o curso (acesso à } \\
\text { internet, manutenção do computador, etc). }\end{array}$ & 1528 & 673 & 1,94 & 1,36 & 1 & 50,3 & 5,7 & 13,5 \\
\hline 7. Conteúdo do curso. & 1762 & 439 & 1,93 & 1,34 & 1 & 59,4 & 5,3 & 15,3 \\
\hline $\begin{array}{l}\text { 15. Condições de saúde no período de realização } \\
\text { do curso. }\end{array}$ & 1627 & 574 & 1,91 & 1,39 & 1 & 54,4 & 4,6 & 14,9 \\
\hline
\end{tabular}

Nota: *1-2 (não dificultou o desempenho/dificultou pouco), 3 (dificultou moderadamente), 4-5 (dificultou muito/dificultou totalmente o desempenho)

De forma geral, observa-se que a maioria dos treinados não considerou os aspectos descritos como fatores que dificultaram o seu desempenho, ou seja, atuaram como barreiras durante o curso, uma vez que todos os itens apresentam uma concentração de respostas nos pontos mais baixos da escala; os valores de médias variaram de 1,91 a 2,43, indicando pouca dificuldade encontrada; e os de moda, iguais a 1. Apesar disso, vale ressaltar que o desvio-padrão foi um pouco mais alto nos itens, o que indica certa heterogeneidade de respostas entre os respondentes.

Os itens $10(M=2,43$ e $D P=1,34)$ e $12(M=2,40$ e $D P=1,28)$, com as médias mais altas, tratam do tempo disponível para estudar e da conciliação do curso com as atividades profissionais, indicando que esses aspectos dificultaram, um pouco mais que os demais, o desempenho durante o treinamento. 
Os itens com as médias mais baixas, $7(M=1,93$ e $D P=1,34)$ e $15(M=1,91$ e $D P=1,39$ ), abordam o conteúdo do curso e as condições de saúde no período de realização do curso, sendo os que menos dificultaram o desempenho.

\subsection{Impacto do treinamento no trabalho em profundidade.}

Os resultados descritivos dos 8 itens do instrumento de "Impacto do Treinamento em Profundidade" associados a uma escala de frequência que varia de 1 ("Nunca") a 5 ("Sempre”) podem ser visualizados na Tabela 36 e 37.

Tabela 36. Resultados descritivos do instrumento de autoavaliação de "Impacto do Treinamento em Profundidade" no curso Eficiência Operacional.

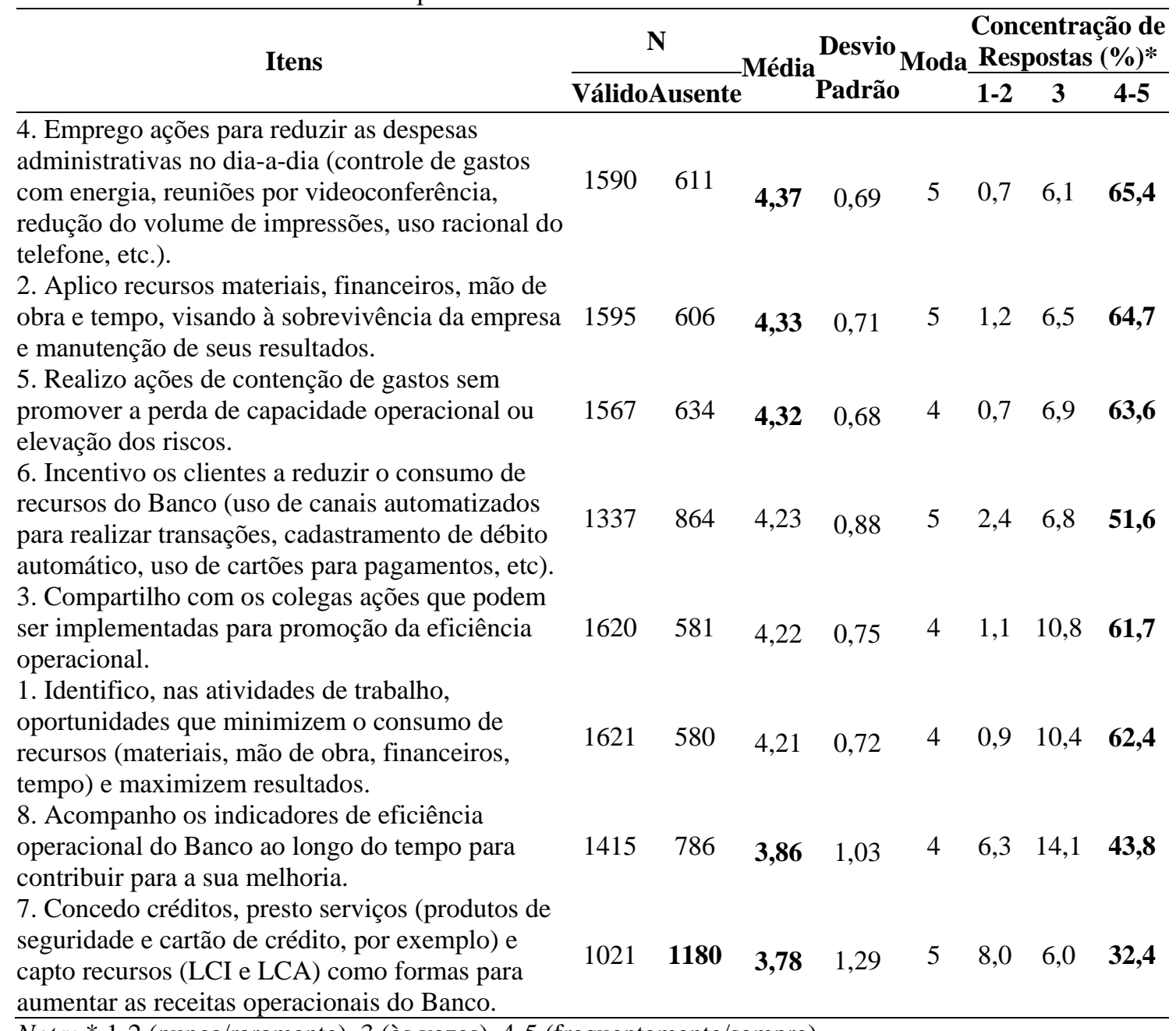

Nota: * 1-2 (nunca/raramente), 3 (às vezes), 4-5 (frequentemente/sempre)

Observa-se que a maioria dos participantes afirma que o curso impacta de maneira positiva no seu trabalho, já que os desempenhos descritos em forma de competências específicas a serem adquiridas com o treinamento "Eficiência Operacional" avaliado, receberam médias que variam entre 3,78 e 4,37, os valores de desvio-padrão são baixos, 
indicando concordância de opiniões quanto aos aspectos avaliados, a concentração de respostas encontra-se nos pontos mais altos da escala, e os valores de moda passam por 4 e 5. Mesmo os itens que receberam médias um pouco mais baixas $-8(M=3,86 \mathrm{e}$ $D P=1,03)$ e $7(M=3,78$ e $D P=1,29)$-, não traduzem uma baixa contribuição do curso, pois são médias satisfatórias; mas, são justamente os dois itens que obtiveram os maiores valores de desvio-padrão, apontando uma maior heterogeneidade nas respostas.

Tabela 37. Resultados descritivos do instrumento de heteroavaliação de "Impacto do Treinamento em Profundidade" no curso Eficiência Operacional.

\begin{tabular}{|c|c|c|c|c|c|c|c|c|}
\hline \multirow[t]{2}{*}{ Itens } & \multicolumn{2}{|c|}{$\mathbf{N}$} & \multirow{2}{*}{ Média } & \multicolumn{2}{|c|}{ Desvio Moda } & \multicolumn{3}{|c|}{$\begin{array}{l}\text { Concentração de } \\
\text { Respostas }(\%)^{*}\end{array}$} \\
\hline & Válido & usente & & Padrão & & $1-2$ & 3 & 4-5 \\
\hline $\begin{array}{l}\text { 2. Aplica recursos materiais, financeiros, mão de } \\
\text { obra e tempo, visando à sobrevivência da empresa } \\
\text { e manutenção de seus resultados. }\end{array}$ & 2307 & 104 & 4,22 & 0,72 & 4 & 1,8 & 11,3 & 82,6 \\
\hline $\begin{array}{l}\text { 3. Compartilha com os colegas ações que podem } \\
\text { ser implementadas para promoção da eficiência } \\
\text { operacional. }\end{array}$ & 2317 & 94 & 4,15 & 0,86 & 4 & 4,5 & 14,5 & 77,1 \\
\hline $\begin{array}{l}\text { 1. Identifica, nas atividades de trabalho, } \\
\text { oportunidades que minimizem o consumo de } \\
\text { recursos (materiais, mão de obra, financeiros, } \\
\text { tempo) e maximizem resultados. }\end{array}$ & 2338 & 73 & 4,14 & 0,76 & 4 & 2,4 & 14,3 & 80,3 \\
\hline $\begin{array}{l}\text { 4. Emprega ações para reduzir as despesas } \\
\text { administrativas no dia-a-dia (controle de gastos } \\
\text { com energia, reuniões por videoconferência, } \\
\text { redução do volume de impressões, uso racional do } \\
\text { telefone, etc.). }\end{array}$ & 2218 & 193 & 4,13 & 0,82 & 4 & 3,4 & 13,5 & 75,1 \\
\hline $\begin{array}{l}\text { 5. Realiza ações de contenção de gastos sem } \\
\text { promover a perda de capacidade operacional ou } \\
\text { elevação dos riscos. }\end{array}$ & 2186 & 225 & 4,12 & 0,79 & 4 & 2,9 & 14,0 & 73,8 \\
\hline $\begin{array}{l}\text { 6. Incentiva os clientes a reduzir o consumo de } \\
\text { recursos do Banco (uso de canais automatizados } \\
\text { para realizar transações, cadastramento de débito } \\
\text { automático, uso de cartões para pagamentos, etc). }\end{array}$ & 1808 & 603 & 4,10 & 0,90 & 4 & 4,1 & 11,1 & 59,9 \\
\hline $\begin{array}{l}\text { 8. Acompanha os indicadores de eficiência } \\
\text { operacional do Banco ao longo do tempo para } \\
\text { contribuir para a sua melhoria. }\end{array}$ & 1904 & 507 & 3,79 & 1,04 & 4 & 9,0 & 17,3 & 52,6 \\
\hline $\begin{array}{l}\text { 7. Concede créditos, presta serviços (produtos de } \\
\text { seguridade e cartão de crédito, por exemplo) e } \\
\text { capta recursos (LCI e LCA) como formas para } \\
\text { aumentar as receitas operacionais do Banco. }\end{array}$ & 1183 & 1128 & 3,69 & 1,30 & 4 & 8,9 & 7,5 & 32,8 \\
\hline
\end{tabular}
Nota: * 1-2 (nunca/raramente), 3 (às vezes), 4-5 (frequentemente/sempre)

Observa-se que a maioria dos gestores afirmou que o curso impactou de maneira positiva no trabalho de seus subordinados, já que os desempenhos descritos em forma de competências específicas a serem adquiridas com o treinamento "Eficiência Operacional" avaliado receberam médias que variam entre 3,69 e 4,22, os valores de desvio-padrão são baixos na maioria dos itens, indicando concordância de opiniões quanto aos aspectos avaliados, a concentração de respostas encontra-se nos pontos mais altos da escala, e os 
valores de moda são todos iguais a 5. Mesmo os itens que receberam médias um pouco mais baixas $-8(M=3,79$ e $D P=1,04)$ e $7(M=3,69$ e $D P=1,30)-$, não traduzem uma baixa contribuição do curso, pois são médias satisfatórias; mas são justamente os dois itens que obtiveram os maiores valores de desvio-padrão, apontando uma maior heterogeneidade nas respostas.

$\mathrm{Na}$ percepção dos funcionários treinados, o nível de aprimoramento geral em desempenhos específicos (impacto em profundidade) adquirido com o curso, foi igual a $M=4,16(D P=0,84)$; e para os gestores, $M=4,04(D P=0,89)$. Na visão dos funcionários e gestores, sobre o impacto do treinamento em profundidade, a maior contribuição do treinamento foi para expressar o desempenho específico: "Aplicar recursos materiais, financeiros, mão de obra e tempo, visando à sobrevivência da empresa e manutenção de seus resultados"; e a menor: "Acompanhar os indicadores de eficiência operacional do Banco ao longo do tempo para contribuir para a sua melhoria".

\subsection{Impacto do treinamento no trabalho em amplitude.}

Os resultados descritivos dos 7 itens do instrumento de "Impacto do Treinamento em Amplitude" associados a uma escala de concordância que varia de 1 ("Não concordo") a 5 ("Concordo totalmente") podem ser visualizados na Tabela 38 e 39.

Tabela 38. Resultados descritivos do instrumento de autoavaliação de "Impacto do Treinamento em Amplitude" no curso Eficiência Operacional.

\begin{tabular}{|c|c|c|c|c|c|c|c|c|}
\hline \multirow[t]{2}{*}{ Itens } & \multirow{2}{*}{\multicolumn{2}{|c|}{$\frac{\mathrm{N}}{\text { VálidoAusente }}$}} & \multirow{2}{*}{ eMédia } & \multicolumn{2}{|c|}{${ }^{\text {Desvio }}$ Moda } & \multicolumn{3}{|c|}{$\begin{array}{l}\text { Concentração de } \\
\text { Respostas }(\%)^{*}\end{array}$} \\
\hline & & & & Padrão & & 1-2 & 3 & $4-5$ \\
\hline $\begin{array}{l}\text { 1. Aproveito as oportunidades que tenho } \\
\text { para praticar as novas habilidades. }\end{array}$ & 1552 & 649 & 4,37 & 0,66 & 5 & 0,2 & 6,5 & 63,8 \\
\hline $\begin{array}{l}\text { 3. Realizo meus trabalhos com mais } \\
\text { agilidade. }\end{array}$ & 1542 & 659 & 4,31 & 0,71 & 4 & 0,9 & 6,8 & 62,3 \\
\hline 7. Esclareço dúvidas dos meus colegas. & 1534 & 667 & 4,28 & 0,73 & 5 & 0,9 & 8,9 & 59,9 \\
\hline 2. Cometo menos erros no trabalho. & 1537 & 664 & 4,25 & 0,71 & 4 & 1,4 & 6,7 & 61,7 \\
\hline 4. Melhorou a qualidade do meu trabalho. & 1533 & 668 & 4,24 & 0,73 & 4 & 1,0 & 8,2 & 60,4 \\
\hline $\begin{array}{l}\text { 5. Aumentou minha motivação para o } \\
\text { trabalho. }\end{array}$ & 1530 & 671 & 4,02 & 0,86 & 4 & 3,0 & 13,7 & 52,7 \\
\hline $\begin{array}{l}\text { 6. Sugiro com mais frequência mudanças } \\
\text { nas rotinas de trabalho. }\end{array}$ & 1528 & 673 & 3,98 & 0,84 & 4 & 2,9 & 14,9 & 51,6 \\
\hline
\end{tabular}

Nota: *1-2 (não concordo/concordo pouco), 3 (concordo moderadamente), 4-5 (concordo muito/concordo totalmente)

As médias obtidas, variando entre 3,98 e 4,37, com baixos valores de desviopadrão, valores de moda entre 4 e 5, e a concentração das respostas nos pontos mais altos 
da escala (acima de 50\% em todos os itens), demonstram bom nível de contribuição do curso "Eficiência Operacional" para a melhoria do desempenho geral dos funcionários treinados. A maioria refere que aproveita as oportunidades que tem para colocar em prática o aprendido no curso (Item 1: $M=4,37$ e $D P=0,66$ ) e que o treinamento influenciou na agilidade na realização dos trabalhos (Item 2: $M=4,31$ e $D P=0,71$ ). Mesmo o item 6 $(M=3,98$ e $D P=0,84)$, que apresentou a menor média, representa contribuição satisfatória do curso para que os funcionários sugiram com mais frequência mudanças nas rotinas de trabalho.

Tabela 39. Resultados descritivos do instrumento de heteroavaliação de "Impacto do Treinamento em Amplitude" no curso Eficiência Operacional.

\begin{tabular}{|c|c|c|c|c|c|c|c|c|}
\hline \multirow[t]{2}{*}{ Itens } & \multirow{2}{*}{\multicolumn{2}{|c|}{$\frac{\mathrm{N}}{\text { VálidoAusente }}$}} & \multirow{2}{*}{ Média } & \multicolumn{2}{|c|}{ Desvio Moda } & \multicolumn{3}{|c|}{$\begin{array}{l}\text { Concentração de } \\
\text { Respostas (\%)* }\end{array}$} \\
\hline & & & & Padrão & & $1-2$ & 3 & $4-5$ \\
\hline 7. Esclarece dúvidas dos colegas. & 2140 & 271 & 4,14 & 0,88 & 4 & 4,4 & 12,3 & 72,1 \\
\hline 2. Comete menos erros no trabalho. & 2132 & 279 & 4,11 & 0,83 & 4 & 4,2 & 11,2 & 73,0 \\
\hline 4. Melhorou a qualidade do trabalho. & 2131 & 280 & 4,09 & 0,85 & 4 & 4,3 & 12,5 & 71,6 \\
\hline 3. Realiza trabalhos com mais agilidade. & 2149 & 262 & 4,07 & 0,86 & 4 & 4,5 & 14,4 & $\mathbf{7 0 , 3}$ \\
\hline $\begin{array}{l}\text { 1. Aproveita oportunidades para praticar as } \\
\text { novas habilidades. }\end{array}$ & s 2145 & 266 & 4,04 & 0,84 & 4 & 3,8 & 16,3 & 68,8 \\
\hline 5. Aumentou a motivação para o trabalho. & 2132 & 279 & 3,92 & 0,91 & 4 & 6,4 & 18,0 & 64,1 \\
\hline $\begin{array}{l}\text { 6. Sugere com mais frequência mudanças } \\
\text { nas rotinas de trabalho. }\end{array}$ & 2124 & 287 & 3,82 & 0,96 & 4 & 7,7 & 21,6 & 58,9 \\
\hline
\end{tabular}

Nota: * 1-2 (não concordo/concordo pouco), 3 (concordo moderadamente), 4-5 (concordo muito/concordo totalmente)

As médias obtidas, variando entre 3,82 e 4,14, com baixos valores de desviopadrão, valores de moda iguais a 4 , e a concentração das respostas nos pontos mais altos da escala (acima de 58,9\% em todos os itens), demonstram bom nível de contribuição do curso "Eficiência Operacional" para a melhoria do desempenho geral dos funcionários treinados, principalmente no que diz respeito ao esclarecimento de dúvidas dos colegas de trabalho (Item 7: $M=4,14$ e $D P=0,88$ ) e cometimento de menos erros. Mesmo o item $6(M=3,82$ e $D P=0,96)$, que apresentou a menor média, representa contribuição satisfatória do curso para que os funcionários sugiram com mais frequência mudanças nas rotinas de trabalho.

$\mathrm{Na}$ verificação de impacto do treinamento sobre os desempenhos gerais (impacto em amplitude), obteve-se média geral dos treinados, igual a $M=4,31(D P=0,70)$ e dos gestores, $M=4,07(D P=0,83)$, indicando que ambos concordam que o curso ajuda a: “Contribuir para o aprimoramento de um clima de trabalho produtivo (comunicação, 
satisfação, trabalho em equipe, relacionamento interpessoal)"; e em menor medida a: "Sugerir com mais frequência mudanças nas rotinas de trabalho".

Houve alta concordância entre os resultados quantitativos obtidos na auto e heteroavaliação no que tange ao grau de manifestação no trabalho das competências impacto do treinamento no trabalho (profundidade e amplitude) -, sendo ambos favoráveis. Em síntese, o treinamento "Eficiência Operacional” produziu efeitos positivos no desempenho dos egressos, tanto na medida em profundidade quanto em amplitude, segundo os próprios funcionários treinados e seus gestores. Isso significa que o curso teve resultados nos desempenhos diretamente observados (comportamento no cargo) dos egressos e também indiretos, incluindo efeitos sobre o desempenho global, atitudes e estados motivacionais.

\subsubsection{Análises de consistência interna.}

Como esperado, ao aplicarem-se os instrumentos à amostra do estudo de campo, formada por trabalhadores participantes de um treinamento autoinstrucional a distância, e, portanto, com características apropriadas às medidas e aos construtos avaliados, além das modificações realizadas em alguns dos instrumentos, mais especificadamente no de reações, devido aos resultados obtidos no estudo piloto, houve um incremento nos valores dos alfas, como mostra a Tabela 40.

Tabela 40. Informações psicométricas dos instrumentos utilizados na pesquisa.

\begin{tabular}{|c|c|c|c|c|c|}
\hline \multirow[t]{2}{*}{ Instrumento } & \multirow[t]{2}{*}{ Fatores } & \multirow{2}{*}{$\begin{array}{l}\mathrm{N}^{\text {o. }} \text { de } \\
\text { Itens }\end{array}$} & \multirow[t]{2}{*}{ Alfa } & \multicolumn{2}{|c|}{$\begin{array}{c}\text { Cargas } \\
\text { Fatoriais }\end{array}$} \\
\hline & & & & Mín. & Máx. \\
\hline $\begin{array}{l}\text { Reação aos Procedimentos } \\
\text { Instrucionais }\end{array}$ & Unifatorial & 09 & 0,92 & 0,65 & 0,81 \\
\hline Barreiras e Facilitadores em EAD & Unifatorial & 18 & 0,98 & 0,74 & 0,94 \\
\hline \multirow{5}{*}{ Estratégias de Aprendizagem } & Cognitivas/Busca de Ajuda & 08 & 0,85 & 0,35 & 0,76 \\
\hline & Controle da Emoção & 03 & 0,80 & 0,69 & 0,85 \\
\hline & Elaboração/Aplicação & 05 & 0,84 & $-0,30$ & $-0,83$ \\
\hline & Prática & & & & \\
\hline & Controle da Motivação & 03 & 0,81 & $-0,50$ & $-0,88$ \\
\hline \multirow{3}{*}{ Suporte à Transferência } & Suporte de Supervisores & 06 & 0,95 & 0,83 & 0,89 \\
\hline & Suporte de Pares & 06 & 0,93 & $-0,70$ & 0,92 \\
\hline & Suporte Material & 02 & 0,85 & 0,86 & 0,87 \\
\hline Impacto em Profundidade (Auto) & Unifatorial & 08 & 0,85 & 0,44 & 0,77 \\
\hline
\end{tabular}


Tabela 40. Informações psicométricas dos instrumentos utilizados na pesquisa. (Continuação)

\begin{tabular}{ccccccc}
\hline Instrumento & Fatores & \multirow{2}{*}{$\mathbf{N}^{\mathbf{0}}$ de Itens } & Alfa & \multicolumn{2}{c}{ Cargas Fatoriais } \\
\cline { 5 - 7 } & & & & Mín. & Máx. \\
\hline Impacto em Amplitude (Auto) & Unifatorial & 07 & 0,89 & 0,62 & 0,86 \\
\hline Impacto em Profundidade (Hetero) & Unifatorial & 08 & 0,89 & 0,52 & 0,85 \\
\hline Impacto em Amplitude (Hetero) & Unifatorial & 07 & 0,94 & 0,78 & 0,90 \\
\hline
\end{tabular}

Os índices de confiabilidade variaram de 0,80 a 0,98 e as cargas fatoriais, de - 0,30 a 0,94, indicando que as escalas são consistentes, válidas e contemplam itens representativos de cada fator.

Tabela 41. Comparação dos alfas e número de itens entre as escalas originais e as do estudo de campo.

\begin{tabular}{|c|c|c|c|c|c|}
\hline \multirow[t]{2}{*}{ Instrumento } & \multicolumn{2}{|c|}{$\begin{array}{l}\text { Estudo de } \\
\text { campo }\end{array}$} & \multicolumn{2}{|c|}{ Originais } & \multirow{2}{*}{$\begin{array}{l}\mathrm{N}^{0} \text { itens } \\
\text { reduzidos }\end{array}$} \\
\hline & $\mathbf{N}^{\circ}$ itens & $\alpha$ & $\mathrm{N}^{\circ}$ itens & $\alpha$ & \\
\hline Estratégias de Aprendizagem & 20 & 0,89 & 29 & 0,92 & 09 \\
\hline Reação aos Procedimentos Instrucionais & 09 & 0,92 & 17 & 0,96 & 08 \\
\hline Barreiras e Facilitadores em EAD & 18 & 0,98 & 63 & $0,72 / 0,96$ & 45 \\
\hline Suporte à Transferência & 14 & 0,94 & 16 & $0,86 / 0,91$ & 02 \\
\hline Impacto em Amplitude & 07 & 0,89 & 12 & 0,93 & 05 \\
\hline
\end{tabular}

Em comparação às escalas originais, que vêm sendo utilizadas nos últimos anos em estudos nacionais na área de avaliação de treinamentos e outras ações educacionais, presenciais e a distância, os ganhos com as adaptações realizadas nos instrumentos no presente estudo são consideráveis, como pode-se observar na Tabela 41. Logrou-se diminuir o número de itens e os pontos das escalas, mantendo-se as qualidades psicométricas dos instrumentos; em alguns casos, inclusive, houve a melhora dos índices e das estruturas empíricas com menos fatores (unifatoriais) e sem a presença de multicolinearidade entre os itens - com exceção das escalas "Barreiras e Facilitadores em EAD" e "Suporte à Transferência", que apresentaram pares de itens altamente correlacionadas entre si, sobre os quais discute-se adiante. Antes, alguns instrumentos estavam inflados com muitos itens desnecessários e que mediam os mesmos aspectos, necessitando adaptação e a proposição de versões mais enxutas.

A principal consequência do processo de adaptação foi a produção de instrumentos mais parcimoniosos e adequados ao contexto corporativo, pois ao terem menos itens e menos pontos nas escalas, tornam-se mais fáceis e rápidos de responder. 
Se até mesmo o treinamento foi feito durante a jornada de trabalho, a aplicação de instrumentos para sua avaliação provavelmente também competirá com as atividades laborais dos participantes, podendo afetar, por exemplo, a qualidade dos resultados obtidos e o número de respondentes alcançados, especialmente se a avaliação resulta demasiadamente longa e demorada.

As novas versões dos instrumentos devem ser aplicadas em outros contextos e amostras para comprovar a adequação e manutenção das evidências de validade e confiabilidade conseguidas. Em seguida, apresentam-se os resultados das análises fatoriais exploratórias e confirmatórias dos instrumentos.

\subsubsection{Análises fatoriais exploratórias.}

Realizaram-se análises fatoriais exploratórias, antes das análises fatoriais confirmatórias das estruturas empíricas das escalas, já que após a adaptação, os instrumentos haviam sido aplicados a uma amostra (estudo piloto) com características não ideais às medidas e apenas nas versões no idioma espanhol. Considerando que o processo de validação anterior se deu junto a amostras de participantes muito particulares e diferentes dos casos analisados no estudo de campo, mais uma vez foram testadas as estruturas fatoriais dos instrumentos. Por isso, a AFE foi feita para explorar novamente as estruturas empíricas dos instrumentos e então dar prosseguimento à AFC.

\subsection{Estratégias de aprendizagem.}

$\underline{\text { Tabela 42. Estrutura empírica do instrumento de "Estratégias de Aprendizagem". }}$

\section{Itens}

1. Mantive a calma quando tive dificuldades durante o curso.

2. Mantive a calma com a possibilidade de ter um rendimento abaixo do esperado.

3. Mantive a calma diante dos erros que cometi ao realizar atividades do curso.

4. Esforcei-me mais quando percebi que estava perdendo a concentração.

5. Esforcei-me mais quando percebi que estava perdendo o interesse no assunto.

6. Esforcei-me para verificar minha compreensão sobre o que estava sendo ensinado.

7. Busquei auxílio de colegas para esclarecer minhas dúvidas sobre os conteúdos do curso.

8. Busquei solucionar minhas dúvidas ao consultar os materiais didáticos do curso.

\begin{tabular}{ccccccc}
\multicolumn{3}{c}{ Cargas fatoriais } & & \multirow{2}{*}{$\boldsymbol{h}^{2}$} & $\boldsymbol{M}$ & $\boldsymbol{D} \boldsymbol{D}$ \\
& $\mathbf{2}$ & $\mathbf{3}$ & $\mathbf{4}$ & & & \\
& 0,69 & & & 0,57 & 4,55 & 0,63 \\
& 0,76 & & 0,52 & 4,17 & 0,91 \\
& 0,85 & & 0,69 & 4,29 & 0,76 \\
& & $-0,88$ & 0,72 & 4,39 & 0,76 \\
& & $-0,80$ & 0,65 & 4,21 & 0,86 \\
& & $-0,50$ & 0,48 & 4,42 & 0,71 \\
& & & & 0,41 & 2,93 & 1,35 \\
0,66 & & & 0,40 & 4,02 & 1,04 \\
0,38 & & & & & &
\end{tabular}


Tabela 42. Estrutura empírica do instrumento de "Estratégias de Aprendizagem". (Continuação)

\begin{tabular}{|c|c|c|c|c|c|c|c|}
\hline \multirow{2}{*}{ Itens } & \multicolumn{4}{|c|}{ Cargas fatoriais } & \multirow{2}{*}{$h^{2}$} & \multirow{2}{*}{$M$} & \multirow{2}{*}{$D P$} \\
\hline & 1 & 2 & 3 & 4 & & & \\
\hline $\begin{array}{l}\text { 9. Busquei compreender melhor os conteúdos ao } \\
\text { estudá-los nos materiais didáticos do curso. }\end{array}$ & 0,35 & & & & 0,43 & 4,13 & 0,94 \\
\hline $\begin{array}{l}\text { 10. Busquei outras fontes de pesquisa relacionadas } \\
\text { ao curso para me ajudar a aprender. }\end{array}$ & 0,76 & & & & 0,53 & 2,82 & 1,31 \\
\hline $\begin{array}{l}\text { 11. Tentei entender o conteúdo ao aplicá-lo na } \\
\text { prática, ao invés de dedicar tempo lendo ou pedindo } \\
\text { ajuda a alguém. }\end{array}$ & & & & & 0,22 & 3,83 & 1,02 \\
\hline $\begin{array}{l}\text { 12. Realizei os exercícios práticos propostos ao } \\
\text { longo do curso para me ajudar a aprender. }\end{array}$ & & & $-0,30$ & & 0,29 & 4,36 & 0,83 \\
\hline $\begin{array}{l}\text { 13. Li o conteúdo do curso várias vezes como } \\
\text { método para aprender. }\end{array}$ & 0,74 & & & & 0,55 & 3,35 & 1,12 \\
\hline $\begin{array}{l}\text { 14. Repeti mentalmente os conteúdos do curso que } \\
\text { gostaria de aprender até perceber que havia } \\
\text { entendido. }\end{array}$ & 0,63 & & & & 0,52 & 3,44 & 1,13 \\
\hline $\begin{array}{l}\text { 15. Fiz anotações, resumos e/ou esquemas dos } \\
\text { conteúdos do curso como método para aprender. }\end{array}$ & 0,69 & & & & 0,49 & 3,22 & 1,32 \\
\hline $\begin{array}{l}\text { 16. Refleti sobre as implicações que os conteúdos } \\
\text { aprendidos poderiam ter. }\end{array}$ & & & $-0,66$ & & 0,55 & 4,13 & 0,84 \\
\hline $\begin{array}{l}\text { 17. Identifiquei situações diárias em que eu pudesse } \\
\text { aplicar os conteúdos do curso. }\end{array}$ & & & $-0,83$ & & 0,66 & 4,15 & 0,81 \\
\hline $\begin{array}{l}\text { 18. Busquei desenvolver uma ideia global sobre } \\
\text { como os conteúdos do curso se relacionavam entre } \\
\text { si. }\end{array}$ & & & $-0,77$ & & 0,64 & 4,08 & 0,85 \\
\hline $\begin{array}{l}\text { 19. Associei os conteúdos do curso aos meus } \\
\text { conhecimentos anteriores. }\end{array}$ & & & $-0,78$ & & 0,62 & 4,29 & 0,75 \\
\hline $\begin{array}{l}\text { 20. Revisei os conteúdos relativos aos exercícios em } \\
\text { que cometi erros. }\end{array}$ & 0,42 & & & & 0,40 & 3,88 & 1,04 \\
\hline$N$ & 1790 & 1929 & 1877 & 1851 & & & \\
\hline Eigenvalue (Valor próprio) & 6,99 & 2,51 & 1,46 & 1,16 & & & \\
\hline \% da Variância Explicada $(P A F)$ & 32,63 & 10,31 & 5,36 & 3,89 & & & \\
\hline No. de itens & 08 & 03 & 05 & 03 & & & \\
\hline $\operatorname{Alfa}(\alpha)$ & 0,85 & 0,80 & 0,84 & 0,81 & & & \\
\hline KMO & 0,90 & & & & & & \\
\hline \% da variância total explicada $(P C)$ & 34,98 & 12,55 & 7,33 & 5,80 & & & \\
\hline
\end{tabular}

A $P C$ indicou uma estrutura empírica com 4 componentes que explicam, em conjunto, 60,67\% da variância total das respostas dos participantes aos itens do questionário, ratificada pela análise dos valores próprios, variância explicada e scree plot.

A $P A F$ com a fixação de 4 fatores mostrou que as estratégias de aprendizagem agrupam-se da seguinte forma: 1) Estratégias cognitivas e busca de ajuda (8 itens: 7 ao $10,13$ ao 15 e 20; $\alpha=0,85$; cargas fatoriais: 0,35 a 0,76$) ; 2$ ) Controle da emoção ( 3 itens, 1 ao $3 ; \alpha=0,80$; cargas fatoriais: 0,69 a 0,85$)$; 3) Elaboração e aplicação prática (5 itens: 12,16 ao $19 ; \alpha=0,84$; cargas fatoriais: $-0,30$ a $-0,83$ ); 4 ) Controle da motivação (3 itens: 4 ao $6 ; \alpha=0,81$; cargas fatoriais: $-0,50$ a $-0,88$ ).

O fator 1, "Estratégias cognitivas e busca de ajuda", engloba estratégias cognitivas de repetição e organização, bem como estratégias comportamentais de busca de ajuda 
interpessoal e ao material didático. O fator 2, "Controle da emoção", tem sido sucessivamente encontrado e mantido na estrutura empírica do instrumento, separado das demais estratégias, em estudos anteriores. O fator 3, "Elaboração e aplicação prática", junta itens de estratégias cognitivas com um comportamental, indicando que a reflexão sobre as possíveis implicações e conexões entre o material aprendido e os conhecimentos já existentes faz-se simultaneamente à aplicação do aprendido na prática, por meio dos exercícios propostos. O fator 4, "Controle da motivação", confirma, juntamente ao fator 2, a importância da inclusão de estratégias autorregulatórias no instrumento. O item 11 “Tentei entender o conteúdo ao aplicá-lo na prática, ao invés de dedicar tempo lendo ou pedindo ajuda a alguém", estratégia de aplicação prática não se agrupou a nenhum fator e, portanto, não permaneceu na estrutura empírica do instrumento.

A solução com 4 fatores apresenta sentido teórico, tendo sido encontrada em estudo prévio (Martins \& Zerbini, 2014b), mas com agrupamento diferenciado de algumas estratégias de aprendizagem. $\mathrm{O}$ instrumento apresenta um excelente índice de consistência interna $(\alpha=0,89)$, com um total de 20 itens que medem a frequência de uso de estratégias de aprendizagem.

\subsection{Reação aos procedimentos instrucionais.}

Tabela 43. Estrutura empírica do instrumento de "Reação aos Procedimentos Instrucionais".

\begin{tabular}{|c|c|c|c|c|}
\hline Itens & $\begin{array}{c}\begin{array}{c}\text { Cargas } \\
\text { fatoriais }\end{array} \\
1 \\
\end{array}$ & $h^{2}$ & $M$ & $D P$ \\
\hline $\begin{array}{l}\text { 1. Correspondência entre o conteúdo proposto e os objetivos do } \\
\text { curso. }\end{array}$ & 0,76 & 0,58 & 4,20 & 0,61 \\
\hline $\begin{array}{l}\text { 2. Correspondência entre o conteúdo do curso e os seus objetivos } \\
\text { pessoais. }\end{array}$ & 0,71 & 0,51 & 4,11 & 0,68 \\
\hline 3. Sequência de apresentação do conteúdo do curso. & 0,78 & 0,61 & 4,20 & 0,64 \\
\hline 4. Linguagem utilizada no material do curso. & 0,75 & 0,57 & 4,30 & 0,63 \\
\hline $\begin{array}{l}\text { 5. Novidades, lembretes e links divulgados no ambiente virtual do } \\
\text { curso. }\end{array}$ & 0,78 & 0,61 & 4,07 & 0,71 \\
\hline 6. Atividades/tarefas propostas ao final de cada unidade. & 0,79 & 0,63 & 4,09 & 0,68 \\
\hline 7. Orientação para solução de erros nas atividades/tarefas. & 0,75 & 0,56 & 3,99 & 0,73 \\
\hline 8. Conteúdos disponibilizados em cada unidade. & 0,81 & 0,66 & 4,15 & 0,64 \\
\hline 9. Horas de estudo sugeridas para o curso. & 0,65 & 0,42 & 4,01 & 0,79 \\
\hline$N$ & 1754 & & & \\
\hline Eigenvalue (Valor próprio) & 5,61 & & & \\
\hline \% da Variância Explicada $(P A F)$ & 57,77 & & & \\
\hline No. de itens & 09 & & & \\
\hline Alfa $(\alpha)$ & 0,92 & & & \\
\hline KMO & 0,94 & & & \\
\hline \% da variância total explicada $(P C)$ & 62,38 & & & \\
\hline
\end{tabular}


A escala "Reação aos Procedimentos Instrucionais" apresenta 9 itens, cujas cargas fatoriais variam entre 0,65 e 0,81 , em uma estrutura unifatorial $(\alpha=0,92)$ - o fator único explica $57,77 \%$ da variância total das respostas aos itens do instrumento.

\subsection{Suporte à transferência.}

A partir da análise da matriz de correlações, foram identificados 3 pares de itens altamente correlacionados entre si $(p<0,01)$ :

- Par 1 (Supervisores): 2 "Fornecem as informações necessárias ao uso eficaz das novas habilidades aprendidas em treinamento" e 3 "Removem as dificuldades ao uso eficaz das novas habilidades aprendidas em treinamento" $(r=0,82)$;

- Par 2 (Supervisores): 3 "Removem as dificuldades ao uso eficaz das novas habilidades aprendidas em treinamento" e 4 "Criam oportunidades de usar no trabalho as novas habilidades aprendidas em treinamento" $(r=0,82)$;

- Par 3 (Pares): 9 "Removem as dificuldades ao uso eficaz das novas habilidades aprendidas em treinamento" e 10 "Criam oportunidades de usar no trabalho as novas habilidades aprendidas em treinamento" $(r=0,80)$.

Os conteúdos presentes nos itens que compõem os 3 pares são distintos, contendo verbos e objetos de ação diferentes - fornecer informações, remover dificuldades e criar oportunidades -, mas, por terem sido correlacionados entre si, indicam que para posteriores aplicações, deva-se atentar para o aperfeiçoamento da redação dos mesmos, para que possam ser diferenciados uns dos outros, principalmente os que tratam da remoção das dificuldades e criação de oportunidades, que apareceram altamente correlacionados nos dois tipos de suporte: supervisores e pares.

Ou que possa ser elaborado um novo item que dê conta desses comportamentos simultaneamente, já que ao supor que quando oportunidades são criadas para o uso no trabalho das novas habilidades aprendidas em treinamento, já foram tomadas providências para a remoção das possíveis dificuldades ou dos entraves à sua aplicação.

Tabela 44. Estrutura empírica do instrumento de "Suporte à Transferência".

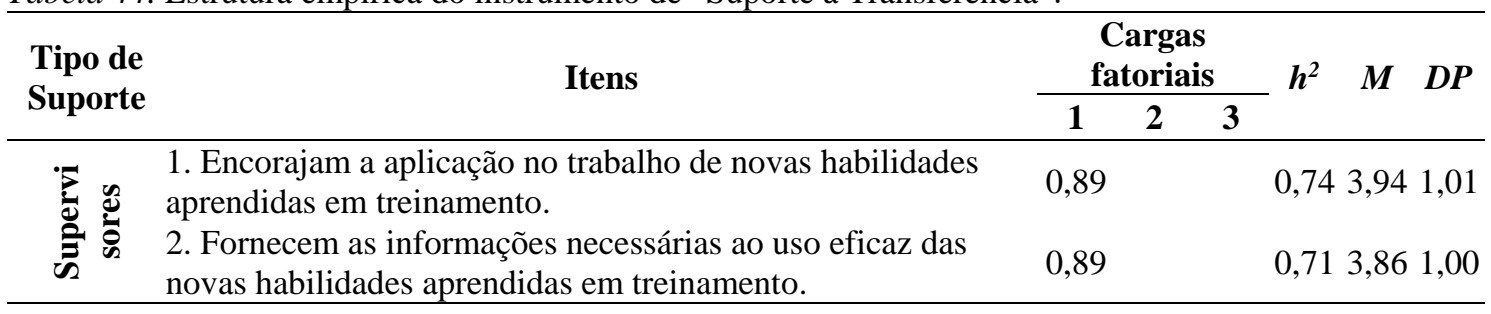


Tabela 44. Estrutura empírica do instrumento de "Suporte à Transferência". (Continuação)

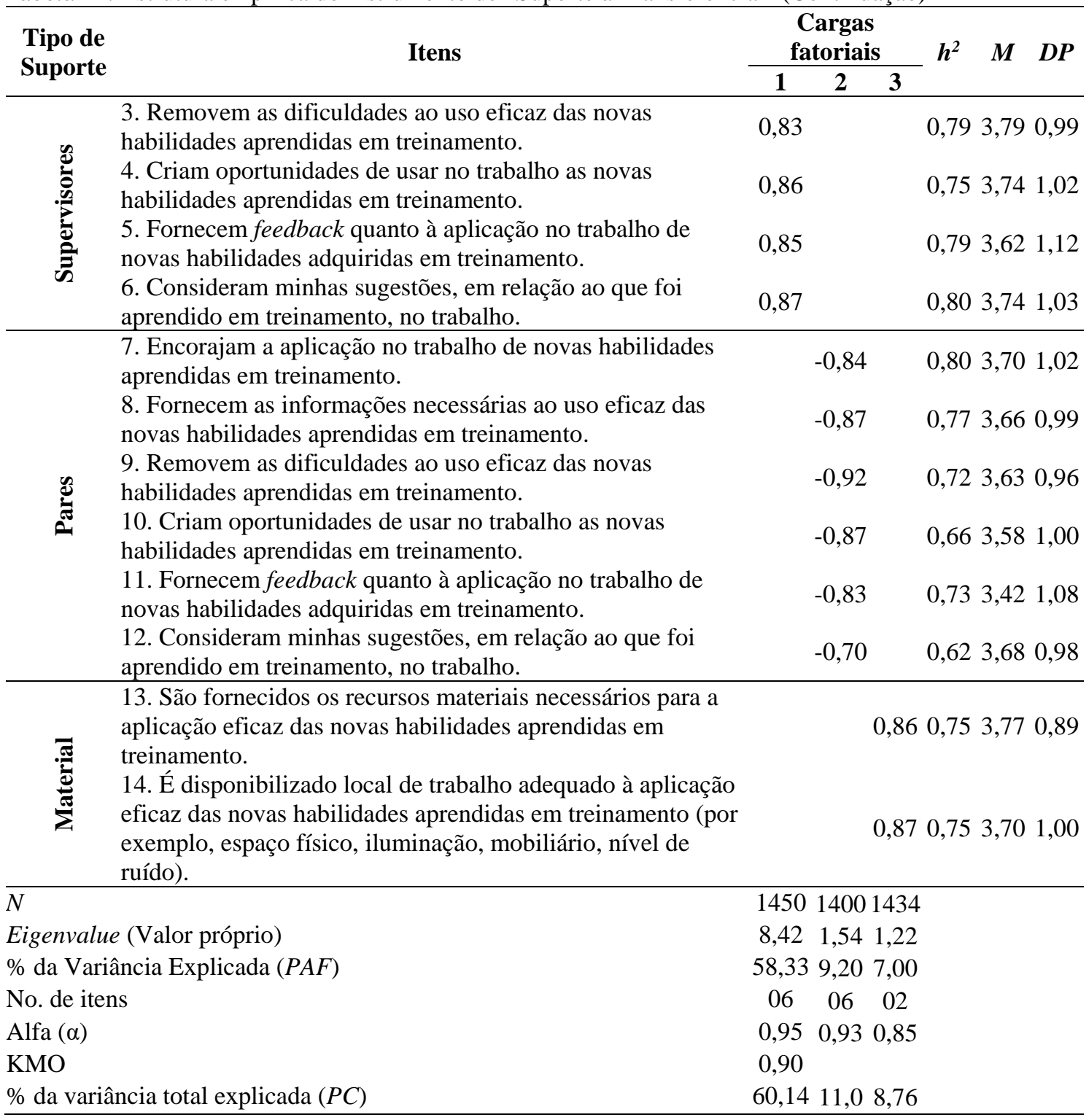

A $P C$ indicou uma estrutura empírica com 3 componentes que explicam, em conjunto, 79,92\% da variância total das respostas dos participantes aos itens do questionário, ratificada pela análise dos valores próprios, variância explicada e scree plot.

Com a fixação de 3 fatores por meio da $P A F$, obteve-se a seguinte configuração dos tipos de suporte presentes no instrumento: 1) Suporte de Supervisores (6 itens; $\alpha=0,95$; cargas fatoriais: 0,83 a 0,89 ); 2 ) Suporte de Pares (6 itens; $\alpha=0,93$; cargas fatoriais: $-0,70$ a 0,92 ) e 3 ) Suporte Material ( 2 itens; $\alpha=0,85$; cargas fatoriais: 0,86 a $0,87)$.

Tal estrutura empírica encontrada mostra-se bastante adequada tanto teórica como empiricamente e valida a adaptação feita no instrumento, na qual os tipos de suporte psicossocial (supervisores e pares) foram medidos separadamente, além do suporte 
material oferecido pela organização. A escala possui excelente índice de consistência interna $(\alpha=0,94)$, com um total de 14 itens que medem os diferentes tipos de apoio.

\subsection{Barreiras e facilitadores em EAD.}

A partir da análise da matriz de correlações, foram identificados muitos pares de itens (72) altamente correlacionados entre si $(p<0,01)$ neste instrumento, como mostra a Tabela 45. Deve-se assegurar que os itens construídos para medir um determinado construto comum tenham correlações moderadas entre si (Laros, 2004), sendo desejável a presença de certa multicolinearidade (Hair et al., 2005); mas, o fato de haver tantas correlações fortes entre os itens traz consequências, como por exemplo, certamente ter contribuído para o altíssimo índice de consistência interna obtido em uma estrutura de fator único (acima de 10 itens), pois o $\alpha$ é um indicador muito influenciado pelo número de itens. 
Tabela 45. Pares de itens altamente correlacionados entre si no instrumento de "Barreiras e Facilitadores em EAD".

\begin{tabular}{|c|c|c|c|c|c|c|c|c|c|c|c|c|c|c|c|c|c|c|}
\hline 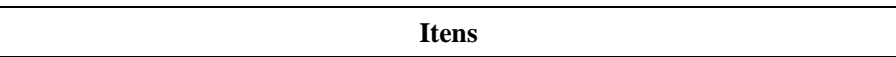 & 1 & 2 & 3 & 4 & 5 & 6 & 7 & 8 & 9 & 10 & 11 & 12 & 13 & 14 & 15 & 16 & 17 & 18 \\
\hline 1. Suporte técnico oferecido pela instituição. & - & & & & & & & & & & & & & & & & & \\
\hline 2. Conexão à internet. & & - & & & & & & & & & & & & & & & & \\
\hline 3. Acesso ao ambiente virtual do curso com a regularidade proposta. & $\mathbf{0 , 8 1}$ & $\mathbf{0 , 8 4}$ & - & & & & & & & & & & & & & & & \\
\hline 4. Material didático do curso. & 0,82 & & 0,82 & - & & & & & & & & & & & & & & \\
\hline $\begin{array}{l}\text { 5. Custos financeiros associados às tecnologias e materiais necessários durante } \\
\text { o curso (acesso à internet, manutenção do computador, etc.). }\end{array}$ & $\mathbf{0 , 8 0}$ & & 0,81 & 0,86 & - & & & & & & & & & & & & & \\
\hline 6. Duração do curso. & 0,80 & & $\mathbf{0 , 8 0}$ & 0,88 & 0,84 & - & & & & & & & & & & & & \\
\hline 7. Conteúdo do curso. & 0,80 & & 0,81 & $\mathbf{0 , 9 2}$ & 0,87 & 0,91 & - & & & & & & & & & & & \\
\hline 8. Recursos de ensino utilizados (figuras, vídeos, slides, etc.). & 0,80 & & 0,80 & 0,90 & 0,86 & 0,88 & 0,92 & - & & & & & & & & & & \\
\hline 9. Quantidade das atividades propostas durante o curso. & 0,80 & & 0,80 & 0,90 & 0,85 & 0,88 & 0,92 & 0,92 & - & & & & & & & & & \\
\hline 10. Conciliação do curso com as atividades profissionais. & & & & & & & & & & - & & & & & & & & \\
\hline 11. Conciliação do curso com os compromissos familiares. & & & & 0,81 & & $\mathbf{0 , 8 0}$ & 0,83 & 0,80 & $\mathbf{0 , 8 2}$ & & - & & & & & & & \\
\hline 12. Tempo disponível para estudar. & & & & & & & & & & $\mathbf{0 , 8 0}$ & & - & & & & & & \\
\hline 13. Conciliação do curso com outras atividades de estudo. & & & & & & & & & & & 0,83 & & - & & & & & \\
\hline 14. Condições do ambiente de estudo em casa. & & & & & & & & & & & $\mathbf{0 , 8 1}$ & & $\mathbf{0 , 8 1}$ & - & & & & \\
\hline 15. Condições de saúde no período de realização do curso. & & & & 0,87 & 0,84 & 0,86 & 0,89 & 0,88 & 0,88 & & 0,82 & & & & - & & & \\
\hline 16. Correspondência do curso às expectativas pessoais. & & & & 0,87 & 0,82 & 0,85 & 0,88 & 0,87 & 0,88 & & 0,82 & & & & 0,88 & - & & \\
\hline $\begin{array}{l}\text { 17. Habilidades pessoais de organização e planejamento de atividades de } \\
\text { estudo. }\end{array}$ & & & & 0,88 & 0,84 & 0,87 & 0,90 & 0,88 & 0,89 & & 0,82 & & & 0,80 & 0,90 & 0,89 & - & \\
\hline 18. Habilidades pessoais para uso das ferramentas web (e-mails, fóruns, etc.). & & & & 0,87 & 0,85 & 0,85 & 0,89 & 0,88 & 0,87 & & & & & & 0,87 & 0,86 & 0,91 & - \\
\hline
\end{tabular}


De modo geral, apesar dos itens estarem muito correlacionados entre si, tratam de conteúdos claramente distintos (verbos e objetos de ação), mas que ao mesmo tempo mantêm assuntos comuns e, por esse motivo, apresentam correlações altas entre si, não indicando, no entanto, sobreposição entre eles.

Em seguida, comentam-se algumas das correlações mais importantes e interessantes que aparecem em negrito na Tabela 45: os itens 1, 2, 3 e 5, referem-se às condições e ao suporte tecnológico oferecidos pela organização, sendo que a presença desses fatores dependiam totalmente da empresa, já que o curso avaliado foi realizado durante a jornada de trabalho e, portanto, contou com o uso de recursos da mesma (computador, internet, apoio técnico); os itens 4, 6, 7, 8 e 9 fazem referência ao desenho do curso e às características da instrução (material, recursos de ensino, atividades, duração e conteúdo); os itens 10 e 12 tratam de conciliar atividades de trabalho com o curso, uma vez que o tempo disponível para estudar estava intimamente relacionado às atividades de trabalho a serem cumpridas, pois o curso deveria ser realizado durante a jornada de trabalho; os itens 15, 16, 17 e 18 dizem respeito às características próprias dos participantes do treinamento (condições de saúde, expectativas, habilidades pessoais) estando fortemente correlacionados com os itens (4, 5, 6, 7, 8 e 9) sobre o desenho do curso, principalmente, que por sua vez, correlacionam-se aos apoios da organização.

Os agrupamentos de itens mencionados são similares ao que ocorreu na validação do instrumento no estudo de Umekawa (2013), no qual 4 fatores foram encontrados na estrutura empírica do instrumento, a saber: Suporte tecnológico e de tutoria, Características exógenas ao curso, Características do aluno, Desenho do curso. Contudo, na presente amostra testada, os itens comportaram-se de maneira distinta, tendo-se juntado em um único fator, representativo das barreiras encontradas para se estudar a distância, como mostra a Tabela 46, a seguir.

Para futuras aplicações do instrumento, recomenda-se a testagem de uma versão ainda mais reduzida, com menos itens que pudessem expressar os temas em comum comentados (suporte tecnológico, desenho do curso, etc.), visando diminuir a redundância observada (presença de multicolinearidade) e, especialmente no caso em que a escala possui uma estrutura unifatorial, que pretende avaliar uma dimensão única, adaptá-la e adequá-la em busca de uma medida mais parcimoniosa. 
Tabela 46. Estrutura empírica do instrumento de "Barreiras e Facilitadores em EAD".

\begin{tabular}{|c|c|c|c|c|}
\hline Itens & $\begin{array}{c}\text { Cargas } \\
\text { fatoriais } \\
1\end{array}$ & $h^{2}$ & $M$ & $D P$ \\
\hline 1. Suporte técnico oferecido pela instituição. & 0,87 & 0,76 & 2,05 & 1,30 \\
\hline 2. Conexão à internet. & 0,78 & 0,60 & 2,28 & 1,35 \\
\hline 3. Acesso ao ambiente virtual do curso com a regularidade proposta. & 0,87 & 0,76 & 2,16 & 1,32 \\
\hline 4. Material didático do curso. & 0,93 & 0,87 & 1,96 & 1,34 \\
\hline $\begin{array}{l}\text { 5. Custos financeiros associados às tecnologias e materiais } \\
\text { necessários durante o curso (acesso à internet, manutenção do } \\
\text { computador, etc.). }\end{array}$ & 0,90 & 0,81 & 1,94 & 1,36 \\
\hline 6. Duração do curso. & 0,92 & 0,85 & 2,00 & 1,32 \\
\hline 7. Conteúdo do curso. & 0,94 & 0,90 & 1,93 & 1,34 \\
\hline 8. Recursos de ensino utilizados (figuras, vídeos, slides, etc.). & 0,93 & 0,87 & 1,94 & 1,35 \\
\hline 9. Quantidade das atividades propostas durante o curso. & 0,94 & 0,88 & 1,96 & 1,32 \\
\hline 10. Conciliação do curso com as atividades profissionais. & 0,74 & 0,56 & 2,43 & 1,34 \\
\hline 11. Conciliação do curso com os compromissos familiares. & 0,88 & 0,78 & 1,97 & 1,31 \\
\hline 12. Tempo disponível para estudar. & 0,74 & 0,55 & 2,40 & 1,28 \\
\hline 13. Conciliação do curso com outras atividades de estudo. & 0,85 & 0,73 & 2,13 & 1,29 \\
\hline 14. Condições do ambiente de estudo em casa. & 0,85 & 0,73 & 2,17 & 1,37 \\
\hline 15. Condições de saúde no período de realização do curso. & 0,92 & 0,85 & 1,91 & 1,39 \\
\hline 16. Correspondência do curso às expectativas pessoais. & 0,92 & 0,85 & 1,99 & 1,32 \\
\hline $\begin{array}{l}\text { 17. Habilidades pessoais de organização e planejamento de } \\
\text { atividades de estudo. }\end{array}$ & 0,93 & 0,87 & 1,97 & 1,35 \\
\hline $\begin{array}{l}\text { 18. Habilidades pessoais para uso das ferramentas web (e-mails, } \\
\text { fóruns, etc.). }\end{array}$ & 0,92 & 0,85 & 1,97 & 1,37 \\
\hline$N$ & 1145 & & & \\
\hline Eigenvalue (Valor próprio) & 14,34 & & & \\
\hline \% da Variância Explicada $(P A F)$ & 78,59 & & & \\
\hline No. de itens & 18 & & & \\
\hline $\operatorname{Alfa}(\alpha)$ & 0,98 & & & \\
\hline KMO & 0,97 & & & \\
\hline \% da variância total explicada $(P C)$ & 79,70 & & & \\
\hline
\end{tabular}

A escala "Barreiras e Facilitadores em EAD" apresenta 18 itens, cujas cargas fatoriais variam entre 0,74 e 0,94 , em uma estrutura unifatorial $(\alpha=0,98)$ - o fator único explica $78,59 \%$ da variância total das respostas aos itens do instrumento.

A adaptação desse instrumento mostra ganhos bastante importantes: a redução de 45 itens e a obtenção de um excelente índice de consistência interna para a escala, com um total de 18 itens que medem fatores que poderiam dificultar o desempenho, ou seja, atuariam como barreiras durante o curso.

\subsection{Impacto do treinamento no trabalho em profundidade.}


Tabela 47. Estrutura empírica do instrumento de autoavaliação de "Impacto do Treinamento em Profundidade".

\begin{tabular}{|c|c|c|c|c|}
\hline Itens & $\begin{array}{c}\text { Cargas } \\
\text { fatoriais } \\
1\end{array}$ & $h^{2}$ & $M$ & $D P$ \\
\hline $\begin{array}{l}\text { 1. Identifico, nas atividades de trabalho, oportunidades que } \\
\text { minimizem o consumo de recursos (materiais, mão de obra, } \\
\text { inanceiros, tempo) e maximizem resultados }\end{array}$ & 0,67 & 0,45 & 4,21 & 0,72 \\
\hline $\begin{array}{l}\text {. Aplico recursos materiais, financeiros, mão de obra e tempo, } \\
\text { visando à sobrevivência da empresa e manutenção de seus resultados. }\end{array}$ & 0,76 & 0,57 & 4,33 & 0,71 \\
\hline $\begin{array}{l}\text { 3. Compartilho com os colegas ações que podem ser implementadas } \\
\text { ara promoção da eficiência operacional. }\end{array}$ & 0,73 & 0,54 & 4,22 & 0,75 \\
\hline $\begin{array}{l}\text { Emprego ações para reduzir as despesas administrativas no dia-a- } \\
\text { dia (controle de gastos com energia, reuniões por videoconferência, } \\
\text { cedução do volume de impressões, uso racional do telefone, etc.). }\end{array}$ & 0,76 & 0,58 & 4,37 & 0,69 \\
\hline $\begin{array}{l}\text { 5. Realizo ações de contenção de gastos sem promover a perda de } \\
\text { capacidade operacional ou elevação dos riscos. }\end{array}$ & 0,77 & 0,60 & 4,32 & 0,68 \\
\hline $\begin{array}{l}\text { 6. Incentivo os clientes a reduzir o consumo de recursos do Banco } \\
\text { (uso de canais automatizados para realizar transações, cadastramento } \\
\text { de débito automático, uso de cartões para pagamentos, etc). }\end{array}$ & 0,64 & 0,41 & 4,23 & 0,88 \\
\hline $\begin{array}{l}\text { 7. Concedo créditos, presto serviços (produtos de seguridade e cartão } \\
\text { de crédito, por exemplo) e capto recursos (LCI e LCA) como formas } \\
\text { para aumentar as receitas operacionais do Banco. }\end{array}$ & 0,44 & 0,19 & 3,78 & 1,29 \\
\hline $\begin{array}{l}\text { 8. Acompanho os indicadores de eficiência operacional do Banco ao } \\
\text { longo do tempo para contribuir para a sua melhoria. }\end{array}$ & 0,54 & 0,29 & 3,86 & 1,03 \\
\hline$N$ & 976 & & & \\
\hline Eigenvalue (Valor próprio) & 4,17 & & & \\
\hline \% da Variância Explicada $(P A F)$ & 45,83 & & & \\
\hline No. de itens & 08 & & & \\
\hline $\operatorname{Alfa}(\alpha)$ & 0,85 & & & \\
\hline KMO & 0,87 & & & \\
\hline \% da variância total explicada $(P C)$ & 66,54 & & & \\
\hline
\end{tabular}

A escala de autoavaliação de "Impacto do Treinamento em Profundidade" referente ao curso "Eficiência Operacional" apresenta 8 itens, cujas cargas fatoriais variam entre 0,44 e 0,77 , em uma estrutura unifatorial $(\alpha=0,85)$ - o fator único explica $45,83 \%$ da variância total das respostas aos itens do instrumento.

Tabela 48. Estrutura empírica do instrumento de heteroavaliação de "Impacto do Treinamento em Profundidade".

\begin{tabular}{|c|c|c|c|c|}
\hline Itens & $\begin{array}{c}\text { Cargas } \\
\text { fatoriais }\end{array}$ & $h^{2}$ & $M$ & $D P$ \\
\hline $\begin{array}{l}\text { 1. Identifica, nas atividades de trabalho, oportunidades que } \\
\text { minimizem o consumo de recursos (materiais, mão de obra, } \\
\text { financeiros, tempo) e maximizem resultados. }\end{array}$ & 0,78 & 0,61 & 4,14 & 0,76 \\
\hline $\begin{array}{l}\text { 2. Aplica recursos materiais, financeiros, mão de obra e tempo, } \\
\text { visando à sobrevivência da empresa e manutenção de seus resultados. }\end{array}$ & 0,80 & 0,64 & 4,22 & 0,72 \\
\hline $\begin{array}{l}\text { 3. Compartilha com os colegas ações que podem ser implementadas } \\
\text { para promoção da eficiência operacional. }\end{array}$ & 0,78 & 0,61 & 4,15 & 0,86 \\
\hline $\begin{array}{l}\text { 4. Emprega ações para reduzir as despesas administrativas no dia-a- } \\
\text { dia (controle de gastos com energia, reuniões por videoconferência, } \\
\text { redução do volume de impressões, uso racional do telefone, etc.). }\end{array}$ & 0,80 & 0,64 & 4,13 & 0,82 \\
\hline
\end{tabular}


Tabela 48. Estrutura empírica do instrumento de heteroavaliação de "Impacto do Treinamento em Profundidade". (Continuação)

\begin{tabular}{|c|c|c|c|c|}
\hline Itens & $\begin{array}{c}\text { Cargas } \\
\text { fatoriais }\end{array}$ & $h^{2}$ & $M$ & $D P$ \\
\hline $\begin{array}{l}\text { 5. Realiza ações de contenção de gastos sem promover a perda de } \\
\text { capacidade operacional ou elevação dos riscos. }\end{array}$ & 0,85 & 0,73 & 4,12 & 0,79 \\
\hline $\begin{array}{l}\text { 6. Incentiva os clientes a reduzir o consumo de recursos do Banco } \\
\text { (uso de canais automatizados para realizar transações, cadastramento } \\
\text { de débito automático, uso de cartões para pagamentos, etc). }\end{array}$ & 0,63 & 0,39 & 4,10 & 0,90 \\
\hline $\begin{array}{l}\text { 7. Concede créditos, presta serviços (produtos de seguridade e cartão } \\
\text { de crédito, por exemplo) e capta recursos (LCI e LCA) como formas } \\
\text { para aumentar as receitas operacionais do Banco. }\end{array}$ & 0,52 & 0,27 & 3,69 & 1,30 \\
\hline $\begin{array}{l}\text { 8. Acompanha os indicadores de eficiência operacional do Banco ao } \\
\text { longo do tempo para contribuir para a sua melhoria. }\end{array}$ & 0,75 & 0,56 & 3,79 & 1,04 \\
\hline$N$ & 1112 & & & \\
\hline Eigenvalue (Valor próprio) & 4,89 & & & \\
\hline \% da Variância Explicada $(P A F)$ & 56,15 & & & \\
\hline No. de itens & 08 & & & \\
\hline $\operatorname{Alfa}(\alpha)$ & 0,89 & & & \\
\hline KMO & 0,91 & & & \\
\hline \% da variância total explicada $(P C)$ & 61,22 & & & \\
\hline
\end{tabular}

A escala de heteroavaliação de "Impacto do Treinamento em Profundidade" referente ao curso "Eficiência Operacional" apresenta 8 itens, cujas cargas fatoriais variam entre 0,52 e 0,85 , em uma estrutura unifatorial $(\alpha=0,89)$ - o fator único explica $56,15 \%$ da variância total das respostas aos itens do instrumento.

\subsection{Impacto do treinamento no trabalho em amplitude.}

Tabela 49. Estrutura empírica do instrumento de autoavaliação de "Impacto do Treinamento em Amplitude".

\begin{tabular}{|c|c|c|c|c|}
\hline Itens & $\frac{\text { Cargas fatoriais }}{1}$ & $h^{2}$ & $M$ & $D P$ \\
\hline $\begin{array}{l}\text { 1. Aproveito as oportunidades que tenho para } \\
\text { praticar as novas habilidades. }\end{array}$ & 0,66 & 0,43 & 4,37 & 0,66 \\
\hline 2. Cometo menos erros no trabalho. & 0,79 & 0,63 & 4,25 & 0,71 \\
\hline 3. Realizo meus trabalhos com mais agilidade. & 0,86 & 0,74 & 4,31 & 0,71 \\
\hline 4. Melhorou a qualidade do meu trabalho. & 0,85 & 0,73 & 4,24 & 0,73 \\
\hline 5. Aumentou minha motivação para o trabalho. & 0,75 & 0,56 & 4,02 & 0,86 \\
\hline $\begin{array}{l}\text { 6. Sugiro com mais frequência mudanças nas rotinas } \\
\text { de trabalho. }\end{array}$ & 0,67 & 0,45 & 3,98 & 0,84 \\
\hline 7. Esclareço dúvidas dos meus colegas. & 0,62 & 0,38 & 4,28 & 0,73 \\
\hline$N$ & 1451 & & & \\
\hline Eigenvalue (Valor próprio) & 4,35 & & & \\
\hline \% da Variância Explicada $(P A F)$ & 56,39 & & & \\
\hline No. de itens & 07 & & & \\
\hline $\operatorname{Alfa}(\alpha)$ & 0,89 & & & \\
\hline KMO & 0,88 & & & \\
\hline \% da variância total explicada $(P C)$ & 62,24 & & & \\
\hline
\end{tabular}


A escala de autoavaliação de "Impacto do Treinamento em Amplitude" apresenta 7 itens, cujas cargas fatoriais variam entre 0,62 e 0,86, em uma estrutura unifatorial $(\alpha=0,89)$ - o fator único explica $56,39 \%$ da variância total das respostas aos itens do instrumento.

Tabela 50. Estrutura empírica do instrumento de heteroavaliação de "Impacto do Treinamento em Amplitude".

\begin{tabular}{|c|c|c|c|c|}
\hline Itens & $\begin{array}{c}\begin{array}{c}\text { Cargas } \\
\text { fatoriais }\end{array} \\
1\end{array}$ & $h^{2}$ & $\boldsymbol{M}$ & $D P$ \\
\hline 1. Aproveita oportunidades para praticar as novas habilidades. & 0,79 & 0,62 & 4,04 & 0,84 \\
\hline 2. Comete menos erros no trabalho. & 0,80 & 0,65 & 4,11 & 0,83 \\
\hline 3. Realiza os trabalhos com mais agilidade. & 0,87 & 0,76 & 4,07 & 0,86 \\
\hline 4. Melhorou a qualidade do trabalho. & 0,90 & 0,82 & 4,09 & 0,85 \\
\hline 5. Aumentou a motivação para o trabalho. & 0,85 & 0,72 & 3,92 & 0,91 \\
\hline 6. Sugere com mais frequência mudanças nas rotinas de trabalho. & 0,81 & 0,66 & 3,82 & 0,96 \\
\hline 7. Esclarece dúvidas dos colegas. & 0,78 & 0,61 & 4,14 & 0,88 \\
\hline$N$ & 1992 & & & \\
\hline Eigenvalue (Valor próprio) & 5,17 & & & \\
\hline \% da Variância Explicada $(P A F)$ & 69,60 & & & \\
\hline No. de itens & 07 & & & \\
\hline $\operatorname{Alfa}(\alpha)$ & 0,94 & & & \\
\hline $\mathrm{KMO}$ & 0,92 & & & \\
\hline$\%$ da variância total explicada $(P C)$ & 73,85 & & & \\
\hline
\end{tabular}

A escala de heteroavaliação de "Impacto do Treinamento em Amplitude" apresenta 7 itens, cujas cargas fatoriais variam entre 0,78 e 0,90, em uma estrutura unifatorial $(\alpha=0,94)$ - o fator único explica $69,60 \%$ da variância total das respostas aos itens do instrumento.

\subsubsection{Análises fatoriais confirmatórias.}

Como método confirmatório, a análise fatorial permite avaliar a validade de construto das medidas e testar se a estrutura fatorial teórica se adequa aos dados observados, sendo um processo de revisão e refinamento dos instrumentos e suas estruturas fatoriais (Laros, 2004). Foram analisadas as estruturas fatoriais dos instrumentos utilizados na pesquisa, visando corroborá-las por meio da análise fatorial confirmatória (AFC), uma vez que foram amplamente validadas em diferentes estudos realizados anteriormente em contextos organizacionais, mediante o uso de análises fatoriais exploratórias, na maioria dos casos. 
Para avaliar os ajustes dos diversos modelos, primeiramente testou-se o modelo hipotético inicial, tal qual como foi proposto, sem introduzir os índices de modificação e utilizando-se diferentes métodos de estimação: Maximum Likelihood (ML) ou Asymptotic Distribution Free $(A D F)$. O estimador deve ser condizente às características dos itens do instrumento, para que estimativas precisas sejam obtidas, além de estar de acordo com os dados amostrais, ou seja, adequado ao modelo empírico. Assim, o método $M L$ é apropriado a modelos que atendem ao pressuposto da normalidade multivariada e o $A D F$, apesar de não exigir a normalidade, requer uma amostra grande (Browne, 1984).

Para verificar a normalidade, observaram-se dois componentes de análise: a assimetria (skewness) e a curtose (kurtosis) das variáveis. Se a distribuição das variáveis é normal, os valores de assimetria e curtose são zero. Contudo, a ocorrência de distribuições normais com valores iguais a zero de assimetria e curtose é bastante rara, sobretudo em pesquisas na área de Ciências Sociais. No âmbito da Psicologia, por exemplo, a maioria dos instrumentos psicométricos apresenta itens com distribuição nãonormal. Nos casos em que as distribuições das variáveis são normais, o método $M L$ é muito confiável, e quanto maior o tamanho da amostra, menor deve ser a preocupação com a normalidade. Os valores de referência para a assimetria e curtose considerados foram entre $-2,0$ e 2,0 .

As amostras do presente estudo são suficientemente grandes, tendo respeitados os pressupostos da variabilidade de respostas entre os participantes e a normalidade multivariada - na maioria dos instrumentos, todos os itens apresentaram distribuição normal, estando seus valores muito abaixo dos de referência (-2 e 2), ou em poucos casos, havia apenas pequenos desvios de normalidade em alguns itens. Assim, o método $M L$ configura-se como adequado à testagem dos modelos e robusto para estimar parâmetros, influindo sobre a fidedignidade dos resultados encontrados.

Posteriormente, utilizando-se os arquivos de dados sem os dados ausentes (substituição dos omissos pelas médias das respostas para cada instrumento), foram testados modelos re-especificados, tendo como base a análise dos indicadores de ajuste, as variâncias explicadas dos itens (comunalidades) e as covariâncias das variáveis observadas com a variável latente, as cargas fatoriais e os resíduos - quanto mais alta a carga fatorial, menor o resíduo. Decisões foram tomadas a partir da observação desses valores, levando à retirada de itens ou à inclusão de covariâncias significativas entre os erros, sempre respaldadas pelos limites da teoria sobre os dados empíricos. Dessa forma, 
compararam-se os modelos mais simples com os re-especificados, buscando o modelo mais parcimonioso e ajustado aos dados empíricos.

Observando-se os índices de modificação, em alguns casos, encontraram-se indícios para melhorar o ajuste do modelo. Ao introduzir parâmetros significativos ao modelo, os valores obtidos para os diferentes índices de ajuste melhoram, havendo pouca alteração nos valores das cargas fatoriais, correlações, etc. Dessa maneira, uma vez introduzidos os índices de modificação, pôde-se ponderar os ganhos e tomar decisões pautadas em justificativas teóricas.

Os critérios utilizados para realizar as re-especificações nos modelos seguiram os pressupostos propostos por Byrne (2010): a) alteração/eliminação de trajetórias e/ou erros correlacionados quando o índice de modificação era superior a $50(p<0,001)$; b) exclusão de itens apenas se justificável do ponto de vista teórico; c) quando possível, optou-se pela eliminação de um determinado item do par ao invés de se acrescentar a correlação entre os erros; d) preferencialmente, eliminaram-se itens cujos erros apresentavam covariância elevada com dois ou mais erros de outros itens.

Foram utilizados diferentes tipos de indicadores de ajuste para comparar os vários modelos: medidas absolutas de ajuste - o grau em que o modelo estimado se aproxima da matriz de (co)variância, a qual deseja-se aproximar-se (CMIN, CMIN/DF, RMSR, GFI, RMSEA); medidas incrementais de ajuste - comparam o modelo estimado com o modelo nulo (modelo de independência onde se supõe que não há relações entre as variáveis) (TLI, CFI); e medidas de parcimônia - indicadores de comparação de modelos, relacionam a bondade de ajuste do modelo com o número de parâmetros estimados - um modelo é mais parcimonioso quando consegue um bom ajuste estimando poucos parâmetros (AIC, BIC, PRATIO).

Os valores de referência adotados para os indicadores de bondade de ajuste do modelo podem ser observados na Tabela 51.

Tabela 51. Valores de referência dos indicadores de bondade de ajuste do modelo.

\begin{tabular}{c|c|c|c|c}
\hline \multirow{2}{*}{$\begin{array}{c}\text { Tipo de Indicador } \\
\text { de Ajuste }\end{array}$} & $\begin{array}{c}\text { Indicador de Bondade } \\
\text { de Ajuste }\end{array}$ & \multicolumn{3}{|c}{ Valores de Referência } \\
\cline { 3 - 5 } & CMIN/DF & $<1,96$ & $<2$ & $<5$ \\
& $R M S R$ & $<0,05$ & - & $<0,08$ \\
Absoluta & Satisfatório/Bom & Aceitável \\
& RMSEA & $>0,95$ & $>0,90$ & - \\
& $T L I$ & $<0,05$ & - & $<0,08$ \\
\hline Incremental & ThI & $>0,95$ & $>0,90$ & - \\
\hline
\end{tabular}


Tabela 51. Valores de referência dos indicadores de bondade de ajuste do modelo. (Continuação)

\begin{tabular}{c|c|c|c|c}
\hline \multirow{2}{*}{$\begin{array}{c}\text { Tipo de Indicador } \\
\text { de Ajuste }\end{array}$} & $\begin{array}{c}\text { Indicador de Bondade } \\
\text { de Ajuste }\end{array}$ & \multicolumn{3}{|c}{ Valores de Referência } \\
\cline { 3 - 5 } & $C F I$ & $>0,95$ & $>0,90$ & - \\
\hline Incremental & $A I C$ & Modelo com & - & Satisfatório/Bom \\
\hline \multirow{3}{*}{ Parcimônia } & BIC & menor valor & - & - \\
& PRATIO & & - & - \\
\hline
\end{tabular}

Notas: CMIN/DF $\left(\chi^{2} / d f\right), R M S R$ (Root Mean Square Residual), GFI (Goodness-of-Fit Index), RMSEA (Root Mean Square Error Approximation),TLI (Tucker Luwis Index), CFI (Comparative-Fit Index), AIC (Akaike Information Criterion), BIC (Bayesian Information Criterion), PRATIO (razão de parcimônia).

Amostras muito grandes, notória e comprovadamente, interferem sobre os valores do qui-quadrado $\left(\chi^{2}\right)$ e, por conseguinte no $C M I N / D F$, que deixa de ser um bom indicador de ajuste do modelo (Rios \& Wells, 2014). No mesmo sentido, em modelos complexos, com muitas variáveis ou parâmetros estimados e com a presença de resíduos, é provável obter um alto RMSEA, que indica o grau de erro de especificação do modelo. O RMSEA depende do número de parâmetros estimados, portanto seu valor pode ser penalizado pelo número de graus de liberdade $(D F)$. Nesses casos, os outros índices citados, dentre as medidas absolutas de ajuste, foram levados em consideração, como é o caso do RMSR e GFI, além das medidas incrementais de ajuste (CFI e $T L I)$.

\subsection{Estratégias de aprendizagem.}

O modelo hipotético inicial (estrutura empírica com 4 fatores, 19 itens e $0,80<\alpha$ $<0,85)$ apresenta falhas na bondade de ajuste, indicando que a análise fatorial confirmatória para o instrumento de Estratégias de Aprendizagem, sem a introdução dos índices de modificação e as re-especificações, não se ajusta bem.

A análise dos índices de modificação indicou o resíduo que possuía o valor mais alto na correlação entre o par de erros e8-e9, apontando para a redundância entre os mesmos, uma vez que seus conteúdos são muito similares (Item 8 "Busquei solucionar minhas dúvidas ao consultar os materiais didáticos do curso" e 9 "Busquei compreender melhor os conteúdos ao estudá-los nos materiais didáticos do curso") e provavelmente foram entendidos como uma mesma medida pelos respondentes. A decisão de retirar um deles justifica-se teoricamente, pois se referem à busca pela compreensão de conteúdos mediante consulta ao material didático do curso, sendo que as ações de solucionar dúvidas e compreender melhor os conteúdos são semelhantes, podendo a primeira (solucionar dúvidas) estar contida e expressa na segunda (compreender melhor). O item 8 foi 
escolhido para ser eliminado, já que possuía menor carga fatorial em comparação ao item 9, havia outros resíduos altos associados a ele, além do alfa da escala geral permanecer o mesmo $(\alpha=0,89)$ com a sua retirada. Com a sua exclusão, os indicadores obtidos para o modelo re-especificado 1 são melhores que o do modelo original.

Mas, como a bondade de ajuste do modelo ainda não continha índices muito bons, introduziu-se a correlação entre os erros e7-e10 $(r=0,35)$, também do mesmo fator de estratégias cognitivas/busca de ajuda: 7 "Busquei auxílio de colegas para esclarecer minhas dúvidas sobre os conteúdos do curso" e 10 "Busquei outras fontes de pesquisa relacionadas ao curso para me ajudar a aprender" - ambos tratam de estratégias de busca de ajuda (interpessoal e ao material didático) que se agruparam em um mesmo fator neste estudo. Os resultados para o modelo re-especificado 2 mostram melhoras no ajuste (Tabela 52 e Figura 6).

Quanto à análise da normalidade, a distribuição dos itens, no geral, é normal - os valores de assimetria e curtose variaram, respectivamente, de -1,60 a 0,08, e de -1,00 a 1,94, havendo apenas 4 itens, do total de 18, que apresentam valores superiores aos do intervalo de referência |-2 e 2|, são eles: $1(3,94), 12(2,56), 4(2,74)$ e $6(2,43)$.

Tabela 52. Indicadores de ajuste para os modelos original e re-especificados do instrumento de "Estratégias de Aprendizagem".

\begin{tabular}{lcccccccc}
\hline Modelo & $\chi^{2}$ & $\boldsymbol{g}$ & $\boldsymbol{C M I N / D F}$ & $\boldsymbol{G F I}$ & $\boldsymbol{R M S R}$ & $\boldsymbol{C F I}$ & $\boldsymbol{T L I}$ & $\boldsymbol{R M S E A}$ \\
\hline Original & 2336,949 & 146 & 16,0 & 0,88 & 0,06 & 0,87 & 0,85 & 0,08 \\
Re-especificado 1 & 1500,119 & 129 & 11,62 & 0,93 & 0,05 & 0,91 & 0,89 & 0,07 \\
Re-especificado 2 & 1267,803 & 128 & 9,90 & 0,93 & 0,05 & 0,92 & 0,91 & 0,06 \\
\hline
\end{tabular}

Notas: $N=2071$; o modelo re-especificado 1 não inclui o item 8; o modelo re-especificado 2 exclui o item 8 e contém as correlações entre o par de erros e7-e10. 


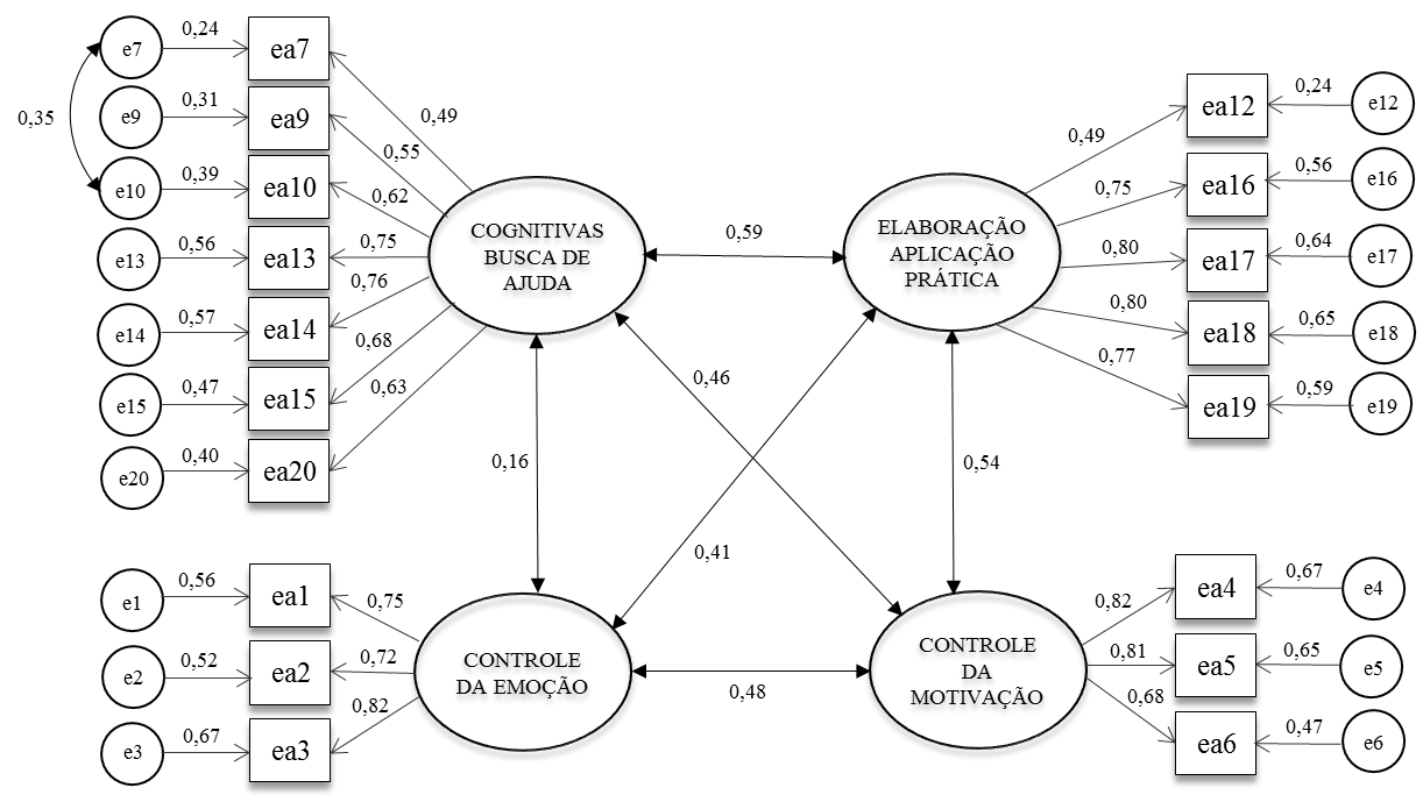

Figura 6. Cargas fatoriais estandardizadas, coeficientes de correlação e erros padrão da AFC para o instrumento de Estratégias de Aprendizagem (modelo re-especificado 2).

\subsection{Reação aos procedimentos instrucionais.}

O modelo hipotético inicial (estrutura empírica unifatorial com 9 itens e $\alpha=0,92$ ), para o instrumento de Reação aos Procedimentos Instrucionais, apresenta bons valores para os indicadores de ajuste, com exceção do CMIN/DF e do RMSEA.

Uma opção seria considerar o modelo re-especificado 1, em que aos dois pares de erros (e1-e2 e e6-e7) apontados com valores mais altos na análise dos resíduos, foram introduzidas correlações. Os itens 1 "Correspondência entre o conteúdo proposto e os objetivos do curso" e 2 "Correspondência entre o conteúdo do curso e os seus objetivos pessoais" e 6 "Atividades/tarefas propostas ao final de cada unidade" e 7 "Orientação para solução de erros nas atividades/tarefas" apresentam similaridade de conteúdo em sua redação, o que pode ter levado a que os participantes do estudo entendessem os dois itens como uma mesma medida, contribuindo para que fosse encontrada a covariância entre eles, embora sejam baixas: $r=0,29$ (e1-e2) e $r=0,19$ (e6-e7). Nesse modelo, obtiveram-se valores incrementados dos indicadores e uma estimação aceitável do RMSEA.

Ao testar um novo modelo (modelo re-especificado 2) apenas com a correlação entre o par de itens 1 e 2, que apresenta a maior correlação - a covariância entre os pares de erros (e1-e2) é igual a $r=0,30$ - os valores dos índices tiveram um leve aumento e o valor de BIC diminui, indicando que este é mais ajustado que o modelo hipotético inicial $(\triangle B I C=146,07)$ - Tabela 53 e Figura 7. 
A análise da normalidade aponta que todos os itens estão dentro do limite de referência estabelecido |-2 e 2|, indicando distribuição normal - variação de assimetria de $-0,86$ a - $-0,48$, e de curtose, de 1,06 a 1,94 -, com exceção do item 6 que apresenta valor levemente fora do limite $(2,03)$.

Tabela 53. Indicadores de ajuste para os modelos original e re-especificados do instrumento de "Reação aos Procedimentos Instrucionais".

\begin{tabular}{lcccccccc}
\hline Modelo & $\chi^{\mathbf{2}}$ & $\boldsymbol{g l}$ & $\boldsymbol{C M I N / D F}$ & $\boldsymbol{G F I}$ & $\boldsymbol{R M S R}$ & $\boldsymbol{C F I}$ & $\boldsymbol{T L I}$ & $\boldsymbol{R M S E A}$ \\
\hline Original & 497,955 & 27 & 18,44 & 0,94 & 0,01 & 0,95 & 0,93 & 0,09 \\
Re-especificado 1 & 294,449 & 25 & 11,77 & 0,96 & 0,01 & 0,97 & 0,96 & 0,07 \\
Re-especificado 2 & 344,325 & 26 & 13,24 & 0,95 & 0,01 & 0,96 & 0,95 & 0,08 \\
\hline
\end{tabular}

Notas: $N=1915$; o modelo re-especificado 1 contém as correlações entre os pares de erros e1-e2 e e6-e7; o modelo re-especificado 2, apenas as correlações entre e1-e2.

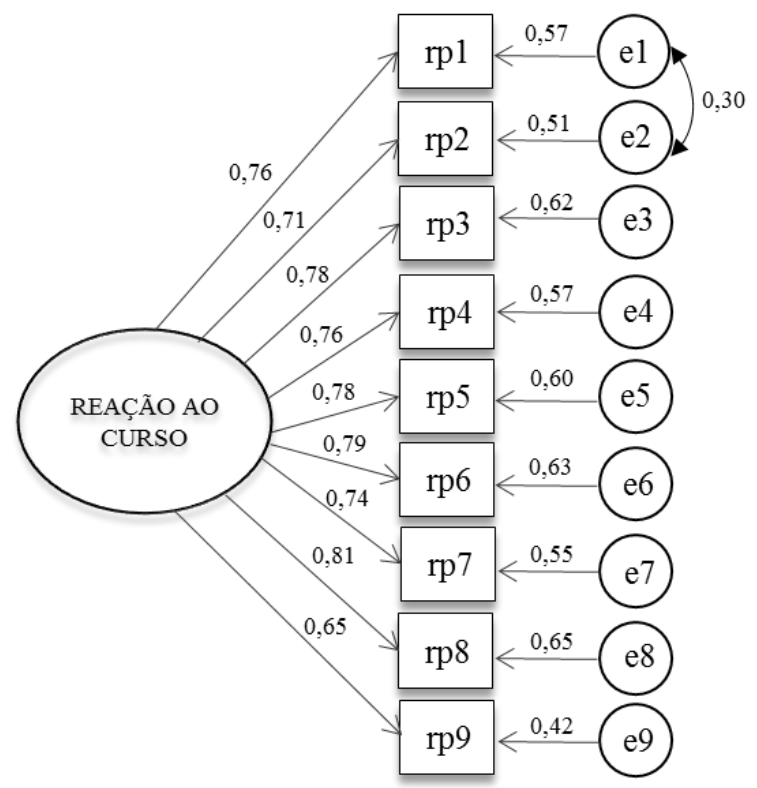

Figura 7. Cargas fatoriais estandardizadas, coeficientes de correlação e erros padrão da AFC para o instrumento de Reação aos Procedimentos Instrucionais (modelo re-especificado 2).

\subsection{Suporte à transferência.}

O modelo hipotético inicial (estrutura empírica com 3 fatores, 14 itens e $0,85<\alpha$ $<$ 0,95) apresenta falhas na bondade de ajuste, indicando que a análise fatorial confirmatória para o instrumento de Suporte à Transferência, sem a introdução dos índices de modificação e as re-especificações, não se ajusta bem (Tabela 54 e Figura 8).

Logo, com a indicação da presença de multicolinearidade entre os mesmos itens presentes nos fatores de suporte de supervisores e de pares ("Removem as dificuldades ao uso eficaz das novas habilidades aprendidas em treinamento" e "Criam oportunidades 
de usar no trabalho as novas habilidades aprendidas em treinamento") - itens 3 e 4 (supervisores: $r=0,82$ ) e itens 9 e 10 (pares: $r=0,80$ ) - optou-se por testar o modelo com a retirada dos itens 3 e 9, já que há altos indícios de que os participantes consideraram similares os atos de "remover dificuldades" e "criar oportunidades". Faz sentido supor que ao criar oportunidades para a aplicação das habilidades aprendidas é necessário que antes tenham sido removidas as dificuldades que poderiam obstaculizar o uso eficaz das novas competências no trabalho.

Esse modelo (modelo re-especificado 1) apresentou valores ainda não satisfatórios para os indicadores de ajuste. Em comparação com o anterior, o índice de parcimônia BIC aponta que este, com a exclusão dos itens altamente correlacionados entre si, é mais ajustado que aquele, com os 14 itens iniciais na estrutura proposta $(\triangle \mathrm{BIC}=511,45)$.

Com vistas a melhorar o ajuste do modelo, foram analisados os índices de modificação, que apresentaram valores importantes entre os erros e5-e6 (5 "Fornecem feedback quanto à aplicação no trabalho de novas habilidades adquiridas em treinamento" e 6 "Consideram minhas sugestões, em relação ao que foi aprendido em treinamento, no trabalho"), tanto para o fator referente ao apoio de supervisores como pares, indicando que os participantes entenderam tais itens como uma mesma medida. Uma vez introduzidas as correlações entre esses pares de erros, os valores para os indicadores obtidos não foram satisfatórios (modelo re-especificado 2). Em comparação com o anterior, o índice de parcimônia BIC aponta que este, com a exclusão dos itens altamente correlacionados entre si e a inclusão das correlações entre os erros (e5-e6) em ambos fatores (supervisores e pares), é mais ajustado $(\triangle \mathrm{BIC}=88,09)$, mas ainda não apresenta bons indicadores.

Isso pode ser devido à forte e positiva correlação entre os fatores de suporte de supervisores e de pares $(r=0,71)$, o que impede o ajuste do modelo, pois desrespeita um dos principais pressupostos da AFC, o da ausência de multicolinearidade. Talvez os fatores não deveriam ser estimados em separado, mas como uma única medida, como preconiza a literatura dominante da área: o suporte psicossocial.

Desse modo, testou-se um modelo com somente dois fatores, suporte psicossocial (12 itens relativos ao apoio de supervisores e de pares) e suporte material (2 itens). Inicialmente, este modelo mostrou o pior ajuste em comparação aos anteriormente citados: $N=1540, \chi^{2}=5769,016, g l=76, C M I N / D F=75,90, \quad G F I=0,55, \quad R M S E A=0,22$, $R M S R=0,09 ; C F I=0,72, T L I=0,67, B I C=5981,863$ (acréscimo de 3461,06 em comparação ao modelo hipotético inicial). Observados os índices de modificação, como tentativa a 
ajustá-lo, foram feitas alterações no modelo, mas obtiveram-se valores dos indicadores ainda inferiores aos da solução com 3 fatores:

a) Modelo com a retirada dos itens sc2 e sc3: $N=1540, \chi^{2}=3214,980, g l=53$, $C M I N / D F=60,66, G F I=0,72, R M S E A=0,19, R M S R=0,08 ; C F I=0,80, T L I=0,75$, $B I C=3398,468$;

b) Modelo com a retirada dos itens sc2 e sc3 e inclusão de correlação entre os pares de erros e_sc1-e_sc4: $N=1540, \chi^{2}=2745,817, g l=52, C M I N / D F=52,80, G F I=0,78$, $R M S E A=0,18, R M S R=0,08 ; C F I=0,83, T L I=0,78, B I C=2936,645$.

Ainda foram testados um modelo bifator e um de segunda ordem, mas ambos apresentaram falhas na bondade de ajuste. Finalmente, ao testar separadamente a escala que avalia o apoio de supervisores (Figura 9) da escala de suporte de pares (Figura 10) cada uma associada ao fator que mede o suporte material -, obtiveram-se os melhores índices, bem como os valores dos resíduos baixos, como mostra a Tabela 55. O cômputo do Alfa de Cronbach para as novas escalas, com 8 itens cada, resultou em $\alpha=0,92$ para a de suporte de supervisores/material e $\alpha=0,90$ para a de suporte de pares/material, tendo havido um leve decréscimo comparado com o índice de consistência interna da escala total $(\alpha=0,94)$, que continha os 3 fatores juntos.

Todos os itens apresentam distribuição normal, estando seus valores muito abaixo dos de referência |-2 e 2|: assimetria (de -0,92 a -0,41) e curtose (de -0,26 a 0,58).

Tabela 54. Indicadores de ajuste para os modelos original e re-especificados do instrumento de "Suporte à Transferência".

\begin{tabular}{lcccccccc}
\hline Modelo & $\chi^{\mathbf{2}}$ & $\boldsymbol{g l}$ & $\boldsymbol{C M I N / D F}$ & $\boldsymbol{G F I}$ & $\boldsymbol{R M S R}$ & $\boldsymbol{C F I}$ & $\boldsymbol{T L I}$ & $\boldsymbol{R M S E A}$ \\
\hline Original & 2293,272 & 74 & 30,99 & 0,82 & 0,03 & 0,89 & 0,86 & 0,14 \\
Re-especificado 1 & 1811,171 & 51 & 35,51 & 0,84 & 0,03 & 0,89 & 0,85 & 0,15 \\
Re-especificado 2 & 1708,399 & 49 & 34,86 & 0,85 & 0,03 & 0,89 & 0,86 & 0,14 \\
\hline
\end{tabular}

Notas: $N=1540$; o modelo re-especificado 1 não inclui os itens 3 e 9; modelo re-especificado 2 contém a correlação entre o par de erros e5-e6, além da exclusão dos itens 3 e 9. 


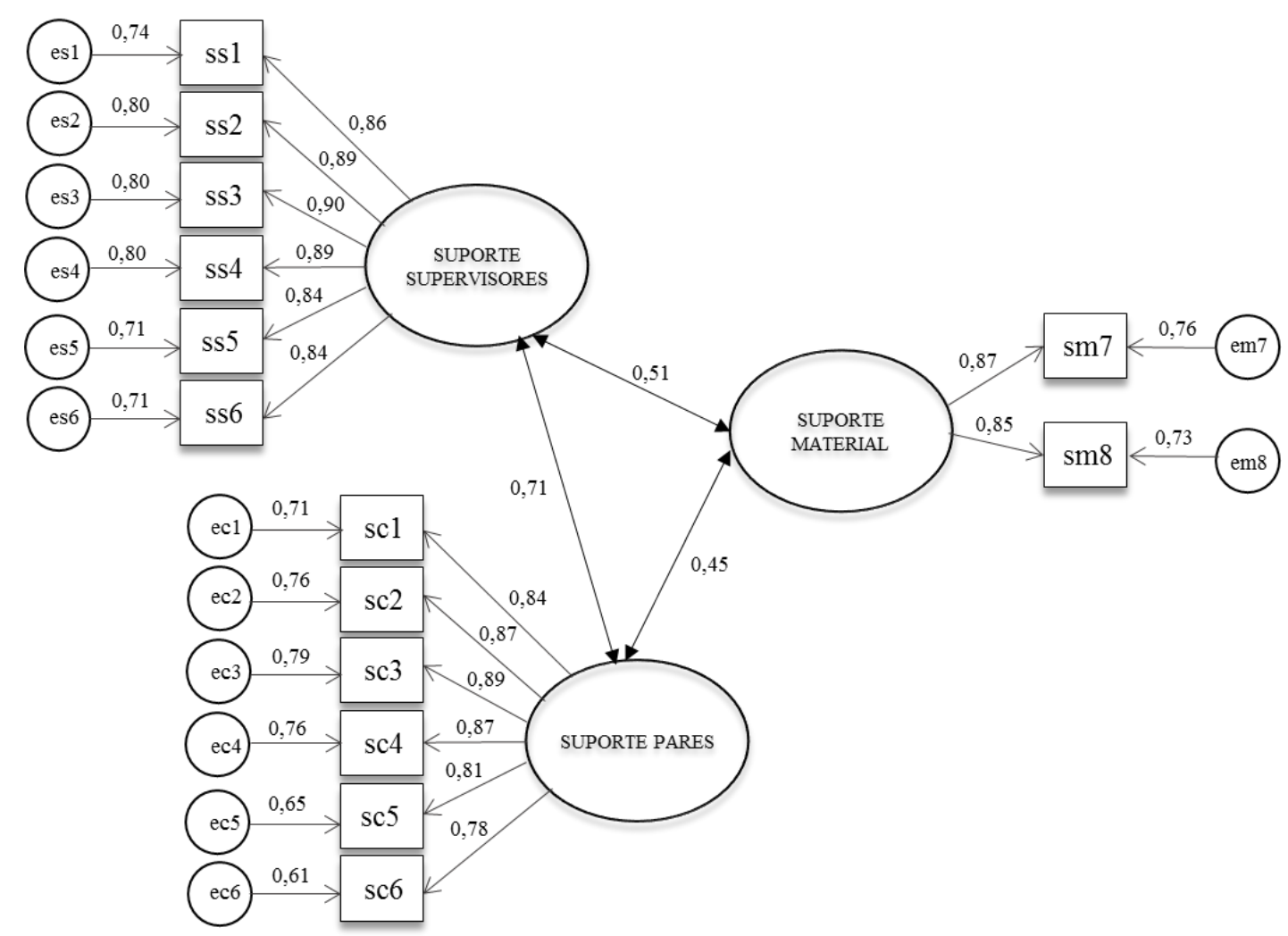

Figura 8. Cargas fatoriais estandardizadas, coeficientes de correlação e erros padrão da AFC para o instrumento de Suporte à Transferência (modelo hipotético inicial).

Tabela 55. Indicadores de ajuste para as escalas do instrumento de "Suporte à Transferência".

\begin{tabular}{lcccccccc}
\hline Modelo & $\chi^{2}$ & $\boldsymbol{g l}$ & $\boldsymbol{C M I N / D F}$ & $\boldsymbol{G F I}$ & $\boldsymbol{R M S R}$ & $\boldsymbol{C F I}$ & $\boldsymbol{T L I}$ & $\boldsymbol{R M S E A}$ \\
\hline Suporte Supervisores & 230,888 & 19 & 12,15 & 0,96 & 0,01 & 0,98 & 0,97 & 0,08 \\
Suporte Pares & 217,514 & 19 & 11,44 & 0,96 & 0,02 & 0,97 & 0,96 & 0,08 \\
\hline
\end{tabular}

Notas: $N=1540$; cada modelo, além do fator de suporte supervisores ou pares, contém o fator de suporte material.

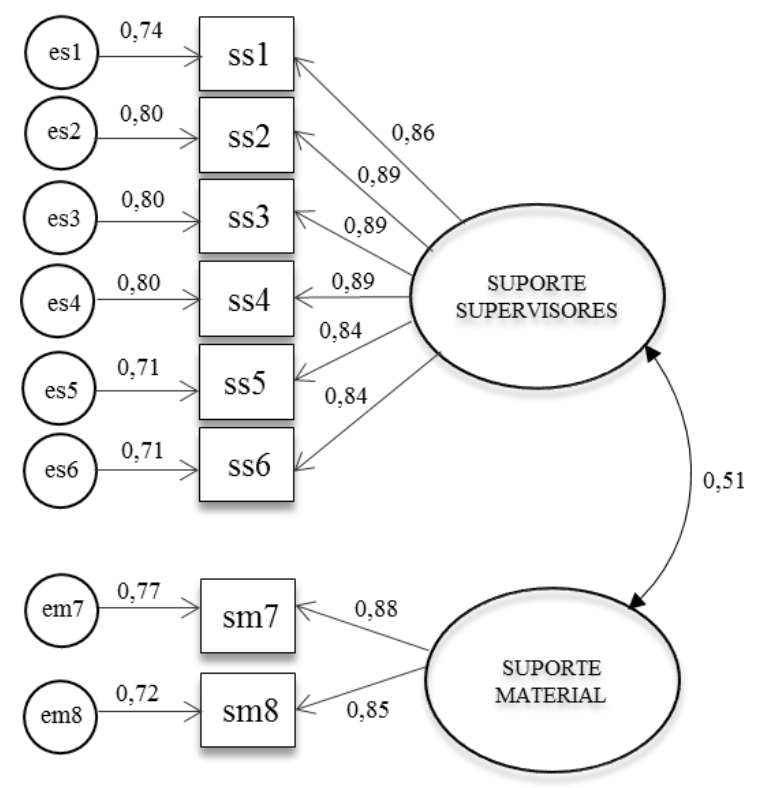

Figura 9. Cargas fatoriais estandardizadas, coeficientes de correlação e erros padrão da AFC para a escala de Suporte de Supervisores e Material do instrumento de Suporte à Transferência. 


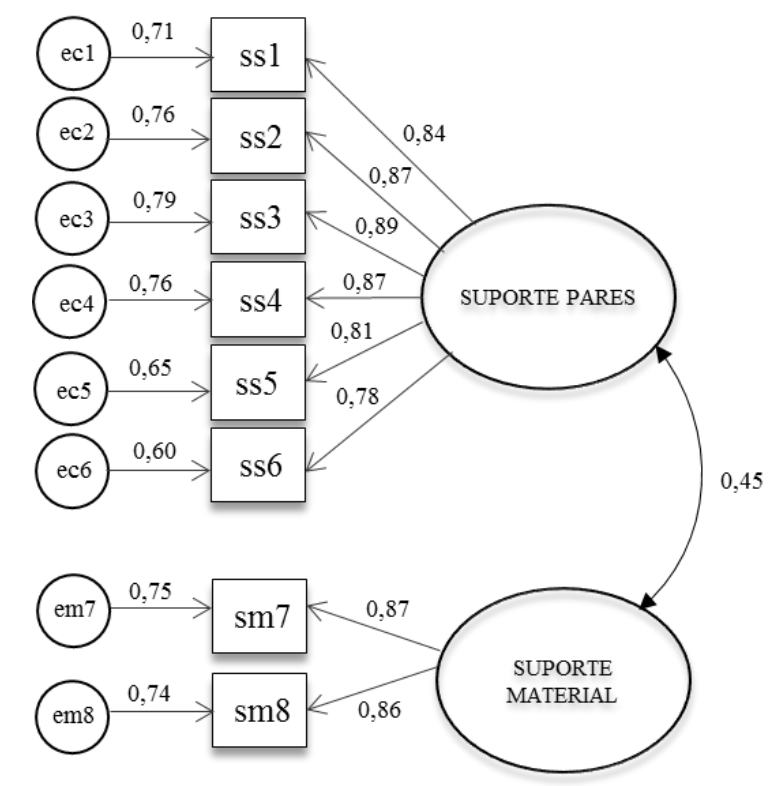

Figura 10. Cargas fatoriais estandardizadas, coeficientes de correlação e erros padrão da AFC para a escala de Suporte de Pares e Material do instrumento de Suporte à Transferência.

\subsection{Barreiras e facilitadores em EAD.}

O modelo hipotético inicial (estrutura empírica unifatorial com 18 itens e $\alpha=0,98$ ) apresenta falhas na bondade de ajuste, indicando que a análise fatorial confirmatória para o instrumento de Barreiras e Facilitadores em EAD, sem a introdução dos índices de modificação e as re-especificações, não se ajusta bem.

Em seguida, considerando-se a análise dos índices de modificação, os resíduos (covariância residual entre os itens), as cargas fatoriais e as variâncias com o construto, os itens 2, 10 e 12 aparecem como os mais problemáticos - já apontados na AFE com as cargas fatoriais mais baixas e menor variância explicada com a variável latente: item 2 "Conexão à internet" (carga fatorial= 0,$78 ; h^{2}=0,60$ ); item 10 "Conciliação do curso com as atividades profissionais" (carga fatorial=0,74; $h^{2}=0,56$ ); item 12 "Tempo disponível para estudar" ( carga fatorial $=0,74 ; h^{2}=0,55$ ).

Especialmente no caso dos itens 10 (conciliação do curso com as atividades profissionais) e 12 (tempo disponível para estudar), no contexto estudado, poderiam significar o mesmo, pois o curso deveria ser realizado durante a jornada de trabalho, indicando uma barreira praticamente idêntica, ou seja, percebida como uma mesma medida pelos respondentes. Provavelmente, por esse motivo, a análise dos resíduos apontou um valor tão alto para esse par de itens.

Por isso, testou-se um modelo sem esses itens (2, 10 e 12). Embora os índices tenham melhorado, indicando um modelo mais ajustado que o anterior (modelo hipotético 
inicial), a análise dos resíduos e das cargas fatoriais, apontaram os itens 11 "Conciliação do curso com os compromissos familiares", 13 "Conciliação do curso com outras atividades de estudo" e 14 "Condições do ambiente de estudo em casa" como possíveis empecilhos para o bom ajuste do modelo. Cabe ressaltar que, mais uma vez, principalmente o item 14 (condições do ambiente de estudo em casa) não corresponde à realidade e à especificidade da situação em questão, já que o curso era realizado no ambiente de trabalho e não em casa. Assim, excluíram-se mais esses 3 itens para testar o ajuste. $\mathrm{O}$ valor do $B I C$ aponta este modelo (retirada de 6 itens da estrutura: 2, 10, 11, 12, 13 e 14) como mais ajustado que o anterior (retirada de 3 itens da estrutura: 2, 10 e 12) $\triangle B I C=943,60$.

Testou-se também uma solução que contivesse o item 12 e excluísse os itens 2 , 10, 11, 13 e 14, pois a análise da literatura dominante aponta o fator "tempo" como uma das principais barreiras ao desempenho durante a realização de treinamentos. Além disso, os conteúdos presentes nos itens que tratam da conciliação do curso com outras atividades diversas podem já estar expressas nesse item mais genérico que se refere ao tempo disponível para estudar. O modelo re-especificado 3 (Tabela 56 e Figura 11) apresenta um ajuste bastante semelhante ao anterior, indicando a adequação de se manter o item 12 na estrutura fatorial do instrumento, que pode incidir sobre a explicação dos resultados embora este item apresente a menor covariância com a variável latente em comparação com os demais. Para futuras aplicações do instrumento, deve-se observar as particularidades do contexto e da amostra investigados e ponderar a inclusão de alguns dos itens ora excluídos em sua estrutura.

O cômputo do Alfa de Cronbach para a nova escala com 13 itens resultou igual que o da anterior (18 itens), $\alpha=0,98$, indicando a manutenção da confiabilidade do instrumento, mesmo com a retirada de 5 itens de sua estrutura empírica. Isso levaria a pensar que mais itens poderiam estar inflando a estrutura fatorial da escala, mas não foram encontrados outros valores altos de resíduos entre os seus itens constituintes que justificassem novos cortes, nem que pudessem ser explicados teoricamente. Portanto, conforme os limites estatísticos e teóricos citados, não foram realizadas novas modificações na escala, que apresenta excelente validade (cargas fatoriais) e confiabilidade (consistência interna).

Todos os itens apresentam distribuição normal, estando seus valores muito abaixo dos de referência |-2 e 2|: assimetria (de 0,47 a 1,26) e curtose (de -1,00 a 0,29). 
Tabela 56. Indicadores de ajuste para os modelos original e re-especificados do instrumento de "Barreiras e Facilitadores em EAD”.

\begin{tabular}{lcccccccc}
\hline Modelo & $\chi^{2}$ & $\boldsymbol{g l}$ & $\boldsymbol{C M I N / D F}$ & $\boldsymbol{G F I}$ & $\boldsymbol{R M S R}$ & $\boldsymbol{C F I}$ & $\boldsymbol{T L I}$ & $\boldsymbol{R M S E A}$ \\
\hline Original & 4268,450 & 135 & 31,61 & 0,75 & 0,06 & 0,90 & 0,89 & 0,13 \\
Re-especificado 1 & 2050,573 & 90 & 22,78 & 0,84 & 0,04 & 0,95 & 0,94 & 0,11 \\
Re-especificado 2 & 1151,974 & 54 & 21,33 & 0,89 & 0,03 & 0,96 & 0,95 & 0,10 \\
Re-especificado 3 & 1323,307 & 65 & 20,35 & 0,88 & 0,03 & 0,96 & 0,95 & 0,10 \\
\hline
\end{tabular}

Notas: $N=1810$; o modelo re-especificado 1 não inclui os itens 2, 10 e 12; o modelo re-especificado 2, exclui além destes, os itens 11, 13 e 14. O modelo re-especificado 3 não contém os itens 2, 10, 11, 13 e 14.

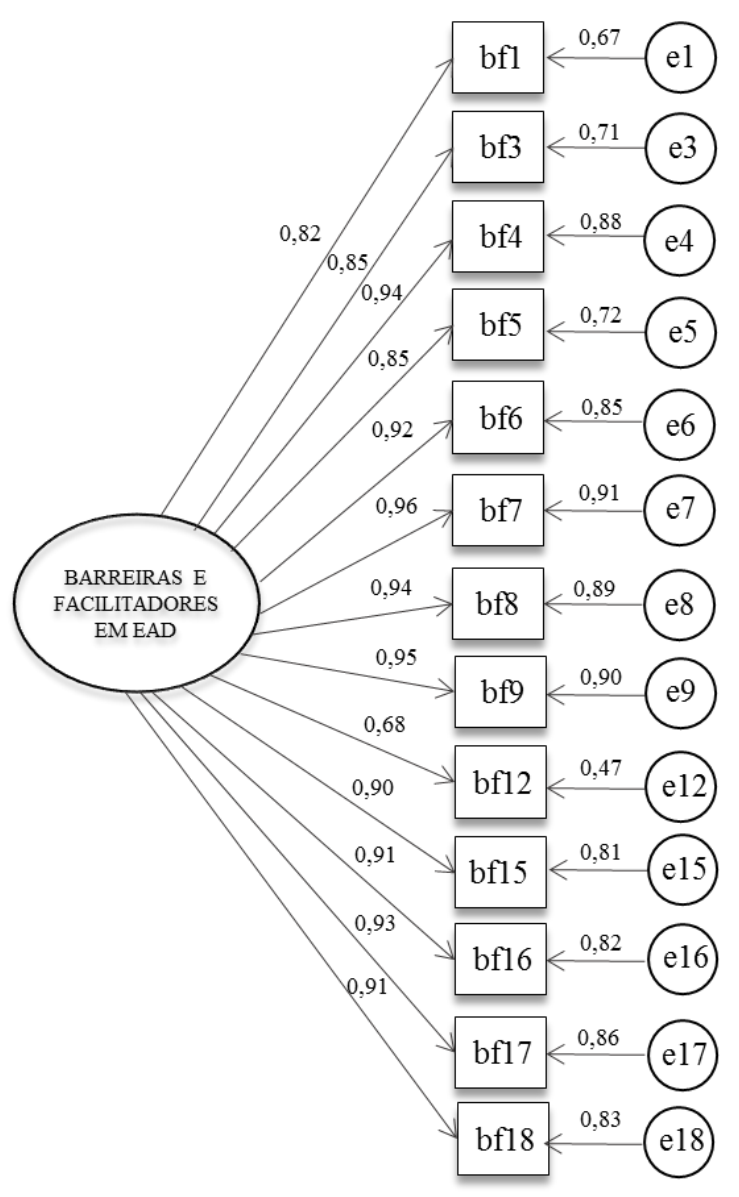

Figura 11. Cargas fatoriais estandardizadas, coeficientes de correlação e erros padrão da AFC para o instrumento de Barreiras e Facilitadores em EAD (modelo re-especificado 3).

\subsection{Impacto do treinamento no trabalho em profundidade.}

O modelo hipotético inicial (estrutura empírica unifatorial com 8 itens e $\alpha=0,85$ ), para o instrumento de autoavaliação de Impacto em Profundidade, apresenta falhas na bondade de ajuste. Com vistas a melhorar os indicadores, investigaram-se os índices de modificação: a análise dos resíduos apontou valores muito altos nas correlações entre os pares de erros e6-e7 e e7-e8. Tais itens (6, 7 e 8) são menos diretamente relacionados aos objetivos específicos do treinamento avaliado "Eficiência Operacional". Podiam 
representar comportamentos mais distantes do dia a dia de trabalho ou indiretamente aplicados no trabalho, ou seja, menos propícios a serem colocados em prática; ou ainda, não eram compatíveis a determinados cargos de trabalhadores que participaram do treinamento, que não desempenhavam atividades que tivesse contato com clientes do Banco, por exemplo, e nem concediam créditos, prestavam serviços diversos ou captavam ativamente recursos. São eles:

6. Incentiva os clientes a reduzir o consumo de recursos do Banco (uso de canais automatizados para realizar transações, cadastramento de débito automático, uso de cartões para pagamentos, etc).

7. Concede créditos, presta serviços (produtos de seguridade e cartão de crédito, por exemplo) e capta recursos (LCI e LCA) como formas para aumentar as receitas operacionais do Banco.

8. Acompanha os indicadores de eficiência operacional do Banco ao longo do tempo para contribuir para a sua melhoria.

Como o item 7 apresentava a carga fatorial mais baixa $(0,28)$, e a análise do Alfa de Cronbach se este item fosse excluído resultaria no incremento do índice de consistência interna da escala global - de $\alpha=0,85$ para $\alpha=0,87$, propôs-se um novo modelo com a sua retirada. Tal item parece representar: a) uma competência não requerida por todas as áreas de trabalho do Banco; b) uma competência não compatível a determinados cargos que participaram do treinamento, mas específica a apenas certos postos de trabalho; c) uma competência menos diretamente relacionada ao treinamento avaliado, já que tinha como foco a redução de despesas ou o aumento da eficiência operacional nas atividades administrativas de trabalho, e não o incremento das receitas do Banco, mas a melhora dos resultados como consequência. No modelo re-especificado 1, com a exclusão do item 7 e a inclusão de correlação entre os pares de erros e6-e8, embora fosse baixa $(r=0,19)$, obtiveram-se os melhores valores dos indicadores de ajuste (Tabela 57 e Figura 12).

A análise da normalidade dos itens aponta somente o item 6 com distribuição nãonormal $(3,76)$, considerando-se o intervalo de referência $\mid-2,0$ e 2,0|; os demais possuem valores bastante inferiores ao limite estabelecido (assimetria entre -1,57 e -0,58; curtose entre $-0,002$ e 1,56).

Tabela 57. Indicadores de ajuste para os modelos original e re-especificados do instrumento de autoavaliação de "Impacto do Treinamento no Trabalho em Profundidade".

\begin{tabular}{lcccccccc}
\hline Modelo & $\chi^{2}$ & $\boldsymbol{g l}$ & $\boldsymbol{C M I N / D F}$ & $\boldsymbol{G F I}$ & $\boldsymbol{R M S R}$ & $\boldsymbol{C F I}$ & $\boldsymbol{T L I}$ & $\boldsymbol{R M S E A}$ \\
\hline Original & 528,480 & 20 & 26,42 & 0,92 & 0,06 & 0,89 & 0,85 & 0,12 \\
Re-especificado 1 & 141,922 & 13 & 10,91 & 0,97 & 0,01 & 0,97 & 0,95 & 0,07 \\
\hline Notas: $N=1638 ;$ o modelo re-especificado 1 não inclui o item 7 e contém as correlações entre o par de \\
erros e6-e8.
\end{tabular}




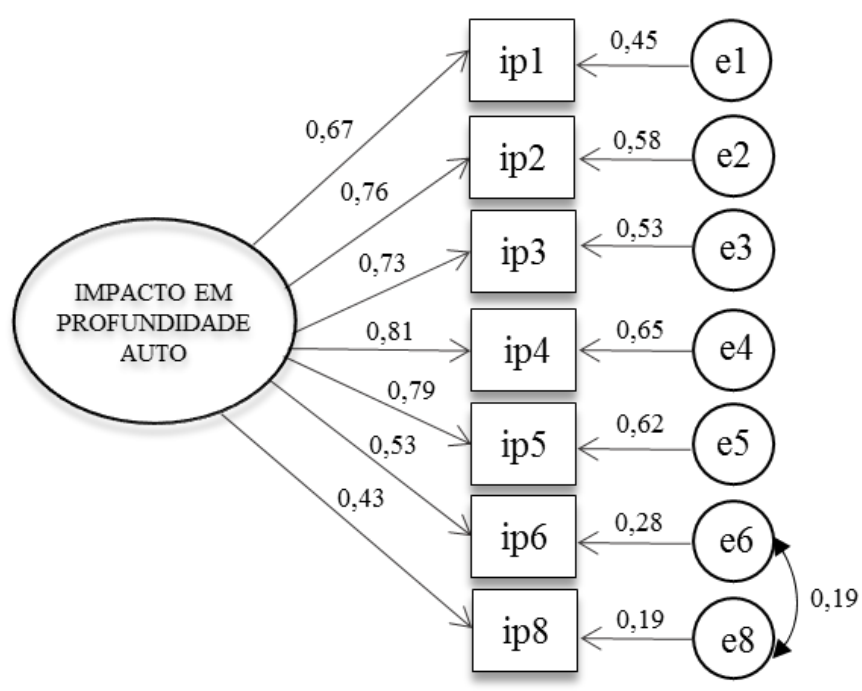

Figura 12. Cargas fatoriais estandardizadas, coeficientes de correlação e erros padrão da AFC para o instrumento de autoavaliação de Impacto do Treinamento no Trabalho em Profundidade (modelo reespecificado 1).

Da mesma maneira, o modelo hipotético inicial (estrutura empírica unifatorial com 8 itens, $\alpha=0,89$ ), para o instrumento de heteroavaliação de Impacto em Profundidade, apresenta falhas na bondade de ajuste.

Tal qual como ocorreu com o instrumento de autoavaliação de Impacto do Treinamento no Trabalho em Profundidade, os índices de modificação apontaram valores muito altos nas correlações entre os pares de erros e6-e7 e e7-e8. Seguiu-se, portanto, o mesmo procedimento para o instrumento de heteroavaliação, retirando-se primeiramente o item 7, que apresentava a menor carga fatorial entre os itens do instrumento, bem como um número bastante elevado de dados ausentes, indicando provavelmente que se trata de uma competência menos diretamente relacionada aos objetivos específicos do treinamento avaliado e que os participantes não a souberam avaliar, por isso deixaram a questão sem resposta em quase $50 \%$ dos casos, indicando que os supervisores, ao responder esse item, não poderiam avaliar um comportamento não desempenhado por seus subordinados, pois estes não trabalhavam com o atendimento a clientes: concedendo créditos, prestando serviços ou captando recursos.

No modelo re-especificado 1, obtiveram-se melhores valores dos indicadores de ajuste, com um descenso no valor de $B I C(\triangle B I C=414,06)$, o que é positivo, pois indica que este modelo é mais ajustado que o anterior. Porém, como a análise dos resíduos seguiu apontando alta correlação entre os erros e6-e8, inclui-se tal correlação no modelo reespecificado 2 (Tabela 58 e Figura 13) - embora o valor da correlação entre esse par de 
erros fosse baixa $(r=0,17)$-, obtendo-se os melhores índices de ajuste, em comparação com os anteriores e menor valor de $B I C=409,954(\triangle B I C=53,24)$.

A análise da normalidade dos itens aponta os itens $6(2,52)$ e $7(2,34)$ com distribuição não-normal, considerando-se o intervalo de referência |-2,0 e 2,0|; os demais possuem valores bastante inferiores ao limite estabelecido - assimetria (de -1,23 a -0,69) e curtose (de 0,52 a 1,21$)$.

Tabela 58. Indicadores de ajuste para os modelos original e re-especificados do instrumento de heteroavaliação de "Impacto do Treinamento no Trabalho em Profundidade".

\begin{tabular}{lcccccccc}
\hline Modelo & $\chi^{2}$ & $\boldsymbol{g}$ & $\boldsymbol{C M I N / D F}$ & $\boldsymbol{G F I}$ & $\boldsymbol{R M S R}$ & $\boldsymbol{C F I}$ & $\boldsymbol{T L I}$ & $\boldsymbol{R M S E A}$ \\
\hline Original & 753,036 & 20 & 37,65 & 0,92 & 0,04 & 0,92 & 0,89 & 0,12 \\
Re-especificado 1 & 354,501 & 13 & 25,32 & 0,95 & 0,02 & 0,96 & 0,94 & 0,10 \\
Re-especificado 2 & 293,490 & 13 & 22,57 & 0,96 & 0,01 & 0,96 & 0,94 & 0,09 \\
\hline
\end{tabular}

Notas: $N=2355$; o modelo re-especificado 1 não inclui o item 7; o modelo re-especificado 2, exclui o item 7 e contém as correlações entre o par de erros e6-e8.

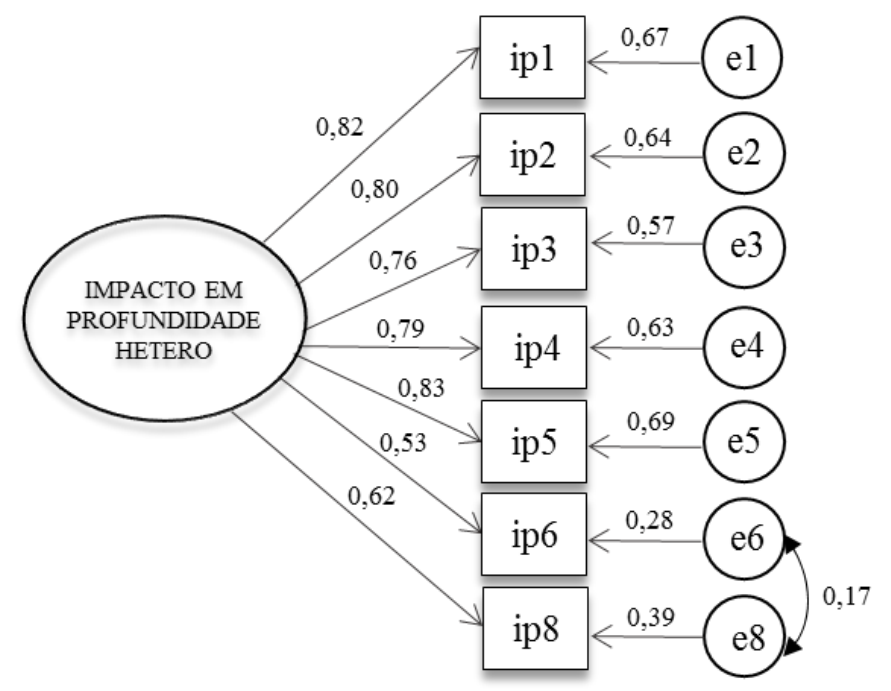

Figura 13. Cargas fatoriais estandardizadas, coeficientes de correlação e erros padrão da AFC para o instrumento de heteroavaliação de Impacto do Treinamento no Trabalho em Profundidade (modelo reespecificado 2).

\subsection{Impacto do treinamento no trabalho em amplitude.}

O modelo hipotético inicial (estrutura empírica unifatorial com 7 itens e $\alpha=0,89$ ) apresenta falhas na bondade de ajuste, indicando que a análise fatorial confirmatória para o instrumento de autoavaliação de Impacto em Amplitude, sem as re-especificações, não se ajusta bem.

Se o item 7, que apresenta a menor carga fatorial e variância explicada com a variável latente fosse eliminado (carga fatorial $=0,62 ; h^{2}=0,38$ ), o índice de consistência interna do instrumento permaneceria idêntico $(\alpha=0,89)$ - segundo a análise do Alfa de 
Cronbach se este item fosse excluído. A análise dos índices de modificação indicou os resíduos que apresentavam valores muito altos nas correlações entre os pares de erros e6e7, e1-e7, e5-e6: item 1 "Aproveito as oportunidades que tenho para praticar as novas habilidades", item 5 "Aumentou minha motivação para o trabalho", item 6 "Sugiro com mais frequência mudanças nas rotinas de trabalho" e item 7 "Esclareço dúvidas dos meus colegas". Como o item 7 aparece em dois dos pares mencionados, testou-se primeiramente o ajuste do modelo sem este item (modelo re-especificado 1).

Com vistas a melhorar o ajuste, foi introduzida a correlação entre os erros e5-e6 os itens 5 e 6 tratam respectivamente do aumento da motivação no trabalho ocasionado pela participação no treinamento avaliado ("Eficiência Operacional”) e a sugestão de mudanças nas rotinas com mais frequência depois de haver participado do curso; ambos indicam comportamentos relacionados entre si: ao aumentar a motivação do trabalhador, pode-se afetar também a sua segurança em fazer sugestões com relação às rotinas de trabalho, o que pode ter influenciado que os respondentes vissem esses itens como similares, embora a correlação entre eles não seja tão alta $(r=0,32)$. No modelo reespecificado 2, com a exclusão do item 7 e a inclusão de correlação entre o par de erros e5-e6, obtiveram-se melhores valores dos indicadores de ajuste (Tabela 59 e Figura 14), em comparação com o anterior, corroborado pelo índice de parcimônia BIC, apontando que este é mais ajustado $(\triangle B I C=138,47)$, embora o $R M S E A$ mantenha-se fora do padrão considerado aceitável.

Todos os itens apresentam distribuição normal, estando seus valores muito abaixo dos de referência |-2 e 2|: assimetria (de -0,92 a -0,61) e curtose (de -0,11 a 1,21).

Tabela 59. Indicadores de ajuste para os modelos original e re-especificados do instrumento de autoavaliação de "Impacto do Treinamento no Trabalho em Amplitude".

\begin{tabular}{lcccccccc}
\hline Modelo & $\chi^{2}$ & $\boldsymbol{g}$ & $\boldsymbol{C M I N / D F}$ & $\boldsymbol{G F I}$ & $\boldsymbol{R M S R}$ & $\boldsymbol{C F I}$ & $\boldsymbol{T L I}$ & $\boldsymbol{R M S E A}$ \\
\hline Original & 472,412 & 14 & 33,74 & 0,92 & 0,03 & 0,92 & 0,88 & 0,14 \\
Re-especificado 1 & 327,630 & 09 & 36,40 & 0,93 & 0,02 & 0,94 & 0,90 & 0,15 \\
Re-especificado 2 & 181,797 & 08 & 22,72 & 0,96 & 0,01 & 0,96 & 0,94 & 0,11 \\
\hline
\end{tabular}

Notas: $N=1566$; o modelo re-especificado 1 não inclui o item 7; o modelo re-especificado 2, exclui o item 7 e contém a correlação entre o par de erros e5-e6. 


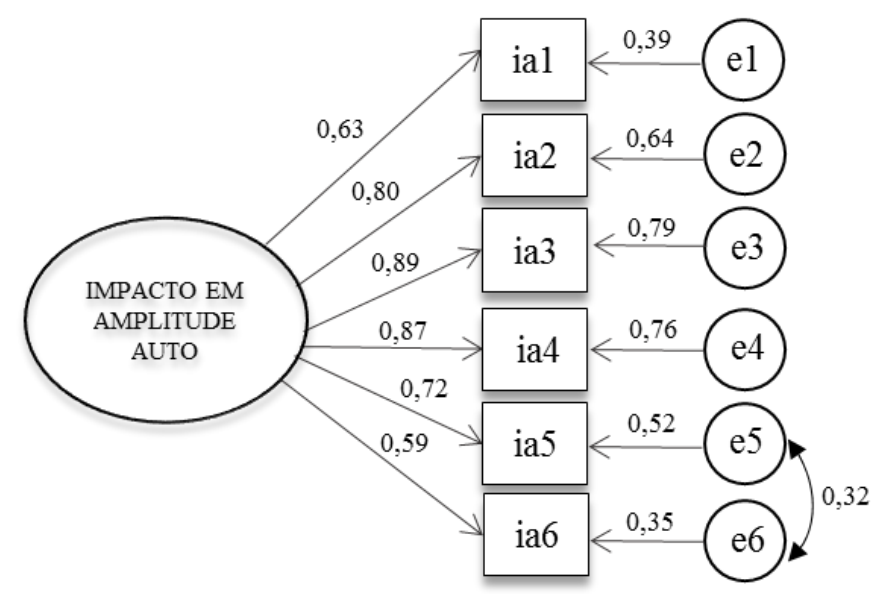

Figura 14. Cargas fatoriais estandardizadas, coeficientes de correlação e erros padrão da AFC para o instrumento de autoavaliação de Impacto do Treinamento no Trabalho em Amplitude (modelo reespecificado 2).

Para o instrumento de heteroavaliação de Impacto em Amplitude, o modelo hipotético inicial (estrutura empírica unifatorial com 7 itens e $\alpha=0,94$ ) apresenta bons índices de ajuste, com exceção do RMSEA.

Com vistas a melhorar o ajuste, foi introduzida a correlação entre os erros e6-e7 (6 "Sugere com mais frequência mudanças nas rotinas de trabalho" e 7 "Esclarece dúvidas dos colegas"), apontados na análise dos resíduos com o valor mais alto. Contudo, a introdução dessa correlação entre os erros não produziu melhoras importantes no ajuste. Além disso, a correlação entre os erros é bastante baixa $r=0,21$, não justificando a escolha por este modelo (modelo re-especificado 1), mas pelo hipotético inicial.

Outro par de erros apontado na análise de resíduos com alto valor entre si foram o dos itens e1-e7: 1 "Aproveita oportunidades para praticar as novas habilidades" e 7 "Esclarece dúvidas dos colegas". A introdução dessa correlação entre os erros resultou em valores ainda mais baixos para os indicadores de ajuste do modelo re-especificado 2 , e o valor de $B I C$ indica que apresenta pior ajuste que o modelo anterior ( $\triangle B I C$ acréscimo de 44,81) e a correlação entre os erros é ainda menor: $r=0,14$. Portanto, optou-se pela estrutura fatorial do modelo original (Tabela 60 e Figura 15).

Todos os itens apresentam distribuição normal, estando seus valores muito abaixo dos de referência |-2 e 2|: assimetria (de -1,08 a -0,65) e curtose (de 0,23 a 1,49).

Tabela 60. Indicadores de ajuste para os modelos original e re-especificados do instrumento de heteroavaliação de "Impacto do Treinamento no Trabalho em Amplitude".

\begin{tabular}{lcccccccc}
\hline Modelo & $\chi^{2}$ & $\boldsymbol{g l}$ & $\boldsymbol{C M I N / D F}$ & $\boldsymbol{G F I}$ & $\boldsymbol{R M S R}$ & $\boldsymbol{C F I}$ & $\boldsymbol{T L I}$ & $\boldsymbol{R M S E A}$ \\
\hline Original & 532,948 & 14 & 38,06 & 0,92 & 0,02 & 0,95 & 0,93 & 0,13 \\
Re-especificado 1 & 451,188 & 13 & 34,70 & 0,93 & 0,02 & 0,96 & 0,94 & 0,12 \\
Re-especificado 2 & 496,003 & 13 & 38,15 & 0,93 & 0,02 & 0,96 & 0,93 & 0,13 \\
\hline
\end{tabular}

Notas: $N=2191$; o modelo re-especificado 1 contém as correlações entre o par de erros e6-e7; o modelo re-especificado 2, entre e1-e7. 


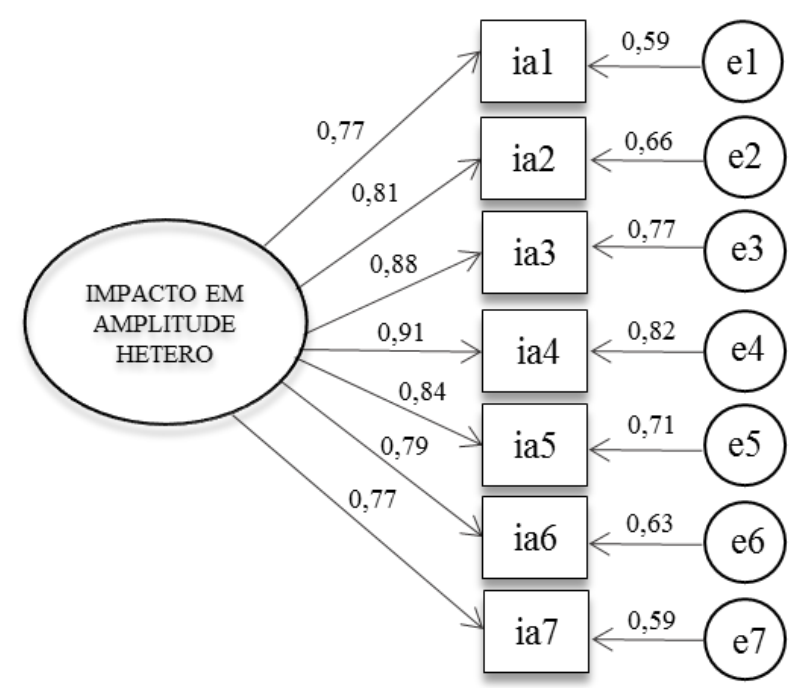

Figura 15. Cargas fatoriais estandardizadas, coeficientes de correlação e erros padrão da AFC para o instrumento de heteroavaliação de Impacto do Treinamento no Trabalho em Amplitude (modelo hipotético inicial).

\subsubsection{Análises de regressão múltipla}

\subsubsection{Autoavaliação.}

Após a realização das análises fatoriais exploratórias e a partir da média das variáveis originais dos fatores, produziram-se os escores fatoriais utilizados em análises de regressão múltipla padrão, realizadas para explorar e antecipar os principais preditores de impacto do treinamento no trabalho, em profundidade e em amplitude.

Para essa etapa de análise foi utilizado o arquivo de dados completo, contendo o modelo multivariado com todas as variáveis pareadas e tendo sido excluídos os 95 casos observados de outliers multivariados presentes na amostra: $N$ (2201) - 95 (outliers multi) = 2106 casos válidos, e não foram identificados casos extremos univariados.

Foram incluídas nas análises as seguintes variáveis antecedentes: média das respostas aos itens do fator único do instrumento de Reação aos Procedimentos Instrucionais (RP); média das respostas aos itens do fator único do instrumento de Barreiras e Facilitadores em EAD (BF); média das respostas aos itens dos 4 fatores do instrumento de Estratégias de Aprendizagem: EA1 (cognitivas/busca de ajuda), EA2 (controle da emoção), EA3 (elaboração/aplicação prática) e EA4 (controle da motivação); média das respostas aos itens dos 3 fatores do instrumento de Suporte à Transferência: SC (suporte de colegas), SS (suporte de supervisores) e SM (suporte material). As variáveis dependentes configuram os indicadores de efetividade do treinamento "Eficiência Operacional” em profundidade (IP) e em amplitude (IA). 
Através dessas análises ( $N=2106$ casos válidos; $p<0,05)$, descobriram-se que as 9 variáveis antecedentes juntas explicam $37 \%$ da variabilidade do impacto do treinamento no trabalho em profundidade $\left(R^{2}=0,379\right)$ e em amplitude $\left(R^{2}=0,378\right)$ - Tabelas 61 e 62 .

Tabela 61. Regressão múltipla padrão para o Impacto do Treinamento no Trabalho em Profundidade.

\begin{tabular}{|c|c|c|c|c|c|c|c|c|c|c|}
\hline Variável & IP (VD) & $\mathbf{R P}$ & BF & EA1 & EA2 & EA3 & EA4 & $\mathrm{SC}$ & $\mathrm{SS}$ & SM \\
\hline $\mathrm{RP}$ & $0,50 *$ & & & & & & & & & \\
\hline BF & $0,09^{*}$ & $-0,04^{+}$ & & & & & & & & \\
\hline EA1 & $0,36^{*}$ & $0,42 *$ & $0,10^{*}$ & & & & & & & \\
\hline EA2 & $0,27 *$ & $0,35^{*}$ & $-0,01$ & $0,15^{*}$ & & & & & & \\
\hline EA3 & $0,52 *$ & $0,56^{*}$ & 0,00 & $0,52 *$ & $0,38^{*}$ & & & & & \\
\hline EA4 & $0,37 *$ & $0,43^{*}$ & $-0,03$ & $0,45^{*}$ & $0,40 *$ & $0,51^{*}$ & & & & \\
\hline $\mathrm{SC}$ & $0,27 *$ & $0,28 *$ & 0,03 & $0,26^{*}$ & $0,15^{*}$ & 0,20 * & $0,19 *$ & & & \\
\hline SS & $0,29 *$ & $0,32 *$ & $-0,00$ & $0,26^{*}$ & $0,14 *$ & $0,24 *$ & $0,17 *$ & $0,70^{*}$ & & \\
\hline SM & $0,37 *$ & $0,44 *$ & 0,01 & $0,31 *$ & $0,22 *$ & 0,37 * & $0,22 *$ & $0,42 *$ & $0,48^{*}$ & \\
\hline$B$ & & $0,25 *$ & $0,05 *$ & 0,01 & 0,01 & $0,26^{*}$ & $0,08^{+}$ & 0,02 & 0,03 & $0,07 *$ \\
\hline$\beta$ & & 0,22 & $\mathbf{0 , 1 0}$ & 0,01 & 0,01 & 0,27 & 0,08 & 0,03 & 0,05 & 0,11 \\
\hline$S r^{2}$ & & 0,02 & 0,01 & 0,00 & 0,00 & 0,04 & 0,00 & 0,00 & 0,00 & 0,00 \\
\hline$X$ & 4,15 & 4,13 & 2,11 & 3,49 & 4,33 & 4,20 & 4,33 & 3,64 & 3,81 & 3,75 \\
\hline$D P$ & 0,61 & 0,53 & 1,24 & 0,80 & 0,65 & 0,64 & 0,66 & 0,87 & 0,90 & 0,87 \\
\hline Constante $=$ & $20 \quad R^{2}=$ & $9 * R^{2}$ & ustado) & $0,370^{*}$ & $R=0,6$ & & & & & \\
\hline
\end{tabular}

Explicam, em conjunto, o impacto em profundidade, as variáveis: reação aos procedimentos instrucionais, barreiras e facilitadores em EAD, estratégias de aprendizagem de elaboração/aplicação prática e suporte material.

As variáveis antecedentes que contribuíram significativamente para a explicação de impacto do treinamento no trabalho em profundidade, tendo considerado o intervalo de confiança de $99 \%$, foram: $\operatorname{RP}(\beta=0,22), \operatorname{BF}(\beta=0,10), \operatorname{EA} 3(\beta=0,27)$ e $\operatorname{SM}(\beta=0,11)$. Agrupadas, as 9 variáveis iniciais, explicam 37\% (37\% ajustado) da variabilidade de impacto do treinamento no trabalho em profundidade. Ao considerar um intervalo de confiança menos rígido (90\%), as estratégias autorregulatórias de controle da motivação foram marginalmente significativas na explicação do impacto em profundidade.

Em suma, os funcionários treinados que aplicaram no trabalho as competências adquiridas no treinamento "Eficiência Operacional" foram aqueles que avaliaram favoravelmente os procedimentos instrucionais do curso, não perceberam como barreiras aspectos que pudessem dificultar o desempenho durante a instrução, usaram com frequência as estratégias de aprendizagem cognitivas de elaboração/aplicação prática e perceberam o apoio material dado pela organização. 
Tabela 62. Regressão múltipla padrão para o Impacto do Treinamento no Trabalho em Amplitude.

\begin{tabular}{|c|c|c|c|c|c|c|c|c|c|c|}
\hline Variável & IA (VD) & RP & $\mathrm{BF}$ & EA1 & EA2 & EA3 & EA4 & SC & SS & SM \\
\hline $\mathrm{RP}$ & $0,52 *$ & & & & & & & & & \\
\hline $\mathrm{BF}$ & 0,08 & $-0,04^{+}$ & & & & & & & & \\
\hline EA1 & $0,39 *$ & $0,42 *$ & $0,10 *$ & & & & & & & \\
\hline EA2 & $0,25^{*}$ & $0,35^{*}$ & $-0,01$ & $0,15^{*}$ & & & & & & \\
\hline EA3 & $0,49 *$ & $0,56^{*}$ & 0,00 & $0,52 *$ & $0,38 *$ & & & & & \\
\hline EA4 & $0,39 *$ & $0,43^{*}$ & $-0,03$ & $0,45^{*}$ & $0,40^{*}$ & $0,51^{*}$ & & & & \\
\hline $\mathrm{SC}$ & $0,31 *$ & $0,28 *$ & 0,03 & $0,26^{*}$ & $0,15^{*}$ & 0,21 * & $0,19 *$ & & & \\
\hline SS & $0,33 *$ & $0,32 *$ & $-0,00$ & $0,26^{*}$ & $0,14 *$ & $0,24^{*}$ & $0,17 *$ & $0,70^{*}$ & & \\
\hline SM & $0,37 *$ & $0,44 *$ & 0,01 & $0,31 *$ & $0,22 *$ & $0,33^{*}$ & $0,22 *$ & $0,42 *$ & $0,48^{*}$ & \\
\hline$B$ & & $0,28^{*}$ & 0,05 & $0,05^{+}$ & $-0,00$ & $0,18^{*}$ & $0,09 *$ & $0,05^{+}$ & $0,05^{+}$ & $0,05^{* *}$ \\
\hline$\beta$ & & 0,25 & 0,01 & $\mathbf{0 , 0 7}$ & $-0,00$ & 0,19 & 0,10 & $\mathbf{0 , 0 7}$ & $\mathbf{0 , 0 7}$ & $\mathbf{0 , 0 7}$ \\
\hline$S r^{2}$ & & 0,03 & 0,00 & 0,00 & 0,00 & 0,01 & 0,00 & 0,00 & 0,00 & 0,00 \\
\hline$X$ & 4,22 & 4,13 & 2,11 & 3,49 & 4,33 & 4,20 & 4,33 & 3,64 & 3,81 & 3,75 \\
\hline$D P$ & 0,58 & 0,53 & 1,24 & 0,80 & 0,65 & 0,64 & 0,66 & 0,87 & 0,90 & 0,87 \\
\hline
\end{tabular}

Nota: ${ }^{*} p<0,01 ; * * p<0,05 ;{ }^{+} p<0,10$

Explicam, em conjunto, o impacto em amplitude, as variáveis reação aos procedimentos instrucionais, as estratégias de aprendizagem de elaboração/aplicação prática e controle da motivação e o suporte material.

As variáveis antecedentes que contribuíram significativamente para a explicação de impacto do treinamento no trabalho em amplitude, tendo considerado o intervalo de confiança de 95\%, foram: RP $(\beta=0,25)$, EA3 $(\beta=0,19)$, EA4 $(\beta=0,10)$ e SM $(\beta=0,07)$. Agrupadas, as 9 variáveis iniciais, explicam 37\% (37\% ajustado) da variabilidade de impacto do treinamento no trabalho em amplitude. Considerando o nível de significância de $99 \%$, somente o suporte material não entra na explicação de impacto em amplitude. Ao considerar um intervalo de confiança menos rígido (90\%), as estratégias de aprendizagem cognitivas/busca de ajuda e os suportes de supervisores e pares foram marginalmente significativos na explicação do impacto em amplitude.

Em síntese, os funcionários treinados que tiveram ganhos em seus desempenhos globais a partir da participação no treinamento "Eficiência Operacional" foram aqueles que avaliaram favoravelmente os procedimentos instrucionais do curso, usaram com frequência as estratégias de aprendizagem de elaboração/aplicação prática e as autorregulatórias de controle da motivação, e perceberam o apoio material dado pela organização.

Algumas considerações sobre as análises de regressão merecem destaque, com respeito às variáveis estratégias de aprendizagem e suporte à transferência. As estratégias de aprendizagem cognitivas de elaboração/aplicação prática (EA3), no caso do impacto em profundidade (IP), juntamente às autorregulatórias de controle da motivação (EA4), no caso do impacto em amplitude (IA), aparecem como preditoras significativas das 
respectivas variáveis dependentes (VDs). Os outros tipos de estratégias de aprendizagem (cognitivas/busca de ajuda [EA1] e controle da emoção [EA2]), embora não tenham entrado como explicativas de impacto, estão correlacionadas com as demais variáveis independentes e com as estratégias de aprendizagem preditoras (EA3 e EA4), o que indica, provavelmente, que possam ter um efeito mediador, ou seja, sua explicação passa por EA3 ou EA4 para explicar os diferentes tipos de impacto - respectivamente, IP e IA. Além de que, no caso do impacto em profundidade, as estratégias de controle da motivação (EA4), e no caso do impacto em amplitude, as estratégias cognitivas/busca de ajuda (EA1), apresentaram-se como marginalmente significativas na explicação de sua ocorrência.

Da mesma maneira, a variável de suporte à transferência, em ambos os casos, somente o suporte material (SM) prediz significativamente os impactos em profundidade e em amplitude. Isso não quer dizer, necessariamente, que o suporte dos colegas (SC) e o suporte de supervisores (SS) não tenham influência sobre os diferentes tipos de impacto, mas que sua influência está expressa através de SM, ou oculta ali, uma vez que as três variáveis estão fortemente correlacionadas entre si - presença de colinearidade. Ou da mesma forma que discutido anteriormente, podem ter efeito mediador sobre o suporte material.

Talvez, os suportes de pares e de supervisores não deveriam aparecer e ser avaliados separadamente, mas como uma única variável (suporte psicossocial), pois, no contexto estudado - setor bancário -, pares e supervisores trabalham conjuntamente e suas tarefas estão intimamente e diariamente relacionadas, não havendo uma distância entre chefes e subordinados, como ocorre em outros contextos, mas o contrário. Dessa forma, ao responder ao questionário, ao mesmo tempo que o superior é chefe, também é companheiro de trabalho, e isso pode afetar o entendimento das medidas como diferentes.

Os resultados sugerem que as variáveis SS e SC deveriam ser investigadas como variáveis preditoras de impacto em modelos de regressão simples, contendo somente uma das variáveis por vez, para saber o efeito das mesmas sobre IP e IA e analisar também os resíduos, já que duas variáveis antecedentes correlacionadas positiva e fortemente entre si na equação $(r=0,70)$ podem ocasionar perda de parcimônia na explicação das VDs, sendo um sinal de redundância (Abbad \& Torres, 2002). Tal redundância pode ser observada quando os pesos $\beta$ e os $S r^{2}$ para cada variável antecedente são muito menores do que a correlação bivariada entre cada variável antecedente e a critério, o que de fato acontece neste caso. 
No momento da análise estatística de regressão, a variável antecedente com maior correlação com a variável critério tem prioridade e sobrepõe-se àquela com segunda maior correlação, retirando ou ocultando seu poder explicativo. Nos casos em que há variância compartilhada entre duas variáveis antecedentes - como acontece com os tipos de suporte (material, de supervisores e de pares) -, a entrada da primeira oculta o poder explicativo da segunda, ocasionando que esta não apareça como preditora.

Ao testar separadamente as variáveis SS e SC como preditoras de IP e IA, encontraram-se os seguintes valores significativos $(p<0,01)$ para o impacto em profundidade: $\mathrm{SS}\left(R^{2}=0,087 ; \beta=0,29\right)$ e $\mathrm{SC}\left(R^{2}=0,073 ; \beta=0,27\right)$; e para o impacto em amplitude: $\mathrm{SS}\left(R^{2}=0,112 ; \beta=0,33\right)$ e SC $\left(R^{2}=0,101 ; \beta=0,31\right)$. Como previsto, as variáveis relativas ao suporte psicossocial (supervisores e pares) são também importantes na explicação da ocorrência do impacto do treinamento no trabalho tanto em profundidade como em amplitude, contribuindo, em média, quase 10\% para a variabilidade de sua explicação com destaque para a maior influência do suporte de supervisores em comparação com o suporte de pares na explicação de ambos impactos. Esses resultados reafirmam a suspeita de que a análise de regressão múltipla, com a inclusão de todas as variáveis antecedentes simultaneamente, junto à alta correlação entre as variáveis de suporte, ocultou a influência do suporte psicossocial sobre os indicadores da efetividade de treinamento, ou seja, os dois tipos de impacto.

A investigação e a discussão dos possíveis efeitos mediadores dessas variáveis mencionadas (EA1 e EA2; SS e SC) foram viabilizadas por meio das análises de equações estruturais para testagem do modelo de investigação proposto.

\subsubsection{Heteroavaliação.}

Utilizando-se as mesmas variáveis antecedentes já mencionadas, respondidas exclusivamente pelos funcionários treinados, e incluindo-se como variáveis critério as medidas de impacto do treinamento no trabalho em profundidade e em amplitude respondidas pelos superiores hierárquicos dos participantes do curso avaliado, ou seja, a heteroavaliação de impacto, também foram realizadas análises de regressão múltipla padrão para testar os efeitos das variáveis de natureza perceptual (reações e estratégias de aprendizagem) e relativas a aspectos externos (suporte à transferência e barreiras e facilitadores em EAD) sobre os indicadores de efetividade de treinamento. A correlação bivariada entre IP e IA é significativa e bastante alta $(r=0,72 ; p<0,01)$. 
Quanto à heteroavaliação de impacto em profundidade, a explicação conjunta das variáveis não foi significativa $\left(R^{2}=0,02\right)$, apenas $\operatorname{RP}(\beta=0,25 ; p<0,05)$ contribuiu parcialmente para a explicação da variabilidade de IP, isto é, os funcionários treinados que avaliaram favoravelmente os procedimentos da instrução foram os que aplicaram no trabalho as competências adquiridas no treinamento "Eficiência Operacional" segundo a avaliação das chefias. Dentre as demais variáveis, além de RP $(r=0,09 ; p<0,01)$, as estratégias de elaboração/aplicação prática [EA3] $(r=0,07 ; p<0,05)$, estiveram positiva e significativamente correlacionadas a IP.

Já no caso do impacto em amplitude $\left(R^{2}=0,05^{* *} ; p<0,01\right)$, as variáveis $\mathrm{RP}$ $(\beta=0,17)$, EA1 $(\beta=0,13)$ e SC $(\beta=-0,14)$ contribuíram significativamente para a sua explicação. Agrupadas, as 9 variáveis contribuem em 5\% (4\% ajustado) para a variabilidade compartilhada na explicação de impacto em amplitude percebido pelos gestores. As variáveis reação aos procedimentos instrucionais, as estratégias de aprendizagem cognitivas/busca de ajuda e o suporte de pares, contribuíram significativamente para a explicação da heteroavaliação do impacto do treinamento no trabalho em amplitude percebido pelas chefias dos participantes do treinamento. Considerando o intervalo de confiança de $99 \%$, as variáveis RP $(r=0,16)$, suporte de pares $(r=-0,07)$, EA1 $(r=0,14)$, EA3 $(r=0,12)$ e EA4 $(r=0,07)$ estiveram significativamente correlacionadas a IA.

Em comparação aos resultados da autoavaliação de impacto em amplitude, na qual, com exceção das reações que entraram como significativas em ambas, outras variáveis mostraram sua influência: estratégias de aprendizagem de elaboração/aplicação prática e de controle da motivação, e o apoio material dado pela organização. Apesar das diferenças encontradas quanto aos preditores, é interessante observar que tanto as variáveis individuais como as contextuais, em ambas avaliações (auto e hetero), foram importantes para a ocorrência do impacto em amplitude e, portanto, afetam o desempenho geral dos participantes quando retornam ao ambiente de trabalho, sob a perspectiva tanto dos egressos do treinamento, como de seus superiores.

Por um lado, as estratégias cognitivas de elaboração/aplicação prática (avaliação das implicações do novo conteúdo aprendido e as suas conexões com os conhecimentos já adquiridos, buscando vias para entendê-lo por meio da sua aplicação prática) e as autorregulatórias de controle da motivação estiveram associadas à autoavaliação de IA, e as cognitivas (repetição e organização das informações) e de busca de ajuda (material didático e interpessoal), no caso da heteroavaliação de IA. Os tipos de suporte à 
transferência também distinguem na autoavaliação, na qual o apoio material foi mais importante, e na heteroavaliação, o apoio dos companheiros de trabalho.

Esses achados diferem dos encontrados em estudos anteriores, nos quais variáveis autorreferentes não tiveram quaisquer contribuições na explicação da variabilidade da heteroavaliação de impacto (Meneses \& Abbad, 2003), mas apenas o suporte psicossocial à transferência, percebido pelos participantes do treinamento e suas chefias, contribuíram significativamente na explicação da auto e heteroavaliação de impacto do treinamento no trabalho em amplitude.

\subsubsection{Equações estruturais - teste do modelo de investigação}

A verificação do relacionamento entre as variáveis de interesse foi realizada por meio da modelagem por equações estruturais (MEE). Para testar as hipóteses, os efeitos diretos entre as variáveis antecedentes (estratégias de aprendizagem: cognitivas e busca de ajuda [EA1], controle da emoção [EA2], elaboração e aplicação prática [EA3], controle da motivação [EA4]; reação aos procedimentos instrucionais [RP]; barreiras e facilitadores em EAD [BF]; suporte à transferência: suporte de supervisores [SS], suporte de pares $[\mathrm{SC}]$, suporte material $[\mathrm{SM}]$ ) e as variáveis critério (impacto do treinamento no trabalho em profundidade [IP] e em amplitude [IA]) foram examinados através dos coeficientes de regressão padronizados $(\beta)$. Além de terem sido realizadas análises complementares para investigar os efeitos indiretos, as relações de mediação e de moderação entre certas variáveis.

Antes das análises de MEE, foram calculadas as correlações bivariadas (Pearson) entre as variáveis do modelo, que podem ser observadas na Tabela 63. Com exceção da variável barreiras e facilitadores em EAD, todas as demais estiveram significativamente $(p<0,01)$ correlacionadas com o impacto do treinamento no trabalho em profundidade $\mathrm{e}$ em amplitude na autoavaliação. Na heteroavaliação, as estratégias de aprendizagem cognitivas e busca de ajuda [EA1] e o suporte de supervisores apareceram correlacionados ao impacto em profundidade $(p<0,05)$; mas nenhuma variável esteve correlacionada significativamente com o impacto em amplitude. Tanto na autoavaliação $(r=0,595)$ como na heteroavaliação $(r=0,746)$, o impacto em profundidade aparece fortemente relacionado ao impacto em amplitude. 
Tabela 63. Correlações entre as variáveis independentes e dependentes na auto e heteroavaliação de impacto em profundidade e em amplitude.

\begin{tabular}{|c|c|c|c|c|c|c|c|c|c|c|c|c|c|}
\hline$r$ & EA1 & EA2 & EA3 & EA4 & $\mathrm{RP}$ & $\mathrm{BF}$ & $\mathrm{SS}$ & SC & SM & $\mathrm{IP}_{\text {AUTO }}$ & $\mathrm{IA}_{\mathrm{AUTO}}$ & IP $_{\text {HETERO }}$ & IA $_{\text {HETERO }}$ \\
\hline EA1 & - & & & & & & & & & & & & \\
\hline EA2 & $0,140 *$ & - & & & & & & & & & & & \\
\hline EA3 & $0,510 *$ & $0,382 *$ & - & & & & & & & & & & \\
\hline EA4 & $0,421 *$ & $0,409 *$ & $0,513^{*}$ & - & & & & & & & & & \\
\hline $\mathrm{RP}$ & $0,400 *$ & $0,359 *$ & $0,568^{*}$ & $0,432 *$ & - & & & & & & & & \\
\hline $\mathrm{BF}$ & $0,130 *$ & $-0,003$ & 0,004 & $-0,033$ & $-0,034$ & - & & & & & & & \\
\hline SS & $0,250 *$ & $0,145^{*}$ & $0,248^{*}$ & $0,175^{*}$ & $0,327 *$ & $-0,004$ & - & & & & & & \\
\hline $\mathrm{SC}$ & $0,253^{*}$ & $0,155^{*}$ & $0,210^{*}$ & $0,197 *$ & $0,287 *$ & 0,045 & $0,702 *$ & - & & & & & \\
\hline SM & $0,296^{*}$ & $0,223^{*}$ & $0,338^{*}$ & $0,225^{*}$ & $0,443 *$ & 0,017 & $0,481 *$ & $0,424 *$ & - & & & & \\
\hline $\mathrm{IP}_{\text {AUTO }}$ & $0,332 *$ & $0,278^{*}$ & $0,536^{*}$ & $0,374 *$ & $0,488 *$ & 0,060 & $0,314 *$ & $0,301 *$ & $0,364 *$ & - & & & \\
\hline $\mathrm{IA}_{\mathrm{AUTO}}$ & $0,380 *$ & $0,258^{*}$ & $0,494 *$ & $0,393 *$ & $0,524 *$ & 0,023 & $0,336^{*}$ & $0,317 *$ & $0,370^{*}$ & $0,595^{*}$ & - & & \\
\hline IP $_{\text {HETERO }}$ & $0,074 * *$ & $-0,002$ & 0,025 & 0,054 & 0,033 & $-0,028$ & $0,072 * *$ & 0,022 & 0,035 & 0,024 & 0,034 & - & \\
\hline IA $_{\text {HETERO }}$ & 0,032 & $-0,014$ & $-0,012$ & 0,005 & $-0,003$ & $-0,001$ & 0,020 & $-0,009$ & $-0,014$ & 0,001 & 0,010 & $0,746^{*}$ & - \\
\hline
\end{tabular}

Nota: $* p<0,01 ; * * p<0,05$ 


\subsubsection{Autoavaliação.}

\subsection{Impacto do treinamento no trabalho em profundidade.}

Tabela 64. Indicadores de ajuste para o modelo estrutural com o Impacto do Treinamento no Trabalho em Profundidade como variável dependente.

\begin{tabular}{lcccccc}
\hline Modelo & $\chi^{2}$ & $\boldsymbol{g l}$ & $\boldsymbol{C M I N / D F}$ & $\boldsymbol{C F I}$ & $\boldsymbol{T L I}$ & $\boldsymbol{R M S E A}$ \\
\hline Impacto em Profundidade (VD) & 9078,688 & 1748 & 5,19 & 0,91 & 0,91 & 0,04 \\
\hline Notas: $N=2411 ;$ introduzidas correlações entre os fatores de &
\end{tabular}

A Tabela 64 mostra que o modelo estrutural apresenta um bom ajuste aos dados empíricos na autoavaliação de impacto do treinamento no trabalho em profundidade $(C F I=0,91 ; T L I=0,91$ e $R M S E A=0,04)$.

Tabela 65. Efeitos estandardizados totais, diretos e indiretos das variáveis independentes com a variável dependente "Impacto do Treinamento no Trabalho em Profundidade".

\begin{tabular}{cc|c|c}
\hline \multirow{2}{*}{ Variáveis } & \multicolumn{3}{c}{ Efeitos estandardizados $(\boldsymbol{\beta})$} \\
\cline { 2 - 4 } & Totais & Diretos & Indiretos \\
\hline EA1 & $-0,059$ & $-0,059^{+}$ & 0,000 \\
EA2 & 0,060 & 0,060 & 0,000 \\
EA3 & 0,477 & $0,477^{*}$ & 0,000 \\
EA4 & 0,037 & 0,037 & 0,000 \\
RP & 0,204 & $0,204^{*}$ & 0,000 \\
BF & $-0,001$ & $-0,001$ & 0,000 \\
SS & 0,041 & 0,041 & 0,000 \\
SC & 0,081 & $0,081^{* *}$ & 0,000 \\
SM & 0,158 & $0,158^{*}$ & 0,000 \\
\hline
\end{tabular}

Nota: $* p<0,000 ; * * p<0,05 ;{ }^{+} p<0,10$

As variáveis que tiveram efeito significativo $(p<0,000)$ na explicação do impacto do treinamento no trabalho em profundidade [IP], conforme a Tabela 65, foram: estratégias de aprendizagem de elaboração e aplicação prática [EA3] $(\beta=0,477)$, reação aos procedimentos instrucionais $(\beta=0,204)$ e suporte material à transferência $(\beta=0,158)$. Esse conjunto de variáveis influenciou diretamente a ocorrência do fenômeno da transferência das competências específicas desenvolvidas em treinamento no trabalho, relacionadas às atividades e atribuições dos cargos desempenhados pelos egressos. A variável suporte de pares $(\beta=0,081)$, a um nível de significância de 95\%, também contribuiu para a explicação de IP. Marginalmente significativas $(p<0,10)$ encontram-se as estratégias cognitivas e busca de ajuda $(\beta=-0,059)$.

Os participantes mais satisfeitos com os aspectos formais do curso, que utilizaram frequentemente as estratégias de aprendizagem que requerem a reflexão sobre as implicações do material aprendido, as conexões deste com os seus conhecimentos prévios e identificaram situações diárias passíveis da aplicação dos conteúdos do curso, bem 
como perceberam que a organização fornecia os recursos materiais necessários à transferência das novas habilidades e recebiam o apoio dos colegas de trabalho, foram os que modificaram seus comportamentos, relacionados aos objetivos do treinamento, no posto de trabalho, e obtiveram ganhos diretos sobre o desempenho específico (impacto em profundidade) - ver Figura 16.

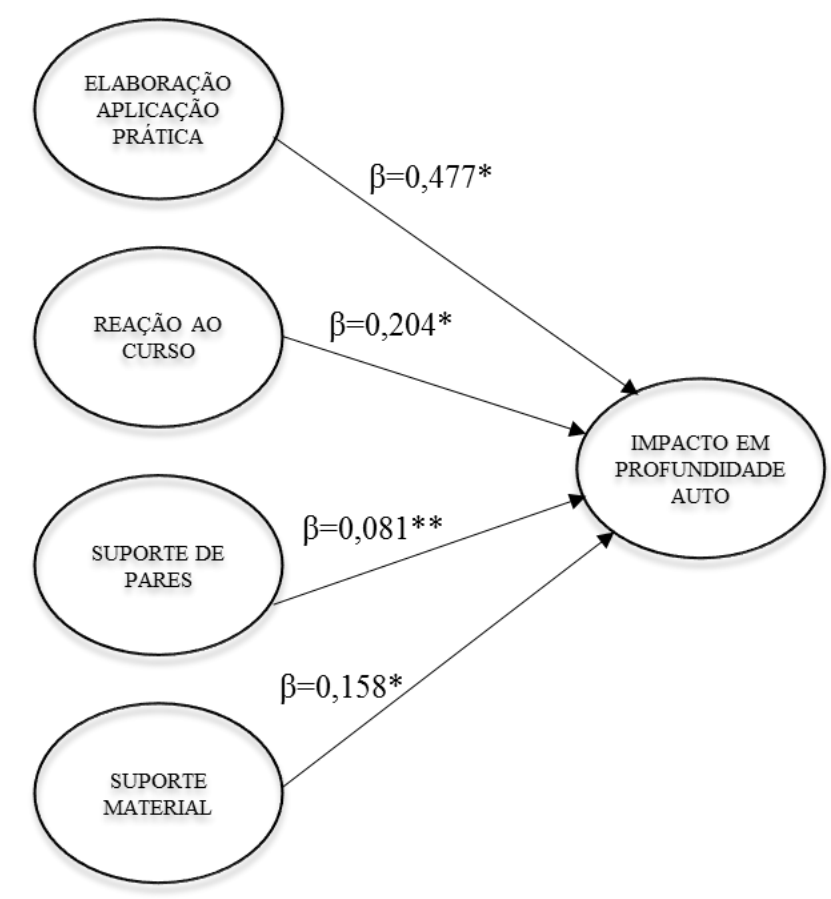

Figura 16. Modelo simplificado com os coeficientes de regressão estandardizados significativos na autoavaliação de Impacto do Treinamento no Trabalho em Profundidade.

\subsection{Impacto do treinamento no trabalho em amplitude.}

Tabela 66. Indicadores de ajuste para o modelo estrutural com o Impacto do Treinamento no Trabalho em Amplitude como variável dependente.

\begin{tabular}{lcccccc}
\hline Modelo & $\chi^{2}$ & $\boldsymbol{g l}$ & $\boldsymbol{C M I N} / \boldsymbol{D F}$ & $\boldsymbol{C F I}$ & $\boldsymbol{T L I}$ & $\boldsymbol{R M S E A}$ \\
\hline Impacto em Amplitude (VD) & 9555,405 & 1749 & 5,46 & 0,91 & 0,90 & 0,04 \\
\hline
\end{tabular}

Notas: $N=2411$; introduzidas correlações entre os fatores de uma mesma variável

A Tabela 66 mostra que o modelo estrutural apresenta um bom ajuste aos dados empíricos na autoavaliação de impacto do treinamento no trabalho em amplitude $(C F I=0,91 ; T L I=0,90$ e $R M S E A=0,04)$.

Tabela 67. Efeitos estandardizados totais, diretos e indiretos das variáveis independentes com a variável dependente "Impacto do Treinamento no Trabalho em Amplitude".

\begin{tabular}{cc|c|c}
\hline \multirow{2}{*}{ Variáveis } & \multicolumn{3}{c}{ Efeitos estandardizados $(\boldsymbol{\beta})$} \\
\cline { 2 - 4 } & Totais & Diretos & Indiretos \\
\hline EA1 & 0,088 & $0,088^{* *}$ & 0,000 \\
EA2 & $-0,040$ & $-0,040$ & 0,000 \\
EA3 & 0,250 & $0,250^{*}$ & 0,000 \\
\hline
\end{tabular}


Tabela 67. Efeitos estandardizados totais, diretos e indiretos das variáveis independentes com a variável dependente "Impacto do Treinamento no Trabalho em Amplitude". (Continuação)

\begin{tabular}{cc|c|c}
\hline \multirow{2}{*}{ Variáveis } & \multicolumn{3}{c}{ Efeitos estandardizados $(\boldsymbol{\beta})$} \\
\cline { 2 - 4 } & Totais & Diretos & Indiretos \\
\hline EA4 & 0,143 & $0,143^{*}$ & 0,000 \\
RP & 0,318 & $0,318^{*}$ & 0,000 \\
BF & 0,024 & 0,024 & 0,000 \\
SS & 0,056 & 0,056 & 0,000 \\
SC & 0,100 & $0,100^{* *}$ & 0,000 \\
SM & 0,096 & $0,096^{* *}$ & 0,000 \\
\hline
\end{tabular}

Nota: $* p<0,000 ; * * p<0,05$

Como pode ser observado na Tabela 67 , as variáveis que tiveram efeito significativo $(p<0,000)$ na explicação do impacto do treinamento no trabalho em amplitude foram: estratégias de aprendizagem de elaboração e aplicação prática [EA3] $(\beta=0,250)$ e de controle da motivação [EA4] $(\beta=0,143)$, e reação aos procedimentos instrucionais $(\beta=0,318)$. Tais variáveis influenciaram o desempenho geral dos egressos, de maneira que resultados não esperados pelo treinamento tiveram efeitos no comportamento global dos trabalhadores, inclusive afetando seus estados motivacionais e suas atitudes no trabalho. Considerando um intervalo de confiança de $95 \%$, ainda entraram como preditores as estratégias cognitivas e busca de ajuda [EA1] $(\beta=0,088)$, e os suportes de pares $(\beta=0,100)$ e material $(\beta=0,096)$.

Similarmente ao exposto anteriormente, os participantes que tiveram ganhos no desempenho geral (impacto em amplitude), foram os que julgaram bem os procedimentos instrucionais do curso, utilizaram com mais frequência as estratégias que supõem ponderar a utilidade prática dos conteúdos ensinados e associá-los aos conhecimentos consolidados anteriormente à instrução, combinadas às estratégias autorregulatórias que tratam do esforço consciente para manter a concentração no assunto, embora houvesse pouco interesse, e verificar a compreensão do que estava sendo ensinado no treinamento. Ademais, as estratégias cognitivas e busca de ajuda, que se referem à repetição e criação de esquemas mentais para auxiliar o aprendizado, bem como a busca de auxílio no material didático e de outras pessoas para esclarecer dúvidas sobre o conteúdo do curso, ao lado do apoio dado pela organização e por companheiros de trabalho, explicaram a ocorrência do impacto em amplitude (ver Figura 17). 


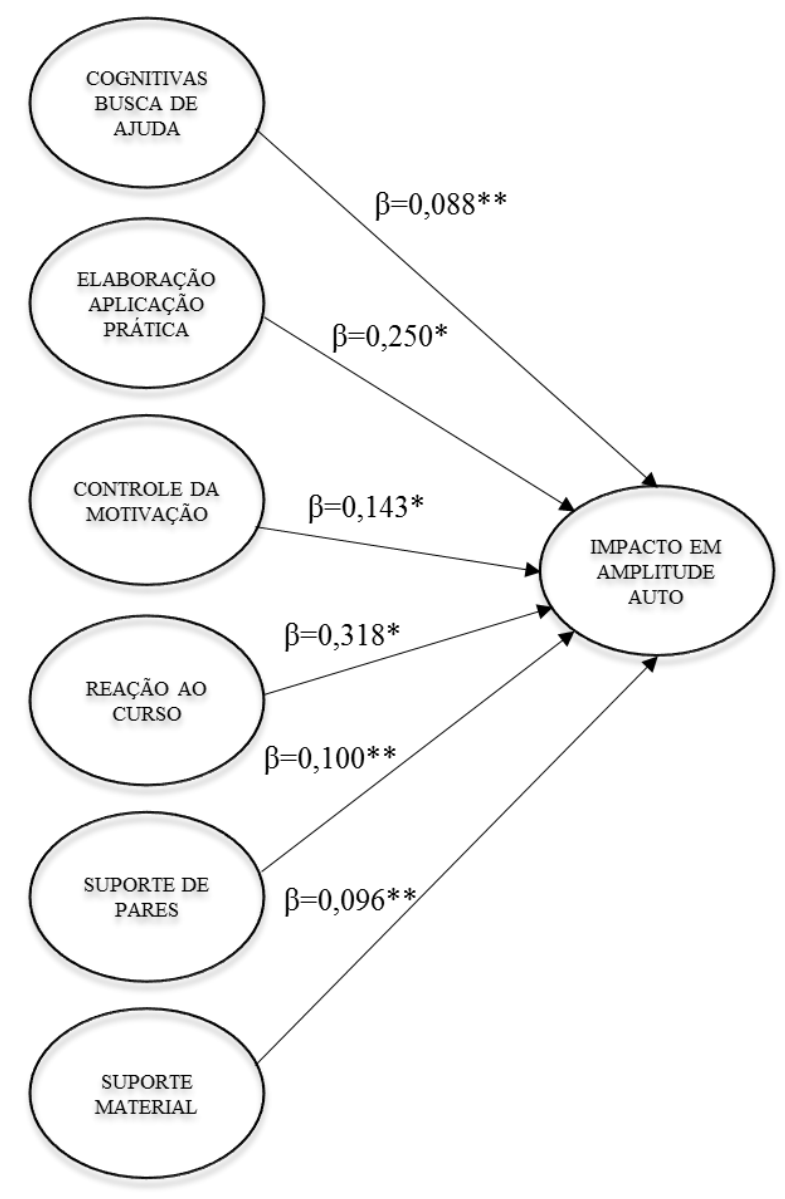

Figura 17. Modelo simplificado com os coeficientes de regressão estandardizados significativos na autoavaliação de Impacto do Treinamento no Trabalho em Amplitude.

Em síntese, na autoavaliação, para que ocorresse o impacto em profundidade e em amplitude, destaca-se a importância dos indicadores da qualidade do curso (reação) e o uso de estratégias de aprendizagem que aliam teoria e prática, em outras palavras, aspectos cognitivos (elaboração) e comportamentais (aplicação prática), capazes de antecipar, no momento de estudo, as implicações do conteúdo no dia a dia de trabalho. Especificamente, a percepção dos participantes de que os recursos materiais e o ambiente físico do local de trabalho são adequados à aplicação das novas competências adquiridas em treinamento teve relação com a transferência do aprendido para o cargo, isto é, trouxe influências diretas sobre o seu desempenho no trabalho. Por outro lado, para que fossem notados resultados nos comportamentos globais do indivíduo, incluindo motivação e atitudes, as estratégias de aprendizagem autorregulatórias de controle da motivação foram significativas. Ao considerar um intervalo de confiança um pouco menos rígido (95\%), acrescenta-se a explicação do suporte de pares em ambos casos [IP e IA]; e a contribuição 
das estratégias de aprendizagem cognitivas e busca de ajuda exclusivamente para o impacto em amplitude.

Os resultados obtidos evidenciam que além dos efeitos serem significativos, confirmando as correlações fortes existentes entre as variáveis testadas, os bons índices apontam que o modelo teórico se ajusta bem aos dados empíricos, confirmando a adequação do modelo estrutural proposto.

\subsection{Impacto do treinamento no trabalho em profundidade e amplitude.}

Tabela 68. Indicadores de ajuste para o modelo estrutural com as variáveis dependentes IP e IA.

\begin{tabular}{lcccccc}
\hline Modelo & $\chi^{2}$ & gl & CMIN/DF & CFI & TLI & RMSEA \\
\hline IP e IA (VDs) & 10611,110 & 2179 & 4,87 & 0,91 & 0,90 & 0,04 \\
\hline
\end{tabular}

Nota: $N=2411$

A Tabela 68 mostra que o modelo estrutural apresenta um bom ajuste aos dados empíricos na autoavaliação dos impactos do treinamento no trabalho em profundidade e amplitude $(C F I=0,91 ; T L I=0,90$ e $R M S E A=0,04)$. Em seguida, as Tabelas 69 e 70 expõem os efeitos de cada variável antecedente sobre as dependentes [IP e IA] e de IP sobre IA.

Tabela 69. Efeitos estandardizados totais, diretos e indiretos das variáveis independentes com a variável dependente "Impacto do Treinamento no Trabalho em Profundidade".

\begin{tabular}{cc|c|c}
\hline \multirow{2}{*}{ Variáveis } & \multicolumn{3}{c}{ Efeitos estandardizados $(\boldsymbol{\beta})$} \\
\cline { 2 - 4 } & Totais & Diretos & Indiretos \\
\hline EA1 & $-0,060$ & $-0,060$ & 0,000 \\
EA2 & 0,059 & 0,059 & 0,000 \\
EA3 & 0,477 & $0,477^{*}$ & 0,000 \\
EA4 & 0,039 & 0,039 & 0,000 \\
RP & 0,204 & 0,000 & 0,000 \\
BF & 0,000 & 0,041 & 0,000 \\
SS & 0,041 & $0,081^{* *}$ & 0,000 \\
SC & 0,081 & $0,159^{*}$ & 0,000 \\
SM & 0,159 & $0,334^{*}$ & 0,000 \\
IA & 0,334 &
\end{tabular}

Nota: $* p<0,000 ; * * p<0,05$

Tabela 70. Efeitos estandardizados totais, diretos e indiretos das variáveis independentes com a variável dependente "Impacto do Treinamento no Trabalho em Amplitude".

\begin{tabular}{cc|c|c}
\hline \multirow{2}{*}{ Variáveis } & \multicolumn{3}{c}{ Efeitos estandardizados $(\boldsymbol{\beta})$} \\
\cline { 2 - 4 } & Totais & Diretos & Indiretos \\
\hline EA1 & 0,090 & $0,110^{* *}$ & $-0,020$ \\
EA2 & $-0,035$ & $-0,055$ & 0,020 \\
EA3 & 0,252 & $0,093^{* *}$ & 0,159 \\
EA4 & $0,129^{*}$ & 0,013 \\
RP & 0,142 & $0,247^{*}$ & 0,068 \\
BF & 0,315 & 0,024 & 0,000 \\
SS & 0,024 & 0,043 & 0,014 \\
SC & 0,057 & 0,072 & 0,027 \\
SM & 0,099 & 0,048 & 0,053 \\
IP & 0,101 & $0,334^{*}$ & 0,000 \\
\hline
\end{tabular}


Ao testar o modelo com todas as variáveis antecedentes relacionadas a IP e a IA ao mesmo tempo, as estratégias de aprendizagem de elaboração e aplicação prática $(\beta=0,477)$, as reações aos procedimentos instrucionais $(\beta=0,204)$ e o suporte material $(\beta=0,159)$ tiveram efeito direto significativo $(p<0,000)$ sobre o impacto em profundidade. Por outro lado, as estratégias de aprendizagem de controle da motivação $(\beta=0,129)$, as reações aos procedimentos instrucionais $(\beta=0,247)$ e o impacto em profundidade $(\beta=0,334)$ tiveram efeito direto significativo $(p<0,000)$ sobre o impacto em amplitude (ver Figura 18).

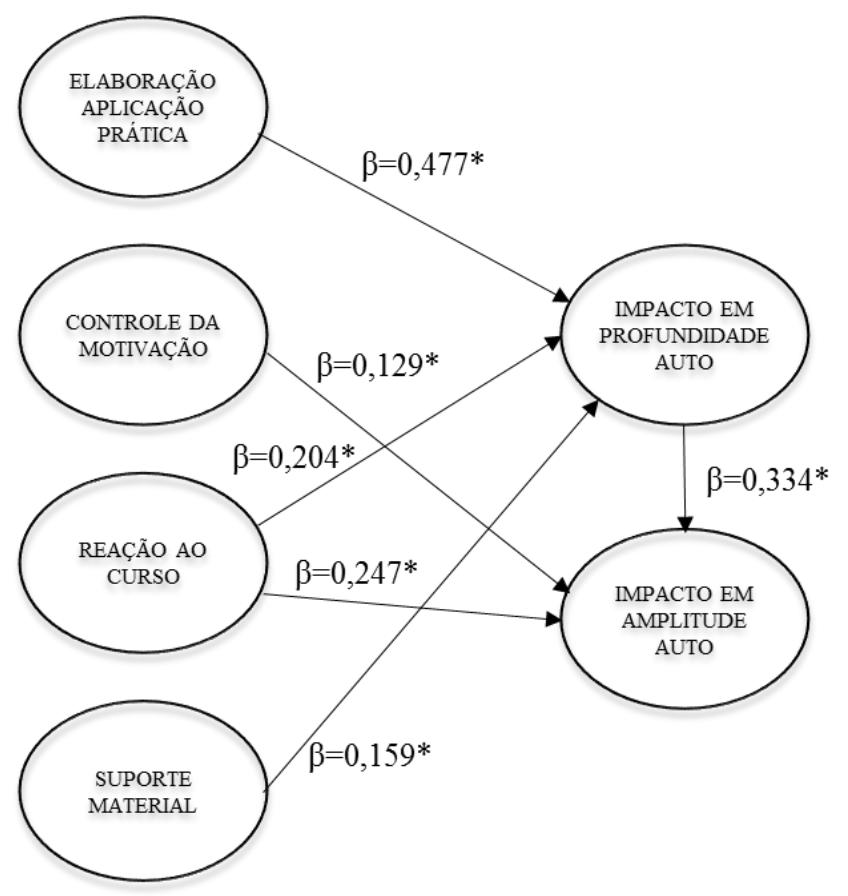

Figura 18. Modelo simplificado com os coeficientes de regressão estandardizados significativos $\left({ }^{*} p<0,000\right)$.

Ao considerar o intervalo de confiança de $95 \%$, o suporte de pares $(\beta=0,081)$ também contribuiu para explicar o impacto em profundidade; e, por sua vez, as estratégias de aprendizagem cognitivas e busca de ajuda $(\beta=0,110)$, bem como as de elaboração e aplicação prática $(\beta=0,093)$ explicaram o impacto em amplitude (ver Figura 19). 


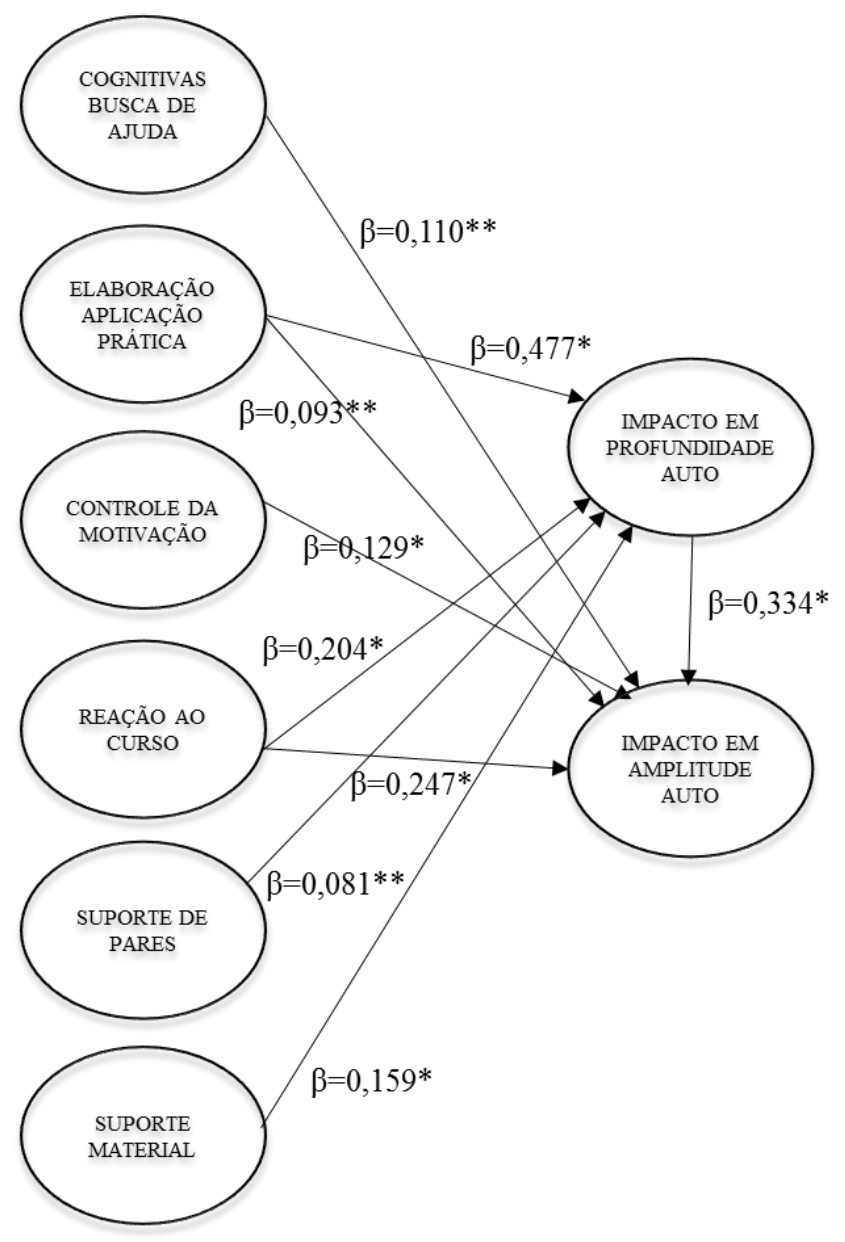

Figura 19. Modelo simplificado com os coeficientes de regressão estandardizados significativos $\left({ }^{*} p<0,000\right.$ $\left.\mathrm{e}^{* *} p<0,05\right)$.

No caso do impacto em profundidade, as estratégias de elaboração e de aplicação prática (estratégias cognitivas e comportamentais), a satisfação com os aspectos formais do curso junto à percepção de apoio material fornecido pela organização e pelos colegas de trabalho tiveram contribuição importante para que as novas competências desenvolvidas no treinamento fossem aplicadas no ambiente de trabalho. Aqueles que usaram com mais frequência as estratégias de aprendizagem autorregulatórias de controle da motivação e as de elaboração/aplicação prática, e estavam satisfeitos com o curso, foram os que obtiveram ganhos no desempenho geral, além de terem transferido o conhecimento específico aprendido.

Com exceção das barreiras e facilitadores em EAD (efeito nulo) e das estratégias cognitivas e busca de ajuda (efeito indireto negativo), as demais variáveis mostraram efeitos indiretos positivos sobre o impacto em amplitude: as modificações no desempenho global, incluindo atitudes e motivação do indivíduo [IA], passam pela aplicação direta no cargo das habilidades específicas desenvolvidas no treinamento [IP]. Dessa maneira, 
confirmam-se que os efeitos diretos e específicos do treinamento, relacionados aos objetivos educacionais, sobre o desempenho do trabalhador treinado (comportamento no cargo) apresenta relação com a influência indireta do treinamento sobre o desempenho global do egresso quando retorna ao ambiente de trabalho - ver Figura 20.

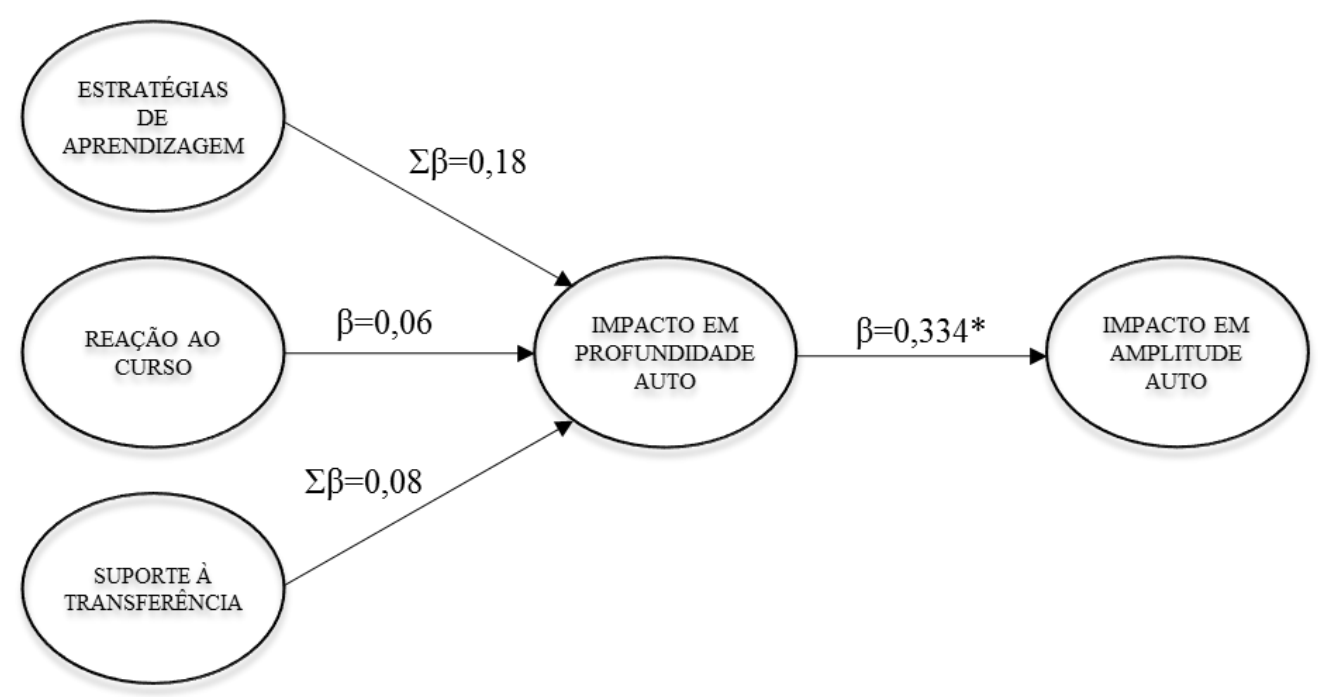

Figura 20. Efeitos indiretos positivos de variáveis independentes sobre o Impacto em Amplitude na autoavaliação.

\subsubsection{Heteroavaliação.}

\subsection{Impacto do treinamento no trabalho em profundidade.}

Tabela 71. Indicadores de ajuste para o modelo estrutural com o Impacto do Treinamento no Trabalho em Profundidade como variável dependente.

\begin{tabular}{lcccccc}
\hline Modelo & $\chi^{2}$ & $\boldsymbol{g l}$ & $\boldsymbol{C M I N / D F}$ & $\boldsymbol{C F I}$ & $\boldsymbol{T L I}$ & $\boldsymbol{R M S E A}$ \\
\hline Impacto em Profundidade (VD) & 8857,141 & 1748 & 5,06 & 0,92 & 0,91 & 0,04 \\
\hline
\end{tabular}

Notas: $N=2411$; introduzidas correlações entre os fatores de uma mesma variável

A Tabela 71 mostra que o modelo estrutural apresenta um bom ajuste aos dados empíricos na heteroavaliação de impacto do treinamento no trabalho em profundidade $(C F I=0,92 ; T L I=0,91$ e $R M S E A=0,04)$.

Tabela 72. Efeitos estandardizados totais, diretos e indiretos das variáveis independentes com a variável dependente "Impacto do Treinamento no Trabalho em Profundidade".

\begin{tabular}{cc|c|c}
\hline \multirow{2}{*}{ Variáveis } & \multicolumn{3}{c}{ Efeitos estandardizados $(\boldsymbol{\beta})$} \\
\cline { 2 - 4 } & Totais & Diretos & Indiretos \\
\hline EA1 & 0,041 & 0,041 & 0,000 \\
EA2 & $-0,030$ & $-0,030$ & 0,000 \\
EA3 & $-0,030$ & $-0,030$ & 0,000 \\
EA4 & 0,034 & 0,034 & 0,000 \\
RP & $-0,033$ & $-0,033$ & 0,000 \\
BF & $-0,020$ & $-0,020$ & 0,000 \\
\hline
\end{tabular}


Tabela 72. Efeitos estandardizados totais, diretos e indiretos das variáveis independentes com a variável dependente "Impacto do Treinamento no Trabalho em Profundidade". (Continuação)

\begin{tabular}{cc|c|c}
\hline \multirow{2}{*}{ Variáveis } & \multicolumn{3}{c}{ Efeitos estandardizados $(\boldsymbol{\beta})$} \\
\cline { 2 - 4 } & Totais & Diretos & Indiretos \\
SS & 0,078 & $0,078^{* *}$ & 0,000 \\
SC & $-0,036$ & $-0,036$ & 0,000 \\
SM & $-0,042$ & $-0,042$ & 0,000 \\
\hline
\end{tabular}

Nota: $* p<0,000 ; * * p<0,05$

Considerando significativo $p<0,05$, somente o suporte de supervisores $(\beta=0,078)$ contribuiu para a explicação do impacto do treinamento no trabalho em profundidade na heteroavaliação, conforme mostra a Tabela 72 e a Figura 21.

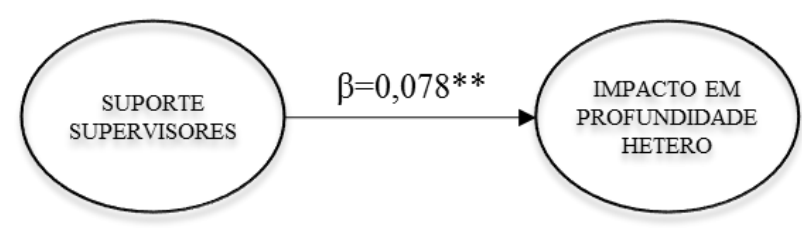

Figura 21. Modelo simplificado com os coeficientes de regressão estandardizados significativos $(* * p<0,05)$.

\subsection{Impacto do treinamento no trabalho em amplitude.}

Tabela 73. Indicadores de ajuste para o modelo estrutural com o Impacto do Treinamento no Trabalho em Amplitude como variável dependente.

\begin{tabular}{lcccccc}
\hline Modelo & $\chi^{2}$ & $\boldsymbol{g l}$ & $\boldsymbol{C M I N / D F}$ & $\boldsymbol{C F I}$ & $\boldsymbol{T L I}$ & $\boldsymbol{R M S E A}$ \\
\hline Impacto em Amplitude (VD) & 9101,360 & 1749 & 5,20 & 0,92 & 0,91 & 0,04 \\
\hline
\end{tabular}

Notas: $N=2411$; introduzidas correlações entre os fatores de uma mesma variável

A Tabela 73 mostra que o modelo estrutural apresenta um bom ajuste aos dados empíricos na heteroavaliação de impacto do treinamento no trabalho em amplitude $(C F I=0,92 ; T L I=0,91$ e $R M S E A=0,04)$.

Tabela 74. Efeitos estandardizados totais, diretos e indiretos das variáveis independentes com a variável dependente "Impacto do Treinamento no Trabalho em Amplitude".

\begin{tabular}{cc|c|c}
\hline \multirow{2}{*}{ Variáveis } & \multicolumn{3}{c}{ Efeitos estandardizados $(\boldsymbol{\beta})$} \\
\cline { 2 - 4 } & Totais & Diretos & Indiretos \\
EA1 & 0,069 & $0,069^{+}$ & 0,000 \\
EA2 & $-0,017$ & $-0,017$ & 0,000 \\
EA3 & $-0,075$ & $-0,075$ & 0,000 \\
RP & $-0,004$ & $-0,004$ & 0,000 \\
BF & $-0,018$ & $-0,018$ & 0,000 \\
SS & $-0,014$ & $-0,014$ & 0,000 \\
SC & 0,040 & 0,040 & 0,000 \\
SM & $-0,018$ & $-0,018$ & 0,000 \\
& $-0,017$ & $-0,017$ & 0,000 \\
\hline
\end{tabular}

Nota: $* p<0,000 ; * * p<0,05 ;{ }^{+} p<0,10$ 
Como pode ser observado na Tabela 74, nenhuma das variáveis teve efeito significativo na explicação do impacto do treinamento no trabalho em amplitude na heteroavaliação. As estratégias cognitivas e busca de ajuda, no entanto, aparecem como marginalmente significativas $(p<0,10)$.

3.4.3.2.3. Impacto do treinamento no trabalho em profundidade e amplitude.

Tabela 75. Indicadores de ajuste para o modelo estrutural com as variáveis dependentes IP e IA.

\begin{tabular}{lcccccc}
\hline Modelo & $\chi^{2}$ & $\boldsymbol{g l}$ & $\boldsymbol{C M I N / D F}$ & $\boldsymbol{C F I}$ & $\boldsymbol{T L I}$ & $\boldsymbol{R M S E A}$ \\
\hline IP e IA (VDs) & 10179,862 & 2179 & 4,67 & 0,92 & 0,91 & 0,03 \\
\hline Nota: $N=2411$ & & & & & &
\end{tabular}

A Tabela 75 mostra que o modelo estrutural apresenta um bom ajuste aos dados empíricos na heteroavaliação dos impactos do treinamento no trabalho em profundidade e amplitude ( $C F I=0,92 ; T L I=0,91$ e $R M S E A=0,03)$. Em seguida, as Tabelas 76 e 77 expõem os efeitos de cada variável antecedente sobre as dependentes [IP e IA] e de IP sobre IA.

Tabela 76. Efeitos estandardizados totais, diretos e indiretos das variáveis independentes com a variável dependente "Impacto do Treinamento no Trabalho em Profundidade".

\begin{tabular}{cc|c|c}
\hline \multirow{2}{*}{ Variáveis } & \multicolumn{3}{c}{ Efeitos estandardizados $(\boldsymbol{\beta})$} \\
\cline { 2 - 4 } & Totais & Diretos & Indiretos \\
\hline EA1 & 0,041 & 0,041 & 0,000 \\
EA2 & $-0,027$ & $-0,027$ & 0,000 \\
EA3 & $-0,031$ & $-0,031$ & 0,000 \\
EA4 & 0,036 & 0,036 & 0,000 \\
RP & $-0,035$ & $-0,035$ & 0,000 \\
BF & $-0,021$ & $-0,021$ & 0,000 \\
SS & 0,074 & $0,074 * *$ & 0,000 \\
SC & $-0,036$ & $-0,036$ & 0,000 \\
SM & $-0,038$ & $-0,038$ & 0,000 \\
IA & $0,878^{*}$ & $0,878^{*}$ & 0,000 \\
\hline
\end{tabular}

Nota: $* p<0,000 ; * * p<0,05$

Tabela 77. Efeitos estandardizados totais, diretos e indiretos das variáveis independentes com a variável dependente "Impacto do Treinamento no Trabalho em Amplitude".

\begin{tabular}{cc|c|c}
\hline \multirow{2}{*}{ Variáveis } & \multicolumn{3}{c}{ Efeitos estandardizados $(\boldsymbol{\beta})$} \\
\cline { 2 - 4 } & Totais & Diretos & Indiretos \\
EA1 & 0,087 & $0,052^{* *}$ & 0,036 \\
EA2 & 0,001 & 0,025 & $-0,024$ \\
EA3 & $-0,112$ & $-0,085$ & $-0,027$ \\
EA4 & $-0,007$ & 0,039 & 0,032 \\
RP & $-0,020$ & 0,011 & $-0,031$ \\
BF & $-0,012$ & $-0,031$ & $-0,018$ \\
SS & 0,074 & 0,026 & 0,065 \\
SC & $-0,005$ & 0,014 & $-0,031$ \\
SM & $-0,038$ & $0,878^{*}$ & $-0,034$ \\
IP & $0,878^{*}$ & & 0,000 \\
\hline
\end{tabular}

Nota: $*_{p}<0,000 ; * * p<0,05$ 
Apenas o efeito de IP sobre IA $(\beta=0,878)$ mostrou-se significativo a $p<0,000$, com um coeficiente de regressão muito alto, indicando forte influência. A $p<0,05$, no caso da heteroavaliação do impacto em profundidade, o suporte de supervisores $(\beta=0,074)$ contribuiu para sua explicação; para o impacto em amplitude, as estratégias de aprendizagem cognitivas e busca de ajuda $(\beta=0,052)$ - ver Figura 22.

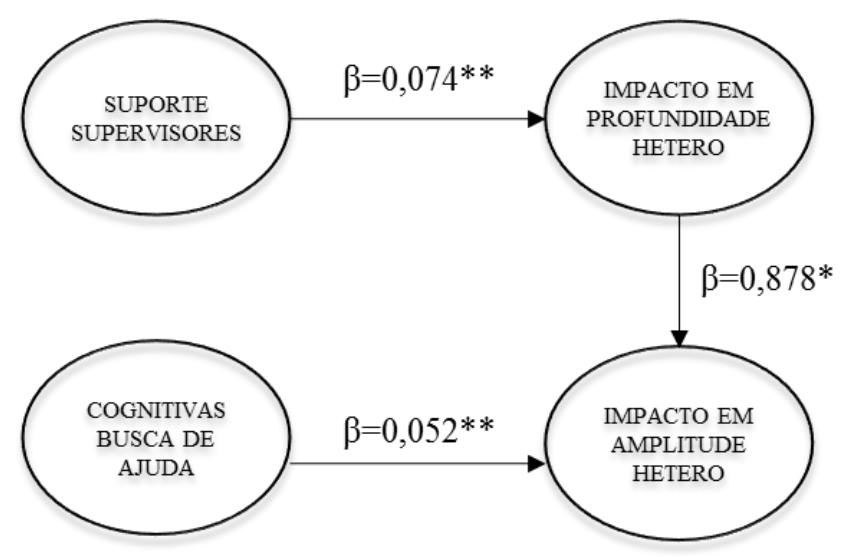

Figura 22. Modelo simplificado com os coeficientes de regressão estandardizados significativos $\left({ }^{*} p<0,000\right.$; $* * p<0,05)$.

Da mesma forma que na autoavaliação, o processo de modificação no desempenho global, incluindo atitudes e motivação do indivíduo [IA], passa pela aplicação direta das habilidades específicas desenvolvidas no treinamento para o cargo [IP]. Neste caso, as estratégias de aprendizagem cognitivas/busca de ajuda e de controle da motivação, bem como o suporte de supervisores tiveram efeitos indiretos positivos sobre tal relação (ver Figura 23).

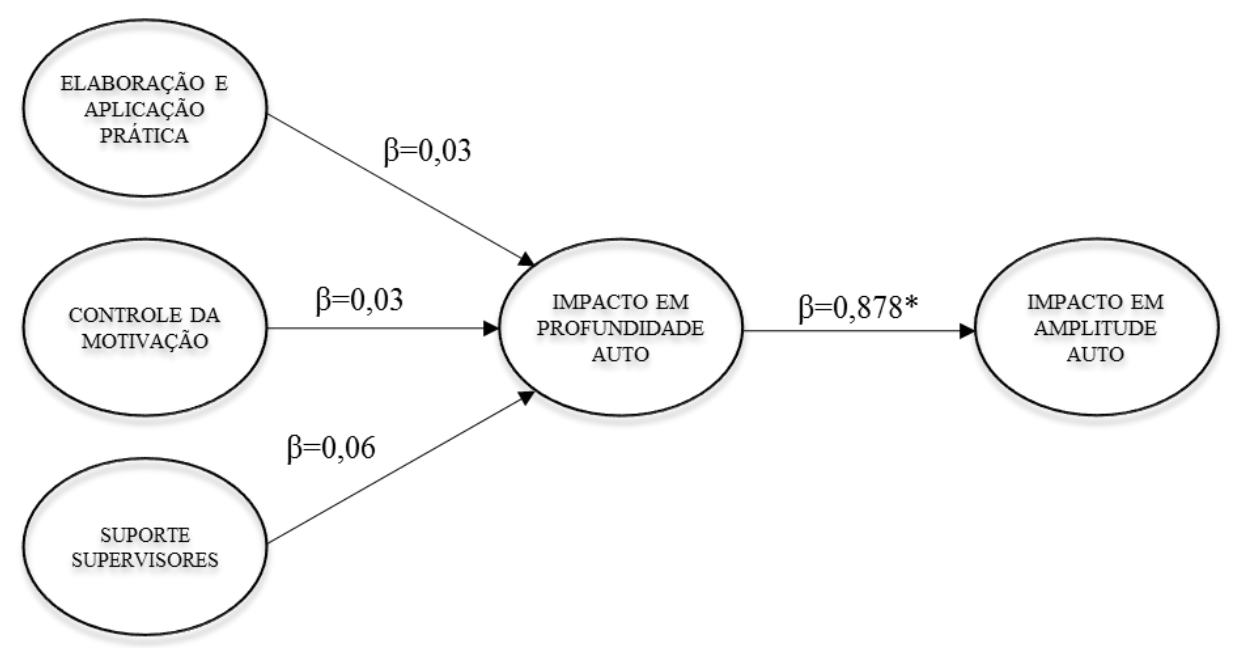

Figura 23. Efeitos indiretos positivos de variáveis independentes sobre o Impacto em Amplitude na heteroavaliação. 


\subsubsection{Relações de mediação e moderação entre variáveis}

A realização de análises de mediação e moderação serviu para investigar as relações entre as variáveis presentes no modelo segundo as hipóteses previamente elaboradas ou que surgiram a partir dos resultados obtidos, visando explorar e antecipar os principais mediadores e moderadores das relações entre as variáveis antecedentes do modelo e o impacto do treinamento no trabalho. Primeiramente, as análises foram realizadas por meio de regressões (Baron \& Kenny, 1986) e, posteriormente, mediante a utilização do procedimento PROCESS no SPSS (Hayes, 2013). Este, apresenta vantagens em relação ao primeiro, pois facilita a estimação de efeitos indiretos com o método bootstrap para obter os intervalos de confiança; ainda, é robusto a violações de normalidade multivariada e a distribuição é baseada em dados empíricos.

\subsubsection{Hipótese mediadora.}

A hipótese que propunha a mediação das reações aos procedimentos instrucionais do curso sobre o suporte à transferência e os indicadores de efetividade de treinamento previa que o suporte à transferência prediria o impacto via mediação das reações $\left(\mathrm{H}_{\mathrm{med}}\right)$.

A relação de mediação supõe uma variável intermediária por meio da qual a variável independente (VI) causa ou afeta a dependente (VD); ela pretende responder a pergunta "por quê" existe a relação entre a VI e a VD. A variável mediadora diminui a magnitude entre a VI e VD, podendo reduzir ou neutralizar a força da primeira sobre a segunda (Aiken \& West, 1991; Baron \& Kenny, 1986; Preacher \& Hayes, 2004). Assim, a relação entre a VI e a VD ficaria enfraquecida ou poderia ser nula com a inserção da variável mediadora. Caso sua presença faça com que a relação entre VI e VD seja nula, a variável mediadora teria bloqueado o efeito anteriormente existente da VI sobre a VD, tornando a relação não significativa, o que é denominado de mediação completa ou pura. O modelo com a inserção da variável mediadora pode ser observado na Figura 24. 


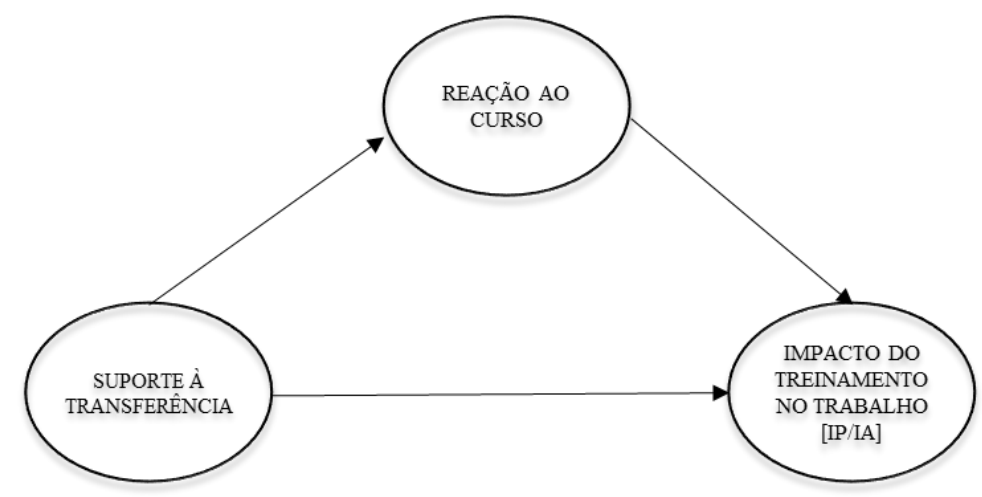

Figura 24. Modelo da variável mediadora reação aos procedimentos instrucionais entre suporte à transferência e impacto do treinamento no trabalho.

Para tanto, foram realizadas análises de regressão simples com as VIs [RP e SP], separadamente, e as VDs [IP/IA], na auto e heteroavaliação de impacto; e logo, incluíramse ambas em um modelo de regressão múltipla. Ao verificar as condições necessárias para a mediação ocorrer, deve-se cumprir os seguintes pressupostos: a) a VI [SP] afeta significativamente as VDs [IP/IA] na falta da variável mediadora [RP]; b) a variável mediadora [RP] tem efeito significativo único sobre as VDs [IP/IA]; c) o efeito da VI [SP] sobre as VDs [IP/IA] enfraquece no momento da adição da variável mediadora [RP].

Tabela 78. Regressão simples de Reação aos Procedimentos Instrucionais sobre o Impacto do Treinamento no Trabalho em Profundidade e em Amplitude.

\begin{tabular}{lcc}
\hline & IP $_{\text {AUtO }}$ & IA $_{\text {AUtO }}$ \\
\hline$R P$ & $\beta=0,488^{*}$ & $\beta=0,524 *$ \\
\hline$R^{2}$ & 0,238 & 0,274 \\
\hline
\end{tabular}

Nota: $* p<0,000$

Tabela 79. Regressão simples de Suporte à Transferência sobre o Impacto do Treinamento no Trabalho em Profundidade e em Amplitude.

\begin{tabular}{lcc} 
& IP $_{\text {AUTO }}$ & IA $_{\text {AUTO }}$ \\
\hline $\mathrm{SS}$ & $\beta=0,123^{*}$ & $\beta=0,125^{*}$ \\
$\mathrm{SC}$ & $\beta=0,107^{*}$ & $\beta=0,127^{*}$ \\
$\mathrm{SM}$ & $\beta=0,256^{*}$ & $\beta=0,260^{*}$ \\
\hline$R^{2}$ & 0,165 & 0,180 \\
\hline
\end{tabular}

Nota: $* p<0,000$

Tabela 80. Regressão múltipla de Reação aos Procedimentos Instrucionais e Suporte à Transferência sobre o Impacto do Treinamento no Trabalho em Profundidade e em Amplitude.

\begin{tabular}{lcc} 
& IP $_{\text {AUTO }}$ & IA $_{\text {AUTO }}$ \\
\hline $\mathrm{RP}$ & $\beta=0,400^{*}$ & $\beta=0,407^{*}$ \\
$\mathrm{SS}$ & $\beta=0,106^{*}$ & $\beta=0,089^{*}$ \\
$\mathrm{SC}$ & $\beta=0,069^{\mathrm{ns}}$ & $\beta=0,100^{*}$ \\
\hline
\end{tabular}


Tabela 80. Regressão múltipla de Reação aos Procedimentos Instrucionais e Suporte à Transferência sobre o Impacto do Treinamento no Trabalho em Profundidade e em Amplitude. (Continuação)

\begin{tabular}{lcc}
\hline & IP $_{\text {AUTO }}$ & IA $_{\text {AUTO }}$ \\
\hline $\mathrm{SM}$ & $\beta=0,091^{*}$ & $\beta=0,113^{*}$ \\
\hline$R^{2}$ & 0,288 & 0,316 \\
\hline
\end{tabular}

Nota: $* p<0,000 ; \mathrm{ns}=$ não significativo

$\mathrm{Na}$ autoavaliação, as reações e o suporte à transferência - representada pelos fatores de suporte de supervisores $[\mathrm{SS}]$, pares [SC] e material [SM] -, são preditores diretos e significativos de impacto do treinamento no trabalho em profundidade e em amplitude (ver Tabelas 78 e 79). Quando incluídas as VIs juntas no modelo de regressão, o poder explicativo do suporte à transferência enfraquece na presença da medida de satisfação, inclusive o suporte de pares torna-se não significativo, e os valores dos coeficientes de regressão também diminuem, indicando o papel mediador da variável RP sobre SP na explicação de impacto (ver Tabela 80). Por outro lado, na heteroavaliação de impacto em profundidade e em amplitude, nenhuma das VIs mostrou-se significativa sobre as VDs.

Conclui-se, a partir desses resultados, que a percepção de suporte à transferência depende da satisfação dos participantes com o curso; em outras palavras, a opinião dos participantes quanto aos aspectos formais da instrução influencia na percepção do suporte recebido pela organização ou por companheiros de trabalho (chefes ou pares) e, por conseguinte, na ocorrência de impacto. A explicação de impacto tem relação com ambas variáveis [RP e SP]; ademais, a contribuição do suporte à transferência passa pela satisfação com os procedimentos instrucionais.

Tal mediação foi corroborada pelas análises realizadas no PROCESS, obtendo-se os seguintes resultados expostos na Tabela 81.

Tabela 81. Resultados para mediação simples de reação aos procedimentos instrucionais sobre suporte à transferência e impacto do treinamento no trabalho.

\begin{tabular}{|c|c|c|c|c|c|c|c|c|c|}
\hline \multirow{2}{*}{$\mathbf{X}$} & \multirow{2}{*}{$\mathbf{Y}$} & \multirow{2}{*}{$n$} & \multicolumn{3}{|c|}{ Efeitos diretos $(\beta)$} & \multirow{2}{*}{ Efeitos indiretos (ab) } & \multicolumn{2}{|c|}{$95 \% \mathrm{CI}$} & \multirow{2}{*}{$\kappa^{2}$} \\
\hline & & & $\mathbf{a}$ & b & c' & & $\mathbf{L L}$ & $\mathbf{U L}$ & \\
\hline \multirow{2}{*}{ SS } & IP & 905 & $0,17 * *$ & $0,52 * *$ & $0,11 * *$ & 0,09 & $+0,0707$ & $+0,1181$ & 0,14 \\
\hline & IA & 1147 & $0,17 * *$ & $0,56^{* *}$ & $0,12 * *$ & 0,09 & $+0,0739$ & $+0,1202$ & 0,14 \\
\hline \multirow{2}{*}{$\mathrm{SC}$} & IP & 874 & $0,17 * *$ & $0,51 * *$ & $0,11 * *$ & 0,09 & $+0,0694$ & $+0,1187$ & 0,13 \\
\hline & IA & 1112 & $0,14 * *$ & $0,55^{* *}$ & $0,13 * *$ & 0,08 & $+0,0601$ & $+0,1046$ & 0,12 \\
\hline \multirow{2}{*}{ SM } & IP & 918 & $0,26^{* *}$ & $0,51 * *$ & $0,10 * *$ & 0,13 & $+0,1091$ & $+0,1698$ & 0,19 \\
\hline & IA & 1156 & $0,24 * *$ & $0,54 * *$ & $0,12 * *$ & 0,13 & $+0,1102$ & $+0,1651$ & 0,19 \\
\hline
\end{tabular}

Notas: $\mathrm{M}=\mathrm{RP} ; \mathrm{XM}=\mathrm{a} ; \mathrm{MY}=\mathrm{b} ; \mathrm{XY}=\mathrm{c}$. $.{ }^{*}{ }^{*} p<0,000 ; * p<0,05 ;{ }^{+} p<0,10$. Modelo 4 , método Bootstrap CI (bias corrected), número de amostras bootstrap $=5000$. BootLLCI=lower limit $;$ BootULCI=upper limit . $\kappa^{2}=$ Kappa-squared (Preacher \& Kelly, 2011). 
Além dos efeitos diretos positivos observados, pode-se concluir que RP possui um efeito indireto positivo sobre IP/IA através do aumento de SP (suporte à transferência representado pelo apoio de supervisores, pares e material), confirmando o seu papel mediador - o efeito ab é significativo (o valor 0 não se encontra dentro do intervalo de confiança de $95 \%$, que pode ser observado pelos sinais positivos de LL e UL).

\subsection{Outras relações de mediação.}

Seguindo-se exatamente os mesmos procedimentos anteriormente apresentados (seção 3.4.4.1), foram realizadas análises para investigar o papel mediador das reações sobre as demais variáveis presentes no modelo, quais sejam: as estratégias de aprendizagem e as barreiras e facilitadores em EAD.

\section{Estratégias de aprendizagem}

Tabela 82. Regressão simples de Estratégias de Aprendizagem sobre o Impacto do Treinamento no Trabalho em Profundidade e em Amplitude.

\begin{tabular}{lcc}
\hline & IP $_{\text {AUTO }}$ & IA $_{\text {AUTO }}$ \\
\hline EA1 & $\beta=0,086^{*}$ & $\beta=0,152^{*}$ \\
EA2 & $\beta=0,029$ & $\beta=0,051^{+}$ \\
EA3 & $\beta=0,435^{*}$ & $\beta=0,312^{*}$ \\
EA4 & $\beta=0,098^{*}$ & $\beta=0,170^{*}$ \\
\hline$R^{2}$ & 0,310 & 0,297 \\
\hline
\end{tabular}

Nota: ${ }^{*} p<0,01 ;{ }^{+} p<0,10$

Tabela 83. Regressão múltipla de Reação aos Procedimentos Instrucionais e Estratégias de Aprendizagem sobre o Impacto do Treinamento no Trabalho em Profundidade e em Amplitude.

\begin{tabular}{lcc} 
& IP $_{\text {AUTO }}$ & IA $_{\text {AUTO }}$ \\
\hline RP & $\beta=0,259^{*}$ & $\beta=0,337^{*}$ \\
EA1 & $\beta=0,065^{* *}$ & $\beta=0,125^{*}$ \\
EA2 & $\beta=-0,016$ & $\beta=-0,019$ \\
EA3 & $\beta=0,345^{*}$ & $\beta=0,196^{*}$ \\
EA4 & $\beta=0,058$ & $\beta=0,128^{*}$ \\
\hline$R^{2}$ & 0,310 & 0,297
\end{tabular}

Nota: $* p<0,01 ; * * p<0,05 ;{ }^{+} p<0,10$

$\mathrm{Na}$ autoavaliação, as reações e as estratégias de aprendizagem - representadas pelos fatores: cognitivas e busca de ajuda [EA1]; controle da emoção [EA2]; elaboração e aplicação prática [EA3]; controle da motivação [EA4] - são preditores diretos e 
significativos de impacto do treinamento no trabalho em profundidade e em amplitude (ver Tabelas 82 e 83), com exceção de EA2 no caso de IP. Quando incluídas as VIs juntas no modelo de regressão, o poder explicativo das estratégias de aprendizagem enfraquece na presença da medida de satisfação e os valores dos coeficientes de regressão também diminuem, indicando o papel mediador da variável RP sobre EA na explicação de impacto (ver Tabela 84). Por outro lado, na heteroavaliação de impacto em profundidade e em amplitude, nenhuma das VIs mostrou-se significativa sobre as VDs.

Conclui-se, a partir desses resultados, que a utilização dos diferentes tipos de estratégias de aprendizagem depende da satisfação dos participantes com o curso; em outras palavras, a opinião dos participantes quanto aos aspectos formais da instrução influencia no emprego das estratégias de aprendizagem e, consequentemente, na ocorrência de impacto (ver Figura 25). A explicação de impacto tem relação com ambas variáveis [RP e EA]; ademais, a contribuição das estratégias de aprendizagem passa pela satisfação com os procedimentos instrucionais.

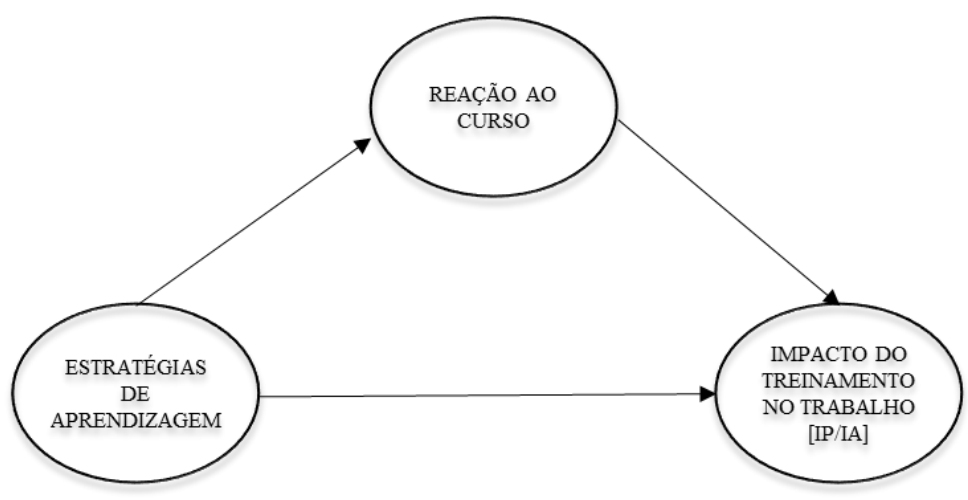

Figura 25. Efeito mediador das reações aos procedimentos instrucionais entre as estratégias de aprendizagem e o impacto do treinamento no trabalho na autoavaliação.

Tais resultados foram confirmados por meio de análises feitas no PROCESS (Tabela 84), os quais mostram que além dos efeitos diretos positivos observados, RP possui um efeito indireto positivo sobre IP/IA através do aumento de EA (estratégias de aprendizagem: cognitivas e busca de ajuda, controle da emoção, elaboração e aplicação prática e controle da motivação), ratificando o seu papel mediador - o efeito ab é significativo (o valor 0 não se encontra dentro do intervalo de confiança de $95 \%$, que pode ser observado pelos sinais positivos de LL e UL). 
Tabela 84. Resultados para mediação simples de reação aos procedimentos instrucionais sobre estratégias de aprendizagem e impacto do treinamento no trabalho.

\begin{tabular}{|c|c|c|c|c|c|c|c|c|c|}
\hline \multirow{2}{*}{$\mathbf{X}$} & \multirow{2}{*}{$\mathbf{Y}$} & \multirow{2}{*}{$n$} & \multicolumn{3}{|c|}{ Efeitos diretos $(\boldsymbol{\beta})$} & \multirow{2}{*}{ Efeitos indiretos (ab) } & \multicolumn{2}{|c|}{$95 \%$ CI } & \multirow{2}{*}{$\kappa^{2}$} \\
\hline & & & a & b & c' & & $\mathbf{L L}$ & $\mathbf{U L}$ & \\
\hline \multirow{2}{*}{ EA1 } & IP & 917 & $0,21 * *$ & $0,50 * *$ & $0,13 * *$ & 0,10 & $+0,0842$ & $+0,1384$ & 0,15 \\
\hline & IA & 1100 & $0,21 * *$ & $0,54 * *$ & $0,17 * *$ & 0,11 & $+0,0947$ & $+0,1471$ & 0,16 \\
\hline \multirow{2}{*}{ EA2 } & IP & 986 & $0,32 * *$ & $0,54 * *$ & $0,08^{*}$ & 0,17 & $+0,1435$ & $+0,2186$ & 0,18 \\
\hline & IA & 1197 & $0,31 * *$ & $0,62 * *$ & $0,05^{*}$ & 0,19 & $+0,1604$ & $+0,2332$ & 0,20 \\
\hline \multirow{2}{*}{ EA3 } & IP & 976 & $0,44 * *$ & $0,33 * *$ & $0,39 * *$ & 0,15 & $+0,1124$ & $+0,1949$ & 0,15 \\
\hline & IA & 1185 & $0,44 * *$ & $0,45 * *$ & $0,31 * *$ & 0,20 & $+0,1611$ & $+0,2494$ & 0,19 \\
\hline \multirow{2}{*}{ EA4 } & IP & 968 & $0,33 * *$ & $0,49 * *$ & $0,18 * *$ & 0,16 & $+0,1302$ & $+0,2073$ & 0,17 \\
\hline & IA & 1163 & $0,30 * *$ & $0,53 * *$ & $0,21 * *$ & 0,16 & $+0,1320$ & $+0,2046$ & 0,17 \\
\hline
\end{tabular}

Notas: $\mathrm{M}=\mathrm{RP} ; \mathrm{XM}=\mathrm{a} ; \mathrm{MY}=\mathrm{b} ; \mathrm{XY}=\mathrm{c}{ }^{\prime} .{ }^{*} p<0,000 ;{ }^{*} p<0,05 ;{ }^{+} p<0,10$. Modelo 4, método Bootstrap CI (bias corrected), número de amostras bootstrap $=5000$. BootLLCI=lower limit $;$ BootULCI=upper limit . $\kappa^{2}=$ Kappa-squared (Preacher \& Kelly, 2011).

\section{Barreiras e facilitadores em EAD}

A contribuição da variável barreiras e facilitadores em EAD somente foi marginalmente significativa na explicação do impacto do treinamento no trabalho em profundidade na autoavaliação $\left(\beta=0,06 ; R^{2}=0,04 ; p<0,10\right)$. Porém, ao testar o papel mediador das reações sobre $\mathrm{BF}$, os resultados mostraram um incremento do coeficiente de regressão de BF, tornando sua contribuição significativa (ver Tabela 85), justamente o oposto do exposto anteriormente, em que a inclusão de ambas variáveis na análise de regressão múltipla resultava na diminuição do poder explicativo da VI na presença da variável mediadora $(\mathrm{RP})$.

Tabela 85. Regressão múltipla de Reação aos Procedimentos Instrucionais e Barreiras e Facilitadores em EAD sobre o Impacto do Treinamento no Trabalho em Profundidade e em Amplitude.

\begin{tabular}{lcc}
\hline & $\mathrm{IP}_{\text {AUTO }}$ & IA $_{\text {AUTO }}$ \\
\hline $\mathrm{RP}$ & $\beta=0,489^{*}$ & $\beta=0,561^{*}$ \\
$\mathrm{BF}$ & $\beta=0,098^{*}$ & $\beta=0,053^{* *}$ \\
\hline$R^{2}$ & 0,242 & 0,315
\end{tabular}

Nota: ${ }^{*} p<0,01 ; * * p<0,05$

Já na heteroavaliação de impacto em profundidade e em amplitude, não ocorreu o mesmo, o que era esperado, pois as reações não tiveram influência sobre o impacto do treinamento no trabalho na avaliação referida pelos gestores.

Visando confirmar ou refutar tais achados, foram efetuadas análises no PROCESS, tendo sido obtidos os resultados apresentados a seguir (Tabela 86). 
Tabela 86. Resultados para mediação simples de reação aos procedimentos instrucionais sobre barreiras e facilitadores em EAD e impacto do treinamento no trabalho.

\begin{tabular}{|c|c|c|c|c|c|c|c|c|c|}
\hline \multirow{2}{*}{$\mathbf{X}$} & \multirow{2}{*}{$\mathbf{Y}$} & \multirow{2}{*}{$n$} & \multicolumn{3}{|c|}{ Efeitos diretos $(\beta)$} & \multirow{2}{*}{ Efeitos indiretos (ab) } & \multicolumn{2}{|c|}{$95 \% \mathrm{CI}$} & \multirow{2}{*}{$\kappa^{2}$} \\
\hline & & & $\mathrm{a}$ & $\mathrm{b}$ & $\mathrm{c}^{\prime}$ & & $\mathbf{L L}$ & UL & \\
\hline \multirow{2}{*}{$\mathrm{BF}$} & IP & 789 & $-0,02^{+}$ & $0,59 * *$ & $0,04 *$ & $-0,01$ & $-0,0316$ & $+0,0011$ & 0,03 \\
\hline & IA & 907 & $-0,02^{+}$ & $0,66 * *$ & $0,02 *$ & $-0,01$ & $-0,0321$ & $+0,0027$ & 0,03 \\
\hline
\end{tabular}

Os resultados encontrados mostram que BF possui um efeito negativo indireto sobre IP/IA através do aumento da satisfação (RP) $\left(\beta=-0,01,95 \%, \kappa^{2}=0,03\right)$. Como o valor 0 encontra-se dentro do intervalo de confiança de $95 \%$, que pode ser observado pelos sinais diferentes (+/-) de LL e UL, conclui-se que não há mediação.

\subsubsection{Hipótese moderadora.}

Contrariando as expectativas de que à medida em que os participantes percebessem os recursos como facilitadores e não como barreiras estaria positivamente relacionada com os indicadores de efetividade de treinamento $\left(\mathrm{H}_{7}\right)$, a variável barreiras e facilitadores em EAD [BF] não entrou como preditora significativa em nenhum dos modelos testados. Com vistas a compreender melhor o papel dessa variável sobre o impacto do treinamento no trabalho, realizaram-se análises complementares, uma vez que, embora não foram encontrados efeitos diretos nem indiretos no modelo completo testado por meio de MEE, sua contribuição foi observada nas análises de regressão múltipla padrão anteriormente descritas, explicando em parte a ocorrência do impacto em profundidade na autoavaliação $(\beta=0,10 ; p<0,01)$, mas não o impacto em amplitude.

Dentre as variáveis incluídas no modelo de investigação completo proposto, BF é a única que se refere ao contexto, além do suporte à transferência [SP], sendo as outras relativas ao indivíduo ou ao curso - medidas autorreferentes e perceptuais. Dessa forma, buscou-se investigar o papel moderador da variável de suporte à transferência entre BF (variável contextual) e o impacto em profundidade [IP] e em amplitude [IA], segundo a hipótese que propunha que o suporte à transferência atuaria como moderador da relação entre as barreiras e facilitadores em EAD e os indicadores de efetividade de treinamento.

A definição conceitual de moderação refere-se a uma variável qualitativa ou quantitativa que afeta a direção e/ou a força da relação entre uma variável independente (VI) e uma dependente (VD), ou seja, afeta a relação direta entre VI e VD (Aiken \& West, 1991; Baron \& Kenny, 1986) - ela pretende responder às questões "quando" e "para quem", isto é, sob que circunstâncias se dá a relação entre a VI e a VD. Neste caso, 
buscou-se verificar se o suporte à transferência [SP] afetaria a relação entre a VI barreiras e facilitadores em EAD [BF] e a VD impacto [IP e IA]; em outras palavras, objetivou-se investigar se a relação entre BF e impacto poderia ser reduzida, igualada a zero - sendo tal relação não significativa - ou o sinal da relação poderia ser invertido, dada a utilização de uma terceira variável, a variável moderadora SP. O modelo com a inserção da variável moderadora pode ser observado na Figura 26.

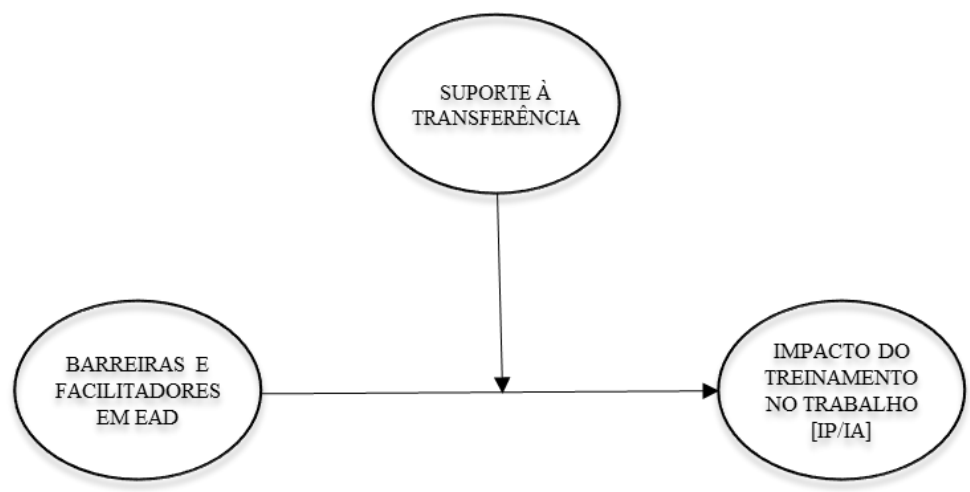

Figura 26. Modelo da variável moderadora suporte à transferência entre barreiras e facilitadores em EAD e impacto do treinamento no trabalho.

Ao testar, em modelos de regressão simples, a variável BF com os impactos em profundidade e amplitude, sua contribuição foi apenas marginalmente significativa $(p<0,10)$ na explicação de IP na autoavaliação $\left(R^{2}=0,04 ; \beta=0,06\right)$. Diferentemente do que ocorre com os tipos de suporte como antecedentes de impacto, obtendo-se resultados significativos ( $p<0,01)$ na autoavaliação de IP $\left(R^{2}=0,165\right.$; SS: $\beta=0,123$; SC: $\beta=0,107$; SM: $\beta=0,256)$ e IA $\left(R^{2}=0,180 ;\right.$ SS: $\beta=0,125$; SC: $\beta=0,127$; SM: $\left.\beta=0,260\right)$ - vide Tabela 81 .

Em seguida, para testar a moderação da variável suporte à transferência sobre as barreiras e facilitadores em EAD e os tipos de impacto [IP/IA], foram adotados os seguintes passos: i) centradas as VIs (BF, SS, SC e SM) por meio do cálculo da média de cada variável; ii) computadas novas variáveis, quais sejam os fatores antigos subtraídos das médias encontradas $\left(\mathrm{BF}^{*}, \mathrm{SS}^{*}, \mathrm{SC}^{*}\right.$ e $\left.\mathrm{SM}^{*}\right)$; iii) calculada a interação entre suporte e barreiras e facilitadores em EAD, multiplicando-se as duas novas VIs, isto é, a VI [BF*] e a variável moderadora [SS*, SC* e SM*] a ser testada, criando desta maneira a "variável de interação" (VI x Mod: BF* x SS*; BF* x SC*; BF* x SM*).

Logo, uma alteração significativa no $\mathrm{R}$ quadrado - o valor do índice $R^{2}$ deveria ser superior ao da regressão simples com as variáveis originais como antecedentes - após a inclusão da variável de interação na regressão hierárquica indicaria se existe moderação da variável testada. As variáveis antecedentes foram agrupadas e inseridas na análise na 
seguinte ordem de entrada: 1) $\mathrm{BF}^{*}$; 2) $\mathrm{SS}^{*}, \mathrm{SC}^{*}$ e $\mathrm{SM}^{*}$; e 3) a variável de interação entre as duas variáveis citadas $\left(\mathrm{BF}^{*} \mathrm{x} \mathrm{SS}^{*} ; \mathrm{BF}^{*} \mathrm{x} \mathrm{SC}^{*} ; \mathrm{BF}^{*} \times \mathrm{SM}^{*}\right)$.

A inclusão da variável de interação na regressão resultou no incremento do $R^{2}$ ao considerar o fator de suporte material [BF* $\left.\mathrm{x} \mathrm{SM}^{*}: \beta=0,062\right]\left(\Delta R^{2}=0,003[0,142-0,139]\right.$; $p<0,10)$, indicando que a variável SM modera a relação entre BF e IP na autoavaliação (ver Figura 27). Portanto, a influência das barreiras e facilitadores em EAD sobre o impacto em profundidade parece depender da percepção de suporte material pelo treinando.

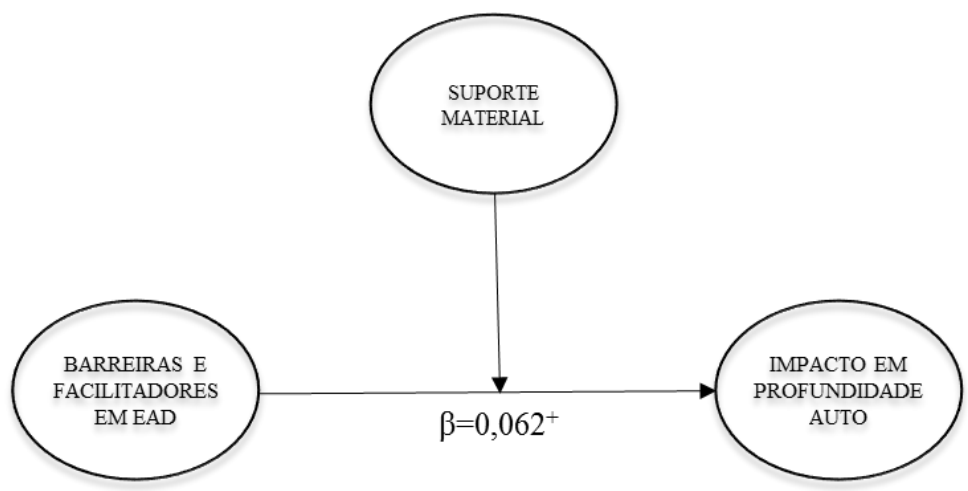

Figura 27. Efeito moderador do suporte material sobre barreiras e facilitadores em EAD e o impacto em profundidade na autoavaliação.

Quando testadas as relações via PROCESS (Modelo 1, método Bootstrap CI (bias corrected), número de amostras bootstrap $=5000)$, obtiveram-se resultados semelhantes, indicando que o suporte material modera o efeito de BF sobre IP $(\beta=0,03 ; p<0,10)$, ou seja, para os participantes que julgaram bem o apoio material oferecido pela organização, os efeitos de BF sobre IP foram enfraquecidos.

Para os participantes do treinamento com pontuação alta em suporte material ( $\mathrm{SM}=4,64$ em uma escala de 5 pontos), BF teve efeito positivo sobre IP $(95 \% \mathrm{CI}=$ $[+0,0120 ;+0,0874])$. Contudo, os egressos que tiveram médias baixas $(\mathrm{SM}=3,00 ; 95 \%$ $\mathrm{CI}=[-0,0558 ;+0,0466])$ a moderadas $(\mathrm{SM}=3,82 ; 95 \% \mathrm{CI}=[-0,0090 ;+0,0541]) \mathrm{na}$ percepção de suporte material, o efeito tornou-se insignificante.

A visualização dos efeitos pode ser observada por meio da representação gráfica a seguir (Figura 28) - as figuras foram construídas utilizando-se o valor de corte de um desvio-padrão abaixo (-1DP) e acima (+1DP) da média das variáveis (Aiken \& West, 1991), possibilitando determinar a natureza e a forma das interações analisadas. 


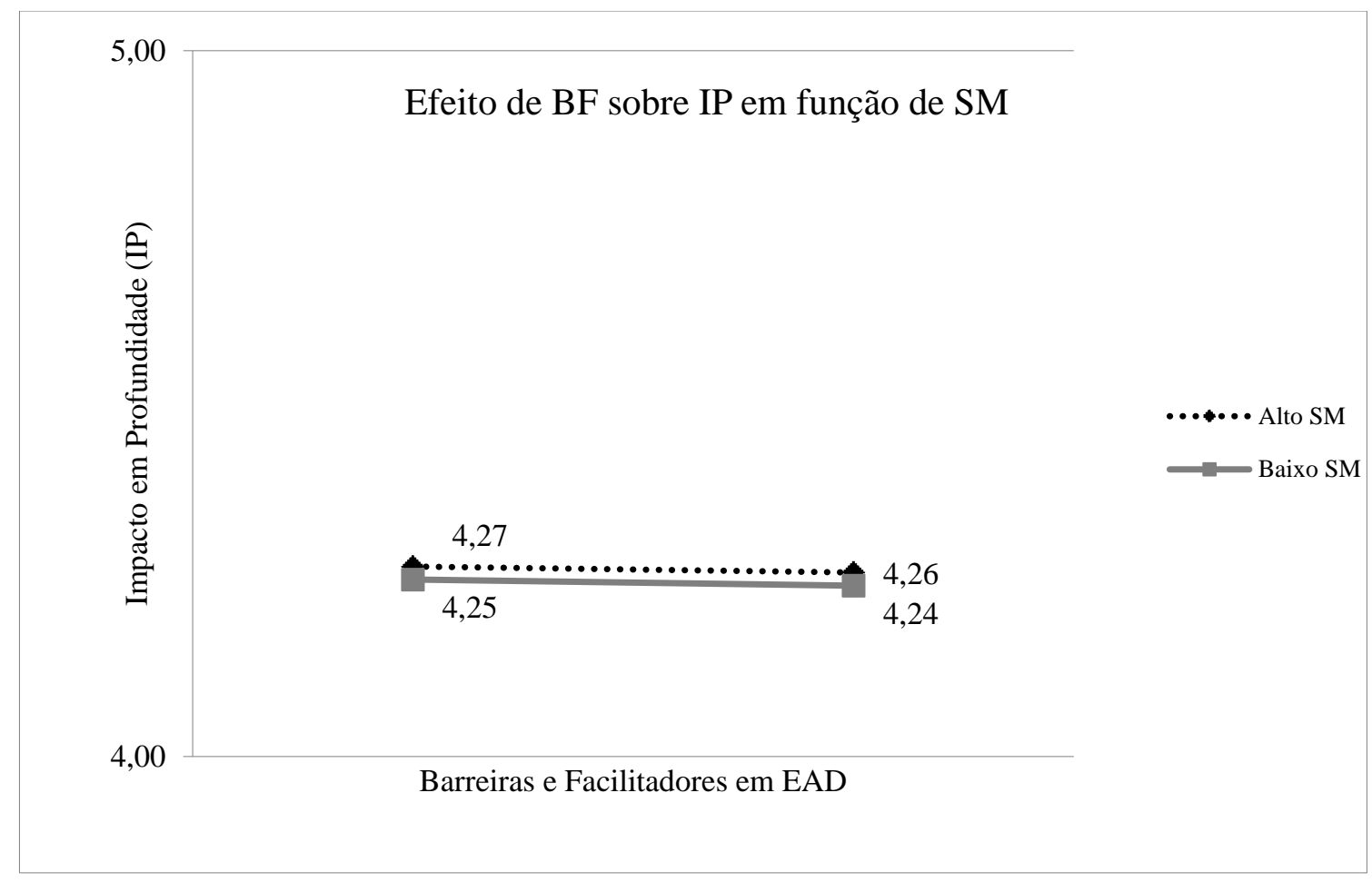

Figura 28. Relação entre as barreiras e facilitadores em EAD e o impacto em profundidade em função do suporte material.

Conforme pode ser observado na Figura 28, as barreiras e facilitadores em EAD predisseram o impacto em profundidade segundo os níveis de percepção do suporte material de maneira quase inexpressiva. Portanto, segundo a inspeção gráfica, parece não haver tal moderação antes constatada ou esta foi mínima em magnitude.

\subsection{Outras relações de moderação.}

Os mesmos procedimentos anteriormente apresentados foram adotados (seção 3.4.4.2) e foram realizadas análises para investigar o papel moderador das reações sobre as barreiras e facilitadores em EAD e sobre as estratégias de aprendizagem, bem como do suporte à transferência sobre as estratégias de aprendizagem.

\section{Moderação das reações sobre barreiras e facilitadores em EAD}

Como já exposto, as barreiras e facilitadores em EAD tiveram pouca contribuição na explicação do impacto do treinamento no trabalho, mas quando mediadas pelas reações, o coeficiente de regressão padronizado de $\mathrm{BF}$ aumentou, tornando sua contribuição significativa na explicação de IP e IA na autoavaliação. Por isso, ao testar as reações como moderadoras da relação de BF, buscou-se confirmar o papel mediadormoderador dessa variável sobre a percepção dos possíveis obstáculos que dificultariam o 
desempenho dos participantes durante o treinamento avaliado, isto é, as barreiras e facilitadores em EAD.

$\mathrm{Na}$ autovaliação do impacto em profundidade e em amplitude, os resultados foram significativos indicando a moderação da relação entre BF e RP sobre os indicadores de efetividade de treinamento. A inclusão da variável de interação na regressão, com IP e IA, respectivamente, como VD, resultou no incremento do $R^{2}$ : a) IP [BF* $\mathrm{x} \mathrm{RP}^{*}$ : $\beta=0,078$ ] $\left(\Delta R^{2}=0,005\right.$ [0,247 - 0,242]; $\left.p<0,05\right)$; b) IA [BF* $\left.\mathrm{x} \mathrm{RP}^{*}: \beta=0,069\right]\left(\Delta R^{2}=0,003\right.$ [0,318 0,315]; $p<0,05)$, indicando que a variável RP modera a relação entre BF e IP/IA na autoavaliação (ver Figuras 29 e 30). Portanto, a influência das barreiras e facilitadores em EAD sobre os diferentes tipos de impacto depende da satisfação do treinando com o curso.

Interessante notar que além da contribuição marginalmente significativa já constatada de $\mathrm{BF}$ sobre IP na autoavaliação $\left(R^{2}=0,04 ; \beta=0,06 ; p<0,10\right)$, as análises das relações de moderação adicionam elementos importantes para a compreensão da variável BF, uma vez que esta, ao ser moderada pelas reações com o curso, passa a ser significativamente importante na explicação de ambos indicadores de efetividade de treinamento [IP e IA] na autoavaliação - a explicação de BF sobre IA apenas foi significativa quando moderada por RP.

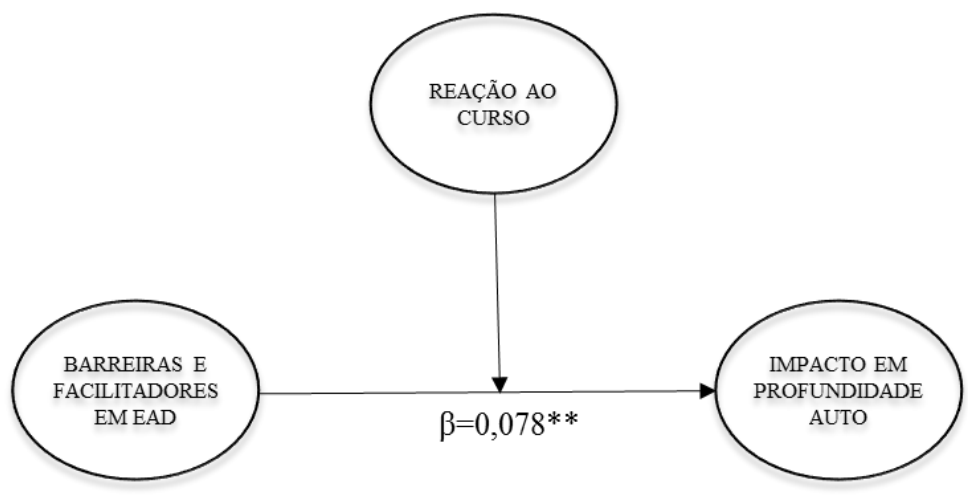

Figura 29. Efeito moderador de reações aos procedimentos instrucionais sobre barreiras e facilitadores em EAD e o impacto em profundidade na autoavaliação. 


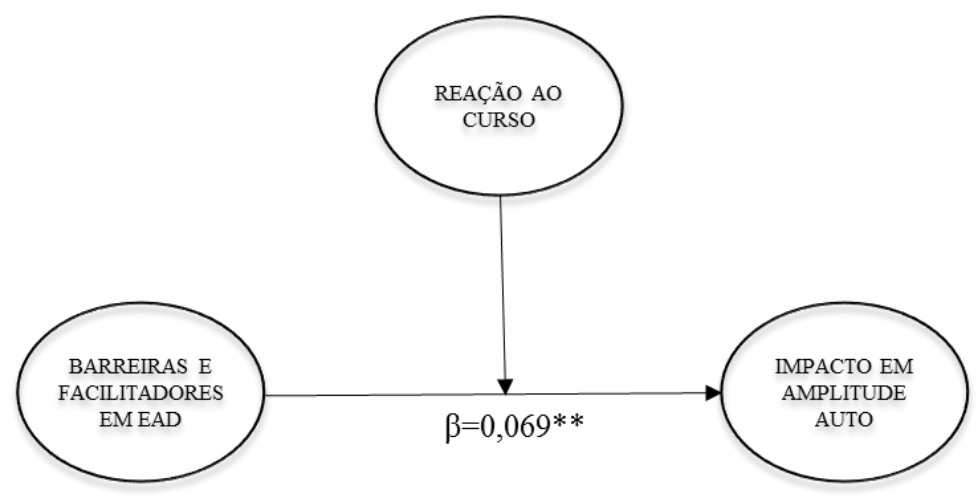

Figura 30. Efeito moderador de reações aos procedimentos instrucionais sobre barreiras e facilitadores em EAD e o impacto em amplitude na autoavaliação.

No caso do impacto em profundidade, conclui-se que há uma dupla moderação entre esta VD e as barreiras e facilitadores em EAD exercida pelo suporte material e pela reação ao curso. Isso significa que a contribuição de BF na explicação de IP na autoavaliação depende tanto do papel moderador de SM quanto de RP; a predição de IA, no entanto, está sujeita apenas ao papel moderador de RP. Exemplificam-se tais relações na Figura 31.

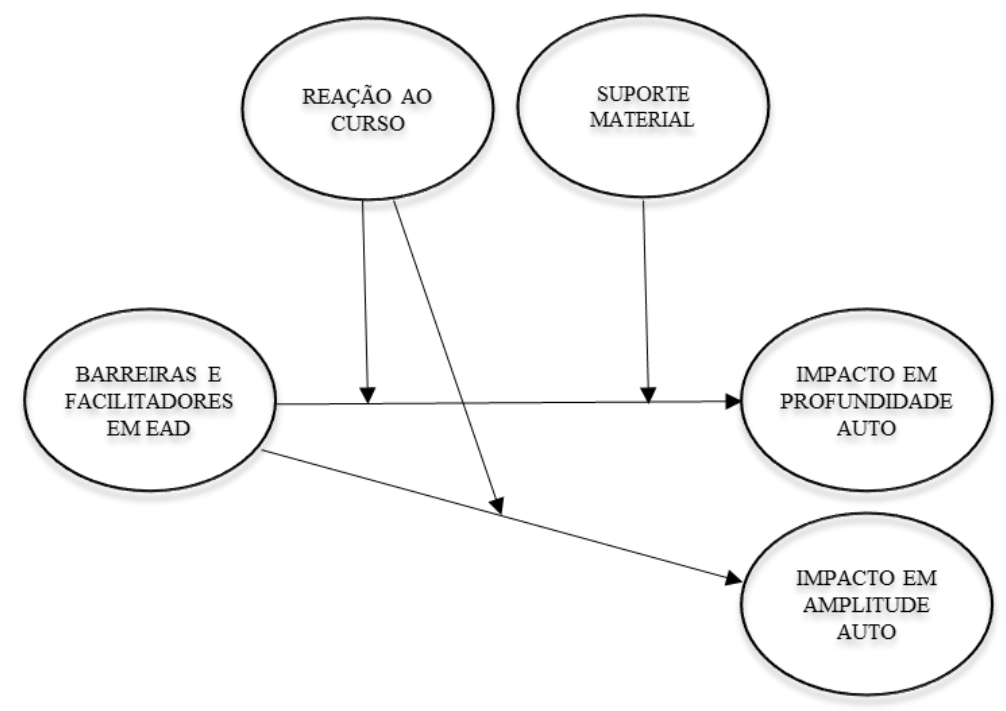

Figura 31. Moderadores das barreiras e facilitadores em EAD sobre os indicadores de efetividade de treinamento na autoavaliação.

Da mesma maneira, as análises no PROCESS mostraram que as reações moderam tanto o efeito de BF sobre IP $(\beta=0,06 ; p<0,05)$, como sobre IA $(\beta=0,05 ; p<0,05)$. Isso demonstra que para os participantes satisfeitos com os procedimentos instrucionais do curso, os efeitos de BF sobre IP/IA diminuem. 
Para os participantes do treinamento com pontuações mais baixas $(\mathrm{RP}=3,73 ; 95 \%$ $\mathrm{CI}=[+1,6214 ;+2,9408])$ a moderadas $(\mathrm{RP}=4,21 ; 95 \% \mathrm{CI}=[+0,2982 ;+0,5992]) \mathrm{em}$ reações, BF teve efeito positivo sobre IP. Entretanto, aqueles com médias mais altas $(\mathrm{RP}=4,70$ em uma escala de 5 pontos), o efeito tornou-se insignificante $(95 \% \mathrm{CI}=[-$ $0,5142 ;+0,0113])$.

O oposto ocorreu no caso da moderação do impacto em amplitude, pois justamente para os egressos mais satisfeitos ( $\mathrm{RP}=4,69$ em uma escala de 5 pontos), $\mathrm{BF}$ teve efeito positivo sobre IA $(95 \% \mathrm{CI}=[+0,0137 ;+0,0731])$. Para os demais, com as médias mais baixas $(\mathrm{RP}=3,73 ; 95 \% \mathrm{CI}=[-0,0549 ;+0,0273])$ e moderadas $(\mathrm{RP}=4,21$; $95 \% \mathrm{CI}=[-0,0108 ;+0,0404])$, o efeito foi insignificante. Os efeitos relatados podem ser observados nas Figuras 32 e 33.

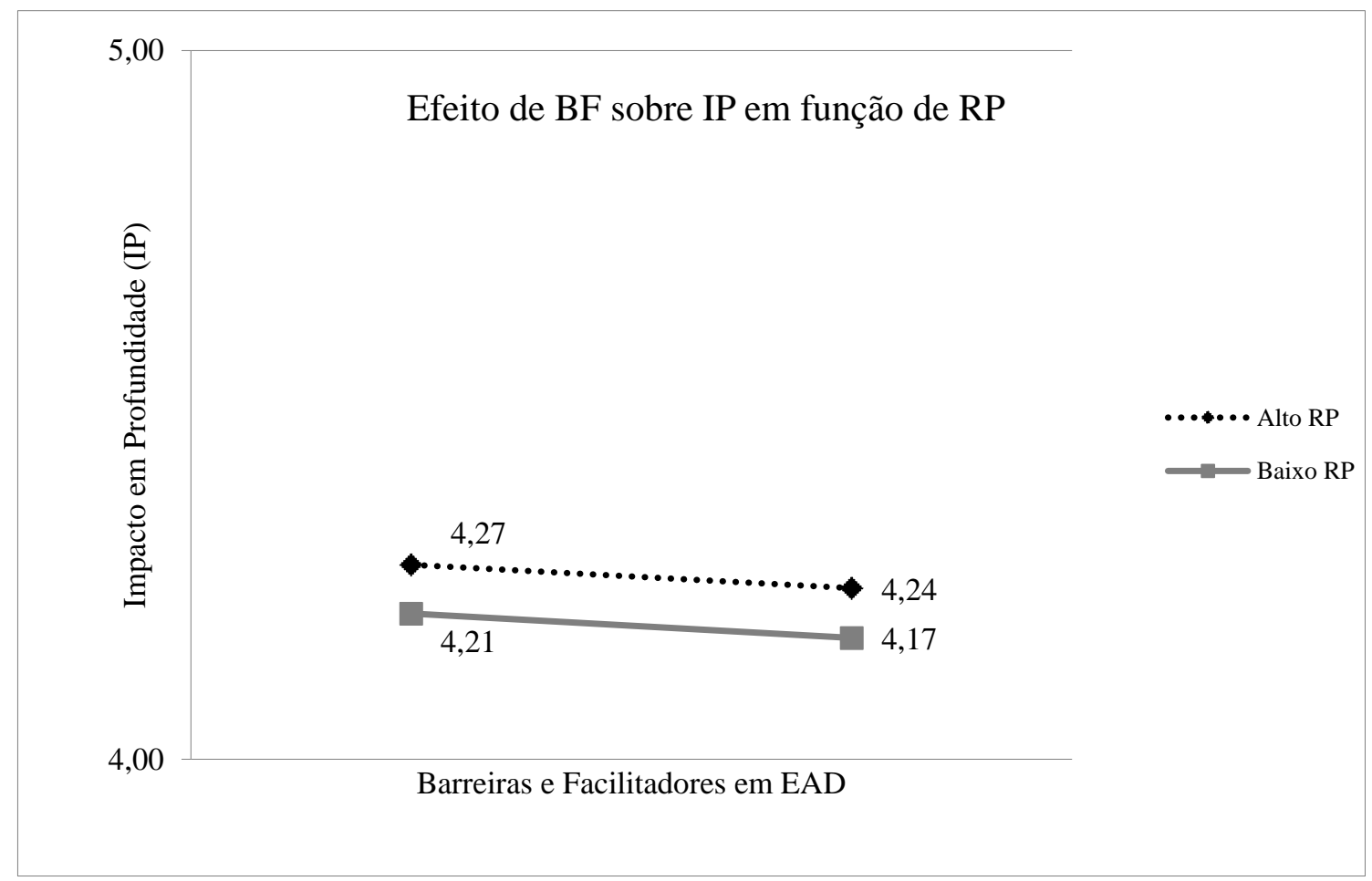

Figura 32. Relação entre as barreiras e facilitadores em EAD e o impacto em profundidade em função das reações ao curso. 


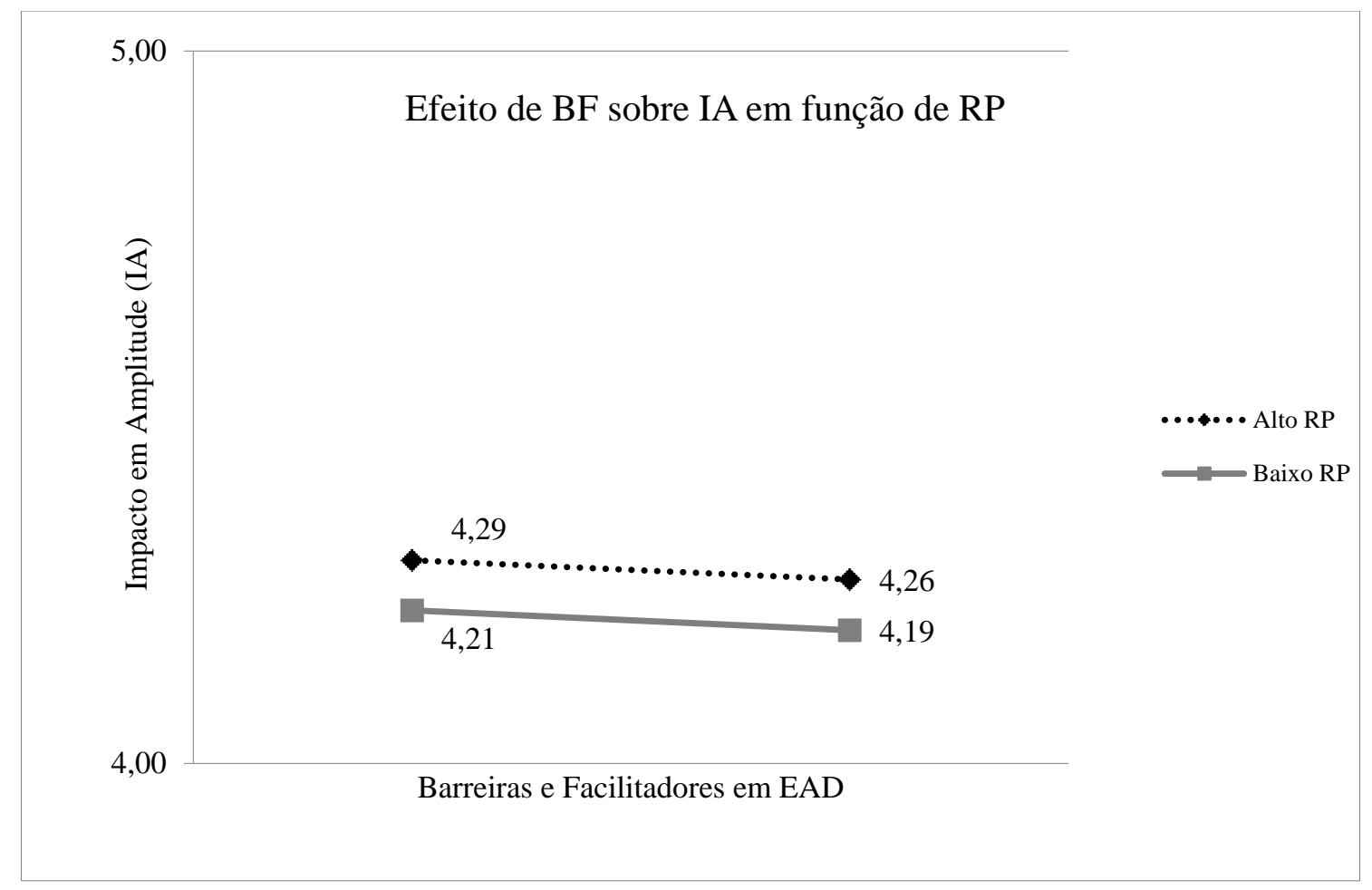

Figura 33. Relação entre as barreiras e facilitadores em EAD e o impacto em amplitude em função das reações ao curso.

A observação das Figuras 32 e 33 mostra que as barreiras e facilitadores em EAD foram preditores mais fortes de impacto quando os níveis de satisfação com o curso foram mais altos do que quando foram mais baixos. $\mathrm{O}$ efeito das barreiras e facilitadores em EAD sobre o desempenho geral parece depender da satisfação com o curso: os egressos com níveis baixos de reações avaliam de maneira menos favorável o impacto do treinamento no trabalho. Contudo, essa influência provocada pelas reações sobre o efeito de BF sobre IP/IA foi pouco expressiva.

\section{Moderação do suporte à transferência sobre as estratégias de aprendizagem}

Foram testados cada um dos fatores das estratégias de aprendizagem (EA1, EA2, EA3 e EA4) e os de suporte à transferência (SS, SC e SM), incluindo-se as variáveis de interação em sucessivas regressões hierárquicas para testar a variação do $R^{2}$, na auto e heteroavaliação de impacto em profundidade e em amplitude.

$\mathrm{Na}$ heteroavaliação de impacto em profundidade e em amplitude, o suporte à transferência não moderou as estratégias de aprendizagem. Na autoavaliação, os resultados significativos que indicam o papel moderador de SP sobre EA, podem ser observados na Tabela 87. 
Tabela 87. Papel moderador do suporte à transferência sobre as estratégias de aprendizagem na explicação de impacto do treinamento no trabalho.

\begin{tabular}{lcccc}
\hline \multicolumn{1}{c}{ Estratégia de aprendizagem } & $\begin{array}{c}\text { Suporte à } \\
\text { transferência }\end{array}$ & $\boldsymbol{\Delta R}^{2}$ & $\boldsymbol{\beta}$ & VD \\
\hline EA1 (cognitivas e busca de ajuda) & $\mathrm{SM}$ (suporte material) & $\begin{array}{c}0,008 \\
{[0,214-0,206]}\end{array}$ & $0,085^{* *}$ & IP $_{\text {AUTO }}$ \\
\hline EA2 (controle da emoção) & SM (suporte material) & $\begin{array}{c}0,003 \\
{[0,182-0,179]}\end{array}$ & $0,055^{+}$ & IP $_{\text {AUTO }}$ \\
\hline $\begin{array}{l}\text { EA3 (elaboração e aplicação } \\
\text { prática) }\end{array}$ & SC (suporte de pares) & $\begin{array}{c}0,004 \\
{[0,290-0,286]}\end{array}$ & $-0,059^{* *}$ & IA AUTO $_{\text {AUTO }}$ \\
\hline Nota: $*{ }^{*} p<0,05 ;{ }^{+} p<0,10$ & & & &
\end{tabular}

Os resultados mostram que na explicação do impacto do treinamento no trabalho, além da influência direta das estratégias de aprendizagem (IP: EA3; IA: EA1, EA3 e EA4) e do suporte à transferência (IP/IA: SC e SM), SP altera a relação direta entre a VI [EA] e as VDs [IP/IA], atuando como variável moderadora.

No caso das estratégias cognitivas e busca de ajuda [EA1], não havia sido encontrada contribuição significativa desse conjunto de estratégias de aprendizagem na explicação direta de IP na autoavaliação - apenas de IA. Mas, a percepção do suporte material pelos participantes altera a relação de EA1 sobre IP (Figura 34), moderando tal relação. No mesmo sentido, as estratégias de controle da emoção [EA2], que não mostraram quaisquer efeitos significativos no modelo completo proposto, quando moderadas pelo suporte material, tiveram contribuição na explicação de IP (Figura 35). Por fim, as estratégias de elaboração e aplicação prática [EA3] que foram igualmente importantes na explicação de IP como de IA, quando moderadas pelo apoio de pares, apresentaram uma influência negativa sobre IA (Figura 36). Somente as estratégias de controle da motivação [EA4] não são moderadas pelo suporte à transferência.

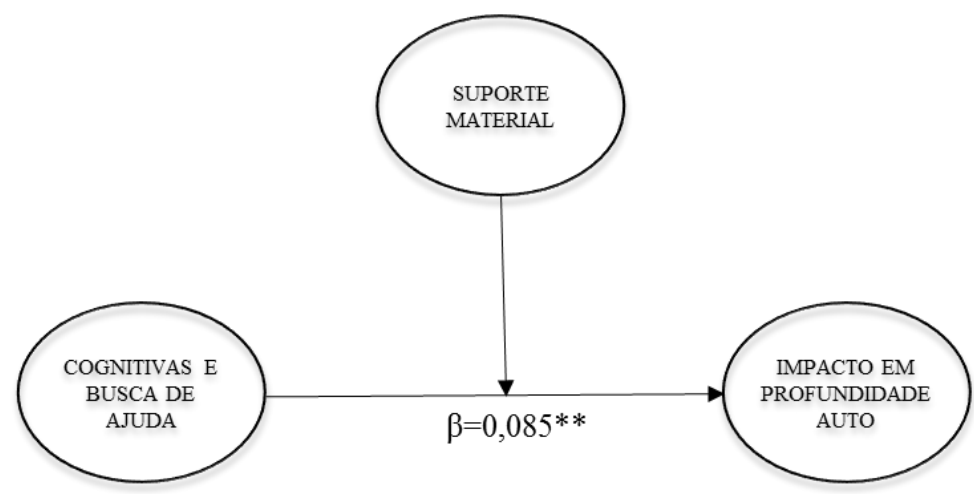

Figura 34. Efeito moderador do suporte material sobre as estratégias cognitivas e busca de ajuda e o impacto em profundidade na autoavaliação. 


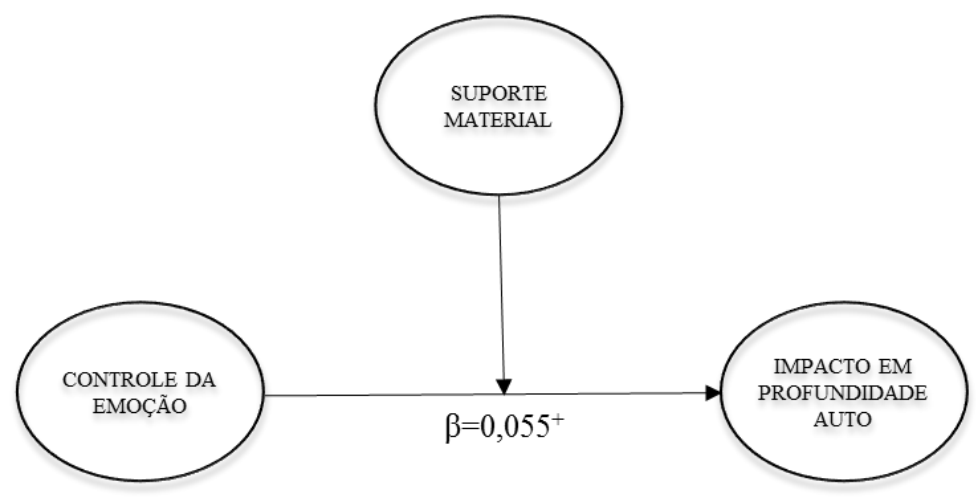

Figura 35. Efeito moderador do suporte material sobre as estratégias de controle da emoção e o impacto em profundidade na autoavaliação.

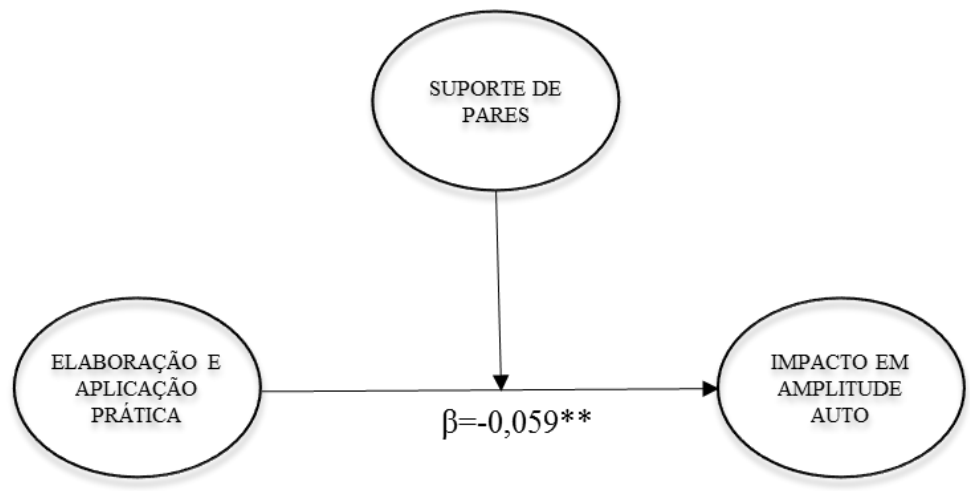

Figura 36. Efeito moderador do suporte de pares sobre as estratégias de elaboração e aplicação prática e o impacto em amplitude na autoavaliação.

O efeito moderador dos diferentes tipos de suporte (SM e SC) sobre as estratégias de aprendizagem EA2 e EA3 e os impactos (IP/IA), também foi encontrado nas análises no PROCESS. O suporte material modera o efeito de EA2 sobre IP $(\beta=0,05 ; p<0,10)$, e o suporte de pares modera o efeito de EA3 sobre IA $(\beta=-0,06 ; p<0,05)$, ou seja, para os participantes que percebem o apoio material oferecido pela organização, os efeitos de EA2 sobre o impacto em profundidade (IP) são atenuados - ou permanecem inalterados como mostra a representação gráfica na Figura 37; já para aqueles cujo suporte dos colegas de trabalho (pares) é percebido, aumentam-se os efeitos de EA3 sobre o impacto em amplitude (IA).

De maneira indistinta, para os participantes do treinamento com médias - escala de 5 pontos - baixas $(\mathrm{SM}=2,90 ; 95 \% \mathrm{CI}=[+0,0895 ;+0,2294])$, moderadas $(\mathrm{SM}=3,76$; $95 \% \mathrm{CI}=[+0,1496 ;+0,2648])$ ou altas $(\mathrm{SM}=4,62 ; 95 \% \mathrm{CI}=[+0,1710 ;+0,3389]) \mathrm{em}$ suporte material, EA2 teve efeito positivo sobre IP. Da mesma forma, para os egressos com pontuações baixas ( $\mathrm{SC}=2,78 ; 95 \% \mathrm{CI}=[+0,4310 ;+0,5698])$, moderadas $(\mathrm{SC}=3,64$; $95 \% \mathrm{CI}=[+0,3902 ;+0,4940])$ ou altas $(\mathrm{SC}=4,51 ; 95 \% \mathrm{CI}=[+0,3075 ;+0,4601]) \mathrm{em}$ 
suporte de pares, EA3 teve efeito positivo sobre IA. Os efeitos descritos podem ser observados nas Figuras 37 e 38.

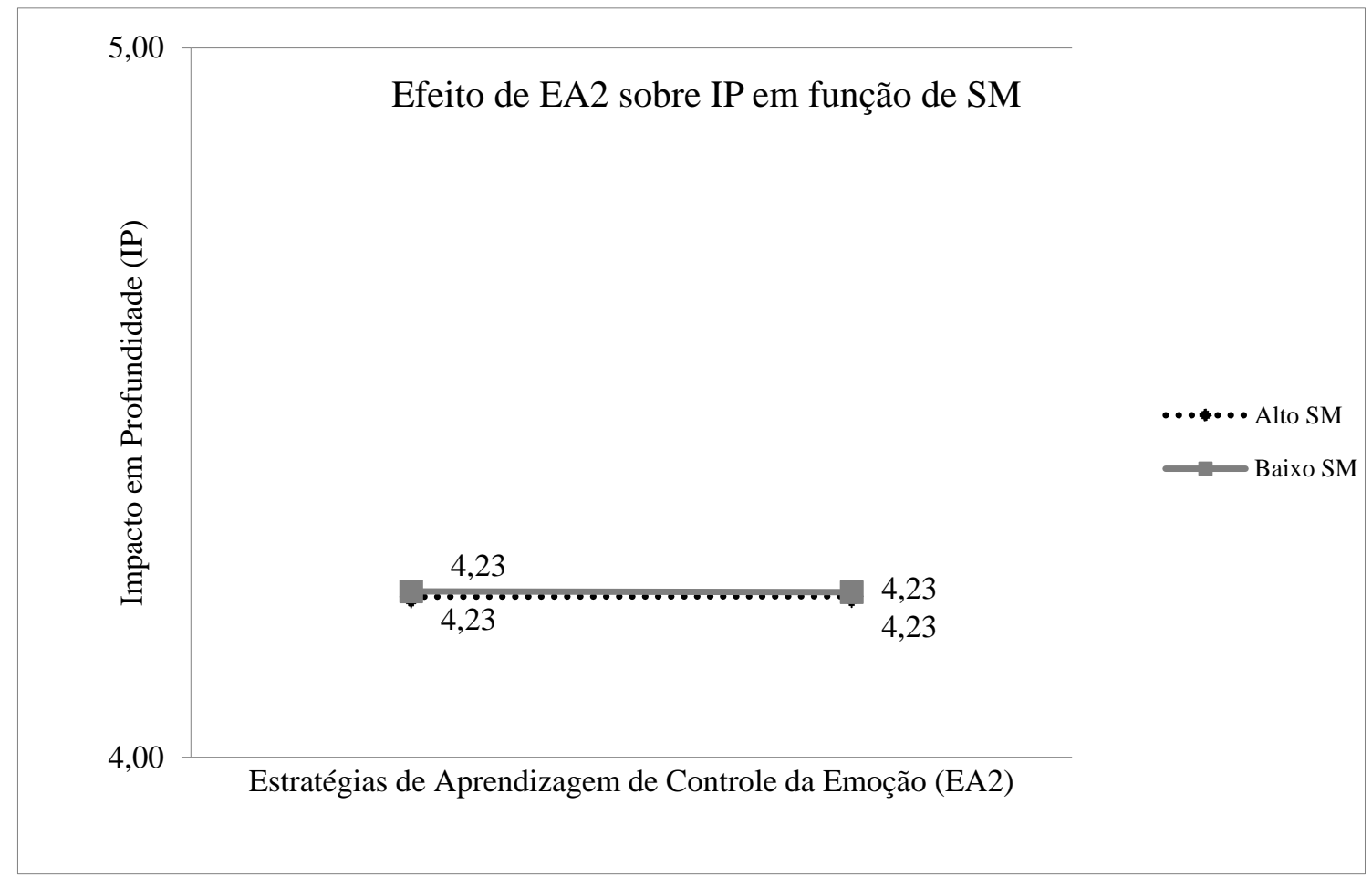

Figura 37. Relação entre as estratégias de aprendizagem de controle da emoção e o impacto em profundidade em função do suporte material.

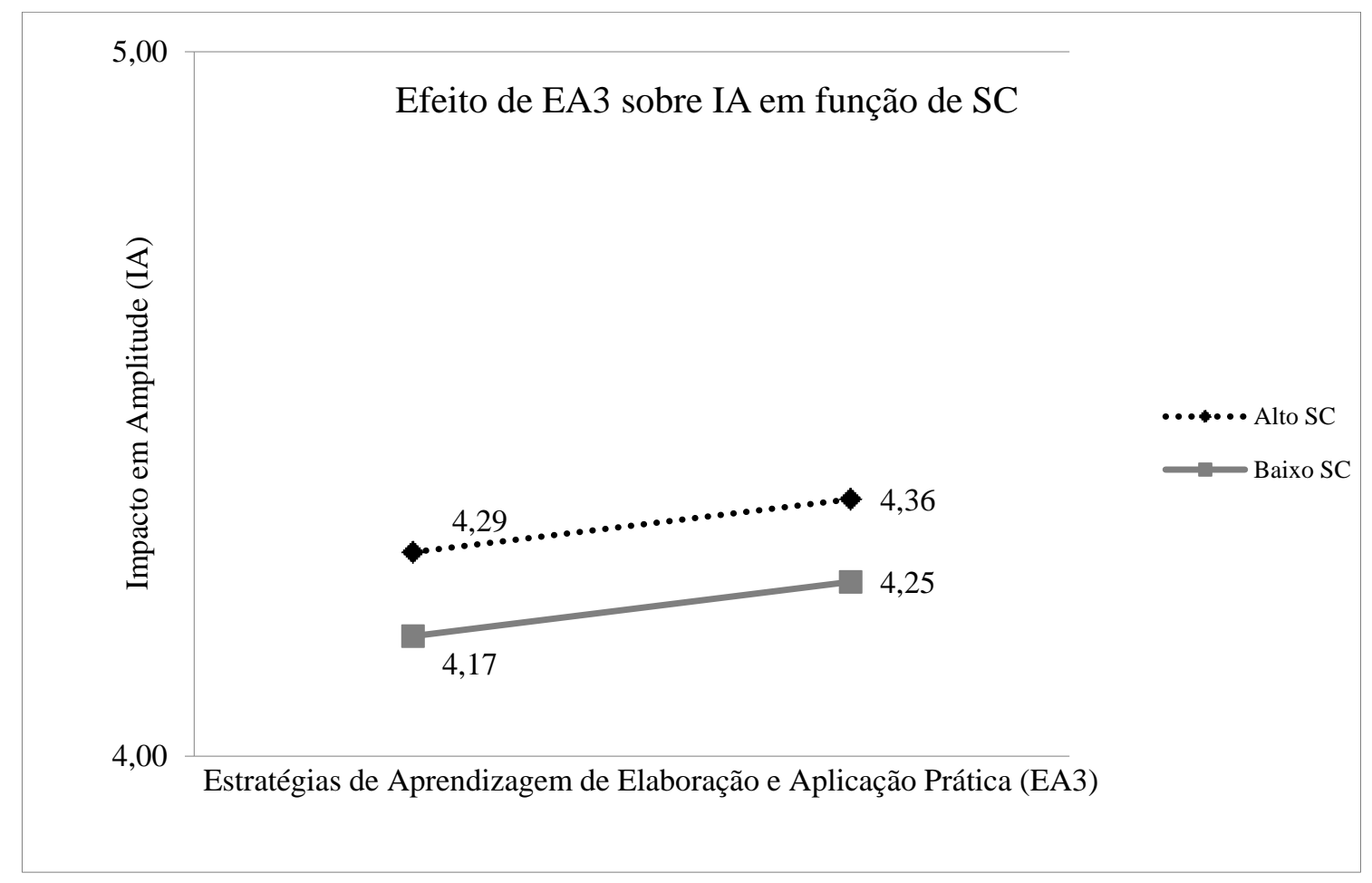

Figura 38. Relação entre as estratégias de aprendizagem de elaboração e aplicação prática e o impacto em amplitude em função do suporte de pares. 
A Figura 37 mostra que, na verdade, as estratégias de controle da emoção não predisseram o impacto em profundidade segundo os níveis de percepção do suporte material, como indicado por meio das análises estatísticas de moderação. Já a Figura 38 indica que as estratégias de elaboração e aplicação prática foram preditoras mais fortes de impacto em amplitude quando os níveis de percepção de suporte de pares foram mais elevados do que quando foram mais baixos, ainda que essa diferença seja pouco pronunciada. Isso aponta que quanto mais intensa for a percepção de SC no ambiente de trabalho, mais intensa é a percepção sobre as contribuições do treinamento a distância, em termos do desempenho global (IA), de acordo com os egressos.

Apesar de terem sido realizadas análises complementares para a investigação do papel de moderadores, a moderação estatística encontrada do suporte à transferência sobre as estratégias de aprendizagem na explicação de impacto do treinamento no trabalho não faz sentido teórico. As estratégias de aprendizagem, por serem variáveis perceptuais e respondidas apenas pelos funcionários que participaram do treinamento quanto à utilização no momento de estudo do material do curso, e o suporte à transferência, variável contextual alcançada após a finalização do treinamento e que envolve a percepção de aspectos do meio, não poderia atuar como moderador desta relação entre os diferentes tipos de estratégias de aprendizagem usados e a aplicação do aprendido no ambiente de trabalho - transferência de competências adquiridas. Contudo, optou-se por manter tais análises, pois podem servir como guias, que devem ser aperfeiçoadas nas próximas pesquisas realizadas com essas mesmas variáveis combinadas a outras diferentes.

\section{Moderação das reações sobre as estratégias de aprendizagem}

Ao testar o papel moderador das reações sobre os tipos de estratégias de aprendizagem (EA1, EA2, EA3 e EA4), na auto e heteroavaliação de impacto em profundidade e em amplitude, encontraram-se resultados significativos, ou seja, houve o incremento do valor de $R^{2}$ na autoavaliação de IP: [EA1* x RP*: $\beta=0,065$ ] $\left(\Delta R^{2}=0,004\right.$ [0,276 - 0,272]; $p<0,05)$, indicando que a variável RP modera a relação entre as estratégias de aprendizagem cognitivas e busca de ajuda e o impacto do treinamento no trabalho em profundidade (ver Figura 39). Portanto, a influência das estratégias cognitivas e busca de ajuda [EA1] sobre IP, provavelmente, depende da satisfação do treinando com o curso. 


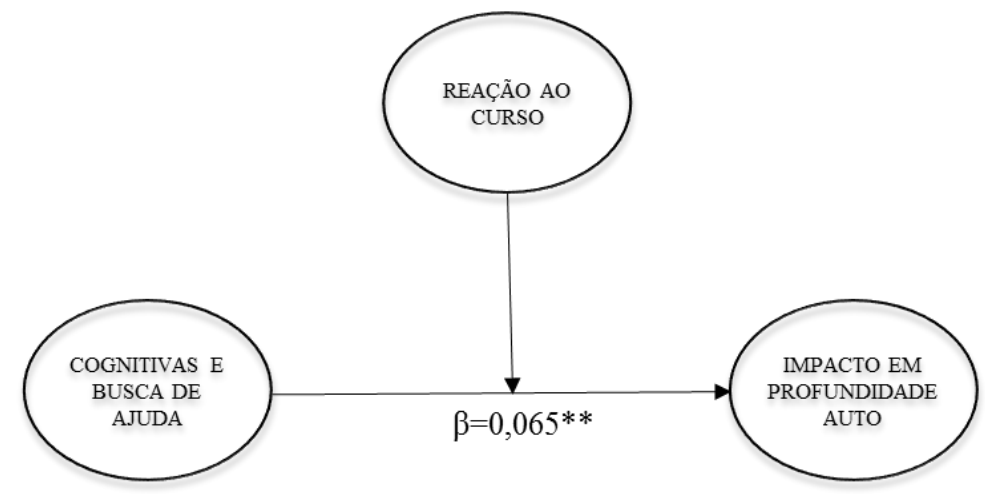

Figura 39. Efeito moderador de reações aos procedimentos instrucionais sobre as estratégias cognitivas e busca de ajuda e o impacto em profundidade na autoavaliação.

As reações não foram as únicas moderadoras da relação entre as estratégias cognitivas e busca de ajuda e o impacto em profundidade na autoavaliação. Como apresentado anteriormente, conforme mostra a Figura 34, o suporte material também exerceu um papel moderador entre EA1 e IP. Portanto, novamente, o suporte material e a reação ao curso tiveram juntos uma dupla moderação entre essa VD e as estratégias cognitivas e busca de ajuda (Figura 40) - similar ao ocorrido com as barreiras e facilitadores em EAD.

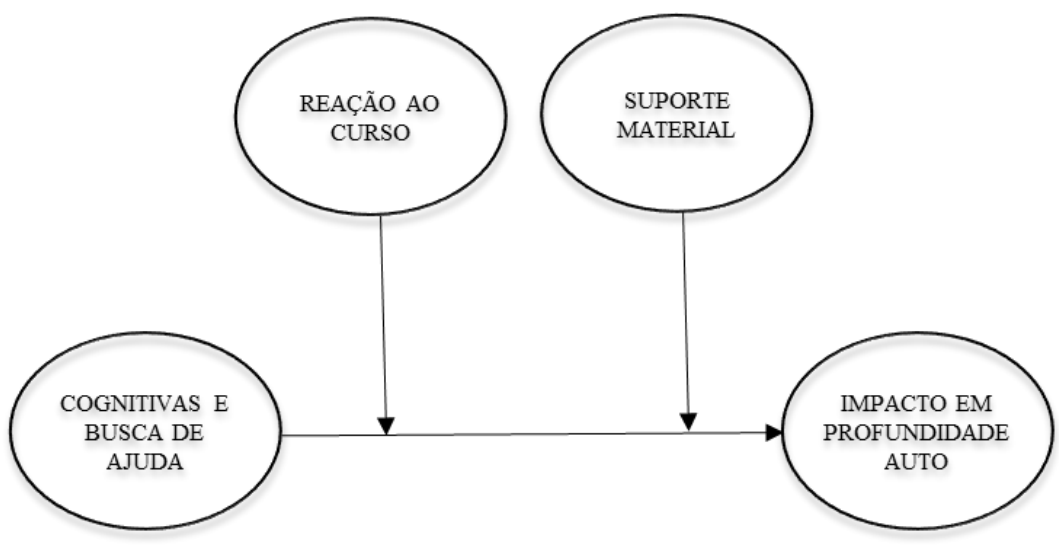

Figura 40. Moderadores das estratégias de aprendizagem cognitivas e busca de ajuda sobre o impacto em profundidade na autoavaliação.

Resultados semelhantes foram encontrados por meio das análises realizadas no PROCESS. As reações moderam o efeito de EA1 sobre IP $(\beta=0,08 ; p<0,05)$, bem como o suporte material $(\beta=0,06 ; p<0,01)$. Isso demonstra que para os participantes satisfeitos com os procedimentos instrucionais do curso e que percebem o apoio material oferecido pela organização, os efeitos de EA1 sobre IP são atenuados. 
Igualmente para os participantes do treinamento com médias - escala de 5 pontos - mais baixas $(\mathrm{RP}=3,69 ; 95 \% \mathrm{CI}=[+0,0396 ;+0,1522])$, moderadas $(\mathrm{RP}=4,18 ; 95 \% \mathrm{CI}$ $=[+0,0949 ;+0,1806])$ ou altas $(\mathrm{RP}=4,66 ; 95 \% \mathrm{CI}=[+0,1237 ;+0,2355])$ em reações, EA1 teve efeito positivo sobre IP. O mesmo ocorreu no caso da moderação do suporte material, considerando uma escala com 5 pontos: para os egressos com pontuações mais baixas $(\mathrm{SM}=2,89 ; 95 \% \mathrm{CI}=[+0,0862 ;+0,2049])$, moderadas $(\mathrm{SM}=3,76 ; 95 \% \mathrm{CI}=$ $[+0,1541 ;+0,2470])$ ou altas $(\mathrm{SM}=4,62 ; 95 \% \mathrm{CI}=[+0,1942 ;+0,3169]) \mathrm{em} \mathrm{SM}, \mathrm{EA} 1$ teve efeito positivo sobre IP. Os efeitos expostos podem ser observados nas Figuras 41 e 42.

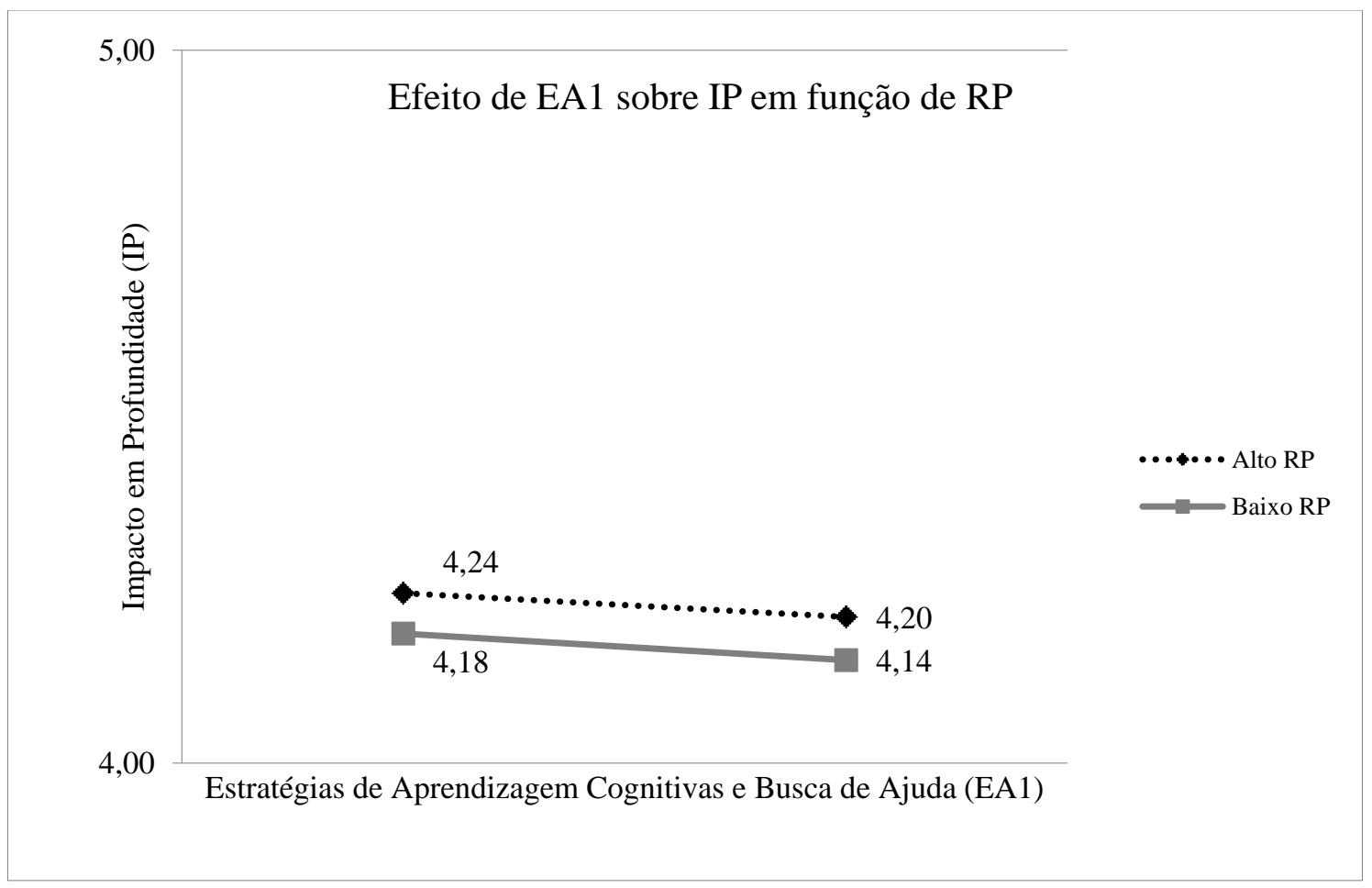

Figura 41. Relação entre as estratégias de aprendizagem cognitivas e busca de ajuda e o impacto em profundidade em função das reações ao curso. 


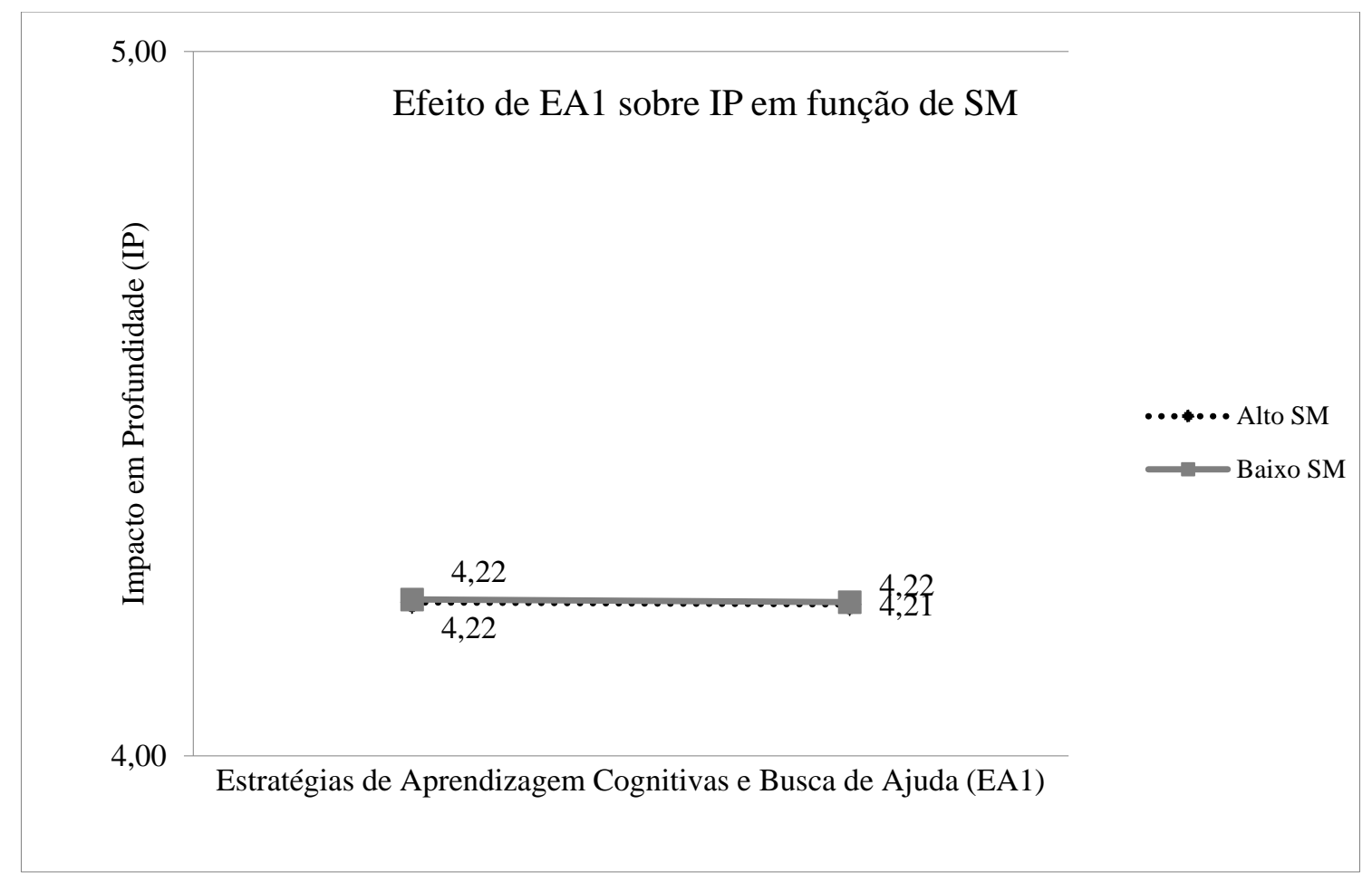

Figura 42. Relação entre as estratégias de aprendizagem cognitivas e busca de ajuda e o impacto em profundidade em função do suporte material.

Conforme pode ser observado na Figura 41, as estratégias de aprendizagem cognitivas e busca de ajuda foram preditoras mais fortes de impacto em profundidade quando os níveis de satisfação foram mais elevados do que quando foram mais baixos embora essa diferença seja pouco expressiva. A Figura 42 mostra que essas estratégias de aprendizagem predisseram o impacto em profundidade segundo os níveis de percepção do suporte material de maneira quase inexpressiva. Portanto, segundo a inspeção gráfica, parece não haver tal moderação antes constatada ou esta foi mínima em magnitude.

\subsubsection{Teste de hipóteses}

O objetivo de verificação das hipóteses propostas foi cumprido. Os principais resultados são expostos a seguir.

$H_{1 a}:$ As estratégias de aprendizagem serão preditores positivos dos indicadores de efetividade de treinamento.

$\mathrm{Na}$ autoavaliação, as estratégias de aprendizagem cognitivas e busca de ajuda [EA1], elaboração e aplicação prática [EA3] e controle da motivação [EA4] tiveram contribuição positiva na explicação dos indicadores de efetividade de treinamento. Tanto 
para o impacto em profundidade como em amplitude, as estratégias de elaboração e aplicação prática foram importantes e fortes preditores, sendo que no caso do impacto em profundidade, foram as únicas estratégias de aprendizagem que contribuíram para a sua ocorrência; já para o impacto em amplitude, além destas, as estratégias cognitivas e busca de ajuda, bem como as de controle da motivação também foram significativas.

Tais estratégias de aprendizagem referem-se aos três tipos anteriormente classificados: cognitivas, comportamentais e autorregulatórias. As duas primeiras, juntaram-se em um mesmo fator - elaboração (cognitiva) e aplicação prática (comportamental); repetição e organização (cognitivas) e busca de ajuda (comportamentais) - indicando que, possivelmente, em treinamentos online e corporativos, não são diferenciadas pelos participantes e constituem-se como um conjunto similar e útil de estratégias a serem escolhidas no momento de estudo, contribuindo para assimilar os conteúdos ensinados e posteriormente aplicá-los no contexto de trabalho. Por outro lado, as autorregulatórias, mantiveram-se separadas em dois fatores distintos (controle da emoção e controle da motivação), mas apenas o controle da motivação mostrou-se preditor significativo de impacto em amplitude. O controle da emoção não entrou como variável preditora dos indicadores de efetividade de treinamento; inclusive, no impacto em amplitude, o seu coeficiente de regressão possui sinal negativo. Portanto, as estratégias de aprendizagem de controle da emoção foram as únicas que não entraram como preditoras significativas dos indicadores de efetividade de treinamento - embora tenham apresentado efeitos indiretos positivos sobre o impacto em amplitude na autoavaliação.

Já na heteroavaliação, as estratégias cognitivas e busca de ajuda [EA1] foram as únicas que estiveram positivamente relacionadas ao impacto em amplitude quando foram introduzidos no modelo ambos tipos de impacto, em profundidade e em amplitude.

Como de quatro variáveis latentes, três foram importantes preditores positivos dos indicadores de efetividade de treinamento, confirma-se quase completamente a $\mathrm{H}_{1 a}$.

$H_{1 b}$ : As estratégias de aprendizagem autorregulatórias interferirão mais sobre os indicadores de efetividade de treinamento do que as estratégias cognitivas e comportamentais.

As estratégias de aprendizagem autorregulatórias foram representadas pelo controle da emoção e controle da motivação. As primeiras não tiveram nenhuma contribuição para a explicação dos indicadores de efetividade do treinamento; já as 
segundas, entraram como preditoras do impacto em amplitude na autoavaliação. Embora a contribuição do controle da motivação tenha sido significativa para a ocorrência de modificações no desempenho global dos egressos (impacto em amplitude), refuta-se a $\mathrm{H}_{1 \mathrm{~b}}$, uma vez que justamente as estratégias cognitivas e comportamentais, unidas nos fatores EA1 (cognitivas e busca de ajuda) e EA3 (elaboração e aplicação prática), estiveram presentes como preditores de ambos impactos e foram as mais expressivamente responsáveis pela sua ocorrência. Contrário ao que se esperava, as estratégias autorregulatórias não interferiram mais sobre os indicadores de efetividade de treinamento. Assim, as estratégias de aprendizagem cognitivas e comportamentais tiveram maior influência sobre os indicadores de efetividade de treinamento do que as autorregulatórias.

$\mathrm{H}_{2}$ : A satisfação com os aspectos formais do curso será preditor positivo dos indicadores de efetividade de treinamento.

As reações aos procedimentos instrucionais foram preditores positivos dos indicadores de efetividade de treinamento na autoavaliação. Os indicadores da qualidade do curso (reação aos procedimentos instrucionais) foram importantes preditores do impacto em profundidade e em amplitude na autoavaliação de treinamento. A satisfação com o curso parece influir no posterior processo de transferência das competências adquiridas: os egressos mais satisfeitos com o treinamento aplicaram os novos conhecimentos, habilidades e atitudes no trabalho. Portanto, confirma-se a $\mathrm{H}_{2}$, apontando as relações positivas e significativas das reações com os indicadores de efetividade de treinamento. Resultado não confirmado na heteroavaliação, já que as reações dos participantes não tiveram contribuição para a explicação do impacto segundo a avaliação dos supervisores.

H3: A satisfação com o desempenho do tutor será preditor positivo dos indicadores de efetividade de treinamento.

Hipótese não testada, pois o treinamento avaliado possuía caráter autoinstrucional, portanto, não contava com a presença de tutor, impossibilitando a avaliação desse quesito.

$H_{m e d:}$ As reações aos procedimentos instrucionais do curso mediarão o suporte à transferência e os indicadores de efetividade de treinamento. 
A satisfação dos participantes com os procedimentos instrucionais teve influência sobre a percepção do suporte recebido pela organização ou por companheiros de trabalho (chefes ou pares) e, por conseguinte, na ocorrência de impacto. A explicação de impacto possui relação com ambas variáveis, sendo que a percepção do suporte à transferência passa pela opinião dos participantes sobre os procedimentos instrucionais. Desse modo, confirma-se a hipótese mediadora de que o suporte à transferência e os indicadores de efetividade de treinamento são mediados pelas reações dos participantes com o curso.

$H_{4 a}$ : O suporte à transferência de novas competências adquiridas em treinamento estará positivamente relacionado aos indicadores de efetividade de treinamento.

$\mathrm{Na}$ autoavaliação, o suporte material e o suporte de pares tiveram contribuição positiva na explicação dos indicadores de efetividade de treinamento, tanto para o impacto em profundidade como em amplitude. Na heteroavaliação, precisamente o suporte de supervisores explicou a ocorrência do impacto em profundidade. Portanto, pode-se afirmar que $\mathrm{a}_{4 a}$ foi confirmada pelos resultados, mostrando que o suporte à transferência se relaciona positiva e significativamente aos indicadores de efetividade de treinamento. Em síntese, o suporte à transferência foi preditor significativo dos indicadores de efetividade de treinamento, tanto na autoavaliação (suporte de pares e material) como na heteroavaliação (suporte de supervisores).

H4b: O suporte psicossocial interferirá mais sobre os indicadores de efetividade de treinamento do que o suporte material.

Como o suporte de supervisores entrou como preditor na heteroavaliação de impacto em profundidade, e o suporte de pares, na autoavaliação de ambos tipos de impacto (profundidade e amplitude), juntamente ao suporte material, ratifica-se a $\mathrm{H}_{4 \mathrm{~b}}$. A presença dos suportes de pares e de supervisores na autoavaliação e heteroavaliação, respectivamente, confirma o papel importante do apoio psicossocial na ocorrência do processo de impacto do treinamento no trabalho. A percepção pelos participantes do apoio advindo da organização, ao fornecer os recursos materiais necessários e propiciar o ambiente físico do local de trabalho adequado à transferência das novas habilidades, também apresenta forte influência sobre o impacto em profundidade e em amplitude.

Resumindo, o suporte psicossocial foi preditor significativo de impacto do treinamento no trabalho na autoavaliação (profundidade e amplitude) - juntamente ao suporte material - e na heteroavaliação (profundidade). Assim, o suporte psicossocial 
interferiu mais que o suporte material sobre os indicadores de efetividade de treinamento. Porém, o poder preditivo do suporte material em termos da magnitude do efeito sobre os indicadores de efetividade foi superior que os dos demais suportes, supervisores e pares.

H5: ̀̀ medida em que os participantes perceberem os recursos como facilitadores e não como barreiras será positivamente relacionada com os indicadores de efetividade de treinamento.

A variável barreiras e facilitadores em EAD não entrou como preditora em nenhum dos modelos. Na autoavaliação, ao lado das estratégias de aprendizagem autorregulatórias de controle da emoção e suporte de supervisores, não teve contribuição significativa sobre os indicadores de efetividade de treinamento. A $\mathrm{H}_{5}$ deve ser refutada, pois as barreiras e facilitadores em EAD não foram preditores significativos dos indicadores de efetividade de treinamento - contribuições nulas ou negativas.

$H_{\text {mod: }} O$ suporte à transferência atuará como moderador da relação entre as barreiras e facilitadores em EAD e os indicadores de efetividade de treinamento.

As barreiras e facilitadores em EAD foram moderadas pelo suporte material na explicação dos indicadores de efetividade de treinamento em profundidade na autoavaliação. Os achados indicaram a variável suporte material como moderadora da relação entre barreiras e facilitadores em EAD e o impacto do treinamento no trabalho em profundidade na autoavaliação, embora a magnitude dessa relação tenha sido muito

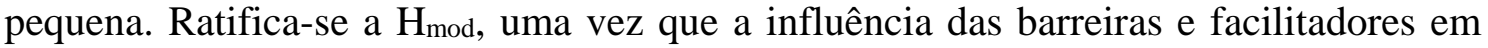
EAD sobre o impacto em profundidade parece não ocorrer de maneira direta, mas moderada pela percepção de suporte material pelos egressos, com a ressalva sobre a baixa expressividade dos indicadores encontrados.

H6: Os participantes que aplicarem as novas competências diretamente em seus cargos (impacto em profundidade) também modificarão seu desempenho global, motivação e atitudes (impacto em amplitude).

Os resultados apontaram que o impacto em profundidade e em amplitude estão fortemente relacionados entre si. As análises que incluíram ambos tipos de impacto simultaneamente no modelo mostraram que os participantes egressos que aplicaram as novas competências diretamente em seus cargos também tiveram ganhos em seu desempenho global, apoiando a H6. Na autoavaliação, as estratégias de aprendizagem - 
com exceção das cognitivas e busca de ajuda -, as reações aos procedimentos instrucionais e o suporte à transferência tiveram influência indireta positiva sobre a explicação de IA através de IP. Na heteroavaliação, as estratégias de elaboração/aplicação prática e controle da motivação, além do suporte de supervisores, tiveram influência indireta positiva sobre IA.

Os efeitos diretos da transferência de treinamento sobre o desempenho subsequente do egresso (comportamento no cargo) relacionados aos objetivos instrucionais (impacto em profundidade) teve forte influência sobre o desempenho global, as atitudes e a motivação do indivíduo (impacto em amplitude). Principalmente sob o ponto de vista dos gestores (heteroavaliação), a percepção positiva de melhoria nos desempenhos específicos acompanha a dos desempenhos gerais dos egressos - correlação de alta intensidade $(r=0,746)$ e alto coeficiente de regressão $(\beta=0,878 ; p<0,000)$.

Em suma, os resultados obtidos levam a apoiar as hipóteses 1a, 2, 4a, 4b e 6, e a refutar as hipóteses 1 b e 5. A maioria das estratégias de aprendizagem mostrou-se preditor significativo de impacto $\left(\mathrm{H}_{1 \mathrm{a}}\right)$ - com exceção das estratégias de controle da emoção; contudo, as estratégias autorregulatórias não foram mais importantes que as cognitivas e comportamentais $\left(\mathrm{H}_{1 b}\right)$. A satisfação com os aspectos formais do curso prediz os dois tipos de impacto $\left(\mathrm{H}_{2}\right)$; a $\mathrm{H}_{3}$ não pode ser testada, pois o curso avaliado não dispunha de tutoria. O suporte material e de pares tiveram efeito positivo sobre o impacto em profundidade e em amplitude na autoavaliação, e o suporte de supervisores sobre o impacto em profundidade na heteroavaliação $\left(\mathrm{H}_{4 a}\right)$. Com isso, confirma-se a $\mathrm{H}_{4 b}$, de que o suporte psicossocial (supervisores e pares) interferiria mais sobre os indicadores de efetividade de treinamento do que o suporte material, com a ressalva de que o poder preditivo deste, em termos da magnitude do efeito sobre os indicadores de efetividade, foi superior que os daquele.

Contrário ao que se esperava, a percepção dos participantes dos recursos como facilitadores e não como barreiras não esteve positivamente relacionada aos indicadores de efetividade de treinamento $\left(\mathrm{H}_{5}\right)$. Os treinados que aplicaram as novas competências diretamente em seus cargos também tiveram seu desempenho global modificado $\left(\mathrm{H}_{6}\right)$, tanto sob a perspectiva dos próprios egressos quanto de seus supervisores. Quanto às relações de mediação e moderação, as hipóteses foram confirmadas: as reações dos participantes com o curso mediam o suporte à transferência e os indicadores de efetividade de treinamento $\left(\mathrm{H}_{\mathrm{med}}\right)$; e o suporte à transferência modera as barreiras e os 
facilitadores em EAD e o impacto do treinamento no trabalho em profundidade na autoavaliação ( $\left.\mathrm{H}_{\mathrm{mod}}\right)$.

Ainda com respeito aos mediadores e moderadores das relações entre as variáveis antecedentes do modelo e o impacto do treinamento no trabalho, destaca-se o papel mediador da variável "reação aos procedimentos instrucionais", a qual diminuiu a magnitude do relacionamento entre as VIs "suporte à transferência" e "estratégias de aprendizagem" e as VDs, impacto em profundidade e em amplitude, na autoavaliação. Os moderadores, por sua vez, tiveram um papel fundamental na explicação de variáveis não preditoras diretas de impacto, mas quando moderadas por "reação aos procedimentos instrucionais" e/ou "suporte à transferência" mostraram-se significativas na sua ocorrência. As barreiras e facilitadores em EAD não entraram como preditores significativos dos indicadores de efetividade de treinamento, mas quando moderadas pelo suporte material explicaram IP, e pelas reações dos participantes, IP e IA (autoavaliação). No caso das estratégias de aprendizagem cognitivas e busca de ajuda [EA1] e controle da emoção [EA3], ambas não tiveram contribuição na explicação do impacto em profundidade na autoavaliação; porém o suporte material e as reações moderaram a relação entre EA1 e IP. No mesmo sentido, EA2 que não havia mostrado nenhuma contribuição significativa no modelo de investigação, apresenta relação com IP ao ser moderada pelo suporte material. Ainda, encontrou-se que o suporte de pares modera EA3 e IA. Dos quatro tipos de estratégias de aprendizagem existentes, apenas as autorregulatórias de controle da motivação não foram moderadas pelo suporte à transferência ou pelas reações aos procedimentos instrucionais.

Portanto, o papel de mediadores e moderadores foi identificado na autoavaliação de impacto. As reações aos procedimentos instrucionais foram mediadoras das relações entre o suporte à transferência e as estratégias de aprendizagem e os indicadores de efetividade de treinamento (profundidade e amplitude). Além disso, funcionaram como moderadoras da relação entre as barreiras e facilitadores em EAD (IP/IA) e as estratégias de aprendizagem cognitivas e busca de ajuda (IP). O suporte material moderou as barreiras e facilitadores em EAD, as estratégias cognitivas e busca de ajuda e controle da emoção e o impacto em profundidade; e o suporte de pares moderou as estratégias de elaboração e aplicação prática e o impacto em amplitude. Concluindo, as reações atuaram como mediadoras das relações entre as estratégias de aprendizagem e o suporte à transferência e os impactos em profundidade e amplitude. Dentre os moderadores mais importantes, as reações destacam-se na moderação das barreiras e facilitadores em EAD 
e os impactos em profundidade e amplitude; o suporte material entre as estratégias cognitivas e busca de ajuda e o impacto em profundidade; e o suporte de pares entre as estratégias de elaboração e aplicação prática e o impacto em amplitude. Vale ponderar que algumas das relações de moderação encontradas, como comentado anteriormente, não apresentam sentido teórico, pois foram analisadas medidas autorrelatadas (estratégias de aprendizagem) e também variáveis situacionais (suporte à transferência de treinamento).

As Tabelas 88, 89 e 90 mostram um resumo das relações significativas, preditivas e de mediação/moderação, entre as variáveis de interesse identificadas na auto e heteroavaliação de impacto do treinamento no trabalho, em profundidade [IP] e amplitude [IA]. 
Tabela 88. Resumo das relações preditivas significativas na autoavaliação e heteroavaliação de impacto do treinamento no trabalho.

\begin{tabular}{|c|c|c|c|c|c|c|c|c|}
\hline \multirow{3}{*}{ PREDITORES DIRETOS } & \multicolumn{4}{|c|}{ AUTOAVALIAÇÃO $(\beta)$} & \multicolumn{4}{|c|}{ HETEROAVALIAÇÃO $(\beta)$} \\
\hline & \multirow{2}{*}{ IP } & \multirow{2}{*}{ IA } & \multicolumn{2}{|c|}{ Ambas VDs } & \multirow{2}{*}{ IP } & \multirow{2}{*}{ IA } & \multicolumn{2}{|c|}{ Ambas VDs } \\
\hline & & & IP & IA & & & IP & IA \\
\hline EA1 (cognitivas e busca de ajuda) & $-0,059^{+}$ & $0,088 * *$ & - & $0,110^{* *}$ & - & $0,069^{+}$ & - & $0,052 * *$ \\
\hline EA2 (controle da emoção) & - & - & \multicolumn{2}{|r|}{ (5) } & - & - & \multicolumn{2}{|c|}{-} \\
\hline EA3 (elaboração e aplicação prática) & $0,477 *$ & $0,250^{*}$ & $0,477 *$ & $0,093 * *$ & - & - & \multicolumn{2}{|c|}{-} \\
\hline EA4 (controle da motivação) & - & $0,143^{*}$ & - & $0,129 *$ & - & - & \multicolumn{2}{|c|}{-} \\
\hline RP (reações) & $0,204 *$ & $0,318^{*}$ & $0,204^{*}$ & $0,247 *$ & - & - & \multicolumn{2}{|c|}{-} \\
\hline SS (suporte supervisores) & - & - & \multicolumn{2}{|c|}{-} & $0,078 * *$ & - & $0,074 * *$ & - \\
\hline SC (suporte pares) & $0,081 * *$ & $0,100 * *$ & $0,081 * *$ & - & - & - & \multicolumn{2}{|c|}{-} \\
\hline SM (suporte material) & $0,158^{*}$ & $0,096 * *$ & $0,159 *$ & - & - & - & \multicolumn{2}{|c|}{-} \\
\hline BF (barreiras/facilitadores em EAD) & - & - & \multicolumn{2}{|c|}{ - } & - & - & \multicolumn{2}{|c|}{ - } \\
\hline IP $>$ IA & - & - & \multicolumn{2}{|c|}{$0,334 *$} & - & - & \multicolumn{2}{|c|}{$0,878^{*}$} \\
\hline
\end{tabular}

IP > IA

Notas: Os dados faltantes (-) representam efeitos não significativos omitidos da tabela; ${ }^{*} p<0,000 ; * * p<0,05 ;{ }^{+} p<0,10$

Tabela 89. Resumo das relações de mediação na autoavaliação de impacto do treinamento no trabalho.

EFEITO MEDIADOR DAS REACÕES (RP)

\section{VARIÁVEIS IMPACTO EM PROFUNDIDADE (IP)}

EA1 (cognitivas e busca de ajuda)

EA2 (controle da emoção)

EA3 (elaboração e aplicação prática)

EA4 (controle da motivação)

SS (suporte supervisores)

SC (suporte pares)

SM (suporte material)

Nota: $* * p<0,05$
$0,10^{* *}$
$0,17 * *$
$0,15 * *$
$0,16 * *$
$0,09 * *$
$0,09 * *$
$0,13 * *$

IMPACTO EM AMPLITUDE (IA)

$0,11 * *$

$0,19 * *$

$0,20 * *$

$0,16 * *$

$0,09 * *$

$0,08 * *$

$0,13 * *$ 
Tabela 90. Resumo das relações de moderação na autoavaliação de impacto do treinamento no trabalho.

\begin{tabular}{lcc}
\hline & EFEITO MODERADOR DAS REAÇÕES (RP) & \\
\hline \multicolumn{1}{c}{ VARIÁVEIS } & IMPACTO EM PROFUNDIDADE (IP) & IMPACTO EM AMPLITUDE (IA) \\
\hline EA1 (cognitivas e busca de ajuda) & $0,08^{* *}$ & - \\
BF (barreiras/facilitadores em EAD) & $0,06^{* *}$ & $0,05^{* *}$ \\
\hline & EFEITO MODERADOR DO SUPORTE MATERIAL (SM) & IMPACTO EM AMPLITUDE (IIA) \\
\hline & IMPACTO EM PROFUNDIDADE (II) & - \\
\hline EA1 (cognitivas e busca de ajuda) & $0,06^{* *}$ & - \\
EA2 (controle da emoção) & $0,05^{* *}$ & - \\
BF (barreiras/facilitadores em EAD) & $0,03^{* *}$ & \\
\hline & EFEITO MODERADOR DO SUPORTE DE PARES (SC) & IMPACTO EM AMPLITUDE (IA) \\
\hline & IMPACTO EM PROFUNDIDADE (IP) & $-0,03^{* *}$ \\
\hline EA3 (elaboração e aplicação prática) & - &
\end{tabular}


O próximo passo foi o teste do modelo completo contendo os preditores significativos, inclusive os principais mediadores e moderadores. O programa AMOS permite trabalhar com variáveis observadas (somando ou calculando a média dos itens de cada escala) e, para testar os efeitos de moderação, foi usada a variável criada com a interação entre a VI e a Vmod no SPSS. Depois, importou-se o arquivo de dados para o AMOS já com as interações para cada moderação.

Foram testados, sucessivamente, modelos com a inclusão das variáveis, apontadas nas análises anteriores, que apresentaram maior poder explicativo das VDs e que correspondiam às hipóteses teoricamente formuladas. Primeiro, um modelo com todas as VIs significativas (EA1, EA3, EA4, SM, SC e RP), bem como a Vmod (BFxSM) e a Vmed (SMxRP). Segundo, um modelo com todas as VIs e a Vmed, mas sem a Vmod, a qual obteve o pior coeficiente de regressão $(\beta)$ na explicação de IP. Terceiro, um modelo sem a Vmod e EA1 (estratégias cognitivas e busca de ajuda), que dentre as VIs “estratégias de aprendizagem" obteve o pior valor de $\beta$. Quarto, um modelo sem a Vmod, EA1 e EA4 (estratégias de controle da motivação). Quinto, um modelo sem a Vmod, EA1, EA4 e o suporte de pares [SC]. Sexto, um modelo apenas com EA3 (estratégias de elaboração e aplicação prática), o suporte material [SM], e as reações [RP] como preditores das VDs, tendo sido excluída a Vmed. No geral, os resultados obtidos apontaram para baixos coeficientes de regressão das variáveis antecedentes testadas e a falta de ajuste dos modelos, dentre os quais, comparativamente, o mais ajustado foi o quinto, segundo a análise do indicador de parcimônia PRATIO (modelo com o menor valor), no qual constavam as VIs: EA3, RP, SM e a Vmed (SMxRP), justamente as variáveis que mais contribuíram, em termos da magnitude do efeito, sobre os indicadores de efetividade de treinamento nos modelos parciais (preditores ou mediadores/moderadores) anteriormente testados. A Tabela 91 sintetiza as informações relatadas e os resultados obtidos. 
Tabela 91. Coeficientes de regressão para as relações entre as variáveis e índices de ajuste dos modelos.

\begin{tabular}{|c|c|c|c|c|c|c|}
\hline $\begin{array}{c}\text { RELAÇÕES - } \\
\text { VARIÁVEIS }\end{array}$ & \multicolumn{6}{|c|}{ COEFICIENTES DE REGRESSÃO $(\beta)$} \\
\hline $\mathrm{SM} \rightarrow \mathrm{RP}(\mathrm{Vmed})$ & $0,290 *$ & $0,290 *$ & $0,290 *$ & $0,291 *$ & $0,290 *$ & - \\
\hline $\mathrm{SM} \rightarrow \mathrm{IP}$ & $0,063 *$ & $0,062 * *$ & $0,061 * *$ & $0,060 * *$ & $0,085^{*}$ & $0,093^{*}$ \\
\hline $\mathrm{SC} \rightarrow \mathrm{IP}$ & $0,074 *$ & $0,075^{*}$ & $0,075^{*}$ & $0,074 *$ & - & - \\
\hline $\mathrm{EA} 3 \rightarrow \mathrm{IP}$ & $0,362 *$ & $0,362 *$ & $0,361 *$ & $0,360 *$ & $0,365^{*}$ & $0,364 *$ \\
\hline $\mathrm{BFxSM}(\mathrm{Vmod}) \rightarrow \mathrm{IP}$ & $0,031 * *$ & - & - & - & - & - \\
\hline $\mathrm{RP} \rightarrow \mathrm{IP}$ & $0,288^{*}$ & $0,290 *$ & $0,292 *$ & $0,294 *$ & $0,304 *$ & $0,303 *$ \\
\hline $\mathrm{IP} \rightarrow \mathrm{IA}$ & $0,387 *$ & $0,387 *$ & $0,391 *$ & $0,406^{*}$ & $0,422 *$ & $0,426^{*}$ \\
\hline $\mathrm{SM} \rightarrow \mathrm{IA}$ & $0,075^{*}$ & $0,074 *$ & $0,079 *$ & $0,084^{*}$ & $0,109 *$ & $0,102 *$ \\
\hline $\mathrm{SC} \rightarrow \mathrm{IA}$ & $0,065^{*}$ & $0,066^{*}$ & $0,071^{*}$ & $0,077^{*}$ & - & - \\
\hline $\mathrm{EA} 1 \rightarrow \mathrm{IA}$ & $0,063^{*}$ & $0,063 *$ & - & - & - & - \\
\hline $\mathrm{EA} 3 \rightarrow \mathrm{IA}$ & $0,149 *$ & $0,148 *$ & $0,172 *$ & $0,225^{*}$ & $0,225^{*}$ & $0,228 *$ \\
\hline EA4 $\rightarrow$ IA & $0,116^{*}$ & $0,116^{*}$ & $0,132 *$ & - & - & - \\
\hline \multicolumn{7}{|c|}{ ÍNDICES DE AJUSTE DOS MODELOS } \\
\hline & (1) Completo Sig. & (2) Sem Vmod & (3) Sem EA1 & (4) Sem EA4 & (5) Sem SC & (6) Sem Vmed \\
\hline$C M I N / D F$ & 89,86 & 126,149 & 140,325 & 161,910 & 234,446 & 245,120 \\
\hline$T L I$ & $-0,120$ & $-0,264$ & $-0,318$ & $-0,431$ & $-0,699$ & $-0,776$ \\
\hline CFI & 0,403 & 0,403 & 0,482 & 0,591 & 0,660 & 0,526 \\
\hline RMSEA & 0,192 & 0,228 & 0,240 & 0,258 & 0,311 & 0,318 \\
\hline PRATIO & 0,533 & 0,472 & 0,393 & 0,286 & 0,200 & 0,267 \\
\hline
\end{tabular}

Notas: Os dados faltantes (-) representam as variáveis que foram retiradas das análises em cada modelo testado; $* p<0,000 ; * * p<0,05$ 


\section{Conclusões}

\subsection{Evidências de Validade dos Instrumentos de Medida}

Este estudo logrou fornecer escalas inéditas, após um criterioso processo de adaptação e validação de instrumentos brasileiros, com boas características psicométricas, além da construção de um instrumento de impacto do treinamento no trabalho em profundidade. Por serem mais enxutas, consequência da redução do número de itens e do menor número de pontos nas escalas, são de simples aplicação. Foram confirmadas a validade e a confiabilidade dos instrumentos, contemplando itens representativos de cada fator, sendo importantes ferramentas de avaliação, úteis ao diagnóstico da efetividade de treinamentos em ambientes corporativos. Além de poderem ser utilizados e suas capacidades preditivas testadas em outros contextos educacionais e amostras.

A adequação dos instrumentos produzidos foi corroborada por meio de rigorosas análises estatísticas, que apontaram para as evidências de validade de construto, e o bom ajuste dos modelos, tendo suas estruturas fatoriais provadas. Medidas mais parcimoniosas, além de válidas e confiáveis, tornam-se mais fáceis e rápidas de responder, agilizando o processo de aplicação quando da coleta de dados em avaliações em geral, sendo mais adequadas ao contexto corporativo, implicando ainda na produção de resultados fidedignos. Se até mesmo o treinamento foi feito durante a jornada de trabalho, a aplicação de instrumentos para sua avaliação provavelmente também competirá com as atividades laborais dos participantes, podendo afetar, por exemplo, a qualidade dos resultados obtidos e o número de respondentes alcançados, especialmente se a avaliação for demasiadamente longa e demorada.

Tais instrumentos servem para mensurar: a frequência e o padrão de uso de estratégias de aprendizagem por participantes de diversas ações educacionais, presenciais ou a distância (Anexo P); a satisfação de participantes de eventos educacionais online quanto a diversos aspectos do curso (Anexo Q); os diferentes tipos de apoio percebidos por participantes de treinamento, afetando na transferência de competências para o trabalho (Anexo R); as diferentes barreiras que podem ser encontradas durante um treinamento, impactando em seus resultados (Anexo S); e o grau de aplicação das novas competências adquiridas em treinamento no trabalho, afetando o comportamento no cargo (Anexo T) e o desempenho geral dos trabalhadores, incluindo suas atitudes e sua motivação (Anexo U). 
Quanto ao instrumento de Estratégias de Aprendizagem, a solução de quatro fatores apresenta sentido teórico, tendo sido encontrada em um estudo anterior (Martins \& Zerbini, 2014b), mas com um agrupamento diferente de algumas estratégias de aprendizagem. Os quatro fatores são compostos por estratégias de aprendizagem cognitivas e busca de ajuda, controle da emoção, elaboração e aplicação prática, e controle da motivação. Outros estudos também encontraram estruturas com um número reduzido de fatores (Borges-Ferreira, 2005; Zerbini et al., 2015), em comparação com a versão original, em que os diferentes tipos de estratégias cognitivas foram agrupados no mesmo fator, ou mesmo junto às estratégias comportamentais. É possível que ocorra uma mudança na estrutura fatorial da escala de estratégias de aprendizagem encontrada neste estudo dependendo de aspectos como complexidade do curso, características amostrais e organizacionais, que podem ser mais explorados em pesquisas posteriores.

Apenas alguns estudos nacionais incluíram os itens autorregulatórios na escala, por causa das particularidades (natureza e complexidade) dos cursos avaliados, ou supondo a pouca influência desse tipo de estratégia sobre a explicação dos comportamentos no trabalho - o que deve ser ainda melhor investigado em pesquisas futuras, devido às recentes recomendações sobre este tema (ver Aguinis \& Kraiger, 2009; Burke \& Hutchins, 2007), e os achados do presente estudo. Os resultados mostram que a manutenção de dois componentes separados de estratégias autorregulatórias (controle da emoção e controle da motivação) na estrutura fatorial da escala atual - validada em um contexto organizacional, com uma amostra de trabalhadores que participou de um treinamento online - confirmam a importância de manter os itens no instrumento, como já ocorreu previamente em Zerbini e Abbad (2008a), Martins e Zerbini (2014b) e Zerbini et al. (2015). Além disso, como as estratégias cognitivas e comportamentais, elas foram preditores significativos dos indicadores de efetividade de treinamento, parecendo ser estratégias diferenciais para ajudar no processo de aprendizagem em contextos virtuais de ensino.

A solução unifatorial encontrada para o instrumento de Reação aos Procedimentos Instrucionais em EAD também apresenta sentido teórico. A adaptação do instrumento eliminou um elevado número de itens (8), que corroborado pela presença de multicolinearidade - existência de pares de itens altamente correlacionados entre si indicava a repetição de conteúdo ou sobreposição de aspectos avaliados pelo instrumento original (Martins \& Zerbini, 2015). Os estudos anteriores com a medida optaram pela não exclusão de itens por se tratarem das primeiras aplicações e testagens dos instrumentos 
em contextos específicos a distância (Borges-Ferreira, 2005; Silva, 2004; Zerbini \& Abbad, 2009; Zerbini \& Abbad, 2010). Contudo, a literatura mostra que instrumentos destinados a medir reações costumam ter um número bastante reduzido de itens em soluções unifatoriais (e.g. Klein et. al, 2006), indicando que a exclusão de itens e uma adaptação mais expressiva da escala eram necessárias para gerar um instrumento mais parcimonioso, rápido e fácil de aplicar. Tal objetivo foi alcançado com a produção de uma nova versão que incidiu sobre a multicolinearidade entre os itens da medida, sendo esta extinguida, e mantendo-se as excelentes qualidades psicométricas do instrumento.

Da mesma forma, os resultados confirmaram as evidências de validade e confiabilidade da medida Barreiras e Facilitadores em EAD, que manteve o valor do índice de consistência interna $(\alpha=0,98)$ mesmo com a exclusão de cinco itens de sua estrutura na AFC - além de ter sofrido importantes modificações, como o corte brusco do número de itens (redução de 45 itens), no processo de adaptação. Os ganhos com a adaptação realizada no instrumento são consideráveis, uma vez que logrou-se diminuir o número de itens, mantendo-se as qualidades psicométricas do instrumento; inclusive, houve a melhora do índice de consistência interna e da estrutura empírica com menos fatores (dimensão unifatorial).

A estrutura empírica encontrada para o instrumento de Suporte à Transferência de Treinamento mostrou-se adequada tanto teórica como empiricamente e valida a adaptação feita no instrumento, na qual os tipos de suporte psicossocial (supervisores e pares) foram medidos separadamente, além do suporte material oferecido pela organização. A grande modificação realizada no instrumento de Abbad e Sallorenzo (2001) foi adequar os itens com foco na ação, já que as medidas, apesar de abordar conjuntamente o apoio de supervisores e colegas como pressupõe o conceito de suporte psicossocial à transferência, o separavam em seus itens: alguns deles avaliavam somente o apoio oferecido pelos supervisores e outros, em menor número, o apoio dos pares. A escala adaptada apresenta vantagens ao diferenciar o suporte psicossocial, pois permite avaliar os dois tipos de suporte e em que medida seu oferecimento é percebido pelos egressos de treinamentos, bem como tal separação possibilitará a realização de análises para verificar se há um apoio mais importante que o outro e seus efeitos sobre o impacto do treinamento no trabalho. Ou ainda, quando pertinente, avaliar somente o apoio de supervisores ou o de pares.

A estrutura empírica unidimensional do instrumento de Impacto do Treinamento no Trabalho em Amplitude, bem como sua estrutura teórica foram confirmadas. A adaptação do instrumento foi motivada por recomendações dadas em estudos anteriores 
com a medida (Pilati \& Abbad, 2005), que indicaram ajustes a serem realizados, como a eliminação de itens. Ao encontrarem indicadores de ajuste satisfatórios na AFC, os autores optaram pela não exclusão de itens; porém, apontaram possibilidades de aprimorar a escala por meio da substituição ou da supressão de itens superpostos (presença de covariância), eliminando a redundância existente. Acatando tais sugestões, ajustes e cortes foram realizados no instrumento, e a adequação das modificações realizadas no mesmo foi corroborada pelas análises estatísticas previamente descritas, apontando para as evidências de validade de construto e o ajuste do modelo da estrutura fatorial provado. Vale salientar que também foram encontradas evidências empíricas de validade da escala Impacto do Treinamento no Trabalho em Profundidade, que pode ser considerado um instrumento adequado para mensurar os resultados específicos do curso "Eficiência Operacional".

As medidas produzidas, em português e castelhano, podem auxiliar no desenvolvimento de pesquisas na área de avaliação de treinamentos em países nativos em ambos idiomas - embora ainda seja necessário verificar as evidências de validade de construto e estrutura fatorial das medidas em espanhol por meio da aplicação em amostras compatíveis. Sugere-se a sua aplicação em contextos e amostras diferentes, tanto em instituições de ensino como organizações de trabalho, pois essas variáveis, mensuradas por meio das escalas produzidas, mostraram-se boas preditoras de resultados de desempenho e da aplicação do aprendido no trabalho.

\subsection{Implicações Empíricas - Teste de Hipóteses dos Modelos}

Os principais benefícios empíricos trazidos pelo presente estudo referem-se à verificação da efetividade de treinamento por meio de auto e heteroavaliação do impacto do treinamento no trabalho; ademais da realização do estudo específico dos mecanismos de mediação/moderação existentes no modelo de investigação proposto, baseado no teste de hipóteses teoricamente formuladas.

Além de atestar os efeitos conhecidos e comprovados na literatura dominante sobre os fortes e consistentes preditores do impacto do treinamento no trabalho, e.g. o suporte à transferência, também elucida a significativa contribuição de variáveis individuais na predição da variável em foco, adicionando elementos que esclarecem o processo de transferência de competências no trabalho por meio das explicações dadas 
pelos mecanismos de mediação e moderação partícipes nesse fenômeno, o que traz importantes subsídios à área de avaliação de treinamentos.

$\mathrm{Na}$ autoavaliação de treinamento, todos os tipos de estratégias de aprendizagem estiveram positivamente relacionados com um ou ambos indicadores de efetividade de treinamento, com exceção das estratégias autorregulatórias de controle da emoção. Especialmente as estratégias de elaboração e aplicação prática explicaram a ocorrência do impacto em profundidade e em amplitude na autoavaliação - resultado similar já foi previamente encontrado (Brandão \& Borges-Andrade, 2011; Pantoja \& Borges-Andrade, 2009; Pilati \& Borges-Andrade, 2012; Zerbini \& Abbad, 2005, 2008a, 2010a), indicando a importância das estratégias cognitivas e comportamentais na explicação do processo de aprendizagem e transferência de competências em organizações e trabalho. O impacto em amplitude também foi predito pelas estratégias de elaboração e aplicação prática, acrescidas das estratégias cognitivas e busca de ajuda e as de controle da motivação. Na heteroavaliação, somente as estratégias cognitivas e busca de ajuda contribuíram para explicar o impacto em amplitude. Os participantes que refletiram sobre os novos conteúdos e suas implicações, consideraram as conexões entre o material do curso e o seu conhecimento anterior, e identificaram situações diárias em que eles poderiam aplicar o conteúdo na prática, obtiveram os melhores resultados de transferência, considerando o seu desempenho específico e global. Tais estratégias são compatíveis com a amostra de participantes formada por trabalhadores: relacionar o novo conhecimento ao já obtido, e tentar perceber a utilidade e a aplicabilidade que terá em atividades práticas diárias de trabalho, pode ser de grande importância. Coincidentemente, essas estratégias (elaboração e aplicação prática) foram as mais utilizadas pela amostra, pontuando as maiores médias de acordo com os resultados descritivos, juntamente com as estratégias autorregulatórias de controle emocional e motivacional.

Por outro lado, as estratégias comportamentais (busca de ajuda interpessoal e ao material didático) apresentaram as menores médias, indicando que os participantes não pesquisaram outras fontes de informação (sites da web, documentos, manuais de instruções, programas de computador, etc.), além daquelas disponíveis no material do curso, nem buscaram a ajuda de outros colegas de trabalho para tirar dúvidas. A ausência de ferramentas interativas na plataforma virtual pode explicar a baixa frequência do comportamento proativo de solicitar ajuda de outras pessoas e fazer-lhes perguntas sobre o conteúdo do material do curso. Pode apontar também para o fato de que o material fornecido poderia ter sido suficiente para resolver quaisquer dúvidas, ou ainda para a 
baixa complexidade do curso, que não exigiu mais explicações, quer de outras pessoas ou de outros materiais. Tal achado merece atenção, pois esse tipo de estratégia contribuiu para a ocorrência da transferência de treinamento, afetando o desempenho geral (impacto em amplitude) dos egressos neste estudo, além de já ter sido apontada como fator que exerce um importante papel para a aquisição, retenção e transferência de novas competências em âmbito laboral (Pantoja \& Borges-Andrade, 2009).

Em relação à explicação inferior das estratégias autorregulatórias sobre os resultados de desempenho, algumas justificativas razoáveis estão relacionadas com a natureza (predominantemente cognitiva), a curta duração (2 horas) e a baixa complexidade do treinamento. Este, pode não ter exigido o uso de estratégias que previnem dispersões de concentração causadas por sentimentos de ansiedade e controle da motivação, uma vez que as metas de aprendizagem eram muito simples - embora os resultados descritivos informam que essas estratégias foram frequentemente utilizadas pela amostra durante o curso.

A identificação das preferências no uso de estratégias de aprendizagem permite verificar a adequação e a compatibilidade das estratégias de ensino adotadas às estratégias de aprendizagem mais utilizadas pelos participantes, incidindo sobre o planejamento instrucional de cursos online, tornando-os mais adequados ao público-alvo. Os resultados obtidos contribuem para que participantes possam ser treinados nas estratégias mais efetivas ou recebam orientações prévias à execução do curso, ou ainda que alterações nos procedimentos de ensino sejam realizados em treinamentos subsequentes. Além disso, aquelas estratégias favoritas e mais frequentemente elegidas pela clientela, mas que não entraram como explicativas do impacto do treinamento no trabalho neste estudo, devem continuar a ser investigadas, pois em outros contextos e amostras podem ser importantes e preditoras de impacto. Ou, ao contrário, podem ser comprovadas como inadequadas a alguns tipos de cursos específicos - considerando-se sua natureza, complexidade e modalidade de entrega, por exemplo -, podendo levar ao insucesso do processo de aplicação de competências recém-adquiridas no trabalho.

Os efeitos das reações e do suporte à transferência bem-sucedida das novas competências aprendidas em treinamento para o trabalho foram corroborados. Os egressos que relataram estar satisfeitos com os procedimentos formais do curso avaliado e que perceberam os apoios oriundos da organização (recursos materiais, condições de trabalho, etc.) e dos companheiros de trabalho, principalmente de seus pares, foram os que tiveram seus desempenhos modificados, tanto em termos específicos (impacto em 
profundidade) como gerais (impacto em amplitude). Esses resultados confirmam achados já cotejados em inúmeras investigações prévias (Blume et al., 2010; Chiaburu, 2010; Gunawardena et al., 2010; Homklin et al., 2014; Joo et al., 2011; Mourão et al., 2014; Pham et al., 2012; Pilati \& Borges-Andrade, 2012; Simosi, 2012; Zerbini \& Abbad, 2010a) e indicam a pertinência de se continuar medindo os níveis de satisfação póstreinamento e os suportes oferecidos para a produção de consequências positivas sobre a performance no trabalho de participantes de eventos instrucionais. O quão satisfeitos os egressos ficaram com a formação e tiveram a percepção de suporte à transferência dos novos conhecimentos e habilidades importam e geram implicações de caráter aplicado: o treinamento será transferido para o ambiente de trabalho à medida que essas condições tenham sido atendidas. Por isso, deve-se seguir avaliando as reações afetivas e de utilidade do treinamento ao final do programa, bem como os apoios material e psicossocial fornecidos.

A inclusão de hipóteses mediadoras e moderadoras para a investigação das influências desses mecanismos na explicação dos fenômenos relacionados à mudança no desempenho provocada pelo curso a distância, proporcionaram aprimoramento dos modelos explicativos dos efeitos dessa ação instrucional para o impacto do treinamento no trabalho, configurando-se como uma grande contribuição do presente estudo. Embora haja relações de mediação e moderação propostas teoricamente, são ainda muito escassas pesquisas que as investigam dentro da área de avaliação de TD\&E (Chiaburu \& Tekleab, 2005; Nijman et al., 2006; Zumrah \& Boyle, 2015), principalmente na esfera nacional. A identificação do papel moderador do suporte material sobre as barreiras e facilitadores em EAD é particularmente importante porque enfatiza sua relevância como fator potencializador, enquanto determinante situacional, na predição da transferência de competências aprendidas. No caso em que as barreiras e facilitadores entrassem como preditores significativos de impacto, mostrando de fato que os obstáculos ao desempenho podem interferir sobre os efeitos dos indicadores de efetividade de treinamentos a distância, esse papel moderador do suporte poderia ter sido mais proeminente. Além disso, a mediação das reações, principalmente sobre a percepção do suporte à transferência de treinamento, também acresce significativas informações a respeito do papel da satisfação na explicação das variáveis critério e indica que essa medida deve permanecer nos modelos de avaliação de treinamento nas empresas, e que seus efeitos como mediadora/moderadora precisam ser testados. Esses achados certamente são ainda prematuros, devido às baixas contribuições estatísticas das variáveis 
mediadoras/moderadoras, mas antecipam resultados que podem ser melhor investigados a fim de que alcancem um caráter mais definitivo, futuramente. Avanços sobre o papel mediador e moderador de variáveis, como as reações e o suporte à transferência, poderão auxiliar na explicação dos porquês e sob que circunstâncias outras VIs interferem sobre o fenômeno do resultado do treinamento no desempenho dos egressos, e devem ser incluídas em modelos de investigação para melhor aclarar o processo de transferência de competências no trabalho.

A baixa contribuição significativa das variáveis antecedentes estudadas na explicação do impacto do treinamento no trabalho na heteroavaliação pode ser devido à natureza das medidas utilizadas, todas perceptuais, e à existência de mecanismos de mediação/moderação entre as variáveis não identificados. Vale lembrar que, no presente trabalho, aos gestores foram aplicados apenas os instrumentos de avaliação de impacto (profundidade e amplitude), e não os demais (reações, estratégias de aprendizagem, suporte à transferência, etc.). Talvez por esse motivo, justamente o suporte de supervisores e as estratégias cognitivas e busca de ajuda foram as únicas variáveis que contribuíram para a explicação da variabilidade de impacto em profundidade e em amplitude, respectivamente, pois expressam comportamentos mais diretamente relacionados ao processo de transferência de competências. A natureza das medidas de avaliação, prioritariamente autorreferente, pode referir-se mais a padrões sistemáticos de respostas aos instrumentos, do que aos fenômenos estudados (Meneses \& Abbad, 2003), dificultando o alcance da predição de impacto do treinamento no trabalho. Em segundo lugar, os mecanismos de mediação e/ou moderação podem ser decisivos para explicar a influência indireta de variáveis sobre resultados de treinamento. Embora neste estudo não foram encontrados mediadores e moderadores entre as variáveis investigadas na heteroavaliação, as pesquisas futuras devem centrar-se nesse importante aspecto e seguir buscando explicar o conjunto de variáveis que contribui significativamente para a compreensão do fenômeno do impacto do treinamento no trabalho.

\subsection{Implicações Teórico-Metodológicas}

As implicações teóricas conduzem ao desenvolvimento de um campo do saber ao fornecer novas ideias, significativas e inéditas, à literatura científica. Ainda que não se consiga produzir uma nova teoria, se as perguntas de pesquisa são originais e relevantes, os avanços recentes ou mesmo as contribuições potenciais dos estudos trazem 
conhecimentos importantes à área. Por outro lado, auxiliando esse desenvolvimento, encontram-se os aspectos metodológicos que incluem a amostragem (adequação das fontes e níveis), o desenho do estudo (perguntas de pesquisa e hipóteses), as medidas utilizadas (validade e confiabilidade) e as análises conduzidas (robustez e fidedignidade). Combinados, esses fatores podem levar a que progressos sejam conquistados do ponto de vista teórico.

Algumas implicações importantes desta pesquisa para o desenvolvimento teóricometodológico foram a realização de uma extensa revisão da literatura científica sobre cada uma das variáveis de interesse na investigação, que abarca uma temática de pesquisa muito atual e de interesse tanto da área acadêmica, como do contexto organizacional; e o uso de metodologias avançadas de análise de dados, que possuem significativa robustez probatória dos dados empíricos obtidos.

A ampla verificação dos progressos realizados atualmente no campo de avaliação de TD\&E, por meio do levantamento bibliográfico, permitiu constatar as perguntas de pesquisas comprovadamente testadas, os resultados replicados e confirmados, além das lacunas que deveriam ser superadas para que novos avanços pudessem ser alcançados através das investigações científicas. A partir do exame detalhado do estado da arte que caracteriza a área de conhecimento centrada na avaliação de TD\&E, identificaram-se nas publicações existentes os aspectos já amplamente abordados, e pôde-se então elaborar perguntas específicas e hipóteses pautadas no referencial teórico que atravessa a própria pesquisa, ratificando a sua originalidade e garantindo-se assim o seu compromisso ético e social. Cumpriu-se o intuito fundamental de obter informações sobre a situação atual da temática escolhida, por meio da análise das produções com o mesmo enfoque de estudo em campos de conhecimento diversos, refletindo e avaliando os pontos contraditórios, os tipos de publicação (empírica, revisão, teórica, relato de experiência), as metodologias, as tendências e as lacunas.

Do ponto de vista metodológico, a utilização de modelos mais sofisticados de análise de dados, como a modelagem por equações estruturais, permitiu chegar a conclusões distintas das já publicadas na área ou inéditas, uma vez que as análises de regressão múltipla comumente aplicadas inviabilizam, muitas vezes, que as medidas autorreferentes sejam percebidas como significativas quando incluídas junto às relativas a aspectos externos, ou seja, situacionais, sobressaindo o poder explicativo das segundas sobre as primeiras. Isso não ocorreu na presente pesquisa, tendo sido encontrados, por exemplo, resultados sobre a influência das estratégias de aprendizagem sobre o impacto 
do treinamento no trabalho, que se caracterizam como variáveis cognitivocomportamentais e de autorregulação do aprendizado; além dos mecanismos de mediação/moderação atuantes no processo de transferência de competências, ainda tão negligenciados nas investigações da área, sobretudo no Brasil.

\subsection{Implicações Práticas}

As implicações práticas referem-se às novas orientações, a partir dos resultados empíricos obtidos, que podem ser repassadas aos profissionais da área de avaliação de programas de TD\&E, influindo sobre o desempenho de suas atividades e facilitando as intervenções em contextos organizacionais e de trabalho.

Dentre os principais produtos deste estudo está a proposição de medidas que podem ser úteis e aplicadas nesses ambientes, sendo instrumentos de diagnóstico e de intervenção pertinentes aos processos avaliativos conduzidos em organizações e trabalho.

A construção e o uso de instrumentos específicos à modalidade a distância são imprescindíveis, considerando-se o grande avanço no oferecimento de cursos mediados pela internet na atualidade, embora sejam escassas as validações estatísticas desse tipo de medida nas pesquisas científicas. A evidência dessa lacuna sinaliza para a necessidade de mais investimentos em estudos que agreguem conhecimento e retornos à sociedade com relação à avaliação de cursos EAD, e o fornecimento de meios para atingir tal finalidade, que inclui a preocupação em aperfeiçoar as ações instrucionais a distância, atestar a aplicabilidade da modalidade e conhecer os fatores que a afetam, em termos de aprendizagem e desempenho no trabalho.

Como há evidências empíricas que comprovam o poder explicativo das reações e sua contribuição para a ocorrência da transferência de competências no trabalho e sobre o processo de aprendizagem, o instrumento de Reações aos Procedimentos Instrucionais em EAD pode ser usado para mensurar a satisfação de participantes de eventos educacionais online quanto a diversos aspectos do curso, avaliando a qualidade e a efetividade de treinamentos a distância em contextos corporativos, bem como em instituições de ensino que ofertam cursos desta natureza. A aplicação dessa escala, em contextos e amostras diferentes, pode contribuir para a coleta de informações relevantes ao aprimoramento dessas ações educacionais no que diz respeito aos aspectos instrucionais existentes (ver Goldstein, 1991; Salas et al., 2012), uma vez que a satisfação com os mesmos influi positivamente sobre os resultados e o sucesso acadêmico em 
ambientes de aprendizagem online, produzindo bons efeitos sobre os comportamentos dos egressos.

Além disso, identificar as estratégias de aprendizagem mais eficazes que influenciam o processo subsequente de aplicação das novas habilidades adquiridas em treinamento no trabalho pode ajudar designers de eventos instrucionais ou gerentes de Recursos Humanos/Gestão de Pessoas, responsáveis pelo planejamento, oferecimento e avaliação de programas de formação e desenvolvimento, a orientar e incentivar os treinandos a usar as estratégias mais adequadas e identificar as malsucedidas, reconsiderar e melhorar as medidas a serem tomadas durante o processo de aprendizagem para alcançar resultados positivos (ver Salas, Tannenbaum, Kraiger \& Smith-Jentsch, 2012). O desenho do treinamento em si deve ter em conta as estratégias de sucesso e facilitar a sua utilização, através do planejamento de treinamento, exercícios, trabalhos, simulações, etc.

De acordo com os resultados obtidos no presente estudo, as estratégias de ensino devem ser compatíveis às estratégias de aprendizagem cognitivo-comportamentais e autorregulatórias; portanto, os planejadores instrucionais devem estar atentos para: a construção e a disponibilização de materiais didáticos completos, com qualidade na redação e sequência de exposição dos conteúdos; o fornecimento de exemplos e a proposição de exercícios práticos que auxiliem os participantes a associarem os conteúdos aprendidos aos conhecimentos já adquiridos e situações cotidianas - como atividades e atribuições específicas de trabalho que requeiram a aplicação dos conteúdos; incentiválos, constantemente, a verificar sua concentração, atenção e motivação durante os estudos; a monitorarem o interesse pelas atividades e a compreensão dos conteúdos; e a refletirem sobre quais as implicações que o material ensinado pode ter na vida laboral prática. A adoção dessas estratégias, especialmente as de elaboração e aplicação prática e controle da motivação, teve influência na explicação da transferência de competências bem-sucedida para o trabalho.

A medida Barreiras e Facilitadores em EAD serve para mensurar as diferentes barreiras que podem ser encontradas durante um treinamento, impactando em seus resultados; além de poder ser utilizada em instituições de ensino superior que oferecem cursos online para analisar possíveis obstáculos encontrados pelos estudantes para continuar os estudos, auxiliando-os durante o processo, podendo evitar a sua evasão. $\mathrm{Ou}$ ainda, realizar diagnósticos com os evadidos para investigar quais fatores dificultaram a sua permanência, levantando informações importantes que subsidiem futuras intervenções capazes de amenizar os efeitos negativos apontados. 
A escala de Suporte à Transferência de Treinamento serve para mensurar os diferentes tipos de apoio percebidos por participantes de treinamento, os quais afetam na transferência de competências para o trabalho, segundo os resultados obtidos. E, para a avaliação do grau de aplicação das novas competências adquiridas em treinamento no trabalho, afetando o desempenho geral dos trabalhadores, incluindo suas atitudes e sua motivação, tem-se o instrumento de Impacto do Treinamento no Trabalho em Amplitude. Uma vez que a efetividade de ações educacionais é fundamentalmente avaliada por meio do indicador impacto do treinamento no trabalho, o instrumento pode ser usado para realizar diagnósticos, cumprindo com uma das principais preocupações e objetivos da área de TD\&E, auxiliando equipes responsáveis pela avaliação de programas de treinamento em organizações.

Com vistas a angariar informações que subsidiem a avaliação da efetividade de treinamentos em contextos corporativos, sugere-se combinar medidas de impacto do treinamento no trabalho autorrelatadas (Chiaburu \& Tekleab, 2005; Velada et al., 2007) - uma vez que os treinandos são a fonte mais importante e válida da medição da efetividade de treinamento (Garavan et al., 2010) e possuem a capacidade de expor seus próprios níveis de transferência de competências para o trabalho -, a outras fontes (por exemplo, supervisores, colegas e subordinados), que possam reforçar as estimativas provindas dos treinandos. Ainda, é aconselhável, quando possível, usar medidas diretas e objetivas de desempenho no trabalho do egresso (Velada et al., 2007), pois a diversificação dos indicadores de efetividade em diferentes níveis (individual e organizacional) contribui sobremaneira com a complementariedade dos resultados, ao explicar de modo mais integrado e abrangente o impacto do treinamento no trabalho, incidindo na fidedignidade à realidade corporativa e, por conseguinte, na qualidade das intervenções realizadas.

\subsection{Limitações}

Apesar das contribuições do presente estudo, previamente mencionadas, e da amostra com tamanho expressivo, o uso das medidas adaptadas e validadas pela primeira vez em uma única organização, referente a um treinamento na modalidade EAD de baixa complexidade e curta duração, impede a generalização dos resultados para outros contextos. A partir desse curso, todo o modelo teórico se fundamentou e foram testadas as relações entre as variáveis para investigar sua influência sobre o comportamento dos 
egressos (alterações no desempenho específico e geral), estudar o fenômeno da transferência de competências e seus antecedentes, mediadores e moderadores. Em outras palavras, foi testado um modelo muito complexo, com muitas variáveis e relações distintas, utilizando-se apenas um único treinamento de baixa complexidade e curtíssima duração. Em contrapartida, a manutenção da mesma organização e de apenas um treinamento possibilitou justamente o controle dos efeitos de outras variáveis, como variações no clima para a transferência ou na qualidade, tipologia, modalidade e/ou complexidade do curso, que poderiam interferir sobre os resultados (Mourão et al., 2014). Uma vez que as variáveis intervenientes no impacto do treinamento no trabalho são múltiplas, por causa da adoção dessa estratégia metodológica, pôde-se atribuir a predição às variáveis testadas.

Embora os resultados encontrados tenham relevância ao desenvolvimento teóricometodológico da área de avaliação de eventos instrucionais, há limitações que devem ser superadas para que avanços mais contundentes sejam alcançados, trazendo contribuições a nível das investigações científicas e das intervenções no contexto corporativo. Um ponto fundamental para que os testes de modelos e de relações entre variáveis possam produzir resultados mais confiáveis e fidedignos à realidade organizacional, capazes de gerar implicações práticas mais precisas e de alto teor interventivo no ambiente de trabalho, é que os treinamentos avaliados em pesquisas sejam mais complexos e que demandem resultados de aprendizagem de natureza diversa. Habilidades complexas cobradas nos cursos avaliados favoreceriam o desenvolvimento de pesquisas com metodologias de avaliação mais consistentes e que possam avançar na busca por (outros) preditores, mediadores e moderadores, de efeitos do treinamento sobre o desempenho dos egressos.

Ao contrário, cursos de baixa complexidade e essencialmente pertencentes ao domínio cognitivo (ver Abbad \& Borges-Andrade, 2004) oferecem poucas possibilidades de investigação de processos superiores de aprendizagem e de transferência de competências, ou a necessidade de apoios mais contundentes auxiliares nesse processo; ainda mais quando combinados à situação do ambiente de estudo do treinando, no contexto específico avaliado, que não dispunha de tempo, concentração ou dedicação exclusiva ao aprendizado dos novos conteúdos, pois a própria organização exigia que o treinamento fosse realizado durante a jornada de trabalho. Isso provavelmente inviabiliza que, por exemplo, mecanismos mais complexos de aprendizagem sejam ativados - como o uso de estratégias de aprendizagem autorregulatórias - influenciando no processo de 
aplicação dos novos conhecimentos e das habilidades adquiridas, bem como do estudo das possíveis barreiras ao desempenho.

Devido ao fato da adoção, utilização e influência de estratégias de aprendizagem depender muito das características da amostra, do curso e da organização, algumas limitações do estudo podem ser a impossibilidade de generalização dos resultados; ou a curta duração e complexidade do treinamento avaliado, o que certamente determinou as estratégias adotadas pela amostra e, por conseguinte, os resultados obtidos. Assim, sugere-se a condução de estudos adicionais com a medida de Estratégias de Aprendizagem com outras amostras e organizações, e as relações das estratégias de aprendizagem com outras variáveis do local de trabalho devem ser analisados.

Outro aspecto prioritário para a produção de resultados e o melhor entendimento do fenômeno em questão seria a realização de avaliação do treinamento no nível organizacional. A possibilidade de avaliar treinamentos em termos de seus benefícios financeiros para a organização contribuiria para a produção de conhecimentos na área de avaliação de treinamentos, uma vez que menos de $5 \%$ dos programas de treinamento são avaliados a nível organizacional no mundo (Aguinis \& Kraiger, 2009). O que é um contrassenso, já que as organizações ao disponibilizar e investir tantos recursos em programas de treinamento anualmente, deveriam empreender esforços em analisar se seus efeitos atingem níveis desejados no trabalho (indivíduos e equipes), mas também na organização como um todo. Para tanto, as avaliações deveriam combinar medidas autorreferentes a indicadores objetivos.

No presente estudo, dispusemos de medidas perceptuais da efetividade do treinamento no nível individual, com benefícios evidentes ao tê-las conseguido de diferentes fontes, em autoavaliação e heteroavaliação conduzidas. Os resultados provindos das análises estatísticas realizadas comprovaram que as variáveis analisadas (reações, estratégias de aprendizagem, barreiras e facilitadores em EAD e suporte à transferência) explicam parte da variabilidade do impacto em profundidade e em amplitude, enquanto preditores diretos ou mediante mecanismos de mediação/moderação. Além dos resultados descritivos, disponibilizados ao Banco em relatório específico, apontarem que tanto na auto como na heteroavaliação os respondentes afirmaram terem transferido o treinamento (profundidade e amplitude) para o contexto de trabalho.

Atualmente, além da necessidade de obter mais de uma fonte de informação para comparar os efeitos de treinamentos nas organizações - como é o caso já cumprido da auto e heteroavaliação, sendo um ponto positivo da avaliação conduzida em parceria entre 
o Banco e a presente pesquisa -, uma das principais preocupações na área de avaliação de treinamentos é não restringi-la apenas ao nível individual/equipes, mas investigar como os treinamentos afetam o desempenho organizacional (rentabilidade, efetividade, produtividade, receita operacional por funcionário): direta (redução de custos, melhora na qualidade e quantidade) ou indiretamente (rotatividade, reputação da organização, capital social). Para operacionalizar a coleta de indicadores financeiros e medir o desempenho organizacional, pode-se fazê-lo em termos de efetividade (envolvimento do trabalhador, indicadores de RH e qualidade) ou rentabilidade (volume de vendas, benefícios - taxas e juros).

As medidas mais típicas que vêm sendo utilizadas são: aumento na produtividade, vendas ou rendimento, e rentabilidade total para a empresa. No caso de um contexto bancário, a busca por impactos do treinamento em termos financeiros é bastante plausível, e teríamos, considerando o treinamento avaliado, as medidas já comentadas anteriormente, sobre as quais deveríamos focar a coleta: redução de despesas administrativas e redução de consumo de recursos do Banco pelos funcionários e clientes, o que impactaria nos seus resultados.

Os principais objetivos do treinamento avaliado são justamente que sejam colocadas em prática ações capazes de afetar e reduzir as despesas administrativas e diminuir o consumo dos recursos do Banco. O treinamento em questão, por ter um caráter atitudinal (decisão do funcionário em apagar a luz quando deixa a agência ou de uma sala que não está sendo usada no momento; decidir por não imprimir um e-mail ou material de trabalho, etc.; usar apenas um copo descartável e não um a cada vez que vai tomar água), pode possuir uma relação tangível com os benefícios gerados a nível organizacional. Assim, a avaliação desse treinamento seria completa se além de saber que houve impacto do treinamento no trabalho a nível individual - tanto medido em termos dos desempenhos específicos que deveriam ser desenvolvidos ou aprimorados (impacto em profundidade) através dele, quanto no desempenho geral, incluindo ganhos na motivação e atitudes dos funcionários (impacto em amplitude) -, como o Banco vem conseguindo promover a eficiência operacional nas atividades de trabalho: reduzir suas despesas e aumentar resultados a partir da participação de seus funcionários no treinamento avaliado "Eficiência Operacional", ano após ano.

Em outras palavras, já que o treinamento tem objetivos de reduzir despesas e aumentar os resultados do Banco, ele tem alcançado estes resultados, incidindo sobre os seus indicadores financeiros? Caso se possa afirmar que os efeitos do treinamento estão 
relacionados a esses indicadores, logo poderia ser considerado efetivo a nível organizacional, isto é, além de produzir mudanças nos desempenhos individuais dos funcionários, melhora o desempenho do Banco como um todo; então, a organização deveria seguir investindo e aperfeiçoando sua oferta e realização. Assim, confirma-se a importância de relacionar os possíveis indicadores que poderiam ser afetados pela participação dos funcionários nesse treinamento.

Quanto às implicações práticas desse tipo de avaliação, haveria a possibilidade de oferecer feedback ao Banco, quanto aos resultados do treinamento ("Eficiência Operacional") e seus efeitos na redução de despesas: o investimento neste programa de treinamento, durante $\mathrm{x}$ anos, tem revertido em economias/corte de despesas no nível individual (número de funcionários treinados), regional (número de agências envolvidas) e nacional (em x anos, a partir do início do oferecimento do treinamento e todas as medidas adotadas pelo Banco para aumentar a eficiência operacional nas atividades de trabalho, conseguiu reduzir despesas e melhorar resultados?).

Os dados já coletados serviriam como uma amostra representativa dos funcionários que já participaram desse treinamento antes, isto é, não seria preciso coletar novos dados perceptuais. Ademais, não haveria a necessidade de treinar todos os funcionários de uma organização para obter resultados no nível de desempenho grupal e organizacional, pois existe o chamado "compartilhamento mental", ou seja, como se dá a transferência de competências adquiridas individualmente para equipes e organização, sendo justamente isso o que deveria ser investigado, fundamentado na teoria da aprendizagem organizacional e análise multinível. Os dados objetivos fornecidos, portanto, seriam tratados estatisticamente para analisar além da relação entre treinamentodesempenho individual, a relação entre treinamento-desempenho organizacional - um exemplo: o suporte, uma das variáveis coletadas, poderia servir como mediador/moderador da relação entre treinamento e indicadores brutos.

$\mathrm{Na}$ prática, alguns dos possíveis indicadores a serem coletados, que foram requisitados ao Banco: 1) quantidade de recursos economizados ao longo do tempo, como: i) gastos com energia (Kw/h) - ar-condicionado, luz, etc.; ii) material de consumo (impressão de documentos por funcionários e clientes, papel, cartuchos de impressão, etc. - redução das impressões com os canais de autoatendimento (caixas eletrônicos, internet banking) e o envio por e-mail ou arquivo digital de contratos e extratos bancários); iii) número de agências equipadas com canais de videoconferência - redução de gastos com viagens e deslocamentos de funcionários para reuniões; 2) programas de pontuação para 
redução de despesas por agência (água, luz, etc.): programas para estimular e premiar a redução de despesas nas agências após a participação no treinamento, subsidiando a intervenção.

Esses seriam alguns indicadores objetivos que poderiam provar estatisticamente (percentual/\%) por região que participou do treinamento, ou inclusive nacionalmente, o quanto diminuíram as despesas (economia de $\mathrm{R} \$ \mathrm{x}$ milhões de reais/ano) e observar se houve uma curva decrescente de gastos, aumentando, consequentemente, os resultados do Banco. Seria aconselhável coletar dados em termos de quantidade e não preço, por questões de variação nos valores ao longo do tempo. E ao final das análises, poderia ser quantificada também em valores aproximados a economia em moeda.

O instrumento de Impacto do Treinamento no Trabalho em Profundidade, construído para a avaliação do treinamento "Eficiência Operacional", ao passar por análises de sua estrutura fatorial e aspectos psicométricos (consistência interna), os itens 6 ("Incentivo os clientes a reduzir o consumo de recursos do Banco (uso de canais automatizados para realizar transações, cadastramento de débito automático, uso de cartões para pagamentos, etc.”), 7 (“Concedo créditos, presto serviços (produtos de seguridade e cartão de crédito, por exemplo) e capto recursos (LCI e LCA) como formas para aumentar as receitas operacionais do Banco") e 8 ("Acompanho os indicadores de eficiência operacional do Banco ao longo do tempo para contribuir para a sua melhoria") foram apontados como não representativos de todas as áreas de trabalho do Banco e menos diretamente relacionados aos objetivos específicos do treinamento em questão. Portanto, a coleta de dados dos indicadores financeiros deveria basear-se nas cinco primeiras competências, a saber: minimizar o consumo de recursos, aplicar recursos para promover a eficiência operacional, compartilhar as ações com os colegas, reduzir despesas administrativas e conter gastos.

Todos esses argumentos teórico-metodológicos e as possíveis implicações práticas da avaliação do treinamento no nível organizacional foram expostos à equipe responsável pela área de avaliações do Banco - Diretoria de Gestão de Pessoas - com a qual foram feitos os contatos durante o desenvolvimento da pesquisa, e as negociações com relação aos indicadores brutos entre a pesquisadora e as gerentes/assessoras da equipe de avaliação de treinamentos foram persistentemente conduzidas. Porém, essas informações solicitadas, por se tratarem de dados internos, não geridos pela Diretoria de Gestão de Pessoas, dependiam da autorização de outras áreas gestoras, que além de disponibilizar os dados, teriam de autorizar sua divulgação externa, o que não ocorreu. $\mathrm{O}$ 
Banco, representado pela Diretoria de Gestão de Pessoas, na resposta negativa apresentada, argumentou que, no contexto atual, em que a empresa vem implementando já há algum tempo relevantes normas e ações de âmbito nacional para a melhoria da eficiência operacional e controle de despesas, a análise do impacto da realização do curso na redução de despesas estaria prejudicada.

Como a pouca diversificação dos procedimentos de coleta de dados (Abbad et al., 2006; Abbad et al., 2003; Meneses et al., 2010) constitui-se em uma das limitações apontadas nos estudos de TD\&E, a presente pesquisa pretendia, com o intuito de aumentar a triangulação metodológica, diversificar as técnicas de coleta de dados e complementar as informações obtidas por meio do estudo de campo, incluir os denominados "estudos de diário".

Os estudos de diário tratam-se do uso de instrumentos de autorrelato repetidamente para examinar eventos e experiências em curso, em seu contexto natural e espontâneo, oferecendo a oportunidade de investigar processos sociais, psicológicos e fisiológicos, dentro de situações cotidianas (Bolger, Davis \& Rafaeli, 2003). Em comparação aos métodos mais tradicionais - na maioria de corte transversal, que solicitam aos participantes responderem sobre seus estados psicológicos ou suas experiências, fazendo um retrospecto ao longo de semanas ou meses - permite reduzir o tempo transcorrido entre a experiência e seu relato, diminuindo o viés da retrospecção.

Outras vantagens, além de examinar mudanças nos níveis de variáveis ao longo do tempo, residem no fato de mostrar o quanto cada pessoa varia no tempo em variáveis de interesse (média e variabilidade intrapessoal) e se as pessoas diferem entre si nessas mudanças ao longo do tempo (média e variabilidade interpessoal), indicando os preditores e os determinantes dessa variabilidade (Bolger et al., 2003). Capturam as mudanças com mais fidedignidade que os delineamentos longitudinais, pois estes assumem intervalos mais longos para repetir as medidas, medindo-se menos vezes o construto.

Os estudos de diário são recomendados quando mudanças são prováveis de acontecer e são adequados para responder a perguntas de pesquisa que pretendem verificar: i) mudanças em uma variável, ii) relacionamentos entre comportamentos e experiências/estados transitórios, iii) relacionamentos entre variáveis estáveis (características pessoais ou situacionais) com comportamentos, estados e experiências transitórias. Pesquisadores devem determinar a frequência e a duração das avaliações que são apropriadas para o fenômeno em estudo (horas, dias, semanas, meses) e os dados são geralmente analisados utilizando métodos de análise de dados longitudinais (modelos 
multiníveis, modelos hierárquicos lineares, modelos mistos gerais e modelos de regressão aleatória).

A necessidade de mais pesquisas sobre as estratégias de autogerenciamento/autorregulação da aprendizagem e seu relacionamento com o impacto do treinamento no trabalho (Burke \& Hutchins, 2007; Grossman \& Salas, 2011), indicamna como uma variável a ser explorada em estudo longitudinal e de corte transversal. Além da busca pela resposta à questão se as estratégias de aprendizagem relacionam-se e explicam a ocorrência do fenômeno de resultado do treinamento no desempenho do egresso, seria interessante investigar: a) o padrão de uso das estratégias de aprendizagem pelos participantes dos treinamentos durante todo o evento; b) se o padrão de uso sofre alterações (intra e interpessoal) durante o processo formativo; c) se há mudanças (diferenças significativas) no padrão de uso e dos tipos de estratégias de aprendizagem durante o treinamento por influência dos procedimentos instrucionais - por exemplo, os participantes começam o curso usando estratégias cognitivas e passam a utilizar mais as estratégias autorregulatórias pelas demandas do curso virtual.

Dessa forma, a coleta de dados sobre as estratégias de aprendizagem seria feita antes, durante e depois do treinamento a distância (ou apenas pré e pós-teste), aplicandose a mesma medida em diferentes momentos para medir a variabilidade do construto no tempo. A definição da frequência pertinente de aplicação do instrumento de Estratégias de Aprendizagem dependeria da duração (curta ou média) dos treinamentos a serem avaliados. A amostra dos estudos de diário seria formada por menos participantes, que receberiam treinamento prévio e seriam esclarecidos da maior dedicação e do comprometimento exigidos de sua parte para colaborar com o estudo. Contudo, esse objetivo permaneceu como agenda de pesquisa, devido às dificuldades inerentes ao procedimento e à impossibilidade de aplicação da medida em diferentes momentos por se tratar da avaliação de apenas um treinamento de curta duração.

Uma limitação de caráter metodológicoa, trata-se do programa estatístico PROCESS do SPSS utilizado na pesquisa, que limita as análises a uma única VI e VD por vez, mediadores contínuos, paralelos ou em série, mas não os dois simultaneamente, e resultados dicotômicos ou contínuos, atendendo aos pressupostos da regressão múltipla padrão/logística. Seria necessário utilizar um programa que, além dos cenários mencionados, pudesse lidar com modelos com múltiplas VIs e VDs, estrutura de dados multinível, incorporar variáveis latentes, etc., como é o caso do Mplus. Este, possibilitaria trabalhar com as variáveis latentes (utilizando os itens como indicadores dos escores 
fatoriais), sendo o processo de multiplicação das escalas para avaliar a moderação, por serem consideradas variáveis latentes, mais complicado; além de que, para testar os modelos mais complexos e executar as análises, pode demorar um período considerável de tempo. Ao realizar as análises no AMOS do SPSS, trabalhou-se com variáveis observadas (média dos itens de cada escala) - retirando-se, uma a uma, as variáveis com menor poder preditivo ou que tinham um respaldo teórico mais fraco para explicar as VDs e para verificar o ajuste encontrado -, o que, juntamente aos baixos coeficientes de regressão encontrados nas relações de mediação e moderação, pode ter contribuído para o não ajuste do modelo completo (inclusão de todos os preditores, mediadores e moderadores significativos ao mesmo tempo) - as relações de mediação e moderação descobertas devem ser analisadas em diferentes amostras e contextos, tendo como principal preocupação a complexidade do treinamento avaliado, como discutido anteriormente.

A falta de ajuste, ou possíveis modificações no modelo, pode indicar que existem outras relações entre as variáveis, não modeladas, que poderiam melhorar o modelo. Outrossim, a falta de ajuste é bastante comum quando se testa modelos completos com variáveis mediadores e moderadoras, pois a cada nova variável inserida, divide-se e complica-se a explicação do que de fato influencia a(s) VD(s). Contudo, como a intenção era testar as hipóteses teóricas previamente formuladas, os indicadores de ajuste para o modelo completo não acrescentariam muito, pois as hipóteses puderam ser ratificadas ou refutadas usando-se o PROCESS.

Outra possível limitação referente aos procedimentos metodológicos diz respeito ao instrumental adotado na presente pesquisa. Foram utilizadas unicamente medidas adaptadas locais, desenvolvidas em estudos nacionais prévios; embora todas apresentem boas características psicométricas, comprovadas pelos resultados das análises de validação realizadas, o uso exclusivo dessas medidas torna a investigação restringida ao âmbito nacional, não havendo sido testadas em outros contextos além do brasileiro. A ausência de medidas internacionais na coleta de dados pode trazer inconvenientes à pesquisa, como críticas sobre um dos principais aspectos que conferem fidedignidade e validade aos resultados encontrados, ou seja, como foram medidos os construtos/variáveis de interesse. O impacto da adoção dos instrumentos é diretamente relacionado à qualidade dos achados obtidos e, por esse motivo, trata-se possivelmente de uma deficiência do presente estudo. 


\subsection{Pesquisas Futuras e Agenda de Pesquisa}

Avaliações realizadas em contextos e amostras diferentes devem seguir atestando a capacidade preditiva das medidas, para comprovar a adequação e a manutenção das evidências de validade e confiabilidade conseguidas, tanto em relação a resultados de aprendizagem, quanto de impacto do treinamento no trabalho. Recomenda-se a aplicação das escalas em organizações de trabalho, como parte integrante do instrumental na avaliação de programas de treinamento, com vistas a obter informações sobre os resultados dessas ações educacionais e os seus efeitos sobre o impacto do treinamento no trabalho. É aconselhável também o uso de mais de uma fonte de informação para contrastar as opiniões dos atores envolvidos quanto aos aspectos avaliados e constatar aqueles suficientes ou deficitários que influem sobre os indicadores de efetividade de treinamento e, consequentemente, na aplicação eficaz das novas competências no trabalho.

As investigações futuras devem continuar a investigar as variáveis estudadas, uma vez que estas influenciam a efetividade de treinamentos, sendo preditoras de impacto no nível do comportamento no cargo e integrantes dos diversos níveis de avaliação, podendo obter resultados diferentes, fato que acrescerá subsídios à área de avaliação de programas instrucionais. É imperativo que os estudos persistam na exploração de dimensões, variáveis e níveis diferenciados de análise para a compreensão dos fatores que influenciam, direta e indiretamente, o impacto no trabalho de treinamentos a distância, tanto para o desempenho do indivíduo quanto para as organizações.

Diante dos resultados e das discussões promovidas no presente estudo, a seguinte agenda de pesquisa é proposta:

- Realizar replicações dos resultados desta pesquisa, para atestar a consistência teórica e empírica dos mesmos, em amostras e contextos diferentes, mas principalmente em treinamentos a distância, pois, de maneira geral, há lacunas de investigações que oferecem boas medidas para diagnóstico e intervenção específicas para a modalidade;

- Adicionar novas variáveis ao modelo de investigação que possam aumentar a sua explicação, principalmente aquelas sobre as quais ainda há pouco conhecimento sistematizado (e.g. motivação e gestão de erros), sendo necessários investimentos em termos de pesquisa empírica;

- Incluir diferentes variáveis individuais que poderiam aumentar a explicação do modelo de predição de impacto do treinamento no trabalho, como a autoeficácia, 
apontada como boa preditora de desempenho e de resultados de transferência (Burke \& Hutchins, 2007; Grossman \& Salas, 2011);

- Seguir investigando os mecanismos de mediação e moderação existentes no processo de transferência de competências, assumindo que dificilmente as relações entre as variáveis são estritamente diretas no campo da Psicologia;

- Aprofundar as discussões sobre as estratégias de aprendizagem em contextos corporativos que ofertam treinamentos na modalidade a distância, especialmente as autorregulatórias, uma vez que cursos de mais alta complexidade devem demandar o uso de estratégias específicas, que influirão posteriormente no processo de aplicação do aprendido no trabalho;

- Continuar incluindo as variáveis barreiras e facilitadores em EAD e reação ao desempenho do tutor nos modelos para testar o relacionamento entre variáveis em contextos de EAD, pois os resultados preliminares de pesquisas apontam ambas como importantes na explicação e na produção de bons resultados em ambientes virtuais de aprendizagem;

- Realizar estudos adicionais e complementares, com o uso de outras metodologias, como os estudos de diário, e combinar simultaneamente abordagens quantitativas e qualitativas;

- Realizar estudos (quase-)experimentais - criação de uma situação artificial, com variáveis controle, buscando que se assemelhe a uma situação real - em que uma tarefa (simulação/treinamento), que permita testar as medidas antecedentes e de resultados/rendimento propostas no modelo de investigação, é atribuída a diferentes amostras e os resultados são comparados;

- Incluir diferentes fontes de informação nos casos de pesquisas em que as variáveis tratam de mecanismos psicológicos e são autoinformadas;

- Incluir indicadores objetivos (financeiros, por exemplo) nas pesquisas de avaliação de efetividade de valor final;

- Realizar estudos longitudinais, ou de corte não transversal, para examinar as mudanças ao longo do tempo de fenômenos dinâmicos e que admitem a mensuração em vários momentos, possibilitando o estudo mais aprofundado da variação de determinadas variáveis, investigando se são mais importantes, antes, durante ou depois do treinamento;

- Introduzir outros indicadores de consistência interna, pois o Alfa de Cronbach $(\alpha)$, embora seja amplamente utilizado em investigações, é muito sensível ao número de 
itens da escala e, por essa razão, possivelmente foram encontrados instrumentos com o índice de consistência interna tão alto.

Considerando a crescente inserção e relevância da EAD na esfera organizacional, estudos empíricos, como este, trazem contribuições pertinentes ao planejamento, à implementação e à avaliação desse tipo de ação educacional. Espera-se que a presente investigação tenha contribuído com a área de avaliação de programas de TD\&E na modalidade a distância em contexto corporativo, havendo atendido a recomendações e agendas de pesquisas anteriormente propostas. 


\section{Conclusiones}

\subsection{Evidencias de Validez de las Escalas}

Este estudio proporciona escalas inéditas, después de un cuidadoso proceso de adaptación y validación de instrumentos brasileños con buenas características psicométricas, además de la construcción de una escala de impacto de la formación en el trabajo en profundidad. Debido a que son más concisas, consecuencia de la reducción del número de ítems y de los puntos de las escalas, la aplicación es más sencilla. La validez y la fiabilidad de los instrumentos fueron confirmados, contemplando ítems representativos de cada factor, siendo importantes herramientas de evaluación, útiles para el diagnóstico de la eficacia de la formación en entornos corporativos. Además, pueden ser utilizadas y probadas sus capacidades predictivas en otros contextos de enseñanza y muestras.

La adecuación de los instrumentos producidos se confirmó mediante rigurosos análisis estadísticos, que apuntaron a las evidencias de validez de constructo, y los ajustes de los modelos de las estructuras factoriales probados. Medidas más parsimoniosas, así como fiables y válidas, se vuelven más fáciles y rápidas para responder, acelerando el proceso de aplicación en la recogida de datos en evaluaciones en general, siendo más adecuadas al contexto organizacional e influyendo incluso en la producción de resultados fiables. Si hasta la formación se realizó durante la jornada de trabajo, la aplicación de instrumentos de evaluación, probablemente, también competirá con las actividades laborales de los participantes, lo que puede afectar, por ejemplo, a la calidad de los resultados obtenidos y al número de los encuestados alcanzados, especialmente si la evaluación tarda excesivamente.

Los instrumentos sirven para medir: la frecuencia y el patrón de uso de estrategias de aprendizaje por los participantes de acciones educativas, presenciales o virtuales (Anexo P); la satisfacción de los participantes sobre diversos aspectos del curso online (Anexo Q); los diferentes tipos de apoyo percibidos por los participantes de la formación, que afectan a la transferencia de habilidades para el trabajo (Anexo R); los diferentes obstáculos que se pueden encontrar durante la formación, incidiendo en los resultados (Anexo S); y el grado de aplicación de los nuevos conocimientos adquiridos en la formación en el trabajo, lo que afecta el comportamiento en el puesto de trabajo (Anexo T) y el desempeño global de los trabajadores, incluyendo sus actitudes y motivación (Anexo U). 
En cuanto al instrumento de Estrategias de Aprendizaje, la solución de cuatro factores presenta un sentido teórico y ya ha sido encontrada en un estudio previo (Martins \& Zerbini, 2014b), pero con una agrupación diferente de algunas de las estrategias de aprendizaje. Los cuatro factores están compuestos de estrategias de aprendizaje cognitivas y de búsqueda de ayuda, control de la emoción, elaboración y aplicación práctica, y control de la motivación. Otros estudios también han encontrado estructuras con un número reducido de factores (Borges-Ferreira, 2005; Zerbini et al., 2015), en comparación con la versión original, en que los diferentes tipos de estrategias cognitivas se agruparon en el mismo factor, o junto a las estrategias comportamentales. Es posible que se produzca un cambio en la estructura factorial de la escala de estrategias de aprendizaje en función de aspectos tales como la complejidad del curso, las características organizacionales y del muestreo, que puede mejor explorarse en futuras investigaciones.

Han sido escasos los estudios nacionales que incluyeron ítems relativos a las estrategias de autorregulación en la escala, debido a las características (naturaleza y complejidad) de los cursos evaluados, o porque asumieron poca influencia de ese tipo de estrategia en la explicación del comportamiento en el trabajo - lo que debe ser investigado más profundamente en las investigaciones futuras debido a las recientes recomendaciones sobre el tema (ver Aguinis \& Kraiger, 2009; Burke \& Hutchins, 2007), y a las conclusiones de este estudio. Los resultados muestran que el mantenimiento de dos componentes separados de estrategias de autorregulación (control de la emoción y control de la motivación) en la estructura factorial de la escala actual - validada en un contexto organizacional, con una muestra de trabajadores que participaron en una formación online - confirman la importancia de mantener los ítems en el instrumento, como ocurrió anteriormente en Zerbini y Abbad (2008a), Martins y Zerbini (2014b) y Zerbini et al. (2015). Además, igual que las estrategias cognitivas y comportamentales, las de autorregulación actuaron como predictores significativos de los indicadores de eficacia de la formación, motivo por el cual, parecen ser estrategias diferenciales coadyuvantes en el proceso de aprendizaje en entornos de enseñanza virtual.

La solución de un único factor encontrada para la escala de Reacción a los Procedimientos de Formación también presenta un sentido teórico. La adaptación de dicho instrumento fue capaz de eliminar un gran número de ítems (8), que junto a la presencia de multicolinealidad - existencia de pares de ítems altamente correlacionados entre sí - indicaba la repetición de contenido o aspectos superpuestos evaluados por el instrumento original (Martins \& Zerbini, 2015). Estudios anteriores con la medida 
optaron por no eliminar ítems porque fueron las primeras aplicaciones y pruebas de los instrumentos en contextos específicos a distancia (Borges-Ferreira, 2005; Silva, 2004; Zerbini \& Abbad, 2009; Zerbini \& Abbad, 2010). Sin embargo, la literatura muestra que los instrumentos que miden las reacciones, en general, tienen un número muy pequeño de ítems en soluciones de factor único (por ejemplo, Klein et al., 2006), lo que indicaba la necesidad de supresión de algunos ítems y una adaptación más expresiva de la escala para generar un instrumento más parsimonioso, rápido y fácil de aplicar. Ese objetivo fue alcanzado, después de haber sido producida una nueva versión que eliminó la multicolinealidad entre los ítems y que mantuvo las excelentes propiedades psicométricas del instrumento.

Del mismo modo, los resultados confirmaron las evidencias de validez y fiabilidad de la escala Barreras y Facilitadores en la Enseñanza Virtual, que mantuvo el valor de consistencia interna $(\alpha=0,98)$ con la exclusión de cinco ítems de su estructura en el análisis factorial confirmatorio (AFC) - a más de haber contado con importantes cambios, como el corte del número de ítems (reducción de 45 ítems) en el proceso de adaptación. Los logros derivados de la adaptación realizada en ese instrumento son considerables, ya que, sus cualidades psicométricas fueron mantenidas, aunque una importante reducción del número de ítems fuera conducida; incluso, hubo una mejora del índice de consistencia interna y de la estructura empírica con menos factores (dimensión de factor único).

La estructura empírica encontrada para la escala de Apoyo a la Transferencia es adecuada tanto teórica como empíricamente y valida la adaptación realizada en el instrumento en el que se miden los tipos de apoyo psicosocial (supervisores y compañeros) por separado, además de la ayuda material ofrecida por la organización. El principal cambio realizado en el instrumento de Abbad y Sallorenzo (2001) fue ajustar los ítems con un enfoque en la acción, ya que las medidas, aunque abordaran conjuntamente el apoyo de los supervisores y de los compañeros de trabajo como presupone el concepto de apoyo psicosocial para la transferencia, lo divergían en sus ítems: algunos de ellos evaluaban sólo el apoyo proporcionado por los supervisores y otros, en menor número, el apoyo de los compañeros. La escala adaptada tiene ventajas al diferenciar el apoyo psicosocial, ya que permite la evaluación de los dos tipos de apoyo y en qué medida su ofrecimiento es percibido por los egresados de la formación. Esa separación permite la realización de análisis para comprobar si hay un apoyo más importante que el otro, sus efectos sobre el impacto de la formación en el trabajo; o, en su caso, evaluar sólo el apoyo de los supervisores o de los compañeros. 
La estructura empírica unidimensional del instrumento Impacto de la Formación en el Trabajo en Amplitud y su estructura teórica se confirmaron. La adaptación y prueba de una nueva versión del instrumento fueron motivadas a partir de recomendaciones dadas en estudios previos (Pilati \& Abbad, 2005), que indicaban una serie de ajustes a realizar, tales como la eliminación de ítems. Al haber encontrado indicadores de ajuste satisfactorios en el AFC, los autores optaron por no excluir ítems; sin embargo, señalaron posibilidades de mejorar la escala por medio de la sustitución o eliminación de ítems superpuestos (presencia de covarianza), terminando así con la redundancia existente. Según esas sugerencias, se realizaron ajustes y cortes en el instrumento; asimismo, la adecuación de los cambios realizados en el mismo fue confirmada mediante los análisis estadísticos descritos anteriormente, que apuntaron a la evidencia de validez de constructo y el ajuste del modelo de la estructura de factores probado. También se encontraron evidencias empíricas de la validez de la escala Impacto de la Formación en el Trabajo en Profundidad, que puede considerarse como un instrumento adecuado para medir los resultados específicos del curso "Eficiencia Operacional".

Las medidas producidas en portugués y español, pueden ayudar en el desarrollo de la investigación en el área de evaluación de formaciones en los países nativos en los dos idiomas - aunque todavía es necesario verificar las evidencias de validez de constructo y las estructuras factoriales de las medidas en español a través de la aplicación en muestras compatibles. Se sugiere su aplicación en diferentes contextos y muestras, tanto en instituciones de enseñanza superior como en organizaciones laborales, ya que las variables, medidas a través de las escalas producidas, demostraron ser buenos predictores del desempeño y de la aplicación de lo aprendido en el trabajo.

\subsection{Implicaciones Empíricas - Teste de Hipótesis de los Modelos}

Los principales beneficios empíricos presentados en este estudio se refieren a la verificación de la eficacia de la formación a través de la autoevaluación y la heteroevaluación del impacto de la formación en el trabajo; además de la realización del estudio específico de los mecanismos de mediación y moderación existentes en el modelo de investigación propuesto, basado en las hipótesis formuladas teóricamente.

Más allá de atestiguar los efectos conocidos y probados en la literatura dominante sobre los más fuertes y consistentes predictores del impacto de la formación en el trabajo, como por ejemplo, el apoyo a la transferencia, también aclara la importante contribución 
de las variables individuales en la predicción de la variable en foco, añadiendo elementos que explican el proceso de transferencia de competencias en el trabajo a través de los mecanismos de mediación y moderación presentes en ese fenómeno, lo que aporta información importante para el área de evaluación de formaciones en las empresas.

En la autoevaluación de la formación, todos los tipos de estrategias de aprendizaje se relacionaron positivamente con uno o ambos indicadores de la eficacia de la formación, con excepción de las estrategias de autorregulación de control de la emoción. Especialmente las estrategias de elaboración y aplicación práctica explicaron la ocurrencia del impacto en profundidad y en amplitud en la autoevaluación - resultados similares se han encontrado previamente (Brandão \& Borges-Andrade, 2011; Pantoja \& Borges-Andrade, 2009; Pilati \& Borges-Andrade, 2012; Zerbini \& Abbad, 2005, 2008a, 2010a), lo que indica la importancia de las estrategias cognitivas y comportamentales para explicar el proceso de aprendizaje y la transferencia de las competencias en las organizaciones y en el trabajo. El impacto en amplitud también fue predicho por las estrategias de elaboración y aplicación práctica, acrecidas de las estrategias cognitivas y búsqueda de ayuda y las de control de la motivación. En la heteroevaluación, sólo las estrategias cognitivas y de búsqueda de ayuda contribuyeron para explicar el impacto en amplitud. Los participantes que reflexionaron sobre los nuevos contenidos y sus efectos, tuvieron en cuenta las conexiones entre el material del curso y su conocimiento previo, e identificaron las situaciones cotidianas en las que se podrían aplicar los contenidos en la práctica, consiguieron los mejores resultados en la transferencia, tanto de su desempeño específico como global. Tales estrategias son consistentes con la muestra de participantes formada por trabajadores: relacionar los nuevos conocimientos a los ya obtenidos, y tratar de comprender su utilidad y aplicabilidad en las actividades prácticas laborales diarias, puede ser de gran importancia. Simultáneamente, esas estrategias (elaboración y aplicación práctica) fueron las más utilizadas por la muestra, obteniendo el promedio más alto de acuerdo con los resultados descriptivos, así como las estrategias de autorregulación de control emocional y motivacional.

Por otro lado, las estrategias comportamentales (búsqueda de ayuda interpersonal y de material didáctico) tuvieron los promedios más bajos, lo que indica que los participantes no buscaron otras fuentes de información (sitios web, documentos, manuales de instrucciones, programas informáticos, etc.), además de las disponibles en el material del curso, ni solicitaron la ayuda de otros compañeros para hacerles preguntas. La falta de herramientas interactivas en la plataforma virtual puede explicar la baja 
frecuencia del comportamiento proactivo para solicitar ayuda de otras personas y hacerles preguntas sobre el contenido del material del curso. También se puede señalar el hecho de que el material del curso podría haber sido suficiente para resolver cualquier duda, o que debido a la baja complejidad del curso, no se requiera más explicaciones de otras personas u otros materiales. Ese hallazgo merece atención, pues ese tipo de estrategia de búsqueda de ayuda ha contribuido a la transferencia de la formación, en términos del desempeño global (impacto en amplitud) de los participantes en este estudio, además de ya haber sido identificado su papel importante para la adquisición, retención y transferencia de nuevos conocimientos en el ámbito laboral (Pantoja \& Borges-Andrade, 2009).

En cuanto a la explicación inferior de las estrategias de autorregulación sobre los resultados de desempeño, algunas justificaciones razonables están relacionadas con la naturaleza (predominantemente cognitiva), la corta duración (2 horas) y la baja complejidad de la formación evaluada. Esta puede no haber requerido el uso de estrategias que previenen dispersiones de concentración provocadas por sentimientos de ansiedad y el control de la motivación, debido a la sencillez de los objetivos de aprendizaje - aunque los resultados descriptivos informan que la muestra ha utilizado esas estrategias a menudo durante el curso.

La identificación de las preferencias en el uso de las estrategias de aprendizaje permite verificar la adecuación y la compatibilidad de las estrategias de enseñanza adoptadas a las estrategias de aprendizaje más utilizadas por los participantes, influyendo sobre el diseño instruccional de los cursos online, haciéndolos más apropiados para el público objetivo. Los resultados contribuyen a que los participantes puedan ser entrenados en las estrategias más efectivas, reciban orientación antes del curso, o que se lleven a cabo cambios en los procedimientos de la formación en ediciones subsecuentes. Asimismo, las estrategias favoritas y más frecuentemente elegidas por la clientela, pero que no explicaron el impacto de la formación en el trabajo en este estudio, deben seguir siendo investigadas, pues en otros contextos y muestras pueden ser predictores importantes de impacto. $\mathrm{O}$, por el contrario, pueden ser probadas como inadecuadas para ciertos tipos específicos de cursos - teniendo en cuenta su naturaleza, complejidad y modalidad de entrega, por ejemplo -, lo que podría conducir al fracaso del proceso de aplicación de las habilidades recién adquiridas en el trabajo.

Se corroboraron los efectos de las reacciones y del apoyo a la transferencia exitosa de nuevas habilidades aprendidas en la formación para el trabajo. Los egresados que 
expresaron satisfacción con los procedimientos formales del curso evaluado y percibieron el apoyo de la organización (recursos materiales, condiciones de trabajo, etc.) y de los compañeros de trabajo, especialmente de sus pares, fueron los que tuvieron sus desempeños modificados tanto en términos específicos (impacto en profundidad) como generales (impacto en amplitud). Esos resultados confirman los hallazgos ya recopilados en varias investigaciones anteriores (Blume et al., 2010; Chiaburu, 2010; Gunawardena et al., 2010; Homklin et al., 2014; Joo et al., 2011; Pham et al., 2012; Pilati \& BorgesAndrade, 2012; Mourão et al., 2014; Simosi, 2012; Zerbini \& Abbad, 2010a) e indican la pertinencia de continuar la medición de los niveles de satisfacción después de las formaciones y de los apoyos ofrecidos para producir efectos positivos sobre el desempeño en el trabajo de los participantes. La satisfacción de los egresados con la formación y la percepción del apoyo a la transferencia de los nuevos conocimientos y habilidades, generan implicaciones prácticas: la formación será transferida al ambiente de trabajo si esas condiciones han sido atendidas. Por lo tanto, se debe seguir evaluando las reacciones emocionales y de utilidad de la formación al final del programa, así como el apoyo material y psicosocial proporcionados.

La inclusión de hipótesis mediadoras y moderadoras para la investigación de la influencia de estos mecanismos en la explicación de los fenómenos relacionados con los cambios en el desempeño causado por el curso a distancia, mejoran los modelos explicativos de los efectos de la formación para el impacto de la formación en el trabajo, convirtiéndose como una importante contribución de este estudio. A pesar de que existen relaciones de mediación y moderación propuestas teóricamente, todavía hay muy pocos estudios que las investigan en el área de evaluación de la formación (Chiaburu \& Tekleab, 2005; Nijman et al., 2006; Zumrah \& Boyle, 2015), especialmente en el ámbito nacional. La identificación del papel moderador del apoyo material sobre las barreras y facilitadores en la enseñanza virtual es particularmente importante porque enfatiza su relevancia como factor potenciador, en cuanto a un determinante contextual, de la predicción de la transferencia de las habilidades aprendidas. En el caso de que las barreras y facilitadores entrasen como predictores significativos de impacto, indicando que de hecho los obstáculos al desempeño pueden interferir sobre los efectos de los indicadores de la eficacia de la formación a distancia, el papel moderador del apoyo podría haber sido aún más prominente. Al mismo tiempo, la mediación de las reacciones, principalmente en la percepción de apoyo a la transferencia de la formación, también añade información importante sobre el papel de la satisfacción en la explicación de la variable dependiente 
e indica que esta medida debe permanecer en los modelos de evaluación de la formación en las empresas, y que sus efectos como un mediador/moderador deben ser probados. Esos hallazgos son todavía seguramente prematuros, debido a las bajas contribuciones estadísticas de las variables mediadoras/moderadoras, pero anticipan resultados que pueden ser mejor investigados y se conviertan en más definitivos en el futuro. Los avances sobre el papel mediador y moderador de variables, como las reacciones y el apoyo a la transferencia, podrán ayudar a explicar los porqués y bajo qué circunstancias las variables antecedentes (VIs) interfieren sobre el fenómeno de los resultados de la formación en el desempeño de los egresados, y deben ser incluidas en los modelos de investigación para explicar mejor el proceso de transferencia de competencias en el trabajo.

La baja contribución significativa de las variables antecedentes estudiadas en la explicación del impacto de la formación en el trabajo en la heteroevaluación, puede ser debido a la naturaleza de las medidas empleadas, todas perceptuales, y a la existencia de mecanismos de mediación/moderación entre las variables no identificados. Vale la pena recordar que, en este estudio, solamente los instrumentos de evaluación de impacto (profundidad y amplitud) fueron aplicados a los gestores, los demás no (reacciones, estrategias de aprendizaje, apoyo a la transferencia, etc.). Tal vez por eso, precisamente, el apoyo de los supervisores y las estrategias cognitivas y búsqueda de ayuda fueron las únicas variables que contribuyeron a la explicación de la variabilidad del impacto en profundidad y amplitud, respectivamente, pues expresan comportamientos más directamente relacionados con el proceso de transferencia de habilidades. La naturaleza de las medidas de evaluación, principalmente autorreferente, puede referirse más a patrones sistemáticos de respuesta a los instrumentos, que a los fenómenos estudiados (Meneses \& Abbad, 2003), por lo que es difícil llegar a la predicción del impacto de la formación en el trabajo. En segundo lugar, los mecanismos de mediación y/o moderación pueden ser decisivos para explicar la influencia indirecta de las variables en los resultados de la formación. Aunque en este estudio no se encontraron mediadores y moderadores de las variables investigadas en la heteroevaluación, las investigaciones futuras deberían centrarse en ese importante aspecto y seguir buscando explicar el conjunto de variables que contribuyen significativamente para la comprensión del fenómeno de impacto de la formación en el trabajo.

\subsection{Implicaciones Teóricas y Metodológicas}


Las implicaciones teóricas conducen al desarrollo de un campo de conocimiento al proporcionar nuevas ideas, significativas y no antes publicadas, a la literatura científica. Aunque no se consiga producir una nueva teoría, si las preguntas de investigación son originales y relevantes, los recientes avances o las contribuciones potenciales de los estudios traen conocimientos importantes al área de investigación. Por otro lado, para favorecer ese desarrollo, están los aspectos metodológicos que incluyen el muestreo (adecuación de las fuentes y de los niveles), el diseño del estudio (preguntas e hipótesis de investigación), las medidas utilizadas (validez y fiabilidad) y los análisis llevados a cabo (robustez y fiabilidad). Combinados, esos factores pueden conducir a que se logren progresos desde un punto de vista teórico.

Algunas de las implicaciones importantes de este estudio para el desarrollo teórico y metodológico fue haber llevado a cabo una extensa revisión de la literatura científica sobre cada una de las variables de interés en la investigación, que abarca un tema de investigación muy actual, de interés tanto del campo científico, como del contexto organizacional; y el uso de métodos avanzados de análisis de datos que tienen fuerza probatoria significativa de los datos empíricos.

La amplia verificación de los avances realizados actualmente en el campo de la evaluación de programas de formación, a través de la revisión de la literatura, permitió establecer las preguntas de investigación probadas, los resultados replicados y confirmados, así como las lagunas que deberían ser superadas para que nuevos progresos pudiesen ser logrados a través de la investigación científica. Del detallado examen del estado del arte que caracteriza el área de conocimiento centrado en la evaluación de programas de formación, se han identificado en las publicaciones existentes aspectos ya discutidos ampliamente, y luego se pudo desarrollar preguntas e hipótesis específicas basadas en el marco teórico que atraviesa la propia investigación, lo que confirma su originalidad y garante su compromiso ético y social. Se cumplió el propósito fundamental de obtener información sobre la situación actual del tema elegido, a través del análisis de las producciones con el mismo enfoque de estudio en diversos campos del conocimiento, reflexionándose y evaluándose los puntos conflictivos, los tipos de publicación (empírica, revisión, teórica, relato de experiencia), las metodologías, las tendencias y las lagunas.

Desde un punto de vista metodológico, el uso de modelos más sofisticados de análisis de datos, como las ecuaciones estructurales, ha dado lugar a conclusiones diferentes de las ya publicadas en el área o inéditas, ya que el análisis de regresión múltiple comúnmente aplicado hace inviable, muchas veces, que las medidas 
autorreferentes se perciban como significativas cuando son incluidas junto a las relativas a los aspectos externos, es decir, del contexto/entorno, destacando el poder explicativo de este último tipo sobre el primero. Eso no ocurrió en este estudio, pues se han encontrado, por ejemplo, resultados sobre la influencia de las estrategias de aprendizaje sobre la transferencia, que se caracterizan como variables cognitivo-comportamentales y de autorregulación del aprendizaje; además de los mecanismos de mediación/moderación en el proceso de transferencia de competencias, aún poco investigados en el área, especialmente en Brasil.

\subsection{Implicaciones Prácticas}

Las implicaciones prácticas se relacionan con las nuevas directrices, a partir de los resultados empíricos, que se pueden dar a los profesionales en el área de evaluación de los programas de formación en las empresas, y que influyen en el desempeño de sus actividades y facilitan las intervenciones en contextos de organizaciones y trabajo.

Entre los principales productos de este estudio está la proposición de medidas que pueden ser útiles y aplicadas en esos entornos, en cuanto herramientas de diagnóstico y de intervención pertinentes a los procesos de evaluación llevados a cabo en las organizaciones y en el trabajo. La elaboración y el uso de instrumentos específicos a la modalidad a distancia son esenciales, teniendo en cuenta el gran avance en la oferta de cursos online hoy en día, principalmente porque las validaciones estadísticas de dichas medidas son aún escasas en las investigaciones científicas. La evidencia de esa laguna indica la necesidad de una mayor inversión en los estudios que aportan conocimiento y beneficios a la sociedad con respecto a la evaluación de los cursos a distancia, y la provisión de medios para lograr ese propósito, el cual incluye la preocupación por la mejora de las acciones de enseñanza virtual, atestar la aplicabilidad de la modalidad y conocer los factores que la afectan, en términos de aprendizaje y desempeño en el trabajo.

Como existen evidencias empíricas que comprueban la capacidad explicativa de las reacciones y su contribución a la ocurrencia de la transferencia de las habilidades en el trabajo y del proceso de aprendizaje, el instrumento Reacción a los Procedimientos de Formación se puede utilizar para medir la satisfacción de los participantes del curso online con respecto a los distintos aspectos del mismo, lo que posibilita la evaluación de la calidad y de la eficacia de la formación a distancia en entornos corporativos, así como en instituciones de enseñanza superior que ofrecen cursos a distancia. La aplicación de esa escala, en diferentes contextos y muestras, puede contribuir para la obtención de 
información relevante para mejorar las acciones educativas con respecto a los aspectos de instrucción existentes (ver Goldstein, 1991; Salas et al., 2012), ya que la satisfacción con las mismas tiene una influencia positiva sobre los resultados y el éxito académico en los entornos de aprendizaje virtual, produciendo buenos efectos en el comportamiento de los egresados.

Por otro lado, conocer las estrategias de aprendizaje más eficaces, que influyen en el proceso subsiguiente de aplicación de los nuevos conocimientos adquiridos en la formación para el trabajo, puede ayudar a los diseñadores de programas de formación o gerentes de Recursos Humanos (RRHH), responsables de los programas de planificación, ofrecimiento y evaluación de programas de formación y desarrollo, a guiar e incentivar a los participantes a utilizar las estrategias más adecuadas e identificar las sin éxito, a reconsiderar y mejorar las medidas que deben tomarse durante el proceso de aprendizaje para lograr resultados positivos (ver Salas, Tannenbaum, Kraiger \& Smith-Jentsch, 2012). El diseño de la formación en sí debe tener en cuenta las estrategias de éxito y facilitar su uso, a través de la planificación de la formación, ejercicios, trabajos, simulaciones, etc.

De acuerdo con los resultados obtenidos en este estudio, las estrategias de enseñanza deben ser coherentes con las estrategias de aprendizaje cognitivocomportamentales y de autorregulación; por lo tanto, los planificadores de formaciones deben tener en cuenta: la construcción y la provisión de materiales didácticos completos con calidad en la redacción y secuenciación de los contenidos; proporcionar ejemplos y proponer ejercicios prácticos que ayuden a los participantes a asociar el contenido aprendido a las habilidades ya adquiridas y a situaciones cotidianas - como actividades y tareas específicas de trabajo que requieren la aplicación de los contenidos; animarles constantemente a examinar su concentración, atención y motivación durante los estudios; a monitorizaren el interés en las actividades y la comprensión de los contenidos; y a reflejaren los efectos que el material enseñado puede tener en la vida laboral práctica. La adopción de esas estrategias, especialmente las de elaboración y aplicación práctica y de control de la motivación, tuvieron influencia en la explicación de la transferencia exitosa de habilidades para el trabajo.

La medida Barreras y Facilitadores en la Enseñanza Virtual sirve para medir los diferentes obstáculos que se pueden encontrar durante una formación, incidiendo en los resultados; igualmente, puede ser utilizada en instituciones de enseñanza superior que ofrecen cursos online para analizar los posibles obstáculos que encuentran los estudiantes para continuar sus estudios, ayudándoles durante el proceso, lo que puede impedir su 
evasión. Aparte de poder ser usada para realizar el diagnóstico con los evadidos para investigar los factores que obstaculizaron su permanencia, recogiendo informaciones importantes que ayudarían a las futuras intervenciones capaces de mitigar los efectos negativos encontrados.

La escala de Apoyo a la Transferencia se utiliza para medir los diferentes tipos de apoyo percibidos por los participantes de la formación, que afectan a la transferencia de habilidades para el trabajo, según los resultados obtenidos. Para la evaluación del grado de aplicación de los nuevos conocimientos adquiridos en la formación en el trabajo, lo que afecta el desempeño global de los trabajadores, incluyendo sus actitudes y su motivación, está el instrumento Impacto de la Formación en el Trabajo en Amplitud. Dado que la eficacia de las formaciones se evalúa principalmente por el indicador impacto de la formación en el trabajo, se puede utilizar el instrumento para realizar diagnósticos, cumpliendo una de las principales preocupaciones y objetivos en ese ámbito, ayudando a los equipos responsables de la evaluación de programas de formación en las organizaciones.

Con el fin de obtener información que subvencione la evaluación de la eficacia de la formación en contextos corporativos, se sugiere combinar medidas de impacto de la formación en el trabajo auto-informadas (Chiaburu \& Tekleab, 2005; Velada et al., 2007) - una vez que los participantes son la fuente más importante y valiosa de la medición de la eficacia de la formación (Garavan et al., 2010) y tienen la capacidad de exponer sus propios niveles de transferencia de habilidades para el trabajo -, a otras fuentes (por ejemplo, supervisores, compañeros y subordinados), que pueden mejorar las estimaciones derivadas de los participantes. Aun así, es recomendable, siempre que sea posible, utilizar medidas directas y objetivas del desempeño laboral de los egresados (Velada et al., 2007), pues la diversificación de los indicadores de eficacia en los diferentes niveles (individual y organizacional) contribuye en gran medida a la complementación de los resultados, al explicar de una manera más integrada y global, el impacto de la formación en el trabajo, centrándose en la fiabilidad de la realidad empresarial y, por tanto, en la calidad de las intervenciones.

\subsection{Limitaciones}

A pesar de las contribuciones de esta investigación, anteriormente mencionadas, y la muestra con un tamaño significativo, el uso de medidas adaptadas y validadas por primera vez en una sola organización, relativas a una formación online de baja 
complejidad y de corta duración, impide la generalización de los resultados a otros contextos. A partir de esa formación, se basó todo el modelo teórico y fueron testadas las relaciones entre las variables para investigar su influencia sobre el comportamiento de los egresados (cambios en el desempeño específico y global), estudiar el fenómeno de transferencia de habilidades y sus antecedentes, mediadores y moderadores. En otras palabras, se puso a prueba un modelo muy complejo, con muchas variables y relaciones diferentes, utilizándose sólo una formación de baja complejidad y muy corta duración. En contrapartida, el mantenimiento de la misma organización y sólo una formación precisamente posibilitó el control de efectos de otras variables, tales como las variaciones en el clima para la transferencia o la calidad, el tipo, la modalidad y/o la complejidad del curso, lo que podría interferir en los resultados (Mourão et al., 2014). Una vez que las variables que intervienen en el impacto de la formación en el trabajo son múltiples, debido a la adopción de esa estrategia metodológica, se pudo atribuir la predicción a las variables testadas.

Aunque los resultados sean relevantes para el desarrollo teórico y metodológico del área de evaluación de la formación, existen limitaciones que deben ser superadas para que se logren avances más robustos, trayendo contribuciones a nivel de las investigaciones científicas y de las intervenciones en el contexto organizacional. Un punto clave para que el teste de los modelos y de las relaciones entre variables puedan producir resultados más fiables a la realidad organizacional, capaces de generar implicaciones prácticas e intervenciones más precisas en el entorno laboral, es que las formaciones evaluadas en las investigaciones sean más complejas y que demanden resultados de aprendizaje de naturaleza diversa. Las habilidades complejas en los cursos evaluados favorecerían el desarrollo de investigaciones con metodologías de evaluación más consistentes y que pueden avanzar en la búsqueda de (otros) predictores, mediadores y moderadores, de los efectos de la formación sobre el desempeño de los egresados.

Al contrario, cursos de baja complejidad y que pertenecen principalmente al dominio cognitivo (ver Abbad \& Borges-Andrade, 2004) ofrecen pocas oportunidades de investigación de los procesos superiores de aprendizaje y de transferencia de competencias, o la necesidad de apoyos más contundentes para auxiliar en ese proceso; especialmente cuando fueron combinados con la situación del ambiente de estudio del participante de la formación, en el contexto específico evaluado, sin el tiempo suficiente, concentración o dedicación exclusiva al aprendizaje de los nuevos contenidos, pues la propia organización requiere que la formación sea llevada a cabo durante la jornada 
laboral. Eso probablemente inviabiliza, por ejemplo, que se activen los mecanismos de aprendizaje más complejos - como el uso de estrategias de aprendizaje de autorregulación - que influyen en el proceso de aplicación de los nuevos conocimientos y de las habilidades adquiridas, así como el estudio de las posibles barreras al desempeño.

Debido a la adopción, el uso y la influencia de las estrategias de aprendizaje depender en gran medida de las características de la muestra, del curso y de la organización, algunas limitaciones del estudio pueden conducir a la imposibilidad de generalizar los resultados; o la corta duración y complejidad de la formación evaluada, que ciertamente determinaron las estrategias adoptadas por la muestra y, por consiguiente, los resultados obtenidos. Por lo tanto, se sugiere que los nuevos estudios con la escala de Estrategias de Aprendizaje deben llevarse a cabo en otras muestras y organizaciones, y las relaciones de las estrategias de aprendizaje con otras variables del ambiente de trabajo deben ser analizadas.

Otra de las prioridades para la producción de resultados y una mejor comprensión del fenómeno en cuestión sería llevar a cabo la evaluación de la formación a nivel de la organización. La posibilidad de evaluar la formación en términos de sus beneficios financieros para la organización contribuiría a la producción de conocimiento en el área de evaluación de formaciones en las empresas, ya que menos del 5\% de los programas de formación son evaluados a nivel organizacional en el mundo (Aguinis \& Kraiger, 2009). Lo que es una contradicción, pues las organizaciones al proporcionar e invertir tantos recursos en programas de formación a cada año, deberían hacer esfuerzos para analizar si sus efectos alcanzan los niveles deseados en el trabajo (individuos y equipos), sino también en la organización como un todo. Por lo tanto, se debería combinar medidas autorreferentes a indicadores objetivos.

En este estudio, fueron utilizadas medidas de percepción de la eficacia de la formación a nivel individual, con beneficios claros por haber sido aplicadas a diferentes fuentes, en la auto y heteroevaluación conducidas. Los resultados derivados de los análisis estadísticos mostraron que las variables antecedentes (reacción, estrategias de aprendizaje, barreras y facilitadores en la enseñanza virtual y apoyo a la transferencia) explicaron una parte de la variabilidad del impacto en profundidad y en amplitud, como predictores directos o a través de mecanismos de mediación/moderación. Además de los resultados descriptivos, a disposición del Banco en un informe específico, que indicaron que, tanto en la auto como en la heteroevaluación, los encuestados transfirieron la formación (profundidad y amplitud) para el contexto laboral. 
Actualmente, aparte de la necesidad de obtener más de una fuente de información para comparar los efectos de la formación en las organizaciones - que se cumplió con la auto y heteroevaluación, siendo un punto positivo de la evaluación realizada conjuntamente por el Banco y por esta investigación -, una preocupación importante en el área de evaluación de formaciones es no limitarla sólo a los individuos/equipos, sino investigar cómo las formaciones afectan el desempeño organizacional (rentabilidad, eficacia, productividad, ingresos operativos por empleado): directa (reducción de costes, mejora en la calidad y cantidad) o indirectamente (rotación de empleados, reputación de la organización, capital social). Para poner en práctica la recogida del conjunto de indicadores financieros y medir el desempeño de la organización, se puede hacerlo en términos de eficacia (compromiso de los empleados, indicadores de RRHH y calidad) o rentabilidad (volumen de ventas, beneficios - comisiones e intereses).

Las medidas más comunes utilizadas son: aumento de la productividad, las ventas o los ingresos, y la rentabilidad total de la empresa. En el caso de un contexto bancario, la búsqueda de los impactos de la formación en términos financieros es bastante plausible, y tendríamos, teniendo en cuenta la formación evaluada, las medidas ya mencionadas anteriormente, sobre las que se debería centrar la recogida de datos: la reducción de los costes administrativos y la reducción de consumo de los recursos del Banco por parte de empleados y clientes, que podrían afectar sus resultados.

Los principales objetivos de la formación evaluada son precisamente que se ponga en práctica acciones que afecten y reduzcan los costes administrativos y disminuyan el consumo de recursos del Banco. La formación en cuestión, que posee un carácter actitudinal (la decisión del empleado de apagar la luz cuando salga de la agencia o de una habitación que no se está utilizando en ese momento; decidir no imprimir un e-mail o material de trabajo, etc.; sólo utilizar un vaso desechable y no uno a cada vez que va a tomar agua), puede tener una relación tangible con los beneficios generados a nivel de la organización. Por lo tanto, la evaluación de esa formación estaría completa si además de saber que hubo impacto de la formación en el trabajo a nivel individual - medido en términos de los desempeños específicos que deberían ser desarrollados o mejorados (impacto en profundidad) a través de la formación, y en el desempeño global, incluyendo la motivación y las actitudes de los empleados (impacto en amplitud) - cómo el Banco ha sido capaz de promover la eficiencia operativa en las actividades de trabajo: reducir sus gastos y aumentar los resultados mediante la participación de sus empleados en la formación evaluada "Eficiencia Operacional", año tras año. 
En otras palabras, ya que la formación tiene el objetivo de reducir los costes y aumentar los resultados del Banco, ¿la formación ha conseguido estos resultados, incidiendo sobre sus indicadores financieros? Si se puede afirmar que los efectos de la formación están relacionados con esos indicadores, a continuación, se podría concluir que ha sido eficaz a nivel de la organización, es decir, además de producir cambios en el desempeño individual de los empleados, mejora el desempeño del Banco como un todo; entonces, el Banco debería seguir invirtiendo y mejorando su oferta y realización. Por eso, sería tan importante relacionar los posibles indicadores que podrían ser afectados por la participación de los trabajadores en esa formación.

En cuanto a las implicaciones prácticas de ese tipo de evaluación, sería posible ofrecer retroalimentación al Banco, sobre los resultados de la formación ("Eficiencia Operacional") y sus efectos en la reducción de gastos: la inversión en ese programa de formación durante $\mathrm{x}$ años, se ha revertido en ahorros/corte de gastos a nivel individual (número de personal capacitado), regional (número de agencias involucradas) y nacional (en x años, desde el inicio de la oferta de la formación y todas las medidas adoptadas por el Banco para aumentar la eficiencia operativa en las actividades de trabajo, ¿fueron capaces de reducir los costes y mejorar los resultados?).

Los datos ya recopilados servirían como una muestra representativa de los empleados que han participado antes en esa formación, es decir, no haría falta recoger nuevos datos perceptuales. Por otra parte, no habría la necesidad de capacitar a todos los empleados de una organización para lograr resultados de desempeño a nivel de equipos y de la organización, ya que existe lo que se denomina "intercambio mental", es decir, cómo ocurre la transferencia de competencias adquiridas individualmente para los equipos y la organización, siendo eso justo lo que debería ser investigado, basado en la teoría del aprendizaje organizacional y el análisis multinivel. Los datos objetivos proporcionados, por lo tanto, serían tratados estadísticamente para analizar además de la relación entre la formación-desempeño individual, la relación entre la formación-desempeño organizacional - por ejemplo: el apoyo a la transferencia, una de las variables recogidas, podría servir como mediador/moderador de la relación entre la formación y los indicadores brutos.

En la práctica, algunos de los posibles indicadores a recoger, que fueron solicitados al Banco: 1) cantidad de recursos que se ahorra a lo largo del tiempo, tales como: i) los costos de energía (Kw/h) - aire acondicionado, luz, etc.; ii) materiales (impresión de documentos por parte de empleados y clientes, papel, cartuchos de tinta, 
etc. - reducción de las impresiones con los canales de autoservicio (cajeros automáticos, internet banking) y el envío por correo electrónico o archivos digitales de los contratos y extractos de cuenta bancarios); iii) número de agencias equipadas con canales de videoconferencia - reducción de los gastos de viaje y desplazamientos de los empleados a reuniones de trabajo; 2) programas de puntos para reducir los gastos por agencia (agua, electricidad, etc.): programas para fomentar y recompensar la reducción de los gastos de las agencias después de participar en la formación, apoyando la intervención.

Esos serían algunos indicadores objetivos que podrían comprobar estadísticamente (porcentaje/\%) por región que participó en la formación, o incluso a nivel nacional, cuánto los costos disminuyeron (ahorro de $\mathrm{R} \$ \mathrm{x}$ millones de reales/año), y observar si hubo una curva descendente de gastos, aumentando, consecuentemente, los resultados del Banco. Sería aconsejable recopilar datos en términos de cantidad y no de precio, por la posibilidad de variación de los valores a lo largo del tiempo. Y al final de los análisis, también podría medirse, en valores aproximados, los ahorros en moneda.

El instrumento Impacto de la Formación en el Trabajo en Profundidad, construido para evaluar la formación "Eficiencia Operacional", después del análisis de su estructura factorial y aspectos psicométricas (consistencia interna), los ítems 6 ("Incentivo a los clientes a reducir el consumo de recursos del Banco - uso de canales automatizados para realizar transacciones, registro de débito automático en cuenta, uso de tarjetas de pago, etc."), 7 ("Concedo créditos, presto servicios (productos de seguridad y de tarjetas de crédito, por ejemplo) y capto recursos (Letras de Crédito Inmobiliario y de Agro negocio) como maneras de aumentar los ingresos del Banco") y 8 ("Acompaño los indicadores de eficiencia operativa del Banco a lo largo del tiempo para contribuir para su mejora") fueron identificados como no representativos de todas las áreas de trabajo del Banco y menos directamente relacionados con los objetivos específicos de la formación en cuestión. Por lo tanto, la recogida de datos de los indicadores financieros debería basarse en las cinco primero competencias: minimizar el consumo de recursos, aplicar recursos para promover la eficiencia operativa, compartir acciones con los compañeros de tranajo, reducir los costos administrativos y contener los gastos.

Todos esos argumentos teóricos y metodológicos y las posibles implicaciones prácticas de la evaluación de la formación en el nivel organizacional fueron expuestos al equipo responsable de las evaluaciones del Banco - Directorio de RRHH - con el que se hicieron los contactos durante el desarrollo de la investigación, y las negociaciones, con respecto a los indicadores financieros entre la investigadora y los gestores/asesores del 
equipo responsable de las evaluaciones del Banco, se llevaron a cabo persistentemente. Sin embargo, las informaciones solicitadas, por tratarse de datos internos, no gestionados por el Directorio de RRHH, dependía de la autorización de otras áreas gestoras, que además de facilitar los datos, tendrían que autorizar su divulgación externa, lo que no ocurrió. El Banco, representado por el Directorio de RRHH, en la respuesta negativa presentada, argumentó que, en el contexto actual, en que la empresa ha estado aplicando desde hace algún tiempo normas y acciones nacionales relevantes para mejorar la eficiencia operativa y el control de gastos, el análisis de los efectos de la formación en la reducción de costos estaría comprometida.

La escasa diversificación de los procedimientos de recogida de datos (Abbad et al., 2006; Abbad et al., 2003; Meneses et al., 2010) da lugar a una de las limitaciones identificadas en los estudios del área de formación en las empresas. Esta investigación pretendía, con el fin de aumentar la triangulación metodológica, diversificar las técnicas de recogida de datos y complementar las informaciones obtenidas a través del estudio de campo, incluir la metodología de diario.

Los estudios de diarios consisten en el uso de instrumentos auto-informados repetidas veces para examinar los acontecimientos y experiencias en curso, en su ambiente natural y espontáneo, proporcionando la oportunidad de investigar los procesos sociales, psicológicos y fisiológicos en situaciones cotidianas (Bolger, Davis \& Rafaeli, 2003). En comparación con los métodos más tradicionales - la mayoría de corte transversal, que solicita a los participantes que respondan sobre sus estados psicológicos o experiencias, haciendo una retrospectiva a lo largo de semanas o meses - puede disminuir el tiempo transcurrido entre la experiencia y su relato, lo que reduce el sesgo de la retrospección.

Otras ventajas, además de examinar los cambios en los niveles de las variables en el tiempo, residen en el hecho de mostrar cómo cada persona varía en el tiempo según las variables de interés (media y variabilidad intrapersonal) y si las personas difieren entre sí en esos cambios a lo largo del tiempo (media y variabilidad interpersonal), indicando los predictores y factores determinantes de esa variabilidad (Bolger et al., 2003). Captan los cambios con más fiabilidad que los diseños longitudinales, ya que estos toman intervalos más largos para repetir las mediciones, midiendo los constructos menos veces.

Se recomienda el uso de los estudios de diarios cuando los cambios son probables de ocurrir y son apropiados para responder a las preguntas de investigación que se proponen a verificar: i) cambios en una variable, ii) las relaciones entre los 
comportamientos y experiencias/estados transitorios, iii) las relaciones entre variables estables (características personales o situacionales) con comportamientos, estados y experiencias de transición. Los investigadores deben determinar la frecuencia y la duración de las evaluaciones que sean apropiadas para el fenómeno en estudio (horas, días, semanas, meses) y los datos son analizados, en general, utilizando métodos de análisis de datos longitudinales (modelos multinivel, modelos jerárquicos lineales, modelos mixtos generales y modelos de regresión aleatorio).

La necesidad de más investigaciones sobre las estrategias de autogestión/ autorregulación del aprendizaje y su relación con el impacto de la formación en el trabajo (Burke \& Hutchins, 2007; Grossman \& Salas, 2011), indícalas como una variable que debe explorarse en estudios longitudinales y de corte transversal. Al margen de la búsqueda por la respuesta a la cuestión si las estrategias de aprendizaje se relacionan y explican la ocurrencia del fenómeno de los resultados de la formación en el desempeño de los egresados, sería interesante investigar: a) el patrón de uso de estrategias de aprendizaje de los participantes a lo largo de toda la formación; b) si el patrón de uso sufre cambios (intra e interpersonal) durante el proceso de formación; c) si hay cambios (diferencias significativas) en el patrón de uso y de los tipos de estrategias de aprendizaje durante la formación bajo la influencia de sus procedimientos - por ejemplo, los participantes comienzan el curso usando las estrategias cognitivas y terminan haciendo un mayor uso de las estrategias de autorregulación por las demandas del curso virtual.

Por lo tanto, la recogida de datos sobre las estrategias de aprendizaje se llevaría a cabo antes, durante y después de la formación a distancia (o sólo en pre y post-test), aplicando la misma medida en diferentes momentos para medir la variabilidad del constructo a lo largo del tiempo. La definición de la frecuencia pertinente de aplicación del instrumento de Estrategias de Aprendizaje dependería de la duración (corta o media) de la formación a evaluar. La muestra de los estudios de diarios estaría formada por un menor número de participantes, que recibirían una formación previa y serían informados de su mayor dedicación y compromiso para cooperar con el estudio. Sin embargo, ese objetivo se mantuvo como agenda de investigación, debido a las dificultades inherentes al procedimiento y a la imposibilidad de aplicar la medida en diferentes momentos, ya que fue evaluada solamente una formación de corta duración.

Una limitación de carácter metodológico, fue el programa estadístico PROCESS del SPSS utilizado en la investigación, que limita los análisis a una única VI y VD a la vez, los mediadores continuos, paralelos o en serie, pero no ambos a la vez, y los 
resultados dicotómicos o continuos, dados los supuestos de la regresión múltiple/ logística. Sería necesario utilizar un programa que además de los escenarios mencionados, pudiera manejar modelos con múltiples VIs y VDs, estructura de datos multinivel, incorporar variables latentes, etc., como es el caso del Mplus. Este, posibilitaría trabajar con variables latentes (utilizando los ítems como indicadores de los escores factoriales), pues el proceso de multiplicación de las escalas para evaluar la moderación, por ser consideradas variables latentes, es más complicado; aparte de eso, para probar los modelos más complejos y realizar los análisis, puede tardar un período considerable de tiempo. Al realizar los análisis en el AMOS del SPSS, se ha trabajado con variables observadas (media de los ítems de cada escala) - retirándose, una a una, las variables con menor poder predictivo o que tenían un fundamento teórico más débil para explicar las VDs y para comprobar el ajuste encontrado - lo que, junto con los bajos coeficientes de regresión de los mecanismos de mediación y moderación obtenidos, puede haber contribuido a la falta de ajuste del modelo completo (incluyendo todos los predictores, mediadores y moderadores significativos a la vez) - los hallazgos sobre las relaciones de mediación y moderación deben ser analizados en diferentes muestras y contextos, teniendo como principal preocupación la complejidad de la formación evaluada, como discutido anteriormente.

La falta de ajuste, o los posibles cambios en el modelo, puede indicar que hay otras relaciones entre las variables, que no fueron modeladas, que podrían mejorar el modelo. Por otra parte, la falta de ajuste es bastante común en la comprobación de modelos completos con variables mediadores y moderadoras, ya que, a cada nueva variable inserida, se divide y se complica lo que efectivamente influencia la explicación de la(s) VD(s). Sin embargo, como el objetivo era poner a prueba las hipótesis teóricas previamente formuladas, los indicadores de ajuste para el modelo completo no añadirían mucho, porque las hipótesis pudieran ser ratificadas o refutadas mediante el uso del PROCESS.

Otra posible limitación de carácter metodológico concierne a los instrumentos utilizados en esta investigación. Sólo han sido empleadas medidas locales adaptadas, desarrolladas en estudios brasileños previos, aunque todas poseen buenas características psicométricas demostradas por los resultados de los análisis de validación realizados, el uso exclusivo de estas medidas hace que la investigación esté restringida a nivel nacional, al no haber sido probadas en otros contextos, aparte del brasileño. La ausencia de medidas internacionales en la recogida de datos puede traer inconvenientes a la investigación, 
como críticas respecto a uno de los principales aspectos que proporcionan fiabilidad y validez a los resultados, es decir, cómo fueron medidos los conceptos/variables de interés. El impacto de la elección de los instrumentos está directamente relacionado con la calidad de los resultados obtenidos y, por tanto, posiblemente eso es uno de los inconvenientes con los que cuenta este estudio.

\subsection{Investigaciones Futuras y Agenda de Investigación}

Las evaluaciones que sean llevadas a cabo en diferentes contextos y muestras deben seguir certificando la capacidad predictiva de las medidas para demostrar su adecuación y mantenimiento de la validez y fiabilidad alcanzadas, tanto en términos de resultados de aprendizaje, como de impacto de la formación en el trabajo. Se recomienda la aplicación de las escalas en organizaciones laborales, como parte del instrumental para la evaluación de los programas de formación, con el fin de obtener información sobre sus resultados y efectos sobre la transferencia de competencias para el trabajo. También es recomendable utilizar más de una fuente de información para contrastar las opiniones de los envueltos en el proceso en cuanto a los aspectos evaluados y constatar aquellos suficientes o deficitarios que influyen sobre los indicadores de eficacia de la formación y, por consiguiente, en la aplicación efectiva de las nuevas habilidades en el trabajo.

Las investigaciones futuras deben seguir investigando las variables estudiadas, ya que estas influyen en la eficacia de la formación, siendo predictores del impacto a nivel del comportamiento en el puesto de trabajo e integran diversos niveles de evaluación, y pueden obtener resultados diferentes, un hecho que acrecería conocimientos al área de evaluación de programas de formación. Es imperativo que los estudios persistan en la exploración de las dimensiones, variables y diferentes niveles de análisis para comprender los factores que influyen directa e indirectamente, en el proceso de transferencia en teleformaciones, tanto para el desempeño del individuo como para lo de las organizaciones.

Teniendo en cuenta los resultados y las discusiones realizadas en este estudio, se propone la siguiente agenda de investigación:

- Realizar la replicación de los resultados de esta investigación para probar la consistencia teórica y empírica de los mismos, en diferentes muestras y contextos, pero sobre todo en teleformaciones, ya que, en general, hay lagunas en la investigación que proporcionen buenas medidas para el diagnóstico y la intervención específicas para la modalidad a distancia; 
- Añadir nuevas variables al modelo de investigación que puedan aumentar su explicación, especialmente aquellas sobre las cuales hay poco conocimiento sistemático (por ejemplo, la motivación y la gestión de errores) y, por lo tanto, requieren inversiones en investigación empírica;

- Incluir diferentes variables individuales que podrían aumentar la explicación del modelo de predicción de transferencia de la formación en el trabajo, tales como la auto-eficacia, identificada como buen predictor de desempeño y de resultados de transferencia (Burke \& Hutchins, 2007; Grossman y Salas, 2011);

- Seguir investigando los mecanismos de mediación y moderación existentes en el proceso de transferencia de competencias, asumiéndose que las relaciones entre las variables difícilmente son estrictamente directas en el campo de la Psicología;

- Profundizar las discusiones sobre las estrategias de aprendizaje en contextos corporativos que ofrecen formaciones a distancia, en especial las de autorregulación, ya que cursos más complejos deben requerir el uso de estrategias específicas, que luego influirán en el proceso de aplicación del aprendido en el trabajo;

- Continuar incluyendo las variables barreras y facilitadores en la enseñanza virtual y reacción a la calidad del tutor en los modelos para poner a prueba la relación entre variables en contextos de enseñanza a distancia, ya que los resultados preliminares de investigaciones las indican como importantes para explicar y producir buenos resultados en entornos virtuales de aprendizaje;

- Realizar estudios adicionales y complementarios, utilizando otras metodologías, como los estudios de diario, y la combinación de enfoques cuantitativos y cualitativos a la vez;

- Realizar estudios (casi-)experimentales - creación de una situación artificial con el control de variables, buscando que se asemeje a una situación real -, en los cuales se atribuye una tarea (simulación/formación), que permita poner a prueba los antecedentes y los resultados/desempeño propuestos en el modelo de investigación, a diferentes muestras y los resultados obtenidos son comparados;

- Incluir distintas fuentes de información en los casos en que las variables tratan de mecanismos psicológicos y son auto-informadas;

- Incluir indicadores objetivos (financieros, por ejemplo) en las investigaciones de evaluación de la eficacia de valor final; 
- Realizar estudios longitudinales, o de corte no transversal, para examinar los cambios a lo largo del tiempo de los fenómenos dinámicos, que permitan la medición en diferentes momentos y el estudio más a hondo de la variación de ciertas variables, investigando si son más importantes antes, durante o después de la formación;

- Introducir otros indicadores de consistencia interna, pues el Alfa de Cronbach $(\alpha)$, aunque sea ampliamente utilizado en las investigaciones, es muy sensible al número de ítems de la escala $\mathrm{y}$, por lo tanto, posiblemente fueron encontrados instrumentos con el índice de consistencia interna tan alto.

Considerando la creciente inserción y relevancia de la enseñanza virtual en el ámbito de las organizaciones, los estudios empíricos, tales como este, traen contribuciones pertinentes a la planificación, ejecución y evaluación de ese tipo de acción educativa. Se espera que esta investigación haya contribuido al área de evaluación de los programas de formación en las empresas, por haber cumplido con anteriores recomendaciones y agendas de investigación propuestas. 


\section{Referências}

Abbad, G. (1999). Um modelo integrado de avaliação de impacto de treinamento no trabalho. Tese Doutorado, Instituto de Psicologia, Universidade de Brasília.

Abbad, G. (2007). Educação a distância: O estado da arte e o futuro necessário. In International Seminar on Distance Learning. Brasília.

Abbad, G. \& Borges-Andrade, J. E. (2004). Aprendizagem Humana em Organizações de Trabalho. In: J. C. Zanelli, J. E. Borges-Andrade e A. V. B. Bastos (Eds.). Psicologia, organizações e trabalho no Brasil (pp. 237-275). Porto Alegre: Artmed.

Abbad, G., Carvalho, R. S., \& Zerbini, T. (2006). Evasão em curso via internet: Explorando variáveis explicativas. Revista de Administração de Empresas - RAEeletrônica, 5(2).

Abbad, G., Côrrea, V. P., \& Meneses, P. P. M. (2010). Avaliação de treinamentos a distância: Relações entre estratégias de aprendizagem e satisfação com o treinamento. RAM - Revista de Administração Mackenzie, 11(2), 43-67.

Abbad, G., Gama, A. L., \& Borges-Andrade, J. E. (2000). Treinamento: Análise do relacionamento da avaliação nos níveis de reação, aprendizagem e impacto no trabalho. Revista de Administração Contemporânea, 14(3), 25-45.

Abbad, G., Mourão, L., Meneses, P. P. M., Zerbini, T., Borges-Andrade, J. E., \& VilasBoas, R. (Orgs.) (2012c). Medidas de avaliação em treinamento, desenvolvimento e educação: Ferramentas para gestão de pessoas. Porto Alegre: Artmed.

Abbad, G., Pilati, R., Borges-Andrade, J. E., \& Sallorenzo, L. H. (2012b). Impacto do treinamento no trabalho - medida em amplitude. In G. Abbad, L. Mourão, P. P. M. Meneses, T. Zerbini, J. E. Borges-Andrade, R. Vilas-Boas (Orgs.), Medidas de Avaliação em Treinamento, Desenvolvimento e Educação (pp. 145-162). Porto Alegre: Artmed.

Abbad, G., Pilati, R., \& Pantoja, M. J. (2003). Avaliação de treinamento: Análise da literatura e agenda de pesquisa. Revista de Administração da USP, 38(3), 205-218.

Abbad, G., \& Sallorenzo, L. H. (2001). Desenvolvimento e validação de escalas de suporte à transferência de treinamento. Revista de Administração da USP, 36(2), 33-45.

Abbad, G., Sallorenzo, L. H., Coelho, F. A., Zerbini, T., Vasconcelos, L., \& Todeschini, K. (2012a). Suporte à transferência de treinamento e suporte à aprendizagem. In: G. Abbad, L. Mourão, P. P. M. Meneses, T. Zerbini, J. E. Borges-Andrade, R. Vilas-Boas (Orgs.), Medidas de Avaliação em Treinamento, Desenvolvimento e Educação (pp. 127146). Porto Alegre: Artmed.

Abbad, G., Zerbini, T., \& Souza, D. B. L. (2010). Panorama das pesquisas em educação a distância no Brasil. Estudos de Psicologia, 15(3), 291-298.

Aguinis, H., \& Kraiger, K. (2009). Benefits of training and development for individuals and teams, organizations, and society. Annual Review of Psychology, 60, 451-74. 
Aiken, L. S., \& West, S. G. (1991). Multiple regression: Testing and interpreting interactions. Newbury Park: Sage.

Al-Eisa, A. S., Furayyan, M. A., \& Alhemoud, A. M. (2009). An empirical examination of the effects of self-efficacy, supervisor support and motivation to learn on transfer intention. Management Decision, 47(8), 1221-1244.

Allinger, G. M., \& Janak, E. A. (1989). Kirkpatrick's levels of training criteria: Thirty years later. Personnel Psychology, 42(2), 331-342.

Almeida, O. C. S., Abbad, G., Meneses, P. P. M., \& Zerbini, T. (2013). Evasão em cursos a distância: Fatores influenciadores. Revista Brasileira de Orientação Profissional, 14, 1.

Alonso, K. M. (2010). A expansão do ensino superior no Brasil e a EaD: Dinâmicas e lugares. Educação e Sociedade, 31(113), 1319-1335.

Alvarez, K., Salas, E., \& Garofano, C. M. (2004). An integrated model of training evaluation and effectiveness. Human Resource Development Review, 3(4), 385-416.

Badia, A., \& Monereo, C. (2010). Ensino e aprendizagem de estratégias de aprendizagem em ambientes virtuais. In: C. Coll \& C. Monereo (Orgs.). Psicologia da Educação virtual - Aprender e ensinar com as tecnologias da informação e da comunicação. (pp. 311328). Porto Alegre: Artmed.

Baldwin, T. T., \& Ford, J. K. (1988). Transfer of training: A review and directions for future research. Personnel Psychology, 41(1), 63-105.

Baron, R. M., \& Kenny, D. A. (1986). The moderator-mediator variable distinction in social psychological research: Conceptual, strategic, and statistical considerations. Journal of Personality and Social Psychology, 51(6), 1173-1182.

Bedwell, W. L., \& Salas, E. (2010). Computer-based training: Capitalizing on lessons learned. International Journal of Training and Development, 14(3), 239-249.

Beluce, A. C., \& Oliveira, K. L. (2012). Ambientes virtuais de aprendizagem: Das estratégias de ensino às estratégias de aprendizagem. In: IX ANPED SUL, 1-14.

Bhatti, M. A., Battour, M. M., Sundram, V. P. K., \& Othman, A. A. (2013). Transfer of training: Does it truly happen?: An examination of support, instrumentality, retention and learner readiness on the transfer motivation and transfer of training. European Journal of Training and Development, 37(3), 273-297.

Bjork, R. A., Dunlosky, J., \& Kornell, N. (2013). Self-regulated learning: Beliefs, techniques, and illusions. Annual Review of Psychology, 64, 417-444.

Blume, B. D., Ford, J. K., Baldwin, T. T., \& Huang, J. L. (2010). Transfer of training: A meta-analytic review. Journal of Management, 39, 1065-1105.

Bolger, N., Davis, A., \& Rafaeli, E. (2003). Diary methods: Capturing life as it is lived. Annual Review of Psychology, 54, 579-616. 
Borges-Andrade, J. E. (1982). Avaliação somativa de sistemas instrucionais: Integração de três propostas. Tecnologia Educacional, 11(46), 29-39.

Borges-Andrade, J. E. (1997). Treinamento de pessoal: Em busca de conhecimento e tecnologia relevantes para as organizações brasileiras. In: A. Tamayo, J. E. BorgesAndrade \& W. Codo (Orgs.). Trabalho, Organizações e Cultura (pp. 129-149). São Paulo: Cooperativa de Autores Associados.

Borges-Andrade, J. E. (2006). Avaliação integrada e somativa em TD\&E. In: J. E. Borges-Andrade, G. Abbad, L. Mourão (Orgs.). Treinamento, desenvolvimento e educação em organizações e trabalho: Fundamentos para a gestão de pessoas (pp. 343358). Porto Alegre: Artmed.

Borges-Andrade, J. E., Abbad, G. S., \& Mourão, L. (Orgs.). (2006). Treinamento, desenvolvimento e educação em organizações e trabalho: Fundamentos para a gestão de pessoas. Porto Alegre: Artmed.

Borges-Andrade, J. E., Abbad, G. S., \& Mourão, L. (2012). Modelos de avaliação e aplicação em TD\&E. In: G. S. Abbad, L. Mourão, P. P. M. Meneses, T. Zerbini, J. E. Borges-Andrade, R. Vilas-Boas (Orgs.). Medidas de avaliação em treinamento, desenvolvimento e educação: Ferramentas para gestão de pessoas (pp. 20-35). Porto Alegre: Artmed.

Borges-Ferreira, M. F. (2005). Avaliação de reações e aprendizagem em disciplinas de curso técnico profissionalizante oferecidas a distância. Dissertação de Mestrado, Instituto de Psicologia, Universidade de Brasília.

Brandão, H. P., \& Borges-Andrade, J. E. (2011). Desenvolvimento e validação de uma escala de estratégias de aprendizagem no trabalho. Psicologia: Reflexão e Crítica, 24(3), 448-457.

Brant, S. R. C., Pilati, R., \& Borges-Andrade, J. E. (2015). Estratégias de aplicação do aprendido: Análise baseada em TRI. Psicologia: Reflexão e Crítica, 28, 1-10.

Brauer, S. (2005). Avaliação de um curso a distância: valor instrumental do treinamento, barreiras pessoais à conclusão e evasão. Dissertação de Mestrado, Instituto de Psicologia, Universidade de Brasília.

Brauer, S., Abbad, G., \& Zerbini, T. (2009). Características da clientela e barreiras à conclusão de um curso a distância. Psico-USF, 14, 317-328.

Brown, K. G. (2005). What does recent research tell us about "training satisfaction?" In: C. Saul \& B. Sugrue (Ed.). American Society for Training \& Development: Research-toPractice Conference Proceedings (pp. 27-35). United States of America.

Burke, L. A., \& Hutchins, H. M. (2007). Training transfer: An integrative literature review. Human Resource Development Review, 6(3), 263-297. 
Burke, L. A., \& Saks, A. M. (2009). Accountability in training transfer: Adapting Schlenker's model of responsibility to a persistent but solvable problem. Human Resource Development Review, 8(3), 382-402.

Byrne, B. M. (2010). Structural equation modeling with AMOS: Basic concepts, applications, and programming. New York/London: Routledge Taylor \& Francis Group.

Campbell, J. P. (1971). Personnel training and development. Annual Review of Psychology, 22, 565-602.

Carrol, N., \& Burke, M. (2010). Learning effectiveness using different teaching modalities. American Journal of Business Education, 3(12), 65-76.

Carswell, A. D., \& Venkatesh, V. (2002). Learner outcomes in an asynchronous distance education environment. International Journal of Human-Computer Studies, 56, 475-494.

Carvalho, R. S., \& Abbad, G. (2006). Avaliação de treinamento a distância: Reação, suporte à transferência e impactos no trabalho. Revista de Administração Contemporânea, 10(1), 95-116.

Castro, M. N. M., \& Ferreira, L. D. V. (2006). TD\&E a distância: Múltiplas mídias e clientelas. In: J. E. Borges-Andrade, G. Abbad, L. Mourão (Orgs.). Treinamento, desenvolvimento e educação em organizações e trabalho: Fundamentos para a gestão de pessoas (pp. 322-339). Porto Alegre: Artmed.

Cheng, W. L., \& Hampson, I. (2008). Transfer of training: A review and new insights. International Journal of Management Reviews, 10(4), 327-341.

Cheung, D. (2000). Evidence of a single second-order factor in student ratings of teaching effectiveness. Structural Equation Modeling, 7(3), 442-460.

Chiaburu, D. S. (2010). The social context of training: Coworker, supervisor, or organizational support? Industrial and Commercial Training, 42(1), 53-56.

Chiaburu, D. S., \& Tekleab, A. G. (2005). Individual and contextual influences on multiple dimensions of training effectiveness. Journal of European Industrial Training, 29(8), 604-626.

Chiaburu, D. S., van Dam, K., \& Hutchins, H. M. (2010). Social support in the workplace and training transfer: A longitudinal analysis. International Journal of Selection and Assessment, 18(2), 187-200.

Chyung, S. Y., \& Vachon, M. (2005). An investigation of the profiles of satisfying and dissatisfying factors in e-learning. Performance Improvement Quarterly, 18(2), 97-113.

Codes, A. L. M. (2005). Modelagem de equações estruturais: Um método para análise de fenômenos complexos. Caderno CRH, 18(45), 471-484.

Coelho, F. A. (2004). Avaliação de treinamento a distância: Suporte à aprendizagem e impacto do treinamento no trabalho. Dissertação de mestrado, Instituto de Psicologia, Universidade de Brasília. 
Coll, C. (2004). Psicología de la educación y prácticas educativas mediadas por las tecnologias de la información y la comunicación. Sinéctica, 25, 1-24.

Coll, C., Mauri, T., \& Onrubia, J. (2010). A incorporação das tecnologias da informação e da comunicação na educação - do projeto pedagógico às práticas de uso. In: C. Coll \& C. Monereo (Orgs.). Psicologia da Educação virtual - Aprender e ensinar com as tecnologias da informação e da comunicação (pp. 66-93). Porto Alegre: Artmed.

Colman, A. M., Norris, C. E., \& Preston, C. C. (1997). Comparing rating scales of different lengths: Equivalence of scores from 5-point and 7-point scales. Psychological Reports, 80, 355-362.

Costa, E. R., \& Boruchovitch, E. (2009). As estratégias de aprendizagem e a produção de textos narrativos. Psicologia: Reflexão e Crítica, 22(2), 173-180.

Crouse, P., Doyle, W., \& Young, J. D. (2011). Workplace learning strategies, barriers, facilitators and outcomes: A qualitative study among human resource management practitioners. Human Resource Development International, 14(1), 39-55.

Dermol, V., \& Čater, T. (2013). The influence of training and training transfer factors on organizational learning and performance. Personnel Review, 42(3), 324-348.

DeRouin, R. E., Fritzsche, B. A., \& Salas, E. (2005). E-learning in organizations. Journal of Management, 31(6), 920-940.

Donolo, D., Chiecher, A., \& Rinaudo, C. M. (2004). Estudiantes, estrategias y contextos de aprendizaje presenciales y virtuales. Primer congreso virtual latinoamericano de educación a distancia. Ciudad de México. México.

D’Netto, B., Bakas, F., \& Bordia, P. (2008). Predictors of management development effectiveness: An Australian perspective. International Journal of Training and Development, 12(1), 2-23.

Döös, M., \& Wilhelmson, L. (2011). Collective learning: Interaction and a shared action arena. Journal of Workplace Learning, 23(8), 487-500.

Flavell, J. H. (1970). Developmental studies of mediated memory. In: H. W. Reese \& L. P. Lipsitt (Eds.), Advances in child development and behavior (Vol. 5). New York: Academic Press.

Ford, J. K., \& Kraiger, K. (1995). The application of cognitive constructs and principles to the instructional systems design model of training: Implications for needs assessment, design, and transfer. International Review of Industrial and Organizational Psychology, $10,1-48$.

Freeze, R. D., Alshare, K. A., Lane, P. L., \& Wen, H. J. (2010). IS success model in elearning context based on students' perceptions. Journal of Information Systems Education, 21(2), 173-184.

Garavan, T. N., Carbery, R., O’Malley, G., \& O’Donnell, D. (2010). Understanding participation in e-learning in organizations: A largescale empirical study of employees. International Journal of Training and Development 14(3), 155-168. 
Garrison, D. R., \& Vaughan, N. D. (2008). Blended learning in higher education: Framework, principles and guidelines. São Francisco: Jossey-Bass.

Giangreco, A., Carugati, A., Sebastiano, A., \& Della Bella, D. (2010). Trainees' reactions to training: Shaping groups and courses for happier trainees. The International Journal of Human Resource Management, 21(13), 2468-2487.

Goldstein, I. L. (1991). Training in work organizations. In: Dunnette \& Hough (Orgs.). Handbook of Industrial and Organizational Psychology (pp. 507-619). Palo Alto, California: Consulting Psych.

Ghosh, P., Chauhan, R., \& Rai, A. (2015). Supervisor support in transfer of training: Looking back at past research. Industrial and Commercial Training, 47(4), 201-207.

Griffin, R. (2012). A practitioner friendly and scientifically robust training evaluation approach. Journal of Workplace Learning, 24(6), 393-402.

Grossman, R., \& Salas, E. (2011). The transfer of training: What really matters. International Journal of Training and Development, 15(2), 103-120.

Gunawardena, C. N., Linder-VanBerschot, J. A., LaPointe, D. K., \& Rao, L. (2010). Predictors of learner satisfaction and transfer of learning in a corporate online education program. American Journal of Distance Education, 24, 207-226.

Hair, J. F., Anderson, R. L., Tatham, R. L., \& Black, W. C. (2005). Análise multivariada de dados (5a ed.). Porto Alegre: Bookman.

Hamblin, A. C. (1978). Avaliação e controle do treinamento. São Paulo: McGraw-Hill do Brasil.

Hayes, A. F. (2013). An introduction to mediation, moderation, and conditional process analysis: A regression-based approach. Guilford Press: New York, NY.

Henke, H., \& Russum, J. (2002). Factors influencing attrition rates in a corporate distance education program. Education at a Distance, 14(11).

Hicks, E., Bagg, R., Doyle, W., \& Young, J. D. (2007). Canadian accountants: Examining workplace learning. Journal of Workplace Learning, 19(2), 61-77.

Hillesheim, G. (1998). Distant learning: Barriers and strategies for student and faculty. The Internet and Higher Education, 1, 31-44.

Holladay, C. L., \& Quinones, M. A. (2003). Practice variability and transfer of training: The role of self-efficacy generality. Journal of Applied Psychology, 88(6), 1094-1103.

Holman, D., Epitropaki, O., \& Fernie, S. (2001). Understanding learning strategies in the workplace: A factor analytic investigation. Journal of Occupational and Organizational Psychology, 74, 675-681.

Homklin, T., Takahashi, Y. \& Techakanont, K. (2014). The influence of social and organizational support on transfer of training: Evidence from Thailand. International Journal of Training and Development, 18(2), 116-131. 
Johnson, R. D., Gueutal, H., \& Falbe, C. M. (2009). Technology, trainees, metacognitive activity and e-learning effectiveness. Journal of Managerial Psychology, 24(6), 545-566.

Joo, Y. J., Lim, K. Y., \& Park, S. Y. (2011). Investigating the structural relationships among organizational support, learning flow, learners' satisfaction and learning transfer in corporate e-learning. British Journal of Educational Technology, 42(6), 973-984.

Khasawneh, S., \& Al-Zawahreh, A. (2015). Using the training reactions questionnaire to analyze the reactions of university students undergoing career-related training in Jordan: A prospective human resource development approach. International Journal of Training and Development, 19(1), 53-68.

Klein, H. J., Noe, R. A., \& Wang, C. (2006). Motivation to learn and course outcomes: The impact of delivery mode, learning goal orientation, and perceived barriers and enablers. Personnel Psychology, 59, 665-702.

Lacerda, E. R. M., \& Abbad, G. (2003). Impacto do treinamento no trabalho: Investigando variáveis motivacionais e organizacionais como suas preditoras. Revista de Administração Contemporânea, 7(4), 77-96.

Laros, J. A. (2004). O uso da análise fatorial: Algumas diretrizes para pesquisadores. In: L. Pasquali (Org.). Análise fatorial para pesquisadores. Petrópolis: Laros Vozes.

Lee, Y., \& Choi, J. (2011). A review of online course dropout research: Implications for practice and future research. Education Tech Research, 59, 593-618.

Lee, Y., Tseng, S., Liu, F., \& Liu, S. (2007). Antecedents of learner satisfaction toward e-learning. Journal of American Academy of Business, 11(2), 161-168.

Leung, E. W. C., \& Li, Q. (2006). Distance learning in Hong Kong. International Journal of Distance Education Technologies, 4(3), 1-5.

Levin, J. R. (1986). Four cognitive principles of learning-strategy instruction. Educational Psychologist, 21, 3-17.

Lim, D. H., Morris, M. L., \& Kupritz, V. W. (2007). Online vs. blended learning: Differences in instructional outcomes and learner satisfaction. Journal of Asynchronous Learning Networks, 11(2), 27-42.

Lima, S. M. V., \& Borges-Andrade, J. E. (1985). Meta-análise de avaliação de treinamento. Revista de Administração, 20(3), 39-52.

Lins, M. P. B. E., \& Borges-Andrade, J. E. (2014). Expressão de competências de liderança e aprendizagem no trabalho. Estudos de Psicologia (UFRN), 19, 159-168.

Lissitz, R. W., \& Green, S. B. (1975). Effect of the number of scale points on reliability: A Monte Carlo approach. Journal of Applied Psychology, 60(1), 10-13.

Long, L. K., DuBois, C. Z., \& Faley, R. H. (2008). Online training: The value of capturing trainee reactions. Journal of Workplace Learning, 20(1), 21-37. 
Lu, H. P., \& Chiou, M. J. (2010). The impact of individual differences on e-learning system satisfaction: A contingency approach. British Journal of Educational Technology, 41(2), 307-323.

Marks, R. B., Sibley, S. D., \& Arbaugh, J. B. (2005). A structural equation model of predictors for effective online learning. Journal of Management Education, 29(4), 531563.

Martins, L. B. (2012). Aprendizagem em ações educacionais a distância: Fatores influentes no desempenho acadêmico de universitários. Dissertação de Mestrado, Faculdade de Filosofia, Ciências e Letras de Ribeirão Preto, Universidade de São Paulo.

Martins, L. B., \& Zerbini, T. (2014a). Educação a distância em instituições de ensino superior: Uma revisão das pesquisas. Revista Psicologia: Organizações e Trabalho, 14(3), 271-282.

Martins, L. B., \& Zerbini, T. (2014b). Escala de estratégias de aprendizagem: Evidências de validade em contexto universitário híbrido. Psico-USF, 19(2), 317-328.

Martins, L. B., \& Zerbini, T. (2015). Evidências de validade de instrumentos de reações no ensino superior a distância. Estudos e Pesquisas em Psicologia (UERJ), 15(1), 116134.

Martins, L. L., \& Kellermanns, F. W. (2004). A model of business school students' acceptance of a web-based course management system. Academy of Management Learning and Education, 3, 7-26.

Mathieu, J. E., Tannenbaum, S. I., \& Salas, E. (1992). Influences of individual and situational characteristics on measures of training effectiveness. Academy of Management Journal, 35(4), 828-847.

Mauri, T., \& Onrubia, J. (2010). O professor em ambientes virtuais: Perfil, condições e competências. In: C. Coll \& C. Monereo (Orgs.). Psicologia da Educação virtual Aprender e ensinar com as tecnologias da informação e da comunicação. (pp. 118-135). Porto Alegre: Artmed.

Mauri, T., Onrubia, J., Coll, C., \& Columbia, R. (2005). La calidad de los contenidos educativos reutilizables: Diseño, usabilidad y prácticas de uso. Revista de Educación a Distancia.

Meneses, P. P. M., \& Abbad, G. (2003). Preditores individuais e situacionais de auto e heteroavaliação de impacto do treinamento no trabalho. Revista de Adminstração Contemporânea, 7, ed. especial.

Meneses, P. P. M., \& Abbad, G. (2012). Medidas de insumo: Autoeficácia. In: G. Abbad, L. Mourão, P. P. M. Meneses, T. Zerbini, J. E. Borges-Andrade, R. Vilas-Boas (Orgs.). Medidas de avaliação em treinamento, desenvolvimento e educação: Ferramentas para gestão de pessoas (pp. 190-197). Porto Alegre: Artmed.

Meneses, P. P. M., Abbad, G, Zerbini, T., \& Lacerda, E. (2006). Medidas de características da clientela em avaliação de TD\&E. In: J. E. Borges-Andrade, G. Abbad, L. Mourão (Orgs.). Treinamento, desenvolvimento e educação em organizações e trabalho: Fundamentos para a gestão de pessoas (pp. 422-442). Porto Alegre: Artmed. 
Meneses, P. P. M., \& Zerbini, T. (2005). Levantamento de necessidades de treinamento: Reflexões Atuais [CD-Rom]. In: Associação Nacional dos Programas de Pós-Graduação em Administração (Org.). Anais do XXIX ENANPAD. Brasília: ANPAD.

Meneses, P. P. M., Zerbini, T., \& Abbad, G. (2010). Manual de treinamento organizacional. Porto Alegre: Artmed.

Meneses, P. P. M., Zerbini, T., \& Martins, L. B. (2012). Determinantes situacionais e individuais da aprendizagem em ensino a distância: Desenvolvimento de escala. PSICOPUCRS, 43(2), 208-218.

Moraes, V., \& Borges-Andrade, J. E. (2010a). Aprendizagem relacionada ao trabalho. Revista Psicologia: Organizações e Trabalho, 10, 112-128.

Moraes, V., \& Borges-Andrade, J. E. (2010b). Validação de escala de estratégias de aprendizagem no trabalho entre Prefeitos(as) e Secretários(as) Municipais. Estudos de Psicologia (UFRN), 15, 325-334.

Morgan, R. B., \& Casper, W. J. (2000). Examining the factor structure of participant reactions to training: A multidimensional approach. Human Resource Development Quarterly, 11(3), 301-317.

Mourão, L. (2004). Avaliação de programas públicos de treinamento: Um estudo sobre o impacto no trabalho e na geração de emprego. Tese de Doutorado, Instituto de Psicologia, Universidade de Brasília.

Mourão, L., Abbad, G., \& Zerbini, T. (2014). Avaliação da efetividade e dos preditores de um treinamento a distância em uma instituição bancária de grande porte. RAUSPRevista de Administração, 49(3), 534-548.

Nijman, D. J. M., Nijhof, W. J., Wognum, A. A. M., \& Veldkamp, B. P. (2006). Exploring differential effects of supervisor support on transfer of training. Journal of European Industrial Training, 30(7), 529-549.

Nogueira, R. S. F. (2006). Efeitos do tempo de exposição ao feedback na aprendizagem em treinamento baseado na web. Dissertação de mestrado. Universidade de Brasília, Brasília.

Oliveira, K. C., Boruchovitch, E., \& Santos, A. A. A. (2009). Estratégias de aprendizagem e desempenho acadêmico: Evidências de validade. Psicologia: Teoria e pesquisa, 25(4), 531-536.

Onrubia, J. (2005). Aprender en entornos virtuales de enseñanza y aprendizaje: Actividad conjunta, ayuda pedagógica y construcción del conocimiento. RED: Revista de Educación a Distancia, monográfico II.

Özkan, S., Köseler, R., \& Baykal, N. (2009). Evaluating learning management systems; adoption of hexagonal e-learning assessment model in higher education. Transforming Government: People, Process and Policy, 3(2), 111-130. 
Pantoja, M. J. (2004). Estratégias de aprendizagem no trabalho e percepções de suporte à aprendizagem - uma análise multinível. Tese de Doutorado, Instituto de Psicologia, Universidade de Brasília.

Pantoja, M. J., \& Borges-Andrade, J. E. (2009). Estratégias de aprendizagem no trabalho em diferentes ocupações profissionais. RAC-Eletrônica, 3(1), 41-62.

Pantoja, M. J., Porto, J. B., Mourão, L., \& Borges-Andrade, J. E. (2005). Valores, suporte psicossocial e impacto do treinamento no trabalho. Estudos de Psicologia (Natal), 10(2), 255-265.

Pasquali, L. (2004). Análise fatorial para pesquisadores. Petrópolis: Vozes.

Pereira, S. (2009). Avaliação de efeitos de uma ação de TD\&E no desempenho de egressos e da organização. Dissertação de Mestrado, Instituto de Psicologia, Universidade de Brasília.

Pham, N. T. P., Segers, M. S. R., \& Gijselaers, W. H. (2012). Effects of work environment on transfer of training: Empirical evidence from Master of Business Administration programs in Vietnam. International Journal of Training and Development, 17(1), 1-19.

Pilati, R. (2004). Modelo de efetividade do treinamento no trabalho: Aspectos dos treinandos e moderação do tipo de treinamento. Tese de Doutorado, Instituto de Psicologia, Universidade de Brasília.

Pilati, R., \& Abbad, G. S. (2005). Análise fatorial confirmatória da escala de impacto no treinamento no trabalho. Psicologia: Teoria e Pesquisa, 21(1), 43-51.

Pilati, R., \& Borges-Andrade, J. E. (2005). Estratégias para aplicação no trabalho do aprendido em treinamento: Proposição conceitual e desenvolvimento de uma medida. Psicologia: Reflexão e Crítica, 18(2), 207-214.

Pilati, R., \& Borges-Andrade, J. E. (2006). Construção de medidas e delineamentos em avaliação de TD\&E. In: J. E. Borges-Andrade, G. Abbad, L. Mourão \& colaboradores. Treinamento, desenvolvimento e educação em organizações e trabalho: Fundamentos para a gestão de pessoas (pp. 359-384). Porto Alegre: Artmed.

Pilati, R., \& Borges-Andrade, J. E. (2012). Training effectiveness: Transfer strategies, perception of support and worker commitment as predictors. Revista de Psicología del Trabajo y de las Organizaciones, 28(1), 25-35.

Pilati, R, \& Gonzaléz, C. P. (2009). Validación y test de la equivalencia de la estructura factorial de la escala de estrategias de aplicación de lo aprendido. Revista Interamericana de Psicología/Interamerican Journal of Psychology, 43(1), 39-48.

Preacher, K. J., \& Hayes, A. F. (2004). SPSS and SAS procedures for estimating indirect effects in simple mediation models. Behavior Research Methods, Instruments, \& Computers, Austin, 36(4), 717-731. 
Preston, C. C., \& Colman, A. M. (2000). Optimal number of response categories in rating scales: Reliability, validity, discriminating power, and respondent preferences. Acta Psychologica, 104, 1-15.

Ramayah, T., Ahmad, N. H., \& Hong, T. S. (2012). An assessment of e-training effectiveness in multinational companies in Malaysia. Journal of Educational Technology \& Society, 15(2), 125-137.

Rios, J., \& Wells, C. (2014). Validity evidence based on internal structure. Psicothema, 26(1), 108-116.

Riveiro, J. M. S., \& Nieto, D. A. (2004). Educación a distancia y presencial: Diferencias en los componentes cognitivo y motivacional de estudiantes universitarios. Revista Iberoamericana de Educación a Distancia, 7(1/2), 65-75.

Roszkowski, M. J., \& Sovon, M. (2010). Did you learn something useful today? An analysis of how perceived utility relates to perceived learning and their predictiveness of satisfaction with training. Performance Improvement Quarterly, 23(2), 71-91.

Ruth, D., \& Conners, S. E. (2010). Distance learning in a core business class: Determinants of success in learning outcomes and post-course performance. Academy of Educational Leadership, 15(1), 50-56.

Sahin, I., \& Shelley, M. (2008). Considering students' perceptions: The distance education student satisfaction model. Educational Technology \& Society, 11(3), 216-223.

Salas, E., \& Cannon-Bowers, J. A. (2001). The science of training: A decade of progress. Annual Review of Psychology, 52, 471-499.

Salas, E., Tannenbaum, S. I., Kraiger, K., \& Smith-Jentsch, K. A. (2012). The science of training and development in organizations: What matters in practice. Psychological Science in the Public Interest, 13(2), 74-101.

Sales, P. A. O. (2009). Evasão em cursos a distância: Motivos relacionados às características do curso, do aluno e do contexto de estudo. Dissertação de Mestrado, Instituto de Psicologia, Universidade de Brasília.

Sallorenzo, L. H. (2000). Avaliação de impacto de treinamento no trabalho: Analisando e comparando modelos de predição. Dissertação de Mestrado, Instituto de Psicologia, Universidade de Brasília.

Santos, A. A. A., Boruchovitch, E., Primi, R., Zenorini, R. P. C., \& Bueno, J. M. H (2004). Escala de avaliação de estratégias de aprendizagem para universitários (EAP-U): Aplicação do Modelo de Rasch de créditos parciais. Braga-PT: Psicologia: Teoria, Investigação e Prática, 9(2), 227-242.

Shen, Q., Chung, J. K. H., Challis, D., \& Cheung, R. C. T. (2007). A comparative study of student performance in traditional mode and online mode of learning. Computer Applications in Engineering Education, 15(1), 30-40.

Shin, N., \& Kim, J. (1999). An exploratory of learner progress and drop-out in Korea 
National Open University. Distance Education, 20(3), 81-95.

Silva, A. (2004). Avaliação de uma disciplina semipresencial de graduação ofertada por meio da internet pela Universidade de Brasília. Dissertação de Mestrado, Instituto de Psicologia, Universidade de Brasília.

Simosi, M. (2012). Disentangling organizational support construct: The role of different sources of support to newcomers' training transfer and organizational commitment. Personnel Review, 41(3), 301-320.

Siqueira, M. M. M. (2008) (Org.). Medidas do comportamento organizacional: Ferramentas de diagnóstico e de gestão. Porto Alegre: Artmed.

Siqueira, M. M. M. (2014) (Org.). Novas medidas do comportamento organizacional: Ferramentas de diagnóstico e de gestão. Porto Alegre: Artmed.

Siritongthaworn, S., \& Krairit, D. (2006). Satisfaction in e-learning: The context of supplementary instruction. Campus - Wide Information Systems, 23(2), 76-91.

Sonnentag, S., Niessen, C., \& Ohly, S. (2004). Learning at work: Training and development. In C. L. Cooper \& I. T. Robertson (Orgs.), International Review of Industrial and Organizational Psychology, 19, 249-289.

Souza, L. F. N. I. (2010). Estratégias de aprendizagem e fatores motivacionais relacionados. Educar, 36, 95-107.

Tabachnick, B. G., \& Fidell, L. S. (2007). Using multivariate statistics. New York: Harper-Collins College Publishers.

Tamayo, N. (2002). Autoconceito profissional, suporte à transferência e impacto de treinamento no trabalho. Dissertação de Mestrado, Instituto de Psicologia, Universidade de Brasília.

Tannenbaum, S. I., \& Yukl, G. (1992). Training and development in work organizations. Annual Review of Psychology, 43, 399-441.

Teo, T., \& Wong, S. L. (2013). Modeling key drivers of e-learning satisfaction among student teachers. Journal of Educational Computing Research, 48(1), 71-95.

Testa, M. G., \& Luciano, E. M. (2010). A influência da autorregulação dos recursos de aprendizagem na efetividade dos cursos desenvolvidos em ambientes virtuais de aprendizagem na Internet. Revista Eletrônica de Administração, 16(2), 176-208.

Tien-Chen, C. (2012). Computer self-efficacy and factors influencing e-learning effectiveness. European Journal of Training and Development, 36(7), 670-686.

Tichon, J. G. (2007). Using presence to improve a virtual training environment. Cyberpsychology \& Behavior, 10, 781-788.

Tracey, J. B., \& Tews, M. J. (2005). Construct validity of a general training climate scale. Organizational Research Methods, 8, 353-74. 
Umekawa, E. E. R. (2013). Preditores de fatores relacionados à evasão e à persistência discente em ações educacionais a distância. Dissertação de Mestrado, Faculdade de Filosofia, Ciências e Letras de Ribeirão Preto, Universidade de São Paulo.

Van den Bossche, P., Segers, M., \& Jansen, N. (2010). Transfer of training: The role of feedback in supportive social networks. International Journal of Training \& Development, 14, 81-94.

Vargas, M. R. M. (2002). Educação a distância e as novas tecnologias: O uso da videoconferência em treinamentos organizacionais. Revista Brasileira de Aprendizagem Aberta e a Distância, 1 .

Vaughan, N. (2007). Perspectives on blended learning in higher education. International Journal on E-learning, 6(1), 81-94.

Vaughan, K., \& MacVicar, A. (2004). Employees' pre-implementation attitudes and perceptions to e-learning: A banking case study analysis. Journal of European Industrial Training, 28(5), 400-413.

Velada, R., Caetano, A., Michel, J. W., Lyons, B. D., \& Kavanagh, M. J. (2007). The effects of training design, individual characteristics and work environment on transfer of training. International Journal of Training and Development, 11(4), 282-294.

Vo, A. N., \& Hannif, Z. N. (2012). The transfer of training and development practices in Japanese subsidiaries in Vietnam. Asia Pacific Journal of Human Resources, 50(1), 7591.

Vovides, Y., Sanchez-Alonso, S., Mitropoulou, V., \& Nickmans, G. (2007). The use of e-learning course management system to support learning strategies and to improve selfregulated learning. Educational Research Review, 2(1), 64-74.

Wang, Y., \& Haggerty, N. (2009). Knowledge transfer in virtual settings: The role of individual virtual competency. Information Systems Journal, 19, 571-593.

Warr, P., \& Allan, C. (1998). Learning strategies and occupational training. International Review of Industrial and Organizational Psychology, 13, 83-121.

Warr, P., \& Bunce, D. (1995). Trainee characteristics and outcomes of open learning. Personnel Psychology, 48, 347-375.

Warr, P., \& Downing, J. (2000). Learning strategies, learning anxiety and knowledge acquisition. British Journal Psychology, 91, 311-333.

Weijters, B., Cabooter, E., \& Schillewaert, N. (2010). The effect of rating scale format on response styles: The number of response categories and response category labels. Intern. J. of Research in Marketing, 27, 236-247.

Wexley, K. N. (1984). Personnel training. Annual Review of Psychology, 35, 519-551.

Womble, J. (2008). E-learning: The relationship among learner satisfaction, self-efficacy, and usefulness. The Business Review, Cambridge, 10(1), 182-188. 
Xenos, M., Pierrakeas, C., \& Pintelas, P. (2002). A survey on student dropout rates and dropout causes concerning the students in the Course of Informatics of the Hellenic Open University. Computers \& Education, 39, 361-377.

Yarnall, J. (1998). Line managers as career developers: Rhetoric or reality?. Personnel Review, 27(2), 378-95.

Zabalza, M. (2005). O ensino universitário: Seu cenário e seus protagonistas. Porto Alegre: Artmed.

Zerbini, T. (2007). Avaliação da transferência de treinamento em curso a distância. Tese de Doutorado, Instituto de Psicologia, Universidade de Brasília.

Zerbini, T., Carvalho, R. S., \& Abbad, G. (2005). Treinamento a distância via internet: Construção e validação de escala de estratégias de aprendizagem [CD-Rom]. Em Associação Nacional dos Programas de Pós-Graduação em Administração (Org.). Anais do XXIX ENANPAD. Brasília: ANPAD.

Zerbini, T., \& Abbad, G. (2005). Impacto de treinamento no trabalho via internet. Revista de Administração de Empresas - RAE- eletrônica, 4(2).

Zerbini, T., \& Abbad, G. (2008a). Estratégias de aprendizagem em curso a distância: Validação de uma escala. Psico-USF, 13, 177-187.

Zerbini, T., \& Abbad, G. (2008b). Qualificação profissional a distância: Ambiente de estudo e procedimentos de interação - validação de uma escala. Análise, 19(1), 148-172.

Zerbini, T., \& Abbad, G. (2009a). Reação ao desempenho do tutor em um curso a distância - validação de uma escala. Estudos e Pesquisas em Psicologia, 9, 447-463.

Zerbini, T., \& Abbad, G. (2009b). Reação aos procedimentos instrucionais de um curso via internet: Validação de uma escala. Estudos de Psicologia (Campinas), 26(3), 363371.

Zerbini, T., \& Abbad, G. (2010a). Qualificação profissional a distância: Avaliação da transferência de treinamento. Paideia, 20, 313-323.

Zerbini, T., \& Abbad, G. (2010b). Transferência de treinamento e impacto do treinamento no trabalho: Análise crítica da literatura. Revista Psicologia: Organizações e Trabalho, 10(2), 97-111.

Zerbini, T., \& Abbad, G. (2010c). Reações em cursos a distância: Revisão da literatura. Revista PSICO, 41, 192-200.

Zerbini, T., Abbad, G., Mourão, L., \& Martins, L. B. (2015). Estratégias de aprendizagem em um curso corporativo a distância: Como estudam os trabalhadores? Psicologia: Ciência e Profissão, 35(4), 1024-1041.

Zerbini, T., Carvalho, R. S., \& Abbad, G. (2005). Treinamento a distância via internet: Construção e validação de escala de estratégias de aprendizagem [CD-Rom]. In: 
Associação Nacional dos Programas de Pós-Graduação em Administração (Org.). Anais do XXIX ENANPAD. Brasília: ANPAD.

Zerbini, T., Coelho, F. A., Abbad, G. S., Mourão, L., Alvim, S., \& Loiola, E. (2012a). Transferência de treinamento e impacto do treinamento em profundidade. In: G. S. Abbad, L. Mourão, P. P. M. Meneses, T. Zerbini, J. E. Borges-Andrade, R. Vilas-Boas (Orgs.). Medidas de avaliação em treinamento, desenvolvimento e educação: Ferramentas para gestão de pessoas (pp. 127-144). Porto Alegre: Artmed.

Zumrah, A. R., \& Boyle, S. (2015). The effects of perceived organizational support and job satisfaction on transfer of training. Personnel Review, 44(2), 254-236. 


\section{Anexos}

\section{ANEXO A - TERMO DE CONSENTIMENTO LIVRE E ESCLARECIDO}

Prezado(a) participante,

Convido-o(a) a participar voluntariamente da pesquisa intitulada "Impacto do treinamento no trabalho: determinantes individuais e contextuais em cursos a distância" que faz parte do meu projeto de Doutorado desenvolvido no Programa de Pós-Graduação em Psicologia da Faculdade de Filosofia, Ciências e Letras de Ribeirão Preto da Universidade de São Paulo (FFCLRP-USP).

O objetivo do estudo é propor e testar um modelo de avaliação de ações educacionais corporativas ofertadas a distância, no qual seja possível identificar fatores que influenciam na efetividade de treinamentos dessa natureza, entre variáveis do indivíduo, de reação ao curso e do ambiente. Os resultados obtidos contribuirão com os estudos na área de avaliação de ações educacionais a distância, principalmente em contextos corporativos.

Para obter as informações necessárias, solicito a sua colaboração para responder a um conjunto de questionários que serão aplicados virtualmente. Como forma de sigilo, as informações coletadas serão tratadas de forma agrupada, o que garantirá a confidencialidade de suas respostas e seu nome não será utilizado em qualquer fase da pesquisa, garantindo seu anonimato.

Informamos que não há quaisquer custos, gastos ou riscos na sua participação no estudo; não estão previstos ressarcimentos ou indenizações, e não haverá benefícios imediatos decorrentes da sua participação. Reafirmo que a sua participação é voluntária e você poderá se recusar a participar da pesquisa, retirar seu consentimento, ou ainda descontinuar sua participação a qualquer momento.

Coloco-me à disposição para mais informações pelo e-mail lara_bmartins@ @otmail.com. Outros esclarecimentos sobre a pesquisa, favor entrar em contato com a Prof. ${ }^{a}$ Dr. ${ }^{a}$ Thaís Zerbini, responsável pela orientação do projeto de pesquisa doutoral: (16) 3602-4687/ thaiszerbini@ffclrp.usp.br.

Para esclarecer eventuais dúvidas sobre questões éticas do projeto, consultar o Comitê de Ética em Pesquisa da FFCLRP-USP: Avenida Bandeirantes, 3900 - Bloco 23 - Casa 37 14040-901 - Ribeirão Preto - SP - Brasil. Fone: (16) 3315-4811 / Fax: (16) 3633-2660. E-mail: coetp@ffclrp.usp.br

Confirmo que entendi os objetivos da pesquisa, bem como a forma de participação e suas condições. Li e compreendi este Termo de Consentimento Livre e Esclarecido, portanto, concordo em dar meu consentimento para participar como voluntário da pesquisa e autorizo o uso das informações no estudo. 
Os itens do questionário indicam possíveis comportamentos utilizados por você durante o curso. Leia os itens listados e escolha o ponto da escala $(1,2,3,4$ ou 5) que representa a frequência com que você se comportou da maneira descrita em cada item, registrando sua resposta na coluna à direita (Nota).

\begin{tabular}{|c|c|c|c|c|}
\hline 1 & 2 & 3 & 4 & 5 \\
Nunca & Raramente & Às vezes & Frequentemente & Sempre \\
\hline
\end{tabular}

\begin{tabular}{|c|c|}
\hline Itens & Nota \\
\hline 1. Mantive a calma quando tive dificuldades durante o curso. & \\
\hline 2. Mantive a calma com a possibilidade de ter um rendimento abaixo do esperado. & \\
\hline 3. Mantive a calma diante dos erros que cometi ao realizar atividades do curso. & \\
\hline 4. Esforcei-me mais quando percebi que estava perdendo a concentração. & \\
\hline 5. Esforcei-me mais quando percebi que estava perdendo o interesse no assunto. & \\
\hline $\begin{array}{l}\text { 6. Esforcei-me para verificar minha compreensão sobre o que estava sendo } \\
\text { ensinado. }\end{array}$ & \\
\hline $\begin{array}{l}\text { 7. Busquei auxílio do tutor para esclarecer minhas dúvidas sobre os conteúdos do } \\
\text { curso. }\end{array}$ & \\
\hline $\begin{array}{l}\text { 8. Busquei auxílio de colegas para esclarecer minhas dúvidas sobre os conteúdos } \\
\text { do curso. }\end{array}$ & \\
\hline $\begin{array}{l}\text { 9. Busquei solucionar minhas dúvidas ao consultar os materiais didáticos do } \\
\text { curso. }\end{array}$ & \\
\hline $\begin{array}{l}\text { 10. Busquei compreender melhor os conteúdos ao estudá-los nos materiais } \\
\text { didáticos do curso. }\end{array}$ & \\
\hline $\begin{array}{l}\text { 11. Busquei outras fontes de pesquisa relacionadas ao curso para me ajudar a } \\
\text { aprender. }\end{array}$ & \\
\hline $\begin{array}{l}\text { 12. Tentei entender o conteúdo ao aplicá-lo na prática, ao invés de dedicar tempo } \\
\text { lendo ou pedindo ajuda a alguém. }\end{array}$ & \\
\hline $\begin{array}{l}\text { 13. Realizei os exercícios práticos propostos ao longo do curso para me ajudar a } \\
\text { aprender. }\end{array}$ & \\
\hline 14. Li o conteúdo do curso várias vezes como método para aprender. & \\
\hline $\begin{array}{l}\text { 15. Repeti mentalmente os conteúdos do curso que gostaria de aprender até } \\
\text { perceber que havia entendido. }\end{array}$ & \\
\hline $\begin{array}{l}\text { 16. Fiz anotações, resumos e/ou esquemas dos conteúdos do curso como método } \\
\text { para aprender. }\end{array}$ & \\
\hline 17. Refleti sobre as implicações que os conteúdos aprendidos poderiam ter. & \\
\hline 18. Identifiquei situações diárias em que eu pudesse aplicar os conteúdos do curso. & \\
\hline $\begin{array}{l}\text { 19. Busquei desenvolver uma ideia global sobre como os conteúdos do curso se } \\
\text { relacionavam entre si. }\end{array}$ & \\
\hline 20. Associei os conteúdos do curso aos meus conhecimentos anteriores. & \\
\hline 21. Revisei os conteúdos relativos aos exercícios em que cometi erros. & \\
\hline
\end{tabular}




\section{CUESTIONARIO DE ESTRATEGIAS DE APRENDIZAJE}

Los ítems del cuestionario indican posibles comportamientos utilizados por usted durante el curso. Lea los ítems enumerados y seleccione el punto de la escala $(1,2,3,4$ ó 5) que representa la frecuencia con la que usted se comportó de la manera descrita en cada ítem, mediante el registro de su respuesta en la columna de la derecha (Puntuación).

\begin{tabular}{|c|c|c|c|c|}
\hline 1 & 2 & 3 & 4 & 5 \\
Nunca & Raramente & A veces & A menudo & Siempre \\
\hline
\end{tabular}

\begin{tabular}{|c|c|}
\hline Ítems & Puntuación \\
\hline 1. Mantuve la calma cuando tuve dificultades durante la formación. & \\
\hline $\begin{array}{l}\text { 2. Mantuve la calma ante la amenaza de tener un rendimiento inferior al } \\
\text { esperado. }\end{array}$ & \\
\hline $\begin{array}{l}\text { 3. Mantuve la calma con los errores que cometí en las actividades de la } \\
\text { formación. }\end{array}$ & \\
\hline $\begin{array}{l}\text { 4. Me esforcé más cuando me di cuenta de que estaba perdiendo la } \\
\text { concentración. }\end{array}$ & \\
\hline $\begin{array}{l}\text { 5. Me esforcé más cuando me di cuenta de que estaba perdiendo el interés } \\
\text { en el tema. }\end{array}$ & \\
\hline 6. Me esforcé para verificar si entendía lo que se enseñaba. & \\
\hline $\begin{array}{l}\text { 7. Solicité la ayuda del tutor para aclarar mis dudas sobre los contenidos } \\
\text { de la formación. }\end{array}$ & \\
\hline $\begin{array}{l}\text { 8. Pedí la ayuda de mis compañeros para aclarar mis dudas sobre los } \\
\text { contenidos de la formación. }\end{array}$ & \\
\hline $\begin{array}{l}\text { 9. Busqué la solución a mis dudas al consultar el material didáctico de la } \\
\text { formación. }\end{array}$ & \\
\hline $\begin{array}{l}\text { 10. Busqué comprender los contenidos al estudiarlos en el material } \\
\text { didáctico de la formación. }\end{array}$ & \\
\hline $\begin{array}{l}\text { 11. Busqué otras fuentes de información relacionadas con la formación para } \\
\text { ayudarme a aprender. }\end{array}$ & \\
\hline $\begin{array}{l}\text { 12. Busqué comprender el contenido aplicándolo en la práctica, en lugar de } \\
\text { pasar el tiempo leyendo o pidiendo ayuda a alguien. }\end{array}$ & \\
\hline $\begin{array}{l}\text { 13. Realicé los ejercicios prácticos propuestos a lo largo del curso para } \\
\text { ayudarme a aprender. }\end{array}$ & \\
\hline $\begin{array}{l}\text { 14. Leí el contenido de la formación varias veces como un método para } \\
\text { aprender. }\end{array}$ & \\
\hline $\begin{array}{l}\text { 15. Repetí mentalmente el contenido de la formación que tenía que aprender } \\
\text { hasta que me diera cuenta de que lo entendía. }\end{array}$ & \\
\hline $\begin{array}{l}\text { 16. Hice anotaciones, resúmenes y/o esquemas de los contenidos de la } \\
\text { formación como un método para aprender. }\end{array}$ & \\
\hline 17. Ponderé las implicaciones que los contenidos aprendidos podrían tener. & \\
\hline $\begin{array}{l}\text { 18. Identifiqué situaciones cotidianas en las que yo podría aplicar el } \\
\text { contenido de la formación. }\end{array}$ & \\
\hline $\begin{array}{l}\text { 19. Intenté hacerme una idea general del contenido de la formación } \\
\text { asociando elementos entre sí. }\end{array}$ & \\
\hline 20. Asocié el contenido de la formación a mis conocimientos previos. & \\
\hline 21. Revisé los contenidos relativos a los ejercicios en que cometí errores. & \\
\hline
\end{tabular}




\section{ANEXO C - QUESTIONÁRIO DE REAÇÃO AOS PROCEDIMENTOS INSTRUCIONAIS}

Utilize a escala abaixo para avaliar a qualidade dos procedimentos instrucionais do curso realizado. Leia atentamente os itens listados e escolha o ponto da escala $(1,2,3,4$ ou 5) que melhor representa a sua opinião sobre cada aspecto e registre sua resposta na coluna à direita (Nota).

\begin{tabular}{|c|c|c|c|c|}
1 & 2 & 3 & 4 & 5 \\
Muito ruim & Ruim & $\begin{array}{c}\text { Nem ruim, nem } \\
\text { boa }\end{array}$ & Boa & Muito boa \\
\hline
\end{tabular}

\begin{tabular}{|c|c|c|}
\hline Itens & & Nota \\
\hline & Programação das atividades. & \\
\hline & Atividades, conteúdos, leituras. & \\
\hline 3. & Interação interpessoal entre participantes. & \\
\hline 4. & Recursos didáticos virtuais disponíveis (fóruns, chats, etc.). & \\
\hline & $\begin{array}{l}\text { Informações disponibilizadas no ambiente virtual do curso (novidades, } \\
\text { lembretes, links, etc.). }\end{array}$ & \\
\hline
\end{tabular}

\section{CUESTIONARIO DE REACCIÓN A LOS PROCEDIMIENTOS DE FORMACIÓN}

Utilice la siguiente escala para evaluar la calidad de los procedimientos de instrucción de la formación realizada. Lea los ítems enumerados y seleccione el punto de la escala (1, 2, 3, 4 ó 5) que mejor represente su opinión sobre cada uno de los aspectos y registre su respuesta en la columna de la derecha (Puntuación).

\begin{tabular}{|c|c|c|c|c|}
\hline 1 & 2 & 3 & 4 & 5 \\
Muy mala & Mala & $\begin{array}{c}\text { Ni mala, ni } \\
\text { buena }\end{array}$ & Buena & Muy buena \\
\hline
\end{tabular}

\begin{tabular}{|c|c|c|}
\hline Ítems & & Puntuación \\
\hline 1. & Programación de las actividades. & \\
\hline & Actividades, contenidos, lecturas. & \\
\hline 3. & Interacción interpersonal entre los participantes. & \\
\hline 4. & Los recursos de aprendizaje virtuales disponibles (foros, chats, etc.). & \\
\hline & $\begin{array}{l}\text { La información disponible en el entorno virtual de la formación } \\
\text { (noticias, recordatorios, enlaces, etc.). }\end{array}$ & \\
\hline
\end{tabular}




\section{ANEXO D - QUESTIONÁRIO DE REAÇÃO AO DESEMPENHO DO TUTOR}

Utilize a escala abaixo para avaliar a qualidade do desempenho do tutor durante o curso realizado. Leia atentamente os itens listados e escolha o ponto da escala $(1,2,3,4$ ou 5) que melhor representa a sua opinião sobre cada aspecto e registre sua resposta na coluna à direita (Nota).

\begin{tabular}{|c|c|c|c|c|}
\hline 1 & 2 & 4 & 5 \\
Muito ruim & Ruim & $\begin{array}{c}\text { Nem ruim, nem } \\
\text { boa }\end{array}$ & Boa & Muito boa \\
\hline
\end{tabular}

\begin{tabular}{|c|c|c|}
\hline Itens & & Nota \\
\hline 1. & Incentivo à discussão dos participantes nos fóruns. & \\
\hline 2. & Relacionamento interpessoal com os participantes. & \\
\hline & $\begin{array}{l}\text { Compromisso com as atividades de tutoria (disponibilidade, pontualidade, } \\
\text { linguagem, participação das atividades, etc.). }\end{array}$ & \\
\hline & Respeito ao ritmo de aprendizagem dos participantes. & \\
\hline & Articulação entre teoria e prática em suas explicações. & \\
\hline & Esclarecimento das dúvidas dos participantes. & \\
\hline
\end{tabular}

\section{CUESTIONARIO DE REACCIÓN A LA CALIDAD DEL TUTOR}

Utilice la siguiente escala para evaluar la calidad del rendimiento del tutor durante la formación realizada. Lea los ítems enumerados y seleccione el punto de la escala $(1,2,3,4$ ó 5) que mejor represente su opinión sobre cada uno de los aspectos y registre su respuesta en la columna de la derecha (Puntuación).

\begin{tabular}{|c|c|c|c|c|}
\hline 1 & 2 & 3 & 4 & 5 \\
Muy mala & Mala & $\begin{array}{c}\text { Ni mala, ni } \\
\text { buena }\end{array}$ & Buena & Muy buena \\
\hline
\end{tabular}

\begin{tabular}{|c|c|}
\hline Ítems & Puntuación \\
\hline 1. Promover la discusión de los participantes en los foros. & \\
\hline 2. Facilitar las relaciones interpersonales con los participantes. & \\
\hline $\begin{array}{l}\text { 3. Comprometerse con las actividades de tutoría (disponibilidad, } \\
\text { puntualidad, lenguaje, participación en las actividades, etc.). }\end{array}$ & \\
\hline 4. Respeto al ritmo de aprendizaje de los participantes. & \\
\hline 5. Articulación entre teoría y práctica en sus explicaciones. & \\
\hline 6. Esclarecimiento de las dudas de los participantes. & \\
\hline
\end{tabular}




\section{ANEXO E - QUESTIONÁRIO DE SUPORTE À TRANSFERÊNCIA}

Os itens do questionário indicam comportamentos de supervisores e/ou colegas para apoiar o uso de novas habilidades aprendidas em treinamento no ambiente de trabalho e o suporte fornecido pela organização. Utilize a escala abaixo para avaliar: a) o apoio psicossocial oferecido pelos seus supervisores e/ou colegas e b) o suporte material fornecido pela organização. Leia atentamente os itens listados e escolha o ponto da escala $(1,2,3,4$ ou 5) que representa a frequência com que supervisores, colegas e organização ofereceram os apoios descritos em cada item. Para avaliar o suporte psicossocial, marque sua resposta na coluna correspondente (coluna $\mathrm{S}$ = supervisores e coluna $\mathrm{C}=$ colegas) e para avaliar o suporte material, registre sua resposta na coluna à direita (Nota) aos itens que descrevem tais aspectos.

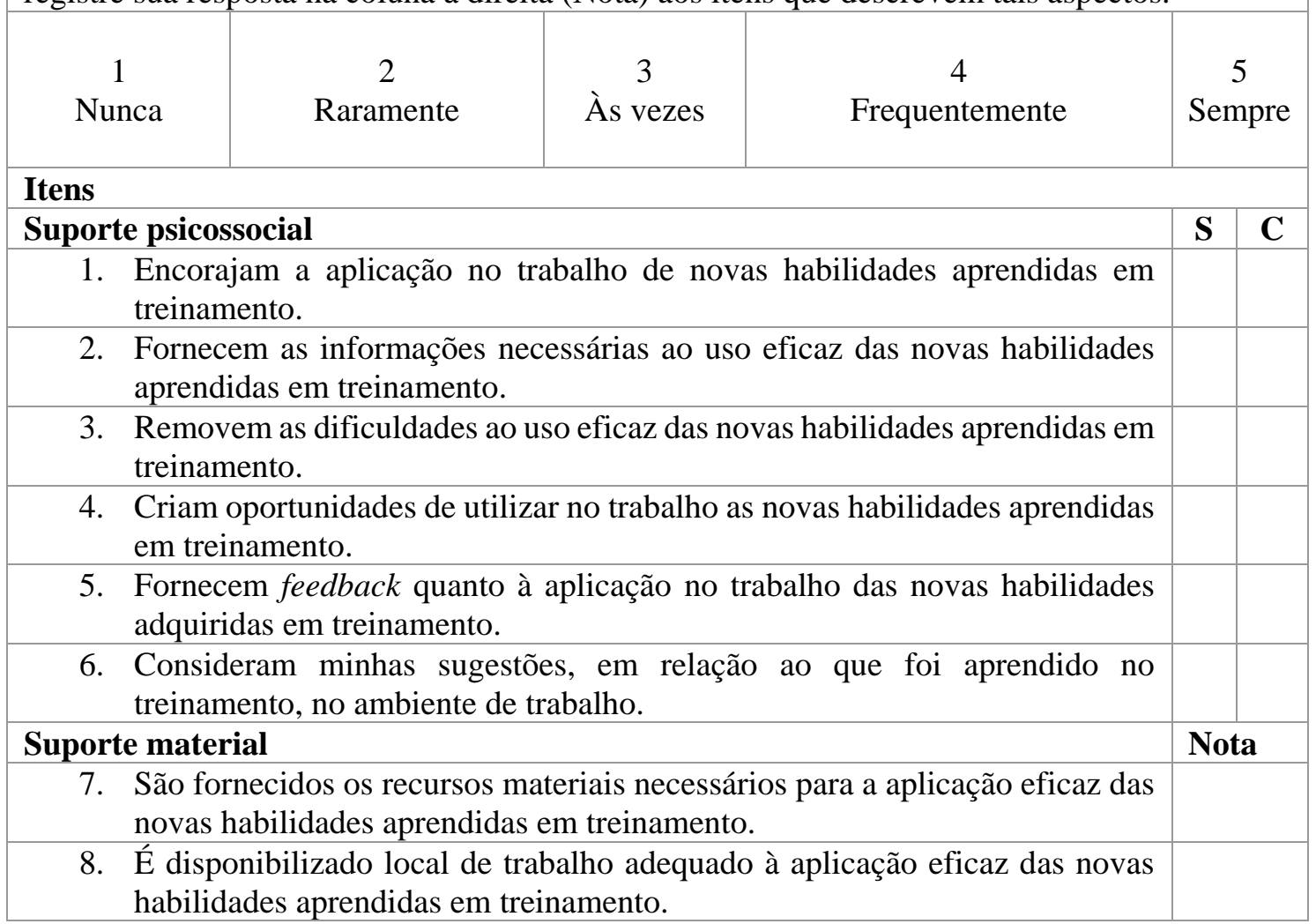




\section{CUESTIONARIO DE APOYO A LA TRANSFERENCIA}

Los ítems del cuestionario indican comportamientos de los supervisores y/o compañeros de trabajo para apoyar el uso de las nuevas habilidades aprendidas en la formación en el lugar de trabajo y el apoyo prestado por la organización. Utilice la siguiente escala para evaluar: a) el apoyo psicosocial ofrecido por sus supervisores y/o compañeros de trabajo y b) el apoyo material proporcionado por la organización. Lea los ítems enumerados y seleccione el punto de la escala $(1,2,3,4$ ó 5) que representa la frecuencia con la que los supervisores, colegas y la organización le ofrecen el apoyo descrito en cada ítem. Para evaluar el apoyo psicosocial, marque su respuesta en la columna correspondiente (columna $\mathrm{S}=$ supervisores y columna $\mathrm{C}=$ colegas) y para evaluar el apoyo material, registre su respuesta en la columna de la derecha (Puntuación) a los ítems que describen estos aspectos.

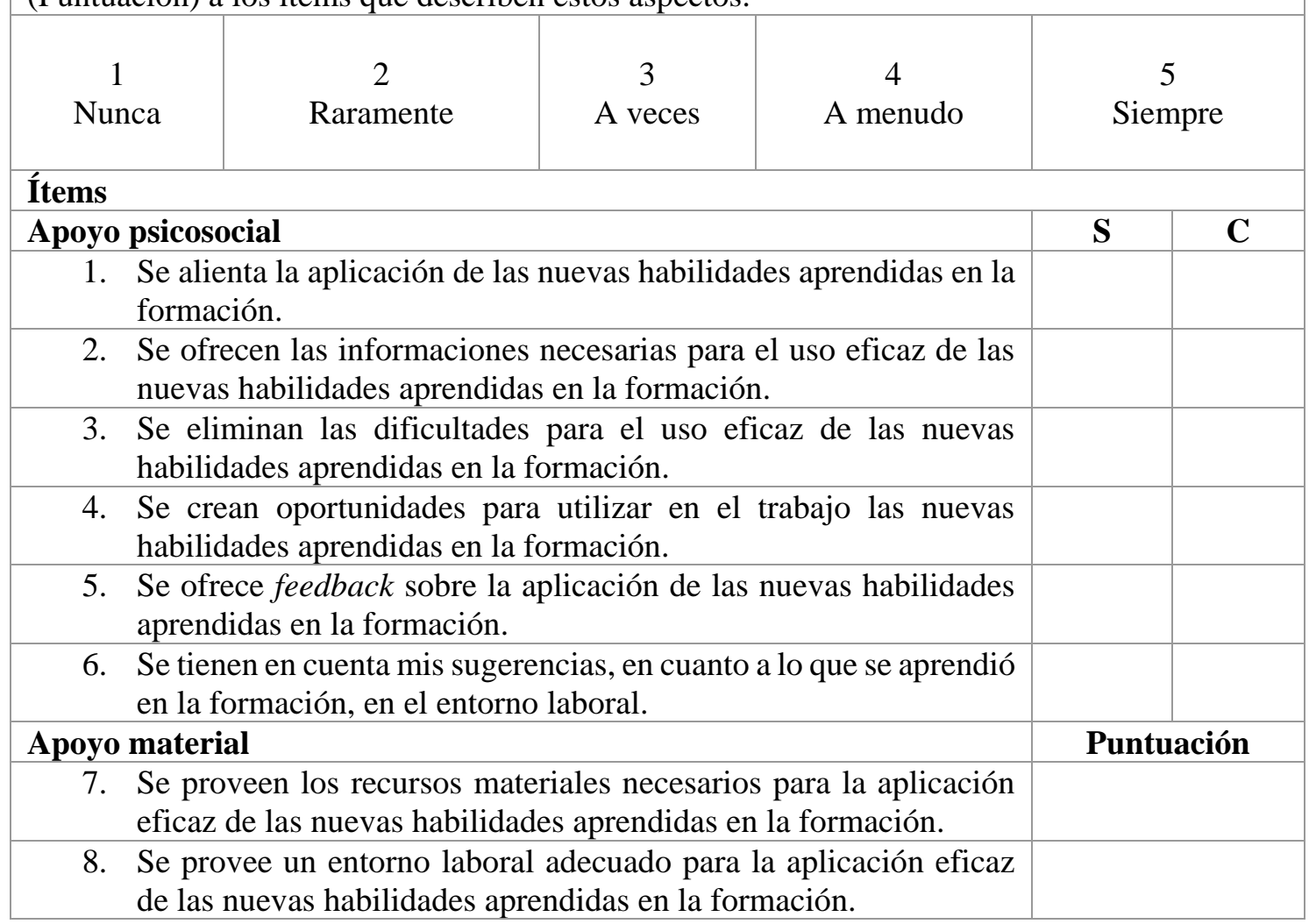


Os itens do questionário indicam fatores que podem ter auxiliado ou prejudicado o seu desempenho durante o treinamento a distância. Leia os itens listados e escolha o ponto da escala $(1,2,3,4$ ou 5) que representa o quanto cada fator dificultou o seu desempenho, ou seja, atuou como uma barreira durante o curso, e registre sua resposta na coluna à direita (Nota).

1

Dificultou totalmente o desempenho
2

Dificultou muito
3

Nem muito, nem pouco
4

Dificultou pouco
5

Não dificultou o desempenho

\section{Itens}

1. Promoção da interação social entre os participantes do curso por parte do tutor.

2. Utilização das ferramentas web (chats, e-mails, fóruns, etc.) para comunicação com tutores e colegas.

3. Relação entre alunos e tutores quanto ao processo de aprendizagem ao longo do curso.

4. Orientações prestadas pelo tutor.

5. Suporte técnico oferecido pela instituição.

6. Conexão à internet.

7. Acesso ao ambiente virtual do curso com a regularidade proposta.

8. Materiais didáticos do curso.

9. Custos financeiros associados às tecnologias e materiais necessários durante $\mathrm{o}$ curso (acesso à internet, manutenção do computador, etc.).

10. Duração do curso.

11. Conteúdo do curso.

12. Recursos de ensino utilizados (figuras, vídeos, slides, etc).

13. Quantidade das atividades propostas durante o curso.

14. Conciliação do curso com as atividades profissionais.

15. Conciliação do curso com os compromissos familiares.

16. Tempo disponível para estudar.

17. Conciliação do curso com outras atividades de estudo.

18. Condições do ambiente de estudo em casa.

19. Condições de saúde no período de realização do curso.

20. Correspondência do curso às expectativas pessoais.

21. Habilidades pessoais de organização e planejamento de atividades de estudo.

22. Habilidades pessoais para uso das ferramentas web (chats, e-mails, fóruns, etc.). 


\section{CUESTIONARIO DE BARRERAS Y FACILITADORES EN LA ENSEÑANZA VIRTUAL}

Los ítems del cuestionario indican los factores que pueden haber ayudado u obstaculizado su desempeño durante la formación a distancia. Lea los ítems enumerados y seleccione el punto de la escala $(1,2,3,4$ ó 5) que representa en qué medida cada factor dificultó su desempeño, o sea, actuó como una barrera durante el curso, mediante el registro de su respuesta en la columna de la derecha (Puntuación).

1

Dificultó totalmente el desempeño
2

Dificultó mucho

\section{3}

Ni mucho, ni poco
5

Dificultó poco
No dificulto el desempeño

\begin{tabular}{|c|c|}
\hline Ítems & Puntuación \\
\hline $\begin{array}{l}\text { 1. La promoción por parte del tutor de la interacción social/relación } \\
\text { interpersonal entre los participantes de la formación. }\end{array}$ & \\
\hline $\begin{array}{l}\text { 2. El uso de los recursos Web (chats, correos electrónicos, foros, etc.) para } \\
\text { la comunicación con los tutores y compañeros. }\end{array}$ & \\
\hline $\begin{array}{l}\text { 3. La relación entre compañeros y tutores en cuanto al proceso de } \\
\text { aprendizaje durante la formación. }\end{array}$ & \\
\hline 4. Las orientaciones proporcionadas por el tutor. & \\
\hline 5. El apoyo técnico ofrecido por la institución. & \\
\hline 6. La conexión a Internet. & \\
\hline $\begin{array}{l}\text { 7. El acceso al entorno virtual de la formación con la regularidad } \\
\text { propuesta. }\end{array}$ & \\
\hline 8. Los materiales didácticos de la formación. & \\
\hline $\begin{array}{l}\text { 9. Los gastos económicos asociados a las tecnologías y los materiales } \\
\text { necesarios para la formación (acceso a Internet, mantenimiento del } \\
\text { ordenador, etc.). }\end{array}$ & \\
\hline 10. La duración de la formación. & \\
\hline 11. El contenido de la formación. & \\
\hline 12. Los recursos educativos utilizados (figuras, vídeos, diapositivas, etc.). & \\
\hline 13. La cantidad de las actividades propuestas durante la formación. & \\
\hline 14. La conciliación de la formación con las actividades profesionales. & \\
\hline 15. La conciliación de la formación con los compromisos de la familia. & \\
\hline 16. El tiempo disponible para estudiar. & \\
\hline 17. La conciliación de la formación con otras actividades de estudio. & \\
\hline 18. Las condiciones del ambiente de estudio en casa. & \\
\hline 19. Mi estado de salud durante la formación. & \\
\hline 20. La correspondencia entre la formación y las expectativas personales. & \\
\hline $\begin{array}{l}\text { 21. Las habilidades personales para organizar y planificar las actividades de } \\
\text { estudio. }\end{array}$ & \\
\hline $\begin{array}{l}\text { 22. Las habilidades personales para utilizar los recursos Web (chats, correos } \\
\text { electrónicos, foros, etc.). }\end{array}$ & \\
\hline
\end{tabular}




\section{ANEXO G - QUESTIONÁRIO DE IMPACTO DO TREINAMENTO NO TRABALHO EM AMPLITUDE}

Os itens do questionário visam avaliar o impacto do treinamento "X" no seu trabalho e o apoio dado pela organização ao uso das novas habilidades aprendidas. Leia atentamente os itens listados e escolha o ponto da escala $(1,2,3,4$ ou 5) que melhor representa a sua opinião sobre cada aspecto, registrando sua resposta na coluna à direita (Nota).

\begin{tabular}{c|c|c|c|c}
1 & 2 & 3 & 4 & 5 \\
$\begin{array}{c}\text { Discordo } \\
\text { totalmente }\end{array}$ & $\begin{array}{c}\text { Discordo um } \\
\text { pouco }\end{array}$ & $\begin{array}{c}\text { Não discordo, } \\
\text { nem concordo }\end{array}$ & Concordo & $\begin{array}{c}\text { Concordo } \\
\text { totalmente }\end{array}$ \\
\hline
\end{tabular}

\begin{tabular}{|c|c|}
\hline Itens & Nota \\
\hline 1. Aproveito as oportunidades que tenho para praticar as novas habilidades. & \\
\hline 2. Cometo menos erros no trabalho. & \\
\hline 3. Realizo meus trabalhos com mais agilidade. & \\
\hline 4. Melhorou a qualidade do meu trabalho. & \\
\hline 5. Aumentou minha motivação para o trabalho. & \\
\hline 6. Sugiro com mais frequência mudanças nas rotinas de trabalho. & \\
\hline 7. Meus colegas aprendem comigo. & \\
\hline
\end{tabular}

\section{CUESTIONARIO DE IMPACTO DE LA FORMACIÓN EN EL TRABAJO EN AMPLITUD}

Los ítems del cuestionario pretenden evaluar el impacto de la formación "X" en su trabajo y el apoyo dado por la organización para el uso de las nuevas habilidades aprendidas. Lea los ítems enumerados y seleccione el punto de la escala $(1,2,3,4$ ó 5) que mejor represente su opinión sobre cada uno de los aspectos descritos en los ítems, mediante el registro de su respuesta en la columna de la derecha (Puntuación).

\section{1}

Totalmente en desacuerdo

\section{2}

Un poco en desacuerdo

\begin{tabular}{|c|c|c|}
3 & 4 & 5 \\
Ni en \\
$\begin{array}{c}\text { desacuerdo, ni } \\
\text { de acuerdo }\end{array}$ & De acuerdo & $\begin{array}{c}\text { Totalmente de } \\
\text { acuerdo }\end{array}$ \\
\hline
\end{tabular}

\begin{tabular}{|c|c|}
\hline Ítems & Puntuación \\
\hline $\begin{array}{l}\text { 1. Aprovecho las oportunidades que tengo para practicar las nuevas } \\
\text { habilidades aprendidas. }\end{array}$ & \\
\hline 2. Tengo un menor número de errores en el trabajo. & \\
\hline 3. Realizo mi trabajo con más agilidad. & \\
\hline 4. Ha mejorado la calidad de mi trabajo. & \\
\hline 5. Ha aumentado mi motivación para trabajar. & \\
\hline $\begin{array}{l}\text { 6. He sido capaz en mayor medida que antes de sugerir innovaciones y } \\
\text { cambios en mi trabajo. }\end{array}$ & \\
\hline 7. Mis compañeros han aprendido de mis habilidades adquiridas. & \\
\hline
\end{tabular}




\section{ANEXO H - QUESTIONÁRIO DE REAÇÃO AOS PROCEDIMENTOS INSTRUCIONAIS}

Utilize a escala abaixo para avaliar a qualidade dos procedimentos instrucionais do curso realizado. Leia atentamente os itens listados e escolha o ponto da escala (1, 2, 3, 4 ou 5) que melhor representa a sua opinião sobre cada aspecto e registre sua resposta na coluna à direita (Nota).

\begin{tabular}{|c|c|c|c|c|}
\hline 1 & & & & \\
Muito ruim & 2 & 3 & 4 & 5 \\
\hline
\end{tabular}

\begin{tabular}{|c|c|}
\hline Itens & Nota \\
\hline 1. Correspondência entre o conteúdo proposto e os objetivos do curso. & \\
\hline 2. Correspondência entre o conteúdo do curso e os seus objetivos pessoais. & \\
\hline 3. Sequência de apresentação das unidades. & \\
\hline 4. Linguagem utilizada no material do curso. & \\
\hline 5. Leituras recomendadas. & \\
\hline 6. Novidades, lembretes e links divulgados no ambiente virtual do curso. & \\
\hline 7. Atividades/tarefas propostas ao final de cada unidade. & \\
\hline 8. Orientação para solução de erros nas atividades/tarefas. & \\
\hline 9. Conteúdos sugeridos para cada unidade. & \\
\hline 10. Horas de estudo sugeridas para cada unidade. & \\
\hline 11. Fóruns e chats. & \\
\hline 12. Troca de mensagens entre os alunos. & \\
\hline
\end{tabular}

\section{CUESTIONARIO DE REACCIÓN A LOS PROCEDIMIENTOS DE FORMACIÓN}

Utilice la siguiente escala para evaluar la calidad de los procedimientos de instrucción de la formación realizada. Lea los ítems enumerados y seleccione el punto de la escala (1, 2, 3, 4 ó 5) que mejor represente su opinión sobre cada uno de los aspectos y registre su respuesta en la columna de la derecha (Puntuación).

\begin{tabular}{|c|c|c|c|c|}
\hline 1 & 2 & 3 & 4 & 5 \\
Muy mala & Mala & $\begin{array}{c}\text { Ni mala, ni } \\
\text { buena }\end{array}$ & Buena & Muy buena \\
\hline
\end{tabular}

\begin{tabular}{|c|c|}
\hline Ítems & Nota \\
\hline 1. La correspondencia entre el contenido propuesto y los objetivos del curso. & \\
\hline 2. La correspondencia entre el contenido del curso y sus objetivos personales. & \\
\hline 3. La secuencia de presentación de las unidades. & \\
\hline 4. El lenguaje utilizado en el material del curso. & \\
\hline 5. Las lecturas recomendadas. & \\
\hline 6. Las novedades, recordatorios y links divulgados en el entorno virtual del curso. & \\
\hline 7. Las actividades/ejercicios propuestos al final de cada unidad. & \\
\hline 8. La orientación para la solución de los errores en las actividades/ejercicios. & \\
\hline 9. Los contenidos sugeridos para cada unidad. & \\
\hline 10. Las horas de estudio sugeridas para cada unidad. & \\
\hline 11. Los foros y chats. & \\
\hline 12. El intercambio de mensajes entre los alumnos. & \\
\hline
\end{tabular}


1

Instruções: Os itens a seguir indicam possíveis comportamentos utilizados por você durante o curso.

Leia-os atentamente e utilize a escala abaixo para registrar, ao final de cada item, o ponto da escala ( 1 , $2,3,4$ ou 5) que representa a frequência com que você se comportou da maneira descrita em cada item.

\begin{tabular}{|c|c|c|c|c|}
\hline 1 & 2 & 3 & 4 & 5 \\
\hline Nunca & Raramente & Às vezes & Frequentemente & Sempre \\
\hline
\end{tabular}

Caso algum item faça referência a aspectos não vivenciados durante a realização do curso, registre "Sem resposta".

\section{2}

Por favor, escolha a resposta adequada para cada item:

01) Mantive a calma quando tive dificuldades durante o curso.

02) Mantive a calma com a possibilidade de ter um rendimento abaixo do esperado.

03) Mantive a calma diante dos erros que cometi ao realizar atividades do curso.

04) Esforcei-me mais quando percebi que estava perdendo a concentração.

05) Esforcei-me mais quando percebi que estava perdendo o interesse no assunto.

06) Esforcei-me para verificar minha compreensão sobre o que estava sendo ensinado.

07) Busquei auxílio de colegas para esclarecer minhas dúvidas sobre os conteúdos do curso.

08) Busquei solucionar minhas dúvidas ao consultar os materiais didáticos do curso.

09) Busquei compreender melhor os conteúdos ao estudá-los nos materiais didáticos do curso.

10) Busquei outras fontes de pesquisa relacionadas ao curso para me ajudar a aprender.

11) Tentei entender o conteúdo ao aplicá-lo na prática, ao invés de dedicar tempo lendo ou pedindo ajuda a alguém.

12) Realizei os exercícios práticos propostos ao longo do curso para me ajudar a aprender.

13) Li o conteúdo do curso várias vezes como método para aprender.

14) Repeti mentalmente os conteúdos do curso que gostaria de aprender até perceber que havia entendido.

15) Fiz anotações, resumos e/ou esquemas dos conteúdos do curso como método para aprender.

16) Refleti sobre as implicações que os conteúdos aprendidos poderiam ter.

17) Identifiquei situações diárias em que eu pudesse aplicar os conteúdos do curso.

18) Busquei desenvolver uma ideia global sobre como os conteúdos do curso se relacionavam entre si.

19) Associei os conteúdos do curso aos meus conhecimentos anteriores.

20) Revisei os conteúdos relativos aos exercícios em que cometi erros.

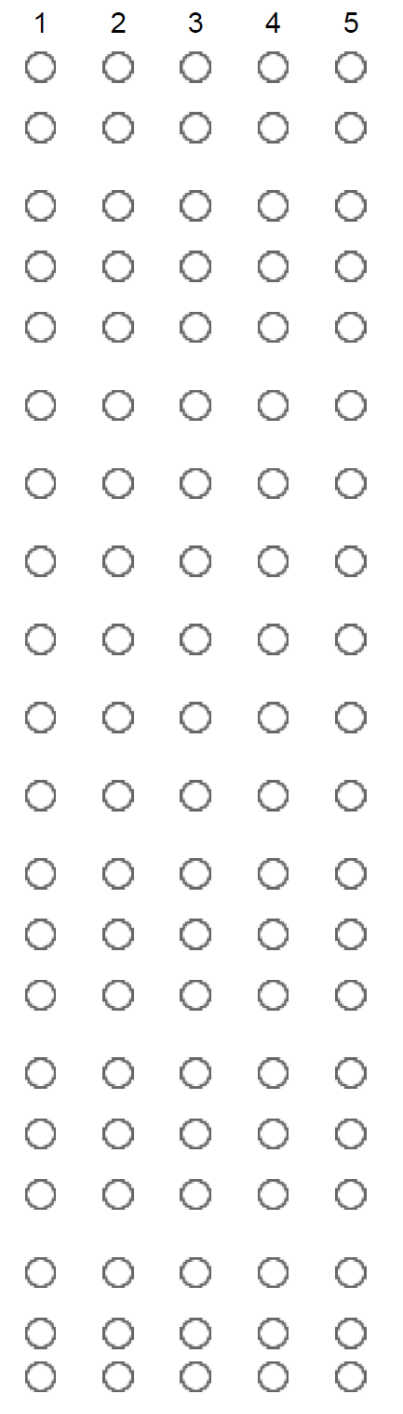




\section{ANEXO J - REAÇÃO AOS PROCEDIMENTOS INSTRUCIONAIS}

3

Instruções: Os itens a seguir referem-se à qualidade dos procedimentos instrucionais do curso realizado.

Leia-os atentamente e utilize a escala abaixo para registrar, ao final de cada item, o ponto da escala (1, $2,3,4$ ou 5 ) que representa a sua opinião sobre cada aspecto.

\begin{tabular}{|c|c|c|c|c|}
\hline 1 & 2 & 3 & 4 & 5 \\
\hline Péssima & Ruim & Regular & Boa & Excelente \\
\hline
\end{tabular}

Caso algum item faça referência a aspectos não vivenciados durante a realização do curso, registre "Sem resposta".

4

Por favor, escolha a resposta adequada para cada item:

01) Correspondência entre o conteúdo proposto e os objetivos do curso.

$12 \quad 3 \quad 4 \quad 5$

02) Correspondência entre o conteúdo do curso e os seus objetivos pessoais

03) Sequência de apresentação do conteúdo do curso.

04) Linguagem utilizada no material do curso.

05) Novidades, lembretes e links divulgados no ambiente virtual do curso.

06) Atividades/tarefas propostas ao final de cada unidade.

07) Orientação para solução de erros nas atividades/tarefas.

08) Conteúdos disponibilizados em cada unidade.

09) Horas de estudo sugeridas para o curso.

00000

00000

00000

00000

00000

00000

00000

00000

00000 


\section{ANEXO L - SUPORTE À TRANSFERÊNCIA}

19

Instruções: Os itens a seguir indicam comportamentos de superiores e colegas para apoiar o uso de novas habilidades aprendidas no curso.

Leia atentamente e utilize a escala abaixo para registrar, ao final de cada item, o ponto da escala $(1,2,3$, 4 ou 5) que representa a frequência com que SUPERIORES (coluna Superior) e COLEGAS (coluna Colegas) ofereceram os apoios descritos em cada item.

\begin{tabular}{|c|c|c|c|c|}
\hline 1 & 2 & 3 & 4 & 5 \\
\hline Nunca & Raramente & Às vezes & Frequentemente & Sempre \\
\hline
\end{tabular}

\section{SUPORTE PSICOSSOCIAL}

Por favor, escreva um número entre 1 e 5 para cada item:

01) Encorajam a aplicação no trabalho de novas habilidades aprendidas em treinamento.

02) Fornecem as informações necessárias ao uso eficaz das novas habilidades aprendidas em treinamento.

03) Removem as dificuldades ao uso eficaz das novas habilidades aprendidas em treinamento.

04) Criam oportunidades de utilizar no trabalho as novas habilidades aprendidas em treinamento

05) Fornecem feedback quanto à aplicação no trabalho das novas habilidades adquiridas em treinamento.

06) Consideram minhas sugestões, em relação ao que foi aprendido no treinamento, no ambiente de trabalho.

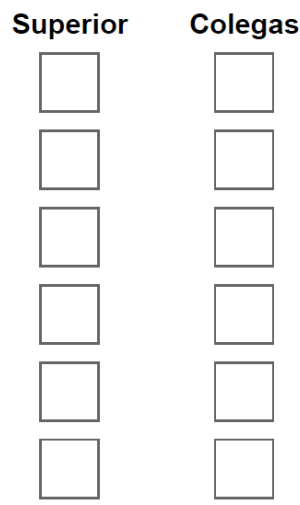

\section{SUPORTE MATERIAL}

Por favor, escolha a resposta adequada para cada item:

09) São fornecidos os recursos materiais necessários para a aplicação eficaz das novas habilidades aprendidas em treinamento.

10) É disponibilizado local de trabalho adequado à aplicação eficaz das novas habilidades aprendidas em treinamento (por exemplo, espaço físico, iluminação, mobiliário, nível de ruído). 
5

Instruções: Os itens a seguir indicam fatores que podem ter prejudicado o seu desempenho durante $\circ$ treinamento a distância.

Leia-os atentamente e utilize a escala abaixo para registrar, ao final de cada item, o ponto da escala ( 1 , 2, 3, 4 ou 5) que representa o quanto cada fator dificultou o seu desempenho, ou seja, atuou como uma barreira durante a realização do curso.

\begin{tabular}{|c|c|c|c|c|}
\hline 1 & 2 & 3 & 4 & 5 \\
\hline $\begin{array}{c}\text { Não dificultou o } \\
\text { desempenho }\end{array}$ & Dificultou pouco & $\begin{array}{c}\text { Dificultou } \\
\text { moderadamente }\end{array}$ & Dificultou muito & $\begin{array}{c}\text { Dificultou } \\
\text { totalmente o } \\
\text { desempenho }\end{array}$ \\
\hline
\end{tabular}

Caso algum item faça referência a aspectos não vivenciados durante a realização do curso, registre "Sem resposta".

\section{6}

Por favor, escolha a resposta adequada para cada item:

01) Suporte técnico oferecido pela instituição.

02) Conexão à internet.

03) Acesso ao ambiente virtual do curso com a regularidade proposta.

04) Material didático do curso.

05) Custos financeiros associados às tecnologias e materiais necessários durante o curso (acesso à internet, manutenção do computador, etc).

06) Duração do curso.

07) Conteúdo do curso.

08) Recursos de ensino utilizados (figuras, vídeos, slides, etc).

09) Quantidade das atividades propostas durante $\circ$ curso.

10) Conciliação do curso com as atividades profissionais.

11) Conciliação do curso com os compromissos familiares.

12) Tempo disponível para estudar.

13) Conciliação do curso com outras atividades de estudo.

14) Condições do ambiente de estudo em casa.

15) Condiçães de saúde no período de realização do curso.

16) Correspondência do curso às expectativas pessoais.

17) Habilidades pessoais de organização e planejamento de atividades de estudo.

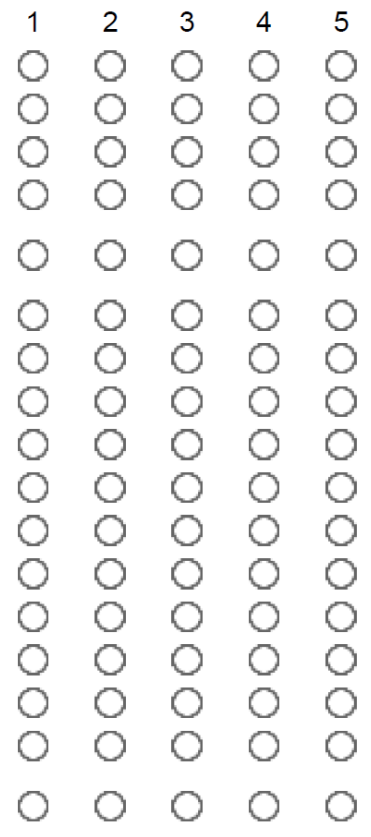

18) Habilidades pessoais para uso das ferramentas web (e-mails, fóruns, etc). 
ANEXO N - IMPACTO DO TREINAMENTO NO TRABALHO EM PROFUNDIDADE

(CURSO EFICIÊNCIA OPERACIONAL)

AUTOAVALIAÇÃO

12

Instruções: Leia atentamente cada item. Pense no seu desempenho antes e depois do curso e avalie com que frequência voce aplica, no seu trabalho, as habilidades descritas nos itens.

Destacamos que nem sempre o treinamento impacta em todos os trabalhos.

Utilize a escala abaixo para registrar, ao final de cada item, o número que corresponde à sua percepção.

\begin{tabular}{|c|c|c|c|c|}
\hline 1 & 2 & 3 & 4 & 5 \\
\hline Nunca & Raramente & Às vezes & Frequentemente & Sempre \\
\hline
\end{tabular}

Caso algum item faça referência a aspectos não vivenciados após a realização do curso, registre "Sem resposta".

Por favor, escolha a resposta adequada para cada item:

01) Identifico, nas atividades de trabalho, oportunidades que minimizem o consumo de recursos (materiais, mão de obra, financeiros, tempo) e maximizem resultados.

02) Aplico recursos materiais, financeiros, mão de obra e tempo, visando à sobrevivência da empresa e manutenção de seus resultados.

03) Compartilho com os colegas ações que podem ser implementadas para promoção da eficiência operacional.

04) Emprego ações para reduzir as despesas administrativas no dia-a-dia (controle de gastos com energia, reuniões por videoconferência, redução do volume de impressões, uso racional do telefone, etc.).

05) Realizo ações de contenção de gastos sem promover a perda de capacidade operacional ou elevação dos riscos.

06) Incentivo os clientes a reduzir o consumo de recursos do Banco (uso de canais automatizados para realizar transações, cadastramento de débito automático, uso de cartões para pagamentos, etc).

07) Concedo créditos, presto serviços (produtos de seguridade e cartão de crédito, por exemplo) e capto recursos ( $L C l$ e LCA) como formas para aumentar as receitas operacionais do banco.

08) Acompanho os indicadores de eficiência operacional do banco ao longo do tempo para contribuir para a sua melhoria. 


\section{HETEROAVALIAÇÃO}

\section{1}

Instruções: Leia atentamente cada item. Pense no desempenho do seu subordinado antes e depois do curso e avalie com que frequência ele aplica, no trabalho, as habilidades descritas nos itens. Destacamos que nem sempre o treinamento impacta em todos os trabalhos.

Utilize a escala abaixo para registrar, ao final de cada item, o número que corresponde à sua percepção.

\begin{tabular}{|c|c|c|c|c|}
\hline 1 & 2 & 3 & 4 & 5 \\
\hline Nunca & Raramente & Às vezes & Frequentemente & Sempre \\
\hline
\end{tabular}

Caso algum item faça referência a aspectos não vivenciados após a realização do curso, registre "Sem resposta".

2

Por favor, escolha a resposta adequada para cada item:

01) Identifica, nas atividades de trabalho, oportunidades que minimizem 0 consumo de recursos (materiais, mão de obra, financeiros, tempo) $e$ maximizem resultados.

02) Aplica recursos materiais, financeiros, mão de obra e tempo, visando à sobrevivência da empresa e manutenção de seus resultados.

03) Compartilha com os colegas ações que podem ser implementadas para promoção da eficiência operacional.

04) Emprega ações para reduzir as despesas administrativas no dia-a-dia (controle de gastos com energia, reuniões por videoconferência, redução do volume de impressões, uso racional do telefone, etc.).

05) Realiza ações de contenção de gastos sem promover a perda de capacidade operacional ou elevação dos riscos.

06) Incentiva os clientes a reduzir o consumo de recursos do Banco (uso de canais automatizados para realizar transações, cadastramento de débito automático, uso de cartões para pagamentos, etc).

07) Concede créditos, presta serviços (produtos de seguridade e cartão de crédito, por exemplo) e capta recursos ( $\mathrm{LCl}$ e LCA) como formas para aumentar as receitas operacionais do banco.

08) Acompanha os indicadores de eficiência operacional do banco ao longo do tempo para contribuir para a sua melhoria.

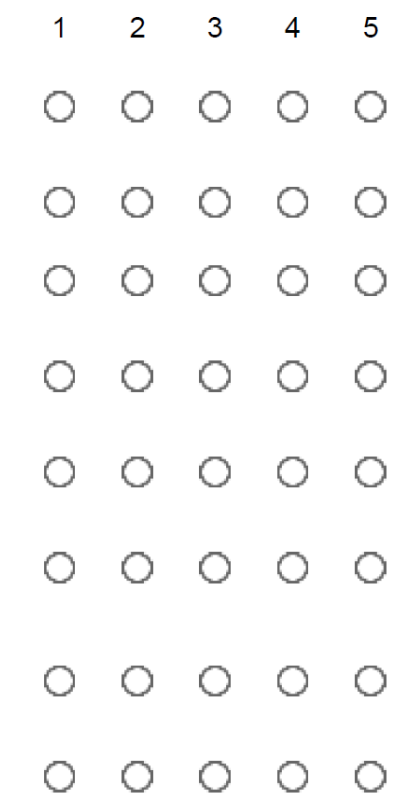


ANEXO O - IMPACTO DO TREINAMENTO NO TRABALHO EM AMPLITUDE

\section{AUTOAVALIAÇÃO}

\section{6}

Instruções: Leia atentamente cada item. Pense no seu desempenho antes e depois do curso e avalie com que frequência você aplica, no seu trabalho, as habilidades descritas nos itens. Destacamos que nem sempre o treinamento impacta em todos os trabalhos.

Utilize a escala abaixo para registrar, ao final de cada item, o número que corresponde à sua percepção.

\begin{tabular}{|c|c|c|c|c|}
\hline 1 & 2 & 3 & 4 & 5 \\
\hline Não concordo & $\begin{array}{c}\text { Concordo } \\
\text { pouco }\end{array}$ & $\begin{array}{c}\text { Concordo } \\
\text { moderadamente }\end{array}$ & $\begin{array}{c}\text { Concordo } \\
\text { muito }\end{array}$ & $\begin{array}{c}\text { Concordo } \\
\text { totalmente }\end{array}$ \\
\hline
\end{tabular}

Caso algum item faça referência a aspectos não vivenciados após a realização do curso, registre "Sem resposta".

08) Aproveito as oportunidades que tenho para praticar as novas habilidades.

09) Cometo menos erros no trabalho.

10) Realizo meus trabalhos com mais agilidade.

11) Melhorou a qualidade do meu trabalho.

12) Aumentou minha motivação para o trabalho.

13) Sugiro com mais frequência mudanças nas rotinas de trabalho.

14) Esclareço dúvidas dos meus colegas.

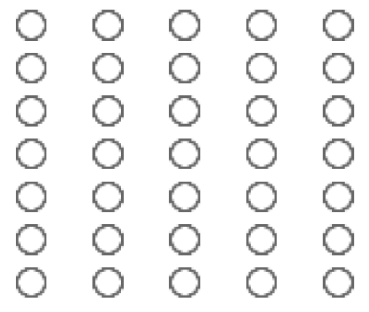

\section{HETEROAVALIAÇÃO}

\section{5}

Instruções: Leia atentamente cada item. Pense no desempenho do seu subordinado antes e depois do curso e avalie a sua concordância com as habilidades descritas nos itens. Destacamos que nem sempre o treinamento impacta em todos os trabalhos.

Utilize a escala abaixo para registrar, ao final de cada item, o número que corresponde à sua percepção.

\begin{tabular}{|c|c|c|c|c|}
\hline 1 & 2 & 3 & 4 & 5 \\
\hline Não concordo & $\begin{array}{c}\text { Concordo } \\
\text { pouco }\end{array}$ & $\begin{array}{c}\text { Concordo } \\
\text { moderadamente }\end{array}$ & $\begin{array}{c}\text { Concordo } \\
\text { muito }\end{array}$ & $\begin{array}{c}\text { Concordo } \\
\text { totalmente }\end{array}$ \\
\hline
\end{tabular}

Caso algum item faça referência a aspectos não vivenciados após a realização do curso, registre "Sem resposta".

08) Aproveita oportunidades para praticar as novas habilidades.

09) Comete menos erros no trabalho.

10) Realiza trabalhos com mais agilidade.

11) Melhorou a qualidade do trabalho.

12) Aumentou a motivação para o trabalho.

13) Sugere com mais frequência mudanças nas rotinas de trabalho

14) Esclarece dúvidas dos colegas.

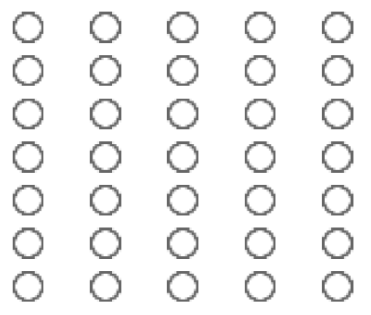




\section{Versões finais após a análise confirmatória da estrutura fatorial das escalas:}

\section{ANEXO P - QUESTIONÁRIO DE ESTRATÉGIAS DE APRENDIZAGEM}

Os itens do questionário indicam possíveis comportamentos utilizados por você durante o curso. Leia os itens listados e escolha o ponto da escala $(1,2,3,4$ ou 5) que representa a frequência com que você se comportou da maneira descrita em cada item, registrando sua resposta na coluna à direita (Nota).

\begin{tabular}{|c|c|c|c|c|}
\hline 1 & & & & \\
Nunca & Raramente & 3 & 4 & 5 \\
\hline
\end{tabular}

\begin{tabular}{|c|c|c|}
\hline \multicolumn{2}{|l|}{ Itens } & \multirow[t]{2}{*}{ Nota } \\
\hline & Mantive a calma quando tive dificuldades durante o curso. & \\
\hline 2. & Mantive a calma com a possibilidade de ter um rendimento abaixo do esperado. & \\
\hline & Mantive a calma diante dos erros que cometi ao realizar atividades do curso. & \\
\hline & Esforcei-me mais quando percebi que estava perdendo a concentração. & \\
\hline & Esforcei-me mais quando percebi que estava perdendo o interesse no assunto. & \\
\hline 6. & Esforcei-me para verificar minha compreensão sobre o que estava sendo ensinado. & \\
\hline 7. & $\begin{array}{l}\text { Busquei auxílio de colegas para esclarecer minhas dúvidas sobre os conteúdos do } \\
\text { curso. }\end{array}$ & \\
\hline & $\begin{array}{l}\text { Busquei compreender melhor os conteúdos ao estudá-los nos materiais didáticos do } \\
\text { curso. }\end{array}$ & \\
\hline & Busquei outras fontes de pesquisa relacionadas ao curso para me ajudar a aprender. & \\
\hline & Li o conteúdo do curso várias vezes como método para aprender. & \\
\hline & $\begin{array}{l}\text { Repeti mentalmente os conteúdos do curso que gostaria de aprender até perceber que } \\
\text { havia entendido. }\end{array}$ & \\
\hline & $\begin{array}{l}\text { Fiz anotações, resumos e/ou esquemas dos conteúdos do curso como método para } \\
\text { aprender. }\end{array}$ & \\
\hline & Revisei os conteúdos relativos aos exercícios em que cometi erros. & \\
\hline & $\begin{array}{l}\text { Realizei os exercícios práticos propostos ao longo do curso para me ajudar a } \\
\text { aprender. }\end{array}$ & \\
\hline & Refleti sobre as implicações que os conteúdos aprendidos poderiam ter. & \\
\hline & . Identifiquei situações diárias em que eu pudesse aplicar os conteúdos do curso. & \\
\hline & $\begin{array}{l}\text { Busquei desenvolver uma ideia global sobre como os conteúdos do curso se } \\
\text { relacionavam entre si. }\end{array}$ & \\
\hline & Associei os conteúdos do curso aos meus conhecimentos anteriores. & \\
\hline
\end{tabular}


Utilize a escala abaixo para avaliar a qualidade dos procedimentos instrucionais do curso realizado. Leia atentamente os itens listados e escolha o ponto da escala (1, 2, 3, 4 ou 5) que melhor representa a sua opinião sobre cada aspecto e registre sua resposta na coluna à direita (Nota).

\begin{tabular}{|c|c|c|c|c|c|}
\hline $\begin{array}{c}1 \\
\text { Muito ruim }\end{array}$ & $\begin{array}{c}2 \\
\text { Ruim }\end{array}$ & $\begin{array}{l}3 \\
\text { Nem ruim, nem boa }\end{array}$ & $\begin{array}{c}4 \\
\text { Boa }\end{array}$ & \multicolumn{2}{|c|}{$\begin{array}{c}5 \\
\text { Muito boa }\end{array}$} \\
\hline \multicolumn{5}{|l|}{ Itens } & Nota \\
\hline \multicolumn{6}{|c|}{ 1. Correspondência entre o conteúdo proposto e os objetivos do curso. } \\
\hline \multicolumn{6}{|c|}{ 2. Correspondência entre o conteúdo do curso e os seus objetivos pessoais. } \\
\hline \multicolumn{6}{|c|}{ 3. Sequência de apresentação do conteúdo do curso. } \\
\hline \multicolumn{6}{|c|}{ 4. Linguagem utilizada no material do curso. } \\
\hline \multicolumn{6}{|c|}{ 5. Novidades, lembretes e links divulgados no ambiente virtual do curso. } \\
\hline \multicolumn{6}{|c|}{ 6. Atividades/tarefas propostas ao final de cada unidade. } \\
\hline \multicolumn{6}{|c|}{ 7. Orientação para solução de erros nas atividades/tarefas. } \\
\hline \multicolumn{6}{|c|}{ 8. Conteúdos disponibilizados em cada unidade. } \\
\hline 9. Horas & o suger & a o curso. & & & \\
\hline
\end{tabular}




\section{ANEXO R - QUESTIONÁRIO DE SUPORTE À TRANSFERÊNCIA}

Os itens do questionário indicam comportamentos de supervisores e/ou colegas para apoiar o uso de novas habilidades aprendidas em treinamento no ambiente de trabalho e o suporte fornecido pela organização. Utilize a escala abaixo para avaliar: a) o apoio psicossocial oferecido pelos seus supervisores e/ou colegas e b) o suporte material fornecido pela organização. Leia atentamente os itens listados e escolha o ponto da escala $(1,2,3,4$ ou 5) que representa a frequência com que supervisores, colegas e organização ofereceram os apoios descritos em cada item. Para avaliar o suporte psicossocial, marque sua resposta na coluna correspondente (coluna $\mathrm{S}$ = supervisores e coluna $\mathrm{C}=$ colegas) e para avaliar o suporte material, registre sua resposta na coluna à direita (Nota) aos itens que descrevem tais aspectos.

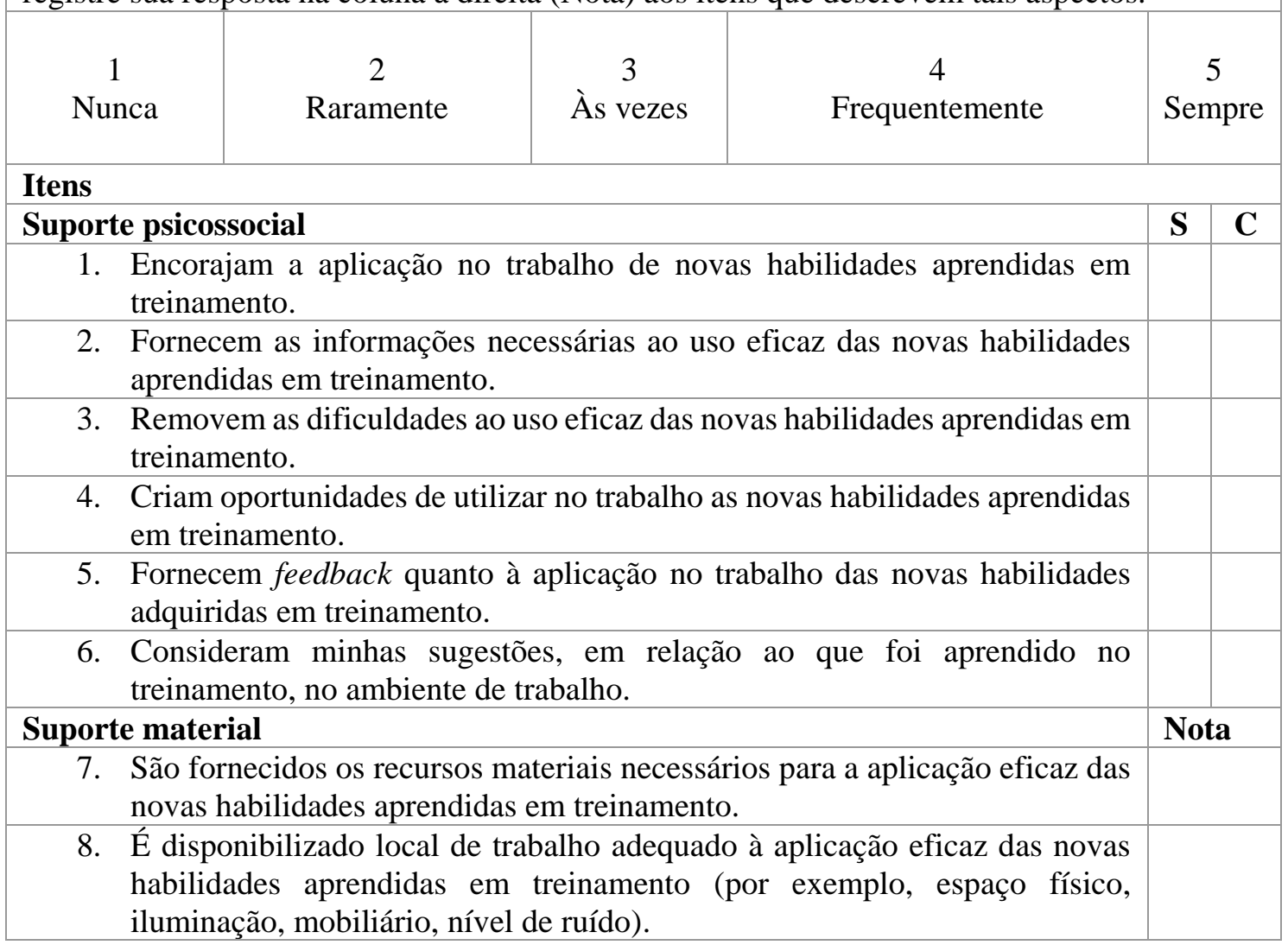


Os itens do questionário indicam fatores que podem ter auxiliado ou prejudicado o seu desempenho durante o treinamento a distância. Leia os itens listados e escolha o ponto da escala $(1,2,3,4$ ou 5) que representa o quanto cada fator dificultou o seu desempenho, ou seja, atuou como uma barreira durante o curso, e registre sua resposta na coluna à direita (Nota).

\begin{tabular}{|c|c|c|c|c|c|}
\hline $\begin{array}{c}1 \\
\text { Dificultou } \\
\text { totalmente o } \\
\text { desempenho }\end{array}$ & $\begin{array}{l}2 \\
\text { Dificultou muito }\end{array}$ & $\begin{array}{c}3 \\
\text { Nem muito, } \\
\text { nem pouco }\end{array}$ & $\begin{array}{c}4 \\
\text { Dificultou } \\
\text { pouco }\end{array}$ & $\begin{array}{r}5 \\
\text { Não dificu } \\
\text { desempe }\end{array}$ & $\begin{array}{l}\text { Itou o } \\
\text { nho }\end{array}$ \\
\hline \multicolumn{5}{|l|}{ Itens } & Nota \\
\hline \multicolumn{6}{|c|}{ 1. Suporte técnico oferecido pela instituição. } \\
\hline \multicolumn{6}{|c|}{ 2. Acesso ao ambiente virtual do curso com a regularidade proposta. } \\
\hline \multicolumn{6}{|c|}{ 3. Material didático do curso. } \\
\hline \multicolumn{5}{|c|}{$\begin{array}{l}\text { 4. Custos financeiros associados às tecnologias e materiais necessários durante o } \\
\text { curso (acesso à internet, manutenção do computador, etc). }\end{array}$} & \\
\hline \multicolumn{5}{|c|}{ 5. Duração do curso. } & \\
\hline \multicolumn{5}{|c|}{ 6. Conteúdo do curso. } & \\
\hline \multicolumn{5}{|c|}{ 7. Recursos de ensino utilizados (figuras, vídeos, slides, etc). } & \\
\hline \multicolumn{5}{|c|}{ 8. Quantidade das atividades propostas durante o curso. } & \\
\hline \multicolumn{5}{|c|}{ 9. Tempo disponível para estudar. } & \\
\hline \multicolumn{5}{|c|}{ 10. Condições de saúde no período de realização do curso. } & \\
\hline \multicolumn{5}{|c|}{ 11. Correspondência do curso às expectativas pessoais. } & \\
\hline \multirow{2}{*}{\multicolumn{5}{|c|}{$\begin{array}{l}\text { 12. Habilidades pessoais de organização e planejamento de atividades de estudo. } \\
\text { 13. Habilidades pessoais para uso das ferramentas web (e-mails, fóruns, etc). }\end{array}$}} & \\
\hline & & & & & \\
\hline
\end{tabular}




\section{ANEXO T - QUESTIONÁRIO DE IMPACTO DO TREINAMENTO NO TRABALHO EM PROFUNDIDADE}

Os itens do questionário visam avaliar o impacto do treinamento "Eficiência Operacional" no seu trabalho. Leia atentamente os itens listados e escolha o ponto da escala $(1,2,3,4$ ou 5) que representa a frequência com que você aplica no seu trabalho as habilidades descritas em cada item, registrando sua resposta na coluna à direita (Nota).

\begin{tabular}{|c|c|c|c|c|}
\hline 1 & 2 & 3 & 4 & 5 \\
Nunca & Raramente & Às vezes & Frequentemente & Sempre \\
\hline Itens
\end{tabular}

\begin{tabular}{|r|r|r|}
\hline Itens & & Nota \\
\hline 1. & $\begin{array}{l}\text { Identifico, nas atividades de trabalho, oportunidades que minimizem o } \\
\text { consumo de recursos (materiais, mão de obra, financeiros, tempo) e } \\
\text { maximizem resultados. }\end{array}$ & \\
\hline 2. & $\begin{array}{l}\text { Aplico recursos materiais, financeiros, mão de obra e tempo, visando à } \\
\text { sobrevivência da empresa e manutenção de seus resultados. }\end{array}$ & \\
\hline 3. & $\begin{array}{l}\text { Compartilho com os colegas ações que podem ser implementadas para } \\
\text { promoção da eficiência operacional. }\end{array}$ & \\
\hline 4. & $\begin{array}{l}\text { Emprego ações para reduzir as despesas administrativas no dia-a-dia } \\
\text { (controle de gastos com energia, reuniões por videoconferência, redução do }\end{array}$ & \\
\hline volume de impressões, uso racional do telefone, etc.). & $\begin{array}{l}\text { Realizo ações de contenção de gastos sem promover a perda de capacidade } \\
\text { operacional ou elevação dos riscos. }\end{array}$ & \\
\hline 6. & $\begin{array}{l}\text { Incentivo os clientes a reduzir o consumo de recursos do Banco (uso de } \\
\text { canais automatizados para realizar transações, cadastramento de débito } \\
\text { automático, uso de cartões para pagamentos, etc). }\end{array}$ & \\
\hline 7. & $\begin{array}{l}\text { Acompanho os indicadores de eficiência operacional do Banco ao longo do } \\
\text { tempo para contribuir para a sua melhoria. }\end{array}$ & \\
\hline
\end{tabular}




\section{ANEXO U - QUESTIONÁRIO DE IMPACTO DO TREINAMENTO NO TRABALHO EM AMPLITUDE}

Os itens do questionário visam avaliar o impacto do treinamento " $\mathrm{X}$ " no seu trabalho e o apoio dado pela organização ao uso das novas habilidades aprendidas. Leia atentamente os itens listados e escolha o ponto da escala (1, 2, 3, 4 ou 5) que melhor representa a sua opinião sobre cada aspecto, registrando sua resposta na coluna à direita (Nota).

\begin{tabular}{|c|c|c|c|c|c|}
\hline $\begin{array}{c}1 \\
\text { Discordo } \\
\text { totalmente }\end{array}$ & $\begin{array}{c}2 \\
\text { Discordo um } \\
\text { pouco }\end{array}$ & $\begin{array}{c}3 \\
\text { Não discordo, } \\
\text { nem concordo }\end{array}$ & $\begin{array}{c}4 \\
\text { Concordo }\end{array}$ & \multicolumn{2}{|c|}{$\begin{array}{c}5 \\
\text { Concordo } \\
\text { totalmente }\end{array}$} \\
\hline \multicolumn{5}{|l|}{ Itens } & Nota \\
\hline \multicolumn{6}{|c|}{ 1. Aproveito as oportunidades que tenho para praticar as novas habilidades. } \\
\hline \multicolumn{6}{|c|}{ 2. Cometo menos erros no trabalho. } \\
\hline \multicolumn{6}{|c|}{ 3. Realizo meus trabalhos com mais agilidade. } \\
\hline \multicolumn{6}{|c|}{ 4. Melhorou a qualidade do meu trabalho. } \\
\hline \multicolumn{6}{|c|}{ 5. Aumentou minha motivação para o trabalho. } \\
\hline \multicolumn{6}{|c|}{ 6. Sugiro com mais frequência mudanças nas rotinas de trabalho. } \\
\hline \multicolumn{5}{|c|}{ 7. Esclareço dúvidas dos meus colegas. } & \\
\hline
\end{tabular}

